\title{
Late Transition Metal Complexes of Pyridyldiphosphines
}

\author{
by \\ Teresa Florence Vaughan
}

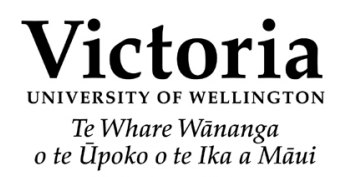

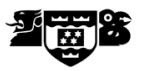

\author{
A thesis \\ submitted to Victoria University of Wellington \\ in fulfilment of the \\ requirements for the degree of \\ Doctor of Philosophy \\ in Chemistry
}

Victoria University of Wellington

2015 


\section{Abstract}

This thesis provides an account of research into the properties of pyridyldiphosphines with $o$-xylene and $m$-xylene backbones. The coordination behaviour of the $o$-xylene based ligand with platinum, palladium, silver, rhodium and iridium metal centres has been studied, with an emphasis on whether the presence of the pyridyl rings affects the products formed. Platinum and palladium pincer complexes have been synthesised and the intermediates investigated. The formation of trimetallic complexes with these ligands acting as bridging ligands has also been explored.

Two new pyridyldiphosphines, $o-\mathrm{C}_{6} \mathrm{H}_{4}\left(\mathrm{CH}_{2} \mathrm{PPy}_{2}\right)_{2}(3)$ and $m-\mathrm{C}_{6} \mathrm{H}_{4}\left(\mathrm{CH}_{2} \mathrm{PPy}_{2}\right)_{2}$ (4), and one known pyridyldiphosphine, $\mathrm{PPy}_{2}\left(\mathrm{CH}_{2}\right)_{3} \mathrm{PPy}_{2}(\mathbf{5})$, have been synthesised via an improved method. Tris(2-pyridyl)phopshine was reacted with a lithium dispersion to give $\mathrm{LiPPy}_{2}$, which was then reacted with the appropriate dichloride or dibromide compound to yield the desired ligand. The phosphine selenides of $\mathbf{3}$ and 4 were synthesised and the ${ }^{1} J_{\mathrm{PSe}}$ values of 738 and $742 \mathrm{~Hz}$ indicated these ligands were less basic than $\mathrm{PPh}_{3}$. While the ligands themselves were not water-soluble, protonation by a strong acid, such as $\mathrm{HCl}$ or $\mathrm{H}_{2} \mathrm{C}\left(\mathrm{SO}_{2} \mathrm{CF}_{3}\right)_{3}$, rendered them soluble in water.

A series of $\left[\mathrm{MX}_{2}(\mathrm{PP})\right]$ complexes (where $\mathrm{M}=\mathrm{Pt}, \mathrm{X}=\mathrm{Cl}$, I, Me, Et, $\mathrm{PP}=\mathbf{3}, \mathbf{5}$; $\mathrm{M}$ $=\mathrm{Pd}, \mathrm{X}=\mathrm{Cl}, \mathrm{Me} \mathrm{PP}=\mathbf{3}, \mathbf{5})$ were synthesised. Complexes of $\mathbf{3}$ displayed dynamic behaviour in solution which was attributed to the backbone of the ligand inverting. When $[\mathrm{PtMeCl}(\mathrm{PP})](\mathbf{2 7})$ was reacted with $\mathrm{NaCH}\left(\mathrm{SO}_{2} \mathrm{CF}_{3}\right)_{2}$ no evidence for the coordination of the pyridyl nitrogens was observed. The synthesis of a series of unsymetrical $[\mathrm{PtMeL}(\mathrm{PP})]^{+}$complexes enabled the comparison of the cis and trans influences of a range of ligands. The following cis influence series was compiled based on ${ }^{31} \mathrm{P}$ NMR data of these complexes: $\mathrm{Py} \approx \mathrm{Cl}>\mathrm{SEt}_{2}>\mathrm{PTA}>\mathrm{PPh}_{3}$. Reaction of $\mathbf{2 7}$ with $\mathrm{NaCH}\left(\mathrm{SO}_{2} \mathrm{CF}_{3}\right)_{2}$ and carbon monoxide slowly formed an acyl complex, where the CO had inserted in the Pt-Me bond.

The bis-chelated complexes $\left[\mathrm{M}(\mathrm{PP})_{2}\right]$ where $\mathrm{M}=\mathrm{Pt}, \mathrm{Pd}$, and $\left[\mathrm{Ag}(\mathrm{PP})_{2}\right]^{+}$were 
formed. In these complexes $\mathbf{3}$ acted as a diphosphine ligand and there was no evidence for any interaction between the pyridyl nitrogen atoms and the metal centre.

Reaction of $\mathbf{3}$ with $[\operatorname{Ir}(\mathrm{COD})(\mu-\mathrm{Cl})]_{2}$ formed $[\operatorname{IrCl}(\mathrm{PP})(\mathrm{COD})](\mathbf{4 2})$. When the chloride ligand in $\mathbf{4 2}$ was abstracted, the pyridyl nitrogens were able to interact with the iridium centre faciliating the isomerisation of the 1,2,5,6- $\eta^{4}$-COD ligand to a $1-\kappa-4,5,6-\eta^{3}-\mathrm{C}_{8} \mathrm{H}_{12}$ ligand. The X-ray crystal structure of $\left[\operatorname{Ir}\left(1-\kappa-4,5,6-\eta^{3}-\right.\right.$ $\left.\left.\mathrm{C}_{8} \mathrm{H}_{12}\right)(\mathrm{PPN})\right] \mathrm{BPh}_{4}(43)$ confirmed the $P, P, N$ chelation mode of the ligand. In solution, 43 displayed hemilabile behaviour, with the pyridyl nitrogens exchanging at a rate faster than the NMR time scale at room temperature. The coordinated pyridyl nitrogen was able to be displaced by carbon monoxide to form $[\operatorname{Ir}(1-\kappa-4,5,6$ $\left.\left.\eta^{3}-\mathrm{C}_{8} \mathrm{H}_{12}\right)(\mathrm{CO})(\mathrm{PP})\right]^{+}$.

A series of $[\mathrm{PtXY}(\mu-\mathrm{PP})]_{2}$ complexes, where $\mathrm{X}=\mathrm{Y}=\mathrm{Cl}, \mathrm{Me}, \mathrm{X}=\mathrm{Cl}, \mathrm{Y}=\mathrm{Me}$ and $\mathrm{PP}=\mathbf{4}$, were formed initially when 4 was reacted with platinum(II) complexes. When heated, the dimers containing methyl ligands eliminated methane to form $[\mathrm{PtX}(\mathrm{PCP})]$ pincer complexes, $\mathrm{X}=\mathrm{Cl}$ (49), Me (51). When the chloride ligand in 49 was abstracted no evidence of pyridyl nitrogen coordination was observed. Protonation of $\mathbf{4 9}$ did not yield a water-soluble pincer complex. The $\left[\mathrm{PdCl}_{2}(\mu-\mathrm{PP})\right]_{2}$ complex readily metallated when heated to give the pincer complex $[\mathrm{PdCl}(\mathrm{PCP})]$.

Given pyridyl nitrogen atoms are known to be good ligands for "hard" metal centres, the ability of the pyridyl nitrogens in $\mathbf{3}$ and $\mathbf{4}$ to coordinate to metal centres was investigated. While complexes with chloride ligands were found to form insoluble products, the synthesis of $\left[\left(\mathrm{PtMe}_{2}\right)_{3}(\mathrm{PP})\right]$, from the reaction of either $\mathbf{3}$ or $\left[\mathrm{PtMe}_{2}(\mathrm{PP})\right](\mathbf{1 7})$ with dimethyl(hexa-1,5-diene)platinum, proceeded smoothly through a dimetallic intermediate. The same reactivity was observed in the synthesis of $\left[\left(\mathrm{PtMe}_{2}\right)_{2} \mathrm{PtMe}(\mathrm{PCP})\right]$. In contrast, the cationic heterotrimetallic complexes $\left[\{\mathrm{M}(\mathrm{COD})\}_{2} \mathrm{PtMe}(\mathrm{PP})\right]^{2+}$ and $\left[\{\mathrm{M}(\mathrm{COD})\}_{2} \mathrm{PtMe}(\mathrm{PCP})\right]^{2+}$, where $\mathrm{M}=\mathrm{Rh}$ or Ir, were synthesised without the detection of any intermediates. However, dimetallic complexes were formed as part of a mixture when $\mathbf{1 7}$ or $\mathbf{5 1}$ was reacted with one equivalent of the appropriate metal complex. 


\section{Acknowledgments}

I would like to acknowledge my two supervisors, Prof. John Spencer and Dr. Joanne Harvey without whom I never would have gotten here. Thank you to the members of the Organometallica Research group both past and present. A special thank you to goes my fellow "witches", Kathryn, Sarah and Melanie. Your support over the years has been invaluable.

A big thank you goes to all the academic and general staff of SCPS who help in little ways every day. A special thank you to Ian Vorster and John Ryan for ALL of the help and patience with the my NMR requests over the years. I am also very grateful to Helen Rowley, Jaime-Anne Elliott, Teresa Gen, Jackie King, Grant Franklin, Alan Rennie, Manu Pouajen-Blakiston and Nick Grinter for all of the many crises they averted with their calm and efficient help. Thank you to all of my friends who are/have been postgraduate students at VUW and other Universities for all of your support and understanding that can only come from going through this journey yourself.

Thanks also go to all of my "non-chemistry" friends; for all of the coffee dates, for listening to me talk about my $\mathrm{PhD}$ when you didn't necessarily understand and for letting me cuddle your cute babies when I was stressed! In particular, Michael and Emma for giving me a cute niece and for being extra patient over these last few months.

I would also like to acknowledge receipt of a Bright Futures Scholarship, the CurtisGordon Research Scholarship and the Victoria University Submission Scholarship.

Finally a HUGE thank you goes to my Mum and Lilah. Their love and support have kept me sane (just) over this journey. Special thanks are required for the lengths they went to during the writing process, including Mum proofreading chapters at 1 am and Lilah keeping me company and giving me cuddles while I wrote. 


\section{Table of Contents}

Abstract

Acknowledgments

Table of Contents $\quad$ v

List of Figures viii

List of Schemes $\quad$ X

List of Tables $\quad$ xii

List of Compounds xiii

Glossary $\quad$ xvi

1 Introduction $\quad 1$

1.1 Coordination Complexes . . . . . . . . . . . . . . . 1

1.2 Phosphorus-Nitrogen Ligands . . . . . . . . . . . . . . . . . . . . . 2

1.3 Pyridylphosphines . . . . . . . . . . . . . . . . 5

1.3.1 Pyridyldiphosphines . . . . . . . . . . . . . 12

1.4 Large Bite Angle Ligands . . . . . . . . . . . . . . . . . . . . . . 15

1.5 Pincer Ligands . . . . . . . . . . . . . . . . . . . . . . . . . . 16

1.6 Research Objectives . . . . . . . . . . . . . . . . . 18

2 Ligand Synthesis and Properties $\quad 20$

2.1 Background . . . . . . . . . . . . . . . . . . . 20

2.2 Ligand Synthesis . . . . . . . . . . . . . . . . . . . . . 21

2.3 Phosphine Selenides . . . . . . . . . . . . . . . . . . 26

2.4 Protonation Behaviour . . . . . . . . . . . . . . . . . 30

2.5 Phosphine-Boranes . . . . . . . . . . . . . . . 34

2.6 Concluding Remarks . . . . . . . . . . . . . . . . . . . 35

3 Monometallic Complexes of dpypox 37

3.1 Platinum(II) and Palladium(II) Reactions . . . . . . . . . . . . 38 
3.2 Unsymmetric Platinum(II) Complexes of dpypox . . . . . . . . . . 48

3.2.1 Reactions of $[\mathrm{PtClMe}(\mathrm{PP})] \ldots \ldots \ldots \ldots$. . . . . . . . . . 52

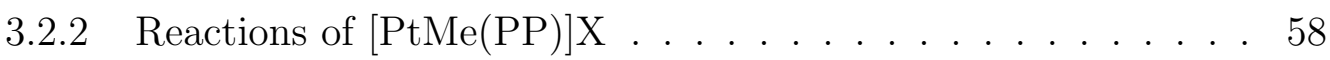

3.3 Platinum(0) and Palladium(0) Complexes of dpypox . . . . . . . 62

3.4 Silver(I) Complexes of dpypox . . . . . . . . . . . . . . . . 65

3.5 Rhodium and Iridium Complexes of dpypox . . . . . . . . . . . . . . 69

3.6 Concluding Remarks . . . . . . . . . . . . . . . . . . . . . . 80

4 Complexes of dpyp $m$ x $\quad 82$

4.1 Platinum(II) Complexes of dpyp $m x$. . . . . . . . . . . . . . . 83

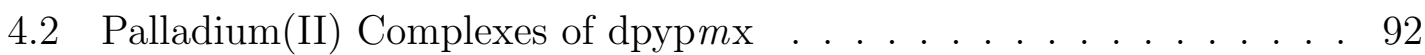

4.3 Concluding Remarks . . . . . . . . . . . . . . . . . . . . . 93

5 Trimetallic Complexes $\quad 95$

5.1 Homotrimetallic Complexes of dpypox . . . . . . . . . . . . . . . 96

5.2 Group 10 Trimetallic Complexes of dpypox . . . . . . . . . . . . . . . 104

5.3 Heterotrimetallic Complexes of dpypox . . . . . . . . . . . . . . 107

5.4 Dimetallic Intermediates of dpypox . . . . . . . . . . . . . . . 110

5.5 Homotrimetallic Complexes of $\operatorname{dpyp} m \mathrm{x}$. . . . . . . . . . . . . . . 116

5.6 Heterotrimetallic Complexes of dpyp $m x$. . . . . . . . . . . . . . 119

5.7 Dimetallic Intermediates of dpyp $m \mathrm{x}$. . . . . . . . . . . . . . . 120

5.8 Concluding Remarks . . . . . . . . . . . . . . . . . . . . . . . 123

6 Conclusions $\quad 125$

$\begin{array}{llr}7 & \text { Experimental } & 129\end{array}$

7.1 General . . . . . . . . . . . . . . . . . . . . . 129

7.2 Initial Ligand Synthesis Method . . . . . . . . . . . . . . . . . 130

7.2.1 Synthesis of the secondary phosphine . . . . . . . . . . 130

7.2.2 Pyridyldiphosphines . . . . . . . . . . . . . . . . . 131

7.3 Improved Ligand Synthesis Method . . . . . . . . . . . . . . . . . . . 131

7.4 Ligand Synthesis using Sodium or Potassium . . . . . . . . . . . . . . 134

7.5 Phosphine Oxides . . . . . . . . . . . . . . . . . . . . . 134

7.5.1 General method . . . . . . . . . . . . . . . . . . 134

7.6 Phosphine Selenides . . . . . . . . . . . . . . . . . . . . 135

7.6.1 General method . . . . . . . . . . . . . . . . 135

7.7 Protonations . . . . . . . . . . . . . . . . . . 137

7.7.1 Protonation of dpypox . . . . . . . . . . . . 137

7.7 .2 Protonation of $\operatorname{dpyp} m \mathrm{x} \ldots \ldots . \ldots 138$

7.7.3 Reaction with $\mathrm{HCl}$ to acheive water-solubility . . . . . . . . . 140

7.8 Borane Protection . . . . . . . . . . . . . . . . . . . . . . . . . . 141

7.8.1 General method . . . . . . . . . . . . . . . . . . 141 
7.8.2 Deprotection method . . . . . . . . . . . . . . . . 141

7.9 Transition Metal Complexes . . . . . . . . . . . . . . . . . . . . 142

7.9.1 Platinum(II) complexes of dpypox . . . . . . . . . . . . 142

7.9.2 Palladium(II) complexes of dpypox . . . . . . . . . . . . . 144

7.9.3 Platinum(II) complexes of dpypp . . . . . . . . . . . . . 145

7.9.4 Palladium(II) complexes of dpypp . . . . . . . . . . . . 146

7.9.5 Unsymmetric platinum(II) complexes of dpypox . . . . . . . . 147

7.9.6 Platinum $(0)$ complexes of dpypox . . . . . . . . . . . . . 156

7.9.7 Palladium $(0)$ complexes of dpypox . . . . . . . . . . 157

7.9.8 Silver(I) complexes of dpypox . . . . . . . . . . . . . 158

7.9 .9 Rhodium complexes of dpypox . . . . . . . . . . . . 159

7.9 .10 Iridium complexes of dpypox . . . . . . . . . . . . . 159

7.9.11 Platinum(II) complexes of dpyp $m$ x . . . . . . . . . . . 162

7.9 .12 Palladium(II) complexes of dpyp $m x$. . . . . . . . . . . . 164

7.10 Trimetallic Complexes . . . . . . . . . . . . . . . . 165

7.10.1 Homotrimetallic complexes of dpypox . . . . . . . . . 165

7.10 .2 Heterotrimetallic complexes of dpypox . . . . . . . . . 168

7.10 .3 Trimetallic complexes of $\operatorname{dpyp} m \mathrm{x} \ldots$. . . . . . . . . . 172

$\begin{array}{lr}\text { References } & 178\end{array}$ 


\section{List of Figures}

1.1 Potential coordination modes of $\mathrm{PPh}_{2} \mathrm{Py} \ldots \ldots \ldots \ldots$

1.2 Schematic representation of the cooperative effect of a $P, N$ ligand. . 6

1.3 Molybdenum complexes of $\mathrm{PPhPy}_{2}$ and $\mathrm{PPy}_{3} \ldots \ldots \ldots \ldots$

1.4 Examples of bimetallic complexes containing $\mathrm{PPhPy}_{2} \ldots \ldots \ldots 11$

1.5 Types of pyridyldiphosphines $\ldots \ldots \ldots \ldots \ldots$

1.6 Two isomers of $\left[\mathrm{RuCl}_{2}(P, P, N\right.$-dpypcp $\left.)\left(\mathrm{PPh}_{3}\right)\right] \ldots \ldots \ldots \ldots$

1.7 A few examples of the xantphos family of ligands. . . . . . . . 15

1.8 The most common pincer ligand backbones. . . . . . . . . 16

1.9 A coordinatively unsaturated pincer complex. . . . . . . . . . 18

$2.1{ }^{31} \mathrm{P}$ NMR spectrum of dpyp $m \times \mathrm{Se}_{2}$ compound $12 \ldots \ldots . \ldots . . .29$

$2.2{ }^{1} \mathrm{H}$ and ${ }^{31} \mathrm{P}$ NMR spectra of protonated ligand $\mathbf{3}$ collected at 20 and

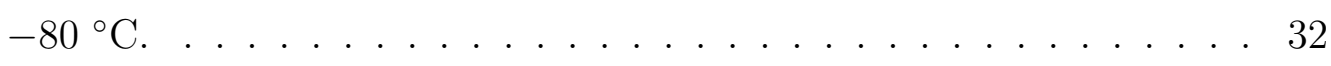

3.1 Fluxional behaviour of $\left[\mathrm{PtX}_{2}(\right.$ dpypox $\left.)\right]$ complexes. . . . . . . . . 39

$3.2 \quad{ }^{1} \mathrm{H}$ NMR spectra of the $\left[\mathrm{PtMe}_{2}(\mathrm{PP})\right]$ complex $\mathbf{1 7}$ collected between 40 and $-80^{\circ} \mathrm{C} \ldots \ldots \ldots \ldots \ldots \ldots \ldots \ldots \ldots \ldots \ldots$

3.3 ORTEP diagrams of $\left[\mathrm{MCl}_{2}(\mathrm{PP})\right]$ complexes $\mathbf{1 6}$ and $\mathbf{2 0} \ldots \ldots \ldots 43$

3.4 ORTEP diagram of $\left[\mathrm{PdCl}_{2}(\mathrm{PP})\right]$ complex $\mathbf{2 0}$ showing the bending of the backbone. . . . . . . . . . . . . . . . 45

3.5 Suzuki cross-coupling of 4-bromoanisole and phenylboronic acid. . . . 46

3.6 ORTEP diagram of $[\mathrm{PtClMe}(\mathrm{PP})]$ complex $27 \ldots \ldots \ldots$

3.7 ORTEP diagram of $[\mathrm{PtClMe}(\mathrm{PP})]$ complex $\mathbf{2 7}$ showing the bending of the backbone. . . . . . . . . . . . . . . . . 52

3.8 NMR spectra of $\left[\mathrm{Pt}(\mathrm{PP})_{2}\right]$ complex $39 \ldots \ldots \ldots \ldots$

$3.9{ }^{1} \mathrm{H}$ NMR spectra of $\left[\mathrm{Pt}(\mathrm{PP})_{2}\right]$ complex 39 collected at 50,20 and

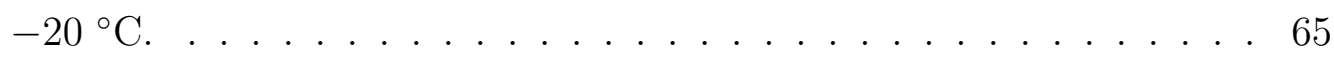

$3.10{ }^{1} \mathrm{H}$ NMR spectra of $\left[\mathrm{Ag}(\mathrm{PP})_{2}\right]^{+}$complex 41 collected between 40 and

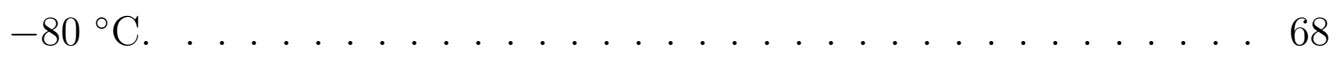

$3.11{ }^{31} \mathrm{P}$ NMR spectra of $\left[\operatorname{Ir}\left(1-\kappa-4,5,6-\eta^{3}-\mathrm{C}_{8} \mathrm{H}_{12}\right)(\mathrm{PPN})\right]^{+}$complex 43 col-

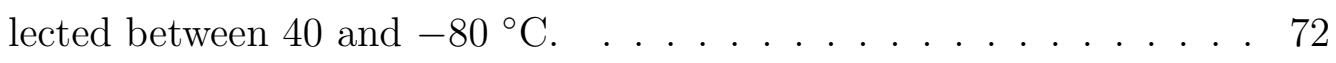

3.12 ORTEP diagram of $\left[\operatorname{Ir}\left(1-\kappa-4,5,6-\eta^{3}-\mathrm{C}_{8} \mathrm{H}_{12}\right)(\mathrm{PPN})\right] \mathrm{BPh}_{4}\left([43] \mathrm{BPh}_{4}\right) . \quad 74$

3.13 ORTEP diagram of $\left[\operatorname{Ir}\left(1-\kappa-4,5,6-\eta^{3}-\mathrm{C}_{8} \mathrm{H}_{12}\right)(\mathrm{PPN})\right]^{+}$complex $43 . \ldots 76$ 
4.1 PCP Pincer ligands . . . . . . . . . . . . . . . . . . . . . . . . 82

4.2 The possible products from the reaction of the dpyp $m \mathrm{x}$ ligand 4 with dichloroplatinum complexes . . . . . . . . . . . . . . . 84

4.3 NMR spectra of $[\mathrm{PtCl}(\mathrm{PCP})]$ complex $49 \ldots \ldots$. . . . . . . . . 89

$5.1{ }^{31} \mathrm{P}$ NMR spectra of the reaction between dpypox and three equivalents of dimethyl(hexa-1,5-diene)platinum . . . . . . . . . . 98

$5.2{ }^{31} \mathrm{P}$ NMR spectrum of the $\left[\left(\mathrm{PtMe}_{2}\right)_{3}(\mathrm{PP})\right]$ complex 55 . . . . . . . . 99

$5.3{ }^{1} \mathrm{H}$ NMR spectrum of the $\left[\{\operatorname{Ir}(\mathrm{COD})\}_{2} \mathrm{PtMe}_{2}(\mathrm{PP})\right]\left\{\mathrm{CH}\left(\mathrm{SO}_{2} \mathrm{CF}_{3}\right)_{2}\right\}_{2}$ compound 61. . . . . . . . . . . . . . . . . . . . . . . . 109 


\section{List of Schemes}

1.1 Schematic representation of hemilabile behaviour. . . . . . . . . . . 3

1.2 Hemilability of a $P, N$ ligand in a $\mathrm{Rh}(\mathrm{I})$ complex. . . . . . . . . . . . 4

1.3 Effect of the trans ligand on hemilabile behaviour. . . . . . . . . . 5

1.4 Synthesis of the $\left[\mathrm{PtMe}\left(P-\mathrm{PPh}_{2} \mathrm{Py}\right)\left(P, N-\mathrm{PPh}_{2} \mathrm{Py}\right)\right]$ complex. . . . . . 7

1.5 Heterolytic cleavage of hydrogen assisted by $\mathrm{PPh}_{2} \mathrm{Py}$. . . . . . . . 8

1.6 Synthesis of a homobimetallic complex of $\mathrm{PPh}_{2} \mathrm{Py}$. . . . . . . . . . 9

1.7 Synthesis of heterobimetallic complexes of $\mathrm{PPh}_{2} \mathrm{Py}$. . . . . . . . . . 9

1.8 Formation of a $P, N, N$ chelate in ruthenium complexes . . . . . . . 10

1.9 Formation of the $\left[\mathrm{Pt}_{2}(\text { dpype })_{2} \mathrm{Ag}_{2}\right]^{6+}$ complex . . . . . . . . . . . 14

1.10 Alkane metathesis. . . . . . . . . . . . . . . . . . 17

2.1 Literature synthesis of 1,2-bis(di-2-pyridylphosphino)ethane . . . . . . 20

2.2 Initial synthesis of dpypox ligand $3 \ldots \ldots$. . . . . . . . . . . 21

2.3 Synthesis of 2-pyridyldiphosphines . . . . . . . . . . . . . . . . . 22

2.4 Formation of the impurity in the ligand synthesis reactions . . . . . . 23

2.5 Formation of $2,2^{\prime}$-bipyridine . . . . . . . . . . . . . . . . . 24

2.6 Synthesis of phosphine selenide 11 . . . . . . . . . . . . . . . 28

2.7 Borane protection of dpypox ligand $3 \ldots \ldots$. . . . . . . . . . . 34

3.1 Synthesis of $\mathrm{Pt}(\mathrm{II})$ and $\mathrm{Pd}(\mathrm{II})$ complexes of the dpypox ligand $\mathbf{3}$. . . 38

3.2 Synthesis of $\mathrm{Pt}(\mathrm{II})$ and $\mathrm{Pd}(\mathrm{II})$ complexes of the dpypp ligand $\mathbf{5}$. . . 47

3.3 Synthesis of the $[\mathrm{PtClMe}(\mathrm{PP})]$ complex $27 \ldots \ldots$. . . . . . . . 48

3.4 Reaction of the $[\mathrm{PtClMe}(\mathrm{PP})]$ complex 27 with competing ligands . . 53

3.5 Reaction of the $[\mathrm{PtClMe}(\mathrm{PP})]$ complex 27 with phosphines . . . . . . 53

3.6 Proposed reaction of $[\mathrm{PtClMe}(\mathrm{PP})]$ complex 27 with $\mathrm{H}_{2} \mathrm{C}\left(\mathrm{SO}_{2} \mathrm{CF}_{3}\right)_{2}$. 56

3.7 Reaction of $[\mathrm{PtClMe}(\mathrm{PP})]$ complex 27 with $\mathrm{NaCH}\left(\mathrm{SO}_{2} \mathrm{CF}_{3}\right)_{2} \ldots \ldots$

3.8 Reaction of the $[\mathrm{PtClMe}(\mathrm{PP})]$ complex 27 with $\mathrm{NaCH}\left(\mathrm{SO}_{2} \mathrm{CF}_{3}\right)_{2}$ and competing ligands . . . . . . . . . . . . . . . . . . . . 5 58

3.9 Reaction of the $[\mathrm{PtMe}(\mathrm{PP})] \mathrm{X}$ complex 33 with $\mathrm{CO} \ldots . . . . . .61$

3.10 Reaction of dpypox ligand 3 with $\mathrm{M}(0)$ alkene complexes . . . . . . . 63

3.11 Reaction of the dpypox ligand 3 with silver salts. . . . . . . . . . . . 66

3.12 Synthesis of $[\operatorname{IrCl}(\mathrm{PP})(\mathrm{COD})]$ complex $42 \ldots \ldots$. . . . . . . . 70

3.13 Synthesis of $\left[\operatorname{Ir}\left(1-\kappa-4,5,6-\eta^{3}-\mathrm{C}_{8} \mathrm{H}_{12}\right)(\mathrm{PPN})\right]^{+}$complex $43 \ldots \ldots$. . . . 71 
3.14 Proposed mechanism for the formation of the $\left[\operatorname{Ir}\left(1-\kappa-4,5,6-\eta^{3}-\mathrm{C}_{8} \mathrm{H}_{12}\right)(\mathrm{PPN})\right]^{+}$ complex 43. . . . . . . . . . . . . . . . . . . . . . . . . 78

3.15 Reaction of $\left[\operatorname{Ir}\left(1-\kappa-4,5,6-\eta^{3}-\mathrm{C}_{8} \mathrm{H}_{12}\right)(\mathrm{PPN})\right]^{+}$complex 43 with $\mathrm{CO}$. . . 79

4.1 Reaction of dpyp $m x$ ligand 4 with dichloroplatinum complexes . . . . 85

4.2 Reaction of dpyp $m$ x ligand 4 with chloromethyl(hexa-1,5-diene)platinum 88

4.3 Reaction of dpyp $m x$ ligand 4 with dimethyl(hexa-1,5-diene)platinum $\quad 90$

4.4 Reaction of dpyp $m$ x ligand 4 with dichlorobis(acetonitrile)palladium 93

5.1 Reaction of the dpypox ligand $\mathbf{3}$ with three equivalents of dimethyl(hexa1,5-diene)platinum . . . . . . . . . . . . . . . . . 9 97

5.2 Synthesis of trimetallic dichloride complexes . . . . . . . . . . . . . 103

5.3 Synthesis of mixed trimetallic complexes . . . . . . . . . . . . . . . . 104

5.4 Reaction of $[\mathrm{PtClMe}(\mathrm{PP})]$ with dimethyl(hexa-1,5-diene)platinum . . 106

5.5 Synthesis of $\left[\{\mathrm{M}(\mathrm{COD})\}_{2} \mathrm{PtMe}_{2}(\mathrm{PP})\right]\left\{\mathrm{CH}\left(\mathrm{SO}_{2} \mathrm{CF}_{3}\right)_{2}\right\}_{2} \ldots \ldots . . .108$

5.6 Synthesis of dimetallic complexes of dpypox ligand 3 . . . . . . . . . 112

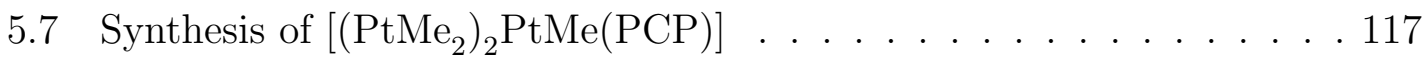

5.8 Synthesis of $\left[\{\mathrm{M}(\mathrm{COD})\}_{2} \mathrm{PtMe}(\mathrm{PCP})\right]\left\{\mathrm{CH}\left(\mathrm{SO}_{2} \mathrm{CF}_{3}\right)_{2}\right\}_{2} \ldots \ldots 119$

5.9 Synthesis of dimetallic complexes of dpyp $m$ x ligand 4 . . . . . . . . 122 


\section{List of Tables}

2.1 Selected ${ }^{1} \mathrm{H}$ and ${ }^{31} \mathrm{P}$ NMR data of the pyridyldiphosphines. . . . . . . 25

2.2 Selected ${ }^{13} \mathrm{C}$ NMR data of the pyridyldiphosphines. . . . . . . . . . . 25

2.3 NMR data of the phosphine selenides . . . . . . . . . . . . . 28

2.4 Selected ${ }^{1} \mathrm{H}$ and ${ }^{31} \mathrm{P}$ NMR data of the protonated compounds . . . . 31

3.1 ${ }^{31} \mathrm{P}$ NMR data of $\mathrm{Pt}(\mathrm{II})$ and $\mathrm{Pd}(\mathrm{II})$ complexes of the dpypox and dpypp ligands. . . . . . . . . . . . . . . . . . . . . 39

3.2 Crystallographic data of $\left[\mathrm{MCl}_{2}(\mathrm{PP})\right]$ complexes $(\mathrm{M}=\mathrm{Pt}$ 16, $\mathrm{Pd}$ 20). 44

3.3 Selected bond distances and angles of $\left[\mathrm{MCl}_{2}(\mathrm{PP})\right]$ complexes $(\mathrm{M}=$ $\mathrm{Pt}$ 16, $\mathrm{Pd}$ 20) . . . . . . . . . . . . . . . . . . . 4 44

3.4 Selected ${ }^{1} \mathrm{H}$ NMR data of $\mathrm{Pt}(\mathrm{II})$ and $\mathrm{Pd}(\mathrm{II})$ complexes of the dpypox and dpypp ligands . . . . . . . . . . . . . . . . . . . . . . 4 48

$3.5{ }^{31} \mathrm{P}$ NMR data of the $[\operatorname{PtMeL}(\mathrm{PP})]$ complexes of dpypox . . . . . . 49

3.6 Crystallographic data of $[\mathrm{PtClMe}(\mathrm{PP})]$ complex $27 \ldots \ldots . . . . .51$

3.7 Selected bond distances and angles of $[\mathrm{PtClMe}(\mathrm{PP})]$ complex 27 . . 51

3.8 Crystallographic data of $\left[\operatorname{Ir}\left(1-\kappa-4,5,6-\eta^{3}-\mathrm{C}_{8} \mathrm{H}_{12}\right)(\mathrm{PPN})\right] \mathrm{BPh}_{4}$ compound $[43] \mathrm{BPh}_{4} \ldots \ldots \ldots \ldots \ldots \ldots$

3.9 Selected bond distances and angles of $\left[\operatorname{Ir}\left(1-\kappa-4,5,6-\eta^{3}-\mathrm{C}_{8} \mathrm{H}_{12}\right)(\mathrm{PPN})\right] \mathrm{BPh}_{4}$ compound $[43] \mathrm{BPh}_{4} \ldots \ldots \ldots \ldots$

4.1 ${ }^{31} \mathrm{P}$ NMR data of the platinum and palladium complexes of dpyp $m \mathrm{x} . \quad 92$

5.1 Selected ${ }^{1} \mathrm{H}$ NMR data of trimetallic complexes of dpypox . . . . . . 101

5.2 IR data of mono- and trimetallic complexes of dpypox . . . . . . . 102

$5.3{ }^{31} \mathrm{P}$ and selected ${ }^{1} \mathrm{H}$ NMR data of the dimetallic complexes of dpypox 111

5.4 Selected ${ }^{1} \mathrm{H}$ NMR data of trimetallic complexes of dpyp $m \mathrm{x}$. . . . . . 118

5.5 IR data of mono- and trimetallic complexes of dpyp $m \mathrm{x}$. . . . . . . . 118

$5.6{ }^{31} \mathrm{P}$ NMR data of dimetallic complexes $[(\mathrm{M}) \mathrm{PtMe}(\mathrm{PCP})] \ldots . . . .121$ 


\section{List of Compounds}<smiles>CCCCCCc1ccccc1CP</smiles>

3

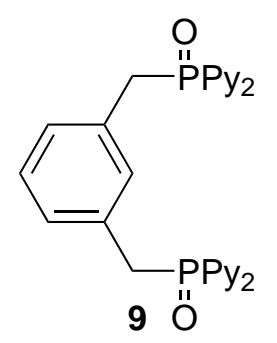<smiles>[18OH]P([Pb])Cc1ccccc1CP[Pb]</smiles>

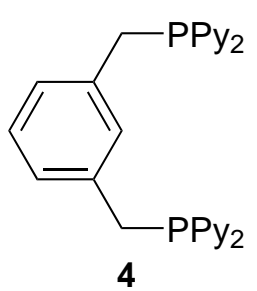

4
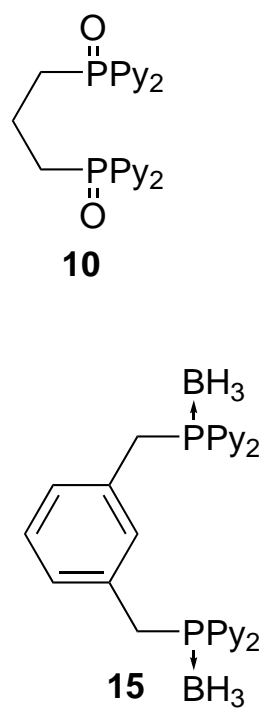

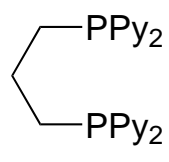

5

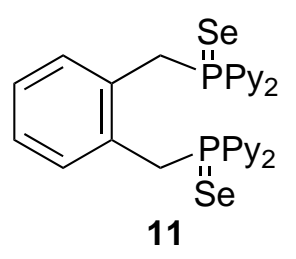<smiles>O=P[PH3+]</smiles>

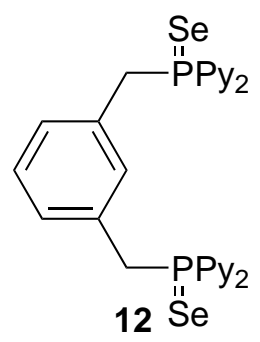

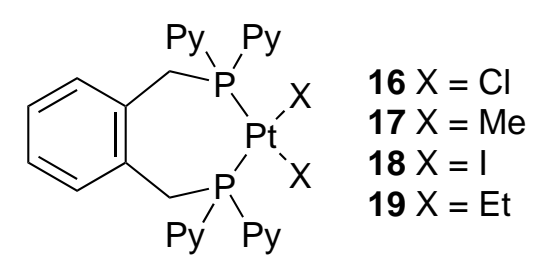<smiles>[Y20][Y20]([H])=[W]</smiles><smiles>[X]C1([Y])[PH]([P])(P)CCCP1([Y])([PH])P</smiles>

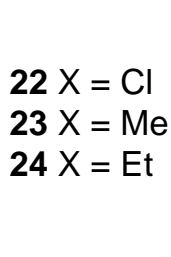<smiles>[X]C1([Y])[PH]([R])([P])CCCP1([Y])([R7])[P]</smiles>

$25 \mathrm{X}=\mathrm{Cl}$ $26 \mathrm{X}=\mathrm{Me}$<smiles>[2H]P1([PH3-])(Cl)Cc2ccccc2C[PH]([PH])([PH])P1(C)([PH])Cl</smiles>

27

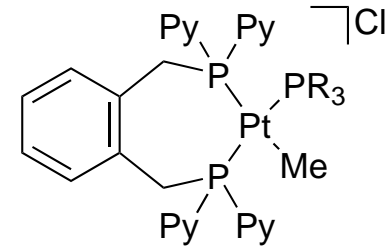

$28 \mathrm{PR}_{3}=\mathrm{PPh}_{3}$ $29 \mathrm{PR}_{3}=\mathrm{PTA}$

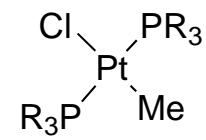

$30 \mathrm{PR}_{3}=\mathrm{PPh}_{3}$ $31 \mathrm{PR}_{3}=\mathrm{PTA}$ 

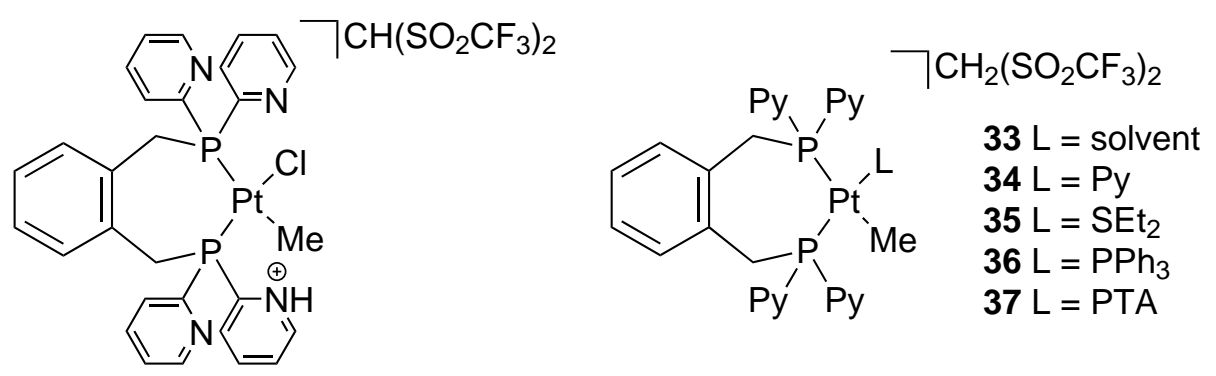

32

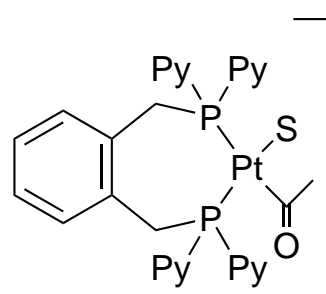

$38 \mathrm{~S}=$ solvent

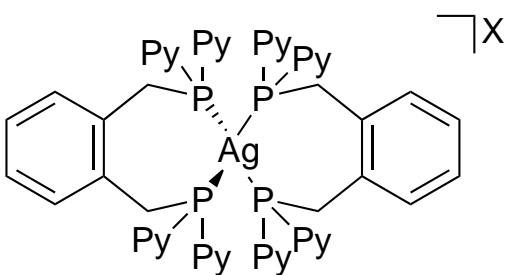

$41 \mathrm{X}=\mathrm{BF}_{4}^{-}, \mathrm{NO}_{3}{ }^{-}$

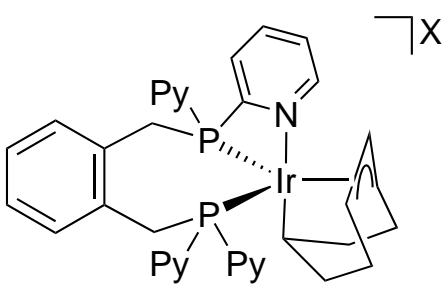

$43 \mathrm{X}=\mathrm{CH}\left(\mathrm{SO}_{2} \mathrm{CF}_{3}\right)_{2}{ }^{-}, \mathrm{BPh}_{4}$

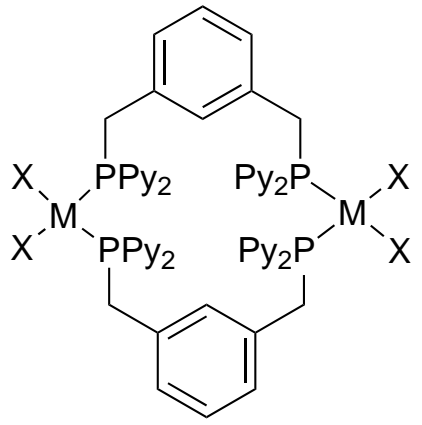

$47 \mathrm{M}=\mathrm{Pt}, \mathrm{X}=\mathrm{Cl}$

$50 \mathrm{M}=\mathrm{Pt}, \mathrm{X}=\mathrm{Me}$

$52 \mathrm{M}=\mathrm{Pd}, \mathrm{X}=\mathrm{Cl}$

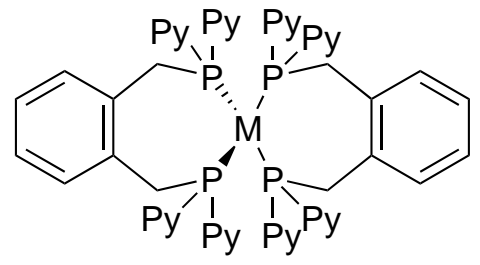

$39 \mathrm{M}=\mathrm{Pt}$

$40 \mathrm{M}=\mathrm{Pd}$

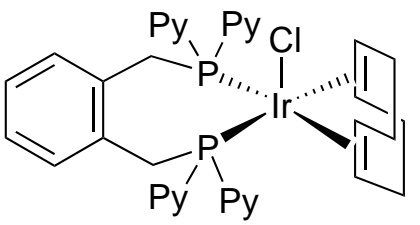

42<smiles>CC(C)[SH](C)(C)OC(C)(C)C</smiles>

44

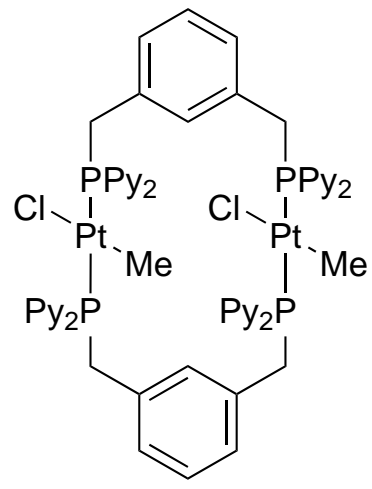

48 


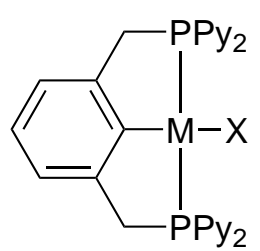

$49 \mathrm{M}=\mathrm{Pt}, \mathrm{X}=\mathrm{Cl}$

$51 \mathrm{M}=\mathrm{Pt}, \mathrm{X}=\mathrm{Me}$

$53 \mathrm{M}=\mathrm{Pd}, \mathrm{X}=\mathrm{Cl}$

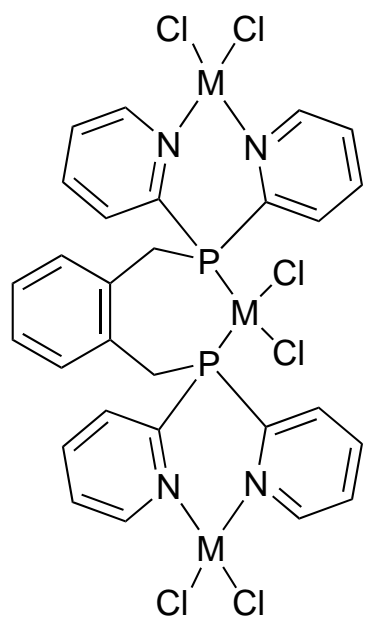<smiles></smiles>

$54[\mathrm{M}]=\mathrm{PtMe}_{2}$

$62[\mathrm{M}]=\mathrm{Rh}(\mathrm{COD})^{+}$

$63[\mathrm{M}]=\operatorname{Ir}(\mathrm{COD})^{+}$<smiles></smiles>

58<smiles></smiles>

$55[\mathrm{M}]=\mathrm{PtMe}_{2}$ $60[\mathrm{M}]=\mathrm{Rh}(\mathrm{COD})^{+}$ $61[\mathrm{M}]=\operatorname{Ir}(\mathrm{COD})^{+}$

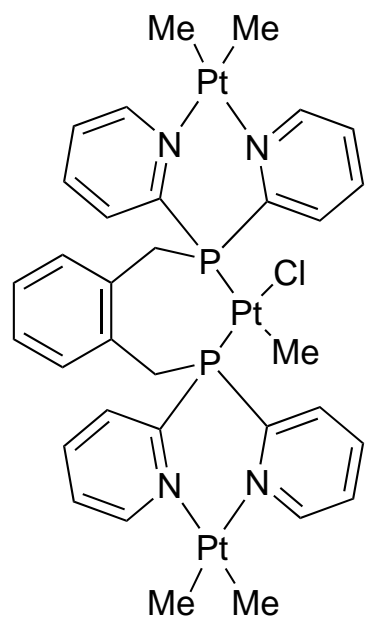

59

$56 \mathrm{M}=\mathrm{Pt}$

$57 \mathrm{M}=\mathrm{Pd}$

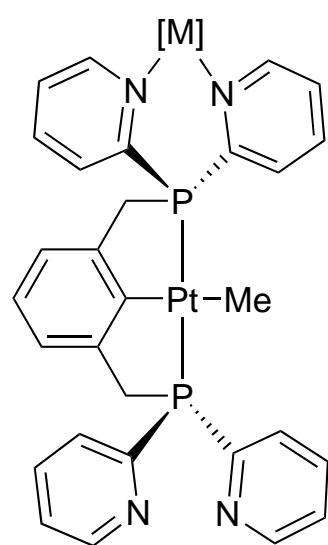

$64[\mathrm{M}]=\mathrm{PtMe}_{2}$ $68[\mathrm{M}]=\mathrm{Rh}(\mathrm{COD})^{+}$ $69[\mathrm{M}]=\operatorname{Ir}(\mathrm{COD})^{+}$

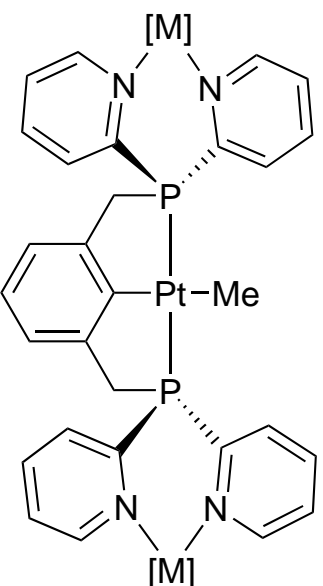

$65[\mathrm{M}]=\mathrm{PtMe}_{2}$ $66[\mathrm{M}]=\mathrm{Rh}(\mathrm{COD})^{+}$ $67[\mathrm{M}]=\operatorname{lr}(\mathrm{COD})^{+}$ 


\title{
Glossary
}

\author{
COD cycloocta-1,5-diene \\ dbpx bis(ditertiarybutylphosphino)-o-xylene \\ dppe 1,2-bis(diphenylphosphino)ethane \\ dppox bis(diphenylphosphino)-o-xylene \\ dppp 1,3-bis(diphenylphosphino)propane \\ dpypcp 1,2-bis(di-2-pyridylphosphino)cyclopentane \\ dpype 1,2-bis(di-2-pyridylphosphino)ethane \\ dpyp $m \mathrm{x} \quad$ bis(di-2-pyridylphosphino)- $m$-xylene \\ dpypox bis(di-2-pyridylphosphino)-o-xylene \\ dpypp 1,3-bis(di-2-pyridylphosphino)propane \\ $\mathrm{Et}_{2} \mathrm{O} \quad$ diethylether \\ IR Infrared spectroscopy \\ Me methyl \\ NMR Nuclear Magnetic Resonance \\ PTA 1,3,5-triaza-7-phosphaadamantane \\ Py 2-pyridyl \\ THF tetrahydrofuran
}

tmeda $\quad N, N, N^{\prime}, N^{\prime}$-tetramethylethane-1,2-diamine

VT-NMR Variable Temperature Nuclear Magnetic Resonance 


\section{Chapter 1}

\section{Introduction}

This thesis provides an account of research into the synthesis and coordination chemistry of pyridyldiphosphine ligands with a xylene based backbone. The coordination modes of these ligands towards platinum, palladium, silver, rhodium and iridium metals were explored. Particular attention was given to attempts to coordinate the pyridyl nitrogen atoms to metal centres, either through chelation or, where these ligands bridge more than one metal centre, to give multimetallic complexes.

\subsection{Coordination Complexes}

The coordination complexes of transition metals have a wide range of potential applications ranging from homogeneous catalysts, ${ }^{1}$ used both in the laboratory and in industrial applications, to biomedical applications, including antitumour drugs and biomedical imaging agents. ${ }^{2,3}$ As such there has been a diverse range of coordination complexes reported and the wide variety of properties displayed by these complexes has been explored.

In transition metal complexes the electron density on the metal centre and the physical environment around the metal are influenced by each ligand present in the complex. When the electron density and environment of the metal centre are modified it affects the properties of the resulting complex. Since the Tolman cone angle and electronic parameter ${ }^{4}$ were first used to quantify the steric and electronic properties, respectively, of a given ligand there have been many reports tabulating the steric and electronic properties of ligands. ${ }^{5-7}$ 
Organophosphorus compounds are common ligands in coordination chemistry. Tertiary phosphines in particular are very versatile ligands as the steric and electronic properties of these ligands can be tuned easily by varying the substituents on the phosphorus donor atom. Also phosphines are useful ligands as they can coordinate to both hard and soft metals in a range of oxidation states. Thus a wide variety of tertiary phosphine complexes have been reported which possess a range of useful properties.

Diphosphine ligands are one of the most common types of bidentate ligands. When these ligands chelate to metal atoms the resulting complexes are more thermodynamically stable than those with comparable monodentate ligands, due to the chelate effect. ${ }^{8}$ Chelating ligands provide extra control over the environment of the metal centre through greater conformational rigidity and manipulation of the bite angle. The bite angle is the ligand-metal-ligand angle formed when a bidentate or polydentate ligand coordinates to a metal centre. ${ }^{8}$ It can be calculated from the crystal structure of a given complex or using computational methods (the "natural" bite angle). ${ }^{9,10}$ When the backbone of the ligand is modified it changes the bite angle of a ligand, which can have a significant effect on the rate and selectivity in transition metal catalysed reactions. ${ }^{11}$ Chelating ligands often enforce a cis coordination of the ligands. This is an advantage in catalysis where the substrates bound to the metal often have to be cis in order to react (for example hydride migration).

Ligands that coordinate to the metal centre through a nitrogen donor atom are also very common in coordination chemistry and homogeneous catalysis. ${ }^{12}$ Given the hard nature of the nitrogen donor atom and their limited $\pi$ back-bonding ability, ligands with nitrogen donors are more limited in their coordination chemistry than phosphorus based ligands. ${ }^{12}$ Moreover, polydentate ligands containing both phosphorus and nitrogen donor atoms have displayed interesting coordination behaviour.

\subsection{Phosphorus-Nitrogen Ligands}

Recently there has been significant interest in polydentate ligands containing phosphorus and nitrogen donor atoms. This is due to the fact that ligands with both soft phosphorus and hard nitrogen donor atoms display a diverse coordination chemistry well beyond that displayed by classical $P, P$ or $N, N$ ligands. One of the important features of $P, N$ ligands is their ability to stabilise metals in a range of oxidation states and geometries. The phosphorus donor is considered to be a "soft" Lewis base and can stabilise "soft" Lewis acids, such as metal centres in low oxidation states. 
In contrast, nitrogen donors are "hard" ligands and therefore are better ligands for "hard" metal centres like those high oxidation states. ${ }^{12}$ Thus these donor atoms often display selective binding to metal ions of different types. ${ }^{13}$

A wide range of $P, N$ ligands has been synthesised. While the majority of the phosphorus donor groups have diaryl or dialkylphosphino moieties, there are many different types of nitrogen donors including amines, imines, pyridines, amides and nitriles. These ligands have been used extensively in coordination chemistry and as ligands in catalysis.

Ligands with both phosphorus and nitrogen donor atoms can potentially display hemilabile behaviour. "Hemilability", a term first used by Jeffery and Rauchfuss in $1979,{ }^{14}$ describes the ability of the weakly bound donor atom in a hybrid ligand to reversibly dissociate while the other donor atom remains coordinated to the metal centre. In the case of $P, N$ ligands coordinated to late transition metals, the phosphorus atom anchors the ligand to the metal centre while the weakly bound nitrogen donor is able to dissociate and recoordinate (Scheme 1.1).

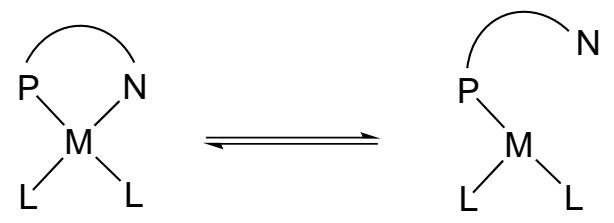

Scheme 1.1 Schematic representation of hemilabile behaviour.

When hemilability is displayed by a $P, N$ ligand it can be due to the dissociation of one donor before the coordination of another or through an associative mechanism where the weakly bound nitrogen donor is displaced by another small molecule. For example, the rhodium(I) complex shown in Scheme 1.2 was observed to display fluxional behaviour in solution. ${ }^{15}$ This fluxional behaviour was attributed to the exchange of the bound and free amino groups in the two aminophosphine ligands. It was also found that the coordinated amine could be displaced by carbon monoxide or ethene.

This behaviour is an advantage in homogeneous catalysis and has led to complexes of $P, N$ ligands being investigated as catalysts. When the more weakly bound atom dissociates it creates a vacant coordination site where a substrate can bind and undergo a transformation, while the facile recoordination of the donor stabilises the catalyst resting state.

When $P, N$ ligands bind to metal centres the combination of the hard nitrogen donor group and the soft phosphorus donor group creates asymmetry in the metal orbitals. This affects the properties of the ligands bound trans to the donor atoms. 

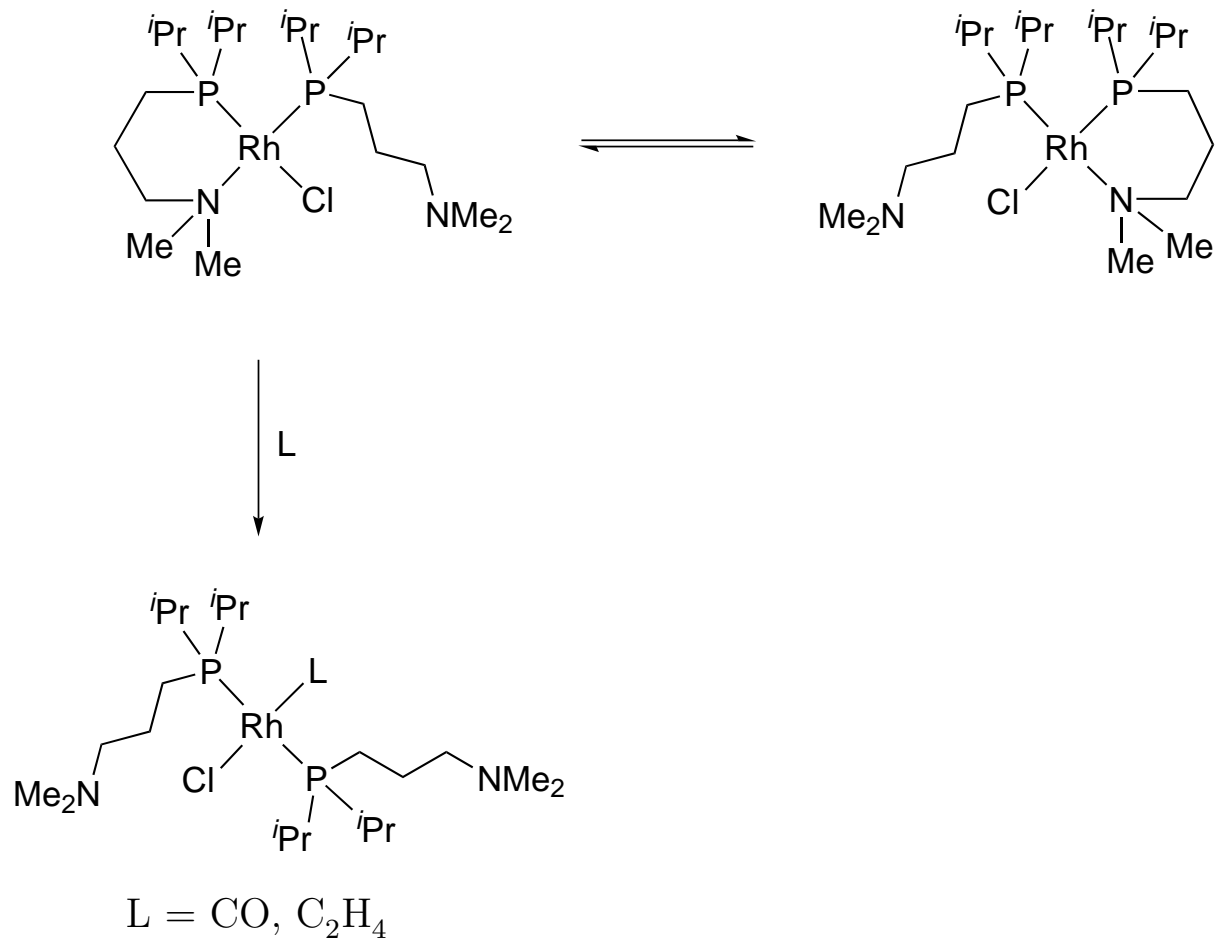

Scheme 1.2 Hemilability of a $P, N$ ligand in a Rh(I) complex.

For example, if a given ligand is bound trans to the phosphorus donor atom the $\mathrm{M}-\mathrm{L}$ bond length would generally be longer than if it were bound trans to the nitrogen donor atom. This is due to the phosphine ligand having a higher trans influence than nitrogen-based ligands. ${ }^{16,17}$ This asymmetry in the metal orbitals also affects the lability of the ligands trans to the different donor atoms (trans effect) and thus the reactivity of the metal complex. The consequences of the trans effect can be observed in the example shown in Scheme 1.3. The two isomers of the ruthenium(II) complex differ in the position of the $\mathrm{PPh}_{3}$ ligand: it is either trans to the pyridyl ligand (Scheme 1.3(top)) or the ether ligand (Scheme 1.3(bottom)). This difference has a striking effect on the reactivity of these isomers. In both isomers the donor group trans to the $\mathrm{PPh}_{3}$ ligand was found to be more labile due to the strong trans effect of the $\mathrm{PPh}_{3}$ ligand. ${ }^{18}$

The potential for hemilability and the difference in trans influence and trans effect make the coordination chemistry of $P, N$ ligands interesting. These properties have also led to the complexes of $P, N$ ligands being investigated as potential catalysts in a range of reactions. ${ }^{19}$ 


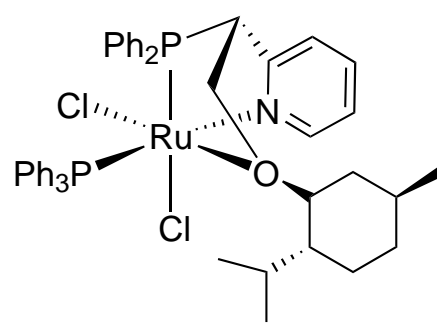<smiles>CC(C)[C@H]1CC[C@@H](C)C[C@H]1O[Pb](Cl)([PbH])[Pb](Cl)([PbH])[PbH]</smiles>

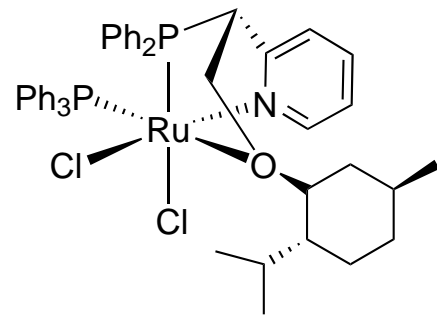

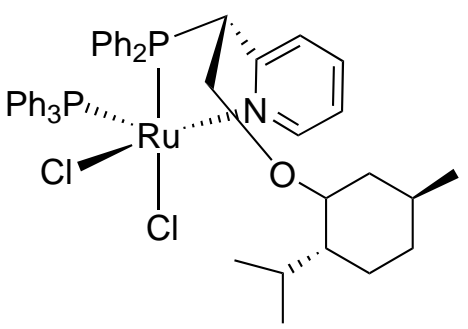

Scheme 1.3 Effect of the trans ligand on hemilabile behaviour.

\subsection{Pyridylphosphines}

Pyridylphosphines are among the most widely studied $P, N$ ligands and are attractive ligands for coordination chemistry. ${ }^{20-22}$ They have been important in the development of water-soluble catalysts ${ }^{23}$ and their silver(I) and gold(I) complexes have proven useful in inorganic medicinal chemistry. ${ }^{2}$

One of the reasons pyridylphosphines are considered to be interesting ligands is due to the different coordination modes they can display. For example, the extensively studied (2-pyridyl)diphenylphosphine $\left(\mathrm{PPh}_{2} \mathrm{Py}\right)$ has four potential bonding modes: monodentate- $P$, chelating- $P, N$, bridging- $P, N$ and monodentate- $N$ (Figure 1.1). ${ }^{21}$<smiles>[M]P(c1ccccc1)c1ccccn1</smiles><smiles></smiles>

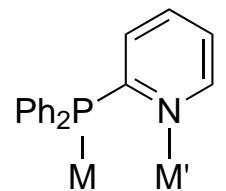<smiles></smiles>

Figure 1.1 Potential coordination modes of $\mathrm{PPh}_{2} \mathrm{Py}$.

In reactions with late transition metals, such as platinum and palladium, pyridylphosphines such as $\mathrm{PPh}_{2} \mathrm{Py}$ usually coordinate through the phosphorus atom alone. ${ }^{24,25}$ While complexes where $\mathrm{PPh}_{2} \mathrm{Py}$ is coordinated through the phosphorus alone can be considered to be similar to the $\mathrm{PPh}_{3}$ complex, the presence of the nitrogen in the pyridyl ring increases the electron density in the ligand and has the potential to alter the Lewis basicity of the phosphine and thus affect the oxidative addition reactions of metal complexes containing these ligands. ${ }^{26}$

In complexes of pyridylphosphines, the uncoordinated pyridyl rings can provide 
an added advantage in catalysis as they can activate a reactant molecule such as water through a secondary hydrogen-bonding interaction. ${ }^{27} \mathrm{~A}$ hydrogen-bonding interaction and subsequent improvement in catalytic activity has been observed when $\mathrm{PPh}_{2} \mathrm{Py}$ was used as a ligand in the catalytic hydration of alkynes and nitriles, and in alkene isomerisation. ${ }^{28-30}$

Catalyst systems where a pendant group on one of the ligands can interact in an advantageous manner with a substrate have been labelled "bifunctional catalysts". ${ }^{27}$ This is due to the fact that the metal ion is acting as a Lewis acid towards the substrate, while the ligand is acting as a Lewis base towards the other reactant. Thus in the hydration of alkynes or nitriles, the alkyne/nitrile is activated through coordination to the metal centre and the nucleophilic attack of water is promoted by a hydrogen-bonding interaction with the pyridyl nitrogen on the ligand, leading to a higher local concentration of reactants and intramolecular nucleophilic attack (Figure 1.2). ${ }^{27}$

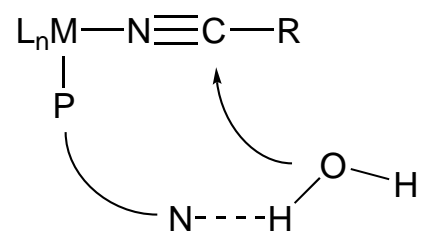

Figure 1.2 Schematic representation of the cooperative effect of a $P, N$ ligand.

Grotjahn and co-workers have reported that $\left[\mathrm{RuCp}(\mathrm{P})_{2}\left(\mathrm{CH}_{3} \mathrm{CN}\right)\right] \mathrm{PF}_{6}$, where $\mathrm{P}$ is a derivative of $\mathrm{PPh}_{2} \mathrm{Py}$ with a tert-butyl group in the 3 position on the pyridyl ring, exhibited an enzyme-like enhancement of rate and selectively in the anti-Markovnikov hydration of terminal alkynes. ${ }^{31}$ This catalyst system also displayed wide functional group tolerance and excellent selectivity.

While Grotjahn's ruthenium catalyst was found to be inactive for the hydration of nitriles, Oshiki and co-workers found that cis- $\left[\mathrm{Ru}(\mathrm{acac})_{2}\left(\mathrm{PPh}_{2} \mathrm{Py}\right)_{2}\right]($ acac $=$ acetylacetonate) was a highly active catalyst for the hydration of a range of aromatic and alphatic nitriles to amides. ${ }^{29}$ The directing effect of the pyridyl ring resulted in a quantitative yield after 10 minutes. In comparison a yield of $66 \%$ was obtained after 24 hours when $\mathrm{PPh}_{3}$ was used in place of $\mathrm{PPh}_{2} \mathrm{Py} .{ }^{29}$ The higher activity of the $\mathrm{PPh}_{2} \mathrm{Py}$ complex was attributed to the uncoordinated pyridyl units of the $\mathrm{PPh}_{2} \mathrm{Py}$ ligands activating the water molecules for the key nucleophilic addition step in this reaction. ${ }^{29}$ Subsequent computational, mechanistic and structural studies support this conclusion. ${ }^{28}$

In particular, NMR studies with ${ }^{15} \mathrm{~N}$-labelled pyridyl groups on the ligand in the catalyst have been extremely useful in determining the identity of the intermediates in the catalyst mixtures. Through comparison of the ${ }^{15} \mathrm{~N}$ NMR data of the 
free ligand, catalyst derivatives and the spectroscopically detectable species in the reaction mixtures, evidence of the pyridyl group participating in hydrogen-bonding and being protonated during the reaction was observed. ${ }^{28,30}$

The hydration of nitriles is a very important reaction from an industrial perspective, with amides such as acrylamide used as starting materials to make a range of polymeric products, which are used in anything from water treatments to paper strengthening and adhesives. ${ }^{32}$ Amides are also important building blocks in synthetic organic chemistry and have a wide range of applications in the pharmaceutical industry. ${ }^{33,34}$ Thus any improvement to the synthesis of amides is desirable.

A common route to a $P, N$-chelate complex is to first form a complex with the ligand acting as a monodentate- $P$ ligand and then abstract one of the other ligands, usually a chloride, to form the $P, N$ chelate. For example, when the $\left[\mathrm{PtClMe}\left(\mathrm{PPh}_{2} \mathrm{Py}\right)_{2}\right]$ complex is reacted with $\mathrm{NaBF}_{4}$ in dichloromethane the chloride ligand is abstracted and the pyridyl nitrogen binds to the metal (Scheme 1.4). ${ }^{24}$
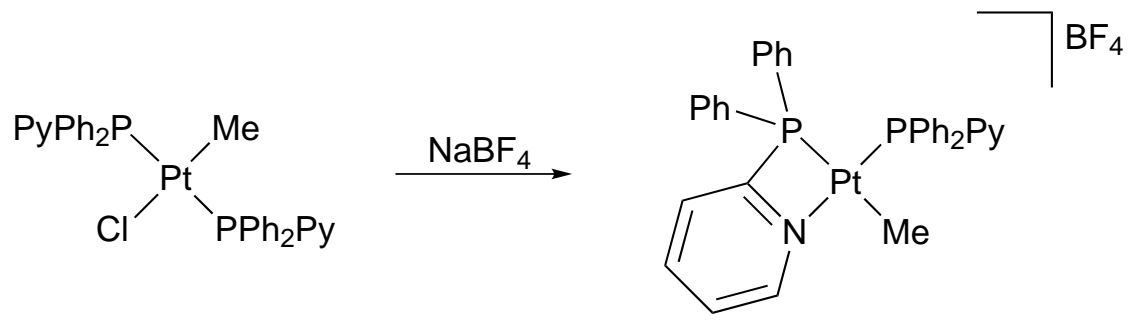

Scheme 1.4 Synthesis of the $\left[\mathrm{PtMe}\left(P-\mathrm{PPh}_{2} \mathrm{Py}\right)\left(P, N-\mathrm{PPh}_{2} \mathrm{Py}\right)\right]$ complex.

Another method for the synthesis of complexes with a $P, N$ chelated $\mathrm{PPh}_{2} \mathrm{Py}$ ligand is shown in Scheme 1.5. ${ }^{35}$ When the complex with the chelated $\mathrm{PPh}_{2} \mathrm{Py}_{\mathrm{P}}$ ligand was put under hydrogen pressure the pyridyl nitrogen dissociates to create a vacant site at the metal centre. However, this example illustrates a further advantage of pyridylphosphine ligands, the ability of the pyridyl nitrogen to act as an internal base. In this reaction the presence of this internal base assists the heterolytic cleavage of the hydrogen to give a hydride ligand and a protonated pyridyl ring.

It has been proposed that sometimes, where a stable chelate is not formed, the transient coordination of the pyridyl nitrogen atom allows the formation of species that would otherwise be unstable. For example, while the $\mathrm{PPh}_{2} \mathrm{Py}$ and $\mathrm{PPh}_{3}$ ligands may be considered very similar, when an excess of $\mathrm{PPh}_{2} \mathrm{Py}$ is present the $\left[\mathrm{Pt}\left(\mathrm{PPh}_{2} \mathrm{Py}\right)_{3}\right]$ complex is the only platinum(0) species detected in solution. In contrast, under the same conditions $\mathrm{PPh}_{3}$ forms $\left[\mathrm{Pt}\left(\mathrm{PPh}_{3}\right)_{4}\right] .{ }^{36}$ However, it is well known that nitrogen donors are not good ligands for "soft" metal centres like platinum(0). For example, when tris(norbornene)platinum is reacted with iminophosphines of the type $o$ - $\left(\mathrm{PPh}_{2}\right) \mathrm{C}_{6} \mathrm{H}_{4} \mathrm{CH}=\mathrm{NR}$, no interaction between the imine nitrogen and the 

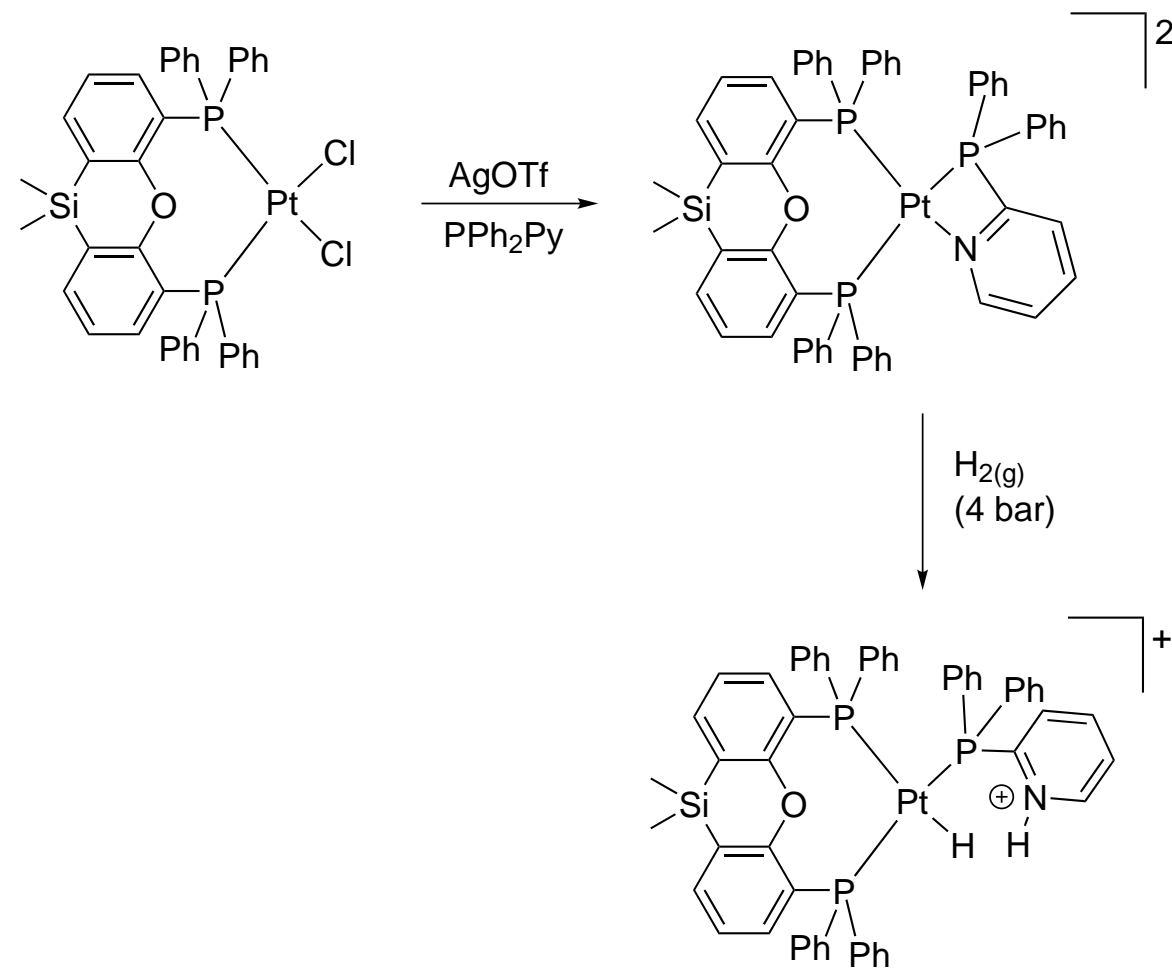

Scheme 1.5 Heterolytic cleavage of hydrogen assisted by $\mathrm{PPh}_{2} \mathrm{Py}$.

platinum(0) centre is observed. ${ }^{37}$ Thus it is unlikely that $\left[\mathrm{Pt}\left(\mathrm{PPh}_{2} \mathrm{Py}\right)_{3}\right]$ was formed due to transient coordination of the pyridyl nitrogen atom to the platinum(0) centre.

There have been many reports of $\mathrm{PPh}_{2} \mathrm{Py}$ acting as a bridging ligand to form bimetallic complexes. ${ }^{25,38-44}$ This is due to the small bite angle of this ligand favouring the formation of $\mathrm{M}-\mathrm{M}$ bonds. Compounds with several metal centres in close proximity often exhibit interesting properties. They usually display different properties to the monometallic fragments that they are composed of. Some of the attractive properties include cooperative reactivity patterns, higher catalytic activity or different selectivity than the monometallic moieties, as well as unusual ligand coordination modes. ${ }^{22}$

The synthesis of bimetallic complexes containing $\mathrm{PPh}_{2} \mathrm{Py}$ as a bridging ligand can be achieved in one of two ways. Firstly, $\mathrm{PPh}_{2} \mathrm{Py}$ can be reacted directly with the appropriate amount of precursor complex. This is often the method used when synthesising homobimetallic complexes. ${ }^{42}$ An example of this method is shown in Scheme 1.6, where $\mathrm{PPh}_{2} \mathrm{Py}$ is reacted with an equimolar amount of a silver salt and the unexpected bimetallic silver complex with three bridging $\mathrm{PPh}_{2} \mathrm{Py}$ ligands results. $^{42}$

The second method involves first making the monometallic complex containing $\mathrm{PPh}_{2} \mathrm{Py}$ acting as a monodentate- $P$ ligand. This complex is then reacted with 
<smiles>Pc1ccccn1</smiles>
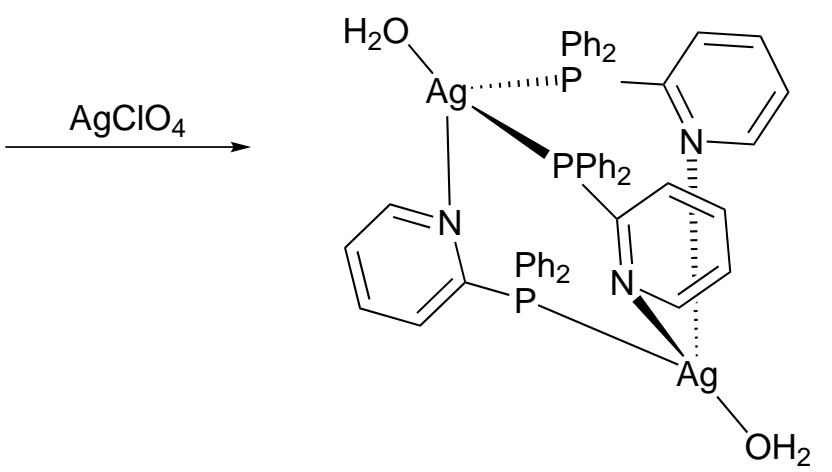

Scheme 1.6 Synthesis of a homobimetallic complex of $\mathrm{PPh}_{2} \mathrm{Py}$.

another equivalent of precursor complex. This method is most commonly employed for the synthesis of heterobimetallic complexes. For example, in Scheme 1.7 the gold(I) complex is reacted with half an equivalent of a rhodium or iridium dimer, $[\mathrm{M}(\mathrm{COD})(\mu-\mathrm{Cl})]_{2}(\mathrm{COD}=$ cycloocta-1,5-diene), to give bimetallic complexes with a metal-metal bond bridged by the $\mathrm{PPh}_{2} \mathrm{Py}$ ligand. ${ }^{25}$
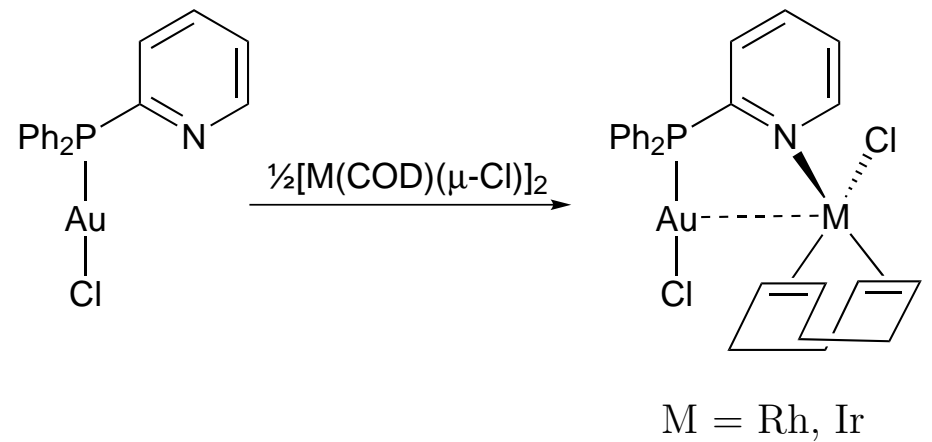

Scheme 1.7 Synthesis of heterobimetallic complexes of $\mathrm{PPh}_{2} \mathrm{Py}$.

These bimetallic $\mathrm{Au} / \mathrm{Rh}$ and $\mathrm{Au} / \mathrm{Ir}$ complexes display luminescence. It was found that the luminescence depended on the second metal present ( $\mathrm{Rh}$ or $\mathrm{Ir}$ ) and the interactions between the two metals. ${ }^{25}$ Bimetallic complexes of $\mathrm{PPh}_{2} \mathrm{Py}$ often display interesting photophysical properties, both in solution and in the solid state. ${ }^{38}$

The substitution of the phenyl rings on the phosphorus atom for pyridyl rings gives bis(2-pyridyl)phenylphosphine $\left(\mathrm{PPhPy}_{2}\right)$ and tris(2-pyridyl)phosphine $\left(\mathrm{PPy}_{3}\right)$ ligands. These ligands are capable of even more bonding modes, including $P, N, N$ chelating, ${ }^{45} \mathrm{~N}, \mathrm{~N}$-chelating, ${ }^{46} \mathrm{~N}, \mathrm{~N}, \mathrm{~N}$-chelating (for $\mathrm{PPy}_{3}$ ) ${ }^{45}$ and $P, N, N$-bridging. ${ }^{47,48}$

When these ligands coordinate through only the phosphorus donor atom the free pyridyl nitrogens can participate in hydrogen-bonding interactions. The benefits of this in catalysis have already been discussed. However, this potential for hydrogenbonding can also lead to complexes of these ligands being soluble in water. ${ }^{49}$ In the cases where the neutral complex is not water-soluble the pyridyl nitrogens can be 
protonated to achieve reversible water-solubility.

The coordination of the pyridyl nitrogen donors alone has been achieved for both $\mathrm{PPhPy}_{2}$ and $\mathrm{PPy}_{3} \cdot{ }^{45,46,50-54}$ Figure 1.3 shows the two analogous molybdenum carbonyl complexes of $\mathrm{PPhPy}_{2}$ and $\mathrm{PPy}_{3}$ coordinated through only the pyridyl nitrogen atoms. ${ }^{46,50}$ This coordination mode has also been reported in $\mathrm{Fe}, \mathrm{Ru}, \mathrm{Co}, \mathrm{Ni}, \mathrm{Cu}$ and Zn complexes. ${ }^{45,51-54}$
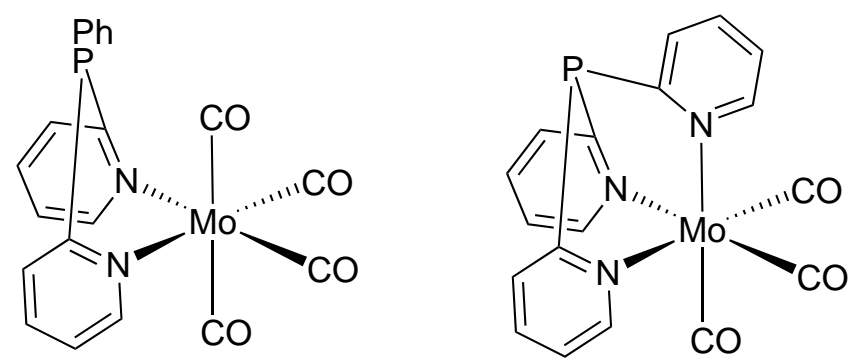

Figure 1.3 Molybdenum complexes of $\mathrm{PPhPy}_{2}$ and $\mathrm{PPy}_{3}$ coordinating through the nitrogen donors alone.

The $P, N, N$ bonding mode has been reported for ruthenium complexes of both $\mathrm{PPh}_{2} \mathrm{Py}$ and $\mathrm{PPy}_{3} .{ }^{45}$ In this case chelation was achieved in one of two ways. The first was through reaction of $\left[\mathrm{RuCl}_{2}\left(\mathrm{PPh}_{3}\right)_{3}\right]$ with the pyridylphosphine and ammonium hexafluorophosphate (Scheme 1.8(top)). The second was through the dissociation of a chloride ligand (Scheme 1.8(bottom)).<smiles></smiles>

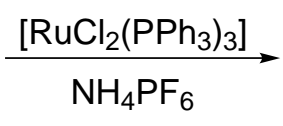

$\mathrm{R}=\mathrm{Ph}, \mathrm{Py}$

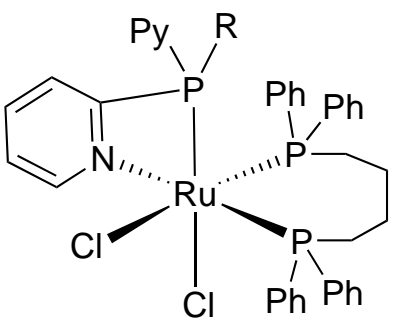

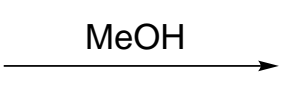

$$
\mathrm{R}=\mathrm{Ph}, \mathrm{Py}
$$

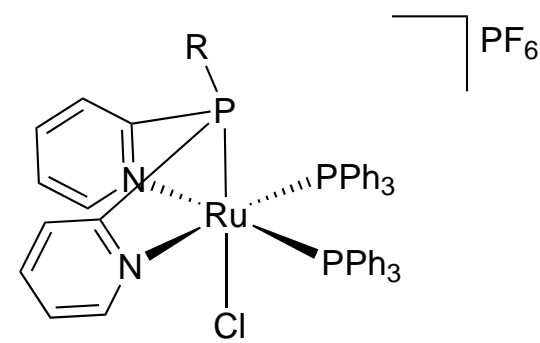

Scheme 1.8 Formation of a $P, N, N$ chelate in ruthenium complexes.

Unsurprisingly, this $P, N, N$ coordination mode is highly strained, due to the formation of two four-membered rings. Thus these complexes readily react to relieve this strain. As a consequence these complexes display hemilabile behaviour, with one 
of the pyridyl nitrogen donors reversibly displaced by carbon monoxide or chloride ligands at room temperature. ${ }^{45}$ This reactivity suggests that these complexes could be effective catalysts as they react readily with potential ligands but the pyridyl nitrogen can recoordinate to stabilise the complex in the absence of an extra ligand.

In a similar manner to the synthesis of bimetallic complexes of $\mathrm{PPh}_{2} \mathrm{Py}$, bimetallic complexes of $\mathrm{PPhPy}_{2}$ and $\mathrm{PPy}_{3}$ are generally synthesised through either the direct reaction of the free ligand with the appropriate metal precursor complex ${ }^{55}$ or by reacting a preformed complex, where the ligand acting as a monodentate- $P$ ligand, with another metal complex. ${ }^{48}$ In the heterobimetallic complexes, the metals coordinated to the phosphorus are often considered to be soft metal centres, like platinum and gold, while the pyridyl nitrogen atoms are coordinated to harder metal centres such as rhodium. ${ }^{47,48}$

Figure 1.4 shows two examples of bimetallic complexes with $\mathrm{PPhPy}_{2}$ acting as a $P, N, N$ ligand. The silver complex was formed through the direct reaction of $\mathrm{PPhPy}_{2}$ with silver nitrate. ${ }^{55}$ Single crystal X-ray analysis showed that there was interaction between the two silver atoms, which confirms that complexes with more than one bridging pyridyl ring can still form metal-metal bonds. This complex was also found to possess antimicrobial activity and luminescent properties. ${ }^{55}$
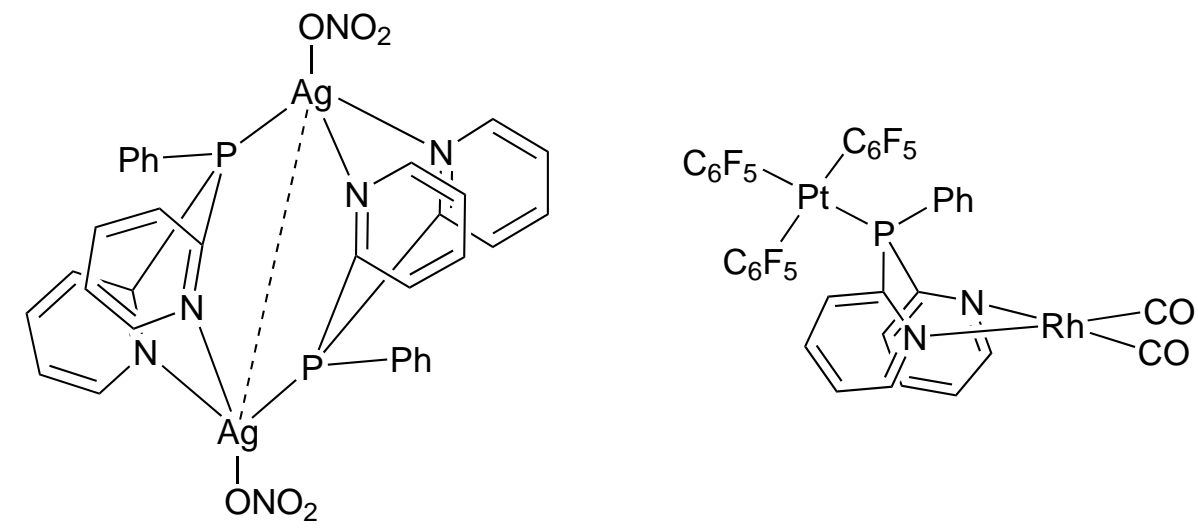

Figure 1.4 Examples of bimetallic complexes containing $\mathrm{PPhPy}_{2}$.

In contrast, in the zwitterionic platinum/rhodium complex there is no metal-metal interaction. ${ }^{47}$ This complex was formed through the reaction of $\left[\mathrm{Pt}\left(\mathrm{C}_{6} \mathrm{~F}_{5}\right)_{3}\left(\mathrm{PPhPy}_{2}\right)\right]^{-}$ with $[\mathrm{Rh}(\mathrm{COD})]^{+}$. From these two examples it can be seen that when the $P, N, N$ bridging mode is adopted a six-membered chelate ring is formed. From the structures of these two complexes and others it is known that the chelate ring adopts a boat conformation (Figure 1.4). This led to the formation of isomers of the $\mathrm{Pt} / \mathrm{Rh}$ complex as, with respect to the boat conformation of the chelate ring, the platinum centre can either coordinate in the axial or equatorial position (as it has been drawn in Figure 1.4). 
There are many more examples of monophosphorus pyridylphosphines where the substituents on the phosphorus have been altered to vary the properties of the ligand or spacers inserted between the phosphorus and the pyridyl ring to make $P, N$ chelation more favourable. These changes would lead to the formation of a fiveor six-membered ring rather than the strained four-membered ring that forms for $\mathrm{PPh}_{3-\mathrm{n}} \mathrm{Py}_{\mathrm{n}}$ ligands. However, this work is interested in the potential hemilability of the pyridyl nitrogen and the formation of a high energy four-membered ring has been shown to lead to interesting reactivity in complexes containing $P, N$ chelated ligands. Thus this work will focus on pyridylphosphine ligands with pyridyl rings directly attached to the phosphorus donors.

\subsubsection{Pyridyldiphosphines}

In contrast to the $\mathrm{PPh}_{3-\mathrm{n}} \mathrm{Py}_{\mathrm{n}}$ ligands discussed above, pyridyldiphosphines have received far less attention. There are two distinct types of pyridyldiphosphines: those with the pyridyl ring as part of the ligand backbone, such as type I and II in Figure 1.5, and those with pyridyl rings as substituents on the phosphorus atoms, type III.<smiles>[R6]c1cccc(P)n1</smiles>

I<smiles>O=Pc1cccc(CP)n1</smiles>

II

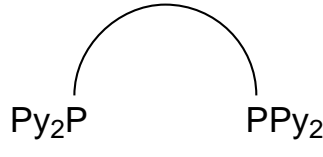

III

Figure 1.5 Types of pyridyldiphosphines.

Ligands of type I frequently bridge metal centres and have been used to form multimetallic complexes. ${ }^{56}$ Often in these complexes the ligand can act as both a bridging $P, N$ ligand and a chelating $P, N$ ligand to different metal centres. ${ }^{57}$

The introduction of the $\mathrm{CH}_{2}$ spacer between the phosphorus donor atoms and the pyridine backbone (type II) provides extra flexibility in the backbone and means that this type of ligand prefers to act as a pincer ligand. Complexes of these ligands have been found to be catalytically active in a range of reactions including the hydroamination of alkenes and the polymerisation of buta-1,3-diene. ${ }^{58,59}$

Pyridyldiphosphines of type III are potentially hexadentate ligands. However, there are few examples of them acting as such. Most often they act as diphosphine ligands with non-coordinated pyridyl rings. For example in the silver(I), gold(I) and copper(I) complexes of 1,2-bis(di-2-pyridylphosphino)ethane (dpype) the ligand acted 
as a chelating and bridging $P, P$ ligand but the pyridyl rings did not interact with the metal centres. ${ }^{2,3,60,61}$

The gold(I) complex $\left[\mathrm{Au}(\mathrm{PP})_{2}\right] \mathrm{Cl}(\mathrm{PP}=1,2$-bis(diphenylphosphino)ethane, dppe) shows high antitumour activity against a range of tumour models in mice. ${ }^{2}$ Unfortunately, this complex displays almost no selectivity for cancer cells over normal cells, which means it cannot be used clinically. Studies have shown that substituting alkyl groups for the phenyl substituents on the phosphorus atoms results in a loss of all activity. However, if pyridyl rings replaced the phenyl rings on the phosphorus atoms the activity was retained. ${ }^{61}$ Thus the $\left[\mathrm{M}(\mathrm{PP})_{2}\right] \mathrm{Cl}$ complexes $(\mathrm{M}=$ $\mathrm{Ag}, \mathrm{Au}, \mathrm{Cu} ; \mathrm{PP}=$ dpype) have been extensively studied as they have shown antitumour activity. ${ }^{3,62,63}$ In the $\mathrm{Ag}(\mathrm{I})$ and $\mathrm{Au}(\mathrm{I})$ complexes the hydrophilic/lipophilic balance of the complexes was modified by varying the position of the pyridyl nitrogen atom, by using 1,2-bis(di-3-pyridylphosphino)ethane (d3pype) and 1,2-bis(di4-pyridylphosphino)ethane (d4pype) in the place of dpype. ${ }^{61}$ This difference in lipophilicity was found to affect the cellular uptake, tumour selectivity and host toxicity of the complexes. ${ }^{62,63}$ Thus the selectivity of the complexes for cancer cells over normal cells can be improved by adjusting the hydrophilicity of these complexes of bidentate phosphines. ${ }^{2,60-62}$

The position of the pyridyl nitrogen atom also influences the complexes formed, with monomeric $\left[\mathrm{M}(\mathrm{PP})_{2}\right] \mathrm{X}$ complexes $(\mathrm{M}=\mathrm{Ag}, \mathrm{Au})$ formed when the diphosphine used was d3pype or d4pype. In contrast, dpype forms an equilibrium between the monomeric complexes and dimers and trimers, where the ligand is acting as a bridging $P, P$ ligand. ${ }^{60,61}$

The lipophilicity of these complexes was also modified by changing the length of the alkane backbone. When 1,3-bis(di-2-pyridylphosphino)propane (dpypp) was used in the place of dpype the resulting gold(I) complex was slightly more lipophilic than the analogous dpype complex, but still within the optimal range for application as an antitumour agent. ${ }^{62,64}$ Thus $\left[\mathrm{Au}(\mathrm{PP})_{2}\right] \mathrm{Cl}(\mathrm{PP}=$ dpypp) was found to be toxic to breast cancer cells and showed good selectivity for cancer cells over healthy cells. ${ }^{64}$

While pyridyldiphosphines usually act as $P, P$ ligands, the chiral ligand 1,2-bis(di2-pyridylphosphino)cyclopentane (dpypcp) has been reported to act as a chelating $P, P, N$ ligand in complexes of the type $\left[\mathrm{RuX}_{2}(\mathrm{dpypcp})\left(\mathrm{PPh}_{3}\right)\right](\mathrm{X}=\mathrm{Cl}, \mathrm{Br}, \mathrm{I}) .{ }^{65}$ This bonding mode was confirmed from the X-ray crystal structure data obtained for the two isomers of $\left[\mathrm{RuCl}_{2}\left(P, P, N\right.\right.$-dpypcp) $\left.\left(\mathrm{PPh}_{3}\right)\right]$, shown in Figure 1.6 (as the reaction was performed with a racemic mixture of dpypcp the configuration of the chiral centres on the ligand is not shown). The NMR data of these complexes in- 
dicated that they displayed fluxional behaviour in solution at room temperature. Variable temperature NMR (VT-NMR) studies indicated that this dynamic behaviour was due to the reversible binding of the pyridyl nitrogens. Catalytic studies indicated that these complexes were active catalysts for the hydrogenation of imines to amines. ${ }^{65}$

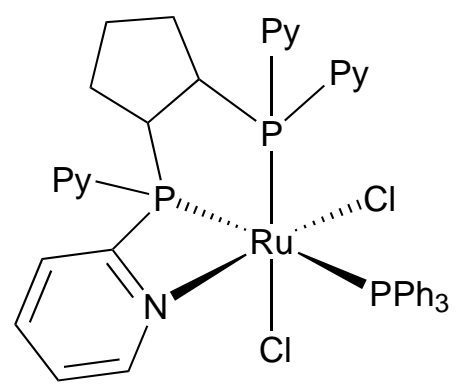

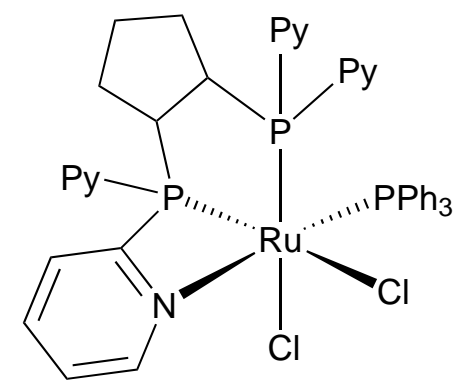

Figure 1.6 Two isomers of $\left[\mathrm{RuCl}_{2}(P, P, N\right.$-dpypcp $\left.)\left(\mathrm{PPh}_{3}\right)\right]$.

A rare example of a pyridyldiphosphine with all six donor atoms coordinated to metal centres was discovered accidentally by Jones et $a l .{ }^{66}$ The reactions of the $\left[\mathrm{PtI}_{2}(\mathrm{PP})\right]$ complexes $(\mathrm{PP}=$ dpype, dpypcp) with an excess of silver nitrate led to the formation of the coordination polymers $\left[\mathrm{Pt}_{2}(\text { dpype })_{2} \mathrm{Ag}_{4}\left(\mathrm{NO}_{3}\right)_{8}\left(\mathrm{H}_{2} \mathrm{O}\right)_{2}\right]_{\mathrm{n}}$ and $\left[\mathrm{Pt}_{2}(\mathrm{dpypcp})_{2} \mathrm{Ag}_{6}\left(\mathrm{NO}_{3}\right)_{10}\right]_{\mathrm{n}}$ (Scheme 1.9).
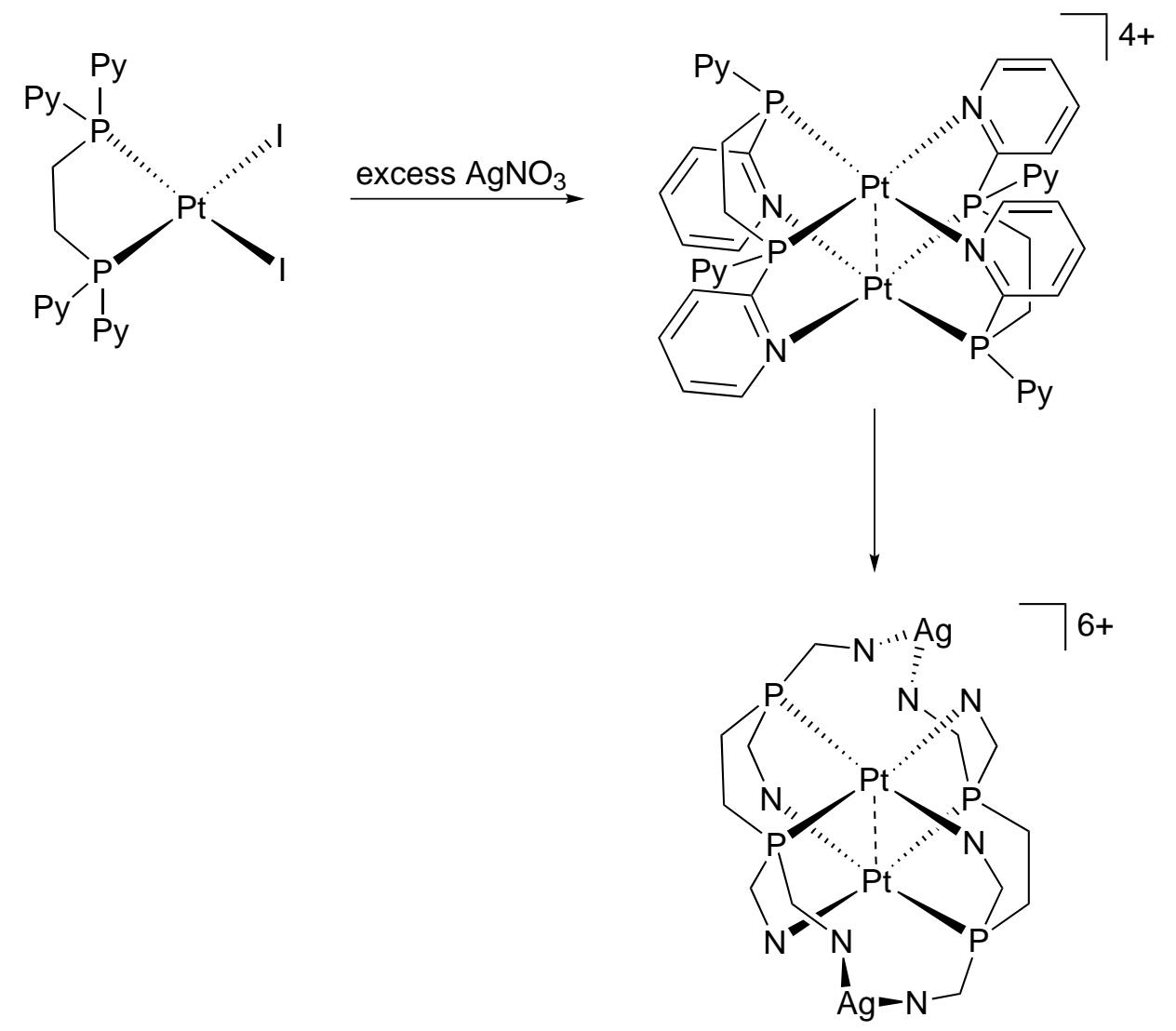

Scheme 1.9 Formation of the $\left[\mathrm{Pt}_{2}(\text { dpype })_{2} \mathrm{Ag}_{2}\right]^{6+}$ fragment of $\left[\mathrm{Pt}_{2}(\text { dpype })_{2} \mathrm{Ag}_{4}\left(\mathrm{NO}_{3}\right)_{8}\left(\mathrm{H}_{2} \mathrm{O}\right)_{2}\right]_{\mathrm{n}}$. Pyridyl rings omitted for clarity.

These complexes were characterised by X-ray crystallography. In these structures each ligand acts as a $P, P$ chelating ligand to one platinum centre as well as a 
$P, N$ bridging ligand across the two platinum centres. Upon crystallisation the final two pyridyl rings on each ligand coordinate to silver centres forming a polymeric structure. However, in solution the silver(I) ions dissociate and only the diplatinum complex is observed.

\section{$1.4 \quad$ Large Bite Angle Ligands}

It was of interest in this study to investigate wide bite angle ligands. Before this work there were no reports of pyridyldiphosphine ligands with large bite angles.

The coordination chemistry of wide bite angle diphosphines has attracted considerable interest owing to the high catalytic activities displayed by complexes of these ligands. In particular, transition metal complexes of these ligands often show reactivity and selectivity quite distinct from that displayed by ligands with smaller bite angles. ${ }^{11}$

An example of a family of wide bite angle ligands that have been extensively studied is the xantphos ligands (Figure 1.7). These ligands have been shown to form highly active transition metal catalysts. ${ }^{67}$ These ligands can enforce deviation from the coordination geometries preferred by transition metals. This is because the natural bite angles of these ligands are between 107.9 and $114.1^{\circ}$, which is larger than what is typically expected for cis coordination in a square planar or octahedral complex. ${ }^{67}$<smiles>CC1(C)c2cccc(-c3ccccc3)c2Oc2c(-c3ccccc3)cccc21</smiles>

Xantphos<smiles>C[Si]1(C)c2cccc(P)c2Oc2c(P)cccc21</smiles>

Sixantphos<smiles>Cc1cc(P)c2c(c1)Sc1cc(C)cc(-c3ccccc3)c1O2</smiles>

Thixantphos<smiles>Pc1cccc(Pc2ccccc2)c1P</smiles>

Nixantphos<smiles>Pc1cccc(P)c1Oc1cccc(P)c1-c1ccccc1</smiles>

Phosxantphos

Figure 1.7 A few examples of the xantphos family of ligands.

Complexes of xantphos-based ligands have been investigated as catalysts in a range of reactions, including hydroformylation, hydrocyanation and hydroesterification. ${ }^{67}$ 
When these ligands were used in the rhodium catalysed hydroformylation of 1octene there was an increase in the selectivity for the linear product observed when the bite angle was increased. ${ }^{68}$ In general, these ligands were found to induce very high selectivities for the linear product in hydroformylations of 1-alkenes. ${ }^{69}$

The bis(ditertiarybutylphosphino)-o-xylene ligand (dbpx) is an industrially significant large bite angle ligand. A highly active palladium catalyst containing this ligand produces methyl propanoate, through the methoxycarbonylation of ethene, with a selectivity of $99.9 \%$ under conditions other diphosphine ligands produce polyketone. ${ }^{70}$ In 2008, Lucite commercialised the production of methyl methacrylate using a two step process, the first of which is the synthesis of methyl propanoate using a palladium dbpx catalyst. ${ }^{71}$ As a consequence of the commercial success of this catalyst system, there has been a large amount of interest in diphosphine ligands containing $o$-xylene backbones. Many unsymmetrical ligands of this type have been synthesised, including $o-\mathrm{C}_{6} \mathrm{H}_{4}\left(\mathrm{CH}_{2} \mathrm{PBu}_{2}{ }_{2}\right)\left(\mathrm{CH}_{2} \mathrm{PPy}_{2}\right) .{ }^{72}$

There are many studies in the literature that indicate transition metal complexes incorporating bis(diphenylphosphino)- $o$-xylene (dppox) are active catalysts for several reactions, including the hydrogenation of carbon dioxide and aldehydes, and hydroformylation. ${ }^{73}$ Given this, diphosphine ligands with a $o$-xylene backbone and pyridyl rings on the phosphorus atoms are considered interesting target ligands.

\subsection{Pincer Ligands}

"Pincer" ligands refer to tridentate chelating ligands which usually coordinate to metal centres in a meridional fashion. There has been a large variety of structures reported. However, the most common backbones are those shown in Figure 1.8. Pincer ligands are often named based on the ligating atoms present. Thus the two examples in Figure 1.8 would be referred to as PCP and PNP ligands.<smiles>PCc1cccc(CP)c1</smiles>

PCP<smiles>PCc1cccc(CP)n1</smiles>

PNP

Figure 1.8 The most common pincer ligand backbones.

A major reason why pincer ligands receive so much attention is due to the high catalytic activity of their complexes. For example, palladium complexes of pincer 
ligands have been shown to be active catalysts in a range of reactions. ${ }^{74}$ In particular, pincer complexes have been found to be highly active catalysts for Heck and Suzuki cross-coupling reactions. ${ }^{75}$ One of the reasons these complexes are attractive catalysts is because they show high thermal stability. This is a consequence of the rigid tridentate coordination typically forming two five-membered metallacycles. ${ }^{74}$

An example of an interesting use of pincer complexes arises from the activity shown by iridium pincer complexes for alkane dehydrogenation. ${ }^{76}$ This activity has led to the development of a tandem catalytic system which effectively achieves "alkane metathesis". The basic process is shown in Scheme 1.10. A dehydrogenation catalyst, usually an iridium pincer complex, reacts with the alkane to give a terminal alkene. Alkene metathesis of the 1-alkene yields an internal alkene and ethene. The alkenes can then act as hydrogen acceptors, regenerating the dehydrogenation catalyst and forming alkanes.

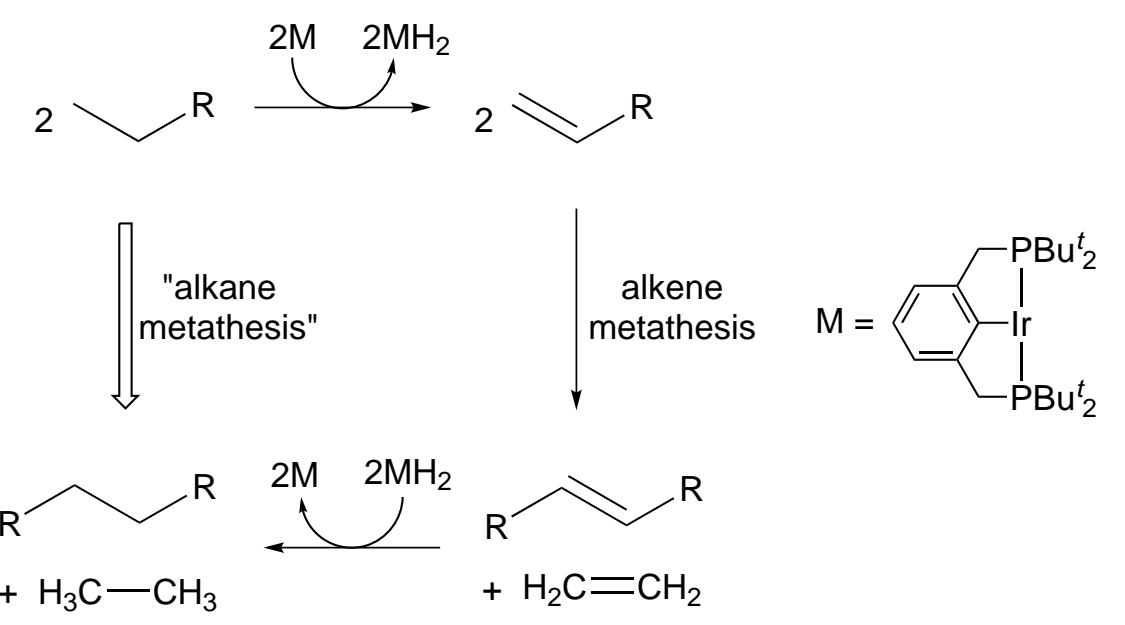

Scheme 1.10 Alkane metathesis via tandem transfer dehydrogenation-alkene metathesis.

This process shows promise for the conversion of carbon sources to transportation fuels. ${ }^{77}$ Given that petroleum sources are dwindling, an economically viable selective method for converting renewable carbon feedstocks into hydrocarbons suitable for transportation fuel would solve one of the major issues facing the global community. While this is a highly active and selective system, the activity is limited by the decomposition of the alkene metathesis catalyst.

Pincer complexes with bulky substituents on the phosphorus atoms are often stable when they are coordinatively unsaturated (Figure 1.9). ${ }^{77}$ It is proposed that the presence of pyridyl rings on the phosphorus donor atoms would also be able to stabilise this type of pincer complex, either through coordination of the pyridyl nitrogen atoms or through a transient interaction. 


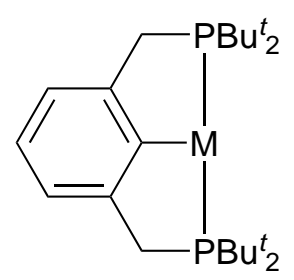

Figure 1.9 A coordinatively unsaturated pincer complex.

\subsection{Research Objectives}

There are many compelling reports in the literature demonstrating the attractive features of pyridylphosphine ligands. These include the potential hemilability, the ability of these ligands to bridge metal centres and, when the pyridyl rings are not coordinated to a metal centre, the potential of the pyridyl nitrogen atoms to participate in hydrogen-bonding interactions which can activate reactant molecules leading to increased catalytic activity or render a complex containing these ligands soluble in water. Complexes of diphosphine ligands with the large bite angle $o$-xylene backbone and pincer ligands with the $m$-xylene backbone have been shown to be highly active catalysts. However, there are limited reports exploring the properties of pyridyldiphosphines in general and large bite angle pyridyldiphosphines or pincer pyridyldiphosphines in particular. Thus this work was intended to combine the attractive features of pyridylphosphines with xylene backbones.

The initial aim of this project was to synthesise new pyridyldiphosphine ligands with $o$-xylene and $m$-xylene backbones. The most common route to pyridyldiphosphines, using chlorophosphine starting materials, was not used to synthesise these ligands. This was because the synthesis of the chlorophosphine compounds with xylene backbones required a complicated multi-step synthesis. Instead, a less common methodology, which has been reported in the synthesis of dpype, was improved. Next the effect of the pyridyl rings on the properties of the ligands was investigated. The phosphine selenides of these ligands were synthesised to investigate the basicity of the phosphorus atoms and the air-sensitivity and water-solubility of these ligands was explored.

The $o$-xylene- and $m$-xylene-based ligands are potentially hexadentate and hepadentate ligands respectively. Thus initially the reactions of the two ligands with platinum and palladium complexes were investigated, with a particular focus on whether the presence of the pyridyl nitrogens had an affect on the products observed. It was considered likely that these ligands would behave in a similar manner to the analogous phenyl ligands. Particular care was taken to fully characterise the products of these reactions as they would potentially serve as starting materials in 
the synthesis of trimetallic complexes. Any complexes with chloride ligands would have the chloride abstracted to investigate if $P, N$ chelation would occur. Next the $o$-xylene-based ligand was reacted with silver, rhodium and iridium complexes as these metals have been reported to frequently show the $P, N$ chelation mode for other pyridylphosphine ligands. Nuclear magnetic resonance (NMR) spectroscopy was used to characterise the products of these reactions and investigate any potential hemilabile behaviour. Infrared (IR) spectroscopy was an important tool for determining whether the pyridyl nitrogen had coordinated to a metal centre. X-ray crystallography was also used to confirm the coordination of a pyridyl nitrogen atom to the metal centre and determine the bite angles in these potentially polydentate ligands.

Finally, the synthesis of trimetallic complexes was explored. Trimetallic complexes, with three metal centres in close proximity to each other, have the potential to display interesting properties, such as novel catalytic behaviour or luminescence. The formation of homotrimetallic complexes from the direct reaction of the $o$-xylene ligand with three equivalents of metal precursor complex was investigated. The synthesis of heterotrimetallic complexes from the reaction of preformed monometallic complexes with metal precursor complexes was also studied. The potential to synthesise dimetallic complexes was also considered. NMR spectroscopy was used to characterise the products of these reactions and IR spectroscopy was used to determine whether a pyridyl nitrogen had coordinated to a metal centre. 


\section{Chapter 2}

\section{Ligand Synthesis and Properties}

\subsection{Background}

The synthesis of 2-pyridylphosphines usually involves the lithiation of 2-bromopyridine and subsequent reaction with a chlorophosphine. For example, tris(2-pyridyl)phosphine is synthesised via the reaction of 2-pyridyllithium with phosphorus trichloride and the most widely used pyridyldiphosphine in the literature, 1,2-bis(di-2pyridylphosphino)ethane (dpype), is formed when 2-pyridyllithium is reacted with 1,2-bis(dichlorophosphino)ethane (Scheme 2.1). ${ }^{78}$

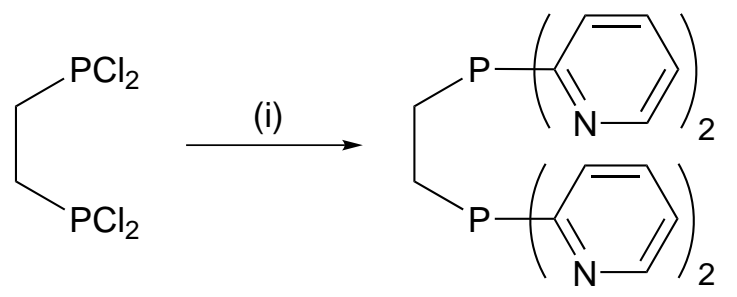

Scheme 2.1 Literature synthesis of 1,2-bis(di-2-pyridylphosphino)ethane. Reagents and conditions: (i) 2-pyridyllithium, $\mathrm{Et}_{2} \mathrm{O},-78^{\circ} \mathrm{C}$.

The disadvantage of this methodology is the use of chlorophosphine reagents which often require a complicated multi-step synthesis or, when commercially available, are expensive.

In 1998 Berners-Price et al. reported an alternative synthetic method involving the cleavage of a P-C bond in tris(2-pyridyl)phosphine using lithium metal. ${ }^{78}$ As this avoids the use of chlorophosphine starting materials, and thus increases the scope of the ligands that can be made, this methodology was followed initially. 


\section{$2.2 \quad$ Ligand Synthesis}

Tris(2-pyridyl)phosphine (1) was synthesised by the lithiation of 2-bromopyridine and subsequent reaction with phosphorus trichloride (Scheme 2.2). The next step was to cleave one of the P-C bonds using lithium metal. However, reports varied as to the conditions required for this reaction, from stirring at room temperature for three hours ${ }^{79}$ to sonication for 16 hours. ${ }^{78}$ While it was found that sonication was indeed required to achieve P-C bond cleavage with lithium granules, only six and a half hours was required to complete the reaction. In exploratory reactions, the lithium dipyridylphosphide was reacted with water to form the secondary phosphine (2). This compound was characterised by ${ }^{31} \mathrm{P}$ and ${ }^{1} \mathrm{H}$ NMR spectroscopy. The NMR data was consistent with the reported literature values, ${ }^{79}$ with the doublet at $5.53 \mathrm{ppm}\left({ }^{1} J_{\mathrm{PH}}=225.3 \mathrm{~Hz}\right)$ in the ${ }^{1} \mathrm{H}$ NMR spectrum confirming the formation of the secondary phosphine. This was then reacted with $n$-BuLi to reform the lithium phosphide, which was reacted with dibromo- $o$-xylene to give bis(di-2pyridylphosphino)-o-xylene (dpypox, 3) (Scheme 2.2).

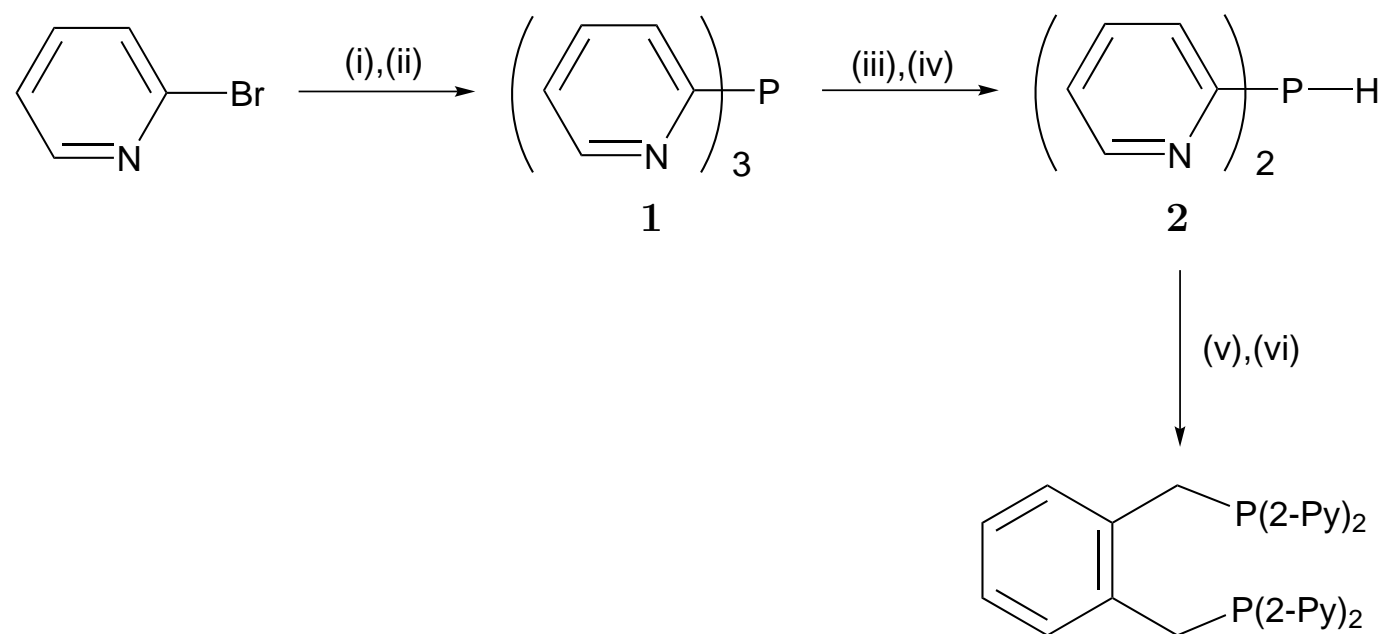

3

Scheme 2.2 Initial synthesis of dpypox ligand 3. Reagents and conditions: (i) $n$-BuLi, Et ${ }_{2} \mathrm{O},-78{ }^{\circ} \mathrm{C}, 1 \mathrm{~h}$; (ii) $\mathrm{PCl}_{3},-78{ }^{\circ} \mathrm{C}, 30 \mathrm{~min}$, rt, $1 \mathrm{~h}$; (iii) Li, THF, 6.5 h sonication; (iv) $\mathrm{H}_{2} \mathrm{O}$; (v) $n$-BuLi, THF, $0{ }^{\circ} \mathrm{C}, 1 \mathrm{~h}$; (vi) dibromo- $O$-xylene, THF, $0{ }^{\circ} \mathrm{C}$, overnight.

After the initial exploration of the P-C bond cleavage reaction with lithium granules it was found that the reaction proceeded more readily with sodium or potassium metal. When sodium or potassium was used the reaction was complete after stirring at room temperature for 20 hours. Also it was unnecessary to isolate the secondary phosphine. Instead, direct reaction of the phosphide with the ligand backbone was possible. As there was also pyridylsodium/potassium present, this was quenched with $t$-butylchloride first. This gave pyridine and isopropene (2-methylpropene), 
both of which were removed under reduced pressure at the end of the reaction. Next the addition of the appropriate bromide or chloride yielded the desired ligand (Scheme 2.3). The work-up of this reaction involved removing the THF, pyridine and isopropene under reduced pressure and then a liquid-liquid separation to remove the metal salts. Isolation of the organic phase and removal of the solvent under reduced pressure gave the ligands as glassy brown solids. While this was the first reported synthesis of $\mathbf{3}$ and $\mathbf{4}$, the synthesis of $\mathbf{5}$ via the reaction of 2-pyridyllithium with 1,3-bis(dichlorophosphino)propane was reported in $2007 .{ }^{64}$

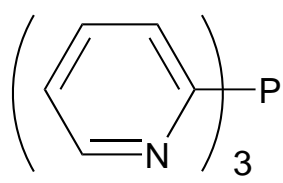

1

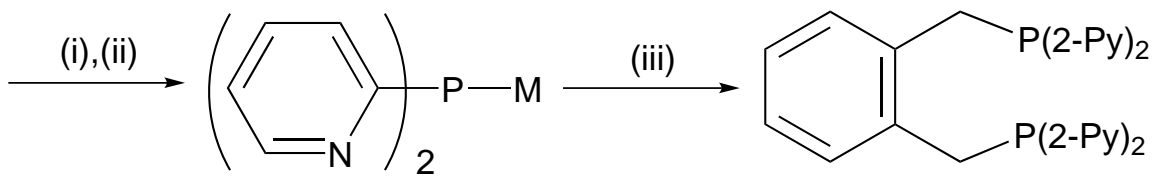

$\mathrm{M}=\mathrm{Na}, \mathrm{K}$

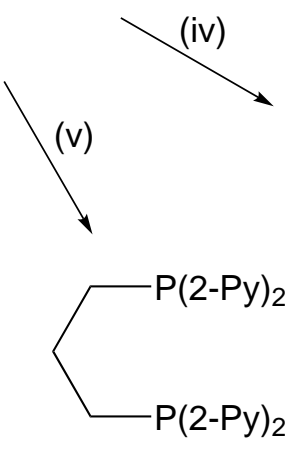

(iv)

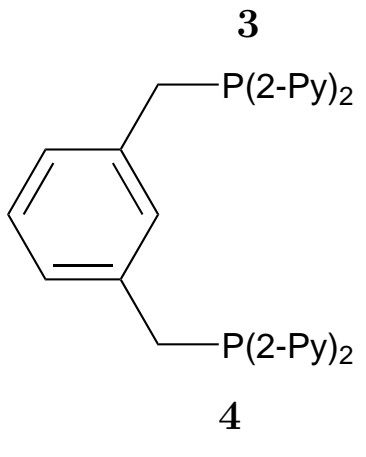

5

Scheme 2.3 Synthesis of 2-pyridyldiphosphines. Reagents and conditions: (i) Na or $\mathrm{K}$, THF, rt, $20 \mathrm{~h}$; (ii) $t$-BuCl, $-78{ }^{\circ} \mathrm{C} \rightarrow \mathrm{rt}, 30 \mathrm{~min}$; (iii) dibromo- $o$-xylene or dichloro- $o$-xylene, $\mathrm{THF},-78^{\circ} \mathrm{C} \rightarrow \mathrm{rt}, 30 \mathrm{~min}$; (iv) dibromo- $m$-xylene or dichloro- $m$ xylene, $\mathrm{THF},-78^{\circ} \mathrm{C} \rightarrow \mathrm{rt}, 30 \mathrm{~min}$; (v) 1,3-dibromopropane or 1,3-dichloropropane, $\mathrm{THF},-78^{\circ} \mathrm{C} \rightarrow \mathrm{rt}, 30 \mathrm{~min}$.

In all of the samples obtained after the workup of these reactions there was an impurity present. This impurity did not have a signal in the ${ }^{31} \mathrm{P}$ NMR spectra but was observed in the ${ }^{1} \mathrm{H}$ NMR spectra, having signals in both the pyridyl and alkyl regions. It has been reported that organometallic reagents similar to the pyridyllithium, -sodium and -potassium produced in these reactions are capable of reacting with THF. ${ }^{80}$ Similar organometallic species have been observed to react with THF in the way shown in Scheme 2.4. In this reaction the intermediate 6 formed can then react further with THF to give $7 .{ }^{81}$ The use of sodium or potassium in the place of lithium makes the organometallic species much more reactive towards THF. ${ }^{81}$ For example, methyllithium has a half-life of 100 hours at $0{ }^{\circ} \mathrm{C}$ in THF, whereas for methylsodium and methylpotassium to have the same half-life they need to be stored at -50 and $-100{ }^{\circ} \mathrm{C}$ respectively. Given that the ligand synthesis reactions required either long reaction times or forcing conditions to cleave the $\mathrm{P}$ $\mathrm{C}$ bond, it is not surprising that an impurity arising from reaction with THF was observed. The amount of impurity present was greatest in the reactions where 
potassium was used and the lowest in the lithium reactions. This is consistent with the literature. ${ }^{81}$

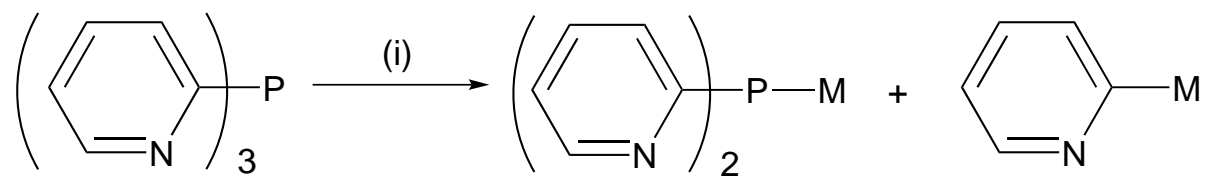

1

$\mathrm{M}=\mathrm{Li}, \mathrm{Na}, \mathrm{K}$

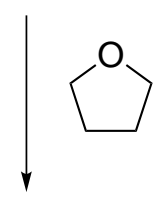

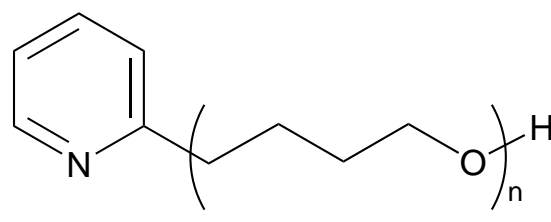

7

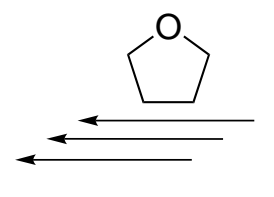

${ }_{N}$

6

Scheme 2.4 Formation of the impurity in the ligand synthesis reactions. Reagents and conditions: (i) Li, $\mathrm{Na}$ or K, THF, rt, 20 h.

This impurity was difficult to remove. Attempts to purify compounds $\mathbf{3}, \mathbf{4}$ and $\mathbf{5}$ via crystallisation were unsuccessful. The solubilities were too similar for liquid-liquid extractions to separate $\mathbf{3}, \mathbf{4}$ or $\mathbf{5}$ from $\mathbf{7}$ successfully. The compounds $\mathbf{3}, \mathbf{4}$ and 5 were protonated and extracted into water. However, the impurity 7 was basic enough that it was also protonated and soluble in water. Attempts to purify the protonated compounds via crystallisation were also unsuccessful. The solubilities of the protonated compounds and impurity were so similar that the only liquid-liquid extraction from which a pure sample of protonated compound could be obtained was $n$-propanol/saturated sodium chloride solution. However, the yield obtained was so low as to make this impractical. The phosphorus atoms were protected with borane groups and the purification of the resulting phosphine-borane compounds was attempted (see Section 2.5). This also did not yield a pure sample of the pyridyldiphosphines.

However, when a lithium dispersion was used in the place of lithium granules or sodium or potassium, the reaction proceeded rapidly and was complete within 40 minutes. Due to the fast reaction time and the low reactivity of the pyridyllithium species compared to the sodium or potassium species the impurity was not observed in any significant amount in this reaction. Instead reaction of tris $(2-$ pyridyl)phosphine with a lithium dispersion in THF gave the desired lithium bis(2pyridyl)phosphide and 2,2'-bipyridine. Uchida and co-workers proposed a mechanism for the formation of the bipyridine based on similar ligand coupling and ligand exchange reactions. ${ }^{82,83}$ The bipyridine was considered to form when one of the initial products, 2-pyridyllithium, reacts with tris(2-pyridyl)phosphine to form the 
intermediate shown in Scheme 2.5. Within this intermediate an axial and equatorial group couple to yield $2,2^{\prime}$-bipyridine and lithium bis(2-pyridyl)phosphide. ${ }^{82,84,85}$ This was consistent with the observation that longer reaction times resulted in a higher proportion of $2,2^{\prime}$-bipyridine being formed, with $2,2^{\prime}$-bipyridine the only product observed after 24 hours. ${ }^{86}$

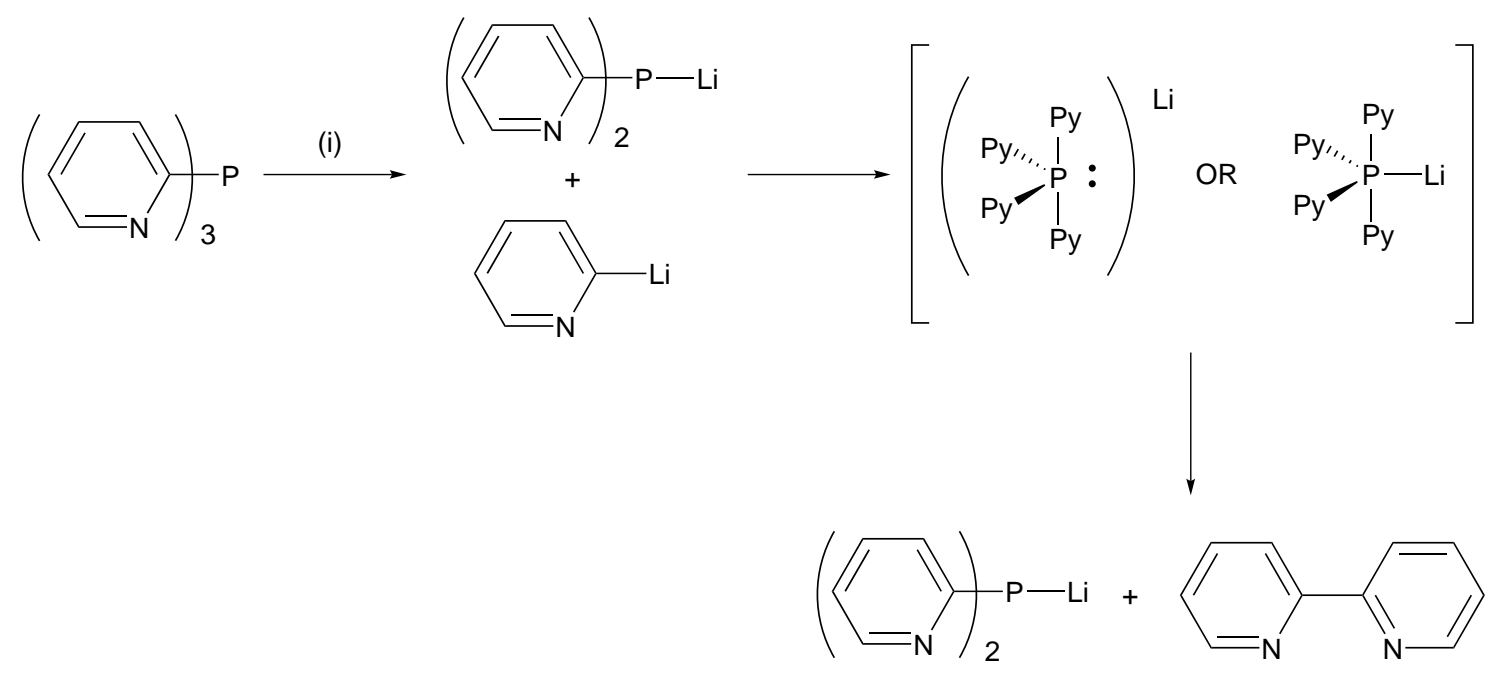

Scheme 2.5 Formation of 2,2'-bipyridine. Reagents and conditions: (i) Li, THF, $-78{ }^{\circ} \mathrm{C} \rightarrow \mathrm{rt}, 40 \mathrm{~min}$.

As Steiner and co-workers reported separating 2,2'-bipyridine and the secondary phosphine 2 by distillation, the lithium reaction was quenched with water and the distillation carried out. ${ }^{83}$ However, it was found that while distillation removed the 2,2'-bipyridine impurity it also resulted in partial decomposition of the phosphine 2 . It was also found that this phosphine was soluble in pentane, thus it was not possible to separate the $2,2^{\prime}$-bipyridine from the phosphine $\mathbf{2}$ by washing with pentane.

Given that the attempts to purify the phosphine $\mathbf{2}$ were unsuccessful, instead of producing $\mathbf{2}$ the pyridyllithium present was quenched by reaction with ammonium chloride and the lithium phosphide was reacted directly with the appropriate dibromide or dichloride compound to yield the desired pyridyldiphosphine. After THF was removed under reduced pressure, a liquid-liquid separation removed the lithium salts. While some of the 2,2'-bipyridine was removed by washing the pyridyldiphosphines with pentane, pure samples were obtained through recrystallisation from an ethanol $/ n$-propanol mixture for $\mathbf{3}$ and $\mathbf{5}$, and by sublimation of the $2,2^{\prime}$-bipyridine for 4. The compounds were isolated as pale yellow microcrystalline solids. They were soluble in chloroform, dichloromethane, acetone and tetrahydrofuran, and insoluble in water, benzene or toluene.

All pyridyldiphosphines were characterised by ${ }^{31} \mathrm{P},{ }^{1} \mathrm{H}$ and ${ }^{13} \mathrm{C} \mathrm{NMR}$ and infrared spectroscopy and high resolution mass spectrometry. Table 2.1 and Table 2.2 show selected NMR data for $\mathbf{3}, \mathbf{4}$ and $\mathbf{5}$ as well as that of dpype for comparison. The ${ }^{31} \mathrm{P}$ 
NMR spectra consisted of a single singlet at $-6.8,-3.8$ and $-10.1 \mathrm{ppm}$ for dpypox ligand $\mathbf{3}$, dpyp $m \mathrm{x}$ ligand $\mathbf{4}$ and dpypp ligand $\mathbf{5}$ respectively. The NMR data for $\mathbf{5}$ were consistent with that already reported. ${ }^{64}$

Table 2.1 Selected ${ }^{1} \mathrm{H}$ and ${ }^{31} \mathrm{P}$ NMR data of the pyridyldiphosphines.

\begin{tabular}{|c|c|c|c|c|c|c|c|}
\hline \multirow{2}{*}{\multicolumn{2}{|c|}{ Compound }} & \multicolumn{4}{|c|}{$\delta^{1} \mathrm{H} / \mathrm{ppm}^{a}$} & \multirow[b]{2}{*}{$\mathrm{CH}_{2} \mathrm{P}$} & \multirow[b]{2}{*}{$\delta^{31} \mathrm{P} / \mathrm{ppm}$} \\
\hline & & $\mathrm{H} 2$ & H3 & H4 & H5 & & \\
\hline dpypox & 3 & 7.45 & 7.54 & 7.15 & 8.66 & 3.97 & -6.8 \\
\hline dpyp $m x$ & 4 & 7.34 & 7.52 & 7.11 & 8.70 & 3.66 & -3.8 \\
\hline dpypp & 5 & 7.39 & 7.55 & 7.15 & 8.64 & 2.51 & -10.1 \\
\hline dyppe $^{b}$ & & 7.43 & 7.69 & 7.29 & 8.56 & 2.44 & -5.8 \\
\hline
\end{tabular}

The NMR signals due to the pyridyl substituents on the phosphorus did not change significantly when the backbone of the ligand was varied, with some of the signals being essentially identical in the different ligands (Table 2.1 and Table 2.2). However, the signals due to the methylene attached to the phosphorus atom did shift depending on the backbone, with the signals in the ${ }^{1} \mathrm{H}$ NMR spectra around 2.5 ppm for $\mathbf{5}$ and dpype and 3.6-3.9 ppm for $\mathbf{3}$ and $\mathbf{4}$. This is to be expected due to the difference between the alkyl backbones and the xylene-based backbones. In the infrared spectra of the ligands the $\mathrm{C}=\mathrm{N}$ stretches were observed at 1573 and 1560 $\mathrm{cm}^{-1}$ for 3 and at 1573 and $1559 \mathrm{~cm}^{-1}$ for 4 .

Table 2.2 Selected ${ }^{13} \mathrm{C}$ NMR data of the pyridyldiphosphines.

\begin{tabular}{|c|c|c|c|c|c|c|c|}
\hline \multirow[b]{2}{*}{ Compound } & & \multicolumn{5}{|c|}{$\delta^{13} \mathrm{C} / \mathrm{ppm}^{a}$} & \multirow[b]{2}{*}{$\mathrm{CH}_{2} \mathrm{P}$} \\
\hline & & $\mathrm{C} 1$ & $\mathrm{C} 2$ & C3 & $\mathrm{C} 4$ & C5 & \\
\hline dpypox & 3 & 163.0 & 129.6 & 135.5 & 122.8 & 150.4 & 31.0 \\
\hline $\operatorname{dpyp} m x$ & 4 & 162.8 & 129.4 & 135.5 & 122.9 & 150.5 & 33.3 \\
\hline dpypp & 5 & 163.4 & 128.6 & 135.7 & 122.5 & 150.4 & 27.8 \\
\hline dyppe $^{b}$ & & 162.3 & 129.1 & 136.3 & 123.0 & 149.8 & 22.1 \\
\hline
\end{tabular}

\footnotetext{
${ }^{a}$ Spectra recorded in $\mathrm{CDCl}_{3}$.

${ }^{b}$ Literature data. ${ }^{61}$
}

Compounds $\mathbf{3}, \mathbf{4}$ and $\mathbf{5}$, could only be handled in the air for very short times without formation of the phosphine oxides occuring. If the compounds were exposed to 
the air for more than a few minutes, stepwise oxidation of the phosphorus atoms occurred. While the first oxidation was rapid, it took 15-25 days for the ligands to be completely oxidised. They were particularly susceptible to oxidation when in solution. When fully oxidised the signal in the ${ }^{31} \mathrm{P}$ NMR spectra shifted to $28.2,26.7$ and 29.1 for the oxides dpypoxO $\mathrm{O}_{2}(\mathbf{8})$, dpyp $m \mathrm{xO}_{2}(\mathbf{9})$ and dpypp $\mathrm{O}_{2}(\mathbf{1 0})$ respectively. In the ${ }^{1} \mathrm{H}$ NMR spectra the signal for the $\mathrm{CH}_{2} \mathrm{P}$ protons moved to higher chemical shift and in the case of $\mathbf{8}$ and $\mathbf{9}$ appeared as a doublet $\left({ }^{2} J_{\mathrm{PH}}=13.9\right.$ and $15.1 \mathrm{~Hz}$ for 8 and 9 respectively). While in the ${ }^{13} \mathrm{C}$ NMR spectra the signal for the methylene carbon atom only moves slightly, the coupling to phosphorus increases significantly, from ${ }^{1} J_{\mathrm{PC}}=9.1$ for dpypox $(\mathbf{3})$ to ${ }^{1} J_{\mathrm{PC}}=65.7 \mathrm{~Hz}$ for $\operatorname{dpypoxO}_{2}(\mathbf{8})$.

\subsection{Phosphine Selenides}

The steric and electronic properties of phosphorus ligands influence the reactivity of metal centres and can have a significant effect on the catalytic activity of metal complexes. As such there has been a large effort in the literature to classify phosphorus ligands according to their size and electronic properties, and correlate these with the reactivity observed. The cone angle suggested by Tolman has been found to be an effective way to quantify the steric bulk of phosphine ligands. ${ }^{4}$ However, the evaluation of the electronic properties of phosphine ligands has been found to be less straight forward. This is due to the fact that the steric bulk and electronic properties of a ligand are often difficult to separate. For example, as the $\mathrm{R}$ groups on $\mathrm{PR}_{3}$ increase in size the R-P-R angles increase reducing the ' $\mathrm{s}$ ' character of the phosphorus lone pair, thus affecting its electronic properties. ${ }^{87,88}$ Also in some bicyclic systems there is geometric strain that causes a decrease in R-P-R angles, and hence the ' $\mathrm{s}$ ' character of the lone pair is increased, which leads to a decrease in phosphine basicity. ${ }^{89,90}$

There have been several ways of determining the electronic properties of phosphine ligands reported in the literature. These can be split into two groups. The first uses the $\nu(\mathrm{CO})$ stretching frequencies in metal complexes such as $\left[\mathrm{Ni}(\mathrm{L})(\mathrm{CO})_{3}\right]$ or trans$\left[\mathrm{RhCl}(\mathrm{CO})(\mathrm{L})_{2}\right] .{ }^{5}$ The second uses NMR measurements of ${ }^{1} J_{\mathrm{PX}}$ between phosphorus and other NMR active nuclei such as ${ }^{195} \mathrm{Pt},{ }^{91}{ }^{11} \mathrm{~B}^{92}$ and ${ }^{77} \mathrm{Se} .{ }^{5,88,90,91,93-96}$

Of these methods the evaluation of ${ }^{1} J_{\mathrm{PSe}}$ has been found to be a reliable method to probe the basicity of phosphines. ${ }^{96}$ One of the main benefits of this method is the ease of synthesis of the phosphine selenides. Usually reaction of the phosphine with excess selenium in refluxing solvent overnight gives exclusively the phosphine 
selenide. ${ }^{95,97}$ This is especially useful when the electronic properties of multidentate heterophosphines are being considered. In systems such as the one explored in this work the proton basicity of the phosphorus atoms cannot be determined by direct titration as the nitrogen atoms on the pyridyl rings are more basic. Thus synthesis of the phosphine selenides and evaluation of ${ }^{1} J_{\mathrm{PSe}}$ is an useful alternative method of determining the basicity of the phosphorus atoms in these systems. Despite the problems of the effect of increasing the size of the substituents on $\mathrm{P}$ on the electronic properties of $\mathrm{P}$, the ${ }^{1} J_{\mathrm{PSe}}$ coupling constant has been found to be a good measure of the phosphine basicity irrespective of the size of the phosphine. ${ }^{87,91}$ For example, the value of ${ }^{1} J_{\mathrm{PSe}}$ has been found to be an additive function dependent on the electronegativity of the substituents on the phosphorus. ${ }^{93,94}$

The coupling constant between two directly linked atoms is governed by the Fermicontact interactions between the s-orbitals. According to Bent's rule, electron withdrawing substituents result in an increase in the 's' character of the phosphorus lone pair. ${ }^{98}$ Thus a phosphine selenide with electron withdrawing substituents would be expected to have a higher ${ }^{1} J_{\mathrm{PSe}}$ coupling constant. Therefore larger values of ${ }^{1} J_{\mathrm{PSe}}$ correspond to less basic parent phosphines. ${ }^{88}$

It was originally thought that a higher ${ }^{1} J_{\mathrm{PSe}}$ would correlate to a shorter P-Se bond length, though not necessarily with stronger bonds. ${ }^{95,99}$ However, further investigation showed that this was not the case over a wide range of phosphines. ${ }^{87}$ The values of ${ }^{1} J_{\mathrm{PSe}}$ cover a range of more than $100 \mathrm{~Hz}$, indicating high sensitivity to changes in the electronic properties of the phosphine ligand. In contrast, the P-Se lengths vary by only $0.12 \AA$ which means they are not as sensitive to the variation of the electronic nature of the phosphine (and the differences observed are usually not crystallographically significant). ${ }^{87}$

The synthesis of the phosphine selenides in this work was straightforward, with the reaction between the phosphine and excess elemental selenium complete after refluxing overnight in the appropriate solvent (Scheme 2.6). Chloroform was used for the pyridylphosphines and toluene for bis(ditertiarybutylphosphino)-o-xylene $(\mathrm{dbpx})$, which was used for comparison. Once the excess selenium was removed and the phosphine selenides isolated, NMR spectra showed that all of the ligands had reacted cleanly to give the corresponding phosphine diselenides. There was no evidence for the formation of any monoselenides.

The ${ }^{31} \mathrm{P}$ NMR spectra of the selenides showed singlets with ${ }^{77}$ Se satellites at 34.19 ppm for dpypoxSe $\sin _{2}$ (11) and $34.92 \mathrm{ppm}$ for dpyp $m \mathrm{xSe}_{2}(\mathbf{1 2})$, with ${ }^{1} J_{\mathrm{PSe}}$ values of 738 and $742 \mathrm{~Hz}$ respectively (Table 2.3). This was consistent with the doublet 


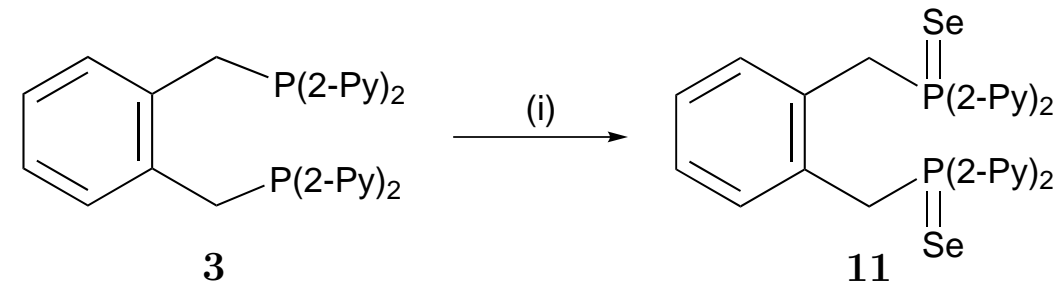

Scheme 2.6 Synthesis of phosphine selenide 11. Reagents and conditions: (i) Excess Se, chloroform, reflux, overnight.

coupling observed in the ${ }^{77} \mathrm{Se}$ NMR spectra. When this is compared to the value for the phenyl analogue $\left(\operatorname{dppox}{ }^{1} J_{\mathrm{PSe}}=724 \mathrm{~Hz}\right)$ it can be seen that these values are higher, indicating that the compounds $\mathbf{3}$ and $\mathbf{4}$ are less basic and the 2-pyridyl substituents are more electron withdrawing than phenyl groups. As expected the ${ }^{1} J_{\mathrm{PSe}}$ value for $\mathrm{dbpxSe}_{2}$ (13) was much lower than the other phosphines $(697 \mathrm{~Hz})$. This is due to dbpx being more basic than the other phosphines as a result of the electron donating $t$-butyl groups.

Table 2.3 NMR data of the phosphine selenides

\begin{tabular}{lccc}
\hline Phosphine & $\delta^{31} \mathrm{P} / \mathrm{ppm}$ & $J_{\mathrm{PSe}} / \mathrm{Hz}^{a}$ & $J_{\mathrm{PP}} / \mathrm{Hz}$ \\
\hline dpyp $o$ x & 34.2 & 738 & 6.6 \\
dpyp $m$ x & 34.9 & 742 & 3.6 \\
dbpx & 76.7 & 697 & 2.8 \\
${\text { dpp } o x^{b}}_{\mathrm{PPh}_{3}}{ }^{c}$ & 32.9 & 724 & - \\
PPy $_{3}{ }^{d}$ & 35.9 & 732 & $\mathrm{n} / \mathrm{a}$ \\
TPPTS $^{e}$ & 27.8 & 750 & $\mathrm{n} / \mathrm{a}$ \\
\hline
\end{tabular}

\footnotetext{
${ }^{a}$ Measured in $\mathrm{CDCl}_{3}$ unless stated otherwise.

${ }^{b}$ Literature data. ${ }^{71}$

${ }^{c}$ Literature data. ${ }^{91}$

${ }^{d}$ Literature data, ${ }^{96}$ spectra recorded in $\mathrm{CD}_{2} \mathrm{Cl}_{2}$.

${ }^{e}$ Literature data. ${ }^{100}$
}

Beckmann et al. found a difference between the ${ }^{1} J_{\mathrm{PSe}}$ coupling constants for the mono- and diselenides of dppe and dppp, which they ascribed to electronic repulsion between the $\mathrm{P}=$ Se groups. ${ }^{96}$ Thus for diphosphines the value of ${ }^{1} J_{\mathrm{PSe}}$ is not entirely independent of steric effects. The difference between the ${ }^{1} J_{\mathrm{PSe}}$ value for the selenides of the monophosphines, triphenylphosphine and tri(2-pyridyl)phosphine, and that of the diphosphines, dppox and dpypox $(\mathbf{3})$, is due both to the electronic effect of replacing one of the substituents for the $o$-xylene backbone and any $\mathrm{P}=$ Se electronic repulsion.

In this work ${ }^{31} \mathrm{P} \_{ }^{31} \mathrm{P}$ coupling was also observed in the ${ }^{77}$ Se satellites (Figure 2.1). These peaks appeared as doublets in the ${ }^{31} \mathrm{P}$ NMR spectrum (Figure 2.1(inset)). 
This was due to the NMR active isotope of selenium, selenium-77 ( $\operatorname{spin}=1 / 2$ ), being only $7.6 \%$ abundant with the rest of the selenium isotopes being NMR inactive. Thus when one phosphorus atom of a diphosphine is bound to a selenium-77 atom, the phosphorus atoms are chemically equivalent but magnetically inequivalent. The phosphorus atom could be seen coupling to the other phosphorus atom as they were magnetically different, with the second phosphorus atom bound to a NMR inactive isotope of selenium.

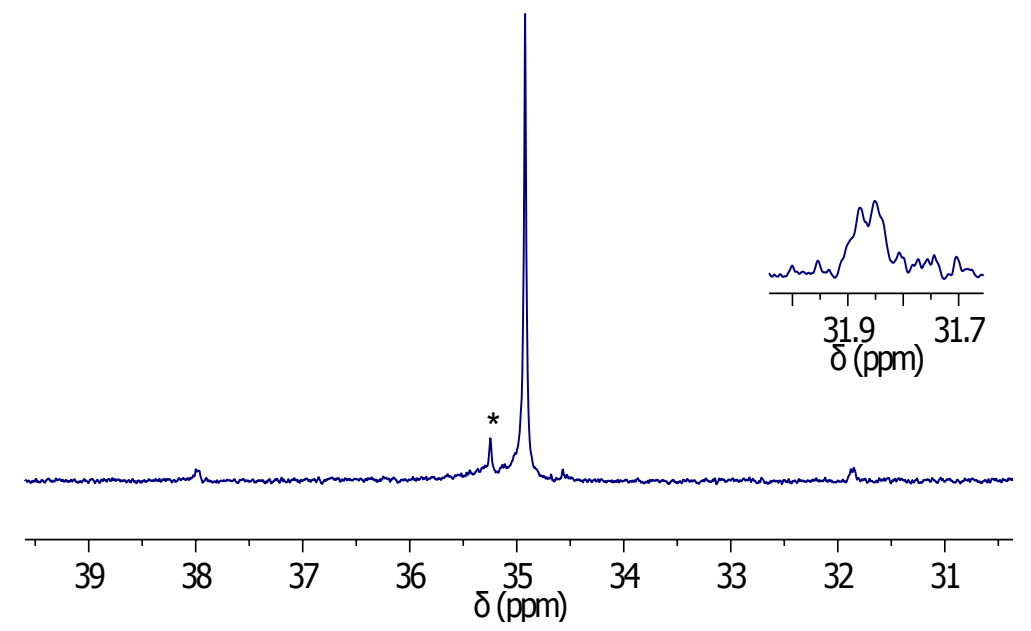

Figure 2.1 ${ }^{31} \mathrm{P}$ NMR spectrum of dpyp $m \times \mathrm{xSe}_{2}$ compound 12 showing the ${ }^{77} \mathrm{Se}$ satellites (inset). Asterisk denotes a sample impurity.

As was observed with the phosphine oxides, in the ${ }^{1} \mathrm{H}$ NMR spectra of the phosphine selenides the signals due to the $\mathrm{CH}_{2} \mathrm{P}$ protons shifted to higher ppm and coupling to phosphorus was observed $\left({ }^{2} J_{\mathrm{PH}}=14.0 \mathrm{~Hz}\right.$ for 11 and ${ }^{2} J_{\mathrm{PH}}=15.3 \mathrm{~Hz}$ for 12). The same trend was also observed in the ${ }^{13} \mathrm{C}$ NMR spectra except the ${ }^{1} J_{\mathrm{PC}}$ coupling constants were not as high as they were for the oxides $(44.1 \mathrm{~Hz}$ for the selenide dpypoxSe 11 compared with $65.7 \mathrm{~Hz}$ for the oxide dpypoxO $\mathrm{X}_{2}$ ).

${ }^{77}$ Se NMR spectra were also recorded of the phosphine selenides. The chemical shifts were found to be -352.46 and and $-363.52 \mathrm{ppm}$ for dpypoxSe $\mathrm{d}_{2}$ (11) and dpyp $m \mathrm{xSe}_{2}(\mathbf{1 2})$ respectively. This once again indicates that the $o$-xylene ligand and the $m$-xylene ligand are very similar electronically.

Beckmann et al. also correlated ${ }^{1} J_{\mathrm{PSe}}$ with $\mathrm{p} K_{\mathrm{b}}$ for a range of known phosphines from the literature. ${ }^{96}$ They found the two measures of basicity correlated well with ${ }^{1} J_{P S e}=7.60 \times p K_{b}+646\left(\mathrm{R}^{2}=0.9492\right)$, when $\mathrm{P}^{t} \mathrm{Bu}_{3}$ was excluded. This equation was then used to calculate the $\mathrm{p} K_{\mathrm{b}}$ of a range of known phosphines and a good agreement between calculated and experimental values of $\mathrm{p} K_{\mathrm{b}}$ was observed. The basicity of phosphines with substituents containing heteroatoms, for which direct titration was not possible, was then calculated using this equation. 
In order to calculate the $\mathrm{p} K_{\mathrm{b}}$ of the ligands studied in this work it is necessary to rearrange this equation to give equation 2.1 :

$$
p K_{b}=\frac{{ }^{1} J_{P S e}-646}{7.60}
$$

From equation $2.1, \mathrm{p} K_{\mathrm{b}}$ values of $12.05,12.59$ and 6.66 were calculated for dpypox (3), dpyp $m \mathrm{x}(4)$ and dbpx respectively. The $\mathrm{p} K_{\mathrm{b}}$ of free pyridine is $8.77 .{ }^{101}$ These calculations confirm that the nitrogen atoms in the pyridyl substituents on the phosphorus are more basic than the phosphorus atoms. Thus the $\mathrm{p} K_{\mathrm{b}}$ of the phosphorus atoms in the ligands explored in this work could not be determined by direct titration as it would be expected that the nitrogens would react with any acid first.

\subsection{Protonation Behaviour}

Next the behaviour of compounds $\mathbf{3}$ and $\mathbf{4}$ when they were reacted with strong

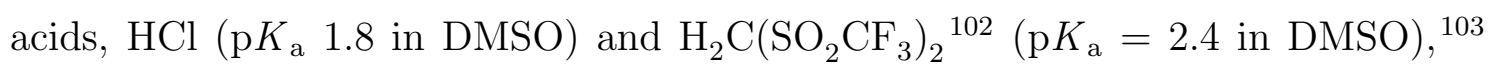
was investigated. This was done for two reasons. Firstly to investigate whether the nitrogen atoms in these molecules would be protonated before the phosphorus atoms as predicted from the phosphine selenide work discussed above. Secondly, it has been reported that reversible water-solubility of tungsten complexes has been achieved through deprotonation/protonation of the acidic group on the nitrogen ligand in $\left[\mathrm{W}\left(\mathrm{CO}_{4}\right)(\mathrm{L})\right]\left(\mathrm{L}=3\right.$-[(2-pyridinylmethylene)amino]benzoic acid). ${ }^{104}$ Given this, it was thought that protonation of the nitrogen atoms in the ligands could infer watersolubility to the ligands and potentially to complexes of these ligands as well. As such it was important to first determine whether protonation of the pyridyl groups in the ligands could induce water-solubility of the ligands.

To confirm that the nitrogen atoms are protonated before the phosphorus atoms, 3 and 4 were reacted with one, four and six equivalents of $\mathrm{H}_{2} \mathrm{C}\left(\mathrm{SO}_{2} \mathrm{CF}_{3}\right)_{2}$ in acetone$d_{6}$. In all reactions only one signal was observed in the ${ }^{31} \mathrm{P}$ NMR spectra and the ${ }^{1} \mathrm{H}$ NMR spectra showed the same number of signals as observed for the free ligand. The signals in the ${ }^{1} \mathrm{H}$ NMR spectra for the proton attached to either nitrogen or phosphorus could not be observed due to rapid H/D exchange with the NMR solvent. This meant that it was not possible to observe coupling to phosphorus which could have indicated whether the proton was bound directly to the phosphorus atom or several bonds away. This indicated that the protons were not statically bound to one nitrogen or phosphorus atom but that there was a dynamic process 
occurring at a rate faster than the NMR time scale. Analogous reactions carried out in chloroform- $d$ and dichloromethane- $d_{2}$ resulted in insoluble products that could not be characterised.

In the ${ }^{31} \mathrm{P}$ NMR spectra of the reactions of compound $\mathbf{3}$ with one or four equivalents of acid the signal of the product appeared at -29.3 and $-27.0 \mathrm{ppm}$ respectively (Table 2.4). Usually when a phosphorus atom is protonated to form a phosphonium ion the signal in the ${ }^{31} \mathrm{P}$ NMR spectrum shifts downfield. ${ }^{105,106}$ However, the shift observed in these reactions was in the opposite direction, which suggests that the proton was not bound to the phosphorus but rather to the nitrogen atoms.

In the ${ }^{1} \mathrm{H}$ NMR spectra of the same reactions the signals due to the pyridyl protons have shifted significantly downfield (Table 2.4). In contrast, the signal for the methylene protons in the ${ }^{1} \mathrm{H}$ NMR spectra has moved slightly upfield. This implies that the environment of the pyridyl protons has changed more than that of the methylene; again suggesting that the protons are bound to the nitrogen atoms rather than the phosphorus atom. The NMR data of the analogous reactions with 4 follow the same trends as the reactions with $\mathbf{3}$ (Table 2.4).

Table 2.4 Selected ${ }^{1} \mathrm{H}$ and ${ }^{31} \mathrm{P}$ NMR data of the protonated compounds

\begin{tabular}{|c|c|c|c|c|c|c|c|}
\hline \multirow[b]{2}{*}{ Ligand } & \multirow[b]{2}{*}{ eq. acid } & \multicolumn{5}{|c|}{$\delta^{1} \mathrm{H} / \mathrm{ppm}^{a}$} & \multirow[b]{2}{*}{$\delta^{31} \mathrm{P} / \mathrm{ppm}$} \\
\hline & & $\mathrm{H} 2$ & H3 & $\mathrm{H} 4$ & H5 & $\mathrm{CH}_{2} \mathrm{P}$ & \\
\hline \multirow[t]{5}{*}{ dpypox } & 0 & 7.46 & 7.66 & 7.25 & 8.64 & 4.09 & -5.9 \\
\hline & 1 & 7.98 & 8.32 & 7.94 & 9.06 & 3.88 & -29.3 \\
\hline & 4 & 8.11 & 8.44 & 8.04 & 9.09 & 3.95 & -27.0 \\
\hline & 6 & 8.26 & 8.56 & 8.14 & 9.09 & 4.14 & -24.1 \\
\hline & $\mathrm{xs}^{b}$ & 8.18 & 8.51 & 8.00 & 8.64 & 4.15 & -19.8 \\
\hline \multirow[t]{5}{*}{ dpyp $m x$} & $0^{c}$ & 7.33 & 7.52 & 7.15 & 8.69 & 3.66 & -3.8 \\
\hline & 1 & 7.98 & 8.30 & 7.87 & 8.99 & 3.64 & -24.5 \\
\hline & 4 & 8.23 & 8.52 & 8.07 & 9.07 & 3.84 & -22.5 \\
\hline & 6 & 8.33 & 8.61 & 8.15 & 9.08 & 3.96 & -19.8 \\
\hline & $\mathrm{xs}^{b}$ & 8.12 & 8.49 & 7.99 & 8.67 & 3.81 & -16.1 \\
\hline
\end{tabular}

${ }^{a}$ Spectra recorded in $\left(\mathrm{CD}_{3}\right)_{2} \mathrm{CO}$ unless stated otherwise.

${ }^{b}$ Spectra recorded in $\mathrm{D}_{2} \mathrm{O}$.

${ }^{c}$ Spectra recorded in $\mathrm{CDCl}_{3}$.

Variable temperature NMR (VT-NMR) spectra of the monoprotonated $\mathbf{3}$ and $\mathbf{4}$ were recorded at $20{ }^{\circ} \mathrm{C}$ intervals between 20 and $-80{ }^{\circ} \mathrm{C}$ in acetone- $d_{6}$. Between 20 and $-40{ }^{\circ} \mathrm{C}$ there was no significant difference in the NMR spectra recorded. It was only at $-60{ }^{\circ} \mathrm{C}$ that the NMR signals began to broaden and at $-80{ }^{\circ} \mathrm{C}$ all the 
signals due to the protonated ligand were broad (Figure 2.2). This indicated that the coalescence point of this dynamic process was below $-80{ }^{\circ} \mathrm{C}$. From this it was concluded that the dynamic process taking place is very facile and has a very low energy barrier.

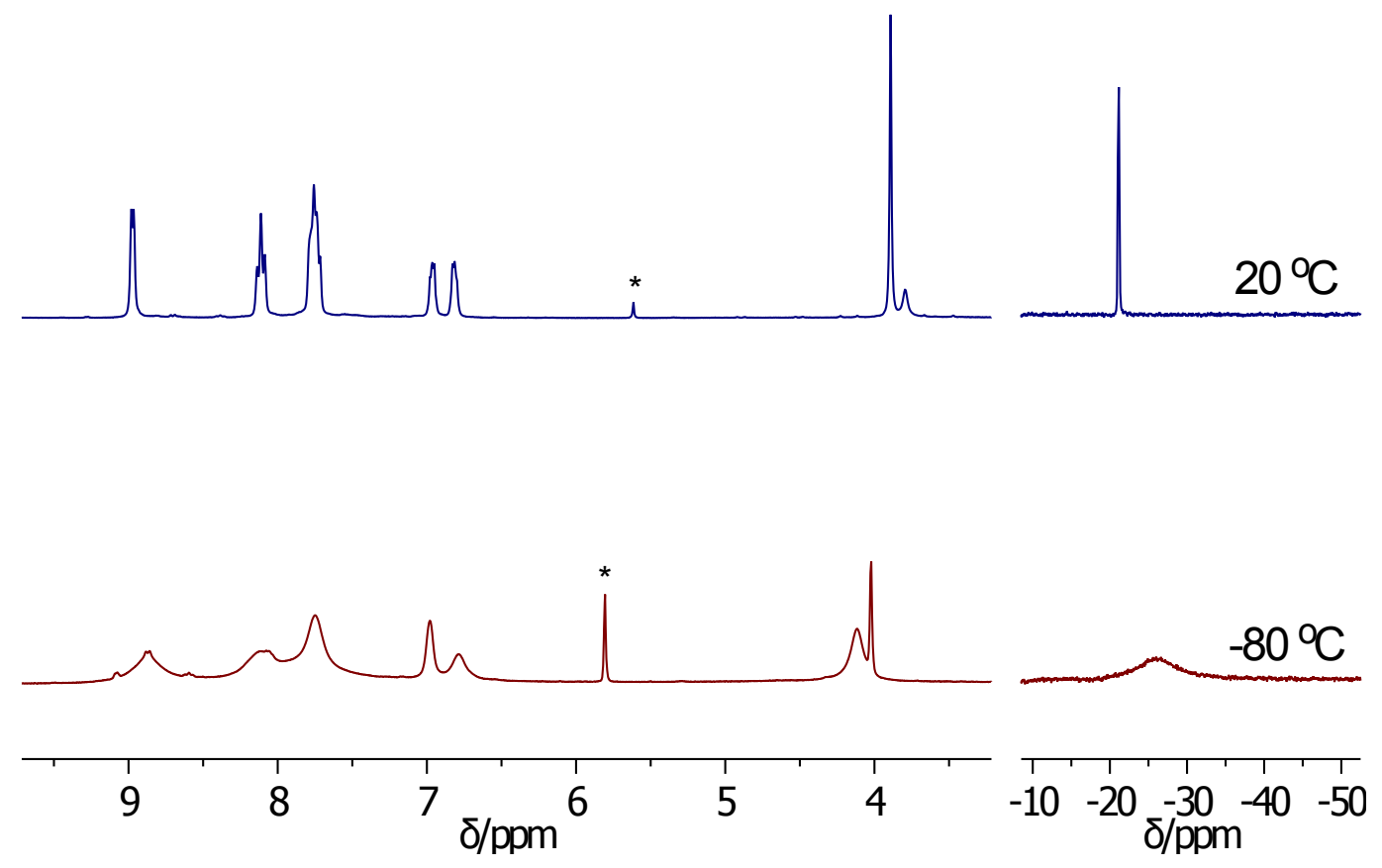

Figure 2.2 ${ }^{1} \mathrm{H}$ (left) and ${ }^{31} \mathrm{P}$ (right) NMR spectra of protonated ligand $\mathbf{3}$ collected at 20 and $-80{ }^{\circ} \mathrm{C}$ in $d_{6}$-acetone. Asterisks denote a sample impurity.

Infrared spectroscopy (IR) was used to confirm that the protons were bound to the nitrogens rather than the phosphorus atoms in these reactions. IR spectra recorded of the products of the reactions of one and four equivalents of $\mathrm{H}_{2} \mathrm{C}\left(\mathrm{SO}_{2} \mathrm{CF}_{3}\right)_{2}$ with 3 showed $\mathrm{N}-\mathrm{H}$ stretches at 3075 and $3103 \mathrm{~cm}^{-1}$ respectively. The position of the $\mathrm{C}=\mathrm{N}$ stretches was further evidence that the protons were bound to the nitrogen atom. A shift of $10-30 \mathrm{~cm}^{-1}$ of the $\nu(\mathrm{C}=\mathrm{N})$ stretching vibration to higher frequences has been reported as indicative of coordination of a metal to the nitrogen in a pyridyl ring. ${ }^{13,107}$ Thus a shift of the $\mathrm{C}=\mathrm{N}$ stretch could be concluded to indicate that the proton was bound to the nitrogen. In the reaction with one equivalent of acid there were two $\mathrm{C}=\mathrm{N}$ stretches present in the IR spectra, at 1574 and $1606 \mathrm{~cm}^{-1}$. This was consistent with protonation of one of the pyridyl nitrogen atoms, with the associated $\mathrm{C}=\mathrm{N}$ stretch at $1606 \mathrm{~cm}^{-1}$, and the others being free, with the corresponding $\mathrm{C}=\mathrm{N}$ stretch unchanged from the free ligand at $1574 \mathrm{~cm}^{-1}$. In the reaction with four equivalents of acid, only the $\mathrm{C}=\mathrm{N}$ stretch at $1607 \mathrm{~cm}^{-1}$ was observed, which was consistent with protonation of all of the nitrogen atoms. The same pattern was observed in the IR spectra of the reactions with 4 . N-H stretches were observed at 3081 and $3100 \mathrm{~cm}^{-1}$ and the $\nu(\mathrm{C}=\mathrm{N})$ stretching vibration had shifted to $1607 \mathrm{~cm}^{-1}$ compared to $1580 \mathrm{~cm}^{-1}$ in the free ligand.

When the ligands were reacted with six equivalents of $\mathrm{H}_{2} \mathrm{C}\left(\mathrm{SO}_{2} \mathrm{CF}_{3}\right)_{2}$ it was expected 
that all of the nitrogen and phosphorus atoms would be protonated. Once again a single signal in the ${ }^{31} \mathrm{P}$ NMR spectra was observed in each reaction. However, this time the signal was a very broad singlet at -24.1 and $-19.8 \mathrm{ppm}$ for the reactions with 3 and 4 respectively. This indicated that not only was there still a dynamic process occurring in solution, but this time the coalescence point was much closer to room temperature. As all possible protonation sites on the ligand should have reacted, this dynamic behaviour is most likely proton exchange between the ligand and the $\mathrm{CH}\left(\mathrm{SO}_{2} \mathrm{CF}_{3}\right)_{2}{ }^{-}$anion in solution, and possibly $\mathrm{H} / \mathrm{D}$ exchange with the solvent. This was supported by the observation of very broad signals for the anion in both the ${ }^{1} \mathrm{H}$ and ${ }^{19} \mathrm{~F}$ NMR spectra.

IR spectroscopy was again used to confirm the extent of protonation of the ligand. Once again $\mathrm{N}-\mathrm{H}$ stretches and $\mathrm{C}=\mathrm{N}$ stretches consistent with the nitrogen atoms being protonated were observed at 3100 and $1606 \mathrm{~cm}^{-1}$. However, this time $\mathrm{P}-\mathrm{H}$ stretches were also observed at 2361 and $2363 \mathrm{~cm}^{-1}$. This confirmed that reaction with six equivalents of $\mathrm{H}_{2} \mathrm{C}\left(\mathrm{SO}_{2} \mathrm{CF}_{3}\right)_{2}$ protonated all of the nitrogen and phosphorus atoms in compounds 3 and $\mathbf{4}$.

The reaction of $\mathbf{3}$ and $\mathbf{4}$ with excess concentrated hydrochloric acid gave watersoluble species. The NMR data of the water-soluble species in $\mathrm{D}_{2} \mathrm{O}$ was similar to that of the protonated species in $d_{6}$-acetone. The signals in the ${ }^{31} \mathrm{P}$ NMR spectra appeared at -19.8 and $-16.1 \mathrm{ppm}$ for 3 and 4 respectively (Table 2.4). The difference in the position of the signals in the ${ }^{31} \mathrm{P}$ and ${ }^{1} \mathrm{H}$ NMR spectra in $\mathrm{D}_{2} \mathrm{O}$ and those of the partially protonated ligands could be due to a solvent effect and cannot be used to determine the extent of protonation of the water-soluble ligands. Once again the signals for the pyridyl protons have moved downfield with respect to the same signals in the free ligand. However, as in acetone- $d_{6}$, in $\mathrm{D}_{2} \mathrm{O}$ there is rapid $\mathrm{H} / \mathrm{D}$ exchange so it was not possible to observe the signals for the protons on the nitrogen or phosphorus atoms. This meant that NMR spectroscopy could not be used to determine whether the ligands were completely protonated. In the IR spectra of the water-soluble species both $\mathrm{N}-\mathrm{H}$ and $\mathrm{P}-\mathrm{H}$ stretches were observed, indicating that the ligands were fully protonated. A pH titration of these species showed that the phosphorus atoms act independently of each other and were both deprotonated at a $\mathrm{pH}$ of about 2. The four nitrogen atoms were all deprotonated simultaneously at a $\mathrm{pH}$ of about 5 (as this is also when the ligand precipitates out of the aqueous solution the $\mathrm{pH}$ could not be determined accurately).

The protonation of either $\mathbf{3}$ or $\mathbf{4}$ could be reversed by reacting the protonated ligand with a solution of sodium bicarbonate. The resulting compound could then be extracted from the aqueous phase into dichloromethane. Thus protonation provides 
a method of manipulating the solubility of the ligands, of making them reversibly water-soluble.

\subsection{Phosphine-Boranes}

Borane-protection of phosphines is useful as it results in air-stable solids and protects the phosphorus atom from oxidation or any side reactions. ${ }^{108}$ As the compounds 3 and 4 used in this work have already been determined to be air sensitive, boraneprotection of the phosphorus atoms was desirable. However, it is known that borane groups have a higher affinity for nitrogen than phosphorus atoms. This is illustrated by the fact that secondary amines are commonly used to remove borane groups from phosphorus atoms. ${ }^{105,108}$ The nitrogen atoms present in $\mathbf{3}$ and $\mathbf{4}$ are part of a pyridyl ring and thus are electronically different to the secondary amines used for deprotection reactions, for example, the $\mathrm{p} K_{\mathrm{b}}$ of pyridine is 8.77 while diethylamine has a $\mathrm{p} K_{\mathrm{b}}$ of 3.07. ${ }^{101}$ Given this, it was postulated that it might be possible to protect the phosphorus atoms in the ligands in the presence of the pyridyl nitrogens.

The reaction of 3 or 4 with two equivalents of $\mathrm{Me}_{2} \mathrm{~S} \cdot \mathrm{BH}_{3}$ for one hour gave the desired phosphine-boranes, 14 and $\mathbf{1 5}$ (Scheme 2.7). This was confirmed from the ${ }^{31} \mathrm{P}$ NMR signals of the products, which were broad multiplets centred at $32.5 \mathrm{ppm}$ for $\mathbf{1 4}$ and $23.0 \mathrm{ppm}$ for $\mathbf{1 5}$, due to coupling to NMR-active boron. The signals in the ${ }^{11} \mathrm{~B}$ NMR spectra appeared at -40.1 and $-40.7 \mathrm{ppm}$ for $\mathbf{1 4}$ and $\mathbf{1 5}$ respectively. This was consistent with the chemical shifts reported in the literature for phosphineboranes. ${ }^{108}$ Very broad peaks in the ${ }^{1} \mathrm{H}$ NMR spectra between 1.0 and $1.8 \mathrm{ppm}$ reflected the presence of the borane group. A B-H stretching peak was also observed in the infrared spectra of the products, at 2383 and $2381 \mathrm{~cm}^{-1}$ for $\mathbf{1 4}$ and $\mathbf{1 5}$ respectively. The $\mathrm{C}=\mathrm{N}$ stretches were observed at 1573 and $1574 \mathrm{~cm}^{-1}$, and as these are identical to that observed in the free ligands, this was further confirmation that the borane groups are bound to the phosphorus atoms and not any of the nitrogen atoms.

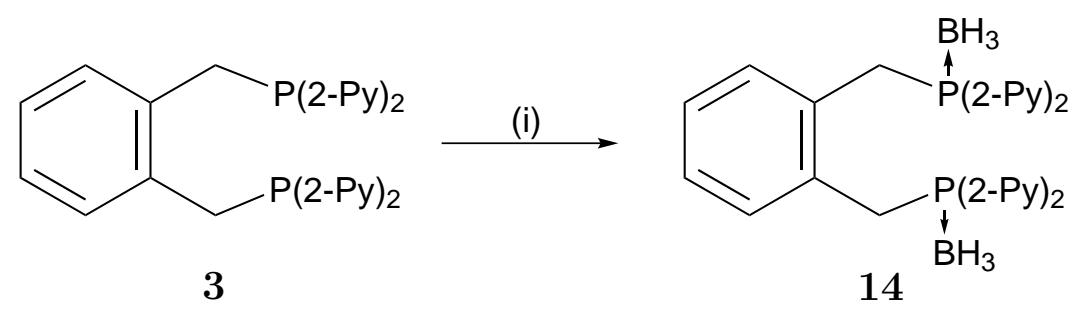

Scheme 2.7 Borane protection of dpypox ligand 3. Reagents and conditions: (i) $\mathrm{Me}_{2} \mathrm{~S} \cdot \mathrm{BH}_{3}, \mathrm{THF}, \mathrm{RT}, 1 \mathrm{~h}$. 
When the reaction of $\mathbf{3}$ or $\mathbf{4}$ with two equivalents $\mathrm{Me}_{2} \mathrm{~S} \cdot \mathrm{BH}_{3}$ was stirred at room temperature for 72 hours the phosphine-boranes, $\mathbf{1 4}$ and 15, were still the only products observed. So even with prolonged reaction times the borane groups remain bound to the phosphorus atoms and do not react with the nitrogen atoms, even though they are in close proximity.

The low solubility of $\mathbf{1 4}$ and $\mathbf{1 5}$ in most solvents meant that they could not be recrystallised. However, they were stable over time and thus an effective way to protect the phosphorus atom from oxidation. The borane groups could be removed by reaction with $\mathrm{Et}_{2} \mathrm{NH}$ at $60{ }^{\circ} \mathrm{C}$ overnight.

\subsection{Concluding Remarks}

Two new pyridyldiphosphines, $\mathbf{3}$ and $\mathbf{4}$, and one known pyridyldiphopshine, $\mathbf{5}$, have been synthesised via an improved methodology. The new compounds have been characterised using a combination of NMR spectroscopy, infrared spectroscopy and high resolution mass spectrometry. As they were found to be air sensitive it was not possible to obtain elemental analysis data.

The compounds 3 and $\mathbf{4}$ were reacted with elemental selenium to produce phosphine selenides. The value of ${ }^{1} J_{\mathrm{PSe}}$ measured in the NMR spectra of these compounds was used as a measure of the basicity of the phosphorus atoms in the ligands. Given ${ }^{1} J_{\mathrm{PSe}}$ values of 738 and $742 \mathrm{~Hz}$ for 3 and 4 respectively, it was concluded that these ligands were less basic than the phenyl analogues and that the 2-pyridyl subsituents were more electron withdrawing than phenyl groups. Values of $\mathrm{p} K_{\mathrm{b}}$ were calculated, 12.05 and 12.59 for $\mathbf{3}$ and $\mathbf{4}$ respectively, indicating the pyridyl nitrogen atoms are more basic than the phosphorus atoms.

When the ligands were reacted with acid it was observed that the nitrogen atoms were protonated first, which was consistent with what was predicted based on the phosphine selenide work. It was also observed that the protons were not statically bound to the nitrogen atoms even at low temperature but that they were moving between the nitrogen atoms at a rate faster than the NMR time scale. Infrared spectroscopy was used to determine the position of the protons through the observation of $\mathrm{N}-\mathrm{H}$ and $\mathrm{P}-\mathrm{H}$ stretches and the movement of the $\mathrm{C}=\mathrm{N}$ stretch with the protonation of the pyridyl nitrogens. Reaction with excess hydrochloric acid rendered the ligands water-soluble. Subsequent reaction with sodium bicarbonate showed that this water-solubility was reversible. 
Finally the phosphorus atoms in these ligands were successfully protected with borane groups. While the insoluble nature of these phosphine-boranes precluded their recrystallisation, they were found to be stable over time and thus an effective method of preventing the oxidation of the phosphorus atoms in compounds $\mathbf{3}$ and $\mathbf{4}$. 


\section{Chapter 3}

\section{Monometallic Complexes of dpypox}

As discussed in Chapter 1 the ligands of the type investigated in this work can coordinate to metals through the phosphorus donors or the nitrogen donors or both the phosphorus and nitrogen donors. This chapter discusses the complexes formed when the phosphorus atoms are coordinated to a metal and attempts to coordinate the pyridyl nitrogen atoms to the same metal. In particular, this chapter explores the coordination chemistry of the dpypox ligand $\mathbf{3}$ with platinum, palladium, silver, rhodium and iridium.

The investigation of the coordination chemistry of ligand $\mathbf{3}$ started with reactions with platinum precursor complexes. This was because these complexes are easily handled, often react in predictable ways with diphosphine ligands and platinum has an NMR active isotope, ${ }^{195} \mathrm{Pt}$ ( $\operatorname{spin}=1 / 2,34 \%$ abundant). The presence of ${ }^{195} \mathrm{Pt}$ leads to satellites in the NMR spectra of platinum complexes, which provide important structural information. Also as platinum complexes tend to be more inert than the analogous palladium complexes they are often used as models for the more catalytically active palladium complexes.

Once the platinum complexes had been fully characterised the analogous palladium complexes were investigated. Palladium coordination complexes with diphosphine ligands are important materials as they have been extensively used as homogeneous catalysts for a wide range of reactions, including $\mathrm{C}-\mathrm{C}, \mathrm{C}-\mathrm{O}$ and $\mathrm{C}-\mathrm{N}$ bond forming reactions. As these catalytic reactions often go through both $\operatorname{Pd}(0)$ and $\operatorname{Pd}(\mathrm{II})$ oxidation states, the coordination chemistry of the ligand 3 with platinum and palladium in both 0 and $2+$ oxidation states was explored. 


\subsection{Platinum(II) and Palladium(II) Reactions}

Reaction of platinum(II) precursors of the type $\left[\mathrm{PtX}_{2}(\right.$ dialkene $\left.)\right]$ (X = Me, Et, $\mathrm{Cl}$, I; dialkene = cycloocta-1,5-diene, hexa-1,5-diene) with the dpypox ligand $\mathbf{3}$ in equimolar ratios at room temperature resulted in the simple diphosphine complexes, $\left[\mathrm{PtX}_{2}(\mathrm{PP})\right](\mathrm{PP}=\mathbf{3})$ (Scheme 3.1).

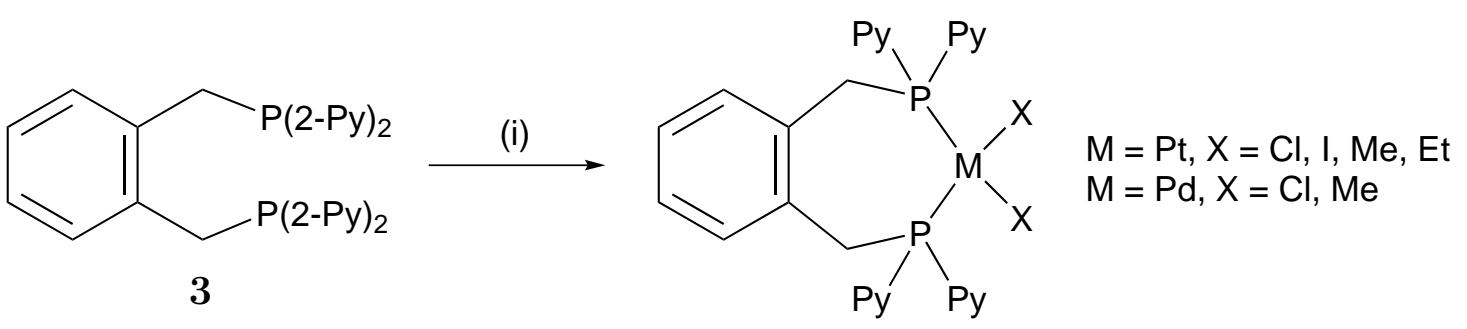

Scheme 3.1 Synthesis of $\mathrm{Pt}(\mathrm{II})$ and $\mathrm{Pd}(\mathrm{II})$ complexes of the dpypox ligand 3. Reagents and conditions: (i) dichloro(hexa-1,5-diene)platinum, diiodo(hexa1,5-diene)platinum, dimethyl(hexa-1,5-diene)platinum, diethyl(cycloocta-1,5diene)platinum, dichloro(cycloocta-1,5-diene)palladium or $\operatorname{dimethyl}\left(N, N, N^{\prime}, N^{\prime}\right.$ tetramethylethylenediamine)palladium, $\mathrm{CDCl}_{3}, 15 \mathrm{~min}$.

The new platinum(II) complexes were characterised by ${ }^{31} \mathrm{P},{ }^{1} \mathrm{H}$ and ${ }^{13} \mathrm{C} \mathrm{NMR}$ and infrared spectroscopy, and mass spectrometry. The NMR data was found to be consistent with that reported of the analogous diphenylphosphino- $o$-xylene (dppox) complexes. ${ }^{71,73}$ The complexes were air stable in solution and in the solid state.

In each reaction ${ }^{1} \mathrm{H}$ and ${ }^{31} \mathrm{P}$ NMR spectroscopy was used to confirm the formation of a platinum complex containing ligand 3 . The ${ }^{31} \mathrm{P}$ NMR spectra recorded of the reaction mixtures after 15 minutes showed that the signal due to phosphorus had shifted 7.4-17.3 ppm downfield on coordination and had ${ }^{195} \mathrm{Pt}$ satellites (Table 3.1). As expected the value of the ${ }^{195} \mathrm{Pt}^{31} \mathrm{P}$ coupling constant was found to vary depending on the ligand trans to the phosphorus donor. ${ }^{16}$ For example, the $\left[\mathrm{PtCl}_{2}(\mathrm{PP})\right]$ complex 16 had a high ${ }^{1} J_{\mathrm{PtP}}$ value, $3500 \mathrm{~Hz}$, as chloride ligands are low in trans influence. ${ }^{16}$ In contrast, ${ }^{1} J_{\mathrm{PtP}}=1840 \mathrm{~Hz}$ for the $\left[\mathrm{PtMe}_{2}(\mathrm{PP})\right]$ complex 17 , as methyl ligands are high in trans influence.

In the ${ }^{1} \mathrm{H}$ NMR spectra of the complexes the signals due to ligand $\mathbf{3}$ had shifted upon coordination. The signals due to the protons on the pyridyl rings shifted downfield to $7.29-8.86 \mathrm{ppm}$, as compared to $7.15-8.66 \mathrm{ppm}$ in the free ligand. The signals due to the aromatic ring in the backbone were the only ones to shift upfield upon coordination. While in the free ligand these protons appeared as two doublets at 6.84 and $6.90 \mathrm{ppm}$, in the complexes they appeared as two multiplets with quite different chemical shifts (about 6.6 and $6.1 \mathrm{ppm}$ ). The signal due to the $\mathrm{CH}_{2} \mathrm{P}$ protons had also shifted downfield to around $4.5 \mathrm{ppm}$ and now appeared as a broad 
Table 3.1 ${ }^{31} \mathrm{P}$ NMR data of $\mathrm{Pt}(\mathrm{II})$ and $\mathrm{Pd}(\mathrm{II})$ complexes of the dpypox and dpypp ligands.

\begin{tabular}{lccc}
\hline Formula & Compound & $\delta^{31} \mathrm{P} / \mathrm{ppm}^{a}$ & ${ }^{1} J_{\mathrm{PtP}} / \mathrm{Hz}$ \\
\hline$\left[\mathrm{PtCl}_{2}(\right.$ dpypox $\left.)\right]$ & $\mathbf{1 6}$ & 0.64 & 3500 \\
{$\left[\mathrm{PtMe}_{2}(\right.$ dpypox $\left.)\right]$} & $\mathbf{1 7}$ & 10.50 & 1840 \\
{$\left[\mathrm{PtI}_{2}(\right.$ dpypox $\left.)\right]$} & $\mathbf{1 8}$ & -13.0 & 3304 \\
{$\left[\mathrm{PtEt}_{2}(\right.$ dpypox $\left.)\right]$} & $\mathbf{1 9}$ & 9.47 & 1687 \\
{$\left[\mathrm{PdCl}_{2}(\right.$ dpypox $\left.)\right]$} & $\mathbf{2 0}$ & 17.56 & $\mathrm{n} / \mathrm{a}$ \\
{$\left[\mathrm{PdMe}_{2}(\right.$ dpypox $\left.)\right]$} & $\mathbf{2 1}$ & 14.71 & $\mathrm{n} / \mathrm{a}$ \\
{$\left[\mathrm{PtCl}_{2}(\right.$ dpypp$\left.)\right]$} & $\mathbf{2 2}$ & 3.05 & 3319 \\
{$\left[\mathrm{PtMe}_{2}(\right.$ dpypp $\left.)\right]$} & $\mathbf{2 3}$ & 9.30 & 1737 \\
{$\left[\mathrm{PtEt}_{2}(\right.$ dpypp$\left.)\right]$} & $\mathbf{2 4}$ & 8.83 & 1569 \\
{$\left[\mathrm{PdCl}_{2}(\right.$ dpypp$\left.)\right]$} & $\mathbf{2 5}$ & 14.03 & $\mathrm{n} / \mathrm{a}$ \\
{$\left[\mathrm{PdMe}_{2}(\right.$ dpypp$\left.)\right]$} & $\mathbf{2 6}$ & 12.64 & $\mathrm{n} / \mathrm{a}$ \\
\hline${ }^{a} \mathrm{Spectra}_{2}$ recorded in $\mathrm{CDCl}_{3}$. & \multicolumn{3}{l}{}
\end{tabular}

singlet, whereas in the free ligand it was a sharp singlet at $3.97 \mathrm{ppm}$. In the different complexes there was very little variation in the chemical shifts or in the appearance of the signals of each proton environment.

The broadness of the signal due to the methylene protons in the ligand indicated that there may be a dynamic process occurring on the NMR timescale. Fluxional behaviour has been reported for complexes of other ligands with the $o$-xylene backbone. For example, in the $\left[\mathrm{PtCl}_{2}(\mathrm{PP})\right]$ complex $\left(\mathrm{PP}=o-\mathrm{C}_{6} \mathrm{H}_{4}\left(\mathrm{CH}_{2} \mathrm{PBu}_{2}{ }_{2}\right)\left(\mathrm{CH}_{2} \mathrm{PPh}_{2}\right)\right)$ the diphosphine backbone assumes an envelope conformation which inverts at room temperature. ${ }^{71}$ In this example the dynamic process renders the substituents on the phosphorus inequivalent and thus at room temperature the ${ }^{1} \mathrm{H}$ NMR spectrum displays several broad signals characteristic of near-coalescence. However, in this work the only broad signals in the ${ }^{1} \mathrm{H}$ NMR spectra of the $\left[\mathrm{PtX}_{2}(\mathrm{PP})\right]$ complexes $(\mathrm{X}=\mathrm{Cl}$, $\mathrm{I}, \mathrm{Me}, \mathrm{Et})$ were those of the methylene protons and the ortho proton on the pyridyl ring. This dynamic behaviour was attributed to the backbone of the dpypox ligand 3 flipping as detailed in Figure 3.1.

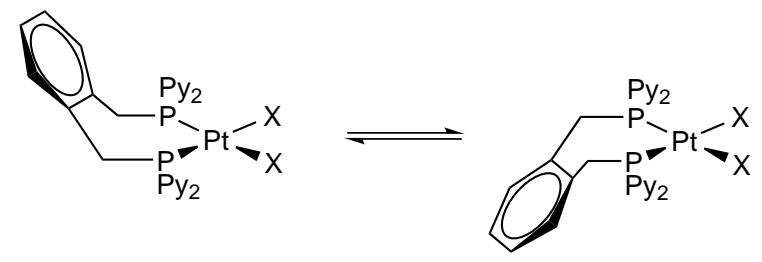

Figure 3.1 Fluxional behaviour of $\left[\mathrm{PtX}_{2}(\operatorname{dpyp} o x)\right]$ complexes.

Variable temperature NMR (VT-NMR) spectra of the $\left[\mathrm{PtMe}_{2}(\mathrm{PP})\right]$ complex 17 were recorded at $20{ }^{\circ} \mathrm{C}$ intervals between 40 and $-80{ }^{\circ} \mathrm{C}$ in a $1: 1$ mixture of dichloromethane- $d_{2}$ and chloroform- $d$. While there was no change to the ${ }^{31} \mathrm{P}$ NMR spectra over this temperature, there was a significant variation in the signals ob- 
served in the ${ }^{1} \mathrm{H}$ NMR spectra.

The ${ }^{1} \mathrm{H}$ NMR spectra (between 3.5 and $9.5 \mathrm{ppm}$ ) are shown in Figure 3.2 (as there was very little change in the signal for the methyl ligands over this temperature range it was omitted). At $40{ }^{\circ} \mathrm{C}$, a doublet with possible ${ }^{195} \mathrm{Pt}$ satellites was observed for the methylene protons, indicating that the dynamic process was rapid on the NMR time scale leading to the methylene protons occupying a single time-averaged chemical environment. As already mentioned, at $20{ }^{\circ} \mathrm{C}$ the signal for the methylene protons was a broad singlet, as this is near the coalescence point. Below $20^{\circ} \mathrm{C}$ the signal for the methylene protons separated: at $0{ }^{\circ} \mathrm{C}$ two broad signals were observed, while at $-20{ }^{\circ} \mathrm{C}$ and below the coupling of the two signals could be clearly seen. While at room temperature the signal appeared at $4.56 \mathrm{ppm}$, when the signals were distinct they appeared as a doublet at $5.11(J=10.8 \mathrm{~Hz})$ and an apparent triplet at $4.18 \mathrm{ppm}(J=14.4 \mathrm{~Hz})$.

In the aromatic region of the ${ }^{1} \mathrm{H}$ NMR spectra there was very little change to the signals associated with the ligand backbone at 6.60 and $6.17 \mathrm{ppm}$. This was consistent with the dynamic process observed being due to the backbone flipping as the protons on the aromatic backbone would remain in the same chemical environment when the backbone flips. In contrast, as the temperature was decreased the signals for the pyridyl protons collapsed into broad signals and then separated out to give signals for the two different pyridyl environments in the static structure, that of the pyridyl ring close to the backbone and the one further away. For example, the doublet at $8.85 \mathrm{ppm}(J=4.2 \mathrm{~Hz})$ at $40{ }^{\circ} \mathrm{C}$, associated with the proton on the carbon next to the nitrogen, split into two doublets at 8.96 and $8.83 \mathrm{ppm}(J=3.0 \mathrm{~Hz})$ below $-20{ }^{\circ} \mathrm{C}$.

The observation of a coalescence point between 20 and $0{ }^{\circ} \mathrm{C}$ is consistent with what was observed in VT-NMR experiments in the diphosphine example described above $^{71}$ and in platinum complexes of the ligand ${ }^{o}-\mathrm{C}_{6} \mathrm{H}_{4}\left(\mathrm{CH}_{2} \mathrm{PBu}_{2}{ }_{2}\right)\left(\mathrm{CH}_{2} \mathrm{SBu}^{t}\right) .{ }^{105}$

Similar broad signals were observed in the ${ }^{1} \mathrm{H}$ NMR spectra at ambient temperature of the $\left[\mathrm{PtCl}_{2}(\mathrm{PP})\right]$ complex 16, $\left[\mathrm{PtEt}_{2}(\mathrm{PP})\right]$ complex 19 and several other complexes discussed below. It was assumed that the same fluxional behaviour was occurring in those complexes.

In the $\left[\mathrm{PtMe}_{2}(\mathrm{PP})\right]$ complex 17 and $\left[\mathrm{PtEt}_{2}(\mathrm{PP})\right]$ complex 19 the signals due to the alkyl ligands in the ${ }^{1} \mathrm{H}$ NMR spectra changed from that of the precursor complexes, which was expected. In complex $\mathbf{1 7}$ the signal due to the methyl ligands moved to a lower chemical shift and showed coupling to the phosphorus atoms. The methyl 


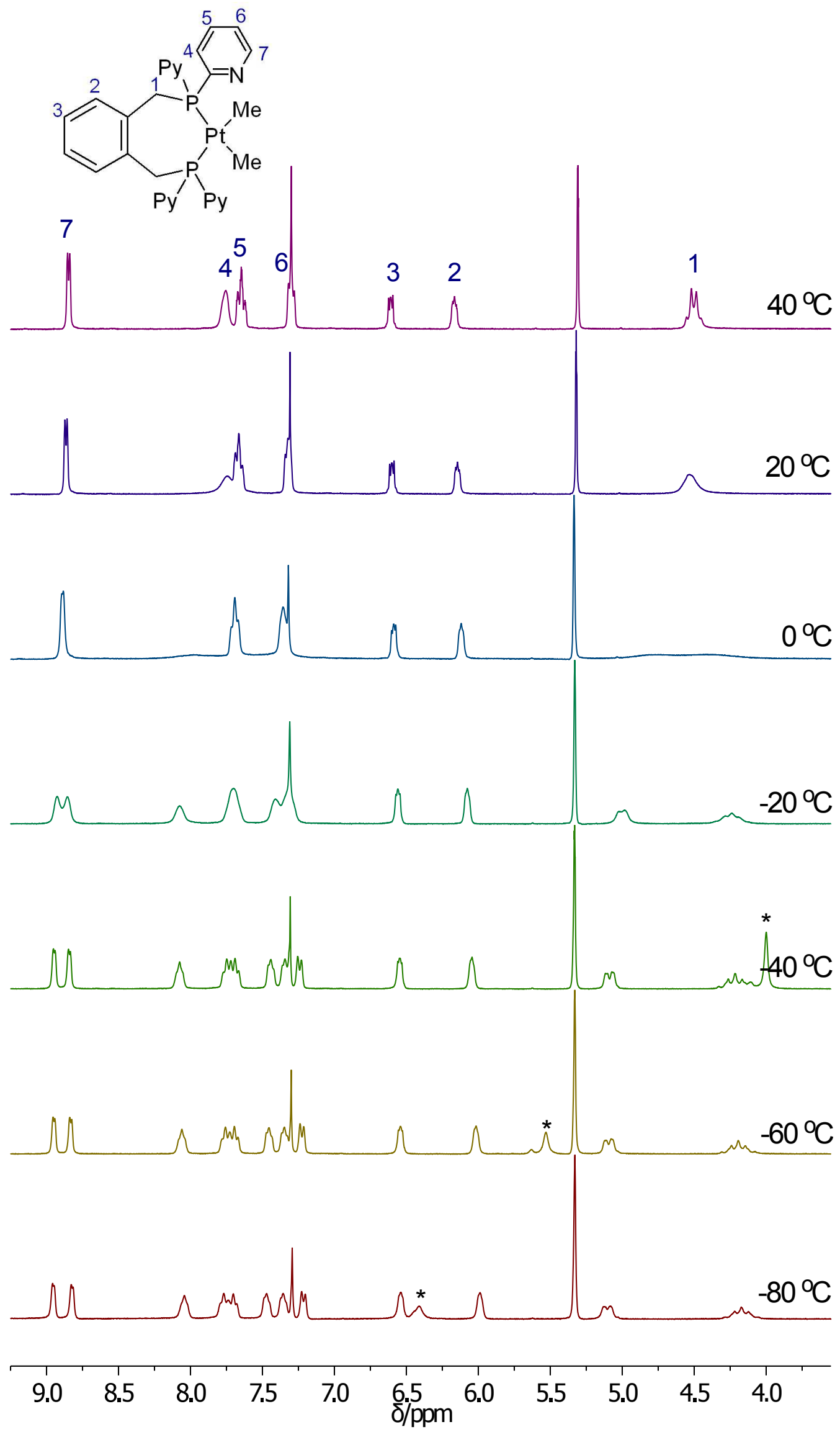

Figure 3.2 ${ }^{1} \mathrm{H}$ NMR spectra of the $\left[\mathrm{PtMe}_{2}(\mathrm{PP})\right]$ complex 17 collected between 40 and $-80{ }^{\circ} \mathrm{C}$ in $\mathrm{CD}_{2} \mathrm{Cl}_{2} / \mathrm{CDCl}_{3}$. Asterisks denote sample impurities. 
signal in the ${ }^{1} \mathrm{H}$ NMR spectrum appeared as a quartet due to an $\mathrm{AA}^{\prime} \mathrm{X}_{3} \mathrm{X}_{3}^{\prime}$ spin system. ${ }^{24}$ The methyl signal in the ${ }^{1} \mathrm{H}$ NMR spectrum of $\left[\mathrm{PtMe}_{2}\left(\mathrm{PPy}_{3}\right)_{2}\right]$ appeared as a quartet for the same reason. ${ }^{24}$ Also the ${ }^{2} J_{\mathrm{PtH}}$ value decreased from $84 \mathrm{~Hz}$ in dimethyl(hexa-1,5-diene)platinum ${ }^{37}$ to $69 \mathrm{~Hz}$ in $\mathbf{1 7}$. This is due to the higher trans influence of a phosphine when compared to an alkene. ${ }^{16}$ While the signals due to the ethyl ligands in complex 19 did not show coupling to phosphorus they showed the same decrease in coupling to platinum seen in complex $\mathbf{1 7 .}$

When ligand 3 was reacted with an excess of the platinum(II) precursors, trimetallic species were formed. This reactivity is discussed further in Chapter 5. Whether the nitrogens in the pyridyl rings of the ligand have coordinated to a metal can be investigated by measuring the stretching frequency of the pyridyl ring in the IR spectrum. Coordination of the nitrogen to a metal is expected to shift the $\nu(\mathrm{C}=\mathrm{N})$ stretching vibration $10-30 \mathrm{~cm}^{-1}$ to higher frequencies. ${ }^{13,107}$ In the IR spectra, the $\nu(\mathrm{C}=\mathrm{N})$ appeared at 1573 and $1562 \mathrm{~cm}^{-1}$ for the $\left[\mathrm{PtCl}_{2}(\mathrm{PP})\right]$ complex 16 and 1574 and $1562 \mathrm{~cm}^{-1}$ for the $\left[\mathrm{PtMe}_{2}(\mathrm{PP})\right]$ complex 17. The fact these values had not shifted from that of the free ligand 3, 1573 and $1560 \mathrm{~cm}^{-1}$, indicated that the nitrogen atoms were not coordinated to the metal centre in these complexes.

The same reactivity was observed when palladium(II) precursors dichloro(cycloocta1,5-diene)palladium or dimethyl $\left(N, N, N^{\prime}, N^{\prime}\right.$-tetramethylethylenediamine)palladium were reacted with the dpypox ligand 3 (Scheme 3.1). The ${ }^{1} \mathrm{H},{ }^{13} \mathrm{C}$ and ${ }^{31} \mathrm{P} \mathrm{NMR}$ data of the $\left[\mathrm{PdCl}_{2}(\mathrm{PP})\right]$ complex 20 and $\left[\mathrm{PdMe}_{2}(\mathrm{PP})\right]$ complex $\mathbf{2 1}$ followed the same trends as observed with the analogous platinum(II) complexes (Table 3.1).

Crystals of the $\left[\mathrm{PtCl}_{2}(\mathrm{PP})\right]$ complex 16 suitable for single crystal X-ray diffraction were grown from a solution of complex 16 in $\mathrm{CDCl}_{3}$, while crystals of the $\left[\mathrm{PdCl}_{2}(\mathrm{PP})\right]$ complex 20 were grown by inwards diffusion of $n$-hexane into a dichloromethane solution of complex 20 at $4{ }^{\circ} \mathrm{C}$. The X-ray structures confirmed that the $\left[\mathrm{MCl}_{2}(\mathrm{PP})\right]$ complexes $\mathbf{1 6}$ and $\mathbf{2 0}$ were simple diphosphine complexes and that the nitrogens were not coordinated to the metal as indicated by the NMR and IR data (Figure 3.3). Crystallographic data is given in Table 3.2 and selected bond lengths and angles are given in Table 3.3.

Unsurprisingly the two structures were very similar, with $\mathrm{P}-\mathrm{M}-\mathrm{P}$ bite angles of $100.83(6)^{\circ}$ and $100.04(3)^{\circ}$ for the platinum and palladium complexes respectively. This was similar to that reported for other $\left[\mathrm{PtCl}_{2} \mathrm{PP}\right]$ complexes of diphosphines with the $o$-xylene backbone $\left(\mathrm{PP}={ }^{o}-\mathrm{C}_{6} \mathrm{H}_{4}\left(\mathrm{CH}_{2} \mathrm{PBu}_{2}{ }_{2}\right)\left(\mathrm{CH}_{2} \mathrm{PPh}_{2}\right) 100.51(3)^{\circ},{ }^{71}{ }^{o-}\right.$ $\left.\mathrm{C}_{6} \mathrm{H}_{4}\left(\mathrm{CH}_{2} \mathrm{PBu}_{2}^{t}\right)_{2} 104.06(10)^{\circ 109}\right)$. While the analogous dppox complex of palladium had an identical bite angle $\left(100.04(6)^{\circ}\right),{ }^{73}$ the bite angle in the analogous 


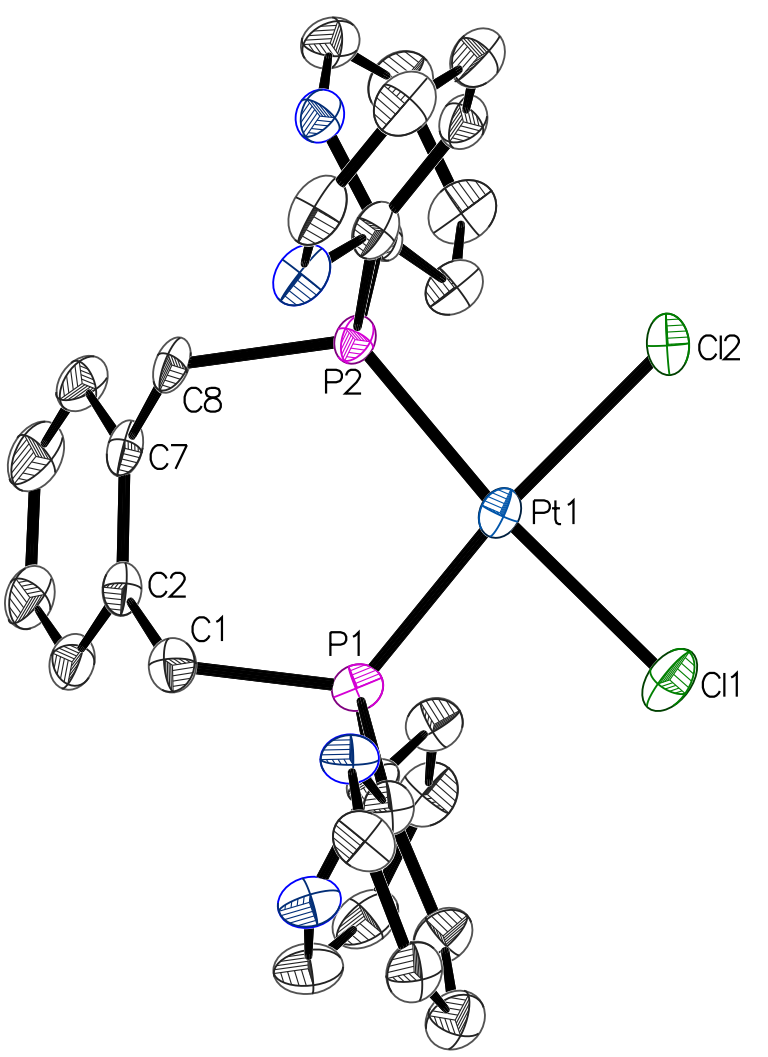

(a)

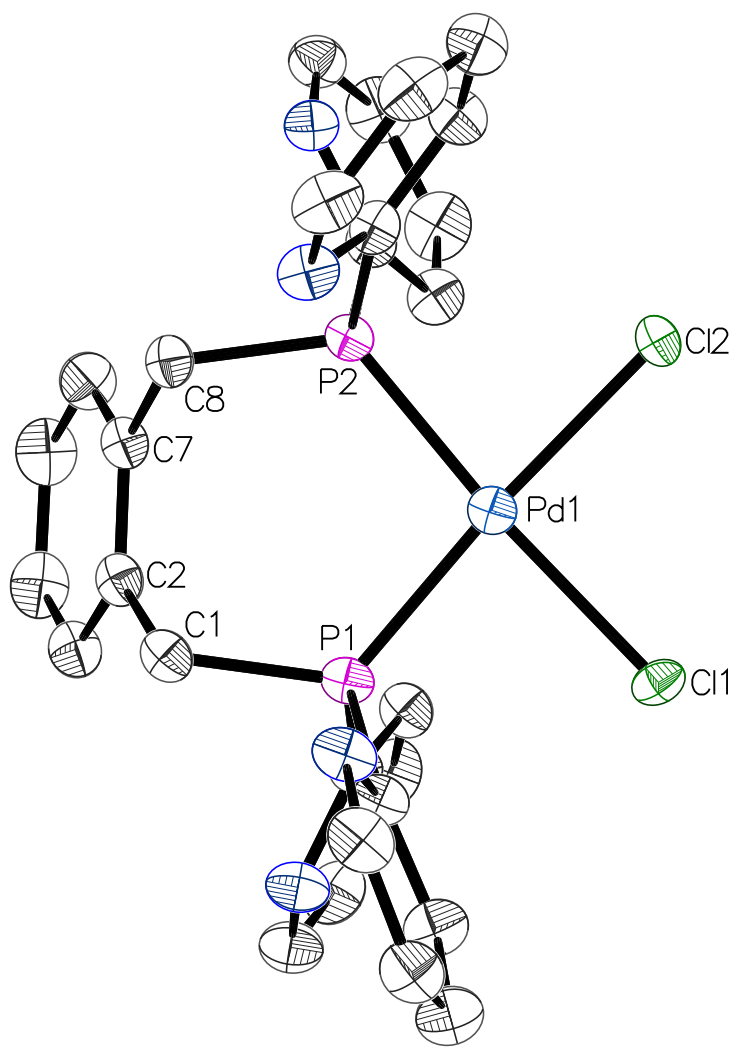

(b)

Figure 3.3 ORTEP diagrams of $\left[\mathrm{PtCl}_{2}(\mathrm{PP})\right]$ complex 16 (a) and $\left[\mathrm{PdCl}_{2}(\mathrm{PP})\right]$ complex 20 (b) (50\% probability thermal ellipsoids). Hydrogen atoms and solvent of crystallisation omitted for clarity. 
Table 3.2 Crystallographic data of $\left[\mathrm{MCl}_{2}(\mathrm{PP})\right]$ complexes $(\mathrm{M}=\mathrm{Pt}$ 16, $\mathrm{Pd} 20)$.

\begin{tabular}{|c|c|c|}
\hline Complex & 16 & 20 \\
\hline Empirical formula & $\mathrm{C}_{28} \mathrm{H}_{24} \mathrm{~N}_{4} \mathrm{P}_{2} \mathrm{Cl}_{2} \mathrm{Pt} \cdot \mathrm{CHCl}_{3}$ & $\mathrm{C}_{28} \mathrm{H}_{24} \mathrm{~N}_{4} \mathrm{P}_{2} \mathrm{Cl}_{2} \mathrm{Pd}$ \\
\hline Formula weight & 863.82 & 655.75 \\
\hline Crystal system & monoclinic & monoclinic \\
\hline Space group & $P 2_{1} / n$ & $P 2_{1} / n$ \\
\hline $\mathrm{a} / \AA$ & $14.5058(5)$ & $14.43316(19)$ \\
\hline $\mathrm{b} / \AA$ & $10.2019(5)$ & $10.2502(2)$ \\
\hline$c / \AA$ & $22.9424(8)$ & $22.5901(5)$ \\
\hline$\alpha /{ }^{\circ}$ & 90 & 90 \\
\hline$\beta /{ }^{\circ}$ & $91.017(3)$ & $90.1316(15)$ \\
\hline$\gamma /{ }^{\circ}$ & 90 & 90 \\
\hline $\mathrm{V} / \AA^{3}$ & $3394.7(2)$ & $3342.02(11)$ \\
\hline $\mathrm{Z}$ & 4 & 4 \\
\hline $\mathrm{D}_{\text {calc }} / \mathrm{g} \mathrm{m}^{-3}$ & 1.6790 & 0.977 \\
\hline$\mu / \mathrm{mm}^{-1}$ & 4.637 & 0.624 \\
\hline Temperature/K & 120.01(10) & 120.02(11) \\
\hline $\mathrm{F}(000)$ & 1664.7 & 990.0 \\
\hline Radiation type & $\operatorname{MoK} \alpha$ & $\operatorname{MoK} \alpha$ \\
\hline $\operatorname{Radiation}(\lambda) / \AA$ & 0.71073 & 0.71073 \\
\hline Index range $h$ & $-19 \rightarrow 20$ & $-24 \rightarrow 24$ \\
\hline Index range $k$ & $-12 \rightarrow 14$ & $-17 \rightarrow 17$ \\
\hline Index range $l$ & $-31 \rightarrow 32$ & $-38 \rightarrow 36$ \\
\hline Reflections collected & 24466 & 43938 \\
\hline$R_{1}[I>2 \sigma(I)]$ & 0.0513 & 0.0633 \\
\hline $\mathrm{w} R_{2}[I>2 \sigma(I)]$ & 0.1412 & 0.1920 \\
\hline$R_{1}$ [all data $]$ & 0.0693 & 0.0869 \\
\hline $\mathrm{w} R_{2}$ [all data] & 0.1593 & 0.2060 \\
\hline
\end{tabular}

Table 3.3 Selected bond distances and angles of $\left[\mathrm{MCl}_{2}(\mathrm{PP})\right]$ complexes $(\mathrm{M}=\mathrm{Pt}$ 16, Pd 20).

\begin{tabular}{lllllll}
\hline \multicolumn{3}{c}{ Bond distances $(\AA)$} & & \multicolumn{3}{c}{ Bond angles $\left(^{\circ}\right)$} \\
\cline { 1 - 2 } \cline { 5 - 6 } & $\mathbf{1 6}$ & $\mathbf{2 0}$ & & $\mathbf{1 6}$ & $\mathbf{2 0}$ \\
\hline M1-P1 & $2.2282(18)$ & $2.2455(7)$ & & P1-M1-P2 & $100.83(6)$ & $100.04(3)$ \\
M1-P2 & $2.2331(16)$ & $2.2513(7)$ & & Cl1-M1-Cl2 & $89.59(7)$ & $91.55(2)$ \\
M1-Cl1 & $2.3527(17)$ & $2.4091(6)$ & & P1-M1-Cl1 & $84.69(7)$ & $84.44(3)$ \\
M1-Cl2 & $2.3549(17)$ & $2.3841(6)$ & & P2-M1-Cl2 & $84.90(6)$ & $84.01(2)$ \\
P1-C1 & $1.843(7)$ & $1.837(3)$ & & P1-M1-Cl2 & $174.26(6)$ & $175.83(3)$ \\
P1-C9 & $1.827(6)$ & $1.818(3)$ & & P2-M1-Cl1 & $174.21(7)$ & $175.09(2)$ \\
P1-C14 & $1.823(7)$ & $1.815(3)$ & & C1-P1-M1 & $122.1(2)$ & $122.46(10)$ \\
P2-C8 & $1.827(6)$ & $1.823(3)$ & & C8-P2-M1 & $122.0(2)$ & $122.04(10)$ \\
P2-C19 & $1.835(7)$ & $1.826(3)$ & & P1-C1-C2 & $110.8(4)$ & $110.24(18)$ \\
P2-C24 & $1.834(7)$ & $1.824(3)$ & & P2-C8-C7 & $113.0(4)$ & $112.24(19)$ \\
\hline
\end{tabular}

palladium dbpx complex was larger $\left(101.88(1)^{\circ}\right) .{ }^{110}$ 
The Pt-P bond lengths in the $\left[\mathrm{PtCl}_{2}(\mathrm{PP})\right]$ complex 16, 2.2282(18) and 2.2351(16) $\AA$, were the same as those in $c i s$ - $\left[\mathrm{PtCl}_{2}(\mathrm{dppp})\right], 2.239(2) \AA^{111}$ but shorter than those observed in the structure of cis- $\left[\mathrm{PtCl}_{2}\left(\mathrm{PPh}_{3}\right)_{2}\right], 2.2515(8)$ and 2.2713(9) $\AA$. ${ }^{112}$ The $\mathrm{Pd}-\mathrm{P}$ bond lengths in the $\left[\mathrm{PdCl}_{2}(\mathrm{PP})\right]$ complex 20 were similar to those in the analogous dppox complex $\left[\mathrm{PdCl}_{2}(\mathrm{PP})\right]\left(\mathrm{PP}=o-\mathrm{C}_{6} \mathrm{H}_{4}\left(\mathrm{CH}_{2} \mathrm{PPh}_{2}\right)_{2}\right), 2.2455(7)$ and $2.2513(7) \AA$ compared to $2.2572(5) \AA .{ }^{73}$

Figure 3.4 shows the square planar coordination of the palladium in complex 20 . It also clearly shows how the backbone is bent away from the coordination plane of the metal. This figure shows the static position of the backbone in the solid state confirming the structure postulated based on the VT-NMR experiments detailed above. This supports the proposal that the dynamic behaviour occurring in solution is the inversion of the backbone as already discussed. The P1-C1-C2 angles of $110.8(4)^{\circ}$ and $110.24(18)^{\circ}$ and the P2-C8-C7 angles of $113.0(4)^{\circ}$ and $112.24(19)^{\circ}$, for the platinum and palladium complexes respectively, show the significant bending of the aromatic backbone away from the coordination plane of the metal. This bending of the backbone observed in the structures of the $\left[\mathrm{MCl}_{2}(\mathrm{PP})\right]$ complexes 16 and 20 was consistent with what has been observed in similar structures in the literature. ${ }^{71,73,109}$

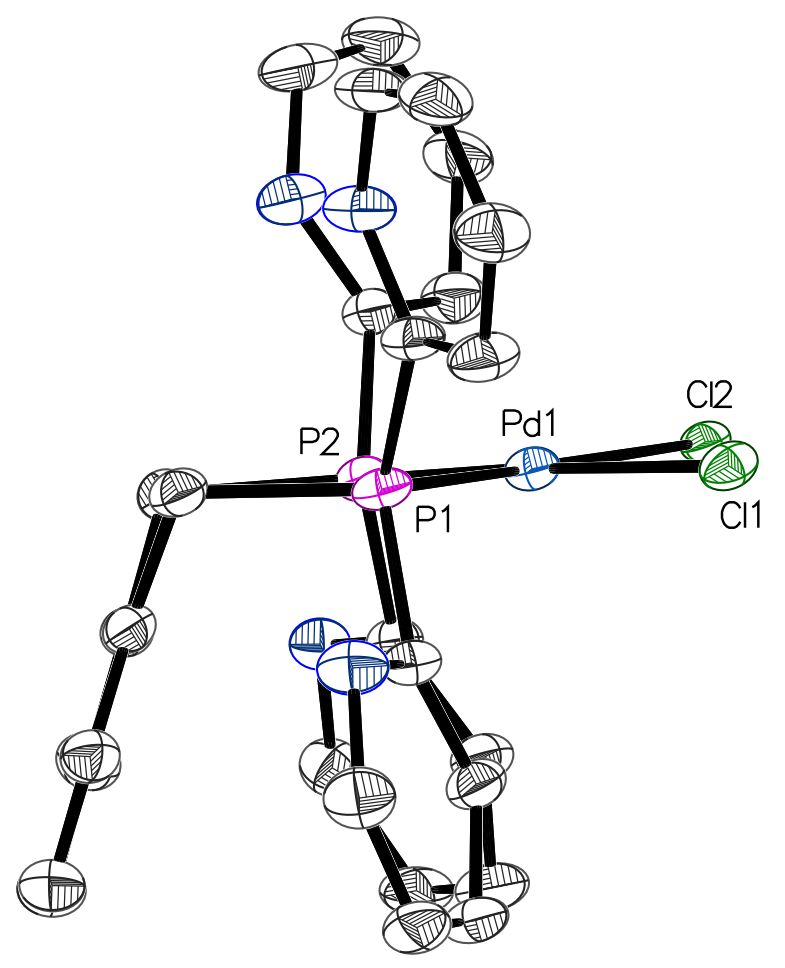

Figure 3.4 ORTEP diagram of $\left[\mathrm{PdCl}_{2}(\mathrm{PP})\right]$ complex 20 showing the bending of the backbone (50\% probability thermal ellipsoids). Hydrogen atoms omitted for clarity.

The activity of the $\left[\mathrm{PdCl}_{2}(\mathrm{PP})\right]$ complex 20 in Suzuki cross-coupling reactions was 
investigated. Reactions were performed with phenylboronic acid and 4-bromoanisole in toluene at $100{ }^{\circ} \mathrm{C}$ and the products analysed by gas chromatography mass spectrometry. Optimal results were observed with a catalyst loading of $0.001 \mathrm{~mol} \%$ and potassium carbonate as the external base (Figure 3.5-blue line). Under these conditions the reaction was $96 \%$ complete after 120 minutes. However, the presence of an induction period suggested that complex 20 was not the catalytically active species but a precatalyst. ${ }^{113}$ To investigate whether the active speices was a homogeneous species or palladium nanoparticles mercury poisoning experiments were undertaken. The addition of one drop of mercury to the reaction mixture resulted in a dramatic decrease in the activity observed (Figure 3.5-red line). This indicated that the majority of the catalytic activity observed was due to complex $\mathbf{2 0}$ forming nanoparticles rather than a homogenous species. ${ }^{114}$

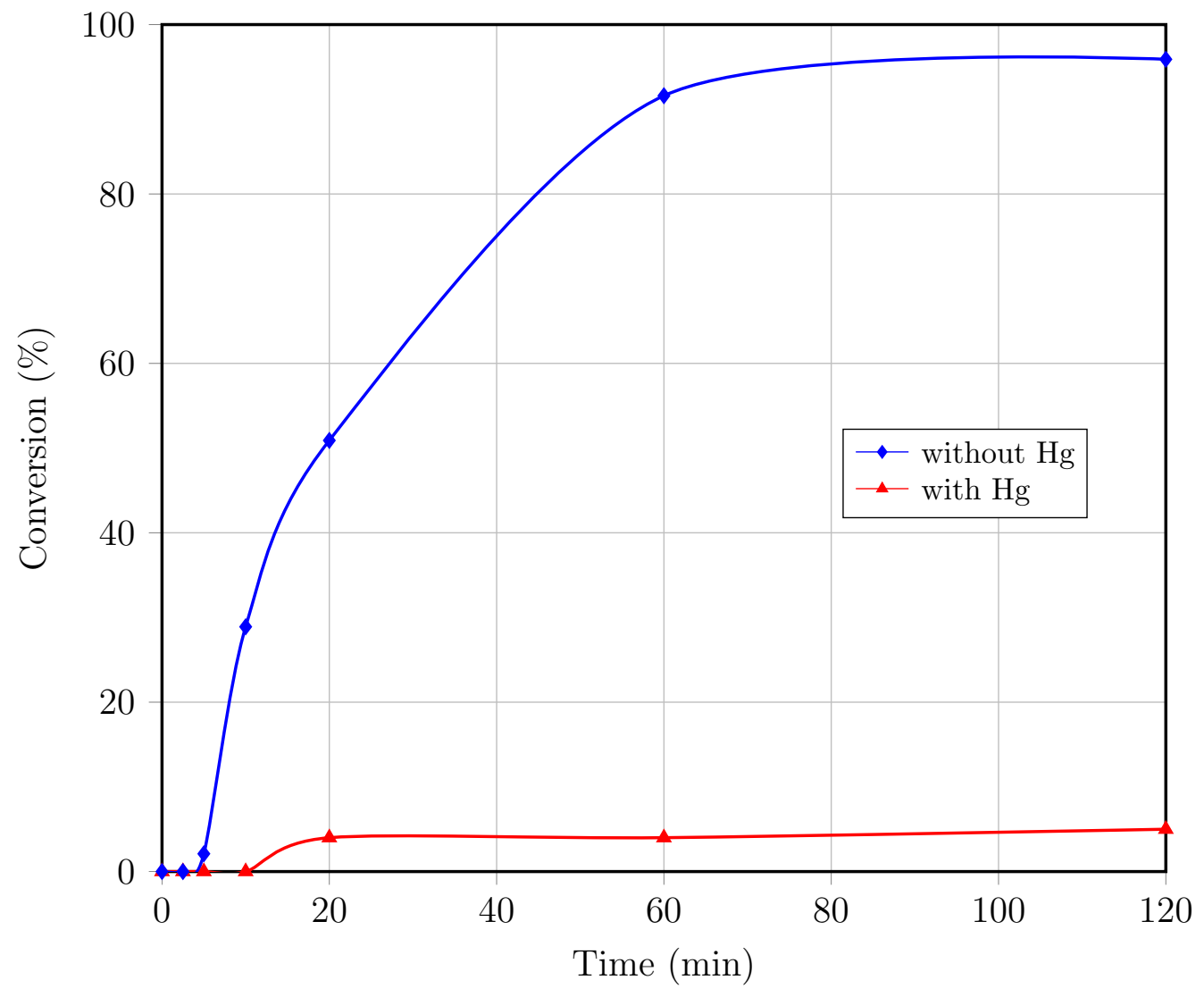

Figure 3.5 Suzuki cross-coupling of 4-bromoanisole and phenylboronic acid catalysed by the $\left[\mathrm{PdCl}_{2}(\mathrm{PP})\right]$ complex 20 .

When the dpypp ligand $\mathbf{5}$ was reacted with the same platinum(II) and palladium(II) precursors analogous reactivity was observed: after 15 minutes at room temperature all reactions quantitatively formed new diphosphine complexes (Scheme 3.2). These complexes were found to be air stable in solution and in the solid state. All were typical diphosphine coordination complexes of square-planar platinum(II) and palladium(II). 


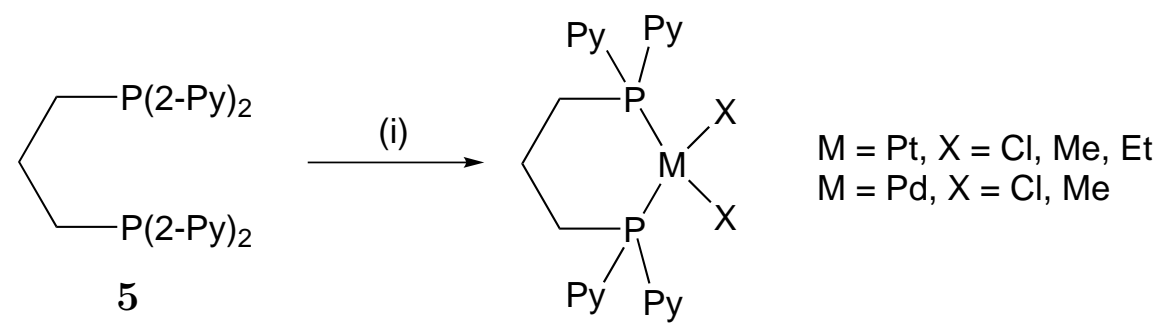

Scheme 3.2 Synthesis of Pt(II) and Pd(II) complexes of the dpypp ligand 5 . Reagents and conditions: (i) dichloro(hexa-1,5-diene)platinum, dimethyl(hexa1,5-diene)platinum, diethyl(cycloocta-1,5-diene)platinum, dichloro(cyclocta-1,5diene)palladium or dimethyl $\left(N, N, N^{\prime}, N^{\prime}\right.$-tetramethylethylenediamine)palladium, $\mathrm{CDCl}_{3}, 15 \mathrm{~min}$.

The new complexes were characterised by ${ }^{1} \mathrm{H},{ }^{13} \mathrm{C}$ and ${ }^{31} \mathrm{P}$ NMR spectroscopy and mass spectrometry. The ${ }^{1} \mathrm{H},{ }^{13} \mathrm{C}$ and ${ }^{31} \mathrm{P}$ NMR data followed the trends displayed by the data of the complexes of the dpypox ligand 3. The ${ }^{31} \mathrm{P}$ NMR signals shifted downfield 13.1-24.1 ppm upon coordination and in the platinum complexes the signals had ${ }^{195} \mathrm{Pt}$ satellites (Table 3.1). Once again, the ${ }^{195} \mathrm{Pt}-{ }^{31} \mathrm{P}$ coupling constants varied as expected depending on the ligand trans to the diphosphine ligand. ${ }^{16}$

The signals in the ${ }^{1} \mathrm{H}$ NMR spectra due to the $\mathrm{CH}_{2} \mathrm{P}$ protons in ligand $\mathbf{5}$ moved approximately $0.3 \mathrm{ppm}$ downfield upon coordination to a metal centre (from 2.51 to approximately $2.8 \mathrm{ppm}$ ), in a similar manner to those in the complexes of ligand $\mathbf{3}$ (see above). However, unlike the complexes of ligand $\mathbf{3}$ the signals were not broad and appeared as triplets. This was due to the absence of fluxional behaviour in this ligand system. Also the other methylene protons in the backbone appeared as quintets in the ${ }^{1} \mathrm{H}$ NMR spectra of the complexes and the signals were barely shifted from that for the free ligand $\mathbf{5}$ (1.79-1.76 and 1.75 ppm respectively).

From Table 3.4 it can been seen that the signals in the ${ }^{1} \mathrm{H}$ NMR spectra due to the protons on the pyridyl rings did not vary markedly between the complexes of the two ligand systems. In particular, the signals for the $\mathrm{H} 2$ and $\mathrm{H} 3$ protons were almost identical when complexes of the same type were considered. The only signal that varied by more than $0.1 \mathrm{ppm}$ was due to the proton next to the nitrogen ( $\mathrm{H} 5)$, with the signals in the complexes of ligand $\mathbf{3}$ appearing at higher chemical shift. However, it can be seen that the signals did shift depending on the nature of the complex. For example, small changes were observed when dichloroplatinum complexes were compared to dichloropalladium complexes, while there were larger shifts when dichloroplatinum complexes were compared to dimethylplatinum complexes.

In contrast, there was a significant difference in the chemical shift of the $\mathrm{CH}_{2} \mathrm{P}$ protons in the two ligand systems in the ${ }^{1} \mathrm{H}$ NMR spectra. This can be explained 
Table 3.4 Selected ${ }^{1} \mathrm{H}$ NMR data of Pt(II) and Pd(II) complexes of the dpypox and dpypp ligands

\begin{tabular}{|c|c|c|c|c|c|c|}
\hline \multirow[b]{2}{*}{ Formula } & \multirow[b]{2}{*}{ Compound } & \multicolumn{5}{|c|}{$\delta^{1} \mathrm{H} / \mathrm{ppm}^{a}$} \\
\hline & & $\mathrm{H} 2$ & H3 & $\mathrm{H} 4$ & H5 & $\mathrm{CH}_{2} \mathrm{P}$ \\
\hline$\left[\mathrm{PtCl}_{2}(\mathrm{dpypox})\right]$ & 16 & 8.14 & 7.70 & 7.38 & 8.82 & 4.54 \\
\hline$\left[\mathrm{PtCl}_{2}(\mathrm{dpypp})\right]$ & 22 & 8.14 & 7.72 & 7.33 & 8.69 & 2.86 \\
\hline$\left[\mathrm{PdCl}_{2}(\mathrm{dpypox})\right]$ & 20 & 8.15 & 7.70 & 7.38 & 8.80 & 4.35 \\
\hline$\left[\mathrm{PdCl}_{2}(\mathrm{dpypp})\right]$ & 25 & 8.15 & 7.70 & 7.33 & 8.64 & 2.84 \\
\hline$\left[\mathrm{PtMe}_{2}(\mathrm{dpypox})\right]$ & 17 & 7.75 & 7.64 & 7.29 & 8.86 & 4.56 \\
\hline$\left[\mathrm{PtMe}_{2}(\mathrm{dpypp})\right]$ & 23 & 7.75 & 7.61 & 7.19 & 8.68 & 2.87 \\
\hline$\left[\mathrm{PdMe}_{2}(\right.$ dpypox $\left.)\right]$ & 21 & 7.80 & 7.60 & 7.27 & 8.83 & 4.36 \\
\hline$\left[\mathrm{PdMe}_{2}(\mathrm{dpypp})\right]$ & 26 & 7.69 & 7.63 & 7.25 & 8.71 & 2.86 \\
\hline
\end{tabular}

${ }^{a}$ Spectra recorded in $\mathrm{CDCl}_{3}$.

by the fact that the methylene in ligand $\mathbf{5}$ is next to another methylene while the one in ligand $\mathbf{3}$ is attached to an aromatic ring which causes a downfield shift in the signal of the methylene.

\subsection{Unsymmetric Platinum(II) Complexes of dpypox}

Reaction of the dpypox ligand 3 with one equivalent of chloromethyl(hexa-1,5diene)platinum at room temperature resulted in the formation of the $[\mathrm{PtClMe}(\mathrm{PP})]$ complex $27(\mathrm{PP}=\mathbf{3})$ (Scheme 3.3). This new complex was characterised by ${ }^{31} \mathrm{P},{ }^{1} \mathrm{H}$ and ${ }^{13} \mathrm{C}$ NMR spectroscopy, mass spectrometry and single-crystal X-ray diffraction. It was found to be air stable in solution and in the solid state.<smiles>[R20]=C(C#CC)Cc1ccccc1CP[R20]#N</smiles>

27

Scheme 3.3 Synthesis of the $[\mathrm{PtClMe}(\mathrm{PP})]$ complex 27. Reagents and conditions: (i) chloromethyl(hexa-1,5-diene)platinum, $\mathrm{CH}_{2} \mathrm{Cl}_{2}, 15 \mathrm{~min}$.

In complex 27 the phosphorus atoms were trans to different ligands, resulting in twice as many chemical environments in this complex as compared to the symmet- 
rical complexes discussed above. As the phosphorus atoms were in two different environments the ${ }^{31} \mathrm{P}$ NMR spectrum is comprised of two doublets, due to the phosphorus atoms coupling to each other $\left({ }^{2} J_{\mathrm{PP}}=14 \mathrm{~Hz}\right)$. The signal for the phosphorus donor trans to the methyl ligand appeared at $11.31 \mathrm{ppm}$ with a small ${ }^{1} J_{\mathrm{PtP}}$ value, $1728 \mathrm{~Hz}$, while the phosphorus trans to the chloride ligand appeared at $9.47 \mathrm{ppm}$ with a large ${ }^{1} J_{\mathrm{PtP}}$ value, $4159 \mathrm{~Hz}$ (Table 3.5 ). The ${ }^{195} \mathrm{Pt}_{-}{ }^{31} \mathrm{P}$ coupling constant of the phosphorus atom trans to the chloride ligand was unusually large when compared to that of the $\left[\mathrm{PtCl}_{2}(\mathrm{PP})\right]$ complex $16(3500 \mathrm{~Hz})$ where both phosphorus atoms were trans to chloride ligands. This was due to the low cis influence of the methyl ligand. ${ }^{115,116}$ Similarly the ${ }^{1} J_{\mathrm{PtP}}$ value of the phosphorus trans to the methyl ligand, $1728 \mathrm{~Hz}$, was smaller than that of the $\left[\mathrm{PtMe}_{2}(\mathrm{PP})\right]$ complex 17, $1840 \mathrm{~Hz}$. This is to be expected as chloride ligands have a higher cis influence than methyl ligands. ${ }^{115,116}$ This confirms reports in the literature that, while historically the cis influence has been considered to be of lower importance than the trans influence, the effect is by no means insignificant. ${ }^{116}$ This was consistent with what was observed in the NMR spectra of the equivalent dppe, ${ }^{117}$ dppox and dbpx complexes. ${ }^{71}$

Table 3.5 ${ }^{31} \mathrm{P}$ NMR data of the $[\mathrm{PtMeL}(\mathrm{PP})]$ complexes of dpypox

\begin{tabular}{|c|c|c|c|c|c|c|}
\hline \multirow[b]{2}{*}{ Complex } & \multirow[b]{2}{*}{$\mathrm{L}$} & \multicolumn{2}{|c|}{$\mathrm{P}$ trans $\mathrm{Me}$} & \multicolumn{2}{|c|}{$\mathrm{P}$ trans $\mathrm{L}$} & \multirow[b]{2}{*}{${ }^{2} J_{\mathrm{PP}} / \mathrm{Hz}$} \\
\hline & & $\delta^{31} \mathrm{P} / \mathrm{ppm}$ & ${ }^{1} J_{\mathrm{PtP}} / \mathrm{Hz}$ & $\delta^{31} \mathrm{P} / \mathrm{ppm}$ & ${ }^{1} J_{\mathrm{PtP}} / \mathrm{Hz}$ & \\
\hline $27^{a}$ & $\mathrm{Cl}$ & 11.31 & 1724.6 & 10.04 & 4210.6 & 14.0 \\
\hline $28^{b}$ & $\mathrm{PPh}_{3}$ & -0.61 & 2076.3 & 8.44 & 2871.4 & 25.0 \\
\hline $29^{a}$ & PTA & -0.68 & 1962.2 & 8.77 & 2803.7 & 0 \\
\hline $33^{a}$ & solvent & 10.86 & 1728.4 & 9.43 & 4159.8 & 13.3 \\
\hline $34^{b}$ & Py & 7.71 & 1720.8 & 3.88 & 3743.5 & 16.5 \\
\hline $35^{b}$ & $\mathrm{SEt}_{2}$ & 5.51 & 1793.7 & 9.88 & 3690.0 & 19.0 \\
\hline
\end{tabular}

${ }^{a}$ Spectra recorded in $\left(\mathrm{CD}_{3}\right)_{2} \mathrm{CO}$.

${ }^{b}$ Spectra recorded in $\mathrm{CD}_{2} \mathrm{Cl}_{2}$.

While at first glance the ${ }^{1} \mathrm{H}$ and ${ }^{13} \mathrm{C}$ NMR spectra of complex 27 appeared to be complicated, closer inspection showed that they were made up of pairs of very similar signals. For example, the methylene protons appeared at 4.53 and $4.43 \mathrm{ppm}$ in the ${ }^{1} \mathrm{H}$ NMR spectra and are both broad singlets. When the ${ }^{1} \mathrm{H}$ NMR data of the [PtClMe(PP)] complex $\mathbf{2 7}$ was compared to that of complexes $\mathbf{1 6}$ and $\mathbf{1 7}$ it became apparent that it was very similar to what would be predicted based on the data of the symmetrical complexes. Interestingly the ${ }^{2} J_{\mathrm{PtH}}$ value of the methyl ligand in complex 27, $53 \mathrm{~Hz}$, was smaller than that observed in complex 17 (69 Hz). This was also a consequence of the high cis influence of the chloride ligand cis to the methyl ligand which results in a lower ${ }^{2} J_{\mathrm{PtH}}$ value than in the dimethyl complex $\mathbf{1 7} .{ }^{115,116}$ For these unsymmetrical complexes, ${ }^{1} \mathrm{H}_{-}{ }^{31} \mathrm{P}$ HMBC data was used to determine which phosphorus atom the pyridyl or methylene groups were attached to. 
When the [PtClMe(PP)] complex 27 was synthesised on a macroscale yellow crystals of sufficient quality for single crystal X-ray diffraction analysis were grown by the diffusion of $n$-hexane into a dichloromethane solution of complex 27 at $4{ }^{\circ} \mathrm{C}$. The $\mathrm{X}$-ray structure is shown in Figure 3.6, confirming that in the solid state complex 27 had the formulation [PtClMe(PP)]. Crystallographic data is given in Table 3.6 and selected bond lengths and angles are given in Table 3.7.

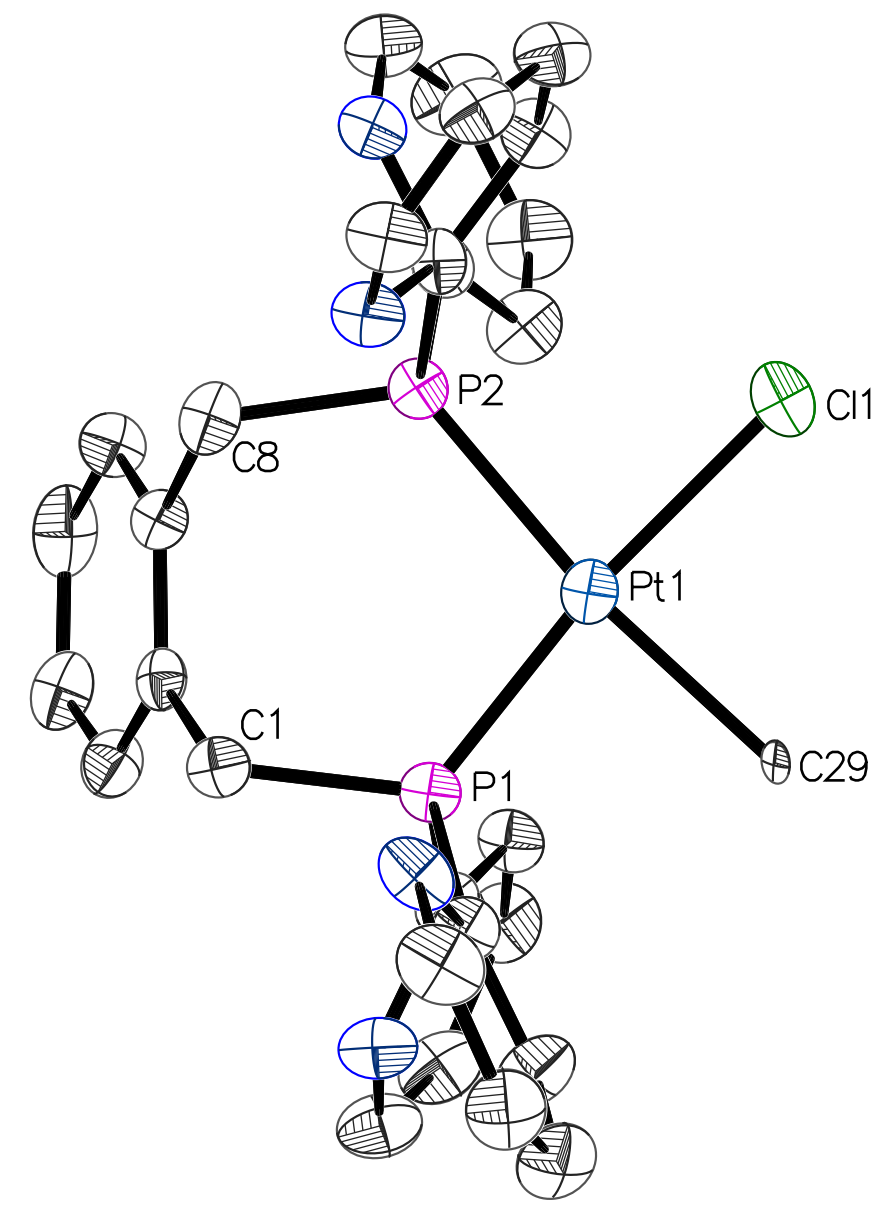

Figure 3.6 ORTEP diagram of [PtClMe(PP)] complex 27 (50\% probability thermal ellipsoids). Hydrogen atoms and solvent of crystallisation omitted for clarity.

The structure of the $[\mathrm{PtClMe}(\mathrm{PP})]$ complex 27 was very similar to that of the dichloride complexes $\left[\mathrm{MCl}_{2}(\mathrm{PP})\right](\mathrm{M}=\mathrm{Pt} \mathbf{1 6}, \mathrm{Pd} 20)$ discussed previously. Figure 3.7 shows that the ligand in complex $\mathbf{2 7}$ displayed the same bending of the backbone and the same conformation of the pyridyl rings in the solid state. The bite angle of the ligand in this complex was $101.30(5)^{\circ}$, which was slightly larger than that observed in the structures of the $\left[\mathrm{MCl}_{2}(\mathrm{PP})\right]$ complexes $\mathbf{1 6}$ and $\mathbf{2 0}$. The difference in the $\mathrm{Pt}-\mathrm{P}$ bond lengths was due to the difference in the trans influences of the methyl and chloride ligands, with the longer bond, Pt1-P2, being trans to the methyl ligand which is higher in trans influence. ${ }^{16}$ The $\mathrm{Pt}-\mathrm{Cl}$ was longer than the 2.323(5) $\AA$ observed in the structure of $[\mathrm{PtClMe}(\mathrm{PP})](\mathrm{PP}=(+)-2 \mathrm{~S}, 3 \mathrm{~S}-\mathrm{O}$-isopropylidene-2,3dihydroxy-1,4-bis(diphenylphosphino)butane) while the $\mathrm{Pt}-\mathrm{C}$ bond length was the 
Table 3.6 Crystallographic data of [PtClMe(PP)] complex 27.

\begin{tabular}{ll}
\hline Empirical formula & $\mathrm{C}_{29} \mathrm{H}_{27} \mathrm{~N}_{4} \mathrm{P}_{2} \mathrm{ClPt}$ \\
\hline Formula weight & 724.04 \\
Crystal system & monoclinic \\
Space group & $P 2_{1} / n$ \\
$\mathrm{a} / \AA$ & $14.4790(4)$ \\
$\mathrm{b} / \AA$ & $10.3594(4)$ \\
$\mathrm{c} / \AA$ & $22.7769(8)$ \\
$\alpha /{ }^{\circ}$ & 90.00 \\
$\beta /{ }^{\circ}$ & $89.905(3)$ \\
$\gamma /{ }^{\circ}$ & 90.00 \\
$\mathrm{~V} / \AA^{3}$ & $3416.4(2)$ \\
$\mathrm{Z}$ & 4 \\
$\mathrm{D}_{\text {calc }} / \mathrm{g}$ m & \\
$\mu /$ mm & \\
Temperature $/ \mathrm{K}$ & 1.394 \\
$\mathrm{~F}(000)$ & 4.292 \\
$\mathrm{Radiation}$ type & $120.01(10)$ \\
$\mathrm{Radiation}(\lambda) / \AA$ & 1400.0 \\
Index range $h$ & 0.71073 \\
Index range $k$ & $-24 \rightarrow 23$ \\
Index range $l$ & $-17 \rightarrow 17$ \\
Reflections collected & 33117 \\
$R_{1}[I>2 \sigma(I)]$ & 0.0695 \\
$\mathrm{w} R_{2}[I>2 \sigma(I)]$ & 0.1587 \\
$R_{1}[$ all data] & 0.1227 \\
$\mathrm{w} R_{2}$ [all data] & 0.1787 \\
\hline
\end{tabular}

Table 3.7 Selected bond distances and angles of $[\mathrm{PtClMe}(\mathrm{PP})]$ complex 27.

\begin{tabular}{llll}
\hline \multicolumn{2}{c}{ Bond distances $(\AA)$} & \multicolumn{2}{c}{ Bond angles $\left(^{\circ}\right)$} \\
\hline Pt1-P1 & $2.2108(14)$ & P1-Pt1-P2 & $101.30(5)$ \\
Pt1-P2 & $2.2924(13)$ & Cl1-Pt1-C29 & $87.43(14)$ \\
Pt1-C29 & $2.180(5)$ & P1-Pt1-C29 & $85.92(14)$ \\
Pt1-Cl1 & $2.3562(15)$ & P2-Pt1-Cl1 & $85.36(5)$ \\
P1-C1 & $1.837(5)$ & P1-Pt1-Cl1 & $173.27(5)$ \\
P1-C9 & $1.827(5)$ & P2-Pt1-C29 & $172.76(14)$ \\
P1-C14 & $1.827(5)$ & C1-P1-Pt1 & $121.63(18)$ \\
P2-C8 & $1.812(6)$ & C8-P2-Pt1 & $122.02(19)$ \\
P2-C19 & $1.831(5)$ & P1-C1-C2 & $110.9(3)$ \\
P2-C24 & $1.838(5)$ & P2-C8-C7 & $111.9(4)$ \\
\hline
\end{tabular}

same as that observed in this structure, 2.17(1) $\AA{ }^{118}$

The $\mathrm{Pt}-\mathrm{Cl}$ bond length was the same in the $[\mathrm{PtClMe}(\mathrm{PP})]$ complex 27 and the

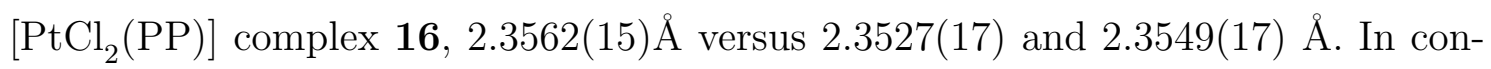
trast the $\mathrm{Pt} 1-\mathrm{P} 1$ bond in $[\mathrm{PtClMe}(\mathrm{PP})]$ (trans to the chloride ligand) was shorter 


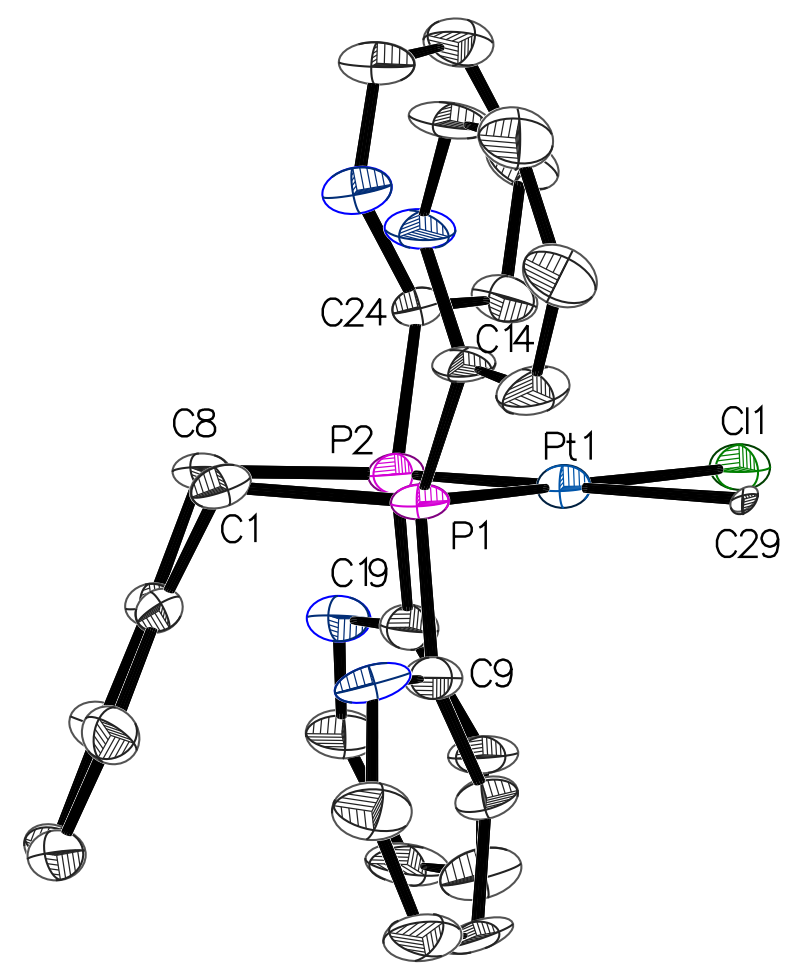

Figure 3.7 ORTEP diagram of $[\mathrm{PtClMe}(\mathrm{PP})]$ complex $\mathbf{2 7}$ showing the bending of the backbone (50\% probability thermal ellipsoids). Hydrogen atoms omitted for clarity.

than the Pt-P bonds in $\left[\mathrm{PtCl}_{2}(\mathrm{PP})\right], 2.2108(14) \AA$ compared to $2.2331(16)$ and $2.2282(18) \AA$.

\subsubsection{Reactions of $[\mathrm{PtClMe}(\mathrm{PP})]$}

Next a range of ligands was added to a solution of complex $\mathbf{2 7}$ in an attempt to displace the chloride ligand. Initial reactions with pyridine, acetonitrile, diethylsulfide, dimethylsulfoxide, carbon monoxide and ethene showed no reaction even when they were heated to $35^{\circ} \mathrm{C}$ over seven days (Scheme 3.4).

However, when the phosphine ligands, 1,3,5-triaza-7-phosphaadamantane (PTA) and triphenylphosphine, were reacted with complex $\mathbf{2 7}$, the chloride ligand was displaced, giving the ionic compounds $[\mathrm{PtMe}(\mathrm{PP})(\mathrm{P})] \mathrm{Cl}\left(\mathrm{PP}=\mathbf{3}, \mathrm{P}=\mathrm{PPh}_{3} \mathbf{2 8}\right.$, PTA 29) (Scheme 3.5). The ${ }^{31} \mathrm{P}$ NMR spectra recorded of the reaction mixtures showed that complex $\mathbf{2 7}$ had completely reacted after 20 minutes. Both new complexes had ${ }^{31} \mathrm{P}$ NMR spectra consisting of three signals with ${ }^{195} \mathrm{Pt}$ satellites. In the $\mathrm{PPh}_{3}$ complex 28 both the cis and trans phosphorus coupling was observed in the ${ }^{31} \mathrm{P}$ NMR spectrum and the signals appeared as two doublets of doublets and a 


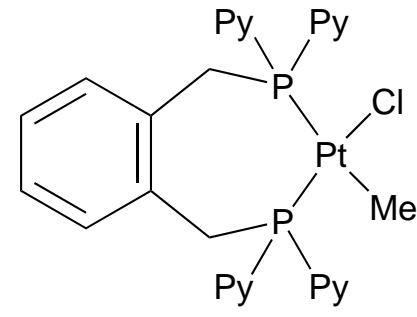

27
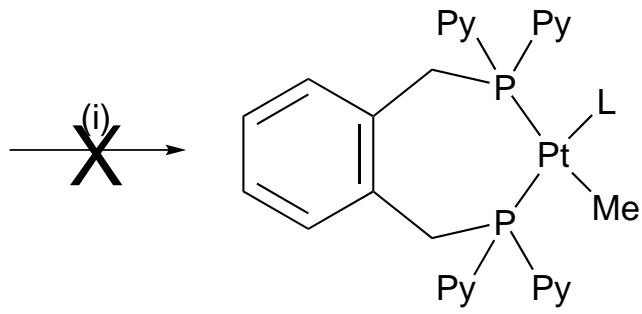

$\mathrm{L}=\mathrm{Py}, \mathrm{MeCN}, \mathrm{SEt}_{2}$, DMSO, CO, $\mathrm{C}_{2} \mathrm{H}_{4}$

Scheme 3.4 Reaction of the $[\mathrm{PtClMe}(\mathrm{PP})]$ complex 27 with competing ligands. Reagents and conditions: (i) pyridine, acetonitrile, diethylsulfide, dimethylsulfoxide, carbon monoxide or ethene, $\mathrm{CD}_{2} \mathrm{Cl}_{2}$.

triplet. The signal due to the $\mathrm{PPh}_{3}$ ligand appeared at $26.57 \mathrm{ppm}$ as a doublet of doublets $\left(\right.$ trans $^{2}{ }^{2} J_{\mathrm{PP}}=376.0$, cis $\left.^{2}{ }^{2} J_{\mathrm{PP}}=23.6 \mathrm{~Hz}\right)$, with ${ }^{1} J_{\mathrm{PtP}}=2904 \mathrm{~Hz}$. In the diphosphine ligand the phosphorus trans to $\mathrm{PPh}_{3}$ appeared at $8.44 \mathrm{ppm}$ as a doublet of doublets $\left(\mathrm{cis}^{2}{ }^{2} J_{\mathrm{PP}}=25.5 \mathrm{~Hz}\right)$ with ${ }^{1} J_{\mathrm{PtP}}=2871 \mathrm{~Hz}$, while the phosphorus cis to $\mathrm{PPh}_{3}$ appeared as a virtual triplet at $-0.61 \mathrm{ppm}$, due to the two cis couplings being essentially the same $\left(\mathrm{cis}^{-}{ }^{2} J_{\mathrm{PP}}=25.0 \mathrm{~Hz}\right)$, with ${ }^{1} J_{\mathrm{PtP}}=2076 \mathrm{~Hz}$.

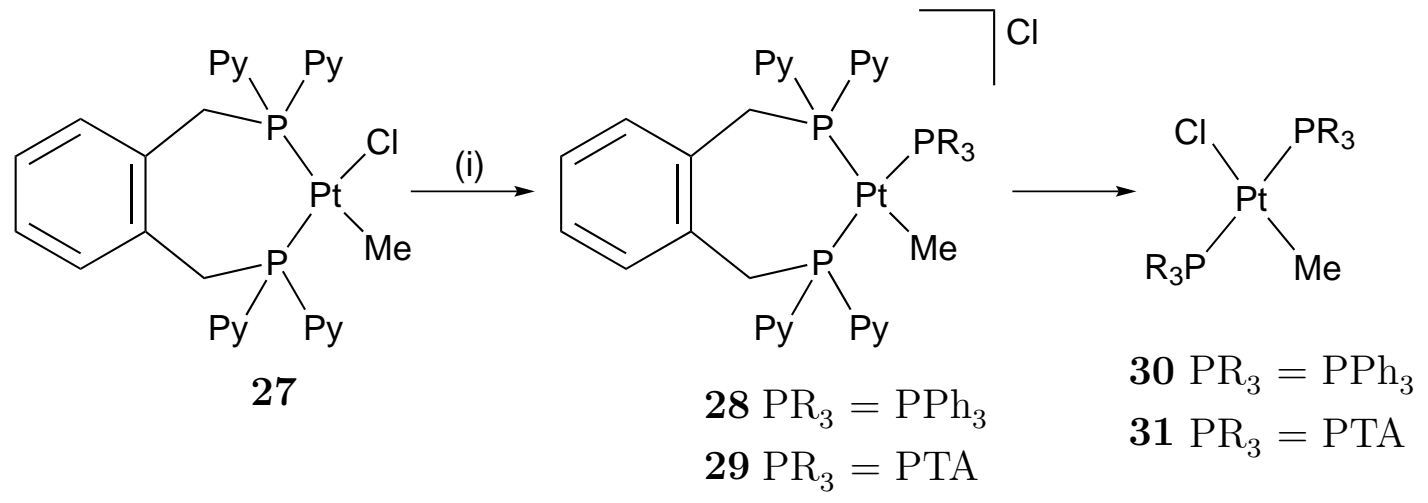

Scheme 3.5 Reaction of the [PtClMe(PP)] complex 27 with phosphines. Reagents and conditions: (i) $\mathrm{PPh}_{3}$ or $\mathrm{PTA}, \mathrm{CD}_{2} \mathrm{Cl}_{2}$.

In the PTA complex 29 the ${ }^{31} \mathrm{P}$ signals for the dpypox ligand appeared as a doublet at $8.77 \mathrm{ppm}$ and a singlet at $-0.68 \mathrm{ppm}$ with ${ }^{1} J_{\mathrm{PtP}}$ values of 2804 and $1962 \mathrm{~Hz}$ respectively while the signal for the PTA ligand appeared as a doublet at -70.16 ppm with ${ }^{1} J_{\mathrm{PtP}}=2496 \mathrm{~Hz}$. The doublet coupling was due to the trans phosphorus atoms coupling to each other $\left({ }^{2} J_{\mathrm{PP}}=348.0 \mathrm{~Hz}\right)$. In this complex the $\operatorname{cis}{ }^{31} \mathrm{P}-{ }^{31} \mathrm{P}$ coupling was not observed.

The cis and trans ${ }^{31} \mathrm{P}-{ }^{31} \mathrm{P}$ and the ${ }^{195} \mathrm{Pt}_{-}{ }^{31} \mathrm{P}$ coupling constants were all consistent with what would be expected of complexes of this type. ${ }^{117,119}$ There was also a surprisingly small variation in the phosphorus chemical shifts $\left(\Delta_{\delta \mathrm{P}}=0.33\right)$ and ${ }^{1} J_{\mathrm{PtP}}$ values of the dpypox ligand 3 between the PTA and $\mathrm{PPh}_{3}$ complexes (Table 3.5). This is interesting as given that PTA is an alkyl phosphine and $\mathrm{PPh}_{3}$ is an aryl 
phosphine it would be expected that they would be different electronically. However, the ${ }^{1} J_{\mathrm{PSe}}$ values of the phosphine selenides of each ligand, $754 \mathrm{~Hz}$ for $\mathrm{PTA}^{87}$ and $732 \mathrm{~Hz}$ for $\mathrm{PPh}_{3},{ }^{91}$ show they are not that different and in fact $\mathrm{PPh}_{3}$ is more basic than PTA.

However, these complexes were not stable over time at room temperature and rearranged to form trans- $\left[\mathrm{PtClMe}(\mathrm{P})_{2}\right]$ complexes $\left(\mathrm{P}=\mathrm{PPh}_{3}\right.$ 30, PTA 31) (Scheme 3.5). In the $\mathrm{PPh}_{3}$ reaction, complex 30 could be observed in the ${ }^{31} \mathrm{P}$ and ${ }^{1} \mathrm{H}$ NMR spectra of the reaction mixture before it crystallised out of solution as white rod-shaped crystals. This reaction took several days with the initial NMR spectra recorded after 20 minutes showing no evidence of complex 30. However, NMR recorded after one day showed the presence of a new signal at $29.42 \mathrm{ppm}$ in the ${ }^{31} \mathrm{P}$ NMR spectrum with ${ }^{1} J_{\mathrm{PtP}}=3147 \mathrm{~Hz}$. This and the ${ }^{1} \mathrm{H}$ NMR data recorded were consistent with that reported for complex $\mathbf{3 0}$ in the literature. ${ }^{120}$

In contrast the trans- $\left[\mathrm{PtClMe}(\mathrm{PTA})_{2}\right]$ complex 31 was never observed in the NMR spectra of the reaction as it was insoluble in $\mathrm{CD}_{2} \mathrm{Cl}_{2}$ and precipitated out of solution. The presence of a white solid in the reaction mixture was observed soon after the addition of PTA suggesting that complex 31 started forming almost immediately. The white solid was isolated and ${ }^{31} \mathrm{P}$ and ${ }^{1} \mathrm{H}$ NMR spectra were recorded in $\mathrm{D}_{2} \mathrm{O}$. The ${ }^{31} \mathrm{P}$ NMR spectrum showed a singlet at $-55.81 \mathrm{ppm}$ with ${ }^{1} J_{\mathrm{PtP}}=2812 \mathrm{~Hz}$. This was consistent with the PTA ligands being in a trans arrangement. In the ${ }^{1} \mathrm{H}$ NMR spectrum the signal for the methyl ligand appeared as a triplet at $0.42 \mathrm{ppm}$ $\left({ }^{3} J_{\mathrm{PP}}=7.2 \mathrm{~Hz}\right)$ with ${ }^{2} J_{\mathrm{PtH}}=82.2 \mathrm{~Hz}$. In comparison, the methyl signal in complex 30 also appeared as a triplet but at $-0.11 \mathrm{ppm}$ with ${ }^{3} J_{\mathrm{PP}}=6.2 \mathrm{~Hz}$ and ${ }^{2} J_{\mathrm{PtH}}=$ $78.1 \mathrm{~Hz}$. As the trans-[PtClMe(PTA $\left.)_{2}\right]$ complex 31 has not been reported in the literature it was identified based on the similarity of the NMR data with that of the trans-[PtClMe $\left.\left(\mathrm{PPh}_{3}\right)_{2}\right]$ complex 30. Given the $[\mathrm{PtMe}(\mathrm{PP})(\mathrm{P})]$ complexes 28 and 29 were not stable over time it was not possible to obtain ${ }^{13} \mathrm{C}$ NMR data of these complexes.

Next the complex 27 was reacted with one equivalent of the acid $\mathrm{H}_{2} \mathrm{C}\left(\mathrm{SO}_{2} \mathrm{CF}_{3}\right)_{2}$ $\left(\mathrm{p} K_{\mathrm{a}}=2.4 \text { in DMSO}\right)^{103}$ to investigate whether the presence of the nitrogen atoms in the dpypox ligand 3 could stabilise an agostic complex. The potential for one of the pyridyl nitrogen atoms to fill the vacant site created by the elimination of methane was also explored. This reaction was carried out in acetone- $d_{6}$ in an attempt to avoid the formation of $\left[\mathrm{PtCl}_{2}(\mathrm{PP})\right]$ through reaction with the $\mathrm{CDCl}_{3}$. The ${ }^{31} \mathrm{P} \mathrm{NMR}$ spectrum recorded after 15 minutes consisted of two signals with ${ }^{195} \mathrm{Pt}$ satellites. There was a broad singlet $6.96 \mathrm{ppm}$, with ${ }^{1} J_{\mathrm{PtP}}=4178 \mathrm{~Hz}$, and another at 4.17 ppm, with ${ }^{1} J_{\mathrm{PtP}}=1671 \mathrm{~Hz}$. As the NMR spectra recorded after two hours showed 
that these signals decreased at the same rate it can be concluded that they were part of the same unsymmetrical complex 32 . The ${ }^{1} J_{\mathrm{PtP}}$ values observed suggested that the signal at $6.96 \mathrm{ppm}$ was due to a phosphorus trans to a chloride ligand while the signal at 4.17 ppm was due to a phosphorus trans to a ligand high in trans influence; this was most likely the methyl ligand.

The ${ }^{1} \mathrm{H}$ NMR spectrum recorded after 15 minutes consisted of mostly broad signals. The signal due to the proton on the carbon next to the pyridyl nitrogen had shifted to above $9 \mathrm{ppm}$. It has been observed in this work that this signal only moves to above $9 \mathrm{ppm}$ when the nitrogen has been protonated (see Chapter 2) or the nitrogen has coordinated to a metal (see Chapter 5). This indicated that one of the nitrogen atoms had been protonated. Given there was also a signal present due to the methyl ligand at $0.45 \mathrm{ppm}$ with coupling to two phosphorus atoms and platinum $\left({ }^{3} J_{\mathrm{PH}}=7.2,5.1 \mathrm{~Hz},{ }^{1} J_{\mathrm{PtH}}=53.1 \mathrm{~Hz}\right)$ it can be concluded that one of the pyridyl nitrogens had been protonated while the rest of the starting complex remained intact (Scheme 3.6). From the protonation of ligand 3, discussed in Chapter 2, it was known that when a nitrogen atom in ligand $\mathbf{3}$ was protonated the proton was not statically bound to one nitrogen. Many of the signals in the ${ }^{1} \mathrm{H}$ NMR spectrum of the protonated complex 32 were broad, including the signal for the $\mathrm{CH}\left(\mathrm{SO}_{2} \mathrm{CF}_{3}\right)_{2}^{-}$ anion, indicating that there was a dynamic process occurring. Thus it was likely that the proton was not statically bound to one nitrogen in complex 32 either and was also potentially undergoing $\mathrm{H} / \mathrm{D}$ exchange with the solvent.

After 24 hours there was only a symmetrical complex present in the NMR spectra. The ${ }^{31} \mathrm{P}$ NMR spectrum consisted of one singlet at $-1.78 \mathrm{ppm}$ with a ${ }^{1} J_{\mathrm{PtP}}$ value of $3501 \mathrm{~Hz}$. This and the signals in the ${ }^{1} \mathrm{H}$ NMR spectrum indicated that a symmetrical dichloride complex had formed. There was also methane formed, confirmed by the signal at $0.17 \mathrm{ppm}^{121}$ in the ${ }^{1} \mathrm{H}$ NMR spectrum, indicating that the proton went on to react with the methyl ligand to form methane. In this reaction the only source of chloride ligands was the starting complex. Therefore in order to produce a dichloride complex once methane was eliminated the complex would have either abstracted a chloride ligand from another molecule of the complex or dimerised forming a symmetrical complex with bridging chloride ligands. It was the latter that would be expected as it has been reported that when a chloride ligand was abstracted from complexes of the type $\left[\mathrm{PtCl}_{2}(\mathrm{PP})\right](\mathrm{PP}=1,4$-bis(diphenylphosphino)butane $(\mathrm{dppb})$ ) dimers with bridging chloride ligands were formed. ${ }^{122}$ When the ${ }^{31} \mathrm{P}$ NMR data of the analogous 1,2-bis(diphenylphosphino)ethane (dppe) and dppb complexes were examined it was observed that there was an increase in the ${ }^{1} J_{\mathrm{PtP}}$ value of $135-$ $175 \mathrm{~Hz}$ when bridging chlorides rather than terminal chlorides were trans to the phosphorus atoms. ${ }^{122-125}$ Given that the value of ${ }^{1} J_{\mathrm{PtP}}$ observed here was identical 


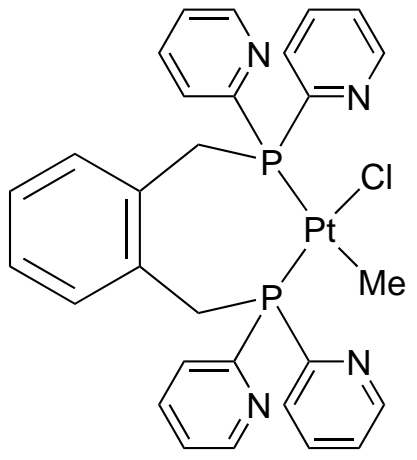

27

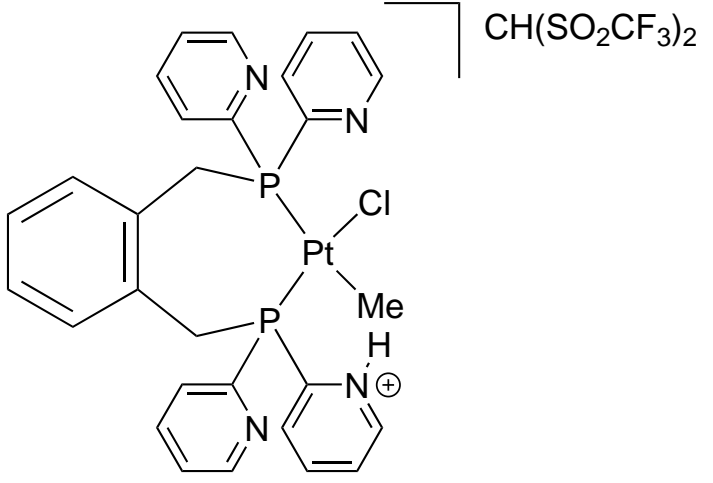

32

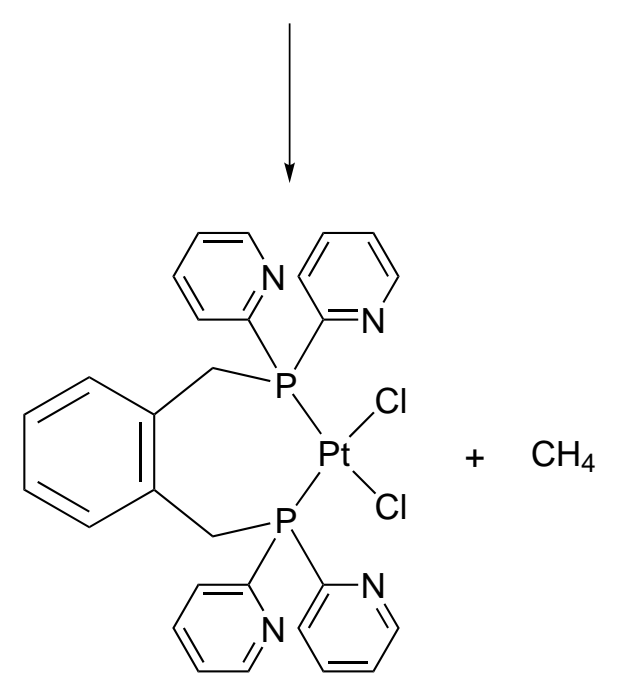

16

Scheme 3.6 Proposed reaction of the $[\mathrm{PtClMe}(\mathrm{PP})]$ complex 27 with $\mathrm{H}_{2} \mathrm{C}\left(\mathrm{SO}_{2} \mathrm{CF}_{3}\right)_{2}$. Reagents and conditions: (i) $\mathrm{H}_{2} \mathrm{C}\left(\mathrm{SO}_{2} \mathrm{CF}_{3}\right)_{2},\left(\mathrm{CD}_{3}\right)_{2} \mathrm{CO}$.

to that of the $\left[\mathrm{PtCl}_{2}(\mathrm{PP})\right]$ complex 16, it was concluded that this reaction formed complex 16. In order to form complex 16 a chloride ligand would need to be abstracted from another molecule of the complex, which was accompanied by the formation of a precipitate. It is suggested that this insoluble product was similar to the paddlewheel complex discussed in Chapter 1 (Scheme 1.9), with two platinum centres bridged by two ligands (3) bound to one platinum through the phosphorus atoms and the other through the pyridyl nitrogen atoms.

The abstraction of the chloride ligand in the $[\mathrm{PtMeCl}(\mathrm{PP})]$ complex $\mathbf{2 7}$ was also attempted. Chloride abstraction from a complex where the pyridylphosphine ligand is coordinated through just the phosphorus atom is a common method to achieve pyridyl nitrogen chelation. For example, when the chloride ligand was abstracted from $\left[\mathrm{PtClMe}\left(\mathrm{PPh}_{2} \mathrm{Py}\right)_{2}\right]$, through reaction with $\mathrm{NaBPh}_{4}$, one of the $\mathrm{PPh}_{2} \mathrm{Py}$ ligands formed a $P, N$ chelate. ${ }^{24}$ Silver salts were not used to abstract the chloride ligand as silver chloride has been reported to coordinate to pyridyl nitrogen atoms in similar systems, ${ }^{66}$ this reactivity is discussed in Chapter 5 . Instead, sodium salts with non- 
coordinating anions were used, as sodium ions have less affinity than silver ions for nitrogen.

The $[\mathrm{PtClMe}(\mathrm{PP})]$ complex 27 was reacted with $\mathrm{NaCH}\left(\mathrm{SO}_{2} \mathrm{CF}_{3}\right)_{2}$ or $\mathrm{NaBArF}_{4}$. As reaction with either sodium salt gave the same product, only the reactions with $\mathrm{NaCH}\left(\mathrm{SO}_{2} \mathrm{CF}_{3}\right)_{2}$ will be discussed. The NMR spectra recorded of the reaction of complex 27 with $\mathrm{NaCH}\left(\mathrm{SO}_{2} \mathrm{CF}_{3}\right)_{2}$ did not change significantly from that of the starting material, suggesting that none of the pyridyl nitrogen atoms on the ligand had coordinated to the platinum. When four-membered rings are formed the signal due to the phosphorus moves to negative ppm in the ${ }^{31} \mathrm{P}$ NMR spectrum. ${ }^{126}$ In the analogous reaction with $\left[\mathrm{PtClMe}\left(\mathrm{PPh}_{2} \mathrm{Py}\right)_{2}\right]$, when $\mathrm{PPh}_{2} \mathrm{Py}$ acts as a $P, N$ ligand the ${ }^{31} \mathrm{P}$ NMR signal moves from 22.0 to $-17.6 \mathrm{ppm} .{ }^{24}$ There are also several examples where the same trend is observed when $\mathrm{PPy}_{3}$ behaves as a chelating $P, N$ ligand in platinum and palladium complexes. ${ }^{35}$ Also when pyridine ligands are coordinated to a metal the signals due to the pyridyl protons become deshielded and shift to higher ppm in the ${ }^{1} \mathrm{H}$ NMR spectra, particularly the signal of the proton next to the nitrogen. ${ }^{35,127}$ As none of the expected changes in the NMR data were observed it was concluded that a pyridyl nitrogen atom had not coordinated to the platinum. A ${ }^{1} \mathrm{H}$ NMR signal at $3.79 \mathrm{ppm}$ and a ${ }^{19} \mathrm{~F}$ NMR signal at $-81.9 \mathrm{ppm}$ confirmed the presence of the non-coordinating counterion $\mathrm{CH}\left(\mathrm{SO}_{2} \mathrm{CF}_{3}\right)_{2}^{-} \cdot{ }^{128}$

When the analogous dppe complex was reacted with $\mathrm{AgBF}_{4}$ or $\mathrm{AgPF}_{6}$ a molecule of solvent, either acetone or methanol, filled the vacant coordination site. ${ }^{117,129}$ Thus it was likely that a molecule of acetone coordinated to the platinum centre in this reaction (Scheme 3.7).

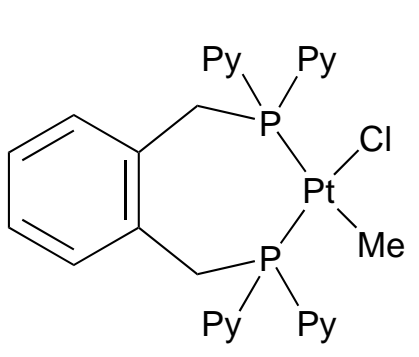

27

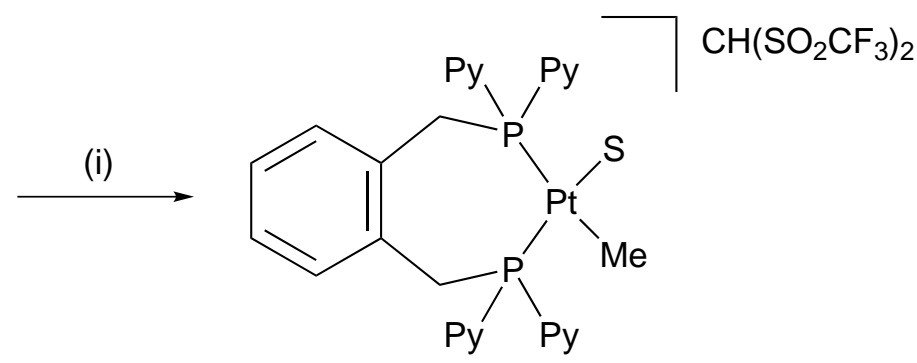

33

$\mathrm{S}=$ solvent

Scheme 3.7 Proposed reaction of the $[\mathrm{PtClMe}(\mathrm{PP})]$ complex $\mathbf{2 7}$ with $\mathrm{NaCH}\left(\mathrm{SO}_{2} \mathrm{CF}_{3}\right)_{2}$. Reagents and conditions: (i) $\mathrm{NaCH}\left(\mathrm{SO}_{2} \mathrm{CF}_{3}\right)_{2},\left(\mathrm{CD}_{3}\right)_{2} \mathrm{CO}$. 


\subsubsection{Reactions of $[\mathrm{PtMe}(\mathrm{PP})] \mathrm{X}$}

When excess pyridine or diethylsulfide was added to a solution of the $[\mathrm{PtMe}(\mathrm{PP})] \mathrm{X}$ complex $33\left(\mathrm{PP}=3, \mathrm{X}=\mathrm{CH}\left(\mathrm{SO}_{2} \mathrm{CF}_{3}\right)_{2}^{-}\right)$in acetone- $d_{6}$ or dichloromethane- $d_{2}$, new platinum complexes of the type $[\mathrm{PtMeL}(\mathrm{PP})] \mathrm{CH}\left(\mathrm{SO}_{2} \mathrm{CF}_{3}\right)_{2}(\mathrm{~L}=$ pyridine 34 , $\mathrm{SEt}_{2} 35$ ) were formed almost immediately at room temperature (Scheme 3.8). This was further evidence that the chloride ligand had been abstracted in complex 33 as when the $[\mathrm{PtClMe}(\mathrm{PP})]$ complex 27 was reacted with an excess of pyridine or diethylsulfide no reaction was observed even after heating the reaction mixtures at $35{ }^{\circ} \mathrm{C}$ for one week.

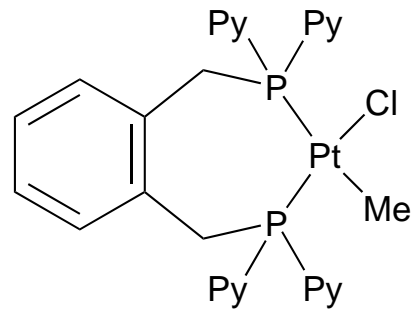

27
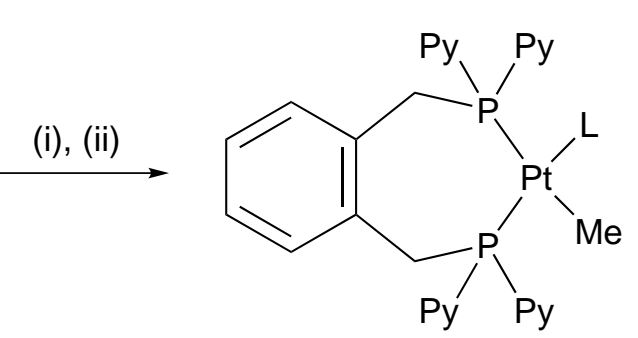

$34 \mathrm{~L}=\mathrm{Py}$

$35 \mathrm{~L}=\mathrm{SEt}_{2}$

Scheme 3.8 Reaction of the $[\mathrm{PtClMe}(\mathrm{PP})]$ complex 27 with $\mathrm{NaCH}\left(\mathrm{SO}_{2} \mathrm{CF}_{3}\right)_{2}$ and competing ligands. Reagents and conditions: (i) $\mathrm{NaCH}\left(\mathrm{SO}_{2} \mathrm{CF}_{3}\right)_{2}, \mathrm{CD}_{2} \mathrm{Cl}_{2}$ or $\left(\mathrm{CD}_{3}\right)_{2} \mathrm{CO}$; (ii) pyridine or diethylsulfide.

In the reaction with pyridine, the ${ }^{31} \mathrm{P}$ NMR spectrum recorded after 20 minutes indicated that the reaction had gone to completion with only the signals for the new pyridine complex 34 present. The signal for the phosphorus atom trans to the methyl ligand appeared at $7.71 \mathrm{ppm}$ with ${ }^{1} J_{\mathrm{PtP}}=1721 \mathrm{~Hz}$, while the phosphorus atom coordinated trans to the pyridine ligand appeared at $3.88 \mathrm{ppm}$ with a ${ }^{1} J_{\mathrm{PtP}}$ value of $3744 \mathrm{~Hz}$. This ${ }^{1} J_{\mathrm{PtP}}$ value was consistent with the low trans influence of pyridine ligands. ${ }^{16}$

The ${ }^{1} \mathrm{H}$ NMR spectrum contained 15 aromatic signals due to the dpypox ligand $\mathbf{3}$ and the pyridine ligand. The signals for the $\mathrm{CH}_{2} \mathrm{P}$ groups in the ${ }^{1} \mathrm{H}$ NMR spectrum appeared as two doublets at $4.47\left({ }^{2} J_{\mathrm{PH}}=13.9 \mathrm{~Hz}\right)$ and $4.41 \mathrm{ppm}\left({ }^{2} J_{\mathrm{PH}}=11.7 \mathrm{~Hz}\right)$, for the methylenes attached to the phosphorus atoms trans to the pyridine and methyl ligands respectively. The signal for the methyl ligand appeared as a broad singlet with ${ }^{1} J_{\mathrm{PtH}}=50.8 \mathrm{~Hz}$. The signals for the $\mathrm{CH}\left(\mathrm{SO}_{2} \mathrm{CF}_{3}\right)_{2}^{-}$anion, at $3.9 \mathrm{ppm}$ in the ${ }^{1} \mathrm{H}$ NMR spectrum and $-81.5 \mathrm{ppm}$ in the ${ }^{19} \mathrm{~F}$ NMR spectrum, confirmed it was not coordinated to the metal centre. ${ }^{128}$

The fact that this pyridine complex $\mathbf{3 4}$ formed and was stable was significant. It indicated that the coordination of a pyridyl nitrogen to the platinum centre in 
this complex was not unfavourable. This meant that there must be another reason why one of the pyridyl nitrogens in the dpypox ligand in complex 33 did not coordinate to the platinum. It was possible that the formation of a fourmembered ring next to the seven-membered diphosphine ring in a square planar complex was too highly strained to occur. Currently there is only one reported example of the formation of a four-membered $P, N$ chelate in a diphosphine complex. ${ }^{65}$ This was in the $\left[\mathrm{RuCl}_{2}\left(P, P, N\right.\right.$-dpypcp) $\left.\left(\mathrm{PPh}_{3}\right)\right]$ complex (dpypcp $=1,2$-bis $($ di-2pyridylphosphino)cyclopentane) (shown in Figure 1.6). The ruthenium in this complex was octahedral. This also indicates that the formation of the $P, P, N$-chelate may be unfavourable in a square planar complex. The majority of the examples in the literature of chelation of a pyridyl nitrogen to a metal already coordinated to the phosphorus atom of the ligand involve the monophosphine $\mathrm{PPh}_{2} \mathrm{Py}$ ligand. ${ }^{13,20,21,130}$ In the examples when the pyridyl nitrogen of a diphosphine ligand has been coordinated to a metal, the ligand has usually been bridging two metal centres rather than chelating to one metal atom. ${ }^{40,66}$

In the new sulfide complex 35 the signals in the ${ }^{31} \mathrm{P}$ NMR spectrum appeared as doublets at 9.88 and $5.51 \mathrm{ppm}\left({ }^{2} J_{\mathrm{PP}}=19.0 \mathrm{~Hz}\right)$ with ${ }^{1} J_{\mathrm{PtP}}$ values of 3690 and $1794 \mathrm{~Hz}$ respectively (Table 3.5). The ${ }^{1} J_{\mathrm{PtP}}$ value of $3690 \mathrm{~Hz}$ for the phosphorus atom coordinated trans to the $\mathrm{SEt}_{2}$ ligand was consistent with reports that the trans influence of sulfide ligands is lower than phosphine ligands but higher than nitrogen ligands. ${ }^{17,131,132}$ The signals due to ligand $\mathbf{3}$ in the ${ }^{1} \mathrm{H}$ NMR spectrum had moved slightly downfield when compared to the $[\mathrm{PtClMe}(\mathrm{PP})]$ complex 27. While the signals for the $\mathrm{CH}_{2} \mathrm{P}$ protons had not moved from where they appeared in the starting complex 27, they now appeared as resolved doublets, with ${ }^{2} J_{\mathrm{PH}}$ values of 14.0 and $12.5 \mathrm{~Hz}$ for the methylenes attached to the phosphorus atoms trans to the $\mathrm{SEt}_{2}$ ligand and the methyl ligand respectively. The signal for the methylene attached to the phosphorus atom trans to the $\mathrm{SEt}_{2}$ ligand also displayed platinum195 satellites, with ${ }^{3} J_{\mathrm{PtH}}=51.0 \mathrm{~Hz}$. This is the only complex of ligand 3 where ${ }^{195} \mathrm{Pt}$ coupling was observed in the $\mathrm{CH}_{2} \mathrm{P}$ signal in the ${ }^{1} \mathrm{H}$ NMR spectrum.

Upon coordination to platinum in the $\left[\mathrm{PtMe}\left(\mathrm{SEt}_{2}\right)(\mathrm{PP})\right] \mathrm{CH}\left(\mathrm{SO}_{2} \mathrm{CF}_{3}\right)_{2}$ complex 35 the signals for the $\mathrm{SEt}_{2}$ ligand in the ${ }^{1} \mathrm{H}$ NMR spectrum indicated the ethyl groups were in different environments, with two signals each for the methylene and methyl groups. The signals also appeared at higher chemical shifts than the ${ }^{1} \mathrm{H}$ NMR signals of free $\mathrm{SEt}_{2}$. In the ${ }^{13} \mathrm{C}$ NMR spectrum the signal for the SEt ${ }_{2}$ methylene had shifted from $25.5 \mathrm{ppm}$ in free $\mathrm{SEt}_{2}$ to $45.3 \mathrm{ppm}$. The signal for the $\mathrm{SEt}_{2}$ methyl group now appeared at $6.89 \mathrm{ppm}$, compared to $14.9 \mathrm{ppm}$ in free $\mathrm{SEt}_{2}$. This was consistent with what has been observed in the ${ }^{1} \mathrm{H}$ and ${ }^{13} \mathrm{C} \mathrm{NMR}$ spectra of $\left[\mathrm{PtL}_{2}\left(\mathrm{SEt}_{2}\right)\right]$ complexes ( $\mathrm{L}=$ ethene, norbornene). ${ }^{133}$ 
In the ${ }^{1} \mathrm{H}$ NMR spectrum of the $\left[\mathrm{PtMe}\left(\mathrm{SEt}_{2}\right)(\mathrm{PP})\right] \mathrm{CH}\left(\mathrm{SO}_{2} \mathrm{CF}_{3}\right)_{2}$ complex 35 the signal for the methyl ligand appeared as an apparent triplet at $0.37 \mathrm{ppm}$ with ${ }^{3} J_{\mathrm{PH}}$ $=5.0 \mathrm{~Hz}$. This is in contrast with $[\mathrm{PtClMe}(\mathrm{PP})]$ complex $\mathbf{2 7}$ where the signal for the methyl ligand appears as a doublet of doublets due to coupling to two phosphorus atoms in different environments. While the signal for the methyl ligand in the ${ }^{13} \mathrm{C}$ NMR spectrum did appear as a doublet of doublets, as it does in complex 27, it had shifted to $4.99 \mathrm{ppm}$ with ${ }^{2} J_{\mathrm{PC}}=79.2,7.0 \mathrm{~Hz}$, whereas it appeared at $9.64 \mathrm{ppm}$ in complex 27 with ${ }^{2} J_{\mathrm{PC}} \approx 93,7 \mathrm{~Hz}$.

As the dpypox ligand 3 and methyl ligand in these $[\mathrm{PtMeL}(\mathrm{PP})] \mathrm{X}$ compounds were constant, the differences in the ${ }^{1} J_{\mathrm{PtP}}$ values observed in Table 3.5 were due to the different cis and trans influences of the chloride, $\mathrm{PPh}_{3}, \mathrm{PTA}$, pyridine and $\mathrm{SEt}_{2}$ ligands. In Table 3.5 it can be seen that the ${ }^{1} J_{\mathrm{PtP}}$ value of the phosphorus trans to $\mathrm{L}$ varied as expected with the trans influence of L, with the PTA complex having the lowest ${ }^{1} J_{\mathrm{PtP}}$ coupling constant while the chloride complex has the highest. The ${ }^{1} J_{\mathrm{PtP}}$ value of the phosphorus trans to the methyl ligand was affected by the cis influence of the different ligands. From the ${ }^{1} J_{\mathrm{PtP}}$ values the following cis influence series could be made: $\mathrm{Py} \approx \mathrm{Cl}>\mathrm{SEt}_{2}>\mathrm{PTA}>\mathrm{PPh}_{3}$. This was consistent with what has been reported in the literature. ${ }^{115,119}$

As the $[\mathrm{PtMe}(\mathrm{PP}) \mathrm{P}] \mathrm{Cl}$ compounds $\mathbf{2 8}$ and $\mathbf{2 9}$ were not stable over time, complex 33 was reacted with $\mathrm{PTA}$ and $\mathrm{PPh}_{3}$ to see if stable phosphine complexes could be synthesised. As expected the $[\mathrm{PtMe}(\mathrm{PP})(\mathrm{P})] \mathrm{CH}\left(\mathrm{SO}_{2} \mathrm{CF}_{3}\right)_{2}$ complexes $(\mathrm{PP}=\mathbf{3} ; \mathrm{P}$ $=\mathrm{PPh}_{3}$ 36, PTA 37), with the anion $\mathrm{CH}\left(\mathrm{SO}_{2} \mathrm{CF}_{3}\right)_{2}^{-}$in place of the chloride, were formed immediately upon addition of the phosphines to a solution of complex $\mathbf{3 3}$. The ${ }^{31} \mathrm{P}$ and ${ }^{1} \mathrm{H}$ NMR data were identical to that of the complexes with the chloride anion. Unfortunately these complexes were not stable and decomposed, this time into unidentifiable products.

When carbon monoxide was bubbled through a solution of complex $\mathbf{3 3}$ in acetone- $d_{6}$ rather than forming a complex with a $\mathrm{CO}$ ligand, $[\mathrm{PtMe}(\mathrm{CO})(\mathrm{PP})]$, the $\mathrm{CO}$ inserted into the Pt-Me bond to form the acyl complex 38 (Scheme 3.9).

This new complex 38 formed slowly with NMR spectra recorded after seven days showing the reaction mixture to be $60 \%$ product and $40 \%$ unreacted complex 33 . The ${ }^{31} \mathrm{P}$ NMR signals of the new complex appeared as two doublets at 3.32 and 1.67 ppm $\left({ }^{2} J_{\mathrm{PP}}=23.0 \mathrm{~Hz}\right)$ with ${ }^{1} J_{\mathrm{PtP}}$ values of 1390 and $4501 \mathrm{~Hz}$ respectively. The ${ }^{1} J_{\mathrm{PtP}}$ values were consistent with the phosphorus at $3.32 \mathrm{ppm}$ being coordinated trans to the acyl ligand while the other phosphorus was trans to a solvent molecule (acetone). ${ }^{16} \mathrm{~A}^{1} \mathrm{H}-{ }^{31} \mathrm{P}$ HMBC correlation from a singlet at $1.54 \mathrm{ppm}$ in the ${ }^{1} \mathrm{H} \mathrm{NMR}$ 


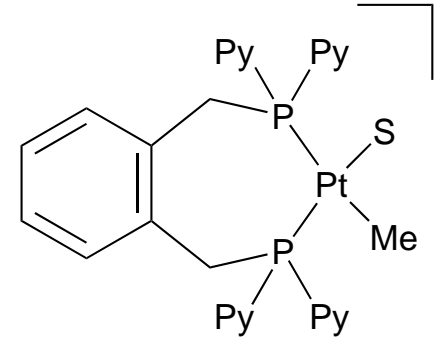

33

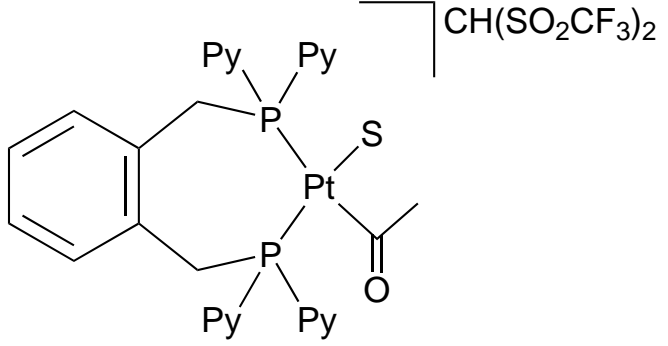

38

Scheme 3.9 Reaction of the $[\mathrm{PtMe}(\mathrm{PP})] \mathrm{X}$ complex 33 with $\mathrm{CO}$ ( $\mathrm{S}=$ solvent). Reagents and conditions: (i) $\mathrm{CO}_{(\mathrm{g})} 1 \mathrm{~atm},\left(\mathrm{CD}_{3}\right)_{2} \mathrm{CO}$.

spectrum to the ${ }^{31} \mathrm{P}$ NMR signal at $3.32 \mathrm{ppm}$ indicated that this was the signal for the methyl protons in the acyl group. The ${ }^{1} \mathrm{H}$ NMR spectrum was consistent with those of the other unsymmetrical complexes (27-37). The IR spectrum of complex 38 contained a $\mathrm{C}=\mathrm{O}$ stretch at $1638 \mathrm{~cm}^{-1}$ consistent with the presence of an acyl group, ${ }^{71}$ while the $\mathrm{C}=\mathrm{N}$ stretches at 1573 and $1562 \mathrm{~cm}^{-1}$ indicated the pyridyl nitrogens were not coordinated to the platinum. ${ }^{40,107,134-136}$

In contrast, when the $\left[\mathrm{PtClMe}\left(\mathrm{P}^{\prime} \mathrm{P}^{\prime}\right)\right]$ complex $\left(\mathrm{P}^{\prime} \mathrm{P}^{\prime}=o-\mathrm{C}_{6} \mathrm{H}_{4}\left(\mathrm{CH}_{2} \mathrm{PBu}_{2}{ }_{2}\right)\left(\mathrm{CH}_{2} \mathrm{PPh}_{2}\right)\right)$ was reacted with carbon monoxide, a mixture of the terminal carbonyl compound $\left[\mathrm{PtMe}(\mathrm{CO})\left(\mathrm{P}^{\prime} \mathrm{P}^{\prime}\right)\right] \mathrm{Cl}$ and the acyl complex $\left[\mathrm{PtCl}(\mathrm{COMe})\left(\mathrm{P}^{\prime} \mathrm{P}^{\prime}\right)\right]$ was formed. ${ }^{71}$ This reaction was also slow, with six days required for the proportion of the products to reach $8 \%$ and $40 \%$ respectively. However, when the $\left[\mathrm{PtClMe}\left(\mathrm{P}^{\prime} \mathrm{P}^{\prime}\right)\right]$ complex was reacted with silver tetrafluoroborate and then $\mathrm{CO}$ the $\left[\mathrm{PtMe}(\mathrm{CO})\left(\mathrm{P}^{\prime} \mathrm{P}^{\prime}\right)\right] \mathrm{BF}_{4}$ compound resulted, which did not react to form the acyl complex. This was in contrast to the reactivity observed in this work, where the $[\mathrm{PtClMe}(\mathrm{PP})]$ complex $\mathbf{2 7}$ did not react with $\mathrm{CO}$ but the $[\mathrm{PtMeS}(\mathrm{PP})] \mathrm{CH}\left(\mathrm{SO}_{2} \mathrm{CF}_{3}\right)_{2}$ compound $\mathbf{3 3}$ formed an acyl complex in the presence of $\mathrm{CO}$.

The insertion of a $\mathrm{CO}$ molecule into a $\mathrm{Pd}-\mathrm{C}$ bond is an important step in the palladium catalysed carbonylation of ethene. ${ }^{71}$ These results suggest that the palladium analogue of $\mathbf{3 3}$ would be an active catalyst in this industrially significant reaction.

In 2013, van Leeuven and co-workers reported the heterolytic activation of hydrogen by platinum and palladium complexes containing pyridylphosphine ligands. ${ }^{35}$ The platinum complexes used in that work were of the type $\left[\mathrm{Pt}\left(\mathrm{PP}^{*}\right)(\mathrm{PN})\right] \mathrm{OTf}$ where $\mathrm{PP}^{*}=$ 9,9-dimethyl-4,5-bis(diphenylphosphino)xanthene (Xantphos), bis(2(diphenylphosphino)phenyl)ether (DPEphos) and $\mathrm{PN}=$ a chelating $\mathrm{PPh}_{2} \mathrm{Py}_{\text {ligand. }}$ While no reaction was observed when solutions of the complexes were put under 1 bar of hydrogen gas, when this was increased to 4 bar of hydrogen a reaction was observed. In this reaction the pyridyl group dissociated from the metal centre creating 
a vacant coordination site. It also acted as an internal base assisting the heterolytic cleavage of hydrogen. This resulted in the formation of a platinum hydride complex with a protonated pyridyl group (Scheme 1.5). ${ }^{35}$

While bubbling hydrogen gas through a solution of the $[\mathrm{PtClMe}(\mathrm{PP})]$ complex 27 had not resulted in any reaction, it was thought that the $[\mathrm{PtMeS}(\mathrm{PP})] \mathrm{CH}\left(\mathrm{SO}_{2} \mathrm{CF}_{3}\right)_{2}$ complex 33 might be a better starting material for this reaction, as it contained a solvent molecule, which should be easier to displace than a chloride ligand. When hydrogen was bubbled through a solution of $\mathbf{3 3}$ in acetone- $d_{6}$ the ${ }^{31} \mathrm{P}$ and ${ }^{1} \mathrm{H}$ NMR spectra recorded after 30 minutes showed that a reaction was taking place. The reaction was followed by NMR methods over the course of a week and the NMR spectra showed that this reaction resulted in the decomposition of the starting materials into an unidentifiable mixture of products. While there was no evidence of hydride formation, there was slow formation of methane observed in the ${ }^{1} \mathrm{H} \mathrm{NMR}$ spectra and evidence of potential protonation of pyridyl nitrogens with some small signals over 9 ppm.

It was probable that the presence of a methyl ligand complicated this reaction. It was already known that a protonated pyridyl group would react with the methyl ligand within complexes of this type to give methane. From the observation of methane and a protonated pyridyl group it was concluded that the hydrogen reacted with complex 33 but that the resulting complex was not stable and decomposed.

In contrast, when acetonitrile, dimethylsulfoxide or ethene was added to a solution of complex 33 no reaction was observed, even when the reaction mixture was heated to $35^{\circ} \mathrm{C}$.

\subsection{Platinum(0) and Palladium(0) Complexes of dpypox}

When tris(norbornene)platinum or tris(norbornene)palladium was reacted with the dpypox ligand 3, complexes of the type $\left[\mathrm{M}(\mathrm{PP})_{2}\right](\mathrm{PP}=\mathbf{3} ; \mathrm{M}=\mathrm{Pt} \mathbf{3 9}, \mathrm{Pd} 40)$ were formed (Scheme 3.10). These complexes were found to form irrespective of the ratio of the reactants. Thus even when one equivalent of ligand $\mathbf{3}$ was reacted with the $\mathrm{M}(0)$ complexes a norbornene complex was not formed, rather a mixture of the $\left[\mathrm{M}(\mathrm{PP})_{2}\right]$ complex and unreacted $\mathrm{M}(0)$ starting material was observed.

The ${ }^{31} \mathrm{P}$ NMR spectrum of the $\left[\mathrm{Pt}(\mathrm{PP})_{2}\right]$ complex 39 in $\mathrm{C}_{6} \mathrm{D}_{6}$ was comprised of 


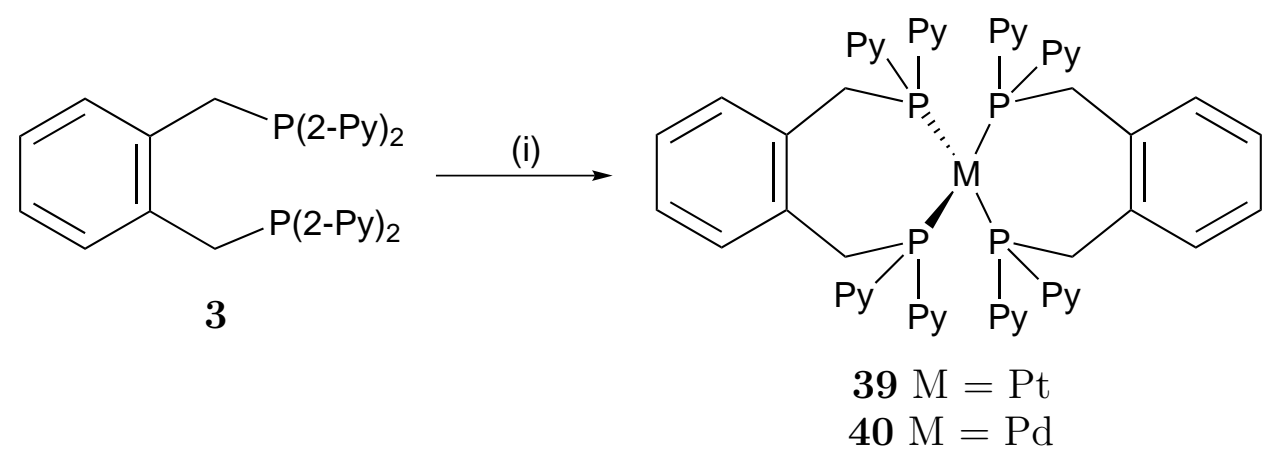

Scheme 3.10 Reaction of dpypox ligand 3 with $\mathrm{M}(0)$ alkene complexes. Reagents and conditions: (i) tris(norbornene)platinum or tris(norbornene)palladium, $\mathrm{C}_{6} \mathrm{D}_{6}$, $15 \mathrm{~min}$.

two triplets at 6.69 and $3.15 \mathrm{ppm}$ with a ${ }^{2} J_{\mathrm{PP}}$ value of 40.7 and ${ }^{1} J_{\mathrm{PtP}}$ values of 3816 and $3548 \mathrm{~Hz}$ respectively (Figure 3.8). The ${ }^{1} \mathrm{H}$ NMR spectrum of this complex contained many broad signals with more than twice the number of aromatic signals observed for the platinum(II) complexes and four broad singlets for the methylene protons. The broad signals for the methylene protons suggested that there was dynamic behaviour occurring in solution. This could either have been due to the backbone flipping as was observed in the platinum(II) complexes or the dissociation and recoordination of one of the phosphorus atoms in a similar manner to $\mathrm{PPh}_{3}$ in a solution of $\left[\mathrm{Pt}\left(\mathrm{PPh}_{3}\right)_{4}\right]{ }^{137}$
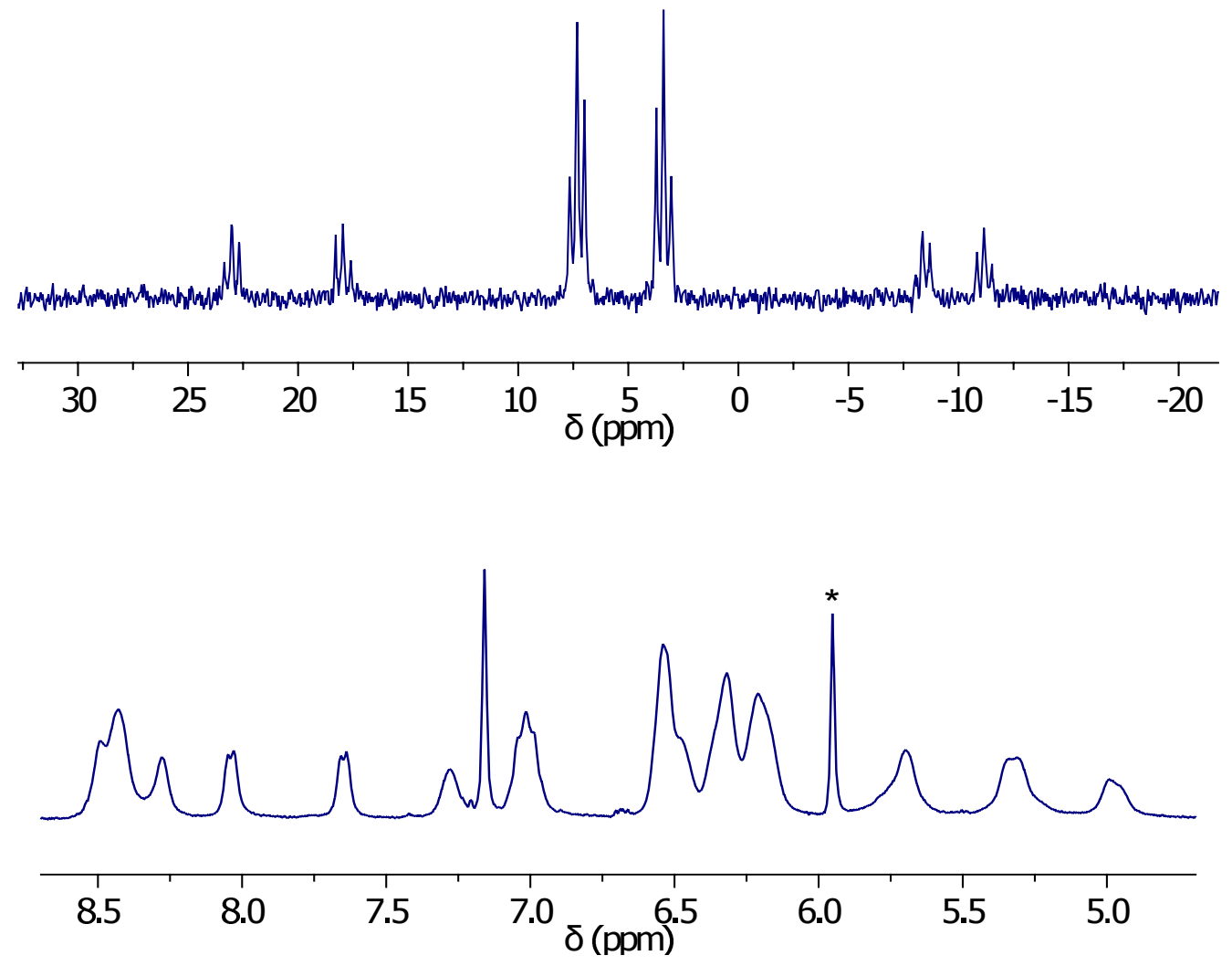

Figure $3.8{ }^{31} \mathrm{P}$ (top) and ${ }^{1} \mathrm{H}$ (bottom) NMR spectra of $\left[\mathrm{Pt}(\mathrm{PP})_{2}\right]$ complex 39 in $\mathrm{C}_{6} \mathrm{D}_{6}$. Asterisk denotes sample impurity. 
The ${ }^{31} \mathrm{P}$ NMR spectrum of the $\left[\mathrm{Pd}(\mathrm{PP})_{2}\right]$ complex 40 in $\mathrm{C}_{6} \mathrm{D}_{6}$ consisted of two broad singlets at 19.5 and $17.0 \mathrm{ppm}$. The ${ }^{1} \mathrm{H}$ NMR spectrum of complex 40 was quite similar to that of the platinum complex 39, if slightly less broad. This indicates that the complex 40 also displays dynamic behaviour in solution. It was highly likely that the same dynamic process was occurring in complexes 39 and 40 and the difference in the appearance of the signals in the NMR spectra was due to the process occurring at a faster rate in the palladium complex.

While the reactions to form these complexes were carried out in benzene these complexes were not completely soluble in this solvent. They were also only sparingly soluble in toluene and acetone, but were completely soluble in chloroform and dichloromethane. However, if left in chlorinated solvents they were found to react to form $\left[\mathrm{MCl}_{2}(\mathrm{PP})\right]$ complexes. The palladium complex 40 reacted quickly, with the $\left[\mathrm{PdCl}_{2}(\mathrm{PP})\right]$ complex 20 present in the NMR spectra after one hour in chloroform. In contrast, it took 24 hours before the $\left[\mathrm{PtCl}_{2}(\mathrm{PP})\right]$ complex 16 was observed in the NMR spectra recorded of a sample of the platinum complex 39 in chloroform- $d$. Given this reactivity and low solubility in other NMR solvents, VT-NMR spectra of the platinum complex 39 was recorded in a 1:1 mixture of dichloromethane- $d_{2}$ and chloroform- $d$, due to the fact that the platinum complex 39 reacted more slowly than the palladium complex $\mathbf{4 0}$.

When dissolved in $\mathrm{CDCl}_{3}$ the signals in the ${ }^{1} \mathrm{H}$ NMR spectra of the $\left[\mathrm{M}(\mathrm{PP})_{2}\right]$ complexes $39(\mathrm{M}=\mathrm{Pt})$ and $40(\mathrm{M}=\mathrm{Pd})$ were sharper than when $\mathrm{C}_{6} \mathrm{D}_{6}$ was used as the solvent (Figure 3.8 compared to $20{ }^{\circ} \mathrm{C}$ spectrum in Figure 3.9).

VT-NMR spectra of the $\left[\mathrm{Pt}(\mathrm{PP})_{2}\right]$ complex 39 were recorded between 50 and $-80{ }^{\circ} \mathrm{C}$ in a 1:1 mixture of dichloromethane- $d_{2}$ and chloroform- $d$. The ${ }^{1} \mathrm{H}$ NMR spectra do not change significantly between -20 and $-80^{\circ} \mathrm{C}$. As the temperature was increased the signals become broader. At $50{ }^{\circ} \mathrm{C}$ the ${ }^{1} \mathrm{H}$ NMR spectra resembled that of the silver complex $4 \mathbf{1}$ recorded at room temperature (see Section 3.4). This suggested that the same dynamic process was occurring in these three $\left[\mathrm{M}(\mathrm{PP})_{2}\right]$ complexes. The ${ }^{31} \mathrm{P}$ NMR spectra recorded only began to broaden at $50{ }^{\circ} \mathrm{C}$, indicating the coalescence point for this dynamic process occurs outside this temperature range.

Similar reactivity was observed when dpypox ligand 3 was reacted with $\left[\mathrm{Pt}(\mathrm{COD})_{2}\right]$, $\left[\mathrm{Pt}\left(\mathrm{C}_{2} \mathrm{H}_{4}\right)_{3}\right]$ or $\left[\mathrm{Pd}_{2}(\mathrm{dba})_{3}\right](\mathrm{dba}=$ trans,trans-dibenzylideneacetone). After 20 minutes at room temperature the $\left[\mathrm{M}(\mathrm{PP})_{2}\right]$ complex, 39 or 40 , was the only complex present in solution. The products formed in these reactions did not depend on the stoichiometry of the reaction, with the bis-chelate complexes formed even in the presence of excess platinum(0) or palladium(0). Even under these conditions no 

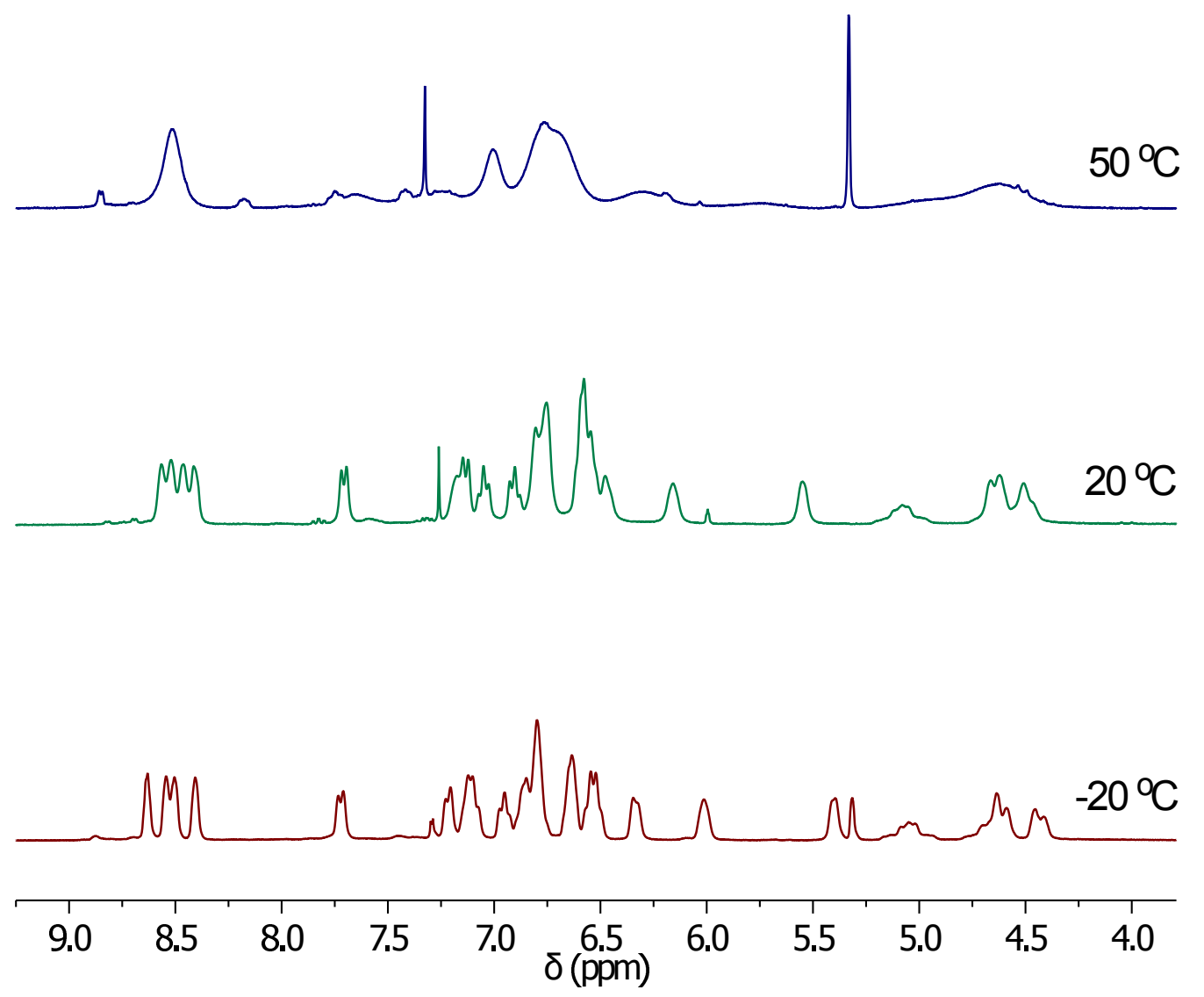

Figure 3.9 ${ }^{1} \mathrm{H}$ NMR spectra of $\left[\mathrm{Pt}(\mathrm{PP})_{2}\right]$ complex 39 collected at 50, 20 and $-20{ }^{\circ} \mathrm{C}$ in $\mathrm{CD}_{2} \mathrm{Cl}_{2} / \mathrm{CDCl}_{3}$.

evidence for the mono-alkene complexes was observed. Also the excess precursor complexes did not react with the pyridyl nitrogens. This was the expected result as it is known that nitrogen donors are not good ligands for platinum(0) and palla$\operatorname{dium}(0) .{ }^{37}$

\subsection{Silver(I) Complexes of dpypox}

The coordination chemistry of silver(I) complexes has received attention due to the wide variety of structural types displayed by these complexes, even with the relatively straightforward equimolar stoichiometry an array of different structures has been reported. ${ }^{40}$ Silver consists of two spin $1 / 2$ isotopes, ${ }^{107} \mathrm{Ag}$ and ${ }^{109} \mathrm{Ag}$ with abundances of $51.85 \%$ and $48.18 \%$ respectively. Thus useful structural information can be gleaned from the value of ${ }^{1} J_{\mathrm{AgP}}$.

The silver(I) complexes of diphosphine ligands have particularly attracted attention as they are potential homogeneous catalysts and often show biological activity. Complexes of diphosphines containing pyridyl substituents have shown potential as 
antitumour agents. ${ }^{2,60,64}$ In silver complexes, $\mathrm{PPh}_{2} \mathrm{Py}$ has been reported to act as a monodentate $P$ ligand or a bridging $P, N$ ligand. ${ }^{40}$ In contrast, when the dpype ligand was reacted with silver nitrate it formed a mixture of monomeric, dimeric and trimeric complexes with the ligands acting as bridging or chelating phosphine ligands. ${ }^{60}$

When two equivalents of the dpypox ligand 3 were reacted with silver tetrafluoroborate or silver nitrate, the bis-chelate $\left[\mathrm{Ag}(\mathrm{PP})_{2}\right] \mathrm{X}$ compounds $[4 \mathbf{1}] \mathrm{X}(\mathrm{PP}=\mathbf{3}, \mathrm{X}=$ $\mathrm{BF}_{4}, \mathrm{NO}_{3}$ ) were formed (Scheme 3.11).

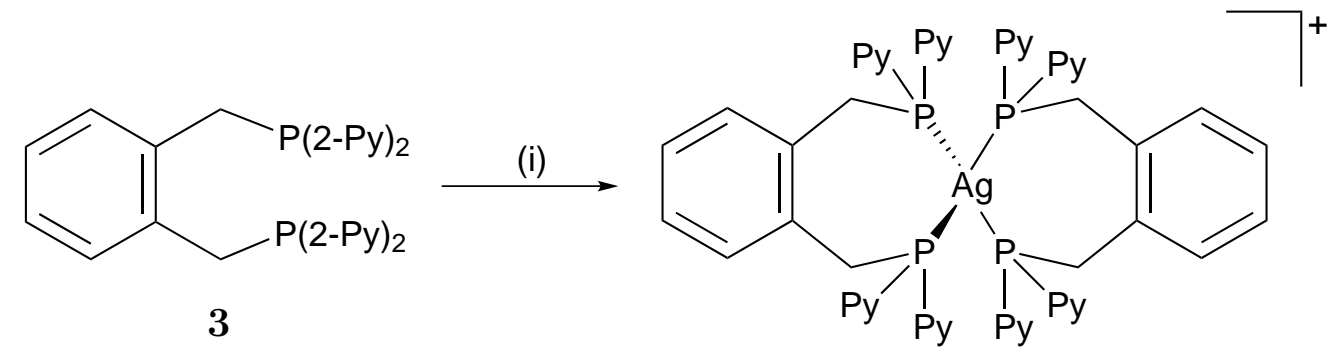

41

Scheme 3.11 Reaction of the dpypox ligand 3 with silver salts. Reagents and conditions: (i) $\mathrm{AgBF}_{4}$ or $\mathrm{AgNO}_{3}, \mathrm{CD}_{2} \mathrm{Cl}_{2}$.

The signal in the ${ }^{31} \mathrm{P}$ NMR spectrum appeared at $4.06 \mathrm{ppm}$ as two doublets, due to coupling to the two NMR active isotopes of silver, ${ }^{1} J_{107} \mathrm{AgP}=224,{ }^{1} J^{109} \mathrm{AgP}=258 \mathrm{~Hz}$. The magnitude of these coupling constants was consistent with a tetrahedral $\mathrm{AgP}_{4}$ species. ${ }^{60,73}$ The ${ }^{1} \mathrm{H}$ NMR spectrum of this complex contained five broad signals. The signals for the pyridyl protons appeared at 8.54, 7.12 and $6.99 \mathrm{ppm}$ while the signals due to the protons on the ligand backbone appeared as broad singlets at 6.37 and $4.47 \mathrm{ppm}$. The ${ }^{19} \mathrm{~F}$ NMR spectrum of $[\mathbf{4 1}] \mathrm{BF}_{4}$ consisted of one sharp signal at $-152.97 \mathrm{ppm}$, which was consistent with a non-coordinating tetrafluoroborate anion. The infrared spectrum of this complex contained $\mathrm{C}=\mathrm{N}$ stretches at 1572 and $1561 \mathrm{~cm}^{-1}$, which was unchanged from that of the free ligand $\mathbf{3}$, confirming the pyridyl nitrogen atoms were not coordinated to the metal centre. This reactivity was consistent with what was observed when dppox was reacted with $\mathrm{AgBF}_{4} \cdot{ }^{73}$

Due to the low solubility of $\mathrm{AgBF}_{4}$ and $\mathrm{AgNO}_{3}$ in chloroform and dichloromethane it was not possible to react these salts in a $1: 1$ ratio with ligand 3 . Thus attempts to react 3 with one equivalent of silver nitrate resulted in the formation of $[\mathbf{4 1}] \mathrm{NO}_{3}$. The formation of the one $\left[\mathrm{Ag}(\mathrm{PP})_{2}\right] \mathrm{NO}_{3}$ species was in contrast to what was observed when dpypp and dpype were reacted with $\mathrm{AgNO}_{3}$, where dimers and trimers with bridging $P, P$ ligands were formed. ${ }^{60,61}$

The signals in the ${ }^{13} \mathrm{C}$ NMR spectrum were also quite broad, with some of the signals overlapping. The number of signals in the ${ }^{13} \mathrm{C}$ NMR spectrum was consistent with 
a fluxional process making the carbon environments equivalent. This ligand system has already been observed to display dynamic behaviour in solution, in the form of the backbone flipping (discussed in Section 3.1). To explore whether this process was also occurring in this complex, VT-NMR spectra were recorded of the $\left[\mathrm{Ag}(\mathrm{PP})_{2}\right] \mathrm{NO}_{3}$ compound $[41] \mathrm{NO}_{3}$ at $20{ }^{\circ} \mathrm{C}$ intervals between 40 and $-80{ }^{\circ} \mathrm{C}$ in a $1: 1$ mixture of acetone- $d_{6}$ and chloroform- $d$.

The ${ }^{31} \mathrm{P}$ NMR spectra did not change over this temperature range. This implies that the dynamic behaviour did not effect the chemical environment of the phosphorus atoms. However, the ${ }^{1} \mathrm{H}$ NMR spectra recorded (between 3.75 and $9.25 \mathrm{ppm}$ ), shown in Figure 3.10, did change dramatically as the temperature was varied. At $40{ }^{\circ} \mathrm{C}$ the signals for the pyridyl protons appeared as a singlet at $8.52 \mathrm{ppm}$, corresponding to the protons on the carbon next to the nitrogen (H7 in the numbering in Figure 3.10), a singlet at $7.12 \mathrm{ppm}$, integrating for 16 protons (H4 and H5), and a multiplet at $6.97 \mathrm{ppm}$ integrating for eight protons (H6). This indicated that the protons on the eight pyridyl rings inhabit time-averaged chemical environments. Thus the dynamic behaviour was rapid on the NMR timescale at this temperature. Focusing on the singlet at $8.52 \mathrm{ppm}$, at $0{ }^{\circ} \mathrm{C}$ it had separated into two signals, a very broad multiplet at $8.69 \mathrm{ppm}$ and a broad singlet at $8.49 \mathrm{ppm}$ which integrated for two and six protons respectively. This indicated that the coalescence temperature for the dynamic behaviour in this system was between 20 and $0{ }^{\circ} \mathrm{C}$. Below $0{ }^{\circ} \mathrm{C}$ these signals sharpened and at $-60{ }^{\circ} \mathrm{C}$ the peaks separated out into three doublets and one multiplet, at $8.74(J=4.7 \mathrm{~Hz}), 8.56(\mathrm{~m}), 8.52(J=4.3 \mathrm{~Hz})$ and $8.47 \mathrm{ppm}$ $(J=4.4 \mathrm{~Hz})$. This indicated that at $-60{ }^{\circ} \mathrm{C}$ the protons on each pyridyl ring inhabited different chemical environments, with the analogous proton on the other ligand inhabiting the same environment. Over this temperature range the signals for the rest of the pyridyl protons also coalesced and then separated out. However, the signals also overlapped in the ${ }^{1} \mathrm{H}$ NMR spectra making it harder to observe these changes.

At $40{ }^{\circ} \mathrm{C}$ the signal for the aromatic protons on the ligand backbone appeared as a singlet at $6.32 \mathrm{ppm}$ while the signal for the methylene protons was a singlet at $4.56 \mathrm{ppm}$. The broadness of these peaks in the ${ }^{1} \mathrm{H}$ NMR spectrum recorded at $20{ }^{\circ} \mathrm{C}$ confirms that the coalescence of this dynamic behaviour is close to room temperature. In the ${ }^{1} \mathrm{H}$ NMR spectrum recorded at $0{ }^{\circ} \mathrm{C}$ the signal for the aromatic protons has separated out into three broad signals at 6.72 and $6.37 \mathrm{ppm}$, which integrated for two protons each, and $6.10 \mathrm{ppm}$, which integrated for four protons. Below $0{ }^{\circ} \mathrm{C}$ these signals sharpened and at $-20{ }^{\circ} \mathrm{C}$ four signals were observed, two broad singlets at 6.71 and $5.96 \mathrm{ppm}$ and two doublets at $6.36(J=6.5 \mathrm{~Hz})$ and $6.00 \mathrm{ppm}(J=7.5 \mathrm{~Hz})$, with the signals at 6.00 and $5.96 \mathrm{ppm}$ overlapping slightly. 

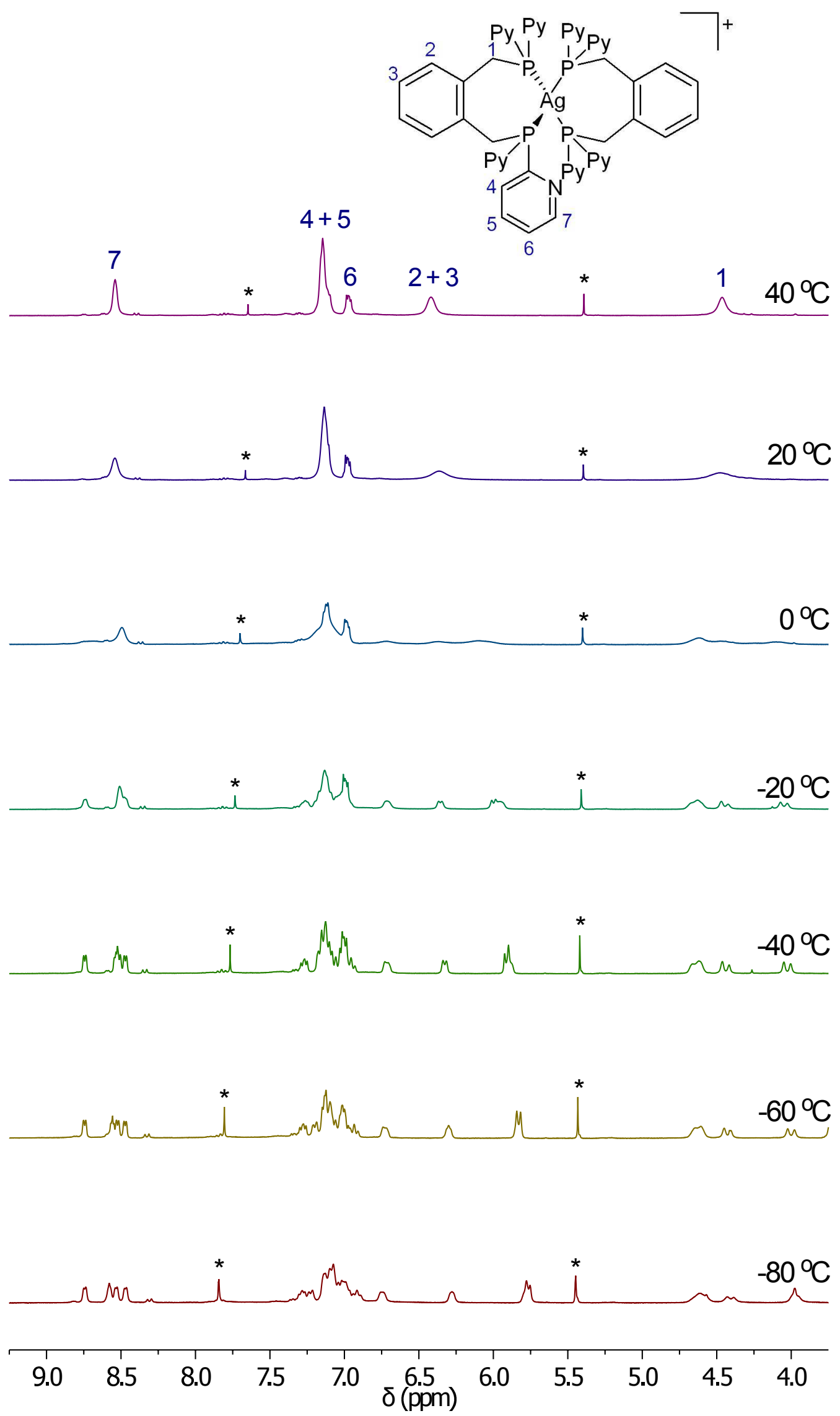

Figure 3.10 ${ }^{1} \mathrm{H}$ NMR spectra of $\left[\mathrm{Ag}(\mathrm{PP})_{2}\right]^{+}$complex 41 collected between 40 and $-80{ }^{\circ} \mathrm{C}$ in $\left(\mathrm{CD}_{3}\right)_{2} \mathrm{CO} / \mathrm{CDCl}_{3}$. Asterisks denote solvent and a sample impurity. 
However, when the temperature is decreased further these two signals overlap further until at $-60{ }^{\circ} \mathrm{C}$ only three signals were observed, two multiplets at 6.74 and 6.30 ppm, integrating for two protons each, and a doublet at $5.83 \mathrm{ppm}(J=7.8 \mathrm{~Hz})$ integrating for four protons. This indicated that at low temperature the aromatic protons in the ligand backbone were also in distinct chemical environments. The signals for the methylene protons displayed similar behaviour when the temperature was decreased. At $0{ }^{\circ} \mathrm{C}$ the signal had separated into three broad signals at 4.62 , 4.47 and $4.10 \mathrm{ppm}$. As the temperature was decreased these signals sharpened and at $-40{ }^{\circ} \mathrm{C}$ these signals appeared as three doublets, one broad at $4.64 \mathrm{ppm}\left({ }^{2} J_{\mathrm{PH}}\right.$ $=12.7 \mathrm{~Hz})$ integrating for four protons and two sharp doublets at $4.44\left({ }^{2} J_{\mathrm{PH}}=\right.$ $14.0 \mathrm{~Hz})$ and $4.03 \mathrm{ppm}\left({ }^{2} J_{\mathrm{PH}}=6.5 \mathrm{~Hz}\right)$ integrating for two protons each. This confirms that at low temperature the fluxional behaviour was slower than the NMR time-scale and the protons on the ligand were in distinct chemical environments.

Given that the ${ }^{31} \mathrm{P}$ NMR spectrum did not change with temperature it is suggested that the fluxional behaviour displayed in the $\left[\mathrm{Ag}(\mathrm{PP})_{2}\right] \mathrm{X}$ compounds $[\mathbf{4 1}] \mathrm{X}(\mathrm{X}=$ $\mathrm{BF}_{4}^{-}, \mathrm{NO}_{3}^{-}$) was most likely due to the backbone flipping. Similar dynamic behaviour has also been observed for the $\left[\mathrm{M}(\mathrm{PP})_{2}\right]$ complexes $39(\mathrm{M}=\mathrm{Pt})$ and $\mathbf{4 0}(\mathrm{M}=\mathrm{Pd})$.

\subsection{Rhodium and Iridium Complexes of dpypox}

Rhodium and iridium complexes of diphosphines have been found to be catalytically active in a range of reactions including hydroformylation ${ }^{69,138}$ and hydrogenation. ${ }^{139}$ Iridium complexes have received attention recently due to their potential as emissive dopants in phosphorescent organic light-emitting diodes (OLEDs). ${ }^{140}$ However, they are of particular interest in this work as they have been found to readily form $P, N$ chelates with $\mathrm{PPh}_{3-\mathrm{n}} \mathrm{Py}_{\mathrm{n}}$ ligands $(\mathrm{n}=1-3) .{ }^{13,21,22,140-142}$

In particular, reaction of $\mathrm{RhCl}_{3} \cdot 3 \mathrm{H}_{2} \mathrm{O}$ or $[\mathrm{Rh}(\mathrm{COD})(\mu-\mathrm{Cl})]_{2}(\mathrm{COD}=$ cycloocta1,5-diene) with $\mathrm{PPh}_{2} \mathrm{Py}$ was found to form products containing a $P, N$ chelate. ${ }^{13,21}$ However, the reactions of dpypox ligand 3 with $\mathrm{RhCl}_{3} \cdot 3 \mathrm{H}_{2} \mathrm{O}$ or $[\mathrm{Rh}(\mathrm{COD})(\mu-\mathrm{Cl})]_{2}$, both in the presence and absence of $\mathrm{NaCH}\left(\mathrm{SO}_{2} \mathrm{CF}_{3}\right)_{2}$, formed intractable solids. It was concluded that the presence of the extra pyridyl rings led to the formation of coordination polymers rather than the monorhodium products observed in the reactions with $\mathrm{PPh}_{2} \mathrm{Py}$.

In contrast, the reaction of the iridium dimer $[\operatorname{Ir}(\mathrm{COD})(\mu-\mathrm{Cl})]_{2}$ with two equivalents of the dpypox ligand 3 gave a single phosphorus containing product, with a singlet at 
$-13.62 \mathrm{ppm}$ in the ${ }^{31} \mathrm{P}$ NMR spectrum of the reaction mixture. When a diphosphine is reacted with $[\operatorname{Ir}(\mathrm{COD})(\mu-\mathrm{Cl})]_{2}$ it can react by either displacing the COD ligands to form complexes of the type $[\operatorname{Ir}(\mathrm{PP})(\mu-\mathrm{Cl})]_{2}{ }^{143,144}$ or by breaking the chloride bridges to form monomeric complexes. ${ }^{145}$ As the signals for free COD were not observed in the ${ }^{1} \mathrm{H}$ NMR spectrum of the reaction mixture, formation of an $[\operatorname{Ir}(\mathrm{PP})(\mu-\mathrm{Cl})]_{2}$ complex was ruled out. The ${ }^{1} \mathrm{H}$ NMR spectrum contained signals for coordinated 3 and COD ligands. A ${ }^{1} \mathrm{H}_{-}{ }^{31} \mathrm{P}$ HMBC experiment showed a correlation between the ${ }^{1} \mathrm{H}$ NMR signal for the $\mathrm{COD} \mathrm{CH}_{2}$ and the ${ }^{31} \mathrm{P}$ NMR signal at $-13.62 \mathrm{ppm}$, confirming ligand 3 and COD were coordinated to the same iridium centre. The infrared spectrum indicated the pyridyl nitrogens were not coordinated to the metal centre, with a $\mathrm{C}=\mathrm{N}$ stretch at $1573 \mathrm{~cm}^{-1}$. The high resolution mass spectrum contained a peak for $\mathrm{C}_{28} \mathrm{H}_{25} \mathrm{ClIrN}_{4} \mathrm{P}_{2}$ at $\mathrm{m} / \mathrm{z}=707.0870$. This indicated that the chloride ligand was still bound to the iridium centre and that the product of this reaction was the $[\operatorname{IrCl}(\mathrm{PP})(\mathrm{COD})]$ complex $42(\mathrm{PP}=\mathbf{3})$ (Scheme 3.12).

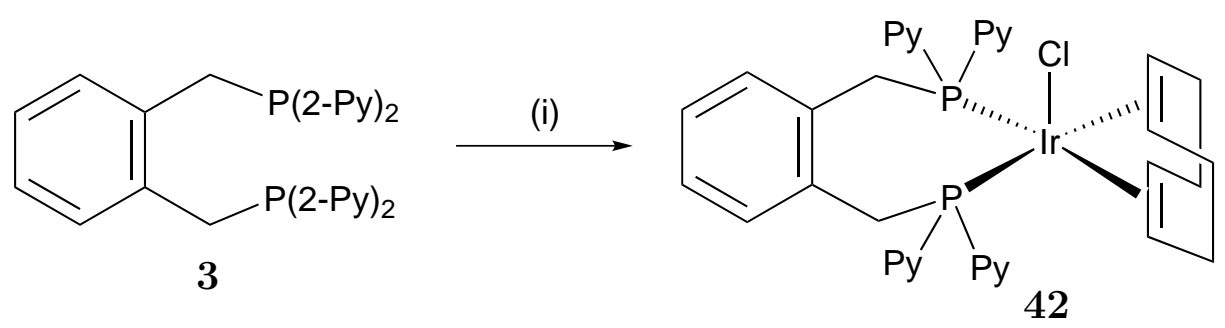

Scheme 3.12 Synthesis of $[\operatorname{IrCl}(\mathrm{PP})(\mathrm{COD})]$ complex 42. Reagents and conditions: (i) $[\mathrm{IrCl}(\mathrm{COD})]_{2}, \mathrm{CDCl}_{3}, 15 \mathrm{~min}$.

This type of complex was also formed when two equivalents of the analogous phenyl ligand, dppox, was reacted with $[\operatorname{Ir}(\mathrm{COD})(\mu-\mathrm{Cl})]_{2} \cdot{ }^{145}$ The spectral data of the $[\operatorname{IrCl}(\mathrm{PP})(\mathrm{COD})]$ complexes $(\mathrm{PP}=$ dpypox 42, dppox) were in good agreement with each other. The ${ }^{31} \mathrm{P}$ NMR signal appeared at $-13.62 \mathrm{ppm}$ for complex 42 while it appeared at $-17.81 \mathrm{ppm}$ for the dppox complex. The signals for the COD ligand in the ${ }^{1} \mathrm{H}$ NMR spectra were particularly similar. For example, the signals for the methylene protons appeared as doublets at 2.21 and $1.75 \mathrm{ppm}\left({ }^{2} J_{\mathrm{HH}}=8.5 \mathrm{~Hz}\right)$ in complex 42, while they were multiplets at $2.25-2.28$ and $1.74-1.77 \mathrm{ppm}$ in the dppox complex. The similar NMR data suggested that the two structures were the same. Thus it was concluded that complex 42 was also square pyramidal. ${ }^{145}$ The single singlet in the ${ }^{31} \mathrm{P}$ NMR spectrum of complex 42 and the single peak for the four alkene protons in COD were consistent with this conclusion. Over time complex 42 decomposed, losing COD and forming an unidentifiable mixture of products.

When the the iridium dimer $[\operatorname{Ir}(\mathrm{COD})(\mu-\mathrm{Cl})]_{2}$ was reacted with two equivalents of the dpypox ligand 3 and $\mathrm{NaCH}\left(\mathrm{SO}_{2} \mathrm{CF}_{3}\right)_{2}$ or $\mathrm{NaBPh}_{4}$, or the chloride ligand was abstracted from complex 42, the $\left[\operatorname{Ir}\left(1-\kappa-4,5,6-\eta^{3}-\mathrm{C}_{8} \mathrm{H}_{12}\right)(\mathrm{PPN})\right]^{+}$complex $43(\mathrm{PPN}$ =3) was formed after 16 hours (Scheme 3.13). 


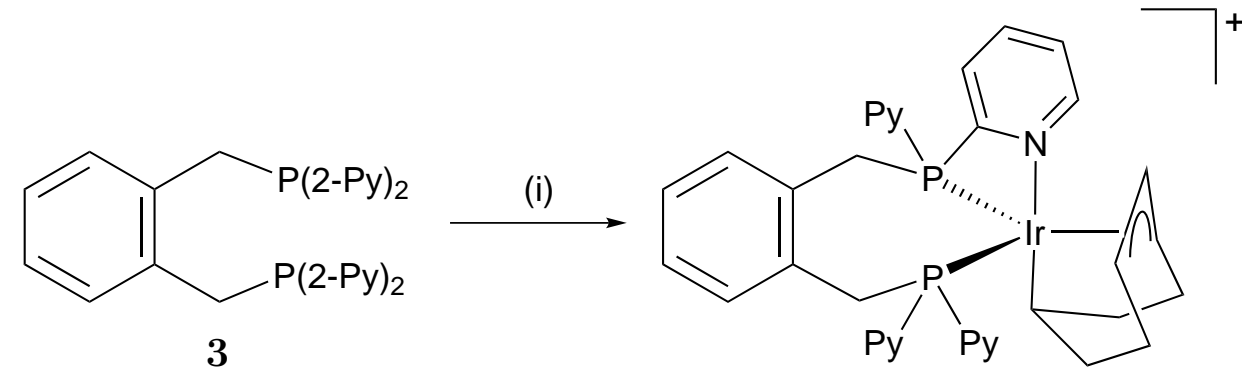

43

Scheme 3.13 Synthesis of $\left[\operatorname{Ir}\left(1-\kappa-4,5,6-\eta^{3}-\mathrm{C}_{8} \mathrm{H}_{12}\right)(\mathrm{PPN})\right]^{+}$complex 43. Reagents and conditions: (i) $[\mathrm{Ir}(\mathrm{COD})(\mu-\mathrm{Cl})]_{2}, \mathrm{NaCH}\left(\mathrm{SO}_{2} \mathrm{CF}_{3}\right)_{2}$ or $\mathrm{NaBPh}_{4}, \mathrm{CDCl}_{3}, 16$ hours.

The signal for complex 43 in the ${ }^{31} \mathrm{P}$ NMR spectrum appeared as a broad singlet centered at $-27.36 \mathrm{ppm}$. In contrast, the signals in the ${ }^{1} \mathrm{H}$ NMR spectrum were well defined and mostly sharp (there were a few broad singlets). The signals in the ${ }^{1} \mathrm{H}$ NMR spectrum indicated that rather than forming the expected $[\operatorname{Ir}(\mathrm{PP})(\mathrm{COD})]^{+}$complex, this reaction had formed a product with lower symmetry, with twice the number of signals for the pyridyl rings and methylene protons of ligand 3 than expected. The fact that the signals at 4.45 and $5.29 \mathrm{ppm}$ integrated for one and two protons respectively indicated that there was no longer a simple $\eta^{4}$-COD ligand coordinated to the iridium but suggested the formation of an allyl ligand. The integrations of the signals between 1.29 and $0.38 \mathrm{ppm}$ for three, two, two and two protons respectively also implied that this $\mathrm{C}_{8} \mathrm{H}_{12}$ ligand may be $\sigma$ bonded as well. In the reaction with $\mathrm{NaCH}\left(\mathrm{SO}_{2} \mathrm{CF}_{3}\right)_{2},{ }^{1}{ }^{1} \mathrm{H}$ NMR peak at $3.75 \mathrm{ppm}$ and ${ }^{19} \mathrm{~F}$ NMR peak at $-80.9 \mathrm{ppm}$ confirmed the presence of the non-coordinating counterion, $\mathrm{CH}\left(\mathrm{SO}_{2} \mathrm{CF}_{3}\right)_{2}^{-} \cdot{ }^{128}$

As there was a single broad signal in the ${ }^{31} \mathrm{P}$ NMR spectrum of complex 43 while the ${ }^{1} \mathrm{H}$ NMR data indicated the complex was unsymmetrical, the potential that this complex displayed dynamic behaviour was explored. VT-NMR spectra were recorded at $20{ }^{\circ} \mathrm{C}$ intervals between 40 and $-80{ }^{\circ} \mathrm{C}$ in a $1: 1$ mixture of dichloromethane- $d_{2}$ and chloroform- $d$. Over this temperature the ${ }^{31} \mathrm{P}$ and ${ }^{1} \mathrm{H}$ NMR spectra changed significantly indicating there was fluxional behaviour occurring in solution. There was no change in the appearance of the ${ }^{19} \mathrm{~F}$ NMR spectra over this temperature range confirming that the $\mathrm{CH}\left(\mathrm{SO}_{2} \mathrm{CF}_{3}\right)_{2}^{-}$anion was not involved in the dynamic behaviour.

The ${ }^{31} \mathrm{P}$ NMR spectra recorded between 40 and $-80{ }^{\circ} \mathrm{C}$ are shown in Figure 3.11. The ${ }^{31} \mathrm{P}$ NMR spectrum recorded at room temperature represented an average phosphorus environment in complex 43. This indicated that the fluxional behaviour occurring in solution converted one phosphorus environment into the other and at room temperature this was occurring at a faster rate than the NMR time scale. 

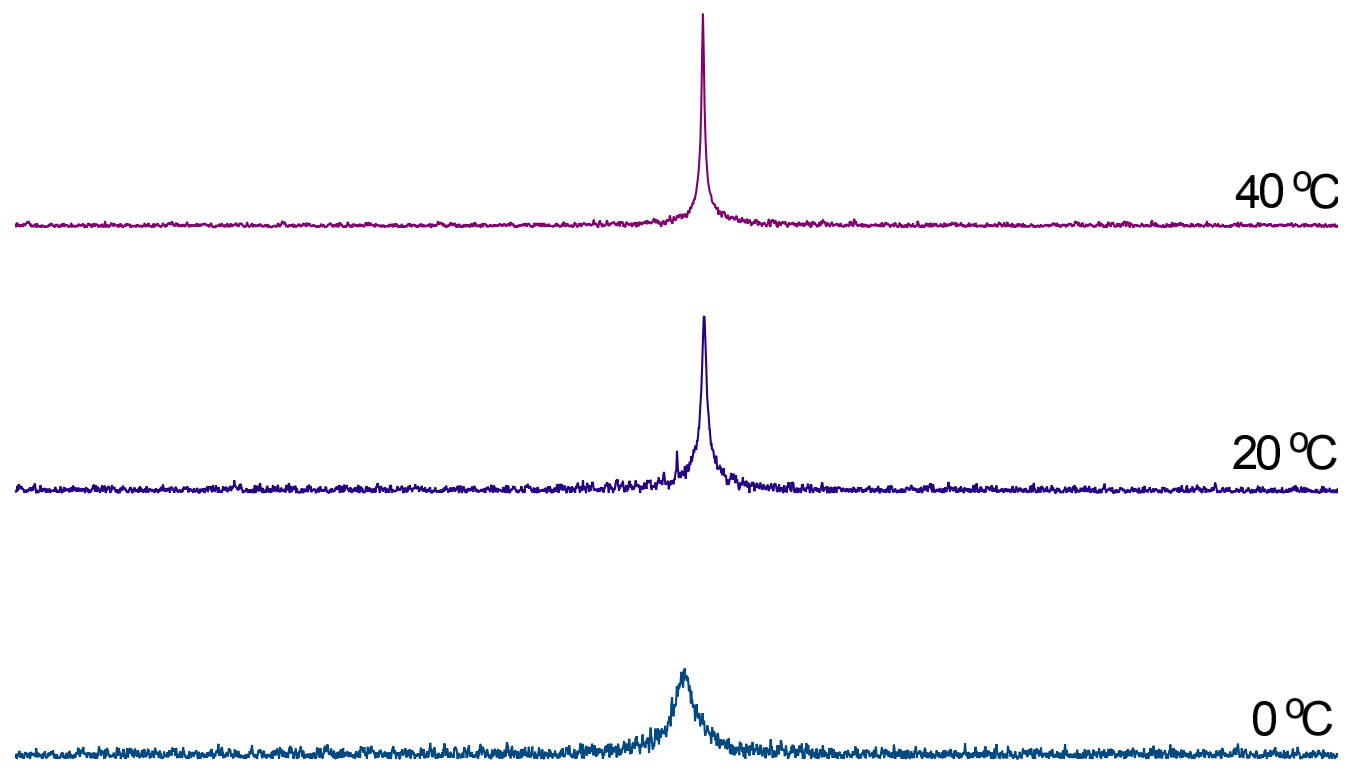

$-20^{\circ} \mathrm{C}$

.
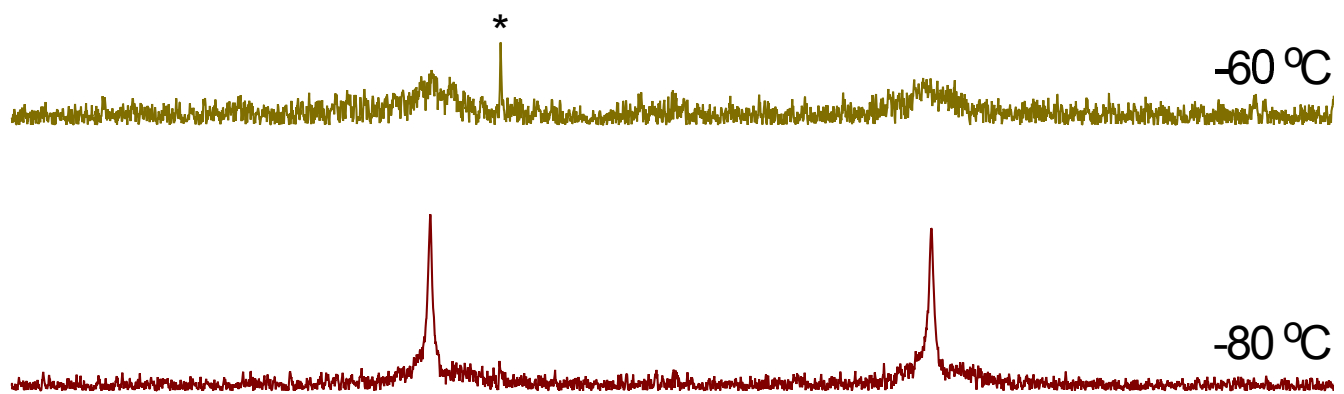

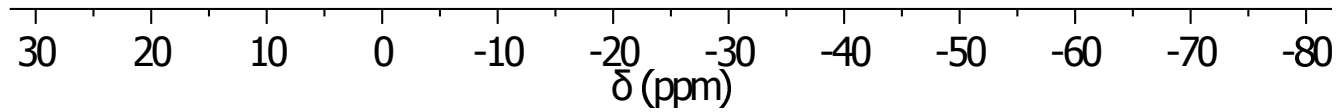

Figure 3.11 ${ }^{31} \mathrm{P}$ NMR spectra of $\left[\operatorname{Ir}\left(1-\kappa-4,5,6-\eta^{3}-\mathrm{C}_{8} \mathrm{H}_{12}\right)(\mathrm{PPN})\right]^{+}$complex 43 collected between 40 and $-80{ }^{\circ} \mathrm{C}$ in $\mathrm{CD}_{2} \mathrm{Cl}_{2} / \mathrm{CDCl}_{3}$. Asterisk denotes a sample impurity. 
When the temperature was increased to $40{ }^{\circ} \mathrm{C}$ the dynamic behaviour occurred at a slightly faster rate resulting in a slightly sharper signal in the ${ }^{31} \mathrm{P}$ NMR spectrum. In contrast, when the temperature was decreased the signal broadened out until it coalesced at around $-40{ }^{\circ} \mathrm{C}$. At $-60{ }^{\circ} \mathrm{C}$ two broad signals were observed, while at $-80{ }^{\circ} \mathrm{C}$ the signals appeared as broad singlets at -3.98 and $-47.36 \mathrm{ppm}$.

The upfield signal at $-47.36 \mathrm{ppm}$ was diagnostic of a four-membered chelate complex. ${ }^{126,146}$ This suggested that a four-membered ring was being formed reversibly at room temperature. It was most likely this four-membered metallacycle formed through the coordination of a pyridyl nitrogen to the iridium centre, which could then dissociate allowing another pyridyl nitrogen to coordinate. This would explain the two different environments for the pyridyl protons of the ligand $\mathbf{3}$ observed in the ${ }^{1} \mathrm{H}$ NMR spectrum of this complex, as at room temperature an average of the two pyridyl rings that coordinated to the iridium would be observed as well as the two pyridyl rings that did not interact with the metal centre. Unfortunately, even at low temperature the signals in the ${ }^{1} \mathrm{H}$ NMR spectrum were broad and no further evidence for nitrogen coordination was observed.

When the $[\operatorname{IrCl}(\mathrm{PP})(\mathrm{COD})]$ complex 42 was reacted with sodium tetraphenylborate the resulting compound, $\left[\operatorname{Ir}\left(1-\kappa-4,5,6-\eta^{3}-\mathrm{C}_{8} \mathrm{H}_{12}\right)(\mathrm{PPN})\right] \mathrm{BPh}_{4}[43] \mathrm{BPh}_{4}$, could be crystallised from the slow evaporation of a $n$-hexane/dichloromethane solution of this complex. The X-ray crystal structure confirmed the structure proposed based on the NMR data, with ligand 3 bound to the iridium through both phosphorus atoms and a pyridyl nitrogen atom and the $\mathrm{C}_{8} \mathrm{H}_{12}$ ligand bound to iridium through both a $\sigma$-bond and a $\pi$-allyl system (Figure 3.12 ). Crystallographic data is given in Table 3.8 and selected bond lengths and angles are given in Table 3.9.

The Ir-P bond lengths were within the range reported for similar iridium complexes with four-membered $P, N$ chelate rings. ${ }^{140,142}$ The Ir-N bond length of 2.289(2) $\AA$ was longer than that reported for the $\left[\operatorname{IrCp}^{*}\left(\mathrm{~N}_{3}\right)\left(P, N-\mathrm{PPh}_{2} \mathrm{Py}\right)\right] \mathrm{O}_{3} \mathrm{SCF}_{3}$ complex $\left(\mathrm{Cp}^{*}=\eta^{5}-\mathrm{C}_{5} \mathrm{Me}_{5}\right), 2.125(3) \AA,{ }^{142}$ and the $\left[\operatorname{Ir}(P, N\right.$-dppiH $)(P, C$-dppi $\left.) \mathrm{Cl}_{2}\right]$ complex, $2.127(5) \AA$ (dppiH $=1$-(diphenylphosphino)isoquinoline). ${ }^{140}$ This was due to the nitrogen being bound trans to a ligand higher in trans influence than in the literature examples (a $\sigma$-bonded carbon versus a $\pi$-bonded carbon or chloride ligand).

The P1-Ir-P2 bond angle was 96.38(2) ${ }^{\circ}$. While this was smaller than the bite angles observed for the dpypox ligand $\mathbf{3}$ in the complexes of platinum and palladium discussed in Section 3.1 and 3.2, it was still within the range of bite angles observed for ligands with the $o$-xylene backbone, particularly when they are bound to Group 9 metals. ${ }^{73,147,148}$ The P1-Ir-N1 bond angle was $66.64(6)^{\circ}$. This small bite angle is 


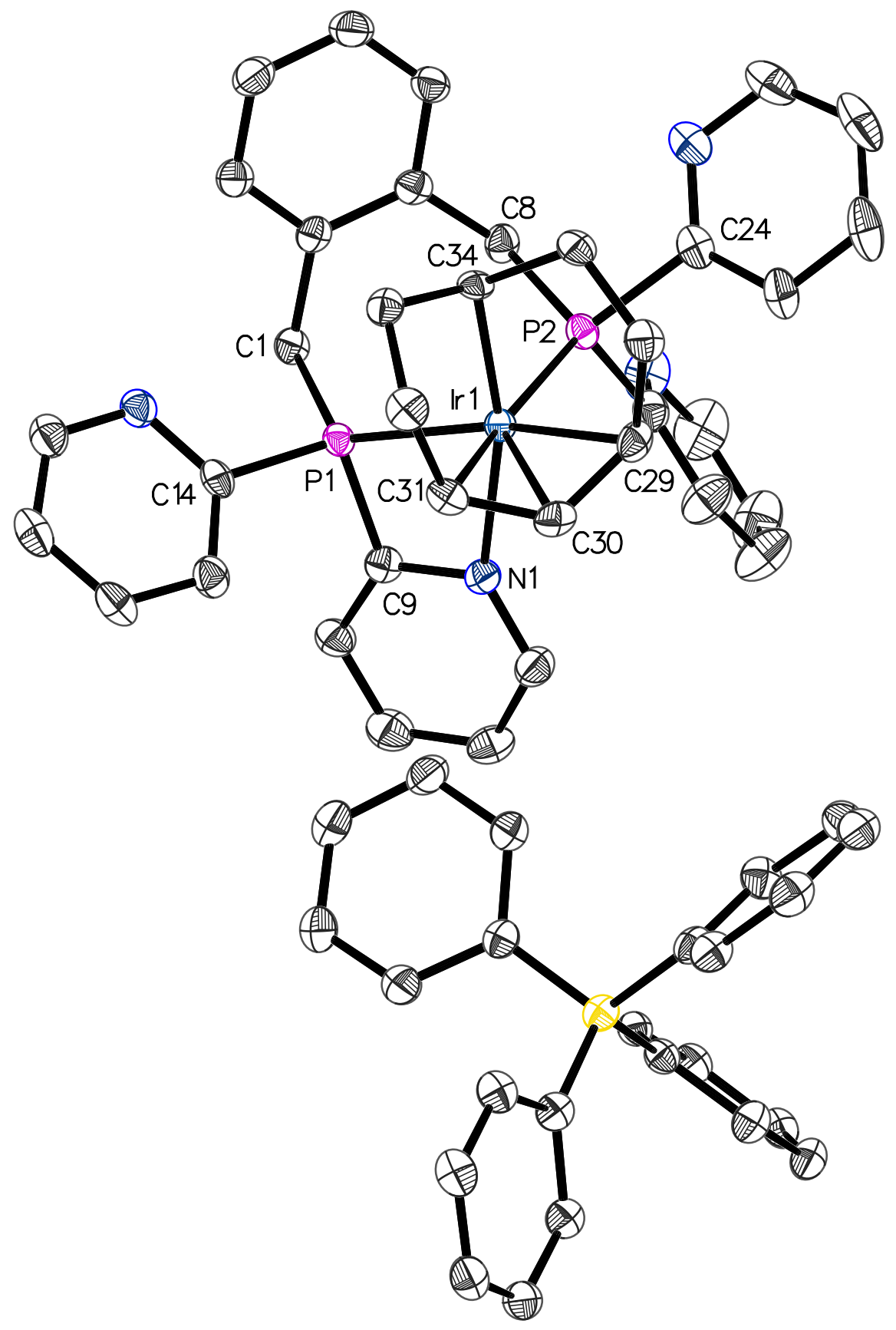

Figure 3.12 ORTEP diagram of $\left[\operatorname{Ir}\left(1-\kappa-4,5,6-\eta^{3}-\mathrm{C}_{8} \mathrm{H}_{12}\right)(\mathrm{PPN})\right] \mathrm{BPh}_{4}$ compound $[43] \mathrm{BPh}_{4}$ (50\% probability thermal ellipsoids). Hydrogen atoms omitted for clarity. 
Table 3.8 Crystallographic data of $\left[\operatorname{Ir}\left(1-\kappa-4,5,6-\eta^{3}-\mathrm{C}_{8} \mathrm{H}_{12}\right)(\mathrm{PPN})\right] \mathrm{BPh}_{4}$ compound $[43] \mathrm{BPh}_{4}$.

\begin{tabular}{|c|c|}
\hline Empirical formula & $\mathrm{C}_{60} \mathrm{H}_{56} \mathrm{BIrN}_{4} \mathrm{P}_{2}$ \\
\hline Formula weight & 1098.13 \\
\hline Crystal system & triclinic \\
\hline Space group & $P \overline{1}$ \\
\hline $\mathrm{a} / \AA$ & $9.38338(15)$ \\
\hline $\mathrm{b} / \AA$ & $14.6521(4)$ \\
\hline$c / \AA$ & $17.9389(5)$ \\
\hline$\alpha /^{\circ}$ & $84.324(2)$ \\
\hline$\beta /{ }^{\circ}$ & $88.2410(17)$ \\
\hline$\gamma /{ }^{\circ}$ & $79.2307(17)$ \\
\hline $\mathrm{V} / \AA^{3}$ & $2410.85(10)$ \\
\hline $\mathrm{Z}$ & 2 \\
\hline $\mathrm{D}_{\text {calc }} / \mathrm{g} \mathrm{m}^{-3}$ & 1.5126 \\
\hline$\mu / \mathrm{mm}^{-1}$ & 6.332 \\
\hline Temperature/K & $120.02(01)$ \\
\hline $\mathrm{F}(000)$ & 1106.9 \\
\hline Radiation type & $\mathrm{CuK} \alpha$ \\
\hline $\operatorname{Radiation}(\lambda) / \AA$ & 1.54184 \\
\hline Index range $h$ & $-11 \rightarrow 5$ \\
\hline Index range $k$ & $-18 \rightarrow 18$ \\
\hline Index range $l$ & $-22 \rightarrow 22$ \\
\hline Reflections collected & 23896 \\
\hline$R_{1}[I>2 \sigma(I)]$ & 0.0305 \\
\hline $\mathrm{w} R_{2}[I>2 \sigma(I)]$ & 0.0798 \\
\hline$R_{1}$ [all data $]$ & 0.0318 \\
\hline $\mathrm{w} R_{2}$ [all data] & 0.0813 \\
\hline
\end{tabular}

typical of $P, N$-(2-pyridyl)phosphine complexes. ${ }^{13,24,65,140,142}$

There have only been two other crystal structures of pyridyldiphosphine ligands reported with both phosphorus atoms and a pyridyl nitrogen coordinated to the same metal. ${ }^{65}$ These two structures were the meridional and facial isomers of the ruthenium complex $\left[\mathrm{RuCl}_{2}\left(P, P, N\right.\right.$-dpypcp) $\left.\mathrm{PPh}_{3}\right]$ (shown in Figure 1.6). From Figure 3.13 it can be seen that ligand $\mathbf{3}$ was coordinated to the iridium centre in a facial manner in $[43] \mathrm{BPh}_{4}$. The $\mathrm{M}-\mathrm{P}$ and $\mathrm{M}-\mathrm{N}$ bond lengths were generally shorter in the fac$\left[\mathrm{RuCl}_{2}(P, P, N\right.$-dpypcp $\left.) \mathrm{PPh}_{3}\right]$ than in complex $[43] \mathrm{BPh}_{4}$. However, this difference was due to the two phosphorus atoms of the dpypcp ligand being coordinated trans to chloride ligands and the nitrogen atom coordinated trans to a phosphorus ligand, all of which were ligands with a lower trans influence than the ligands $\mathbf{3}$ was coordinated trans to in $[43] \mathrm{BPh}_{4}$ (allyl carbons and a $\sigma$-bonded carbon for the phosphorus atoms and the nitrogen atom respectively). ${ }^{16}$ The $\mathrm{P}-\mathrm{Ru}-\mathrm{N}$ bite angle of $67.85(11)^{\circ}$ was of a similar size to that observed in complex $[43] \mathrm{BPh}_{4}$, while the $\mathrm{P}-\mathrm{Ru}-\mathrm{P}$ bite angle, $83.94(5)^{\circ}$, was smaller due to the different ligand backbones. The dpypcp lig- 
Table 3.9 Selected bond distances and angles of $\left[\operatorname{Ir}\left(1-\kappa-4,5,6-\eta^{3}-\right.\right.$ $\left.\left.\mathrm{C}_{8} \mathrm{H}_{12}\right)(\mathrm{PPN})\right] \mathrm{BPh}_{4}$ compound $[43] \mathrm{BPh}_{4}$.

\begin{tabular}{llll}
\hline \multicolumn{2}{c}{ Bond distances $(\AA)$} & \multicolumn{2}{c}{ Bond angles $\left(^{\circ}\right)$} \\
\hline Ir1-P1 & $2.2958(7)$ & P1-Ir1-P2 & $96.38(2)$ \\
Ir1-P2 & $2.3081(7)$ & P1-Ir1-N1 & $66.64(6)$ \\
Ir1-N1 & $2.289(2)$ & P2-Ir1-N1 & $94.32(6)$ \\
Ir1-C29 & $2.256(3)$ & C1-P1-Ir1 & $123.30(9)$ \\
Ir1-C30 & $2.148(3)$ & C9-P1-Ir1 & $88.51(10)$ \\
Ir1-C31 & $2.235(3)$ & C9-P1-C1 & $111.81(13)$ \\
Ir1-C34 & $2.102(3)$ & C14-P1-Ir1 & $123.02(9)$ \\
P1-C1 & $1.839(3)$ & C14-P1-C1 & $103.87(13)$ \\
P2-C9 & $1.831(3)$ & C14-P1-C9 & $102.89(13)$ \\
P2-C14 & $1.839(3)$ & C8-P2-Ir1 & $118.93(10)$ \\
P2-C8 & $1.844(3)$ & & \\
P2-C19 & $1.851(3)$ & & \\
P2-C24 & $1.851(3)$ & & \\
N1-C9 & $1.368(4)$ & & \\
C29-C30 & $1.419(4)$ & & \\
C30-C31 & $1.419(4)$ & & \\
\hline
\end{tabular}

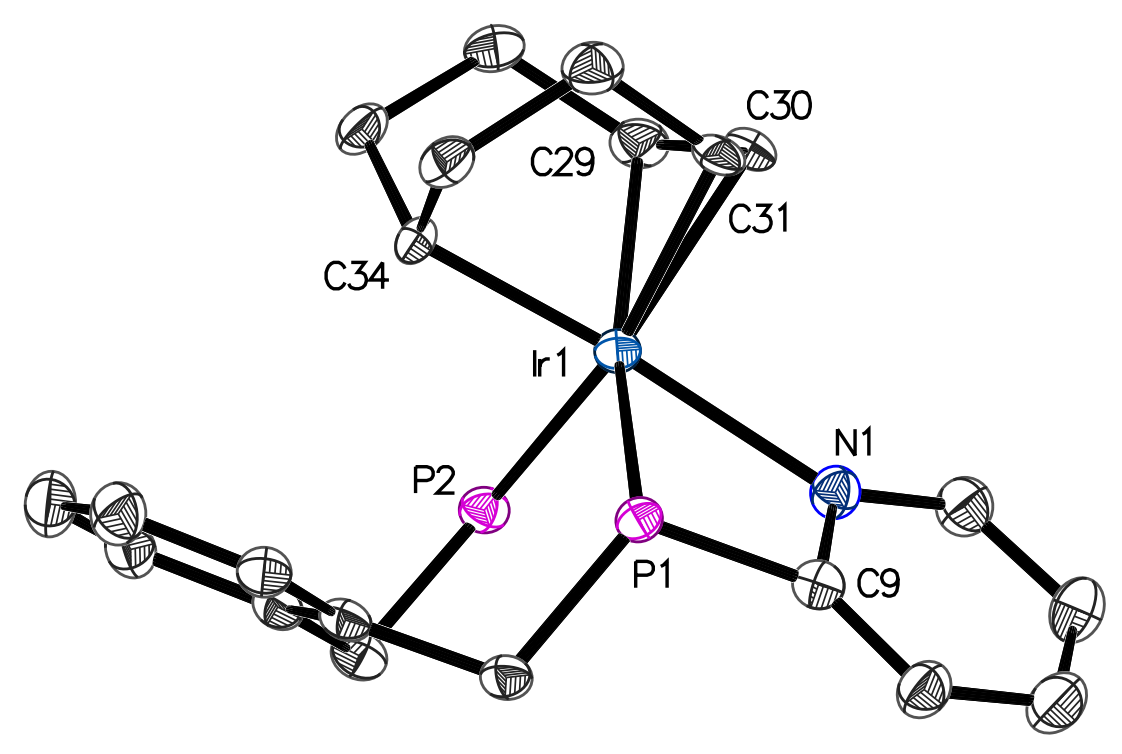

Figure 3.13 ORTEP diagram of $\left[\operatorname{Ir}\left(1-\kappa-4,5,6-\eta^{3}-\mathrm{C}_{8} \mathrm{H}_{12}\right)(\mathrm{PPN})\right]^{+}$complex 43 showing the bending of the $o$-xylene backbone and the conformation of the $\mathrm{C}_{8} \mathrm{H}_{12}$ ligand (50\% probability thermal ellipsoids). Non-coordinated pyridyl rings, the $\mathrm{BPh}_{4}$ anion and hydrogen atoms omitted for clarity. 
and forms a five-membered chelate ring when the two phosphorus atoms coordinate to a metal centre while the dpypox ligand $\mathbf{3}$ forms a seven-membered metallacycle.

Figure 3.13 also clearly shows the conformation of the $1-\kappa-4,5,6-\eta^{3}-\mathrm{C}_{8} \mathrm{H}_{12}$ ligand. The allylic system was coordinated in the usual manner with the central Ir-C bond shorter than the other two Ir-C bonds. ${ }^{149}$ The coordination of the phosphorus atoms trans to the allylic system while the pyridyl nitrogen was coordinated trans to the $\sigma$-bonded carbon was very similar to the structure of $\left[\operatorname{Ir}\left(1-\kappa-4,5,6-\eta^{3}\right.\right.$ $\left.\left.\mathrm{C}_{8} \mathrm{H}_{12}\right)(\mathrm{NCMe})\left(\mathrm{PMe}_{3}\right)_{2}\right] \mathrm{BF}_{4}$, where the $\mathrm{PMe}_{3}$ ligands are bound trans to the allylic system while the NCMe was bound trans to the $\sigma$-bonded carbon. ${ }^{150}$ The Ir-P and Ir-C bond lengths of $\left[\mathrm{Ir}\left(1-\kappa-4,5,6-\eta^{3}-\mathrm{C}_{8} \mathrm{H}_{12}\right)(\mathrm{NCMe})\left(\mathrm{PMe}_{3}\right)_{2}\right] \mathrm{BF}_{4}$ were very similar to those observed for $[\mathbf{4 3}] \mathrm{BPh}_{4}$. The $\mathrm{C}-\mathrm{C}$ bond lengths in the allylic system in compound $[43] \mathrm{BPh}_{4}$ were both $1.419(4) \AA$ which was identical to those observed in $\left[\operatorname{Ir}\left(1-\kappa-4,5,6-\eta^{3}-\mathrm{C}_{8} \mathrm{H}_{12}\right)(\mathrm{NCMe})\left(\mathrm{PMe}_{3}\right)_{2}\right] \mathrm{BF}_{4}, 1.419(5)$ and 1.414(5) $\AA .{ }^{150}$

The isomerisation of a 1,2,5,6- $\eta^{4}$-cycloocta-1,5-diene ligand bound to iridium(I) to a $\sigma$ - and $\eta^{3}$-allyl ligand bound to iridium(III) is a known reaction. ${ }^{149-157}$ Often this has been accomplished through the addition of an external oxidant such as oxygen or hydrogen peroxide. ${ }^{154-157}$ In the absence of an external oxidant or hydride source the first step of the reaction is proposed to be an allylic $\mathrm{C}-\mathrm{H}$ activation to give an $\operatorname{Ir}(\mathrm{III})$ hydride intermediate with an $\eta^{3}, \eta^{2}-\mathrm{C}_{8} \mathrm{H}_{11}$ ligand (Scheme 3.14). ${ }^{150}$ Evidence for this type of intermediate has been obtained through reaction of the $\left[\operatorname{Ir}\left(\eta^{4}-\mathrm{C}_{8} \mathrm{H}_{12}\right)(\mathrm{NCMe})\left(\mathrm{PMe}_{3}\right)\right] \mathrm{BF}_{4}$ compound with diphenylacetylene, which formed an alkenyl Ir(III) complex through the insertion of the alkyne into the Ir-H bond. ${ }^{150}$ When a substrate capable of inserting into the $\mathrm{Ir}-\mathrm{H}$ bond was not present, an intramolecular insertion of the remaining $\mathrm{C}=\mathrm{C}$ bond of the $\eta^{3}, \eta^{2}-\mathrm{C}_{8} \mathrm{H}_{11}$ ligand occurred instead to yield an $\mathrm{Ir}(\mathrm{III})$ complex with a $1-\kappa-4,5,6-\eta^{3}-\mathrm{C}_{8} \mathrm{H}_{12}$ ligand. ${ }^{150,153}$

This metal-mediated isomerisation of COD has been found to require the addition of a fifth ligand, usually acetonitrile. Initially this was thought to be necessary to stabilise the final product. ${ }^{150}$ However, further investigations have indicated that the formation of a five-coordinate intermediate favoured this reactivity, as often this reaction did not occur in the absence of the extra ligand. ${ }^{153}$ This proposed need for a fifth ligand was supported by the results observed in this work. The ligand $\mathbf{3}$ has potential fifth ligands in the form of the pyridyl rings. This would explain why the isomerisation was observed in the reaction involving ligand $\mathbf{3}$ while the analogous reaction with dppox forms the stable square planar $[\operatorname{Ir}(\mathrm{COD})(\mathrm{PP})] \mathrm{PF}_{6}$ complex. $^{73}$

Generally the COD ligand has been assumed to be inert, which has led to the use of complexes such as $[\operatorname{Ir}(\mathrm{COD})(\mu-\mathrm{Cl})]_{2}$ as precatalysts in a number of highly effective 


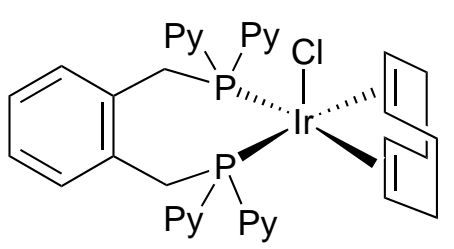

42

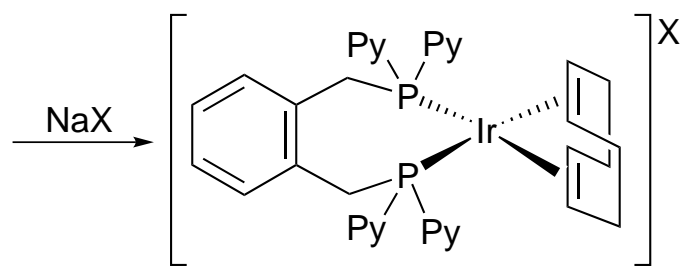<smiles>IC=[IH]</smiles>

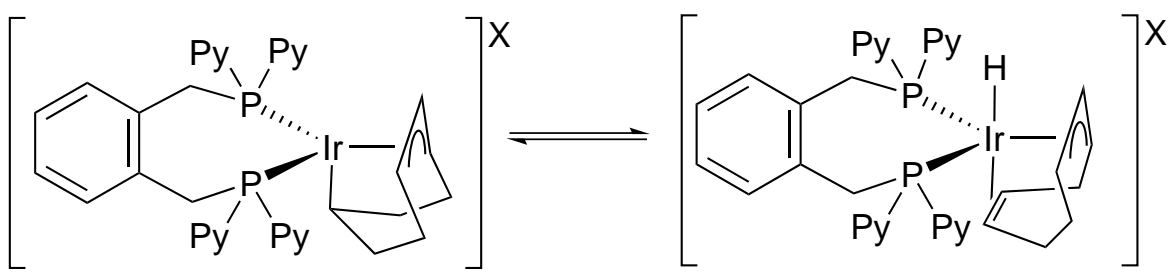

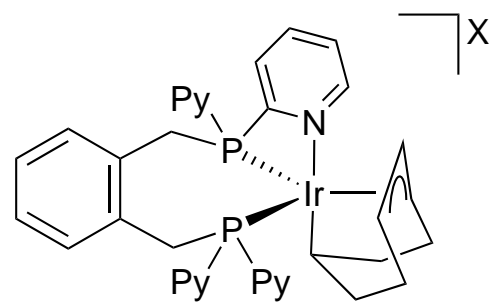

43

Scheme 3.14 Proposed mechanism for the formation of the $\left[\operatorname{Ir}\left(1-\kappa-4,5,6-\eta^{3}-\right.\right.$ $\left.\left.\mathrm{C}_{8} \mathrm{H}_{12}\right)(\mathrm{PPN})\right]^{+}$complex 43 .

organometallic catalyst systems. ${ }^{150,152}$ In these systems it has been presumed that the COD ligand dissociates from the metal centre and has no effect on the catalysis. However, these results indicate that the COD ligand may not be as innocent as it has been assumed to be.

Also, given that in the solid state one of the pyridyl nitrogens was coordinated to the iridium centre, it can be concluded that the dynamic behaviour observed in solution was in fact one of the pyridyl nitrogens coordinating to the iridium centre, then dissociating and another pyridyl nitrogen coordinating. This confirms that the pyridyl nitrogens in ligand $\mathbf{3}$ can display hemilabile behaviour, which meant that complex 43 was stable while having a vacant coordination site being formed reversibly. This behaviour would be a clear advantage in catalytic reactions.

The ability of potential ligands to displace the pyridyl nitrogen in complex 43 was investigated. When ethene was bubbled through a solution of $[43] \mathrm{CH}\left(\mathrm{SO}_{2} \mathrm{CF}_{3}\right)_{2}$ in 
chloroform or a drop of acetonitrile added no reaction occurred. However, when carbon monoxide was bubbled through a solution of $[43] \mathrm{CH}\left(\mathrm{SO}_{2} \mathrm{CF}_{3}\right)_{2}$ in chloroform, $\left[\operatorname{Ir}\left(1-\kappa-4,5,6-\eta^{3}-\mathrm{C}_{8} \mathrm{H}_{12}\right)(\mathrm{CO})(\mathrm{PP})\right] \mathrm{CH}\left(\mathrm{SO}_{2} \mathrm{CF}_{3}\right)_{2}$ compound $[44] \mathrm{CH}\left(\mathrm{SO}_{2} \mathrm{CF}_{3}\right)_{2}$ was formed (Scheme 3.15).

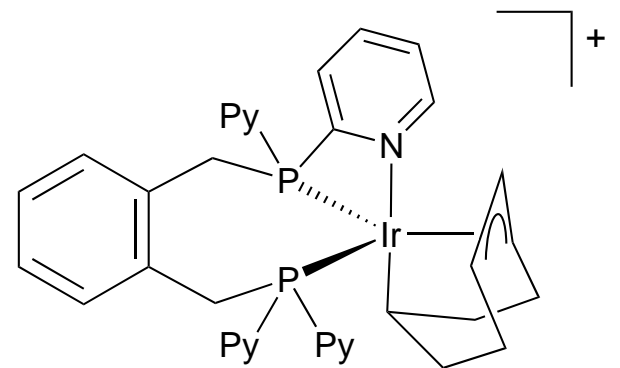

43

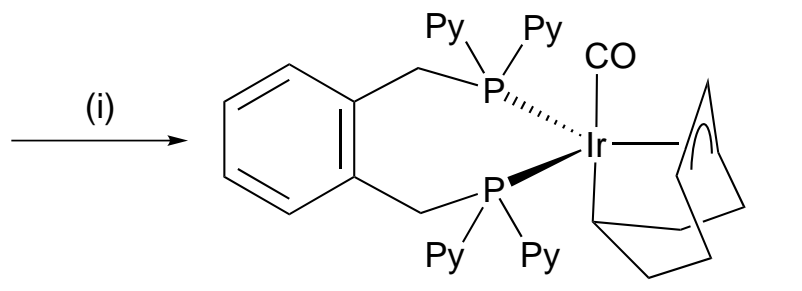

44

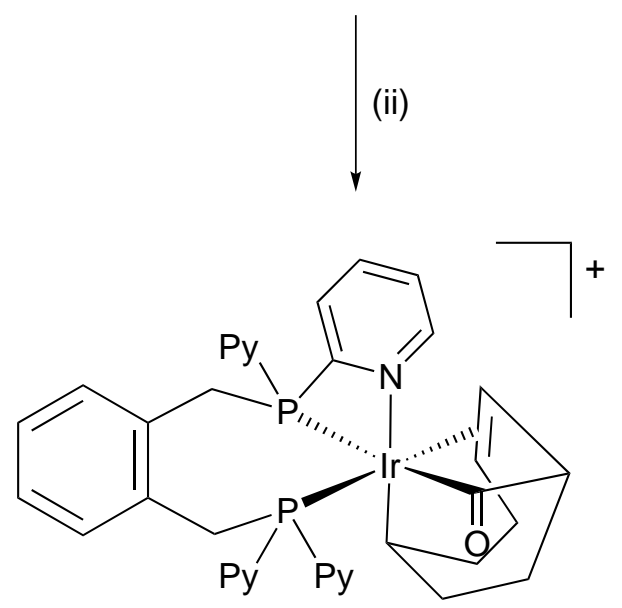

45

Scheme 3.15 Reaction of $\left[\operatorname{Ir}\left(1-\kappa-4,5,6-\eta^{3}-\mathrm{C}_{8} \mathrm{H}_{12}\right)(\mathrm{PPN})\right]^{+}$complex 43 with CO. Reagents and conditions: (i) $\mathrm{CO}_{(\mathrm{g})} 1 \mathrm{~atm}, \mathrm{CDCl}_{3}, 15 \mathrm{~min}$; (ii) 5 hours.

The ${ }^{31} \mathrm{P}$ and ${ }^{1} \mathrm{H}$ NMR spectra recorded after 15 minutes showed complete conversion to complex 44. The presence of a single peak at $-1.64 \mathrm{ppm}$ in the ${ }^{31} \mathrm{P} \mathrm{NMR}$ spectrum indicated that $\mathrm{CO}$ had displaced the pyridyl nitrogen and coordinated in the axial site. The pattern of signals in the ${ }^{1} \mathrm{H}$ NMR spectrum was consistent with the 1- $\kappa-4,5,6-\eta^{3}-\mathrm{C}_{8} \mathrm{H}_{12}$ ligand being intact in complex 44. There were eight pyridyl signals between 8.91 and $7.51 \mathrm{ppm}$. The signals for the methylene protons of ligand 3 appeared as a doublet of doublets and a triplet at 4.81 and $4.44 \mathrm{ppm}$ respectively.

However, after 5 hours at room temperature the ${ }^{31} \mathrm{P}$ NMR spectrum showed two new peaks at -10.51 and $-19.18 \mathrm{ppm}$. The peak at $-19.18 \mathrm{ppm}$ was very broad, similar to the signal observed for complex 43. This suggested that the pyridyl nitrogen atoms were once again reversibly coordinating to the iridium centre. From the combination of ${ }^{1} \mathrm{H}-{ }^{31} \mathrm{P}$ HMBC, HSQC and ${ }^{1} \mathrm{H}-{ }^{13} \mathrm{C}$ HMBC data it was concluded that either there were two very similar complexes present or the two signals in the ${ }^{31} \mathrm{P}$ NMR spectrum were due to the same compound. $\mathrm{A}{ }^{1} \mathrm{H}-{ }^{13} \mathrm{C}$ HMBC correlation 
from a methylene signal at $1.78 \mathrm{ppm}$ in the ${ }^{1} \mathrm{H}$ NMR spectrum to a ${ }^{13} \mathrm{C} \mathrm{NMR}$ signal at $171.62 \mathrm{ppm}$ suggested that the CO ligand had inserted into one of the Ir-C(allyl) bonds to give complex 45 (Scheme 3.15). This conclusion was supported by the rest of the ${ }^{1} \mathrm{H}$ NMR data for what had been the $1-\kappa-4,5,6-\eta^{3}-\mathrm{C}_{8} \mathrm{H}_{12}$ ligand. In particular, the signals at 4.89 and 4.58 ppm integrated for one proton each and there were no COSY correlations to any other possible allyl protons. This suggested that the allylic system had been disrupted and the iridium was now bound to this new ligand through a double bond and a $\sigma$-bond to what was previously the CO ligand; however, further investigation would be required to unequivocally establish the structure of complex 45. The insertion of CO into a $\mathrm{M}-\mathrm{C}$ (allyl) bond has long been known, but usually results in a monodentate ligand bonding through just the $\sigma$-bond. ${ }^{158}$

\subsection{Concluding Remarks}

The dpypox ligand $\mathbf{3}$ and dpypp ligand $\mathbf{5}$ were found to act as diphosphine ligands when reacted with platinum(II) and palladium(II) precursor complexes. VT-NMR experiments indicated that the dynamic behaviour displayed in solution by the complexes of ligand $\mathbf{3}$ was due to inversion of the $o$-xylene ligand backbone.

Reaction of the $[\mathrm{PtClMe}(\mathrm{PP})]$ complex 27 with $\mathrm{NaCH}\left(\mathrm{SO}_{2} \mathrm{CF}_{3}\right)_{2}$ did not lead to the coordination of one of the pyridyl nitrogens, which suggested that $P, P, N$ chelation may be disfavoured in a square planar complex. However, a series of unsymmetrical complexes of the type $[\mathrm{PtMeL}(\mathrm{PP})]^{+}$, where $\mathrm{L}=\mathrm{PPh}_{3}, \mathrm{PTA}, \mathrm{SEt}_{2}$ and Py, were able to be synthesised. Reaction with carbon monoxide resulted in the slow formation of the acyl complex 38 rather than a CO complex. This reactivity suggested the palladium analogue of this complex would be an active catalyst in the carbonylation of ethene.

Reaction of the dpypox ligand 3 with platinum(0) and palladium(0) precursors formed $\left[\mathrm{M}(\mathrm{PP})_{2}\right]$ complexes, where ligand 3 coordinated through the phosphorus atoms alone. These products were formed regardless of the stoichiometry of the reaction and even in the presence of excess platinum(0) or palladium(0) no evidence of the coordination of the pyridyl nitrogens nor the formation of an alkene complex was observed. A similar product, $\left[\mathrm{Ag}(\mathrm{PP})_{2}\right]^{+}$, was formed when ligand 3 was reacted with silver(I) complexes. These bis-chelate complexes all displayed dynamic behaviour in solution at room temperature. 
The reaction of dpypox ligand $\mathbf{3}$ with $[\operatorname{Ir}(\mathrm{COD})(\mu-\mathrm{Cl})]_{2}$ yielded the $[\operatorname{IrCl}(\mathrm{PP})(\mathrm{COD})]$ complex 42. However, when the chloride ligand was abstracted the pyridyl nitrogens were able to coordinate to the iridium centre, facilitating the isomerisation of the $1,2,5,6-\eta^{4}$-COD ligand to $1-\kappa-4,5,6-\eta^{3}-\mathrm{C}_{8} \mathrm{H}_{12}$ and oxidation of $\operatorname{Ir}(\mathrm{I})$ to $\operatorname{Ir}(\mathrm{III})$. The crystal structure of this complex (43) confirmed ligand $\mathbf{3}$ acted as a $P, P, N$ chelating ligand. VT-NMR experiments indicated that the pyridyl ring coordinated to the iridium centre exchanges in solution at room temperature. Reaction of complex $\mathbf{4 3}$ with carbon monoxide displaced the pyridyl nitrogen forming the carbonyl complex 44.

While the dpypox ligand $\mathbf{3}$ acted as a simple diphosphine ligand in complexes of platinum, palladium and silver, in the reactions with iridium the presence of the pyridyl rings resulted in interesting reactivity. The rare $P, P, N$ bonding mode was confirmed in complex 43, as well as evidence of ligand $\mathbf{3}$ displaying hemilabile behaviour in this complex. 


\section{Chapter 4}

\section{Complexes of dpypmx}

Ligands similar to the dpyp $m \mathrm{x}$ ligand 4 (Figure 4.1) have been reported to act as $P, P$ bridging ligands or $P, C, P$ pincer ligands. With the addition of the pyridyl rings on the phosphorus atoms, 4 is also capable of coordinating to a metal centre through the pyridyl nitrogens. Given this potentially diverse coordination chemistry the reactions of $\mathbf{4}$ with platinum and palladium complexes were explored. This chapter outlines attempts to synthesise pincer complexes of platinum and palladium and the possible intermediates formed.

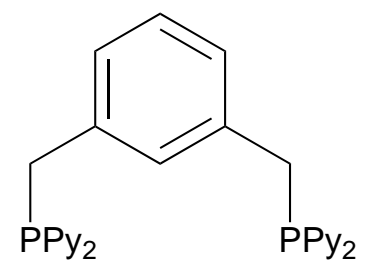

4<smiles>c1ccc(Cc2cccc(Cc3ccccc3)c2)cc1</smiles>

$\operatorname{dpp} m x$<smiles>CCCCCCc1cccc(CPC(C)(C)CC)c1</smiles>

$\operatorname{dbp} m \mathrm{x}$

Figure 4.1 PCP Pincer ligands.

Platinum pincer complexes are common in the literature due to platinum being a good model for the analogous palladium complexes. Palladium pincer complexes have received significant attention recently as they have been reported to be highly active catalysts in a range of reactions, including Suzuki and Heck cross-coupling reactions. ${ }^{74}$ The rigid pincer framework was found to reduce catalyst decomposition, with pincer complexes reported as having high thermal stability. ${ }^{74}$

Platinum(II) precursor complexes were used as a starting point for the investigation of the coordination chemistry of $\mathbf{4}$ as it has been demonstrated that pincer complexes can be obtained in moderate yields directly from platinum(II) precursors. ${ }^{97,159}$ Platinum pincer complexes were an attractive target as they were expected to be 
good starting materials for the formation of trimetallic complexes containing $\mathbf{4}$, this chemistry is discussed further in Chapter 5. As such it was necessary to develop a synthetic strategy and fully characterise these complexes before using them in further reactions.

While pincer ligands with a pyridine ring as part of the backbone are common, ${ }^{22}$ pincer ligands with pyridine rings as substituents on the phosphorus donor atoms are rare. In the reactions of pyridine backbone pincer ligands, the pyridyl nitrogen atom has been found to readily coordinate to platinum(II) and palladium(II) metal centres. ${ }^{22}$ The $P, N$ chelating mode of $\mathrm{PPh}_{2} \mathrm{Py}$ has also been observed in platinum(II) and palladium(II) complexes of this ligand. ${ }^{21}$ This indicates that platinum(II) and palladium(II) complexes of $\mathbf{4}$ are good candidates for not just pincer formation but possible $P, N$ chelation as well.

\subsection{Platinum(II) Complexes of dpyp $m x$}

The reactivity of the dpyp $m$ x ligand 4 with a series of platinum(II) complexes was investigated. The reactions were initially performed on a small scale in NMR tubes to allow the reaction progress to be monitored by NMR spectroscopy. As there has been a large amount of work in the literature on the synthesis of pincer complexes from platinum chlorides, this was the starting point for the investigation of the coordination chemistry of 4. ${ }^{159-162}$ Previous work has found that the reaction of the phenyl analogue of 4 with platinum chloride or $\left[\mathrm{PtCl}_{2}(\mathrm{NCR})_{2}\right]$ complexes resulted in the formation of a large amount of insoluble $\left[\mathrm{PtCl}_{2}(\mathrm{PCPH})\right]_{\mathrm{x}}$ polymer. ${ }^{160,161}$ The use of dichloro(cycloocta-1,5-diene)platinum and dichlorobis(diethylsulfide)platinum has been reported to decrease polymer formation. ${ }^{159,162}$ Given this, the reactions of 4 with dichloro(hexa-1,5-diene)platinum, which is similar to dichloro(cycloocta-1,5diene)platinum, and dichlorobis(diethylsulfide)platinum were investigated first.

The initial investigations into the coordination chemistry of 4 with the dichloride complexes were performed in dichloromethane- $d_{2}$, as 4 and dichloro(hexa-1,5diene)platinum were only sparingly soluble in non-polar solvents.

When one equivalent of the dpypmx ligand 4 was reacted with either of these dichloroplatinum complexes the starting materials reacted completely to form the same new platinum complex after 15 minutes at room temperature. The signal in the ${ }^{31} \mathrm{P}$ NMR spectrum appeared as a broad singlet at $20.23 \mathrm{ppm}$ with ${ }^{195} \mathrm{Pt}$ satellites, ${ }^{1} J_{\mathrm{PtP}}=3902 \mathrm{~Hz}$. This was consistent with a cis arrangement of the ligands on 
the platinum. This was concluded from comparison of the ${ }^{1} J_{\mathrm{PtP}}$ coupling constants with that observed for cis- and trans- $\left[\mathrm{PtCl}_{2}\left(\mathrm{PPh}_{3}\right)_{2}\right], 3673^{116}$ and $2630 \mathrm{~Hz}{ }^{115,163}$ respectively.

The signals due to this new complex were broad in both the ${ }^{31} \mathrm{P}$ and ${ }^{1} \mathrm{H}$ NMR spectra. The broadness of the signals could be due to a dynamic process, a slow tumbling rate of the molecules in solution (which is common for larger molecules) or anisotropic effects. ${ }^{164}$ Variable temperature NMR (VT-NMR) spectra were recorded at $20{ }^{\circ} \mathrm{C}$ intervals between 50 and $-80{ }^{\circ} \mathrm{C}$ in a $1: 1$ mixture of dichloromethane- $d_{2}$ and chloroform- $d$. There was no change in the NMR spectra recorded which does not provide any conclusive answers as to the reason for the line broadening but suggests that it was not due to dynamic behaviour in the complex. As VT-NMR did not change the appearance of the broad signals in the NMR spectra, ${ }^{1} \mathrm{H}$ and ${ }^{13} \mathrm{C}$ NMR data were not able to be assigned for this complex.

In the infrared spectrum recorded of this complex the $\nu(\mathrm{C}=\mathrm{N})$ stretch appeared at $1573 \mathrm{~cm}^{-1}$. Given this was unchanged from that observed in the free ligand, 1573 $\mathrm{cm}^{-1}$, it can be concluded that the pyridyl nitrogens were not coordinated to the platinum in this complex.

From the spectroscopic data it was known that the complex contained chloride and phosphorus ligands in a cis arrangement and that the pyridyl nitrogens were not coordinated to platinum. This meant there were two plausible options for the product of this reaction, the monometallic complex 46 or the dimeric complex 47 (Figure 4.2). This was based on the assumption that any higher oligomers would be insoluble. As there was a large amount of solid present in each of the reactions it was probable that higher oligmers were formed and were insoluble.

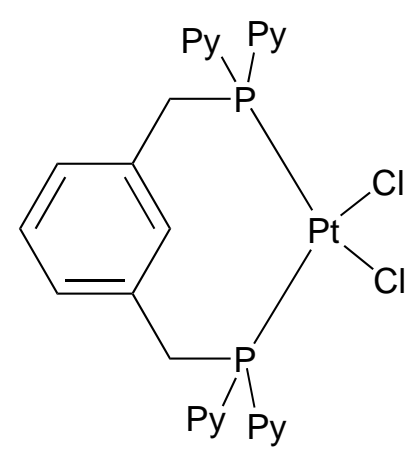

46

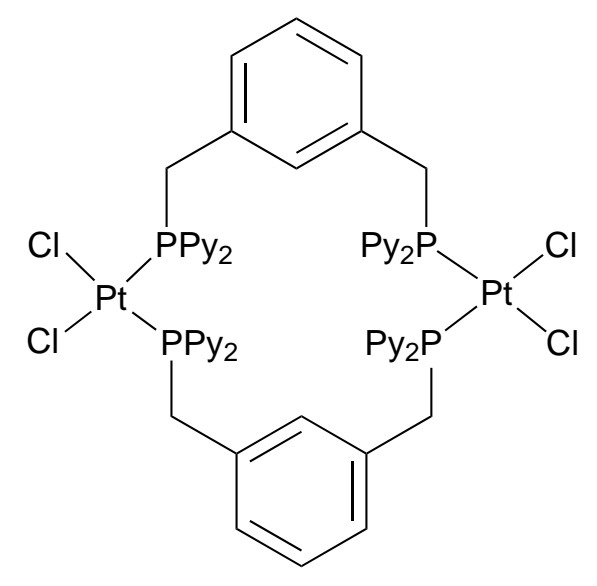

47

Figure 4.2 Two possible products from the reaction of the dpyp $m$ x ligand 4 with dichloroplatinum complexes. 
While monometallic complexes like $\mathbf{4 6}$ are often proposed as intermediates in the formation of pincer complexes ${ }^{165-167}$ they have only been isolated when the backbone was a cyclohexyl rather than an aryl ring ${ }^{168}$ or when cyclometallation was hindered by a methyl group in the place of the $\mathrm{C}-\mathrm{H}$ that is usually activated on the backbone. ${ }^{164}$ There has also been spectroscopic evidence for transient species formed at elevated temperatures that have been postulated to be cis monomers. ${ }^{75,169}$ However, it was highly unlikely that the species observed here was 46 as such structures are rarely formed at room temperature, as they are highly strained due to the formation of a rigid, eight-membered chelate ring. ${ }^{164}$ In contrast, there are many examples in the literature of dimeric complexes like $\mathbf{4 7}$ forming at room temperature, many of which have been isolated and fully characterised by NMR methods. Several crystal structures of these complexes have also been reported. ${ }^{159,164,170}$ Given this, it was most likely that the product formed in this reaction was the dimeric cis- $\left[\mathrm{PtCl}_{2}(\mu\right.$ $\mathrm{PP})]_{2}$ complex $47(\mathrm{PP}=4)$ (Scheme 4.1).

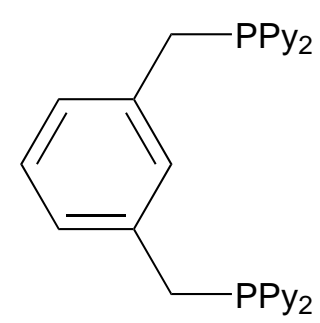

4

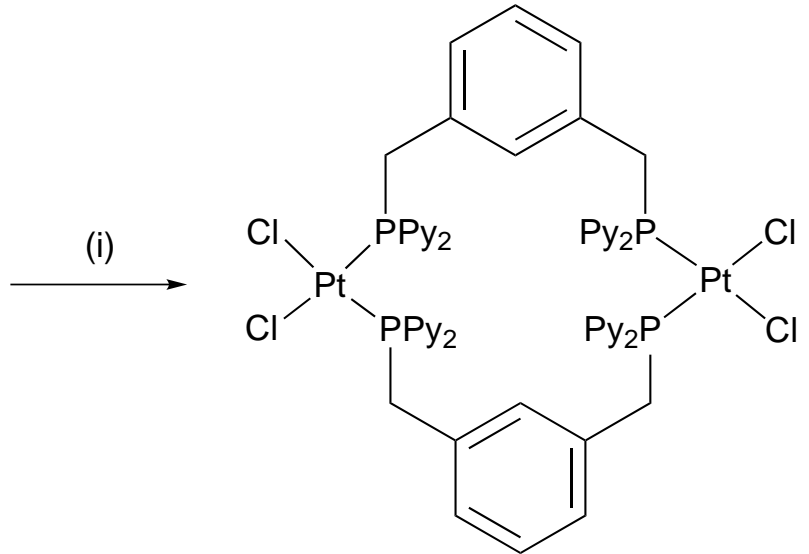

47
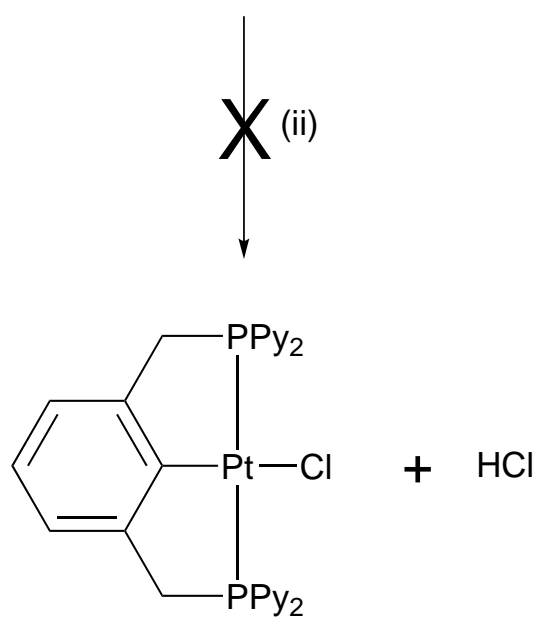

Scheme 4.1 Reaction of the dpyp $m$ x ligand 4 with dichloroplatinum complexes. Reagents and conditions: (i) Dichlorobis(diethylsulfide)platinum or dichloro(hexa1,5-diene)platinum, $\mathrm{CHCl}_{3}$; (ii) $50{ }^{\circ} \mathrm{C}, 1$ week.

The formation of a cis dimer in these reactions was interesting as both cis and trans dimers with bridging phosphine ligands of this type have been reported. ${ }^{171}$ 
When the analogous phenyl $(\operatorname{dpp} m \mathrm{x})$ and tert-butyl $(\mathrm{dbp} m \mathrm{x})$ ligands (shown in Figure 4.1) were reacted with dichloride complexes they formed cis and trans dimers respectively. ${ }^{161}$ In the case of $\operatorname{dbp} m \mathrm{x}$, the large size of the tert-butyl groups favoured the formation of a trans dimer. However, where steric effects do not dominate the formation of a cis or trans dimer depends on a series of factors. Which isomer is formed depends on a balance of antisymbiotic effects, electrostatic interactions and solvation. ${ }^{172}$

As the pyridyl rings on the phosphorus atoms are a similar size to phenyl rings, steric effects do not dominate in this system. Antisymbiotic effects arise from the different trans influences of the ligands. When two different ligands are coordinated in a trans arrangement they compete to donate into the metal bonding orbitals. This means that ligands that are high in trans influence prefer to bind trans to a weaker ligand to prevent mutual destabilisation. ${ }^{173}$ In terms of electrostatic effects an alternating arrangement of the negatively charged chloride ligands and the neutral phosphines is preferred to minimise electrostatic repulsion. ${ }^{172}$ A large contribution from antisymbiotic effects leads to the formation of the cis isomer while electrostatic effects favour the trans complex. The effect of solvation preferentially stabilises the cis isomer in polar solvents. ${ }^{172}$ This is due to complexes of the type cis- $\left[\mathrm{PtX}_{2} \mathrm{P}_{2}\right]$ possessing a net dipole while the individual dipole moments cancel out in the trans complexes. Thus a combination of antisymbiotic and solvation effects dominate in this system leading to the formation of the cis- $\left[\mathrm{PtCl}_{2}(\mu-\mathrm{PP})\right]_{2}$ complex $4 \mathbf{7}$.

The reactions were repeated first in chloroform- $d$ and then in toluene- $d_{8}$ to determine whether prolonged heating would force $\mathbf{4 7}$ to react to form a pincer complex. There was no evidence in the NMR spectra of a pincer complex formed in the reaction in chloroform after heating at $50{ }^{\circ} \mathrm{C}$ for over a week. When one equivalent of 4 was reacted with each of these dichloroplatinum complexes in toluene- $d_{8}$ no phosphorus containing species was observed in the ${ }^{31} \mathrm{P}$ NMR spectrum either at room temperature or after heating at $100{ }^{\circ} \mathrm{C}$ for one week. It was concluded that 47 would not react further (Scheme 4.1). While the lack of an observed reaction in toluene may be due to solubility issues, the fact that complex 47 does not react to form a pincer complex even after prolonged heating in chloroform could be explained by previous reports that compounds of the type cis-[MX $\left.\mathrm{MX}_{2}(\mu-\mathrm{PP})\right]_{2}$ do not cyclometallate while the corresponding trans complexes, where the $\mathrm{C}-\mathrm{H}$ bond to be activated is positioned close to the metal, react readily. ${ }^{161}$ This was further evidence that it was the dimer $\mathbf{4 7}$ formed and not the monometallic complex $\mathbf{4 6}$, since the latter would be expected to readily form the pincer complex as the $\mathrm{C}-\mathrm{H}$ bond that needs to react is already positioned close to the metal in $\mathbf{4 6}$. 
As reaction with the dichloroplatinum precursor complexes failed to give a chloropincer complex, chloromethyl(hexa-1,5-diene)platinum was reacted with the dpyp $m x$ ligand 4. It was expected that the $\mathrm{C}-\mathrm{H}$ activation required to form a pincer complex would be more facile from the chloromethyl starting material than the dichloride complexes, as the elimination of methane is more favourable than the elimination of $\mathrm{HCl} .{ }^{75}$ This reaction was carried out in dichloromethane- $d_{2}$, chloroform- $d$ and toluene- $d_{8}$. The reactions in dichloromethane- $d_{2}$ and chloroform- $d$ showed the formation of a new complex after 20 minutes at room temperature. The NMR spectra of the new complex contained broad signals similar to that observed for the dimer 47. The signal in the ${ }^{31} \mathrm{P}$ NMR spectrum appeared at $29.53 \mathrm{ppm}$ with a smaller ${ }^{1} J_{\mathrm{PtP}}$ coupling of $3070 \mathrm{~Hz}$. The observation of one signal in the ${ }^{31} \mathrm{P}$ NMR spectrum indicated the ligands were in a trans arrangement in the product. If the ligands were cis it would be expected that there would be two signals in the ${ }^{31} \mathrm{P}$ NMR spectrum. ${ }^{71,116}$ The observed ${ }^{1} J_{\mathrm{PtP}}$ coupling was also consistent with the coupling constant observed for trans-[PtClMe $\left.\left(\mathrm{PPh}_{3}\right)_{2}\right], 3147 \mathrm{~Hz} .{ }^{115}$

The infrared spectrum recorded of this complex was almost identical to that recorded of 47. The $\nu(\mathrm{C}=\mathrm{N})$ stretch appeared at $1573 \mathrm{~cm}^{-1}$, indicating that the pyridyl nitrogens were not bound to the platinum in this complex.

Based on this information it was concluded that this complex was likely to be the trans- $[\mathrm{PtClMe}(\mu-\mathrm{PP})]_{2}$ complex $48(\mathrm{PP}=4)$ (Scheme 4.2). Once again in this reaction there was an insoluble material present which was assumed to be an oligomer of the type trans- $[\mathrm{PtClMe}(\mu-\mathrm{PP})]_{\mathrm{x}} \cdot{ }^{166}$

It was not surprising that the trans- $[\mathrm{PtClMe}(\mu-\mathrm{PP})]_{2}$ complex 48 was formed while reaction with dichloride precursor complexes led to a cis complex. In this system both the antisymbiotic effects and the electrostatic effects would favour the formation of the trans dimer. The strong trans influence of the methyl ligand meant that it prefers to coordinate trans to the ligand with the lowest trans influence, the chloride ligand. The stabilisation achieved from the trans coordination of the methyl and chloride ligands and the alternating of the negatively charged ligands with the neutral phosphine ligands would make the mutual trans coordination of the phosphines favourable.

VT-NMR spectra were also recorded of this complex at $20{ }^{\circ} \mathrm{C}$ intervals between 50 and $-80{ }^{\circ} \mathrm{C}$ in a $1: 1$ mixture of dichloromethane- $d_{2}$ and chloroform- $d$. Once again there was no change in the NMR spectra recorded.

After heating complex 48 at $40{ }^{\circ} \mathrm{C}$ for four days in dichloromethane- $d_{2}$, 16 hours 


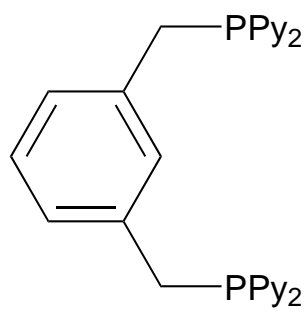

4 (i)

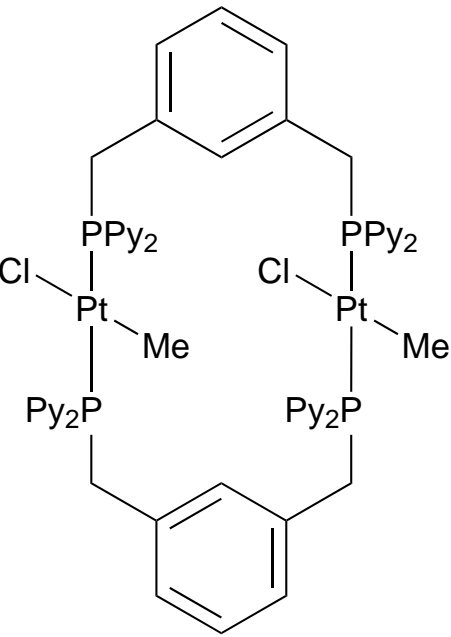

48

(ii)

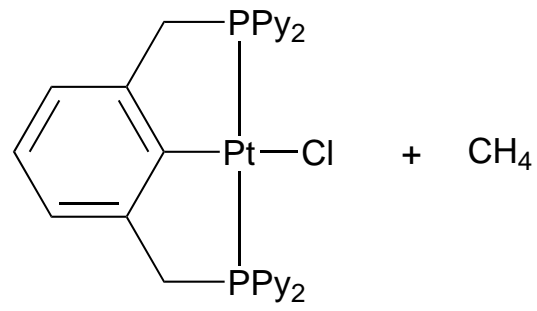

49

Scheme 4.2 Reaction of the dpyp $m x$ ligand 4 with chloromethyl(hexa1,5-diene)platinum. Reagents and conditions: (i) Chloromethyl(hexa-1,5diene)platinum, $\mathrm{CHCl}_{3}$; (ii) $50{ }^{\circ} \mathrm{C}, 16$ hours.

at $50{ }^{\circ} \mathrm{C}$ in chloroform- $d$ and 16 hours at $100{ }^{\circ} \mathrm{C}$ in toluene- $d_{8}$ formation of the $[\mathrm{PtCl}(\mathrm{PCP})]$ complex $49(\mathrm{PCP}=4)$ was observed in all of the NMR spectra. The ${ }^{31} \mathrm{P}$ and ${ }^{1} \mathrm{H}$ NMR spectra of complex 49 in $\mathrm{CDCl}_{3}$ are shown in Figure 4.3. The signal in the ${ }^{31} \mathrm{P}$ NMR spectrum appeared as a sharp singlet at $38.1 \mathrm{ppm}$ with platinum-195 satellites, ${ }^{1} J_{\mathrm{PtP}}=2916 \mathrm{~Hz}$. In the ${ }^{1} \mathrm{H}$ NMR spectra there was a virtual triplet at $4.47 \mathrm{ppm}$ due to the methylene protons, ${ }^{2} J_{\mathrm{PH}}+{ }^{4} J_{\mathrm{PH}}=5.8 \mathrm{~Hz}$. This triplet is characteristic of complexes of this type with strong phosphorus-phosphorus coupling between trans phosphorus donor atoms that are magnetically equivalent. ${ }^{160}$ The signals for the pyridyl protons now appear at $8.72-7.28 \mathrm{ppm}$. These have shifted downfield compared to the signals of the free ligand 4 . This was consistent with what was observed in complexes of the dpypox (3) and dpypp (5) ligands. The protons on the backbone appeared as a doublet and a triplet in the ${ }^{1} \mathrm{H}$ NMR spectrum, coupling to each other, at 7.15 and $7.03 \mathrm{ppm}\left({ }^{3} J_{\mathrm{HH}}=7.4 \mathrm{~Hz}\right)$. This was also shifted to higher ppm than in the free ligand. While the pattern of the signals in the ${ }^{1} \mathrm{H}$ NMR spectrum was consistent with what was observed for the analogous diphenylphos- 
phino complex, the signals for 49 all appeared at higher chemical shifts. ${ }^{161,174}$ The formation of methane during the reaction was also observed in the ${ }^{1} \mathrm{H}$ NMR spectra of the reaction mixtures. When the reaction was repeated on a larger scale it was performed in chloroform as all of the starting materials were soluble and heating at $50{ }^{\circ} \mathrm{C}$ for 16 hours was sufficient to give the desired pincer complex in a $50 \%$ yield (Scheme 4.2).

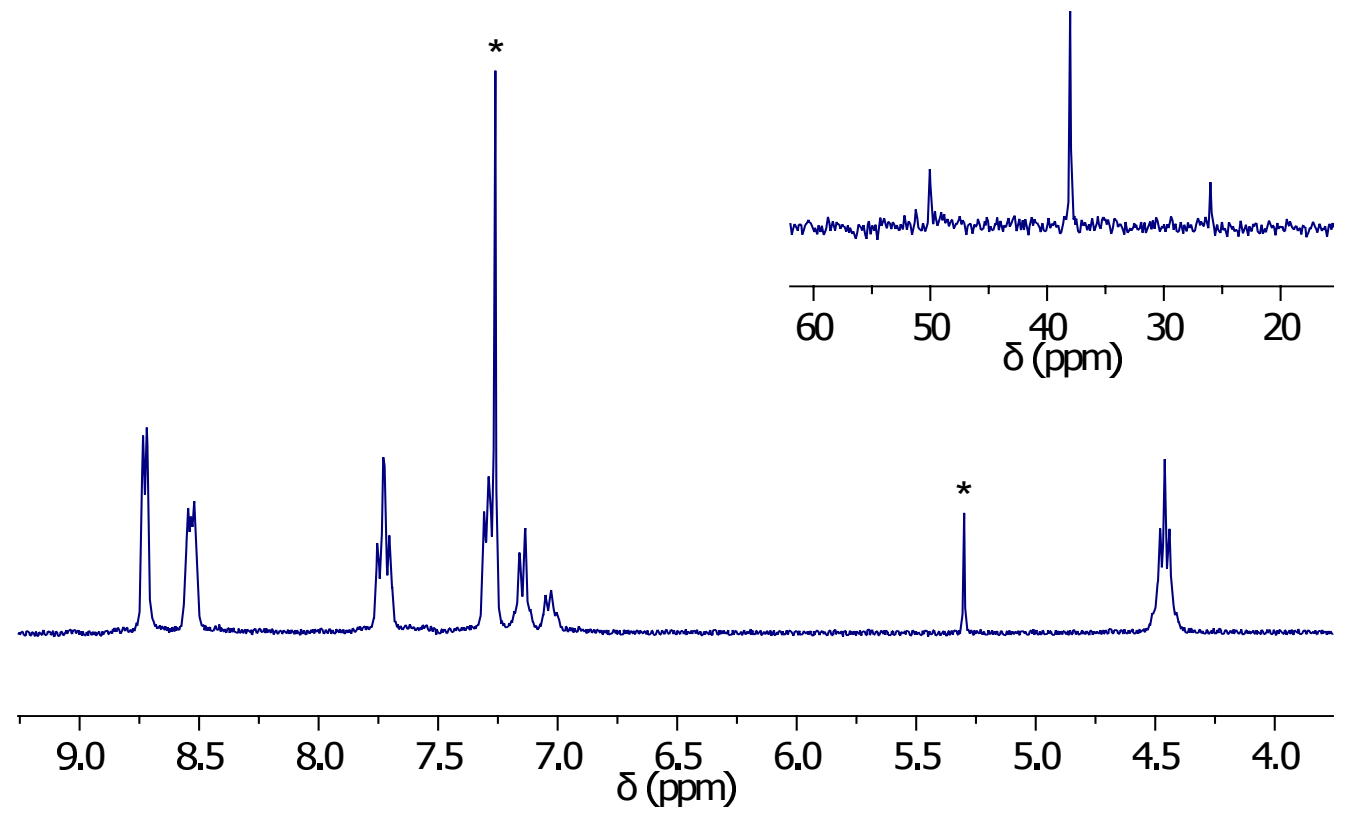

Figure 4.3 ${ }^{31} \mathrm{P}$ (inset) and ${ }^{1} \mathrm{H}$ NMR spectra of $[\mathrm{PtCl}(\mathrm{PCP})]$ complex 49 in $\mathrm{CDCl}_{3}$. Asterisks denote solvent signals.

Next, the $[\mathrm{PtCl}(\mathrm{PCP})]$ complex 49 was reacted with one equivalent of the sodium salt $\mathrm{NaCH}\left(\mathrm{SO}_{2} \mathrm{CF}_{3}\right)_{2}$. It was predicted that when the chloride ligand was abstracted the pyridyl nitrogen atoms may coordinate to the platinum centre. However, this was not the case. Instead, an intractable mixture of products was formed.

Often pyridyl substituents are included in the design of phosphine ligands to impart water-solubility to the ligands and thus the complexes formed with those ligands. ${ }^{23}$ While ligand 4 was determined to be insoluble in water in Chapter 2, it was found that protonation of 4 rendered it soluble in water. Thus the protonation of the $[\mathrm{PtCl}(\mathrm{PCP})]$ complex 49 was investigated as a means to impart water-solubility to complex 49. However, complex 49 was not soluble in water once it was protonated. When 49 was reacted with $4 \mathrm{M} \mathrm{DCl}$ in $\mathrm{D}_{2} \mathrm{O}$ the only species observed in the NMR spectra was fully protonated 4 .

After the successful formation of $\mathbf{4 9}$ from chloromethyl(hexa-1,5-diene)platinum, the dpyp $m$ x ligand 4 was reacted with dimethyl(hexa-1,5-diene)platinum. The formation of platinum pincer complexes from dimethyl(cycloocta-1,5-diene)platinum has been reported. ${ }^{170}$ When the reaction was carried out in either dichloromethane- $d_{2}$ or chloroform- $d$ at room temperature a new complex was formed after 15 minutes. 
The ${ }^{31} \mathrm{P}$ NMR spectrum in $\mathrm{CDCl}_{3}$ showed a broad singlet at $30.99 \mathrm{ppm}$ with a ${ }^{1} J_{\mathrm{PtP}}$ coupling of $1922 \mathrm{~Hz}$. The ${ }^{1} \mathrm{H}$ NMR spectrum also contained broad signals indicating the new complex was similar to the dimers 47 and 48 , formed initially in the above reactions. The chemical shift in the ${ }^{31} \mathrm{P}$ NMR spectrum and the value of ${ }^{1} J_{\mathrm{PtP}}$ were consistent with a cis arrangement of the ligands, suggesting this complex was the cis- $\left[\mathrm{PtMe}_{2}(\mu-\mathrm{PP})\right]_{2}$ complex $50(\mathrm{PP}=\mathbf{4})$ (Scheme 4.3). ${ }^{16,116}$ The infrared spectrum recorded of this complex was similar to that of dimers 47 and 48 with the $\nu(\mathrm{C}=\mathrm{N})$ stretch at $1573 \mathrm{~cm}^{-1}$, confirming the pyridyl nitrogens were not coordinated to the platinum in this complex.

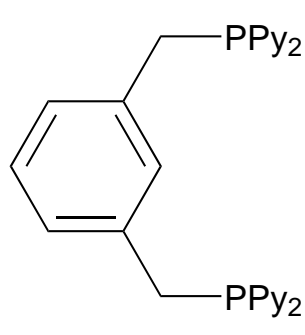

4

\section{(i)}

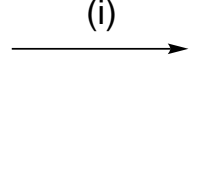

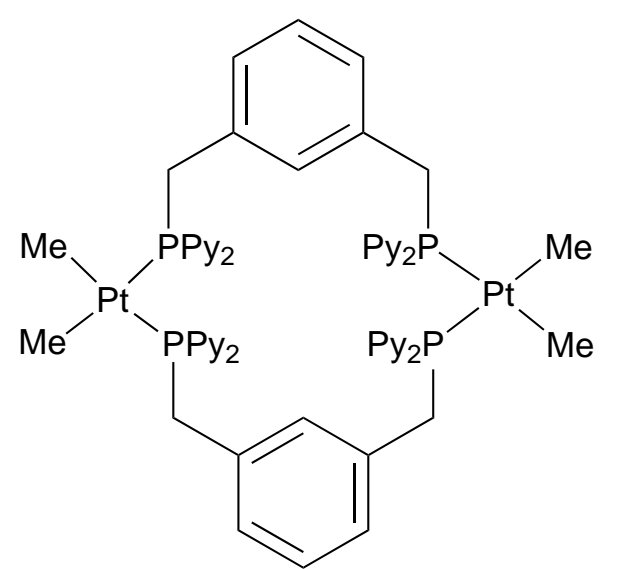

50

(ii)

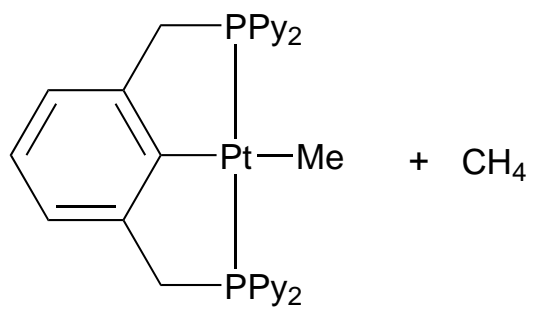

51

Scheme 4.3 Reaction of the dpypmx ligand 4 with dimethyl(hexa-1,5diene)platinum. Reagents and conditions: (i) Dimethyl(hexa-1,5-diene)platinum, $\mathrm{CHCl}_{3}$; (ii) $50{ }^{\circ} \mathrm{C}, 48$ hours.

The cis geometry of this dimer, $\mathbf{5 0}$, was a result of antisymbiotic effects dominating again, with the strong trans influence of the methyl ligands requiring that they coordinate trans to the phosphine ligands, which are lower in trans influence. ${ }^{16}$ It was also likely that the polar nature of dichloromethane and chloroform also favours the formation of this cis complex.

It was interesting to note that this was the only reaction where there was no solid 
formed when the reactants were mixed. This suggested that no higher oligomers were formed at room temperature. As with the other dimers, VT-NMR spectra were recorded between 50 and $-80{ }^{\circ} \mathrm{C}$ and no change in the NMR spectra was observed.

Heating a solution of $\mathbf{5 0}$ in either chloroform- $d$ or toluene- $d_{8}$ for 16 hours resulted in the formation of the desired $[\mathrm{PtMe}(\mathrm{PCP})]$ complex 51 (PCP = 4) (Scheme 4.3). The ${ }^{31} \mathrm{P}$ NMR spectrum of $\mathbf{5 1}$ in $\mathrm{CDCl}_{3}$ contained one singlet at $38.34 \mathrm{ppm}$ with platinum-195 satellites, ${ }^{1} J_{\mathrm{PtP}}=2969 \mathrm{~Hz}$. This was consistent with the NMR data of the analogous diphenylphosphino pincer complex. ${ }^{165}$

The signals for the pyridyl protons in the ${ }^{1} \mathrm{H}$ NMR spectrum of complex 51 were shifted downfield from the free ligand 4 and now appeared at $8.72-7.28 \mathrm{ppm}$. These signals were almost identical to those observed in the ${ }^{1} \mathrm{H}$ NMR spectrum of the $[\mathrm{PtCl}(\mathrm{PCP})]$ complex 49. The signals for the protons on the ligand backbone were also essentially identical to those observed for complex 49, appearing as a doublet at $7.15 \mathrm{ppm}$ and a triplet at $7.03 \mathrm{ppm}\left({ }^{3} J_{\mathrm{HH}}=7.5 \mathrm{~Hz}\right)$. The signal for the methylene protons appeared as a virtual triplet at $4.46 \mathrm{ppm}\left({ }^{2} J_{\mathrm{PH}}+{ }^{4} J_{\mathrm{PH}}=5.9 \mathrm{~Hz}\right)$, confirming the formation of a pincer complex. The signal for the methyl ligand in the ${ }^{1} \mathrm{H}$ NMR spectrum appeared as a singlet at $0.48 \mathrm{ppm}$ with ${ }^{195} \mathrm{Pt}$ satellites, ${ }^{2} J_{\mathrm{PtH}}=75.2 \mathrm{~Hz}$, and in the ${ }^{13} \mathrm{C}$ NMR spectrum it also appeared as a singlet with ${ }^{195} \mathrm{Pt}$ satellites at $-4.72 \mathrm{ppm},{ }^{1} J_{\mathrm{PtC}}=690 \mathrm{~Hz}$.

The infrared spectrum of complex 51 contained $\mathrm{C}=\mathrm{N}$ stretches at 1573 and 1563 $\mathrm{cm}^{-1}$. As these were not shifted from the free ligand they indicated that, as expected, the pyridyl nitrogens were not coordinated to a metal centre in this complex. ${ }^{40,107,134-136}$

The ${ }^{31} \mathrm{P}$ NMR data of the dimeric and pincer complexes of ligand 4 are shown in Table 4.1. When the values of ${ }^{1} J_{\mathrm{PtP}}$ of the various complexes were compared it was observed that the ${ }^{1} J_{\mathrm{PtP}}$ coupling in the dimeric complexes varied greatly. This was due to the large differences in the trans influence of the ligands coordinated trans to the phosphorus donor atoms. In contrast, there was a difference of less than $60 \mathrm{~Hz}$ in the ${ }^{1} J_{\mathrm{PtP}}$ values of the pincer complexes 49 and 51. As the pincer core was the same in both complexes this difference was due to the difference in the cis influence of a methyl ligand compared to a chloride ligand. As methyl ligands have a low cis influence the ${ }^{1} J_{\mathrm{PtP}}$ value was slightly higher in $\mathbf{5 1}$ than $\mathbf{4 9}$, where the chloride ligand has a high cis influence. ${ }^{115,119}$ This was consistent with literature reports that while the trans influence has a more marked effect on the ${ }^{1} J_{\mathrm{PtP}}$ coupling constant, the cis influence is still important in rationalising ${ }^{1} J_{\mathrm{PtP}}$ values. ${ }^{116}$ 
Table 4.1 ${ }^{31} \mathrm{P}$ NMR data of the platinum and palladium complexes of dpyp $m \mathrm{x}$

\begin{tabular}{|c|c|c|c|}
\hline Formula & Complex & $\delta^{31} \mathrm{P} / \mathrm{ppm}^{a}$ & ${ }^{1} J_{\mathrm{PtP}} / \mathrm{Hz}$. \\
\hline cis- $\left[\mathrm{PtCl}_{2}(\mathrm{PP})\right]_{2}$ & 47 & 20.23 & 3902 \\
\hline trans $-[\mathrm{PtClMe}(\mathrm{PP})]_{2}$ & 48 & 29.53 & 3070 \\
\hline cis- $\left[\mathrm{PtMe}_{2}(\mathrm{PP})\right]_{2}$ & 50 & 30.99 & 1922 \\
\hline cis- $\left[\mathrm{PdCl}{ }_{2}(\mathrm{PP})\right]_{2}$ & 52 & 41.11 & $\mathrm{n} / \mathrm{a}$ \\
\hline$[\mathrm{PtCl}(\mathrm{PCP})]$ & 49 & 38.03 & 2916 \\
\hline$[\mathrm{PtMe}(\mathrm{PCP})]$ & 51 & 38.34 & 2969 \\
\hline$[\mathrm{PdCl}(\mathrm{PCP})]$ & 53 & 39.71 & $\mathrm{n} / \mathrm{a}$ \\
\hline
\end{tabular}

${ }^{a}$ Spectra recorded in $\mathrm{CDCl}_{3}$.

\subsection{Palladium(II) Complexes of dpyp $m x$}

While complexes of the type $\left[\mathrm{PtCl}_{2}(\mathrm{NCR})_{2}\right]$ have been reported to have a tendency to form oligomers in reactions with pincer ligands, $\left[\mathrm{PdCl}_{2}(\mathrm{NCMe})_{2}\right]$ has been found to be a useful starting material in the synthesis of chloropalladium pincer complexes. ${ }^{174}$ As with the platinum reactions, the reaction of the dpyp $m$ x ligand 4 with one equivalent of dichlorobis(acetonitrile)palladium was investigated in dichloromethane- $d_{2}$, chloroform- $d$ and toluene- $d_{8}$.

In both dichloromethane- $d_{2}$ and chloroform- $d$ the initial formation of an intermediate was observed in the ${ }^{31} \mathrm{P}$ NMR spectra, with a broad signal at $41.1 \mathrm{ppm}$. Similar to the NMR spectra of the intermediate dimers formed in the platinum reactions, the signals in the ${ }^{1} \mathrm{H}$ NMR spectra were broad, which meant that this complex could not be characterised further by NMR spectroscopy. Due to the similarities between the NMR spectra of this product and those of complex 47 it was concluded that it was highly probable that this complex was the $c i s-\left[\mathrm{PdCl}_{2}(\mu-\mathrm{PP})\right]_{2}$ complex $\mathbf{5 2}(\mathrm{PP}$ $=4)$.

Heating the reaction mixture for six days at $30{ }^{\circ} \mathrm{C}$ in dichloromethane- $d_{2}$, 40 hours at $50{ }^{\circ} \mathrm{C}$ in chloroform- $d$ or 16 hours at $90{ }^{\circ} \mathrm{C}$ in toluene- $d_{8}$ all resulted in the formation of the $[\mathrm{PdCl}(\mathrm{PCP})]$ complex $53(\mathrm{PCP}=\mathbf{4})$. The highest yield was obtained from the reaction in chloroform. Thus, as with the other pincer complexes, when the reaction was carried out on a macroscale it was performed in chloroform and after 40 hours at $50{ }^{\circ} \mathrm{C}$ the ${ }^{31} \mathrm{P}$ and ${ }^{1} \mathrm{H}$ NMR spectra showed complete conversion of complex 52 to the $[\mathrm{PdCl}(\mathrm{PCP})]$ complex 53 (Scheme 4.4).

The signal for the $[\mathrm{PdCl}(\mathrm{PCP})]$ complex 53 in the ${ }^{31} \mathrm{P}$ NMR spectrum appeared as a singlet at $39.71 \mathrm{ppm}$. In the ${ }^{1} \mathrm{H}$ NMR spectrum the characteristic virtual triplet for the methylene protons appeared at $4.53 \mathrm{ppm}\left({ }^{2} J_{\mathrm{PH}}+{ }^{4} J_{\mathrm{PH}}=5.8 \mathrm{~Hz}\right)$. The 

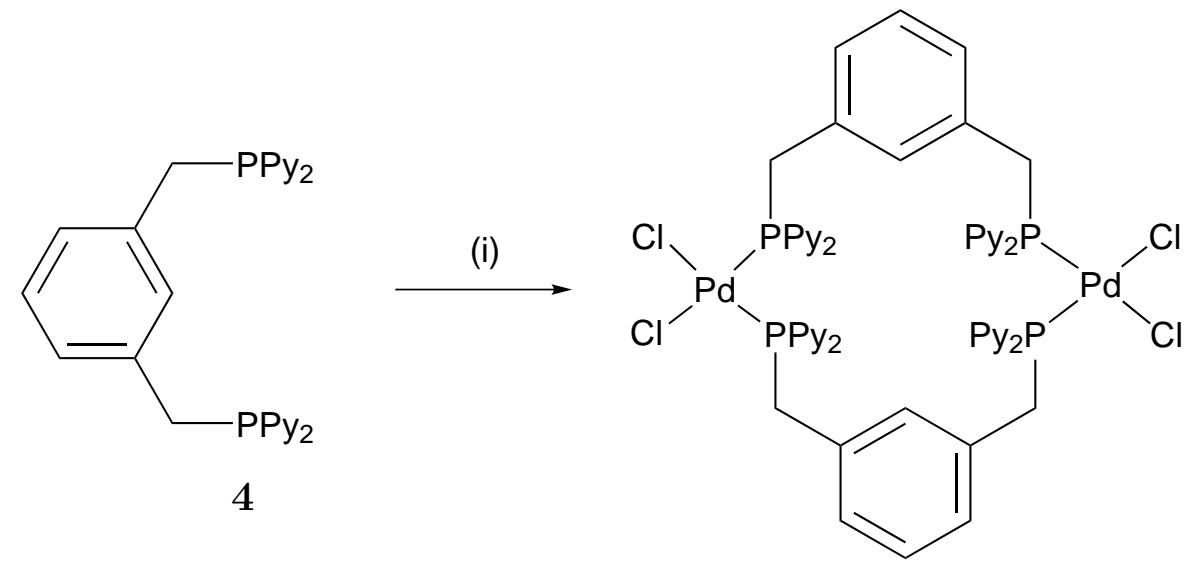

52

(ii)

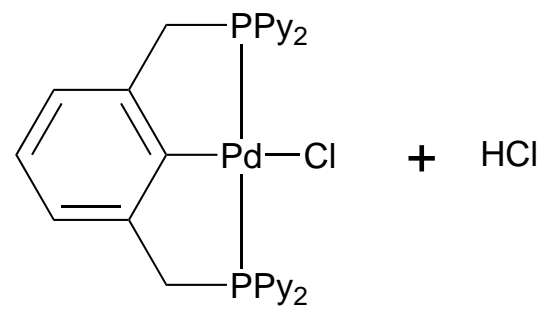

53

Scheme 4.4 Reaction of the dpypmx ligand 4 with dichlorobis(acetonitrile)palladium. Reagents and conditions: (i) Dichlorobis(acetonitrile)palladium, $\mathrm{CDCl}_{3}$; (ii) $50{ }^{\circ} \mathrm{C}, 40$ hours.

signals for the pyridyl protons appeared at 8.69-7.32 ppm, downfield from those in the free ligand 4 . The signals of the protons on the aromatic backbone of the ligand appeared as a doublet at 7.16 and a triplet at $7.03 \mathrm{ppm}$ with a ${ }^{3} J_{\mathrm{HH}}$ value of 7.5 $\mathrm{Hz}$.

Overall the ${ }^{1} \mathrm{H}$ and ${ }^{13} \mathrm{C}$ NMR data of the three pincer complexes 49, 51 and 53 were very similar.

\subsection{Concluding Remarks}

The reaction of the dpyp $m \mathrm{x}$ ligand 4 with platinum(II) precursor complexes resulted in the immediate formation of dimeric $[\mathrm{PtXY}(\mu-\mathrm{PP})]_{2}$ complexes at room temper- 
ature $(\mathrm{X}=\mathrm{Y}=\mathrm{Cl}, \mathrm{Me}, \mathrm{X}=\mathrm{Cl} \mathrm{Y}=\mathrm{Me})$. The NMR signals of these complexes were broad at room temperature and did not change when the NMR spectra were recorded between -80 and $40{ }^{\circ} \mathrm{C}$.

Whether the cis or trans isomer of the dimeric complexes formed depended upon a combination of antisymbiotic effects, electrostatic interactions and the effect of solvation. When $\mathrm{X}=\mathrm{Y}=\mathrm{Cl}$ or $\mathrm{Me}$ a combination of antisymbiotic and solvation effects dominated and the cis dimer was formed. In contrast, when $\mathrm{X}=\mathrm{Cl}$ and $\mathrm{Y}=$ Me the trans isomer was formed due to the methyl ligands preferring to bind trans to the chloride ligands.

The dimeric complexes were heated to promote pincer complex formation. While the cis- $\left[\mathrm{PtCl}_{2}(\mu-\mathrm{PP})\right]_{2}$ complex 47 did not form the desired $[\mathrm{PtCl}(\mathrm{PCP})]$ complex, both the trans- $[\mathrm{PtClMe}(\mu-\mathrm{PP})]_{2}$ complex 48 and the $c i s-\left[\mathrm{PtMe}_{2}(\mu-\mathrm{PP})\right]_{2}$ complex 50 reacted to form pincer complexes. The ${ }^{31} \mathrm{P},{ }^{1} \mathrm{H}$ and ${ }^{13} \mathrm{C}$ NMR data of the $[\mathrm{PtCl}(\mathrm{PCP})]$ complex 49 and [PtMe(PCP)] complex 51 were very similar, showing the characteristic virtual triplet for the methylene protons in the ${ }^{1} \mathrm{H}$ NMR spectra and a ${ }^{1} J_{\mathrm{PtP}}$ coupling constant typical of phosphorus atoms coordinated in a trans arrangement.

In contrast to the reactions with platinum(II) dichloride complexes, while the reaction of ligand $\mathbf{4}$ with dichlorobis(acetonitrile)palladium formed the dimer $\mathbf{5 2}$, it readily reacted to form the $[\mathrm{PdCl}(\mathrm{PCP})]$ complex 53. The $\mathrm{NMR}$ data of 53 was very similar to the other pincer complexes.

Thus the dpyp $m$ x ligand 4 acted as a bridging $P, P$ ligand and a pincer $P, C, P$ ligand when reacted with platinum(II) and palladium(II) precursor complexes. 


\section{Chapter 5}

\section{Trimetallic Complexes}

In contrast to Chapters 3 and 4 , this chapter discusses attempts to coordinate the pyridyl nitrogen atoms of the dpypox ligand $\mathbf{3}$ and the dpypmx ligand $\mathbf{4}$ to different metals than the phosphorus atoms are coordinated to, i.e. to make homotrimetallic and heterotrimetallic complexes.

The widely studied (2-pyridyl)diphenylphosphine, $\mathrm{PPh}_{2} \mathrm{Py}$, has been used extensively in the synthesis of multimetallic complexes. ${ }^{21,22,39,41,43}$ This is due to the small bite angle of this ligand favouring the formation of $\mathrm{M}-\mathrm{M}$ bonds and the combination of the soft phosphorus and the hard nitrogen donor atoms leading to the selective binding of both hard and soft metal centres. While the related ligands $\mathrm{PPhPy}_{2}$ and $\mathrm{PPy}_{3}$ have received less attention they have also been found to be capable of forming interesting bimetallic complexes, such as the zwitterionic complex $\left[\left(\mathrm{C}_{6} \mathrm{~F}_{5}\right)_{3} \mathrm{Pt}(\mu\right.$ $\left.\left.\mathrm{PPhPy}_{2}\right) \mathrm{Rh}(\mathrm{COD})\right]$, where the phosphorus is bound to the platinum metal while the two pyridyl nitrogen atoms are bound to the rhodium metal centre. ${ }^{47,48}$

In contrast, multimetallic complexes of diphosphines with pyridyl substituents are rare. ${ }^{65}$ There are two distinct classes of pyridyldiphosphine, those where the pyridine moiety is part of the backbone and those where the pyridine rings are substituents on the phosphorus. Of these two groups there have been considerably more reports of the former bridging two or three metal centres. ${ }^{20,22}$ While ligands such as dpype and dpypcp, which belong to the latter type of pyridyldiphosphines, are potentially hexadentate ligands, there are very few reports where they act as such. However, when they do act as hexadentate ligands interesting complexes like the paddlewheel complex $\left[\mathrm{Pt}_{2}(\text { dpype })_{2} \mathrm{Ag}_{4}\left(\mathrm{NO}_{3}\right)_{8}\left(\mathrm{H}_{2} \mathrm{O}\right)_{2}\right]_{\mathrm{x}}$ result (shown in Scheme 1.9). ${ }^{66}$ In this complex the two phosphorus atoms of one dpype ligand coordinate to one platinum while one pyridyl ring on each phosphorus coordinates to the other platinum (which 
is also coordinated to the phosphorus atoms of the other ligand) and the final two pyridyl rings coordinate to two different silver atoms forming a coordination polymer.

In the crystal structures of the monometallic $\left[\mathrm{MCl}_{2}(\mathrm{PP})\right](\mathrm{M}=\mathrm{Pt} \mathbf{1 6}, \mathrm{Pd} \mathbf{2 0})$ and $[\mathrm{PtClMe}(\mathrm{PP})] \mathbf{2 7}$ discussed in Chapter 3 the pyridyl rings point in the same direction, away from the coordination sphere of the metal atom. Thus in the solid state it appeared as though the pyridyl rings were already set up to bind to a metal centre. From the conformation of ligand $\mathbf{3}$ observed in the crystal structures it was concluded that if metal atoms were to coordinate to the pyridyl nitrogens they would coordinate to the two pyridyl rings attached to one phosphorus atom on either side of the complex. Given this, the pyridyl rings in the monometallic complexes can be thought of as similar to bipyridine ligands, which have a rich coordination chemistry. ${ }^{137}$

\subsection{Homotrimetallic Complexes of dpypox}

In a similar manner to the investigation of the monometallic complexes of these ligands, initial reactions investigating the ability of pyridyl nitrogen atoms in the dpypox ligand 3 to coordinate to metal atoms were carried out with platinum(II) and palladium(II) precursor complexes. This was because, apart from being easily handled, when these metals are in the $2+$ oxidation state they coordinate pyridine ligands in a straightforward and predictable way. ${ }^{137}$ The platinum complexes were particularly attractive starting materials as there was the potential for ${ }^{195} \mathrm{Pt}$ satellites to be observed in the NMR spectra of the products. Two sets of ${ }^{195} \mathrm{Pt}$ satellites were observed in the ${ }^{31} \mathrm{P}$ NMR spectra of diplatinum complexes of $\mathrm{PPh}_{2} \mathrm{Py}^{41,43}$ and the paddlewheel complex of dpype discussed above. ${ }^{66}$ This would provide a clear indication of whether a platinum centre has coordinated to the pyridyl nitrogen atoms.

Initial attempts to form trimetallic complexes involved the reaction of the dpypox ligand 3 with three equivalents of a precursor metal complex. When three equivalents of dimethyl(hexa-1,5-diene)platinum were reacted with the ligand $\mathbf{3}$ the progress of the reaction was followed by ${ }^{31} \mathrm{P}$ and ${ }^{1} \mathrm{H}$ NMR methods. The initial ${ }^{31} \mathrm{P}$ and ${ }^{1} \mathrm{H}$ NMR spectra recorded of this reaction mixture after 20 minutes showed formation of the monometallic $\left[\mathrm{PtMe}_{2}(\mathrm{PP})\right]$ complex 17 (Figure 5.1(top)). After 24 hours there were three new signals with platinum-195 satellites present in the ${ }^{31} \mathrm{P}$ NMR spectrum (Figure 5.1(middle)). The two new doublets at 13.31 and $25.50 \mathrm{ppm}\left({ }^{2} J_{\mathrm{PP}}=\right.$ 
$10.5 \mathrm{~Hz})$ were due to the intermediate dimetallic $\left[\left(\mathrm{PtMe}_{2}\right)_{2}(\mathrm{PP})\right]$ complex 54, where the pyridyl nitrogens on one side of the molecule were coordinated to a dimethylplatinum moeity while the pyridyl nitrogens on the other side of the molecule were still free (Scheme 5.1). While the doublet at $13.31 \mathrm{ppm}$ had one set of platinum-195 satellites $\left({ }^{1} J_{\mathrm{PtP}}=1828 \mathrm{~Hz}\right)$, the doublet at $25.50 \mathrm{ppm}$ had two sets of platinum-195 satellites $\left({ }^{1} J_{\mathrm{PtP}}=2019,{ }^{3} J_{\mathrm{PtP}}=79.4 \mathrm{~Hz}\right)$. This indicated that the latter signal was due to the phosphorus atom attached to the pyridyl rings that were coordinated to platinum. There was also a signal at $27.11 \mathrm{ppm}$ with two sets of platinum satellites, assumed to be due to the trimetallic complex.<smiles>[R20]#[R20]Cc1ccccc1CP</smiles>

3 (i)

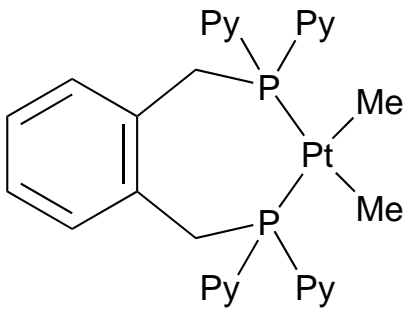

17

(ii)

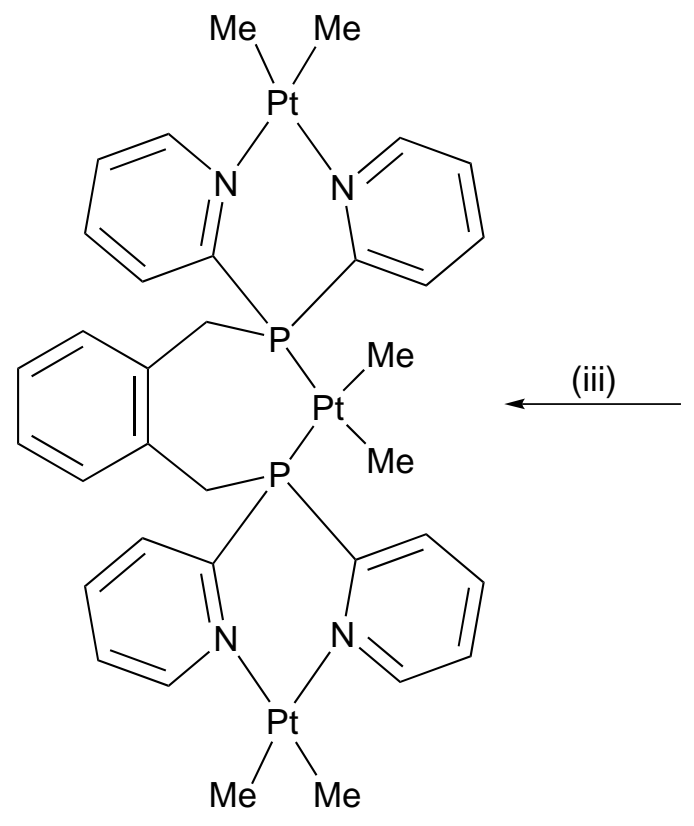<smiles></smiles>

54

55

Scheme 5.1 Reaction of the dpypox ligand 3 with three equivalents of dimethyl(hexa-1,5-diene)platinum. Reagents and conditions: (i) Three equivalents of dimethyl(hexa-1,5-diene)platinum, $\mathrm{CDCl}_{3}, 20$ minutes; (ii) 24 hours; (iii) 48 hours.

The ${ }^{31} \mathrm{P}$ NMR spectrum recorded after 48 hours (Figure 5.1(bottom)) confirmed that the signal at $27.11 \mathrm{ppm}$ was due to the final product of this reaction, $\left[\left(\mathrm{PtMe}_{2}\right)_{3}(\mathrm{PP})\right]$ 

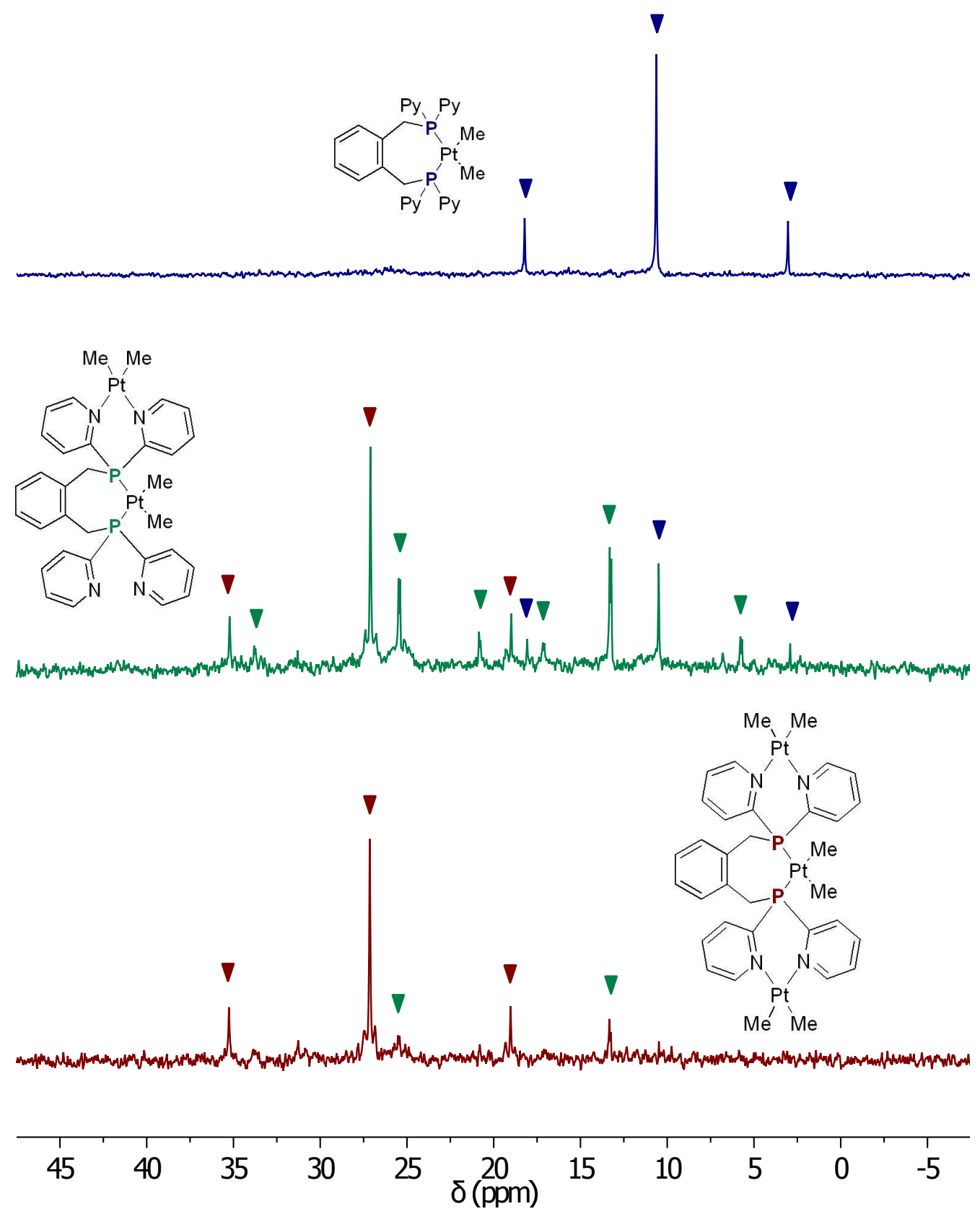

Figure 5.1 ${ }^{31} \mathrm{P}$ NMR spectra of the reaction between the dpypox ligand $\mathbf{3}$ and three equivalents of dimethyl(hexa-1,5-diene)platinum. NMR spectra recorded after 20 minutes (top), 24 hours (middle) and 48 hours (bottom). 
complex 55. The second set of platinum-195 satellites along with the change in the ${ }^{31} \mathrm{P}$ NMR chemical shift indicated that all of the pyridyl nitrogens were coordinated to platinum centres. The ${ }^{1} J_{\mathrm{PtP}}$ value of $1970 \mathrm{~Hz}$ was still within the range typical for a phosphine coordinated trans to a methyl ligand. ${ }^{16}$ In comparison, the ${ }^{1} J_{\mathrm{PtP}}$ value for the $\left[\mathrm{PtMe}_{2}(\mathrm{PP})\right]$ complex 17 was $1840 \mathrm{~Hz}$. This difference of over $100 \mathrm{~Hz}$ indicated that the coordination of the pyridyl nitrogens to platinum has affected the electronic nature of the phosphorus atoms, leading to an increase in the value of the ${ }^{1} J_{\mathrm{PtP}}$ coupling constant. When the dimetallic $\left[\left(\mathrm{C}_{6} \mathrm{~F}_{5}\right)_{3} \mathrm{Pt}\left(\mu-\mathrm{PPh}_{3-\mathrm{n}} \mathrm{Py}_{\mathrm{n}}\right) \mathrm{Rh}(\mathrm{CO})_{2}\right]$ complexes $(\mathrm{n}=2,3)$ were formed the ${ }^{1} J_{\mathrm{PtP}}$ coupling constant decreased, suggesting that the increase observed for the $\left[\left(\mathrm{PtMe}_{2}\right)_{3}(\mathrm{PP})\right]$ complex 55 was not simply due to the inductive effect of coordinating a platinum to the pyridyl nitrogens. ${ }^{47}$ Instead it is proposed that the more rigid conformation of the dpypox ligand $\mathbf{3}$ in the starting complex, $\left[\mathrm{PtMe}_{2}(\mathrm{PP})\right]$, required an increase in the $\mathrm{Py}-\mathrm{P}-\mathrm{Py}$ bond angles to accommodate the coordination of a metal centre to the pyridyl nitrogens. An increase of the angle between substituents on a phosphorus atom is known to decrease the ' $\mathrm{s}$ ' character of the lone pair on the phosphorus atom, making it more basic and thus increasing the value of ${ }^{1} J_{\mathrm{PtP}} .{ }^{87,89,90}$

The ${ }^{3} J_{\mathrm{PtP}}$ value of $74.0 \mathrm{~Hz}$ was of a similar magnitude to that reported for the paddlewheel complex $\left[\mathrm{Pt}_{2}(\text { dpype })_{2} \mathrm{Ag}_{4}\left(\mathrm{NO}_{3}\right)_{8}\left(\mathrm{H}_{2} \mathrm{O}\right)_{2}\right]_{\mathrm{x}}$, where ${ }^{3} J_{\mathrm{PtP}}=69.3 \mathrm{~Hz} .{ }^{66}$ The ${ }^{3} J_{\mathrm{PtP}}$ value for the intermediate $\left[\left(\mathrm{PtMe}_{2}\right)_{2}(\mathrm{PP})\right]$ complex 54 was $79.4 \mathrm{~Hz}$. This decrease in the ${ }^{3} J_{\mathrm{PtP}}$ coupling constant observed between the diplatinum complex 54 and the triplatinum complex 55 was consistent with the trend observed for the ${ }^{1} J_{\mathrm{PtP}}$ values. Figure 5.2 shows the ${ }^{31} \mathrm{P}$ NMR spectrum of $\mathbf{5 5}$ where the two sets of ${ }^{195} \mathrm{Pt}$ satellites are clearly visible. Small ${ }^{195} \mathrm{Pt}$ satellites can also be observed on the ${ }^{195} \mathrm{Pt}$ satellites due to the ${ }^{1} J_{\mathrm{PtP}}$. This was due to the small number of molecules of $\left[\left(\mathrm{PtMe}_{2}\right)_{3}(\mathrm{PP})\right]$ complex 55 where there was a ${ }^{195} \mathrm{Pt}$ atom bound to the phosphorus atoms and a ${ }^{195} \mathrm{Pt}$ atom bound to one of the two sets of pyridyl rings.

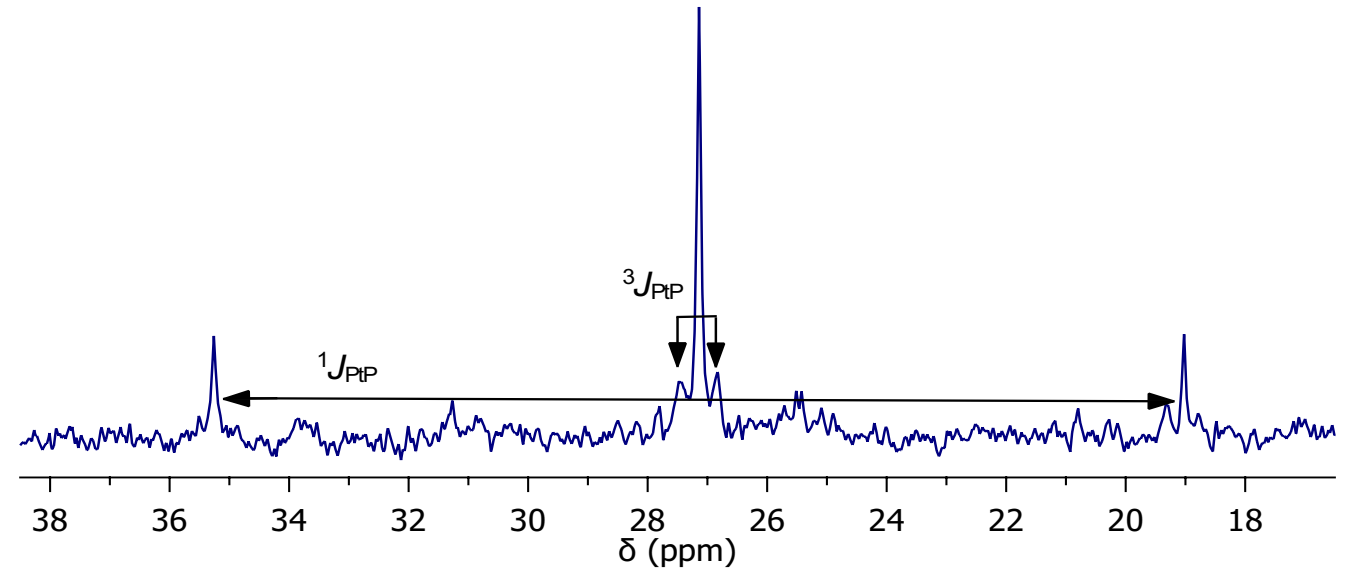

Figure $5.2{ }^{31} \mathrm{P}$ NMR spectrum of the $\left[\left(\mathrm{PtMe}_{2}\right)_{3}(\mathrm{PP})\right]$ complex $5 \mathbf{5}$ showing the two sets of ${ }^{195} \mathrm{Pt}$ satellites. 
The ${ }^{1} \mathrm{H}$ NMR spectra recorded during this reaction were consistent with what was observed in the ${ }^{31} \mathrm{P}$ NMR spectra. After 20 minutes only the $\left[\mathrm{PtMe}_{2}(\mathrm{PP})\right]$ complex 17, unreacted dimethyl(hexa-1,5-diene)platinum and displaced hexa-1,5-diene were observed in the ${ }^{1} \mathrm{H}$ NMR spectrum. After 24 hours the ${ }^{1} \mathrm{H}$ NMR spectrum recorded reflected the presence of three similar complexes, in particular four Pt-Me signals could be observed. There were also signals above $9 \mathrm{ppm}$ which indicated coordination of pyridyl nitrogen atoms to a metal centre had occurred. ${ }^{46,48,127,141,175}$ After 48 hours the ${ }^{1} \mathrm{H}$ NMR spectrum contained only the signals for the triplatinum $\left[\left(\mathrm{PtMe}_{2}\right)_{3}(\mathrm{PP})\right]$ complex 55 and displaced hexa-1,5-diene.

The ${ }^{1} \mathrm{H}$ NMR data of the dpypox ligand 3 in the $\left[\left(\mathrm{PtMe}_{2}\right)_{3}(\mathrm{PP})\right]$ complex 55 is collated in Table 5.1. The absence of broad signals in the ${ }^{1} \mathrm{H}$ NMR spectrum of this complex indicated that this complex was static in solution on the NMR time scale at $20^{\circ} \mathrm{C}$ and that the dynamic behaviour displayed by the $\left[\mathrm{PtMe}_{2}(\mathrm{PP})\right]$ complex $\mathbf{1 7}$ in solution at room temperature (discussed in Chapter 3) was not occurring here. In general, the signals in the ${ }^{1} \mathrm{H}$ NMR spectrum had moved downfield upon the pyridyl nitrogen atoms coordinating to the platinum centres. As mentioned above, the signals around 9 ppm were important evidence for nitrogen coordination. ${ }^{127,141,175}$ From COSY and ${ }^{1} \mathrm{H}-{ }^{31} \mathrm{P}$ HMBC correlations these signals were assigned to the protons next to the nitrogen atoms in the pyridyl rings ( $\mathrm{H} 4 \mathrm{a}$ and $\mathrm{H} 4 \mathrm{~b}$ using the numbering in Table 5.1). The downfield shift of these signals upon pyridyl nitrogen coordination was consistent with what has been reported for ligands of the type $\mathrm{PPh}_{3-\mathrm{n}} \mathrm{Py}_{\mathrm{n}}$ when the pyridyl ring(s) coordinated to transition metals. ${ }^{46,48,141,176}$ However, the signal for the H1b proton at $8.82 \mathrm{ppm}$ overlapped with that of H4a, which was not expected. In contrast, the signal for $\mathrm{H} 1 \mathrm{a}$ appeared at $8.21 \mathrm{ppm}$. Given the rigid conformation that coordination of the pyridyl nitrogens to platinum centres was likely to enforce on this complex, it was reasonable that this downfield shift of the signal of H1b was due to it being in close proximity to the central platinum atom. The downfield shift of ${ }^{1} \mathrm{H}$ NMR signals when ligand protons are in close proximity to the metal centre in transition metal complexes is a well known effect and has been ascribed to long range anagostic interactions between the proton and the metal centre. ${ }^{105,177-180}$ In this case, H1b with its signal at $8.82 \mathrm{ppm}$ was close to the central platinum, while H1a was not.

Also noteworthy were the two signals for the methylene protons. In the monometallic complexes the signal for the $\mathrm{CH}_{2} \mathrm{P}$ group appeared as a broad singlet or multiplet in the ${ }^{1} \mathrm{H}$ NMR spectra due to the dynamic behaviour occurring at room temperature. However, in the $\left[\left(\mathrm{PtMe}_{2}\right)_{3}(\mathrm{PP})\right]$ complex 55 the signals for the methylene protons appeared as a doublet of doublets at $8.42 \mathrm{ppm}$ and a doublet at $3.84 \mathrm{ppm}$. A COSY correlation between the two signals confirmed they were near each other 
Table 5.1 Selected ${ }^{1} \mathrm{H}$ NMR data of trimetallic complexes of dpypox

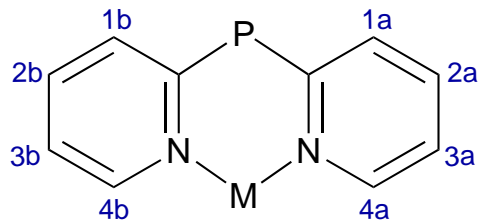

\begin{tabular}{|c|c|c|c|c|c|c|c|c|c|c|}
\hline \multirow[b]{2}{*}{ Compound } & & \multicolumn{9}{|c|}{$\delta^{1} \mathrm{H} / \mathrm{ppm}^{a}$} \\
\hline & & H1a & $\mathrm{H} 2 \mathrm{a}$ & H3a & $\mathrm{H} 4 \mathrm{a}$ & $\mathrm{H} 1 \mathrm{~b}$ & $\mathrm{H} 2 \mathrm{~b}$ & $\mathrm{H} 3 \mathrm{~b}$ & $\mathrm{H} 4 \mathrm{~b}$ & $\mathrm{CH}_{2} \mathrm{P}$ \\
\hline$\left[\left(\mathrm{PtMe}_{2}\right)_{3} \mathrm{PP}\right]$ & 55 & 8.21 & 8.00 & 7.80 & 8.82 & 8.82 & 8.00 & 7.56 & 9.19 & $8.42,3.84$ \\
\hline$\left[\{\mathrm{Rh}(\mathrm{COD})\}_{2} \mathrm{PtMe}_{2}(\mathrm{PP})\right]^{2+}$ & 60 & 8.20 & 7.91 & 7.60 & 8.76 & 8.98 & 8.02 & 7.53 & 9.08 & $8.21,5.28$ \\
\hline$\left[\{\mathrm{Ir}(\mathrm{COD})\}_{2} \mathrm{PtMe}_{2}(\mathrm{PP})\right]^{2+}$ & 61 & 8.27 & 7.98 & 7.68 & 8.91 & 9.10 & 8.08 & 7.59 & 9.04 & $7.38,5.09$ \\
\hline
\end{tabular}

${ }^{a}$ Spectra recorded in $\mathrm{CDCl}_{3}$. 
and comparison to the NMR data of the dirhodiumplatinum and diiridiumplatinum complexes (discussed in Section 5.3) confirmed they were due to the methylene protons. Again it was probable that the rigid structure of this complex meant that these protons were in markedly different chemical environments resulting in the large difference in their chemical shifts.

The signal for the methyl ligands trans to the phosphorus atoms appeared as a "doublet of doublets" due to a $\mathrm{AA}^{\prime} \mathrm{X}_{3} \mathrm{X}_{3}^{\prime}$ spin system. ${ }^{24}$ This is consistent with what was observed for the methyl ligand in the $\left[\mathrm{PtMe}_{2}(\mathrm{PP})\right]$ complex 17. The ${ }^{2} J_{\mathrm{PtH}}$ value of $67.8 \mathrm{~Hz}$ is slightly less than that observed in the starting complex.

Unfortunately, the triplatinum $\left[\left(\mathrm{PtMe}_{2}\right)_{3}(\mathrm{PP})\right]$ complex 55 was not highly soluble and began crystallising almost as soon as it formed. This meant that there was never a large amount of the $\left[\left(\mathrm{PtMe}_{2}\right)_{3}(\mathrm{PP})\right]$ complex 55 in solution. Thus it was not possible to obtain ${ }^{13} \mathrm{C}$ NMR data on this complex.

The coordination of a nitrogen in a pyridyl ring to a metal centre is often confirmed using infrared (IR) spectroscopy. ${ }^{40,107}$ In general, the highest frequency pyridine ring deformation band shifts $10-30 \mathrm{~cm}^{-1}$ upon coordination. ${ }^{40,107,134-136}$ The next highest $\nu(\mathrm{C}=\mathrm{N})$ band also increases in frequency, but typically to a lesser extent. Table 5.2 contains the $\nu(\mathrm{C}=\mathrm{N})$ data for the trimetallic complexes of dpypox ligand $\mathbf{3}$ discussed in this chapter, as well as those of the free ligand $\mathbf{3}$ and some monometallic complexes for comparison. From Table 5.2 it can been seen that the $\nu(\mathrm{C}=\mathrm{N})$ bands do not change between the free ligand $\mathbf{3}$ and the monometallic complexes $\mathbf{1 6}$ and 17. In contrast, the $\mathrm{C}=\mathrm{N}$ stretches of the $\left[\left(\mathrm{PtMe}_{2}\right)_{3}(\mathrm{PP})\right]$ complex $\mathbf{5 5}$ appeared at 1601 and $1587 \mathrm{~cm}^{-1}$, shifted from that of the ligand $\mathbf{3}$, confirming that the pyridyl nitrogens were coordinated to platinum centres.

Table 5.2 IR data of mono- and trimetallic complexes of dpypox

\begin{tabular}{lcc}
\hline Compound & & $\mathrm{C}=\mathrm{N}$ stretch $/ \mathrm{cm}^{-1}$ \\
\hline dpypox & $\mathbf{3}$ & 1573,1560 \\
{$\left[\mathrm{PtCl}_{2}(\mathrm{PP})\right]$} & $\mathbf{1 6}$ & 1573,1562 \\
{$\left[\mathrm{PtMe}_{2}(\mathrm{PP})\right]$} & $\mathbf{1 7}$ & 1574,1562 \\
{$\left[\mathrm{PdCl}_{2}(\mathrm{PP})\right]$} & $\mathbf{2 0}$ & 1574,1563 \\
{$\left[\left(\mathrm{PtMe}_{2}\right)_{3}(\mathrm{PP})\right]$} & $\mathbf{5 5}$ & 1601,1587 \\
{$\left[\left(\mathrm{PtCl}_{2}\right)_{3}(\mathrm{PP})\right]$} & $\mathbf{5 6}$ & 1610,1584 \\
{$\left[\left(\mathrm{PdCl}_{2}\right)_{3}(\mathrm{PP})\right]$} & $\mathbf{5 7}$ & 1613,1585 \\
{$\left[\left(\mathrm{PtMe}_{2}\right)_{2} \mathrm{PtClMe}(\mathrm{PP})\right]$} & $\mathbf{5 9}$ & 1605,1585 \\
{$\left[\left(\mathrm{RhCOD}_{2} \mathrm{PtMe}_{2}(\mathrm{PP})\right]\right.$} & $\mathbf{6 0}$ & 1585 \\
{$\left[(\mathrm{IrCOD})_{2} \mathrm{PtMe}_{2}(\mathrm{PP})\right]$} & $\mathbf{6 1}$ & 1586 \\
\hline
\end{tabular}


When three equivalents of dichloro(hexa-1,5-diene)platinum or dichloro(cycloocta1,5-diene)palladium were reacted with the ligand 3 the ${ }^{31} \mathrm{P}$ and ${ }^{1} \mathrm{H}$ NMR spectra recorded after 20 minutes showed the formation of the monometallic $\left[\mathrm{PtCl}_{2}(\mathrm{PP})\right]$ complex 16 or the $\left[\mathrm{PdCl}_{2}(\mathrm{PP})\right]$ complex 20 (Scheme 5.2). However, after 20 hours at room temperature insoluble yellow solids were formed in both reactions. The ${ }^{31} \mathrm{P}$ and ${ }^{1} \mathrm{H}$ NMR spectra recorded of what remained in solution showed only displaced hexa1,5-diene or cycloocta-1,5-diene. While attempts to grow X-ray quality crystals of these products were unsuccessful, the infrared spectra recorded of the solids showed $\mathrm{C}=\mathrm{N}$ stretches at 1610 and $1584 \mathrm{~cm}^{-1}$ for the platinum reaction and at 1613 and $1585 \mathrm{~cm}^{-1}$ for the palladium reaction (Table 5.2). These shifts in the $\nu(\mathrm{C}=\mathrm{N})$ bands from that observed for the free ligand $\mathbf{3}$ or the monometallic complexes indicated that the pyridyl nitrogens were coordinated to metal centres. ${ }^{40,107,134-136}$ Thus it can be concluded that the desired trimetallic complexes $\left[\left(\mathrm{PtCl}_{2}\right)_{3}(\mathrm{PP})\right](\mathbf{5 6})$ and $\left[\left(\mathrm{PdCl}_{2}\right)_{3}(\mathrm{PP})\right](\mathbf{5 7})$ were formed in these reactions.<smiles>[R16]Cc1ccccc1CP[R20]#N</smiles><smiles></smiles>

Scheme 5.2 Synthesis of trimetallic dichloride complexes. Reagents and conditions: (i) Three equivalents of dichloro(hexa-1,5-diene)platinum or dichloro(cyclocta-1,5-diene)palladium, $\mathrm{CDCl}_{3}, 15$ minutes; (ii) 20 hours. 


\subsection{Group 10 Trimetallic Complexes of dpypox}

As all of the reactions discussed above initially formed monometallic complexes and then reacted further, an alternative synthetic approach involving the reaction of an already formed monometallic complex with two equivalents of a precursor complex was investigated. The benefit of starting from a preformed monometallic complex was that it allowed for different moieties to be bound to the nitrogen atoms than those bound to the phosphorus atoms, leading to mixed trimetallic complexes (Scheme 5.3).

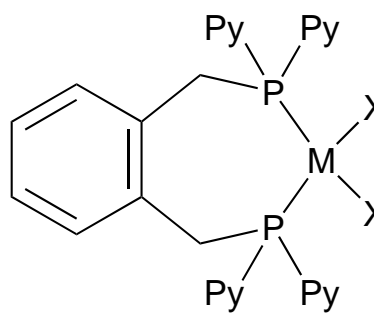

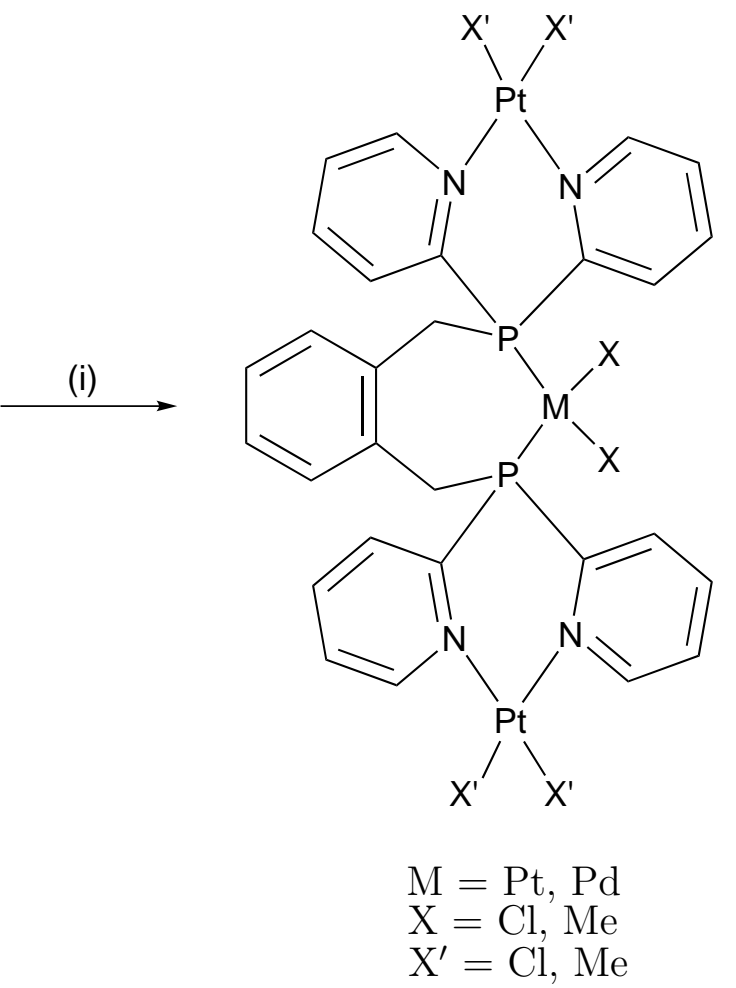

Scheme 5.3 Synthesis of trimetallic complexes. Reagents and conditions: (i) Two equivalents of dimethyl(hexa-1,5-diene)platinum or dichloro(hexa-1,5diene)platinum, $\mathrm{CDCl}_{3}, 24$ hours.

When the $\left[\mathrm{PtCl}_{2}(\mathrm{PP})\right]$ complex 16 or the $\left[\mathrm{PdCl}_{2}(\mathrm{PP})\right]$ complex 20 was reacted with two equivalents of dimethyl(hexa-1,5-diene)platinum yellow crystalline solids were formed after 24 hours. The NMR spectra recorded of the solution showed the signals for the displaced hexa-1,5-diene only. The solids were found to be insoluble in chloroform, dichloromethane, benzene, toluene and acetonitrile, while DMSO was found to react with the complexes. The IR spectra recorded of the solids showed $\mathrm{C}=\mathrm{N}$ stretches, at 1602 and $1588 \mathrm{~cm}^{-1}$, shifted from that of the free ligand, indicating that the pyridyl groups in these complexes were coordinated to metal centres. ${ }^{40,107,134-136}$ From these results it was concluded that trimetallic complexes with a $\mathrm{MCl}_{2}$ moeity $(\mathrm{M}=\mathrm{Pt}, \mathrm{Pd})$ coordinated to the phosphorus atoms possessed low solubility which hindered their characterisation. 
In contrast, when the $\left[\mathrm{PtMe}_{2}(\mathrm{PP})\right]$ complex 17 was reacted with two equivalents of dichloro(hexa-1,5-diene)platinum, rather than forming the expected triplatinum $\left[\left(\mathrm{PtCl}_{2}\right)_{2} \mathrm{PtMe}_{2}(\mathrm{PP})\right]$ complex, the $[\mathrm{PtClMe}(\mathrm{PP})]$ complex $\mathbf{2 7}$ was the major product in solution after 24 hours. There was also evidence of the formation of a small amount of a dimetallic species with signals above $9 \mathrm{ppm}$ in the ${ }^{1} \mathrm{H}$ NMR spectrum and the presence of two small doublets in the ${ }^{31} \mathrm{P}$ NMR spectrum. Due to the scrambling of the ligands on the starting material the NMR spectra recorded after 48 hours were difficult to assign with several very similar products present. Also, as before, the triplatinum products had low solubility and began precipitating out of solution almost immediately. The IR spectrum of the solid contained $\mathrm{C}=\mathrm{N}$ stretches at 1602 and $1587 \mathrm{~cm}^{-1}$, confirming that the pyridyl nitrogen atoms were coordinated to the platinum centres. ${ }^{40,107,134-136}$

Given these results, the $[\mathrm{PtClMe}(\mathrm{PP})]$ complex $\mathbf{2 7}$ was reacted with two equivalents of dimethyl(hexa-1,5-diene)platinum. After 24 hours formation of the diplatinum $\left[\left(\mathrm{PtMe}_{2}\right) \mathrm{PtClMe}(\mathrm{PP})\right]$ complex 58 was observed in the ${ }^{31} \mathrm{P}$ and ${ }^{1} \mathrm{H}$ NMR spectra (Scheme 5.4). In the ${ }^{31} \mathrm{P}$ NMR spectrum two new doublets were present, one at $24.20 \mathrm{ppm}\left({ }^{2} J_{\mathrm{PP}}=12.1 \mathrm{~Hz}\right)$ with two sets of ${ }^{195} \mathrm{Pt}$ satellites, ${ }^{1} J_{\mathrm{PtP}}=1839$ and ${ }^{3} J_{\mathrm{PtP}}=88.7 \mathrm{~Hz}$, and the other doublet at $12.00 \mathrm{ppm}$ with one set of ${ }^{195} \mathrm{Pt}$ satellites, ${ }^{1} J_{\mathrm{PtP}}=4203 \mathrm{~Hz}$. The fact that the signal at $24.20 \mathrm{ppm}$ had two sets of ${ }^{195} \mathrm{Pt}$ satellites indicated that this was the signal for the phosphorus atom attached to the pyridyl rings coordinated to the platinum atom. The ${ }^{1} J_{\mathrm{PtP}}$ value of $1839 \mathrm{~Hz}$ was consistent with this phosphorus atom being trans to the methyl ligand. Thus the pyridyl rings attached to the phosphorus trans to the methyl ligand (and cis to the chloride ligand) reacted first. This was ascribed to the smaller size of the chloride ligand, when compared to a methyl ligand. ${ }^{181}$

In contrast to the rest of the syntheses of trimetallic complexes discussed here, several side reactions occurred in this reaction resulting in many new signals in the ${ }^{31} \mathrm{P}$ NMR spectrum after 48 hours. Over time the reaction mixture formed an intractable mixture of products. However, as the reaction progressed a solid procipitated out of solution. The infrared spectrum recorded of the solid showed $\mathrm{C}=\mathrm{N}$ stretches at 1605 and $1585 \mathrm{~cm}^{-1}$. This confirmed that all of the pyridyl nitrogen atoms were coordinated to platinum centres. ${ }^{40,107,134-136}$ Thus it was concluded that the $\left[\left(\mathrm{PtMe}_{2}\right)_{2} \mathrm{PtClMe}(\mathrm{PP})\right]$ complex 59 had formed, along with several other side products. 


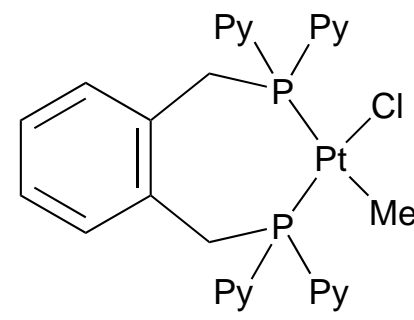

27<smiles></smiles>

58

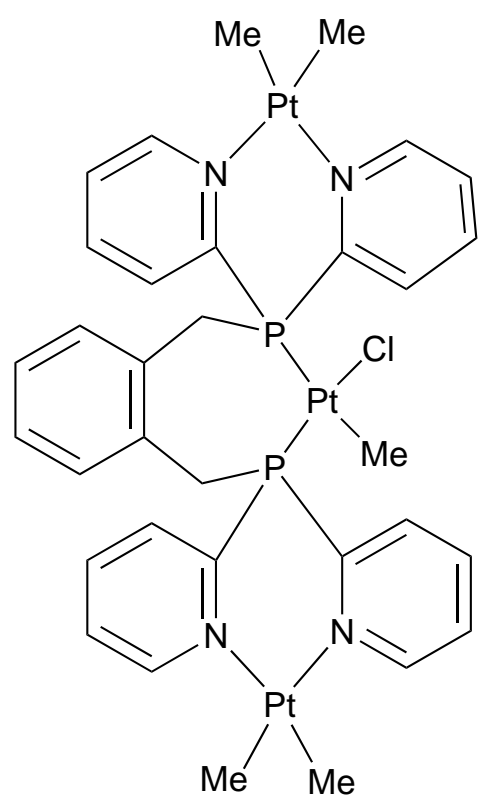

59

Scheme 5.4 Reaction of $[\mathrm{PtClMe}(\mathrm{PP})]$ complex 27 with two equivalents of dimethyl(hexa-1,5-diene)platinum. Reagents and conditions: (i) Two equivalents of dimethyl(hexa-1,5-diene)platinum, $\mathrm{CDCl}_{3}, 24$ hours; (ii) 48 hours. 


\subsection{Heterotrimetallic Complexes of dpypox}

As the products of the reactions involving dichloroplatinum or dichloropalladium moieties were generally insoluble, the $\left[\mathrm{PtMe}_{2}(\mathrm{PP})\right]$ complex 17 was used as the starting material for further investigation into the formation of trimetallic complexes.

Several interesting complexes with $\mathrm{PPhPy}_{2}$ or $\mathrm{PPy}_{3}$ ligands bridging platinum and rhodium ${ }^{47}$ or palladium and rhodium ${ }^{48}$ have been reported. These were synthesised by reacting an already formed complex, with the phosphorus atom bound to the metal, with $[\mathrm{Rh}(\mathrm{COD})(\mu-\mathrm{Cl})]_{2}$ or $\left[\mathrm{Rh}(\mathrm{CO})_{2}(\mu-\mathrm{Cl})\right]_{2}$ in the presence of a silver salt. As the COD ligand would provide more information in NMR spectra of the potential trimetallic products $[\mathrm{Rh}(\mathrm{COD})(\mu-\mathrm{Cl})]_{2}$ was used in these reactions. The $[\operatorname{Ir}(\mathrm{COD})(\mu-\mathrm{Cl})]_{2}$ complex has also been shown to react with $\left[\mathrm{AuCl}\left(\mathrm{PPh}_{2} \mathrm{Py}\right)\right]$ to form dimetallic complexes with the $\mathrm{PPh}_{2} \mathrm{Py}$ ligand bridging gold and iridium. ${ }^{25}$ Given this, and the fact that reactions of $[\operatorname{Ir}(\mathrm{COD})(\mu-\mathrm{Cl})]_{2}$ with the dpypox ligand 3 have already shown interesting results, the complex $\mathbf{1 7}$ was also reacted with this iridium complex. A sodium salt, $\mathrm{NaCH}\left(\mathrm{SO}_{2} \mathrm{CF}_{3}\right)_{2}$, ${ }^{182}$ was used in the place of the silver salt as it was more easily handled and less likely to coordinate to the pyridyl nitrogens.

When the $\left[\mathrm{PtMe}_{2}(\mathrm{PP})\right]$ complex 17 was reacted with one equivalent of $[\mathrm{Rh}(\mathrm{COD})(\mu$ $\mathrm{Cl})]_{2}$ or $[\operatorname{Ir}(\mathrm{COD})(\mu-\mathrm{Cl})]_{2}$ and two equivalents of $\mathrm{NaCH}\left(\mathrm{SO}_{2} \mathrm{CF}_{3}\right)_{2}$ new trimetallic complexes of the type $\left[\{\mathrm{M}(\mathrm{COD})\}_{2} \mathrm{PtMe}_{2}(\mathrm{PP})\right]^{2+}(\mathrm{M}=\mathrm{Rh} \mathbf{6 0}$, Ir 61) were formed after 20 minutes at room temperature (Scheme 5.5).

The ${ }^{31} \mathrm{P},{ }^{1} \mathrm{H},{ }^{13} \mathrm{C}$ and ${ }^{19} \mathrm{~F}$ NMR spectra of the two new complexes were very similar. The ${ }^{31} \mathrm{P}$ NMR spectra recorded of the reaction mixtures showed singlets at 32.15 and $32.56 \mathrm{ppm}$ with ${ }^{1} J_{\mathrm{PtP}}$ values of 1981 and $1975 \mathrm{~Hz}$ for the dirhodium complex 60 and diiridium complex 61 respectively. These ${ }^{1} J_{\mathrm{PtP}}$ values were over $100 \mathrm{~Hz}$ larger than that of the starting complex, where ${ }^{1} J_{\mathrm{PtP}}=1840 \mathrm{~Hz}$. This was consistent with what was observed in the synthesis of the $\left[\left(\mathrm{PtMe}_{2}\right)_{3}(\mathrm{PP})\right]$ complex 55 when the pyridyl nitrogens were coordinated to metal centres. A ${ }^{1} \mathrm{H}$ NMR signal at 3.80 ppm and a ${ }^{19} \mathrm{~F}$ NMR signal at $-80.9 \mathrm{ppm}$ in both reactions confirmed that the $\mathrm{CH}\left(\mathrm{SO}_{2} \mathrm{CF}_{3}\right)_{2}^{-}$counterions were not coordinated to a metal centre. ${ }^{128}$

The absence of broad signals in the ${ }^{1} \mathrm{H}$ NMR spectra of these complexes indicated that these complexes were also static on the NMR time scale at $20{ }^{\circ} \mathrm{C}$. There were eight signals for the pyridyl protons in the ${ }^{1} \mathrm{H}$ NMR spectra of the the new complexes. In particular, the signals due to the pyridyl rings in the ${ }^{1} \mathrm{H}$ and ${ }^{13} \mathrm{C} \mathrm{NMR}$ spectra of the complexes $\mathbf{6 0}$ and $\mathbf{6 1}$ were comprised of two sets of similar signals. 


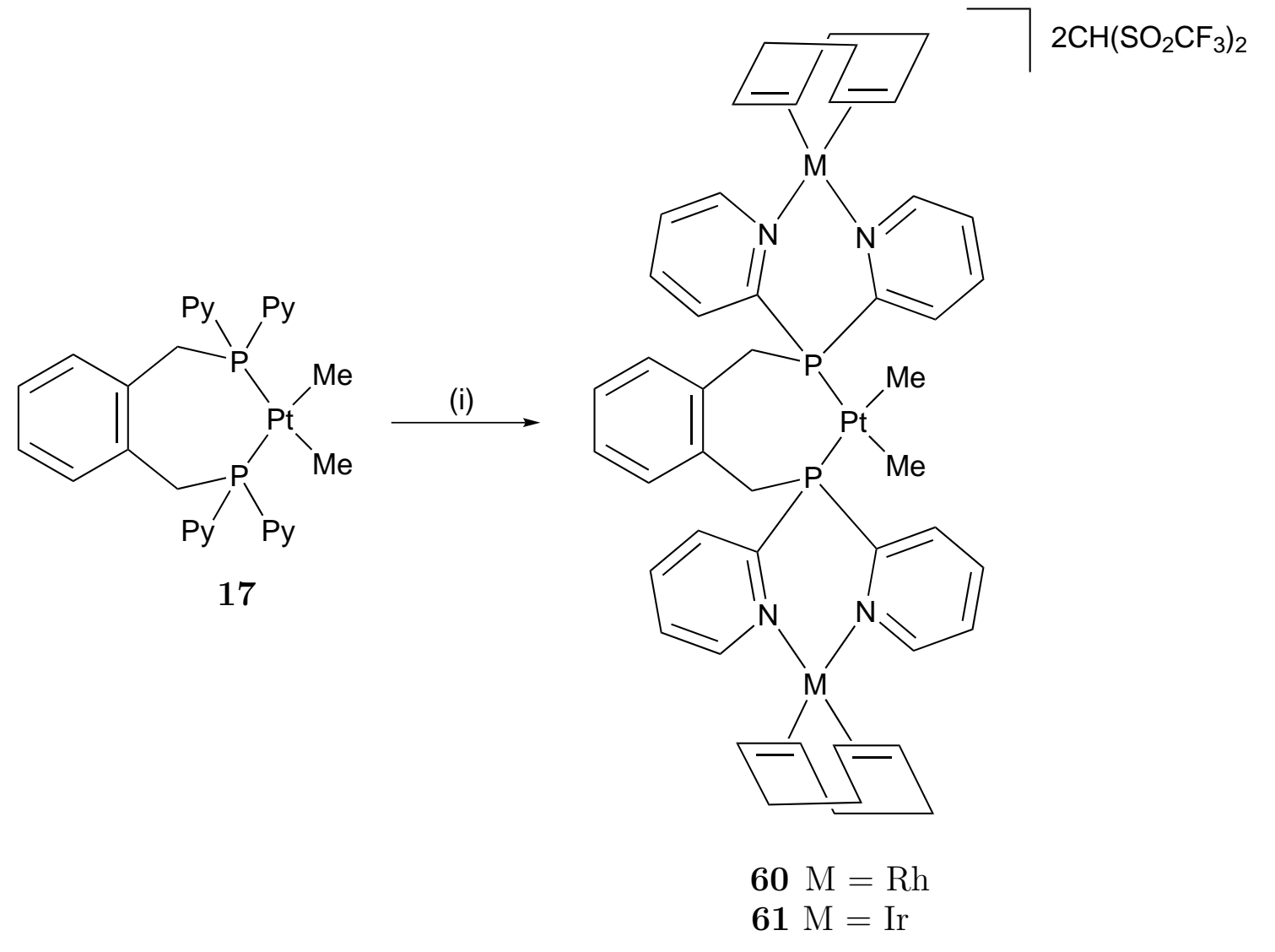

Scheme 5.5 Synthesis of $\left[\{\mathrm{M}(\mathrm{COD})\}_{2} \mathrm{PtMe}_{2}(\mathrm{PP})\right]\left\{\mathrm{CH}\left(\mathrm{SO}_{2} \mathrm{CF}_{3}\right)_{2}\right\}_{2}$. Reagents and conditions: (i) $[\mathrm{Rh}(\mathrm{COD})(\mu-\mathrm{Cl})]_{2}$ or $[\operatorname{Ir}(\mathrm{COD})(\mu-\mathrm{Cl})]_{2}, \quad \mathrm{NaCH}\left(\mathrm{SO}_{2} \mathrm{CF}_{3}\right)_{2}$, $\mathrm{CDCl}_{3}, 20$ minutes.

This indicated that the pyridyl rings were in similar but not identical environments. While in the starting $\left[\mathrm{PtMe}_{2}(\mathrm{PP})\right]$ complex $\mathbf{1 7}$ the signals for the pyridyl protons in the ${ }^{1} \mathrm{H}$ NMR spectrum appeared between 8.86 and $7.29 \mathrm{ppm}$, in the new trimetallic complexes $\mathbf{6 0}$ and $\mathbf{6 1}$ the signals appeared between 9.10 and $7.60 \mathrm{ppm}$ (Table 5.1). This downfield shift of the pyridyl proton signals and in particular the signals around $9 \mathrm{ppm}$ indicated that the nitrogen atoms in the pyridyl rings were coordinated to a metal centre. ${ }^{25,47,48,176}$

The signals due to the dpypox ligand 3 in the ${ }^{1} \mathrm{H}$ NMR spectrum of the trimetallic $\left[\{\operatorname{Ir}(\mathrm{COD})\}_{2} \mathrm{PtMe}_{2}(\mathrm{PP})\right]\left\{\mathrm{CH}\left(\mathrm{SO}_{2} \mathrm{CF}_{3}\right)_{2}\right\}_{2}$ compound $\mathbf{6 1}$ are shown in Figure 5.3. As the signals for the pyridyl protons were very similar in compounds $\mathbf{6 0}$ and $\mathbf{6 1}$, only the signals for the diiridiumplatinum complex $\mathbf{6 1}$ will be discussed here with reference to Figure 5.3. The two doublets around 9 ppm were due to the protons on the carbon next to the nitrogen (H4a and H4b in the numbering in Figure 5.3). It is the downfield shift of the signals due to these protons that is often cited as evidence of nitrogen coordination in the literature. ${ }^{46,127,141,175}$ Also of interest was the triplet at $9.10 \mathrm{ppm}$. This was the signal of H1b. In contrast, the signal for H1a appeared as a triplet at $8.27 \mathrm{ppm}$. This difference in chemical shift was proposed to be due 
to the difference in proximity of these protons to the platinum centre. ${ }^{105,177-180}$ In this case, H1b with its signal at $9.10 \mathrm{ppm}$ was close to the central platinum, while H1a was not. This was consistent with what was observed in the ${ }^{1} \mathrm{H}$ NMR spectra of the $\left[\left(\mathrm{PtMe}_{2}\right)_{3}(\mathrm{PP})\right]$ complex 55 .
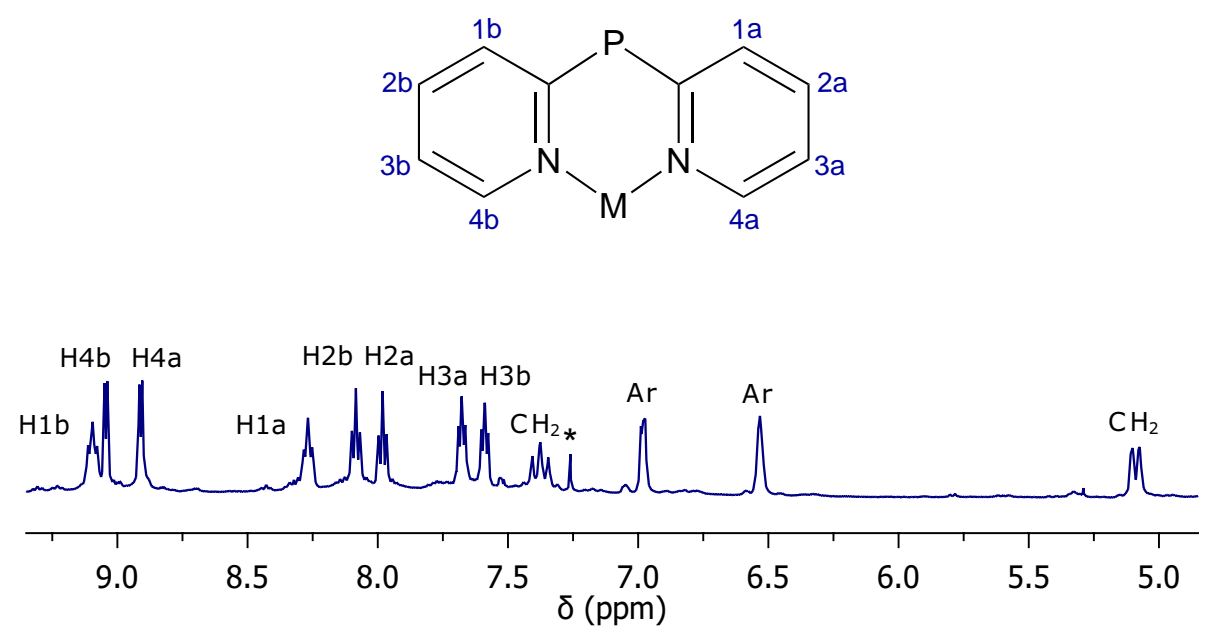

Figure 5.3 ${ }^{1} \mathrm{H}$ NMR spectrum of the $\left[\{\operatorname{Ir}(\mathrm{COD})\}_{2} \mathrm{PtMe}_{2}(\mathrm{PP})\right]\left\{\mathrm{CH}\left(\mathrm{SO}_{2} \mathrm{CF}_{3}\right)_{2}\right\}_{2}$ complex 61. Asterisk denotes solvent signal.

In a similar manner to the rest of the signals due to the ligand $\mathbf{3}$, the signals of the aromatic protons on the ligand backbone have moved downfield $0.4 \mathrm{ppm}$, now appearing at 6.98 and $6.53 \mathrm{ppm}$. The signals for the $\mathrm{CH}_{2} \mathrm{P}$ protons in these complexes had changed significantly from that observed for the starting complex. In the dirhodiumplatinum complex 60 the signals for the $\mathrm{CH}_{2} \mathrm{P}$ protons in the ${ }^{1} \mathrm{H} \mathrm{NMR}$ spectrum appeared as a doublet at 5.28 and a triplet at $8.21 \mathrm{ppm}$. The observation of a COSY correlation between these two signals and an HSQC correlation from both of these signals to a doublet at $35.00 \mathrm{ppm}\left({ }^{1} J_{\mathrm{PC}}=19.5 \mathrm{~Hz}\right)$ in the ${ }^{13} \mathrm{C} \mathrm{NMR}$ spectrum confirmed that these signals were due to the protons of the methylene group attached to the phosphorus atoms. In the diiridiumplatinum complex $\mathbf{6 1}$ the protons of the $\mathrm{CH}_{2} \mathrm{P}$ group also appeared as a doublet and a triplet but this time at 5.09 and $7.38 \mathrm{ppm}$ respectively (Figure 5.3). Once again there was a COSY correlation between these two signals and an HSQC correlation between these two signals and a doublet at $34.84 \mathrm{ppm}\left({ }^{1} J_{\mathrm{PC}}=17.1 \mathrm{~Hz}\right)$ in the ${ }^{13} \mathrm{C} \mathrm{NMR}$ spectrum. It was noteworthy that while the signals for these protons had changed considerably from those for the $\left[\mathrm{PtMe}_{2}(\mathrm{PP})\right]$ complex 17, where the signal was a broad singlet at $4.56 \mathrm{ppm}$, the signals for the carbon had not changed significantly. The ${ }^{13} \mathrm{C} \mathrm{NMR}$ signal in 17 appeared as a doublet at $34.01 \mathrm{ppm}$. While the chemical environment of the methylene carbon had not changed significantly, the large difference in the appearance and chemical shift of the signals for the methylene protons indicated these protons were in very different chemical environments in these trimetallic complexes compared to the monometallic complex $\mathbf{1 7}$. 
The ${ }^{1} \mathrm{H}$ NMR signal for the methyl ligands in both complexes, $\mathbf{6 0}$ and $\mathbf{6 1}$, appeared as a triplet at $-0.01 \mathrm{ppm}\left({ }^{2} J_{\mathrm{PH}} \approx 7.5\right)$ with a ${ }^{2} J_{\mathrm{PtH}}$ value of about $69 \mathrm{~Hz}$. The ${ }^{13} \mathrm{C}$ NMR signal appeared as a doublet of doublets at $8.55 \mathrm{ppm}\left({ }^{2} J_{\mathrm{PC}}=98.4\right.$ and $8.7 \mathrm{~Hz}$ ) with a ${ }^{1} J_{\mathrm{PtC}}$ value of $617.6 \mathrm{~Hz}$. While the ${ }^{1} \mathrm{H}$ and ${ }^{13} \mathrm{C} \mathrm{NMR}$ chemical shifts of the methyl ligands have changed compared to those in the starting complex $\left[\mathrm{PtMe}_{2}(\mathrm{PP})\right]$, indicating as expected that the chemical environment has changed, the value of the coupling constants were not significantly different. This suggested that $\mathrm{Pt}-\mathrm{Me}$ bond has not been substantially affected by the coordination of the pyridyl nitrogen atoms to metal centres.

The infrared spectra recorded of these complexes showed $\mathrm{C}=\mathrm{N}$ stretches at 1585 and $1586 \mathrm{~cm}^{-1}$ for the dirhodiumplatinum complex 60 and the diiridiumplatinum complex 61 respectively. These $\nu(\mathrm{C}=\mathrm{N})$ bands were shifted to higher frequencies from that observed in the free ligand $\mathbf{3}$ confirming that the nitrogen atoms in the pyridyl rings have coordinated to the metal centres (Table 5.2). ${ }^{40,107,134-136}$ The absence of the band at about $1610 \mathrm{~cm}^{-1}$, observed in the IR spectra of the other trimetallic complexes, was consistent with the $\nu(\mathrm{C}=\mathrm{N})$ reported when $\mathrm{PPhPy}_{2}$ or $\mathrm{PPy}_{3}$ bridged platinum or palladium and rhodium. ${ }^{47,48}$

\subsection{Dimetallic Intermediates of dpypox}

In the synthesis of the $\left[\left(\mathrm{PtMe}_{2}\right)_{3}(\mathrm{PP})\right]$ complex 55 evidence for a dimetallic intermediate $\left[\left(\mathrm{PtMe}_{2}\right)_{2}(\mathrm{PP})\right]$ complex 54 was observed in the ${ }^{31} \mathrm{P}$ and ${ }^{1} \mathrm{H}$ NMR spectra recorded after 24 hours. In the ${ }^{31} \mathrm{P}$ NMR spectra there were two doublets observed at 25.50 and $13.13 \mathrm{ppm}\left({ }^{2} J_{\mathrm{PP}}=10.5 \mathrm{~Hz}\right)$ both with ${ }^{1} J_{\mathrm{PtP}}$ values consistent with a phosphorus coordinated trans to a methyl ligand (Table 5.3). ${ }^{16}$ However, there was a difference of approximately $190 \mathrm{~Hz}$ in the coupling constants. The signal at $25.50 \mathrm{ppm}$ in the ${ }^{31} \mathrm{P}$ NMR spectrum had a second set of ${ }^{195} \mathrm{Pt}$ satellites, indicating this signal represented the phosphorus atom attached to the pyridyl rings that had coordinated to a platinum centre. The ${ }^{3} J_{\mathrm{PtP}}$ value of $79 \mathrm{~Hz}$ was slightly larger than that observed for the $\left[\left(\mathrm{PtMe}_{2}\right)_{3}(\mathrm{PP})\right]$ complex 55, but was still consistent with what was reported for $\left[\mathrm{Pt}_{2}(\text { dpype })_{2} \mathrm{Ag}_{4}\left(\mathrm{NO}_{3}\right)_{8}\left(\mathrm{H}_{2} \mathrm{O}\right)_{2}\right]_{\mathrm{x}} \cdot{ }^{66}$

Attempts to isolate this complex were unsuccessful. When ligand $\mathbf{3}$ was reacted with two equivalents of dimethyl(hexa-1,5-diene)platinum a mixture of the $\left[\mathrm{PtMe}_{2}(\mathrm{PP})\right]$ complex 17, the $\left[\left(\mathrm{PtMe}_{2}\right)_{2}(\mathrm{PP})\right]$ complex 54 and the $\left[\left(\mathrm{PtMe}_{2}\right)_{3}(\mathrm{PP})\right]$ complex 55 was formed. The same mixture was obtained when one equivalent of dimethyl(hexa1,5-diene)platinum was reacted with the $\left[\mathrm{PtMe}_{2}(\mathrm{PP})\right]$ complex 17 (Scheme 5.6). 
Table 5.3 ${ }^{31} \mathrm{P}$ and selected ${ }^{1} \mathrm{H}$ NMR data of the dimetallic complexes of dpypox

\begin{tabular}{lccccrccc}
\hline & & \multicolumn{3}{c}{$\mathrm{P}$} & & \multicolumn{3}{c}{$\mathrm{Pt}-\mathrm{CH}_{3}$} \\
\cline { 3 - 5 } \cline { 5 - 8 } Compound & & $\delta^{31} \mathrm{P} / \mathrm{ppm}^{a}$ & ${ }^{1} J_{\mathrm{PtP}} / \mathrm{Hz}$ & ${ }^{2} J_{\mathrm{PP}} / \mathrm{Hz}$ & $\delta^{1} \mathrm{H} / \mathrm{ppm}^{a}$ & ${ }^{3} J_{\mathrm{PH}} / \mathrm{Hz}$ & ${ }^{2} J_{\mathrm{PtH}} / \mathrm{Hz}$ \\
\hline$\left[\left(\mathrm{PtMe}_{2}\right)_{2}(\mathrm{PP})\right]$ & $\mathbf{5 4}$ & 25.50 & 2019 & 10.5 & & 0.41 & $9.0,7.0$ & 68.3 \\
& & 13.13 & 1828 & 10.5 & & -0.12 & $8.0,6.5$ & 68.3 \\
{$\left[\left(\mathrm{PtMe}_{2}\right) \mathrm{PtClMe}(\mathrm{PP})\right]$} & $\mathbf{5 8}$ & 24.21 & 1839 & 12.1 & & 0.64 & $7.0,4.5$ & 62.0 \\
& & 12.00 & 4203 & 12.1 & & $\mathrm{n} / \mathrm{a}$ & $\mathrm{n} / \mathrm{a}$ & $\mathrm{n} / \mathrm{a}$ \\
{$\left[\{\mathrm{Rh}(\mathrm{COD})\} \mathrm{PtMe}_{2}(\mathrm{PP})\right]$} & $\mathbf{6 2}$ & 29.48 & 2003 & 10.7 & & 0.42 & $8.8,7.3$ & 70.0 \\
& & 15.48 & 1819 & 10.7 & & -0.28 & $8.8,6.8$ & 68.0 \\
{$\left[\{\operatorname{Ir}(\mathrm{COD})\} \mathrm{PtMe}_{2}(\mathrm{PP})\right]$} & $\mathbf{6 3}$ & 29.84 & 2000 & 10.3 & & 0.42 & $8.4,7.5$ & 71.4 \\
& & 15.53 & 1811 & 10.3 & & -0.30 & $8.4,6.9$ & 67.2 \\
\hline
\end{tabular}

${ }^{a}$ Spectra recorded in $\mathrm{CDCl}_{3}$. 


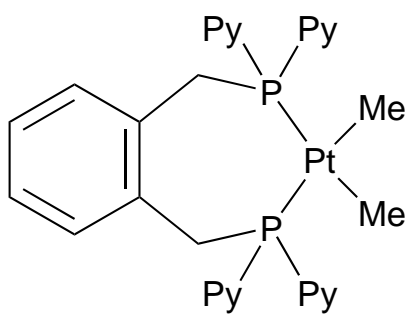

17

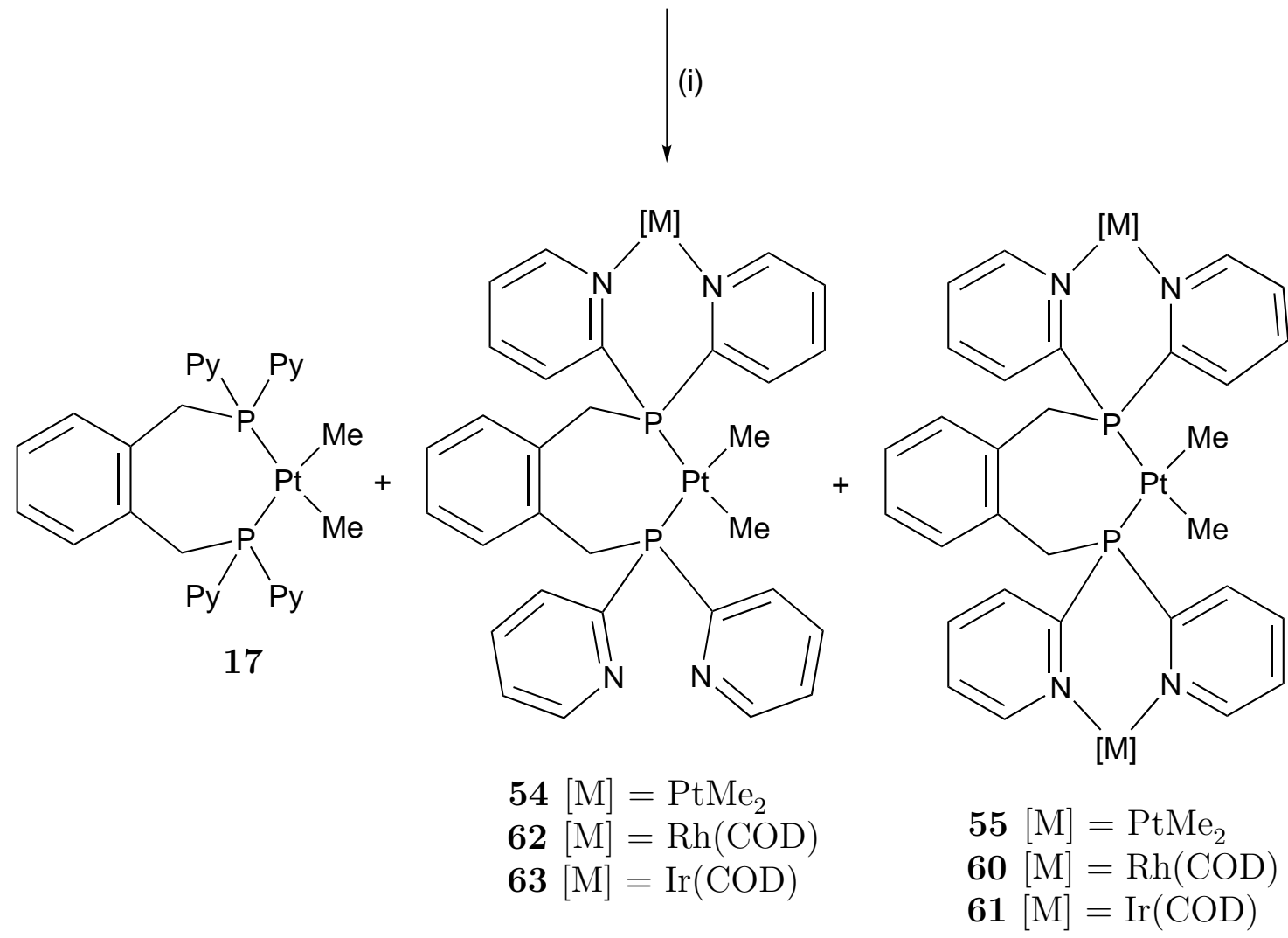

Scheme 5.6 Synthesis of dimetallic complexes of dpypox ligand 3. Reagents and conditions: (i) One equivalent of dimethyl(hexa-1,5-diene)platinum, $[\mathrm{Rh}(\mathrm{COD})]^{+}$or $[\operatorname{Ir}(\mathrm{COD})]^{+}$.

Given this reactivity, the diplatinum complex 54 was not able to be fully characterised. However, selected ${ }^{1} \mathrm{H}$ and ${ }^{13} \mathrm{C}$ NMR signals were assigned. In particular, the signals for the methyl ligands coordinated trans to the phosphorus atoms were identified. In the ${ }^{1} \mathrm{H}$ NMR spectra the signals for these ligands appeared as two doublets of doublets at 0.41 and $-0.12 \mathrm{ppm}$. The ${ }^{3} J_{\mathrm{PH}}$ values of $9.0-6.5 \mathrm{~Hz}$ were slightly higher than that of other methyl ligands coordinated trans to the ligand $\mathbf{3}$ reported in this work. The ${ }^{2} J_{\mathrm{PtH}}$ value of $68.3 \mathrm{~Hz}$ was very similar to that observed in the starting complex $\left[\mathrm{PtMe}_{2}(\mathrm{PP})\right] \mathbf{1 7}$ and the trimetallic complex 55. The similarity of the values of these coupling constants, both ${ }^{3} J_{\mathrm{PH}}$ and ${ }^{2} J_{\mathrm{PtH}}$, with those of the monometallic complex 17 and the trimetallic complex 55 suggested that the $\mathrm{Pt}-\mathrm{Me}$ bond was not appreciably affected by the coordination of dimethylplatinum moeities to the pyridyl nitrogens. From comparison with the ${ }^{1} \mathrm{H}$ NMR data of $\mathbf{1 7}$ 
and 55 it was proposed that the signal at $-0.12 \mathrm{ppm}$ represented the methyl ligand closest to the platinum centre coordinated to the pyridyl nitrogens, while the signal at $0.41 \mathrm{ppm}$ was assigned to the methyl ligand on the side with uncoordinated pyridyl rings.

This NMR data indicated that the nitrogen atoms on two pyridyl rings attached to the same phosphorus coordinate to one platinum, rather than one pyridyl ring on each phosphorus. This results in the formation of six-membered chelate rings, as opposed to the strained eight-membered rings that would form if one pyridyl nitrogen atom on each phosphorus atom coordinated to a platinum centre. Also if one pyridyl ring on each phosphorus coordinated to the metal centre the ${ }^{31} \mathrm{P}$ NMR spectrum of the dimetallic complex would contain one signal as opposed to the two doublets that were observed.

The formation of a mixture, of the $\left[\mathrm{PtMe}_{2}(\mathrm{PP})\right]$ complex 17, $\left[\left(\mathrm{PtMe}_{2}\right)_{2}(\mathrm{PP})\right]$ complex 54 and $\left[\left(\mathrm{PtMe}_{2}\right)_{3}(\mathrm{PP})\right]$ complex 55, when one equivalent of dimethyl(hexa-1,5diene)platinum was reacted with the $\left[\mathrm{PtMe}_{2}(\mathrm{PP})\right]$ complex 17 suggested that the coordination of a platinum centre to one set of pyridyl nitrogens in the $\left[\mathrm{PtMe}_{2}(\mathrm{PP})\right]$ complex 17 was not more favourable than coordinating platinum to the free pyridyl nitrogens in the $\left[\left(\mathrm{PtMe}_{2}\right)_{2}(\mathrm{PP})\right]$ complex 54. This lack of binding preference was interesting as the NMR data of the $\left[\left(\mathrm{PtMe}_{2}\right)_{2}(\mathrm{PP})\right]$ complex 54 indicated that the chemical environment of the $\mathrm{PPy}_{2}$ moiety where the nitrogens were uncoordinated had changed from that in $\mathbf{1 7}$. For example, the ${ }^{31} \mathrm{P}$ NMR signal of the phosphorus with free pyridyl rings appeared at $13.13 \mathrm{pm}$ with ${ }^{1} J_{\mathrm{PtP}}=1828 \mathrm{~Hz}$, compared to $10.50 \mathrm{ppm}$ and ${ }^{1} J_{\mathrm{PtP}}=1840 \mathrm{~Hz}$ for $\mathbf{1 7}$. However, any difference in electronics and the steric bulk caused by the coordination of the dimethylplatinum moiety was not enough to prevent the coordination of another dimethylplatinum moiety. If these changes had disfavoured the coordination of another platinum it would have led to the formation of solely the diplatinum $\left[\left(\mathrm{PtMe}_{2}\right)_{2}(\mathrm{PP})\right]$ complex $\mathbf{5 4}$.

In contrast when one equivalent of dimethyl(hexa-1,5-diene)platinum reacted with the unsymmetrical $[\mathrm{PtClMe}(\mathrm{PP})]$ complex 27 the diplatinum [ $\left.\left(\mathrm{PtMe}_{2}\right) \mathrm{PtClMe}(\mathrm{PP})\right]$ complex 58 was the major species in solution after 24 hours at room temperature. As mentioned earlier, the ${ }^{31} \mathrm{P}$ NMR spectra of this complex contained a doublet at $24.20 \mathrm{ppm}\left({ }^{2} J_{\mathrm{PP}}=12.1 \mathrm{~Hz}\right)$ with two sets of ${ }^{195} \mathrm{Pt}$ satellites, ${ }^{1} J_{\mathrm{PtP}}=1839$ and ${ }^{3} J_{\mathrm{PtP}}=88.7 \mathrm{~Hz}$, and a doublet at $12.00 \mathrm{ppm}$ with one set of ${ }^{195} \mathrm{Pt}$ satellites, ${ }^{1} J_{\mathrm{PtP}}$ $=4203 \mathrm{~Hz}$. This indicated that the platinum centre had coordinated to the same side of the complex as the chloride ligand, a result of the smaller size of the chloride ligand. ${ }^{181}$ 
The ${ }^{1} J_{\mathrm{PtP}}$ value of $1838 \mathrm{~Hz}$ was much lower than that observed for the analogous signal in the $\left[\left(\mathrm{PtMe}_{2}\right)_{2}(\mathrm{PP})\right]$ complex 54 (Table 5.3). This was due to the high cis influence of the chloride ligand, compared to the low cis influence of the methyl ligand in $\mathbf{5 4}$ (see Chapter 3 for further discussion). ${ }^{115,116}$ However, when this ${ }^{1} J_{\mathrm{PtP}}$ value was compared to that of the $[\mathrm{PtClMe}(\mathrm{PP})]$ complex 27, ${ }^{1} J_{\mathrm{PtP}}=1725 \mathrm{~Hz}$, an increase in the coupling constant of about $100 \mathrm{~Hz}$ upon coordination of the pyridyl nitrogen atoms was observed. This was consistent with what was observed for the $\left[\left(\mathrm{PtMe}_{2}\right)_{2}(\mathrm{PP})\right]$ complex 54. The ${ }^{1} J_{\mathrm{PtP}}$ value of $4203 \mathrm{~Hz}$ for the phosphorus coordinated trans to the chloride ligand was slightly lower than that observed for the $[\mathrm{PtClMe}(\mathrm{PP})]$ complex 27, ${ }^{1} J_{\mathrm{PtP}}=4211 \mathrm{~Hz}$. This slight decrease in the ${ }^{1} J_{\mathrm{PtP}}$ value for the phosphorus atom with uncoordinated pyridyl rings was observed for all of the dimetallic complexes of ligand $\mathbf{3}$ synthesised in this work.

In the ${ }^{1} \mathrm{H}$ NMR spectrum of complex 58 the methyl ligand on the central platinum appeared as a doublet of doublets at $0.64 \mathrm{ppm}$. This was consistent with the proposal that in the other dimetallic complexes 54,62 and 63 the signals for the methyl ligands with a negative chemical shift were due to the methyl ligands closest to the second metal centre while those at positive chemical shift were on the opposite side of the complex. The values of ${ }^{2} J_{\mathrm{PtH}}$ and ${ }^{3} J_{\mathrm{PH}}$ were lower than those of the $\left[\left(\mathrm{PtMe}_{2}\right)_{2}(\mathrm{PP})\right]$ complex 54. Once again this was due to the high cis influence of the chloride ligand.

As the diplatinum $\left[\left(\mathrm{PtMe}_{2}\right) \mathrm{PtClMe}(\mathrm{PP})\right]$ complex 58 was the major species in solution after 24 hours, the ${ }^{1} \mathrm{H}$ and ${ }^{13} \mathrm{C}$ NMR data of this complex could be assigned. In a similar manner to the ${ }^{31} \mathrm{P}$ NMR signals, the ${ }^{1} \mathrm{H}$ and ${ }^{13} \mathrm{C}$ NMR signals were found to be slightly shifted from those of the $\left[\left(\mathrm{PtMe}_{2}\right)_{3}(\mathrm{PP})\right]$ complex 55 (for the side with the pyridyl nitrogen atoms coordinated to platinum) or the $[\mathrm{PtClMe}(\mathrm{PP})]$ complex 27 (for the other side). For example, the signals for the aromatic protons on the ligand backbone appeared at 6.73 and $6.67 \mathrm{ppm}$, for the side with coordinated pyridyl nitrogen atoms, and 6.67 and $5.98 \mathrm{ppm}$, for the other side.

The infrared spectrum recorded of 58 showed $\mathrm{C}=\mathrm{N}$ stretches at 1585,1573 and $1562 \mathrm{~cm}^{-1}$. This confirmed the presence of coordinated and uncoordinated pyridyl rings. ${ }^{40,107,134-136}$

No intermediate complexes were observed in the rhodium and iridium reactions. However, when the $\left[\mathrm{PtMe}_{2}(\mathrm{PP})\right]$ complex 17 was reacted with one equivalent of $[\mathrm{Rh}(\mathrm{COD})]^{+}$or $[\operatorname{Ir}(\mathrm{COD})]^{+}$a mixture of $\left[\mathrm{PtMe}_{2}(\mathrm{PP})\right]$ complex $\mathbf{1 7}$, the dimetallic complex, $\left[\{\mathrm{M}(\mathrm{COD})\} \mathrm{PtMe}_{2}(\mathrm{PP})\right]^{+}(\mathrm{M}=\mathrm{Rh}$ 62, Ir 63), and the trimetallic complex $\left[\{\mathrm{M}(\mathrm{COD})\}_{2} \mathrm{PtMe}_{2}(\mathrm{PP})\right]^{2+}(\mathrm{M}=\mathrm{Rh}$ 60, Ir 61) was formed (Scheme 5.6). 
The formation of a similar mixture to that observed in the dimethylplatinum reaction suggested that the formation of the trimetallic $\left[\{\mathrm{M}(\mathrm{COD})\}_{2} \mathrm{PtMe}_{2}(\mathrm{PP})\right]^{2+}$ complexes $(\mathrm{M}=\mathrm{Rh}$ 60, Ir 61) also occurred in a stepwise manner. Given this, the reason the intermediate dimetallic complexes were not observed in the NMR spectra of the reactions when two equivalents of $[\mathrm{Rh}(\mathrm{COD})]^{+}$or $[\operatorname{Ir}(\mathrm{COD})]^{+}$were added must be because the coordination of rhodium or iridium took place on a much shorter timescale than the dimethylplatinum reaction, 20 minutes compared to 48 hours. The formation of a statistical distribution of products indicated that the coordination of rhodium or iridium to the pyridyl nitrogens does not affect the energy required to coordinate another rhodium or iridium to the other two pyridyl nitrogens.

The ${ }^{31} \mathrm{P}$ and ${ }^{1} \mathrm{H}$ NMR spectra of these reaction mixtures were very similar to that of the dimethylplatinum reaction. The signals due to the dimetallic rhodium compound $\left[\{\mathrm{Rh}(\mathrm{COD})\} \mathrm{PtMe}_{2}(\mathrm{PP})\right] \mathrm{CH}\left(\mathrm{SO}_{2} \mathrm{CF}_{3}\right)_{2} \mathbf{6 2}$ in the ${ }^{31} \mathrm{P} \mathrm{NMR}$ spectrum appeared as two doublets at 29.48 and $15.48 \mathrm{ppm}\left({ }^{2} J_{\mathrm{PP}}=10.7 \mathrm{~Hz}\right)$. The ${ }^{1} J_{\mathrm{PtP}}$ values of 2003 and $1819 \mathrm{~Hz}$ were still within the range expected for a phosphorus atom coordinated trans to a methyl ligand. ${ }^{16}$ However, there is a difference of almost $200 \mathrm{~Hz}$ between these two coupling constants, indicating that the coordination of the pyridyl nitrogens to a rhodium centre has affected the nature of the Pt-P bond.

As the rhodiumplatinum complex 62 was only ever formed as part of a mixture it could not be fully characterised. However, the NMR signals of the methyl ligands on platinum could be distinguished from the signals of the other complexes in solution. Two doublets of doublets at 0.42 and $-0.28 \mathrm{ppm}$ in the ${ }^{1} \mathrm{H}$ NMR spectrum were observed for this complex. The ${ }^{3} J_{\mathrm{PH}}$ values of $6.8-8.6 \mathrm{~Hz}$ were consistent with the values observed for the other dimetallic complexes, while the ${ }^{2} J_{\mathrm{PtH}}$ values were of a similar magnitude to the values of the other dimetallic complexes (Table 5.3).

The NMR data of the dimetallic $\left[\{\operatorname{Ir}(\mathrm{COD})\} \mathrm{PtMe}_{2}(\mathrm{PP})\right] \mathrm{CH}\left(\mathrm{SO}_{2} \mathrm{CF}_{3}\right)_{2}$ compound 63 followed the same pattern as the other dimetallic complexes, with two doublets in the ${ }^{31} \mathrm{P}$ NMR spectrum at 29.84 and $15.53 \mathrm{ppm}$ with a ${ }^{2} J_{\mathrm{PP}}$ value of $10.3 \mathrm{~Hz}$. The ${ }^{1} J_{\mathrm{PtP}}$ values were similar to those of the $\left[\{\mathrm{Rh}(\mathrm{COD})\} \mathrm{PtMe}_{2}(\mathrm{PP})\right] \mathrm{CH}\left(\mathrm{SO}_{2} \mathrm{CF}_{3}\right)_{2}$ compound $\mathbf{6 2}$ (2000 and $1881 \mathrm{~Hz})$.

The signals for the methyl ligands in the iridiumplatinum compound $\mathbf{6 3}$ appeared as doublets of doublets at 0.42 and $-0.30 \mathrm{ppm}$ in the ${ }^{1} \mathrm{H}$ NMR spectrum. The ${ }^{3} J_{\mathrm{PH}}$ and ${ }^{2} J_{\mathrm{PtH}}$ values were almost identical to those of the rhodium compound and very similar to the dimetallic platinum complex $\mathbf{5 4}$. 
The ${ }^{31} \mathrm{P}$ NMR data and the ${ }^{1} \mathrm{H}$ NMR signals of the methyl ligands are collected in Table 5.3. It is remarkable that there was such a small variation in the NMR data between the dimetallic complexes. The biggest variation in the ${ }^{1} J_{\mathrm{PtP}}$ values was $19 \mathrm{~Hz}$, while the ${ }^{2} J_{\mathrm{PP}}$ coupling varied less than $1 \mathrm{~Hz}$ between the complexes. This implies that neither the nature of the complex, neutral or charged, nor the nature of the metal centre, $\mathrm{Pt}(\mathrm{II})$ or $\mathrm{Rh}(\mathrm{I})$ or $\mathrm{Ir}(\mathrm{I})$, was significant in determining the chemical environment in these complexes.

\subsection{Homotrimetallic Complexes of dpyp $m \mathrm{x}$}

It was observed with the trimetallic complexes of the dpypox ligand $\mathbf{3}$ that the complexes containing chloride ligands possessed low solubility which limited their characterisation. Given this the $[\mathrm{PtMe}(\mathrm{PCP})]$ complex $\mathbf{5 1}$ was used as the starting material for the synthesis of trimetallic complexes of the dpyp $m \mathrm{x}$ ligand 4 .

As the reactions of the dpypox ligand 3 with three equivalents dimethyl(hexa-1,5diene)platinum proceeded smoothly to give the trimetallic complex, and two sets of ${ }^{195} \mathrm{Pt}$ satellites were observed in the ${ }^{31} \mathrm{P}$ NMR spectra, this was the obvious starting material to use in the initial exploration of the trimetallic complexes of the dpyp $m \mathrm{x}$ ligand 4. Also these reactions used the $[\mathrm{PtMe}(\mathrm{PCP})]$ complex $\mathbf{5 1}$ as the starting material rather than the ligand 4 . This was because reaction of an excess of platinum precursor with ligand $\mathbf{4}$ formed an intractable, probably polymeric, product.

When two equivalents of dimethyl(hexa-1,5-diene)platinum were reacted with the $[\mathrm{PtMe}(\mathrm{PCP})]$ complex 51 the ${ }^{31} \mathrm{P}$ and ${ }^{1} \mathrm{H}$ NMR spectra recorded after 90 minutes contained the signals for the starting complex 51 as well the $\left[\left(\mathrm{PtMe}_{2}\right) \mathrm{PtMe}(\mathrm{PCP})\right]$ complex 64 and the trimetallic $\left[\left(\mathrm{PtMe}_{2}\right)_{2} \mathrm{PtMe}(\mathrm{PCP})\right]$ complex 65. After 23 hours only the signals for the triplatinum complex $\mathbf{6 5}$ and displaced hexa-1,5-diene were observed in the NMR spectra (Scheme 5.7).

In the ${ }^{31} \mathrm{P}$ NMR spectrum the signal for the triplatinum $\left[\left(\mathrm{PtMe}_{2}\right)_{2} \mathrm{PtMe}(\mathrm{PCP})\right]$ complex 65 appeared as a singlet at $52.67 \mathrm{ppm}$ with two sets of ${ }^{195} \mathrm{Pt}$ satellites. The ${ }^{1} J_{\mathrm{PtP}}$ value of $3097 \mathrm{~Hz}$ was larger than that observed for the $[\mathrm{PtMe}(\mathrm{PCP})]$ complex 51, where ${ }^{1} J_{\mathrm{PtP}}=2913 \mathrm{~Hz}$. This increase in the value of ${ }^{1} J_{\mathrm{PtP}}$ of $184 \mathrm{~Hz}$ was consistent with the 130-141 Hz increase observed in the trimetallic complexes of the dpypox ligand 3 . The ${ }^{3} J_{\mathrm{PtP}}$ value of $41.8 \mathrm{~Hz}$ was smaller than the value for the triplatinum $\left[\left(\mathrm{PtMe}_{2}\right)_{3}(\mathrm{PP})\right]$ complex 55 , where ${ }^{3} J_{\mathrm{PtP}}=74.0 \mathrm{~Hz}$. It is proposed that this difference in the ${ }^{3} J_{\mathrm{PtP}}$ values was due to the bond constraints imposed by 


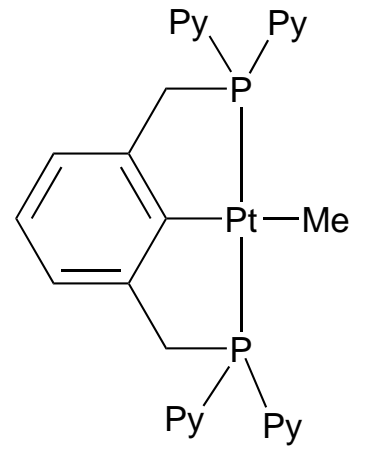

51

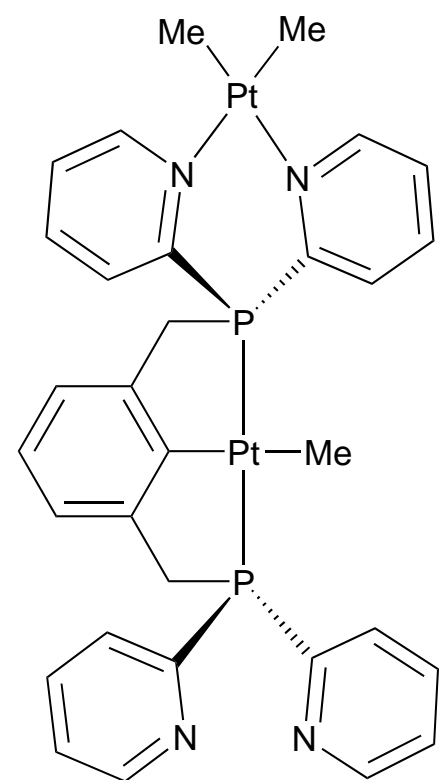

64

(ii)

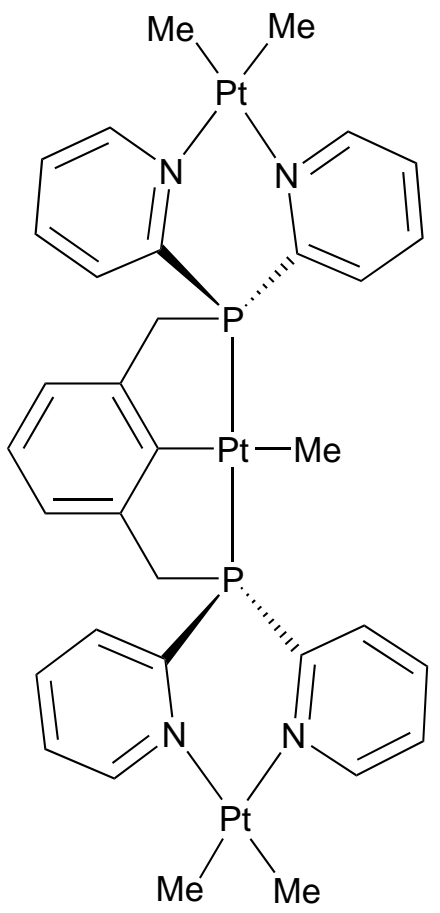

65

Scheme 5.7 Synthesis of $\left[\left(\mathrm{PtMe}_{2}\right)_{2} \mathrm{PtMe}(\mathrm{PCP})\right]$. Reagents and conditions: (i) dimethyl(hexa-1,5-diene)platinum, $\mathrm{CDCl}_{3}, 90$ minutes; (ii) 23 hours. 
the pincer core.

In contrast to the trimetallic complexes of dpypox ligand 3, trimetallic complexes with a planar [PtMePCP] core have two planes of symmetry. Thus the ${ }^{1} \mathrm{H}$ NMR spectra of these complexes contained four signals for the pyridyl protons, as opposed to the eight signals observed in the ${ }^{1} \mathrm{H}$ NMR spectra of the trimetallic complexes of ligand 3. The fact that the $[\mathrm{PtMePCP}]$ core of this molecule was planar also meant that the methylene protons on the ligand backbone inhabited a single environment. The signals for the pyridyl and methylene protons shifted downfield upon coordination of the pyridyl nitrogens to the platinum centre, appearing at 9.13-7.44 and $5.00 \mathrm{ppm}$ in the ${ }^{1} \mathrm{H}$ NMR spectrum respectively (Table 5.4). Once again the signal for the proton on the carbon next to the nitrogen (H4) has moved to above $9 \mathrm{ppm}$, confirming the coordination of the nitrogen atom to the platinum. ${ }^{46,48,127,141,175}$ Also of note was the large downfield shift of the proton H1, suggesting that this proton was in close proximity to the central platinum in this complex as well. ${ }^{105,177-180}$

Table 5.4 Selected ${ }^{1} \mathrm{H}$ NMR data of trimetallic complexes of dpyp $m \mathrm{x}$

\begin{tabular}{|c|c|c|c|c|c|c|}
\hline \multirow[b]{2}{*}{ Compound } & & \multicolumn{5}{|c|}{$\delta^{1} \mathrm{H} / \mathrm{ppm}^{a}$} \\
\hline & & $\mathrm{H} 1$ & $\mathrm{H} 2$ & H3 & $\mathrm{H} 4$ & $\mathrm{CH}_{2} \mathrm{P}$ \\
\hline$[\mathrm{PtMe}(\mathrm{PCP})]$ & 51 & 8.53 & 7.72 & 7.28 & 8.72 & 4.46 \\
\hline$\left[\left(\mathrm{PtMe}_{2}\right)_{2} \mathrm{PtMe}(\mathrm{PCP})\right]$ & 65 & 9.10 & 8.04 & 7.44 & 9.13 & 5.00 \\
\hline$\left[\{\mathrm{Rh}(\mathrm{COD})\}_{2} \mathrm{PtMe}(\mathrm{PCP})\right]^{2+}$ & 66 & 9.27 & 8.24 & 7.81 & 9.25 & 5.97 \\
\hline$\left[\{\operatorname{Ir}(\mathrm{COD})\}_{2} \mathrm{PtMe}(\mathrm{PCP})\right]^{2+}$ & 67 & 9.39 & 8.30 & 7.89 & 9.31 & 5.50 \\
\hline
\end{tabular}

${ }^{a}$ Spectra recorded in $\mathrm{CDCl}_{3}$.

The $\mathrm{C}=\mathrm{N}$ stretches of the triplatinum complex $\mathbf{6 5}$ appeared at 1601 and $1585 \mathrm{~cm}^{-1}$ in the infrared spectrum. This shift of about $30 \mathrm{~cm}^{-1}$ from the $\mathrm{C}=\mathrm{N}$ stretches observed in the infrared spectra of the $[\mathrm{PtMe}(\mathrm{PCP})]$ complex $\mathbf{5 1}$ and the free ligand 4 (Table 5.5) was further evidence that the pyridyl nitrogen atoms had coordinated to the platinum centre. ${ }^{40,107,134-136}$

Table 5.5 IR data of mono- and trimetallic complexes of dpyp $m x$

\begin{tabular}{lcc}
\hline Compound & & $\mathrm{C}=\mathrm{N}$ stretch $/ \mathrm{cm}^{-1}$ \\
\hline dpyp $m \mathrm{x}$ & $\mathbf{4}$ & 1573,1559 \\
{$[\mathrm{PtMe}(\mathrm{PCP})]$} & $\mathbf{5 1}$ & 1573,1563 \\
{$\left[(\mathrm{PtMe})_{2} \mathrm{PtMe}(\mathrm{PCP})\right]$} & $\mathbf{6 5}$ & 1601,1585 \\
{$\left[\{\mathrm{Rh}(\mathrm{COD})\}_{2} \mathrm{PtMe}(\mathrm{PCP})\right]^{2+}$} & $\mathbf{6 6}$ & 1604,1587 \\
{$\left[\{\operatorname{Ir}(\mathrm{COD})\}_{2} \mathrm{PtMe}(\mathrm{PCP})\right]^{2+}$} & $\mathbf{6 7}$ & 1602,1589 \\
\hline
\end{tabular}




\subsection{Heterotrimetallic Complexes of $\operatorname{dpyp} m x$}

The reactions with rhodium and iridium precursor complexes were repeated with the $[\mathrm{PtMe}(\mathrm{PCP})]$ complex $\mathbf{5 1}$ in a attempt to make the analogous dirhodiumplatinum and diiridiumplatinum complexes with a pincer core.

When the $[\mathrm{PtMe}(\mathrm{PCP})]$ complex 51 was reacted with one equivalent of $[\mathrm{Rh}(\mathrm{COD})(\mu-$ $\mathrm{Cl})]_{2}$ or $[\operatorname{Ir}(\mathrm{COD})(\mu-\mathrm{Cl})]_{2}$ and two equivalents of $\mathrm{NaCH}\left(\mathrm{SO}_{2} \mathrm{CF}_{3}\right)_{2}$ new trimetallic complexes of the type $\left[\{\mathrm{M}(\mathrm{COD})\}_{2} \operatorname{PtMe}(\mathrm{PCP})\right]^{2+}(\mathrm{M}=\mathrm{Rh} \mathbf{6 6}$, Ir 67) were formed after 20 minutes at room temperature (Scheme 5.8).

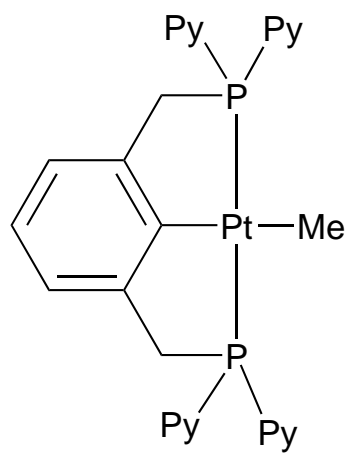

51

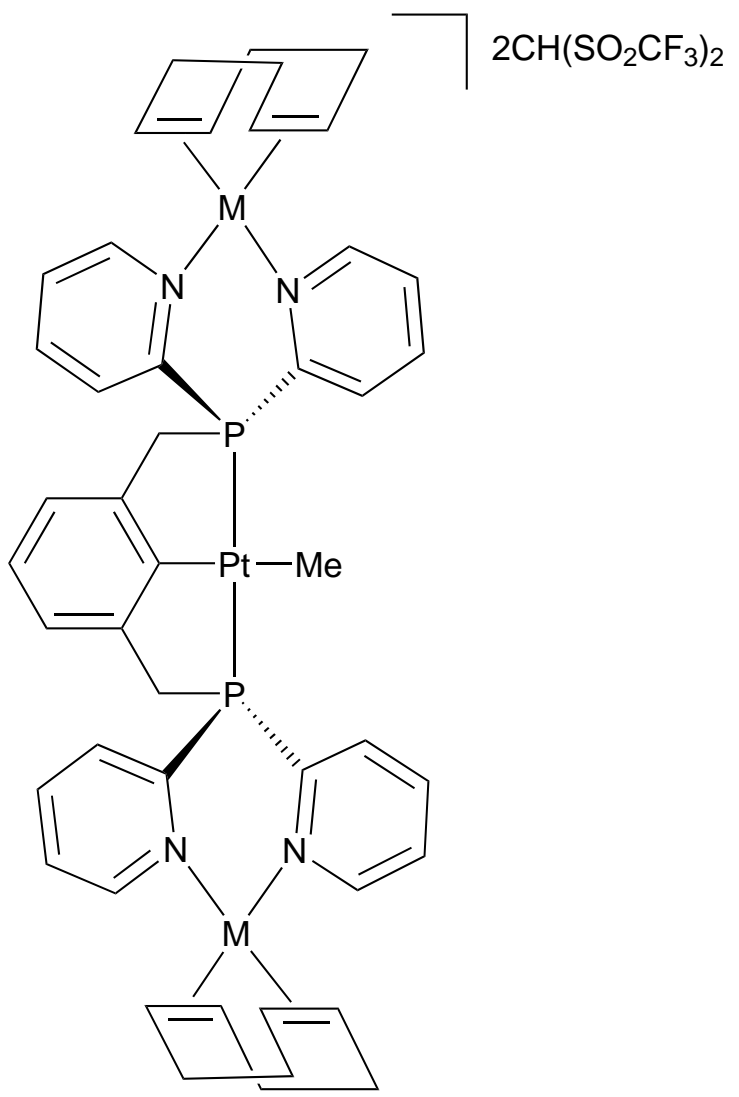

$66 \mathrm{M}=\mathrm{Rh}$

$67 \mathrm{M}=\mathrm{Ir}$

Scheme 5.8 Synthesis of $\left[\{\mathrm{M}(\mathrm{COD})\}_{2} \mathrm{PtMe}(\mathrm{PCP})\right]\left\{\mathrm{CH}\left(\mathrm{SO}_{2} \mathrm{CF}_{3}\right)_{2}\right\}_{2}$. Reagents and conditions: (i) $[\mathrm{Rh}(\mathrm{COD})(\mu-\mathrm{Cl})]_{2}$ or $[\operatorname{Ir}(\mathrm{COD})(\mu-\mathrm{Cl})]_{2}, \mathrm{NaCH}\left(\mathrm{SO}_{2} \mathrm{CF}_{3}\right)_{2}$, $\mathrm{CDCl}_{3}, 20$ minutes, room temperature.

The ${ }^{31} \mathrm{P},{ }^{1} \mathrm{H}$ and ${ }^{19} \mathrm{~F}$ NMR spectra of the new compounds were very similar to each other. In the ${ }^{31} \mathrm{P}$ NMR spectra there were new singlets at 53.08 and $53.76 \mathrm{ppm}$ with ${ }^{1} J_{\mathrm{PtP}}$ values of 3244 and $3250 \mathrm{~Hz}$ for the dirhodiumplatinum compound 66 and the diiridiumplatinum compound 67 respectively. Upon coordination of the pyridyl nitrogen atoms to the metal centres the signals due to the phosphorus atoms shifted 15 ppm downfield. This was a smaller shift than that observed in the analogous re- 
actions with the $\left[\mathrm{PtMe}_{2}(\mathrm{PP})\right]$ complex 17 (22 ppm). In contrast, the increase in the value of ${ }^{1} J_{\mathrm{PtP}}$ was much larger, 331 and $337 \mathrm{~Hz}$ for the dirhodiumplatinum $\mathbf{6 6}$ and diiridiumplatinum 67 compounds respectively. This indicated that the coordination of the pyridyl nitrogen atoms had affected the Pt-P bond significantly.

A singlet peak at $3.81 \mathrm{ppm}$ in the ${ }^{1} \mathrm{H}$ NMR spectrum and a signal in the ${ }^{19} \mathrm{~F}$ NMR spectrum at $-81.9 \mathrm{ppm}$ in both reactions confirmed that the $\mathrm{CH}\left(\mathrm{SO}_{2} \mathrm{CF}_{3}\right)_{2}^{-}$ counterions were not coordinated to any of the metal centres. ${ }^{128}$

The signals of the dpyp $m \mathrm{x}$ ligand 4 had shifted downfield in the ${ }^{1} \mathrm{H}$ NMR spectra of these reactions (Table 5.4). The general pattern of the signals was consistent with what has been observed in all of the trimetallic complexes in this work. For example, the signal for $\mathrm{H} 4$ moved above $9 \mathrm{ppm}$ and the signal for H1 was also shifted dramatically downfield. This once again confirmed the coordination of the pyridyl nitrogens to the metal centres and suggested that the $\mathrm{H} 1$ proton was in close proximity to the central metal atom. ${ }^{46,48,141,175-180}$ Interestingly, the signals for the pyridyl protons in the diiridiumplatinum compound 67 were further downfield than those for the dirhodiumplatinum compound 66. This was consistent with what was observed in the analogous complexes of the dpypox ligand 3, 60 and 61, and for the $\left[\mathrm{AuCl}\left(\mu-\mathrm{PPhPy}_{2}\right) \mathrm{MCl}(\mathrm{COD})\right]$ complexes $(\mathrm{M}=\mathrm{Rh}, \mathrm{Ir}) .{ }^{25}$

After about one hour these complexes formed crystalline solids which do not redissolve in chloroform. While both the dirhodiumplatinum and diiridiumplatinum compounds were soluble in acetone they were not soluble enough for ${ }^{13} \mathrm{C}$ data to be obtained.

The $\mathrm{C}=\mathrm{N}$ stretches of the dirhodiumplatinum complex $\mathbf{6 6}$ appeared in the IR spectra at 1604 and $1587 \mathrm{~cm}^{-1}$, while the $\mathrm{C}=\mathrm{N}$ stretches of the diiridiumplatinum complex 67 were almost identical at 1602 and $1589 \mathrm{~cm}^{-1}$. This was further evidence that the pyridyl nitrogen atoms were coordinated to the metal centres in these complexes, as these $\nu(\mathrm{C}=\mathrm{N})$ values were shifted to higher frequencies from that of the $[\mathrm{PtMe}(\mathrm{PCP})]$ complex $5 \mathbf{1}$ and the free ligand $\mathbf{4}$ (Table 5.5). ${ }^{40,107,134-136}$

\subsection{Dimetallic Intermediates of dpyp $m x$}

In the synthesis of the triplatinum $\left[\left(\mathrm{PtMe}_{2}\right)_{2} \mathrm{PtMe}(\mathrm{PCP})\right]$ complex $\mathbf{6 5}$ the formation of the diplatinum intermediate $\left[\left(\mathrm{PtMe}_{2}\right) \mathrm{PtMe}(\mathrm{PCP})\right]$ complex 64 was observed in the ${ }^{31} \mathrm{P}$ and ${ }^{1} \mathrm{H}$ NMR spectra recorded after 90 minutes. In a similar manner 
to the dimetallic complexes of ligand $\mathbf{3}$, the signals for the $\left[\left(\mathrm{PtMe}_{2}\right) \mathrm{PtMe}(\mathrm{PCP})\right]$ complex 64 appeared as two doublets with ${ }^{195} \mathrm{Pt}$ satellites in the ${ }^{31} \mathrm{P}$ NMR spectra recorded of the reaction mixture. However, as the two phosphorus atoms were in a trans arrangement in these complexes, the ${ }^{2} J_{\mathrm{PP}}$ value was large, at $392 \mathrm{~Hz}$. The doublets appeared at 53.67 and $37.81 \mathrm{ppm}$ with ${ }^{1} J_{\mathrm{PtP}}$ values of 3058 and $2950 \mathrm{~Hz}$ respectively (Table 5.6). The doublet that was greatly shifted downfield from the starting material was due to the phosphorus atom attached to the pyridyl rings that were coordinated to the second platinum centre, while the other doublet was due to the other phosphorus atom. The increase in the values of ${ }^{1} J_{\mathrm{PtP}}$ indicated that the coordination of one set of pyridyl nitrogens to a second platinum affected both Pt-P bonds.

Table 5.6 ${ }^{31} \mathrm{P}$ NMR data of dimetallic complexes $[(\mathrm{M}) \mathrm{PtMe}(\mathrm{PCP})]$

\begin{tabular}{|c|c|c|c|c|c|c|}
\hline \multirow[b]{2}{*}{ M } & \multirow[b]{2}{*}{ Complex } & \multicolumn{2}{|c|}{$\mathrm{P}_{\text {coord Py }}$} & \multicolumn{2}{|c|}{$\mathrm{P}_{\text {free Py }}$} & \multirow[b]{2}{*}{${ }^{2} J_{\mathrm{PP}}$} \\
\hline & & $\delta^{31} \mathrm{P} / \mathrm{ppm}^{a}$ & ${ }^{1} J_{\mathrm{PtP}} / \mathrm{Hz}$ & $\delta^{31} \mathrm{P} / \mathrm{ppm}$ & ${ }^{1} J_{\mathrm{PtP}} / \mathrm{Hz}$ & \\
\hline $\mathrm{PtMe}_{2}$ & 64 & 53.67 & 3058 & 37.81 & 2950 & 392 \\
\hline $\mathrm{Rh}(\mathrm{COD})^{+}$ & 68 & 52.90 & 3079 & 38.40 & 3051 & 405 \\
\hline $\operatorname{Ir}(\mathrm{COD})^{+}$ & 69 & 55.06 & 3080 & 37.84 & 3026 & 401 \\
\hline
\end{tabular}

${ }^{a}$ Spectra recorded in $\mathrm{CDCl}_{3}$.

Reaction of one equivalent of dimethyl(hexa-1,5-diene)platinum with [PtMe(PCP)] complex 51 resulted in a mixture of complex $\mathbf{5 1}$, diplatinum $\left[\left(\mathrm{PtMe}_{2}\right) \mathrm{PtMe}(\mathrm{PCP})\right]$ complex 64 and triplatinum [(PtMe $\left.\left.)_{2}\right)_{2 t M e}(\mathrm{PCP})\right]$ complex 65 (Scheme 5.9). Due to the $\left[\left(\mathrm{PtMe}_{2}\right) \mathrm{PtMe}(\mathrm{PCP})\right]$ complex $\mathbf{6 4}$ only being formed as part of a mixture it was never isolated but characterised by NMR methods.

No intermediate complexes were observed in the rhodium and iridium reactions discussed above. In an identical manner to the reactions of the $\left[\mathrm{PtMe}_{2}(\mathrm{PP})\right]$ complex 17, when the $[\mathrm{PtMe}(\mathrm{PCP})]$ complex 51 was reacted with half an equivalent of $[\mathrm{Rh}(\mathrm{COD})(\mu-\mathrm{Cl})]_{2}$ or $[\mathrm{Ir}(\mathrm{COD})(\mu-\mathrm{Cl})]_{2}$ and one equivalent of $\mathrm{NaCH}\left(\mathrm{SO}_{2} \mathrm{CF}_{3}\right)_{2}$ a mixture of 51, the dimetallic $[\{\mathrm{M}(\mathrm{COD})\} \mathrm{PtMe}(\mathrm{PCP})]^{+}$complex $(\mathrm{M}=\mathrm{Rh} \mathbf{6 8}$, Ir 69), and the trimetallic $\left[\{\mathrm{M}(\mathrm{COD})\}_{2} \mathrm{PtMe}(\mathrm{PCP})\right]^{2+}$ complex $(\mathrm{M}=\mathrm{Rh} \mathbf{6 6}$, Ir 67) was formed (Scheme 5.9).

The ${ }^{31} \mathrm{P}$ NMR signals of the $[\{\mathrm{M}(\mathrm{COD})\} \mathrm{PtMe}(\mathrm{PCP})] \mathrm{CH}\left(\mathrm{SO}_{2} \mathrm{CF}_{3}\right)_{2}$ compounds $(\mathrm{M}$ $=\mathrm{Rh}$ 68, Ir 69) appeared as two doublets with platinum-195 satellites (Table 5.6). Given that in this complex the phosphorus atoms were coordinated trans to each other the doublets were large with ${ }^{2} J_{\mathrm{PP}} \approx 400 \mathrm{~Hz}$. The signals for the rhodiumplatinum complex 68 in the ${ }^{31} \mathrm{P}$ NMR spectrum appeared at 52.90 and $38.40 \mathrm{ppm}$ with ${ }^{1} J_{\mathrm{PtP}}$ values of 3079 and $3051 \mathrm{~Hz}$ respectively. As in the previous dimetallic complexes, the signal at a higher chemical shift with a larger value of ${ }^{1} J_{\mathrm{PtP}}$ was assigned 


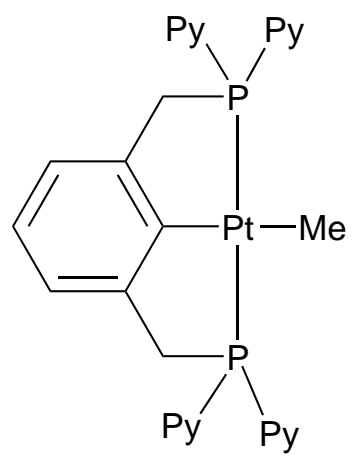

51
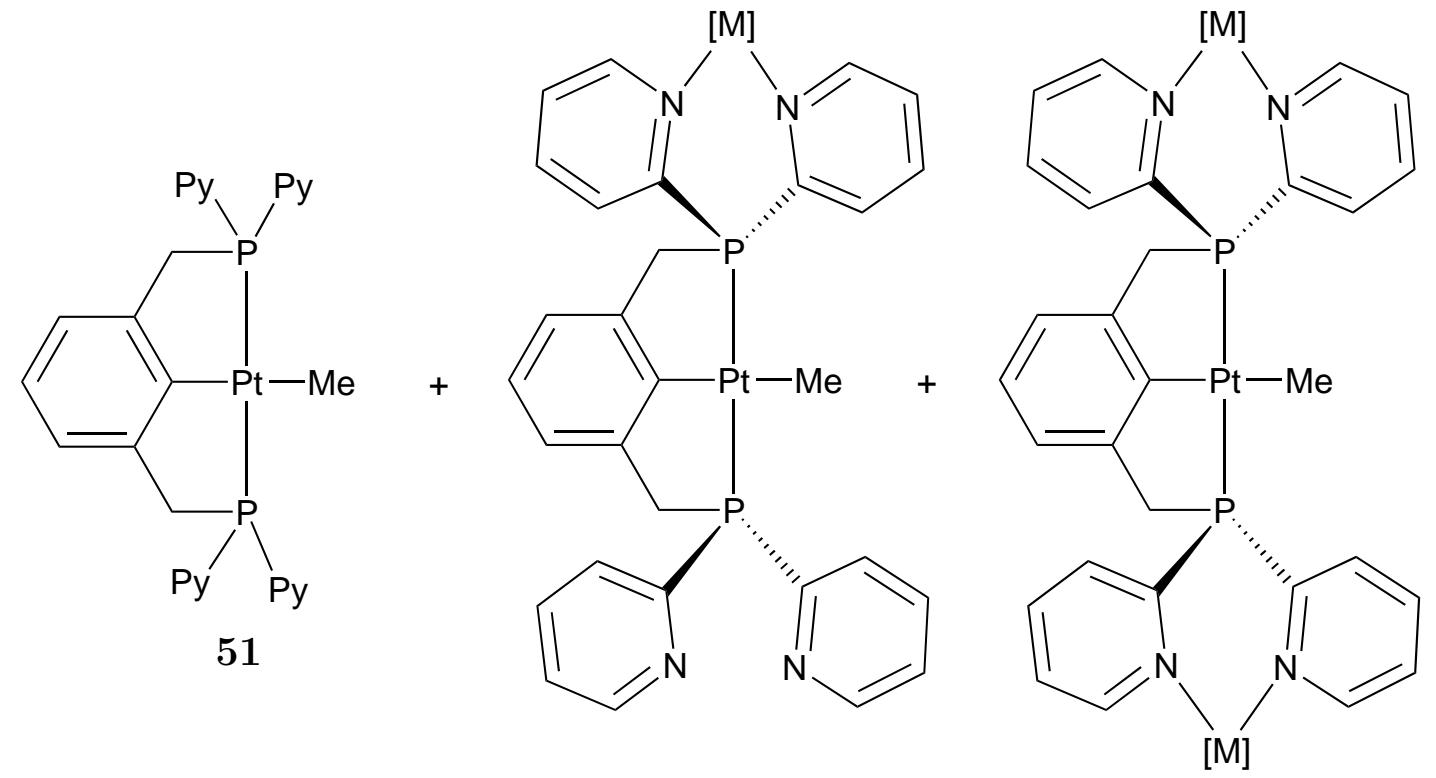

$$
\begin{aligned}
& \mathbf{6 4}[\mathrm{M}]=\mathrm{PtMe}_{2} \\
& \mathbf{6 8}[\mathrm{M}]=\operatorname{Rh}(\mathrm{COD}) \\
& \mathbf{6 9}[\mathrm{M}]=\operatorname{Ir}(\mathrm{COD})
\end{aligned}
$$

$$
\begin{aligned}
& \mathbf{6 5}[\mathrm{M}]=\mathrm{PtMe}_{2} \\
& \mathbf{6 6}[\mathrm{M}]=\operatorname{Rh}(\mathrm{COD}) \\
& \mathbf{6 7}[\mathrm{M}]=\operatorname{Ir}(\mathrm{COD})
\end{aligned}
$$

Scheme 5.9 Synthesis of dimetallic complexes of dpypmx ligand 4. Reagents and conditions: (i) One equivalent of dimethyl(hexa-1,5-diene)platinum, $[\mathrm{Rh}(\mathrm{COD})] \mathrm{CH}\left(\mathrm{SO}_{2} \mathrm{CF}_{3}\right)_{2}$ or $[\mathrm{Ir}(\mathrm{COD})] \mathrm{CH}\left(\mathrm{SO}_{2} \mathrm{CF}_{3}\right)_{2}$. 
to the phosphorus atom with coordinated pyridyl rings attached to it. The signals for the iridiumplatinum complex 69 in the ${ }^{31} \mathrm{P}$ NMR spectrum were similar to those of the rhodiumplatinum complex $\mathbf{6 8}$, with the doublets appearing at 55.06 and 37.84 ppm with ${ }^{1} J_{\mathrm{PtP}}$ values of 3080 and $3026 \mathrm{~Hz}$ respectively.

The increase in both ${ }^{1} J_{\mathrm{PtP}}$ values was consistent with what was observed for the $\left[\left(\mathrm{PtMe}_{2}\right) \mathrm{PtMe}(\mathrm{PCP})\right]$ complex 64. However, in the dimetallic complexes of dpypox ligand 3 only the ${ }^{1} J_{\mathrm{PtP}}$ for the phosphorus atom with coordinated pyridyl rings increased while the ${ }^{1} J_{\mathrm{PtP}}$ of the other phosphorus signal decreased slightly.

The formation of a mixture of products suggested that the formation of the dirhodiumplatinum and diiridiumplatinum complexes 66 and 67 occurred in a stepwise manner, similar to the reactions with dimethyl(hexa-1,5-diene)platinum. Given this, the reason the intermediate dimetallic complexes were not observed in the NMR spectra recorded of the reactions when two equivalents of $[\mathrm{Rh}(\mathrm{COD})]^{+}$or $[\operatorname{Ir}(\mathrm{COD})]^{+}$were added was simply due to the reactions occurring very rapidly.

The formation of a statistical distribution of products in these reactions indicated that there was no major energy difference between the coordination of a metal centre to the pyridyl nitrogens in the $[\mathrm{PtMe}(\mathrm{PCP})]$ complex 51 or a $[(\mathrm{M}) \mathrm{PtMe}(\mathrm{PCP})]$ complex $\left(\mathrm{M}=\mathrm{PtMe}_{2}, \mathrm{Rh}(\mathrm{COD}), \operatorname{Ir}(\mathrm{COD})\right)$. This was consistent with what was observed in the analogous reactions with the $\left[\mathrm{PtMe}_{2}(\mathrm{PP})\right]$ complex 17.

\subsection{Concluding Remarks}

The reactions outlined in this chapter showed that the pyridyl nitrogen atoms in the dpypox and dpyp $m$ x ligands, 3 and 4 , readily react with metal complexes once the phosphorus atoms have reacted. While reactions with platinum precursor complexes generally took 24 hours to occur, reactions with rhodium or iridium complexes were complete after 20 minutes. The trimetallic complexes containing chloride ligands were found to be insoluble solids, which limited their characterisation.

The formation of dimetallic intermediates was observed in the reactions of the $\left[\mathrm{PtMe}_{2}(\mathrm{PP})\right],[\mathrm{PtClMe}(\mathrm{PP})]$ and $[\mathrm{PtMe}(\mathrm{PCP})]$ complexes with two equivalents of dimethyl(hexa-1,5-diene)platinum. The fact that intermediates were not observed in the rhodium and iridium reactions was ascribed to the faster reaction times. Dimetallic complexes could be formed as part of a mixture, with the starting complex and the trimetallic complex, through the reaction of the monometallic com- 
plexes with one equivalent of precursor complex. The exception was the reaction of the $[\mathrm{PtClMe}(\mathrm{PP})]$ complex 27 where the dimetallic $\left[\left(\mathrm{PtMe}_{2}\right) \mathrm{PtClMe}(\mathrm{PP})\right]$ complex 58 was formed as the major product. In this complex the second platinum is coordinated to the pyridyl rings attached to the phosphorus atom trans to the methyl ligand.

The ${ }^{31} \mathrm{P}$ and ${ }^{1} \mathrm{H}$ NMR data of the di- and trimetallic complexes were very similar. In particular, coordination of the pyridyl nitrogens to metal centres resulted in a downfield shift of the ${ }^{31} \mathrm{P}$ NMR signal. The value of ${ }^{1} J_{\mathrm{PtP}}$ was also found to increase. In the di- and triplatinum complexes a second set of ${ }^{195} \mathrm{Pt}$ satellites was observed, with ${ }^{3} J_{\mathrm{PtP}}$ values of $41-79 \mathrm{~Hz}$. There was no long range ${ }^{103} \mathrm{Rh}$ coupling observed in the dirhodiumplatinum complexes $\mathbf{6 0}$ and $\mathbf{6 6}$. The signals of the pyridyl protons in the ${ }^{1} \mathrm{H}$ NMR spectra of all the trimetallic complexes also shifted downfield. The greater downfield shift of the signals H1b in the dpypox complexes and H1 in the dpyp $m x$ complexes was noteworthy and indicated these protons were in close proximity to the central metal atom.

The $\mathrm{C}=\mathrm{N}$ stretching frequency in the infrared spectra of these complexes was also found to be a useful tool for confirming nitrogen coordination to a metal centre. 


\section{Chapter 6}

\section{Conclusions}

Pyridylphosphines have shown promise as ligands in homogeneous catalysis and in the design of new anticancer drugs. The combination of the "soft" phosphorus donor atom and the "hard" pyridyl nitrogen atom leads to transition metal complexes that possess potentially beneficial properties, such as hemilability and asymmetry in the metal orbitals. These ligands can also show a range of coordination modes which makes their coordination chemistry interesting. While the pyridylphosphines have been widely studied, pyridyldiphosphines have received less attention. Diphosphines with pyridyl rings as substituents on the phosphorus atom are particularly rare.

Two new pyridyldiphosphines, dpypox (3) and dpypmx (4), and one known compound, dpypp (5), were synthesised via the cleavage of a $\mathrm{P}-\mathrm{C}$ bond in $\mathrm{PPy}_{3}$ and subsequent reaction with the appropriate dichloride or dibromide compound. This improved methodology increases the scope of pyridyldiphosphines that can be synthesised and avoids the use of chlorophosphines. The new compounds were found to be oxygen sensitive, particularly in solution. However, borane protection of the phosphorus atoms was found to be an effective way to prevent these ligands from oxidising.

The phosphine selenides of pyridylphosphines $\mathbf{3}$ and $\mathbf{4}$ were synthesised through reaction with elemental selenium. The value of ${ }^{1} J_{\mathrm{PSe}}$ can be used to measure the basicity of the phosphorus atom in phosphine ligands. Thus, with ${ }^{1} J_{\mathrm{PSe}}$ values of 738 and $742 \mathrm{~Hz}$ for $\mathbf{3}$ and $\mathbf{4}$ respectively, it was concluded that the phosphorus atoms in these compounds are less basic than $\mathrm{PPh}_{3}$. When the pyridylphosphines were reacted with 1-6 equivalents of a strong acid the pyridyl nitrogen atoms were protonated first. This was consistent with the calculated values of $\mathrm{p} K_{\mathrm{b}}$ (about 12), based on the observed ${ }^{1} J_{\mathrm{PSe}}$, that indicated that the pyridyl nitrogens are more basic 
than the phosphorus atoms. The NMR data indicated that the protons were not statically bound to one nitrogen atom. IR spectroscopy confirmed that the pyridyl nitrogens were protonated first. While the pyridylphosphines themselves are not soluble in water, protonation rendered them water-soluble.

Initially the reactivity of ligands $\mathbf{3}$ and $\mathbf{5}$ with platinum(II) and palladium(II) complexes was explored. The ligands $\mathbf{3}$ and $\mathbf{5}$ were found to act as a simple diphosphine ligand forming $\left[\mathrm{MX}_{2}(\mathrm{PP})\right]$ complexes. The complexes of ligand $\mathbf{3}$ displayed dynamic behaviour in solution at room temperature. This behaviour was attributed to the backbone of the ligand inverting, a process that has been observed for this type of ligand before. In the $\left[\mathrm{MCl}_{2}(\mathrm{PP})\right]$ complexes, ligand $\mathbf{3}$ displayed a bite angle of $100.8^{\circ}$ and $100.0^{\circ}$ for the platinum (16) and palladium (20) complexes respectively. This is within the range typical for $o$-xylene based ligands.

When $[\mathrm{PtMeCl}(\mathrm{PP})](\mathbf{2 7})$ was reacted with $\mathrm{NaCH}\left(\mathrm{SO}_{2} \mathrm{CF}_{3}\right)_{2}$ no evidence for the coordination of the pyridyl nitrogens was observed. However, a series of unsymetrical complexes of the type $[\mathrm{PtMeL}(\mathrm{PP})]^{+}$was synthesised, which enabled the comparison of the cis and trans influences of a range of ligands. The following cis influence series was compiled based on ${ }^{31} \mathrm{P} \mathrm{NMR}$ data of these complexes: $\mathrm{Py} \approx \mathrm{Cl}>\mathrm{SEt}_{2}>$ $\mathrm{PTA}>\mathrm{PPh}_{3}$. Reaction of $\mathbf{2 7}$ with $\mathrm{NaCH}\left(\mathrm{SO}_{2} \mathrm{CF}_{3}\right)_{2}$ and carbon monoxide slowly formed the acyl complex 38, where the CO had inserted in the Pt-Me bond. This indicated that the palladium analogue of this system could be an active catalyst for the carbonylation of ethene.

The $\left[\mathrm{M}(\mathrm{PP})_{2}\right]$ complexes $(\mathrm{M}=\mathrm{Pt} 39, \mathrm{Pd} 40)$ were the only products formed when platinum(0) and palladium(0) complexes were reacted with ligand 3. Even when the reaction was carried out in a 1:1 ratio the unreacted metal complex did not react with the pyridyl nitrogen atoms. This is an example of selective binding behaviour, with the "hard" pyridyl nitrogen donor atoms not being good ligands for "soft" metal centres like platinum(0) and palladium(0). A similar $\left[\operatorname{Ag}(\mathrm{PP})_{2}\right]^{+}$complex $4 \mathbf{1}$ was also formed.

When the chloride ligand was abstracted from $[\operatorname{IrCl}(\mathrm{PP})(\mathrm{COD})]$ complex 42 one of the pyridyl nitrogen atoms coordinated to the iridium atom and facilitated the isomerisation of the $1,2,5,6-\eta^{4}$-COD ligand to a $1-\kappa-4,5,6-\eta^{3}-\mathrm{C}_{8} \mathrm{H}_{12}$ ligand. In the resulting complex (43), 3 displayed hemilabile behaviour, with VT-NMR experiments indicating that the pyridyl nitrogen atoms were interchanging in solution at room temperature. In this complex the $\mathrm{P}-\mathrm{Ir}-\mathrm{P}$ bite angle was $96.4^{\circ}$ while the $\mathrm{P}-\mathrm{Ir}-\mathrm{N}$ bite angle was $66.6^{\circ}$. The nitrogen can be displaced by carbon monoxide to give $\left[\operatorname{Ir}(\mathrm{PP})(\mathrm{CO})\left(1-\kappa-4,5,6-\eta^{3}-\mathrm{C}_{8} \mathrm{H}_{12}\right)\right](44)$. 
The dpypox ligand 3 was found to display the rare $P, P, N$ chelation mode and hemilabile behaviour. Further investigation into the reactivity of 43 and 44 could uncover more interesting reactivity caused by the ability of the pyridyl nitrogens to chelate.

The dimeric cis- $\left[\mathrm{PtX}_{2}(\mu-\mathrm{PP})\right]_{2}\left(\mathrm{X}=\mathrm{Cl}\right.$ 47, Me 50) and trans- $[\mathrm{PtClMe}(\mu-\mathrm{PP})]_{2}$ (48) were formed when ligand 4 was reacted with platinum(II) precursor complexes. Whether the cis or trans isomer was formed depended on a combination of antisymbiotic effects, electrostatic interactions, sterics and solvation effects. These complexes were heated to promote the formation of pincer complexes. While $\mathbf{4 7}$ did not react further, both 48 and 50 reacted to give $[\mathrm{PtCl}(\mathrm{PCP})](49)$ and $[\mathrm{PtMe}(\mathrm{PCP})]$ (51) respectively. In contrast to the analogous platinum complex, the pincer complex $[\mathrm{PdCl}(\mathrm{PCP})]$ (53) formed readily when the cis- $\left[\mathrm{PdCl}_{2}(\mu-\mathrm{PP})\right]_{2}$ dimer (52) was heated. Abstraction of the chloride ligand in 49 did not result in the coordination of a pyridyl nitrogen to the platinum centre and protonation of complex 49 did not result in a water-soluble complex.

The dpyp $m \mathrm{x}$ ligand $\mathbf{4}$ was found to act as either a bridging $P, P$ ligand or a $P, C, P$ pincer ligand in complexes of platinum(II) and palladium(II). Further investigation of the coordination chemistry of this ligand with rhodium and iridium complexes could potentially uncover a new bonding mode of this ligand involving the pyridyl nitrogen(s). This prediction is based on $\mathbf{3}$ acting as a $P, P, N$ chelating ligand in the iridium complex 43.

Ligands $\mathbf{3}$ and $\mathbf{4}$ are potentially hexadentate and heptadentate ligands respectively. Trimetallic complexes where all possible donor atoms were coordinated to metal centres were readily synthesised at room temperature. Initial investigation into the synthesis of trimetallic complexes of $\mathbf{3}$ found that chloride ligands rendered the products of the reactions insoluble in most solvents. However, inclusion of methyl ligands greatly improved the solubility of the trimetallic complexes allowing characterisation by NMR methods. The homotrimetallic $\left[\left(\mathrm{PtMe}_{2}\right)_{2}(\mathrm{PP})\right](\mathbf{5 4})$ and heterotrimetallic $\left[\{\mathrm{M}(\mathrm{COD})\}_{2} \mathrm{PtMe}_{2}(\mathrm{PP})\right]^{2+}(\mathrm{M}=\mathrm{Rh}$ 60, Ir 61) complexes with 3 bridging three metal centres were synthesised from $\left[\mathrm{PtMe}_{2}(\mathrm{PP})\right](\mathbf{1 7})$. In a similar manner, reaction of $[\mathrm{PtMe}(\mathrm{PCP})](51)$ with two equivalents of the appropriate metal precursor yielded the trimetallic complexes $\left[(\mathrm{PtMe})_{2} \mathrm{PtMe}(\mathrm{PCP})\right](\mathbf{6 5})$ and $\left[\{\mathrm{M}(\mathrm{COD})\}_{2} \mathrm{PtMe}(\mathrm{PCP})\right]^{2+}(\mathrm{M}=\mathrm{Rh}$ 66, Ir 67). Dimetallic intermediates were observed in the synthesis of complexes 55 and $\mathbf{6 5}$ but not in the synthesis of the heterotrimetallic complexes. However, the analogous dimetallic complexes could be synthesised as part of a mixture when $\mathbf{1 7}$ or $\mathbf{5 1}$ was reacted with one equivalent of metal complex. 
This reactivity suggests that the formation of the trimetallic complexes occurs via a dimetallic intermediate. The fact that intermediates were not observed in the rhodium and iridium reaction mixtures was attributed to the faster reaction times observed for these reactions. Also the formation of a mixture of the mono-, di- and trimetallic complexes in the one-to-one reaction suggests that the coordination of a metal centre to one side of the molecule does not affect the ability of the metal to coordinate to the pyridyl rings on the other side.

Further investigation into these systems could make the palladium analogues of these complexes and explore their potential catalytic activity. In particular, the activity of the trimetallic complexes could be compared to that of the respective monometallic complexes to determine if there is a synergistic effect having the three metal centres in close proximity.

In summary, two new pyridyldiphosphine ligands were synthesised and the rare $P, P, N$ chelation mode was observed for ligand $\mathbf{3}$ in an iridium(III) complex. These ligands were also found to be capable of bridging three metal centres. In particular, in trimetallic complexes of ligand $\mathbf{3}$ the metals were bound to two phosphorus atoms or two pyridyl nitrogen atoms, while ligand 4 coordinates to two metal centres through two nitrogen atoms each and acts as a pincer ligand to the other metal centre. 


\section{Chapter 7}

\section{Experimental}

\subsection{General}

All reactions were carried out using degassed solvents and standard Schlenk techniques under a nitrogen or argon atmosphere unless stated otherwise. The starting materials used in this work were obtained from Sigma-Aldrich, Merck Chemical Companies, Thermo Fisher Scientific and BOC Industrial Gases, and used without further purification unless stated otherwise. Tetrahydrofuran (THF) and diethyl ether $\left(\mathrm{Et}_{2} \mathrm{O}\right)$ were distilled under a nitrogen or argon atmosphere from sodium benzophenone ketyl immediately prior to use. All other solvents used were of analytical grade and were degassed and dried over molecular sieves. Tris(2pyridyl)phosphine, ${ }^{72}$ 1,3,5-triaza-7-phosphaadamantane (PTA), ${ }^{183}$ [PtClMe(hexa1,5-diene) $],{ }^{75}\left[\mathrm{PtCl}_{2}(\right.$ hexa-1,5-diene) $],{ }^{184}\left[\mathrm{PtCl}_{2}\left(\mathrm{SEt}_{2}\right)_{2}\right],{ }^{185}\left[\mathrm{Pt}(\mathrm{nb})_{3}\right],{ }^{37}\left[\mathrm{Pt}(\mathrm{COD})_{2}\right],{ }^{186}$ $\left[\mathrm{PtEt}_{2}\right.$ (cycloocta-1,5-diene)], ${ }^{187}\left[\mathrm{PtI}_{2}\right.$ (hexa-1,5-diene)], ${ }^{188}\left[\mathrm{PtMe}_{2}\right.$ (hexa-1,5-diene)], ${ }^{37}$ $\left[\mathrm{PdCl}_{2}(\mathrm{NCMe})_{2}\right],{ }^{189}\left[\mathrm{PdMe}_{2}(\right.$ tmeda $\left.)\right],{ }^{190}\left[\mathrm{Pd}(\mathrm{nb})_{3}\right],{ }^{191}\left[\mathrm{Pd}_{2}(\mathrm{dba})_{3}\right],{ }^{192}[\mathrm{Rh}(\mathrm{COD})(\mu-$ $\mathrm{Cl})]_{2},{ }^{193}[\operatorname{Ir}(\mathrm{COD})(\mu-\mathrm{Cl})]_{2},{ }^{194} \mathrm{H}_{2} \mathrm{C}\left(\mathrm{SO}_{2} \mathrm{CF}_{3}\right)_{2}{ }^{102}$ and $\mathrm{NaCH}\left(\mathrm{SO}_{2} \mathrm{CF}_{3}\right)_{2}{ }^{182}$ were synthesised using standard literature methods.

Nuclear Magnetic Resonance (NMR) spectra were recorded using a Varian Unity Inova spectrometer operating at 300,121 and $282 \mathrm{MHz}$ for ${ }^{1} \mathrm{H},{ }^{31} \mathrm{P}$ and ${ }^{19} \mathrm{~F}$ spectra respectively, a Varian Unity Inova spectrometer operating at 500, 125, 95 and $96 \mathrm{MHz}$ for ${ }^{1} \mathrm{H},{ }^{13} \mathrm{C},{ }^{77} \mathrm{Se}$ and ${ }^{11} \mathrm{~B}$ spectra respectively and a Varian DirectDrive spectrometer operating at 600,150 and $61 \mathrm{MHz}$ for ${ }^{1} \mathrm{H},{ }^{13} \mathrm{C}$ and ${ }^{15} \mathrm{~N}$ spectra respectively. All direct-detected ${ }^{1} \mathrm{H}$ and ${ }^{13} \mathrm{C}$ chemical shifts, $\delta$ (ppm), were referenced to the residual solvent peak of the deuterated solvent. ${ }^{195}$ Indirectly-detected ${ }^{15} \mathrm{~N}$ shifts were referenced to the unified TMS scale with a $\Xi$ ratio of $10.136767 .{ }^{196}{ }^{31} \mathrm{P}$, 
${ }^{19} \mathrm{~F}$ and ${ }^{11} \mathrm{~B}$ NMR spectra were referenced to $\mathrm{H}_{3} \mathrm{PO}_{4}, \mathrm{CFCl}_{3}$ and $\mathrm{BF}_{3} \cdot \mathrm{Et}_{2} \mathrm{O}$ respectively. ${ }^{13} \mathrm{C},{ }^{31} \mathrm{P},{ }^{19} \mathrm{~F}$ and ${ }^{11} \mathrm{~B}$ NMR spectra were measured with ${ }^{1} \mathrm{H}$-decoupling. Infrared spectra were obtained using a Perkin Elmer Spectrum One FT-IR spectrophotometer (resolution $4 \mathrm{~cm}^{-1}$ ) in absorbance mode. All spectral data were obtained at ambient temperature, unless otherwise stated. Electrospray ionisation mass spectroscopy was recorded using an Agilent 6530 Q-TOF mass spectrometer or performed by the Carbohydrate Chemistry Group at Industrial Research Limited, Lower Hutt, using a Waters Q-TOF Premier Tandem mass spectrometer. Elemental analysis was performed at the Campbell Microanalytical Laboratory at Otago University, Dunedin.

X-ray diffraction data were collected on a Bruker SMART APEX-II CCD diffractometer using Mo K $\alpha$ radiation or an Agilent SuperNova (Dual Source) CCD diffractometer using $\mathrm{Cu} \mathrm{K} \alpha$ radiation. Data were reduced using Bruker SAINT or Agilent CrysAlisPro software. Absorption correction was performed using the SADABS or SCALE3 ABSPACK programs. OLEX2 (Version 1.2.5) ${ }^{197}$ was used as a front-end for SHELX ${ }^{198}$ or Superflip ${ }^{199}$ executables during structure solution and refinement. The positions of all hydrogen atoms were calculated during refinement.

\subsection{Initial Ligand Synthesis Method}

\subsubsection{Synthesis of the secondary phosphine (2)}

Tris(2-pyridyl)phosphine (1.183 g, $4.46 \mathrm{mmol}$ ) was suspended in THF (25 $\mathrm{mL})$ and lithium granules $(0.062 \mathrm{~g}, 8.92 \mathrm{mmol})$ were added. The reaction mixture was then sonicated for six and a half hours. Distilled water $(25 \mathrm{~mL}$, degassed) was added to quench the reaction. The aqueous layer was separated and $\mathrm{Et}_{2} \mathrm{O}(10 \mathrm{~mL})$ was added to the organic layer. The organic layer was then washed with water $(2 \times 10$ $\mathrm{mL})$. The combined aqueous layers were extracted with $\mathrm{CH}_{2} \mathrm{Cl}_{2}(5 \times 10 \mathrm{~mL})$. The organic layers were combined and the solvent removed under reduced pressure to give a bright orange oil $(0.710 \mathrm{~g}, 85 \%)$.

${ }^{1} \mathrm{H}$ NMR $\left(300 \mathrm{MHz}, \mathrm{CDCl}_{3}\right): \delta / \mathrm{ppm} 8.8-7.0(\mathrm{~m}, 8 \mathrm{H}, \mathrm{Ar}-\mathrm{H}), 5.53\left(\mathrm{~d},{ }^{1} J_{\mathrm{PH}}=\right.$ $225.3 \mathrm{~Hz}, 1 \mathrm{H}, \mathrm{P}-\mathrm{H}) .{ }^{31} \mathrm{P}$ NMR $\left(121 \mathrm{MHz}, \mathrm{CDCl}_{3}\right): \delta / \mathrm{ppm}-34.3$ (s). 


\title{
7.2.2 Pyridyldiphosphines
}

The synthesis of diphosphines reported here is based on the synthesis of $o$-(methoxymethyl)benzyldi-t-butylphosphine-borane. ${ }^{200} \mathrm{HPPy}_{2}(0.276 \mathrm{~g}, 1.47 \mathrm{mmol})$ was dissolved in THF $(15 \mathrm{~mL})$, cooled to $0{ }^{\circ} \mathrm{C}$ and $n$-BuLi $(0.92 \mathrm{~mL}, 1.6 \mathrm{M}, 1.47 \mathrm{mmol})$ was added dropwise. The reaction mixture was allowed to warm to room temperature and was stirred for one hour. The solution was cooled to $0{ }^{\circ} \mathrm{C}$ and a solution of the appropriate dibromide compound $(0.735 \mathrm{mmol})$ in THF $(10 \mathrm{~mL})$ was added dropwise. The reaction mixture was again allowed to warm to room temperature and stirred for one hour. At this point half of the THF was removed and $\mathrm{Et}_{2} \mathrm{O}(5$ $\mathrm{mL})$ was added. This was extracted with distilled water $(3 \times 10 \mathrm{~mL}$, degassed). The combined aqueous phases were extracted with $\mathrm{CH}_{2} \mathrm{Cl}_{2}(3 \times 10 \mathrm{~mL})$. The $\mathrm{Et}_{2} \mathrm{O}$ and $\mathrm{CH}_{2} \mathrm{Cl}_{2}$ layers were combined and the solvent removed under reduced pressure to give brown solids (3: $0.243 \mathrm{~g}, 69 \%$, 4: $0.190 \mathrm{~g}, 54 \%$ ).

\subsection{Improved Ligand Synthesis Method}

\author{
Synthesis of $o-\mathrm{C}_{6} \mathrm{H}_{4}\left(\mathrm{CH}_{2} \mathrm{PPy}_{2}\right)_{2}(\operatorname{dpypox})(3)$
}

A solution of tris(2-pyridyl)phosphine $(1.110 \mathrm{~g}, 4.18 \mathrm{mmol})$ in THF (10 mL) was added dropwise to a dispersion of lithium (0.116 g, $16.7 \mathrm{mmol})$ in THF $(5 \mathrm{~mL})$ at $-78{ }^{\circ} \mathrm{C}$. The reaction mixture was allowed to warm to room temperature with vigorous stirring for 40 minutes. The excess lithium was removed by filtration. The resulting filtrate was cooled to $-78^{\circ} \mathrm{C}$ and ammonium chloride $(0.224 \mathrm{~g}, 4.18 \mathrm{mmol})$ was added. The reaction mixture was allowed to warm to room temperature and stirred for 30 minutes. It was then once again cooled to $-78{ }^{\circ} \mathrm{C}$ and a solution of dichloro- $o$-xylene or dibromo- $o$-xylene $(1.90 \mathrm{mmol})$ in THF $(5 \mathrm{~mL})$ was added dropwise. This was then allowed to warm to room temperature over 30 minutes. The solvent was removed under reduced pressure to give a yellow expanded oil. Dichloromethane $(35 \mathrm{~mL})$ and water $(25 \mathrm{~mL})$ were added and stirred for 5 minutes. The resulting emulsion was allowed to separate and the lower organic layer was isolated. The solvent was removed and the resulting oil was washed with pentane $(3 \times 10 \mathrm{~mL})$. This was then recrystallised from $\mathrm{EtOH} / n \mathrm{PrOH}$ to give $\mathbf{3}$ as a pale yellow solid (0.655 g, $72 \%$ ). 


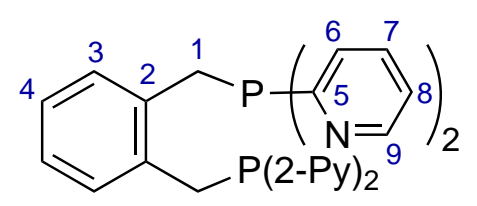

${ }^{1} \mathrm{H} \mathrm{NMR}\left(500 \mathrm{MHz}, \mathrm{CDCl}_{3}\right): \delta / \mathrm{ppm} 8.66$ (d, $\left.J=4.5 \mathrm{~Hz}, 4 \mathrm{H}, \mathrm{H} 9\right), 7.54$ (t, $J=7.5$ $\mathrm{Hz}, 4 \mathrm{H}, \mathrm{H} 7), 7.45$ (d, $J=7.5 \mathrm{~Hz}, 4 \mathrm{H}, \mathrm{H} 6), 7.15$ (t, $J=6.0 \mathrm{~Hz}, 4 \mathrm{H}, \mathrm{H} 8), 6.90$ (d, $J$ $=4.5 \mathrm{~Hz}, 2 \mathrm{H}, \mathrm{H} 3), 6.84(\mathrm{~d}, J=3.5 \mathrm{~Hz}, 2 \mathrm{H}, \mathrm{H} 4), 3.97$ (s, 4H, H1). ${ }^{13} \mathrm{C}$ NMR $(125$ $\left.\mathrm{MHz}, \mathrm{CDCl}_{3}\right): \delta / \mathrm{ppm} 162.95\left(\mathrm{~d},{ }^{1} J_{\mathrm{PC}}=5.2 \mathrm{~Hz}, \mathrm{C} 5\right), 150.41\left(\mathrm{vt},{ }^{3} J_{\mathrm{PC}}+{ }^{8} J_{\mathrm{PC}}=\right.$ $3.9 \mathrm{~Hz}, \mathrm{C} 9), 136.50\left(\mathrm{vt},{ }^{2} J_{\mathrm{PC}}+{ }^{3} J_{\mathrm{PC}}=6.0 \mathrm{~Hz}, \mathrm{C} 2\right), 135.49\left(\mathrm{vt},{ }^{3} J_{\mathrm{PC}}+{ }^{8} J_{\mathrm{PC}}=\right.$ $3.2 \mathrm{~Hz}, \mathrm{C} 7), 130.57\left(\mathrm{vt},{ }^{3} J_{\mathrm{PC}}+{ }^{4} J_{\mathrm{PC}}=2.9 \mathrm{~Hz}, \mathrm{C} 3\right), 129.58\left(\mathrm{~d},{ }^{2} J_{\mathrm{PC}}=28.8 \mathrm{~Hz}\right.$, C6), 125.98 (s, C4), 123.81 (s, C8), $31.00\left(\mathrm{~d},{ }^{1} J_{\mathrm{PC}}=9.1 \mathrm{~Hz}, \mathrm{C} 1\right) .{ }^{15} \mathrm{~N}$ NMR $(60$ $\left.\mathrm{MHz}, \mathrm{CDCl}_{3}\right): \delta / \mathrm{ppm}-56.1$ (s). ${ }^{31} \mathrm{P} \mathrm{NMR}\left(121 \mathrm{MHz}, \mathrm{CDCl}_{3}\right): \delta / \mathrm{ppm}-6.81$ (s). IR (film from $\mathrm{CH}_{2} \mathrm{Cl}_{2}$ ): $\nu_{\max } / \mathrm{cm}^{-1} 3043$ ( $\mathrm{sp}^{2} \mathrm{C}-\mathrm{H}$ stretch), 2960 ( $\mathrm{sp}^{3} \mathrm{C}-\mathrm{H}$ stretch), 1573, $1560\left(\mathrm{C}=\mathrm{N}\right.$ stretch). HRMS calcd for $\mathrm{C}_{28} \mathrm{H}_{25} \mathrm{~N}_{4} \mathrm{O}_{2} \mathrm{P}_{2}[\mathrm{M}+2 \mathrm{O}+\mathrm{H}]^{+}: \mathrm{m} / \mathrm{z}=$ 511.1453, found $=511.1452$. HRMS calcd for $\mathrm{C}_{28} \mathrm{H}_{24} \mathrm{~N}_{4} \mathrm{NaO}_{2} \mathrm{P}_{2}[\mathrm{M}+2 \mathrm{O}+\mathrm{Na}]^{+}: \mathrm{m} / \mathrm{z}$ $=533.1272$, found $=533.1277$.

${ }^{1} \mathrm{H}$ NMR $\left(500 \mathrm{MHz},\left(\mathrm{CD}_{3}\right)_{2} \mathrm{CO}\right): \delta / \mathrm{ppm} 8.64(\mathrm{~d}, J=5.0 \mathrm{~Hz}, 4 \mathrm{H}, \mathrm{H} 9), 7.66(\mathrm{~m}, 4 \mathrm{H}$, H7), 7.46 (br d, $J=7.5 \mathrm{~Hz}, 4 \mathrm{H}, \mathrm{H} 6), 7.25$ (m, 4H, H8), 6.99 (m, 2H, H3), 6.85 (m, 2H, H4), 4.09 (br s, 4H, H1). ${ }^{13} \mathrm{C}$ NMR (125 MHz, $\left.\left(\mathrm{CD}_{3}\right)_{2} \mathrm{CO}\right): \delta / \mathrm{ppm} 163.79$ (d, $\left.{ }^{1} J_{\mathrm{PC}}=5.8 \mathrm{~Hz}, \mathrm{C} 5\right), 150.96\left(\mathrm{vt},{ }^{3} J_{\mathrm{PC}}+{ }^{8} J_{\mathrm{PC}}=3.9 \mathrm{~Hz}, \mathrm{C} 9\right), 137.93\left(\mathrm{vt},{ }^{2} J_{\mathrm{PC}}+\right.$ $\left.{ }^{3} J_{\mathrm{PC}}=6.6 \mathrm{~Hz}, \mathrm{C} 2\right), 136.26\left(\mathrm{vt},{ }^{3} J_{\mathrm{PC}}+{ }^{8} J_{\mathrm{PC}}=3.1 \mathrm{~Hz}, \mathrm{C} 7\right), 131.24\left(\mathrm{vt},{ }^{3} J_{\mathrm{PC}}+\right.$ $\left.{ }^{4} J_{\mathrm{PC}}=2.9 \mathrm{~Hz}, \mathrm{C} 3\right), 130.01\left(\mathrm{~d},{ }^{2} J_{\mathrm{PC}}=30.2 \mathrm{~Hz}, \mathrm{C} 6\right), 126.53(\mathrm{~s}, \mathrm{C} 4), 123.59$ (s, C8), $31.00\left(\mathrm{~d},{ }^{1} J_{\mathrm{PC}}=8.6 \mathrm{~Hz}, \mathrm{C} 1\right) .{ }^{31} \mathrm{P} \operatorname{NMR}\left(121 \mathrm{MHz},\left(\mathrm{CD}_{3}\right)_{2} \mathrm{CO}\right): \delta / \mathrm{ppm}-5.90(\mathrm{~s})$.

\section{Synthesis of $m-\mathrm{C}_{6} \mathrm{H}_{4}\left(\mathrm{CH}_{2} \mathrm{PPy}_{2}\right)_{2}(\operatorname{dpyp} m \mathrm{x})(4)$}

The same procedure as above was performed but in this case the $\mathrm{LiPPy}_{2}$ formed in situ was reacted with dichloro- $m$-xylene rather than dichloro- $o$-xylene. The bipyridine was removed via sublimation to give 4 as a pale yellow solid $(0.591,65 \%)$.

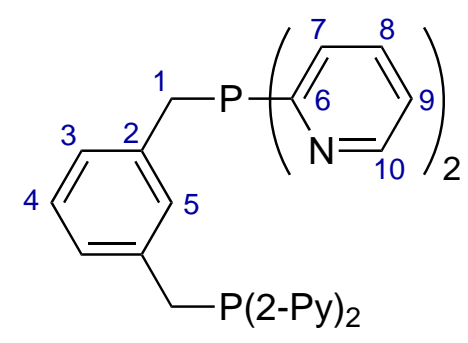

${ }^{1} \mathrm{H}$ NMR $\left(500 \mathrm{MHz}, \mathrm{CDCl}_{3}\right): \delta / \mathrm{ppm} 8.70(\mathrm{~d}, J=5.0 \mathrm{~Hz}, 4 \mathrm{H}, \mathrm{H} 10), 7.52(\mathrm{t}, J=$ 
$7.5 \mathrm{~Hz}, 4 \mathrm{H}, \mathrm{H} 8), 7.34(\mathrm{dd}, J=7.5,4.5 \mathrm{~Hz}, 4 \mathrm{H}, \mathrm{H} 7), 7.16(\mathrm{tm}, J=6.0 \mathrm{~Hz}, 4 \mathrm{H}$, H9), 6.99 (s, 1H, H5), 6.94 (d, $\left.{ }^{3} J_{\mathrm{HH}}=7.5 \mathrm{~Hz}, 1 \mathrm{H}, \mathrm{H} 4\right), 6.88\left(\mathrm{~d},{ }^{3} J_{\mathrm{HH}}=7.5 \mathrm{~Hz}\right.$, $2 \mathrm{H}, \mathrm{H} 3), 3.66$ (s, 4H, H1). ${ }^{13} \mathrm{C} \mathrm{NMR}\left(125 \mathrm{MHz}, \mathrm{CDCl}_{3}\right): \delta / \mathrm{ppm} 162.79\left(\mathrm{~d},{ }^{1} J_{\mathrm{PC}}\right.$ $=5.8 \mathrm{~Hz}, \mathrm{C} 6), 150.46\left(\mathrm{~d},{ }^{3} J_{\mathrm{PC}}=8.2 \mathrm{~Hz}, \mathrm{C} 10\right), 137.85\left(\mathrm{~d},{ }^{2} J_{\mathrm{PC}}=7.2 \mathrm{~Hz}, \mathrm{C} 2\right)$, $135.54\left(\mathrm{~d},{ }^{3} J_{\mathrm{PC}}=6.2 \mathrm{~Hz}, \mathrm{C} 8\right), 130.64\left(\mathrm{t},{ }^{3} J_{\mathrm{PC}}=6.8 \mathrm{~Hz}, \mathrm{C} 5\right), 129.40\left(\mathrm{~d},{ }^{2} J_{\mathrm{PC}}=\right.$ $28.3 \mathrm{~Hz}, \mathrm{C} 7), 128.26$ (s, C4), 127.04 (dd, $\left.J_{\mathrm{PC}}=6.7,2.4 \mathrm{~Hz}, \mathrm{C} 3\right), 122.85$ (s, C9), $33.33\left(\mathrm{~d},{ }^{1} J_{\mathrm{PC}}=12.9 \mathrm{~Hz}, \mathrm{C} 1\right) .{ }^{31} \mathrm{P} \mathrm{NMR}\left(121 \mathrm{MHz}, \mathrm{CDCl}_{3}\right): \delta / \mathrm{ppm}-3.84(\mathrm{~s})$. IR (film from $\mathrm{CH}_{2} \mathrm{Cl}_{2}$ ): $\nu_{\max } / \mathrm{cm}^{-1} 3041$ ( $\mathrm{sp}^{2} \mathrm{C}-\mathrm{H}$ stretch), 2954 ( $\mathrm{sp}^{3} \mathrm{C}-\mathrm{H}$ stretch), 1573, $1559\left(\mathrm{C}=\mathrm{N}\right.$ stretch). HRMS calcd for $\mathrm{C}_{28} \mathrm{H}_{25} \mathrm{~N}_{4} \mathrm{O}_{2} \mathrm{P}_{2}[\mathrm{M}+2 \mathrm{O}+\mathrm{H}]^{+}: \mathrm{m} / \mathrm{z}=$ 511.1453; found $=511.1454$. HRMS calcd for $\mathrm{C}_{28} \mathrm{H}_{24} \mathrm{~N}_{4} \mathrm{NaO}_{2} \mathrm{P}_{2}[\mathrm{M}+2 \mathrm{O}+\mathrm{Na}]^{+}: \mathrm{m} / \mathrm{z}$ $=533.1272$; found $=533.1271$.

\section{Synthesis of $\mathrm{Py}_{2} \mathrm{P}\left(\mathrm{CH}_{2}\right)_{3} \mathrm{PPy}_{2}$ (dpypp) (5)}

The same procedure as above was performed but in this case the $\operatorname{LiP}(2-\mathrm{Py})_{2}$ formed in situ was reacted with 1,3-dibromopropane rather than dichloro- $o$-xylene and recrystallised from EtOH $/ n \mathrm{PrOH}$ to give a pale yellow solid (0.554 g, $70 \%$ ).

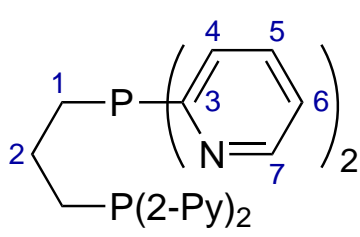

${ }^{1} \mathrm{H}$ NMR (500 MHz, $\mathrm{CDCl}_{3}$ ): $\delta / \operatorname{ppm} 8.64(\mathrm{~d}, J=4.8 \mathrm{~Hz}, 4 \mathrm{H}, \mathrm{H} 7), 7.55$ (m, 4H, H5), $7.39(\mathrm{~d}, J=7.5 \mathrm{~Hz}, 4 \mathrm{H}, \mathrm{H} 4), 7.15(\mathrm{~m} 4 \mathrm{H}, \mathrm{H} 6), 2.51\left(\mathrm{vt},{ }^{2} J_{\mathrm{PH}}+{ }^{4} J_{\mathrm{PH}}=7.5 \mathrm{~Hz}, 4 \mathrm{H}\right.$, $\mathrm{H} 1), 1.75$ (q, $\left.{ }^{3} J_{\mathrm{HH}}=8.0 \mathrm{~Hz}, 2 \mathrm{H}, \mathrm{H} 2\right) .{ }^{13} \mathrm{C} \mathrm{NMR}\left(125 \mathrm{MHz}, \mathrm{CDCl}_{3}\right): \delta / \mathrm{ppm} 163.43$ $\left(\mathrm{d},{ }^{1} J_{\mathrm{PC}}=1.9 \mathrm{~Hz}, \mathrm{C} 3\right), 150.37\left(\mathrm{~d},{ }^{3} J_{\mathrm{PC}}=4.8 \mathrm{~Hz}, \mathrm{C} 7\right), 135.65\left(\mathrm{~d},{ }^{3} J_{\mathrm{PC}}=4.3 \mathrm{~Hz}\right.$, C5), $128.58\left(\mathrm{~d},{ }^{2} J_{\mathrm{PC}}=24.0 \mathrm{~Hz}, \mathrm{C} 4\right), 122.54(\mathrm{~s}, \mathrm{C} 6), 27.83\left(\mathrm{~d},{ }^{1} J_{\mathrm{PC}}=11.0 \mathrm{~Hz}, \mathrm{C} 1\right)$, 22.80 (s, C2). ${ }^{31} \mathrm{P}$ NMR (121 MHz, $\mathrm{CDCl}_{3}$ ): $\delta / \mathrm{ppm}-10.05$ (s). HRMS calcd for $\mathrm{C}_{23} \mathrm{H}_{23} \mathrm{~N}_{4} \mathrm{OP}_{2}[\mathrm{M}+\mathrm{O}+\mathrm{H}]^{+}: \mathrm{m} / \mathrm{z}=433.1342$; found $=433.1340$. HRMS calcd for $\mathrm{C}_{23} \mathrm{H}_{23} \mathrm{~N}_{4} \mathrm{O}_{2} \mathrm{P}_{2}[\mathrm{M}+2 \mathrm{O}+\mathrm{H}]^{+}: \mathrm{m} / \mathrm{z}=449.1291$; found $=449.1291$. HRMS calcd for $\mathrm{C}_{23} \mathrm{H}_{22} \mathrm{~N}_{4} \mathrm{NaO}_{2} \mathrm{P}_{2}[\mathrm{M}+2 \mathrm{O}+\mathrm{Na}]^{+}: \mathrm{m} / \mathrm{z}=471.1110 ;$ found $=471.1111$. 


\subsection{Ligand Synthesis using Sodium or Potassium}

To a solution of tris(2-pyridyl)phosphine (1.128 g, $4.25 \mathrm{mmol})$ in THF (40 mL), chunks of potassium or sodium $(8.93 \mathrm{mmol})$ were added and vigorously stirred at room temperature for 20 hours. The dark red-brown solution was cooled to $-78^{\circ} \mathrm{C}$ and $t$-butylchloride $(0.47 \mathrm{~mL}, 4.25 \mathrm{mmol})$ was added dropwise. The reaction mixture was allowed to warm to room temperature and was stirred for 30 minutes. The reaction mixture was cooled to $-78{ }^{\circ} \mathrm{C}$ once more and a solution of the appropriate dibromo or dichloro compound $(2.13 \mathrm{mmol})$ in THF $(5 \mathrm{~mL})$ was added. The reaction mixture was allowed to warm to room temperature and stirred for 30 minutes. The solvent was then removed under reduced pressure to give a dark brown oil. This was dissolved in chloroform $(40 \mathrm{~mL})$ and degassed distilled water $(30 \mathrm{~mL})$ was added carefully and stirred for 30 minutes. The two layers were allowed to separate and the organic layer was isolated. The solvent was removed under reduced pressure to give brown expanded oils (3: $0.661 \mathrm{~g}, 65 \%$, 4: $0.571 \mathrm{~g}, 56 \%) .{ }^{31} \mathrm{P}$ and ${ }^{1} \mathrm{H} \mathrm{NMR}$ data of the products matched those obtained in initial ligand synthesis reactions.

\subsection{Phosphine Oxides}

\subsubsection{General method}

A solution of the phosphine $(50 \mathrm{mg}, 0.1 \mathrm{mmol})$ in $\mathrm{CH}_{2} \mathrm{Cl}_{2}(2 \mathrm{~mL})$ was exposed to air and stirred until the phosphine had completely oxidised. This took between two and three weeks. In all cases quantitative conversion to the oxide was observed.

dpypoxO $\mathrm{O}_{2}(8)$

${ }^{1} \mathrm{H}$ NMR (500 MHz, $\left.\mathrm{CDCl}_{3}\right): \delta / \mathrm{ppm} 8.80$ (d, $\left.J=3.9 \mathrm{~Hz}, 4 \mathrm{H}, \mathrm{H} 9\right), 7.97$ (m, 4H, H6), 7.71 (m, 4H, H7), 7.33 (m, 4H, H8), 6.90 (m, 2H, H3), 6.78 (m, 2H, H4), 4.42 $\left(\mathrm{d},{ }^{2} J_{\mathrm{PH}}=13.9 \mathrm{~Hz}, 4 \mathrm{H}, \mathrm{H} 1\right) .{ }^{13} \mathrm{C} \mathrm{NMR}\left(125 \mathrm{MHz}, \mathrm{CDCl}_{3}\right): \delta / \mathrm{ppm} 155.50(\mathrm{~d}$, $\left.{ }^{1} J_{\mathrm{PC}}=125.7 \mathrm{~Hz}, \mathrm{C} 5\right), 150.30\left(\mathrm{~d},{ }^{3} J_{\mathrm{PC}}=19.2 \mathrm{~Hz}, \mathrm{C} 9\right), 136.11$ (m, C7), 131.75 (s, C3), $131.65\left(\mathrm{~d},{ }^{2} J_{\mathrm{PC}}=3.5 \mathrm{~Hz}, \mathrm{C} 2\right), 128.19\left(\mathrm{~d},{ }^{2} J_{\mathrm{PC}}=19.6 \mathrm{~Hz}, \mathrm{C} 6\right), 126.61$ (s, C4), 125.50 (s, C8), $32.30\left(\mathrm{~d},{ }^{1} J_{\mathrm{PC}}=65.7 \mathrm{~Hz}, \mathrm{C} 1\right) .{ }^{31} \mathrm{P} \mathrm{NMR}\left(121 \mathrm{MHz}, \mathrm{CDCl}_{3}\right)$ : $\delta /$ ppm 28.19 (s). HRMS calcd for $\mathrm{C}_{28} \mathrm{H}_{25} \mathrm{~N}_{4} \mathrm{O}_{2} \mathrm{P}_{2}[\mathrm{M}+\mathrm{H}]^{+}: \mathrm{m} / \mathrm{z}=511.1453$, found $=511.1452$. HRMS calcd for $\mathrm{C}_{28} \mathrm{H}_{24} \mathrm{~N}_{4} \mathrm{NaO}_{2} \mathrm{P}_{2}[\mathrm{M}+\mathrm{Na}]^{+}: \mathrm{m} / \mathrm{z}=533.1272$, found $=533.1277$. 
$\operatorname{dpyp} m \mathrm{xO}_{2}(9)$

${ }^{1} \mathrm{H}$ NMR $\left(500 \mathrm{MHz}, \mathrm{CDCl}_{3}\right): \delta / \mathrm{ppm} 8.82(\mathrm{~d}, J=3.9 \mathrm{~Hz}, 4 \mathrm{H}, \mathrm{H} 10), 7.95$ (t, $J=6.1$ $\mathrm{Hz}, 4 \mathrm{H}, \mathrm{H} 7$ ), 7.73 (m, 4H, H8), 7.35 (m, 4H, H9), 7.01 (br s, 1H, H4), 6.93 (br s, 3H, $\mathrm{H} 3+5), 3.90\left(\mathrm{~d},{ }^{2} J_{\mathrm{PH}}=15.1 \mathrm{~Hz}, 4 \mathrm{H}, \mathrm{H} 1\right) \cdot{ }^{13} \mathrm{C} \mathrm{NMR}\left(125 \mathrm{MHz}, \mathrm{CDCl}_{3}\right): \delta / \mathrm{ppm}$ $155.47\left(\mathrm{~d},{ }^{1} J_{\mathrm{PC}}=125.8 \mathrm{~Hz}, \mathrm{C} 6\right), 150.47\left(\mathrm{~d},{ }^{3} J_{\mathrm{PC}}=18.7 \mathrm{~Hz}, \mathrm{C} 10\right), 136.19(\mathrm{~s}, \mathrm{C} 8)$, 132.28 (s, C4), 131.28 (s, C2), 128.78 (br s, C3+C5), 128.24 (d, J $J_{\mathrm{PC}}=19.2 \mathrm{~Hz}$, C7), 125.57 (s, C9), $34.57\left(\mathrm{~d},{ }^{1} J_{\mathrm{PC}}=68.7 \mathrm{~Hz}, \mathrm{C} 1\right) .{ }^{31} \mathrm{P} \mathrm{NMR}\left(121 \mathrm{MHz}, \mathrm{CDCl}_{3}\right)$ : $\delta /$ ppm $26.70(\mathrm{~s})$. HRMS calcd for $\mathrm{C}_{28} \mathrm{H}_{25} \mathrm{~N}_{4} \mathrm{O}_{2} \mathrm{P}_{2}[\mathrm{M}+\mathrm{H}]^{+}: \mathrm{m} / \mathrm{z}=511.1453$; found $=511.1454$. HRMS calcd for $\mathrm{C}_{28} \mathrm{H}_{24} \mathrm{~N}_{4} \mathrm{NaO}_{2} \mathrm{P}_{2}[\mathrm{M}+\mathrm{Na}]^{+}: \mathrm{m} / \mathrm{z}=533.1272$; found $=533.1271$.

$\operatorname{dpyppO}_{2}(\mathbf{1 0})$

${ }^{1} \mathrm{H}$ NMR (500 MHz, $\left.\mathrm{CDCl}_{3}\right): \delta / p p m 8.74(\mathrm{~d}, J=6.0 \mathrm{~Hz}, 4 \mathrm{H}, \mathrm{H} 7), 8.02(\mathrm{~m}, 4 \mathrm{H}, \mathrm{H} 4)$, $7.76(\mathrm{~m}, 4 \mathrm{H}, \mathrm{H} 5), 7.34$ (m, 4H, H6), 2.76 (m, 4H, H1), 1.96 (m, 2H, H2). ${ }^{13} \mathrm{C} \mathrm{NMR}$ $\left(125 \mathrm{MHz}, \mathrm{CDCl}_{3}\right): \delta / \mathrm{ppm} 155.65\left(\mathrm{~d},{ }^{1} J_{\mathrm{PC}}=125.3 \mathrm{~Hz}, \mathrm{C} 3\right), 150.54\left(\mathrm{~d},{ }^{3} J_{\mathrm{PC}}=\right.$ $19.1 \mathrm{~Hz}, \mathrm{C} 7), 136.21\left(\mathrm{~d},{ }^{3} J_{\mathrm{PC}}=9.1 \mathrm{~Hz}, \mathrm{C} 5\right), 127.83\left(\mathrm{~d},{ }^{2} J_{\mathrm{PC}}=21.5 \mathrm{~Hz}, \mathrm{C} 4\right), 125.54$ (s, C6), $28.54\left(\mathrm{~d},{ }^{1} J_{\mathrm{PC}}=66.9 \mathrm{~Hz}, \mathrm{C} 1\right), 25.01(\mathrm{~s}, \mathrm{C} 2) .{ }^{31} \mathrm{P} \mathrm{NMR}\left(121 \mathrm{MHz}, \mathrm{CDCl}_{3}\right)$ : $\delta /$ ppm 29.09 (s). HRMS calcd for $\mathrm{C}_{23} \mathrm{H}_{23} \mathrm{~N}_{4} \mathrm{O}_{2} \mathrm{P}_{2}[\mathrm{M}+\mathrm{H}]^{+}: \mathrm{m} / \mathrm{z}=449.1291$; found $=449.1291$. HRMS calcd for $\mathrm{C}_{23} \mathrm{H}_{22} \mathrm{~N}_{4} \mathrm{NaO}_{2} \mathrm{P}_{2}[\mathrm{M}+\mathrm{Na}]^{+}: \mathrm{m} / \mathrm{z}=471.1110$; found $=471.1111$.

\subsection{Phosphine Selenides}

\subsubsection{General method}

Excess selenium (182 mg, $2.3 \mathrm{mmol})$ was added to a solution of the phosphine $(0.23$ $\mathrm{mmol})$ in chloroform $(10 \mathrm{~mL})$ for the pyridyl phosphines or toluene $(10 \mathrm{~mL})$ for dbpx. The reaction mixture was refluxed overnight. The reaction mixture was filtered, to remove the unreacted selenium, and the solvent removed under vacuum. This gave brown solids for the pyridylphosphines $\mathbf{1 1}$ and $\mathbf{1 2}$ (quantitative conversion) and a white solid for $\mathbf{1 3}$ (84 mg, 66\%). 
${ }^{1} \mathrm{H}$ NMR $\left(500 \mathrm{MHz}, \mathrm{CDCl}_{3}\right): \delta / \mathrm{ppm} 8.71(\mathrm{~d}, J=4.0 \mathrm{~Hz}, 4 \mathrm{H}, \mathrm{H} 9), 8.16(\mathrm{t}, J=$ $7.5 \mathrm{~Hz}, 4 \mathrm{H}, \mathrm{H} 6), 7.71$ (m, 4H, H7), 7.31 (m, 4H, H8), 6.85 (m, 2H, H4), 6.81 (m, $2 \mathrm{H}, \mathrm{H} 3), 4.67\left(\mathrm{~d},{ }^{2} J_{\mathrm{PH}}=14.0 \mathrm{~Hz}, 4 \mathrm{H}, \mathrm{H} 1\right) \cdot{ }^{13} \mathrm{C} \mathrm{NMR}\left(125 \mathrm{MHz}, \mathrm{CDCl}_{3}\right): \delta / \mathrm{ppm}$ $154.76\left(\mathrm{~d},{ }^{1} J_{\mathrm{PC}}=97.4 \mathrm{~Hz}, \mathrm{C} 5\right), 149.69\left(\mathrm{~d},{ }^{3} J_{\mathrm{PC}}=18.2 \mathrm{~Hz}, \mathrm{C} 9\right), 136.45\left(\mathrm{~d},{ }^{3} J_{\mathrm{PC}}\right.$ $=9.6 \mathrm{~Hz}, \mathrm{C} 7), 136.13(\mathrm{~m}, \mathrm{C} 2), 131.51$ ( $\mathrm{s}, \mathrm{C} 3), 129.23\left(\mathrm{~d},{ }^{2} J_{\mathrm{PC}}=25.9 \mathrm{~Hz}, \mathrm{C} 6\right)$, 126.76 (s, C4), 125.05 (s, C8), 33.71 (d, $\left.{ }^{1} J_{\mathrm{PC}}=44.1 \mathrm{~Hz}, \mathrm{C} 1\right) .{ }^{31} \mathrm{P}$ NMR $(121 \mathrm{MHz}$, $\left.\mathrm{CDCl}_{3}\right): \delta / \mathrm{ppm} 34.19\left(\mathrm{~s},{ }^{1} J_{\mathrm{PSe}}=737.6,{ }^{5} J_{\mathrm{PP}}=6.6 \mathrm{~Hz}\right) .{ }^{77} \mathrm{Se} \mathrm{NMR}(95 \mathrm{MHz}$, $\left.\mathrm{CDCl}_{3}\right): \delta / \mathrm{ppm}-352.46\left(\mathrm{~d},{ }^{1} J_{\mathrm{PSe}}=737.6 \mathrm{~Hz}\right)$. HRMS calcd for $\mathrm{C}_{28} \mathrm{H}_{25} \mathrm{~N}_{4} \mathrm{P}_{2} \mathrm{Se}_{2}$ $[\mathrm{M}+\mathrm{H}]^{+}: \mathrm{m} / \mathrm{z}=638.9885 ;$ found $=638.9873$.

$\operatorname{dpyp} m \times \mathrm{Se}_{2}(12)$

${ }^{1} \mathrm{H}$ NMR $\left(500 \mathrm{MHz}, \mathrm{CDCl}_{3}\right): \delta / \mathrm{ppm} 8.75(\mathrm{~d}, J=4.8 \mathrm{~Hz}, 4 \mathrm{H}, \mathrm{H} 10), 8.11(\mathrm{t}, J=7.2$ $\mathrm{Hz}, 4 \mathrm{H}, \mathrm{H} 7), 7.71$ (m, 4H, H8), 7.31 (m, 4H, H9), 6.92 (br s, 1H, H5), 6.88 (s, 3H, $\mathrm{H} 3+4), 4.26\left(\mathrm{~d},{ }^{2} J_{\mathrm{PH}}=15.3 \mathrm{~Hz}, 4 \mathrm{H}, \mathrm{H} 1\right) \cdot{ }^{13} \mathrm{C} \mathrm{NMR}\left(125 \mathrm{MHz}, \mathrm{CDCl}_{3}\right): \delta / \mathrm{ppm}$ $154.41\left(\mathrm{~d},{ }^{1} J_{\mathrm{PC}}=97.4 \mathrm{~Hz}, \mathrm{C} 6\right), 149.66\left(\mathrm{~d},{ }^{3} J_{\mathrm{PC}}=17.7 \mathrm{~Hz}, \mathrm{C} 10\right), 136.49\left(\mathrm{~d},{ }^{3} J_{\mathrm{PC}}=\right.$ $10.5 \mathrm{~Hz}, \mathrm{C} 8), 133.20\left(\mathrm{t},{ }^{3} J_{\mathrm{PC}}=5.8 \mathrm{~Hz}, \mathrm{C} 5\right), 130.86\left(\mathrm{vt},{ }^{2} J_{\mathrm{PC}}+{ }^{4} J_{\mathrm{PC}}=5.0 \mathrm{~Hz}, \mathrm{C} 2\right)$, $129.51\left(\mathrm{vt},{ }^{3} J_{\mathrm{PC}}+{ }^{5} J_{\mathrm{PC}}=4.6 \mathrm{~Hz}, \mathrm{C} 3\right), 129.30\left(\mathrm{~d},{ }^{2} J_{\mathrm{PC}}=25.9 \mathrm{~Hz}, \mathrm{C} 7\right), 127.45(\mathrm{t}$, $\left.{ }^{4} J_{\mathrm{PC}}=3.6 \mathrm{~Hz}, \mathrm{C} 4\right), 125.10(\mathrm{~s}, \mathrm{C} 9), 36.23\left(\mathrm{~d},{ }^{1} J_{\mathrm{PC}}=45.6 \mathrm{~Hz}, \mathrm{C} 1\right) .{ }^{31} \mathrm{P} \mathrm{NMR}(121$ $\left.\mathrm{MHz}, \mathrm{CDCl}_{3}\right): \delta / \mathrm{ppm} 34.92\left(\mathrm{~s},{ }^{1} J_{\mathrm{PSe}}=741.7,{ }^{6} J_{\mathrm{PP}}=3.6 \mathrm{~Hz}\right) .{ }^{77} \mathrm{Se} \mathrm{NMR}(95 \mathrm{MHz}$, $\left.\mathrm{CDCl}_{3}\right): \delta / \mathrm{ppm}-363.52\left(\mathrm{~d},{ }^{1} J_{\mathrm{PSe}}=740.8 \mathrm{~Hz}\right)$. HRMS calcd for $\mathrm{C}_{28} \mathrm{H}_{25} \mathrm{~N}_{4} \mathrm{P}_{2} \mathrm{Se}_{2}$ $[\mathrm{M}+\mathrm{H}]^{+}: \mathrm{m} / \mathrm{z}=638.9885$; found $=638.9884$. HRMS calcd for $\mathrm{C}_{28} \mathrm{H}_{24} \mathrm{~N}_{4} \mathrm{NaP}_{2} \mathrm{Se}_{2}$ $[\mathrm{M}+\mathrm{Na}]^{+}: \mathrm{m} / \mathrm{z}=660.9704 ;$ found $=660.9699$.

$\operatorname{dbpxSe}_{2}(13)$

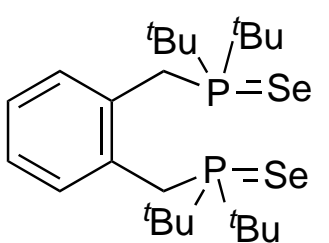

${ }^{1} \mathrm{H}$ NMR (500 MHz, $\mathrm{CDCl}_{3}$ ): $\delta / \mathrm{ppm} 7.76(\mathrm{~m}, 2 \mathrm{H}, \mathrm{Ar}-\mathrm{H}), 7.19$ (m, 2H, Ar-H), 4.13 $\left(\mathrm{d},{ }^{2} J_{\mathrm{PH}}=11.1 \mathrm{~Hz}, 4 \mathrm{H}, \mathrm{CH}_{2}\right) 1.35\left(\mathrm{~d},{ }^{3} J_{\mathrm{PH}}=15.0 \mathrm{~Hz}, 36 \mathrm{H}, \mathrm{C}\left(\mathrm{CH}_{3}\right)_{3}\right) .{ }^{13} \mathrm{C} \mathrm{NMR}$ $\left(125 \mathrm{MHz}, \mathrm{CDCl}_{3}\right.$ ): $\delta /$ ppm 133.60 (dd, $\left.J=7.7,5.7 \mathrm{~Hz}, \mathrm{Ar}-\mathrm{C}\right), 132.95$ (dd, $J=5.3$, $3.4 \mathrm{~Hz}, \mathrm{Ar}-\mathrm{C}), 126.79$ (s, Ar-C), $38.44\left(\mathrm{~d},{ }^{1} J_{\mathrm{PC}}=31.7 \mathrm{~Hz}, \mathrm{CH}_{2}\right), 31.41\left(\mathrm{~d},{ }^{1} J_{\mathrm{PC}}=\right.$ 
$\left.28.9 \mathrm{~Hz}, C\left(\mathrm{CH}_{3}\right)_{3}\right), 28.61\left(\mathrm{~s}, \mathrm{C}\left(\mathrm{CH}_{3}\right)_{3}\right) .{ }^{31} \mathrm{P} \mathrm{NMR}\left(121 \mathrm{MHz}, \mathrm{CDCl}_{3}\right): \delta / \mathrm{ppm} 76.67$ $\left(\mathrm{s},{ }^{1} J_{\mathrm{PSe}}=696.6,{ }^{5} J_{\mathrm{PP}}=2.8 \mathrm{~Hz}\right)$. HRMS calcd for $\mathrm{C}_{24} \mathrm{H}_{45} \mathrm{P}_{2} \mathrm{Se}_{2}[\mathrm{M}+\mathrm{H}]^{+}: \mathrm{m} / \mathrm{z}$ $=555.1326$; found $=555.1325$. HRMS calcd for $\mathrm{C}_{24} \mathrm{H}_{44} \mathrm{NaP}_{2} \mathrm{Se}_{2}[\mathrm{M}+\mathrm{Na}]^{+}: \mathrm{m} / \mathrm{z}=$ 575.1156 ; found $=575.1144$.

\subsection{Protonations}

\subsubsection{Protonation of dpypox}

\section{Reaction of one equivalent of $\mathrm{H}_{2} \mathrm{C}\left(\mathrm{SO}_{2} \mathrm{CF}_{3}\right)_{2}$ with 3}

To a solution of $3(30 \mathrm{mg}, 0.063 \mathrm{mmol})$ in $d_{6}$-acetone $(0.4 \mathrm{~mL})$, one equivalent of $\mathrm{H}_{2} \mathrm{C}\left(\mathrm{SO}_{2} \mathrm{CF}_{3}\right)_{2}(18 \mathrm{mg}, 0.063 \mathrm{mmol})$ was added. The ${ }^{31} \mathrm{P},{ }^{1} \mathrm{H}$ and ${ }^{19} \mathrm{~F}$ NMR spectra recorded 15 minutes after the addition of acid showed the formation of a protonated product (quantitative conversion).

(70) ${ }^{1} \mathrm{H}$ NMR $\left(500 \mathrm{MHz},\left(\mathrm{CD}_{3}\right)_{2} \mathrm{CO}\right): \delta / \mathrm{ppm} 9.06$ (ddd, $J=5.4,1.8,0.9 \mathrm{~Hz}, 4 \mathrm{H}$, H9), 8.32 (tm, $J=7.8 \mathrm{~Hz}, 4 \mathrm{H}, \mathrm{H} 7), 7.98$ (m, 4H, H6), 7.94 (m, 4H, H8), 6.97 (m, $2 \mathrm{H}, \mathrm{H} 4), 6.69$ (dd, $J=5.3,3.6 \mathrm{~Hz}, 2 \mathrm{H}, \mathrm{H} 3), 3.88\left(\mathrm{br} \mathrm{s}, 1 \mathrm{H}, \mathrm{CH}\left(\mathrm{SO}_{2} \mathrm{CF}_{3}\right)_{2}\right), 3.78$ (s, $4 \mathrm{H}, \mathrm{H} 1) .{ }^{13} \mathrm{C} \mathrm{NMR}\left(125 \mathrm{MHz},\left(\mathrm{CD}_{3}\right)_{2} \mathrm{CO}\right): \delta / \mathrm{ppm} 157.81\left(\mathrm{~d},{ }^{1} J_{\mathrm{PC}}=27.2 \mathrm{~Hz}, \mathrm{C} 5\right)$, 147.86 (s, C9), 142.61 (vt, $\left.{ }^{3} J_{\mathrm{PC}}+{ }^{8} J_{\mathrm{PC}}=4.9 \mathrm{~Hz}, \mathrm{C} 7\right), 134.22\left(\mathrm{vt},{ }^{2} J_{\mathrm{PC}}+{ }^{3} J_{\mathrm{PC}}=\right.$ $3.8 \mathrm{~Hz}, \mathrm{C} 2), 133.78\left(\mathrm{dd}, J_{\mathrm{PC}}=39.3,4.1 \mathrm{~Hz}, \mathrm{C} 6\right), 131.55\left(\mathrm{vt},{ }^{3} J_{\mathrm{PC}}+{ }^{4} J_{\mathrm{PC}}=2.0\right.$ $\mathrm{Hz}, \mathrm{C} 3$ ), 128.23 (s, C4), 127.53 (s, C8), 122.06 (q, ${ }^{1} J_{\mathrm{CF}}=326.0 \mathrm{~Hz}, \mathrm{CH}\left(\mathrm{SO}_{2} C \mathrm{~F}_{3}\right)_{2}$ ), 54.82 (br s, $\left.C \mathrm{H}\left(\mathrm{SO}_{2} \mathrm{CF}_{3}\right)_{2}\right), 34.63\left(\mathrm{~d},{ }^{1} J_{\mathrm{PC}}=13.9 \mathrm{~Hz}, \mathrm{C} 1\right) .{ }^{19} \mathrm{~F} \mathrm{NMR}(282 \mathrm{MHz}$, $\left.\left(\mathrm{CD}_{3}\right)_{2} \mathrm{CO}\right): \delta / \mathrm{ppm}-81.69\left(\mathrm{br} \mathrm{s}, \mathrm{CH}\left(\mathrm{SO}_{2} \mathrm{CF}_{3}\right)_{2}\right) .{ }^{31} \mathrm{P} \mathrm{NMR}\left(121 \mathrm{MHz},\left(\mathrm{CD}_{3}\right)_{2} \mathrm{CO}\right)$ : $\delta / \mathrm{ppm}-29.34$ (br s). IR (film from $\left.\left(\mathrm{CH}_{3}\right)_{2} \mathrm{CO}\right): \nu_{\max } / \mathrm{cm}^{-1} 3075$ (N-H stretch), 1606, 1574 ( $\mathrm{C}=\mathrm{N}$ stretch).

\section{Reaction of four equivalents of $\mathrm{H}_{2} \mathrm{C}\left(\mathrm{SO}_{2} \mathrm{CF}_{3}\right)_{2}$ with 3}

To a solution of $3(30 \mathrm{mg}, 0.063 \mathrm{mmol})$ in $d_{6}$-acetone $(0.4 \mathrm{~mL})$, four equivalents of $\mathrm{H}_{2} \mathrm{C}\left(\mathrm{SO}_{2} \mathrm{CF}_{3}\right)_{2}$ (70 mg, $\left.0.25 \mathrm{mmol}\right)$ were added. The ${ }^{31} \mathrm{P},{ }^{1} \mathrm{H}$ and ${ }^{19} \mathrm{~F} \mathrm{NMR}$ spectra recorded 15 minutes after the addition of acid showed the formation of a protonated product (quantitative conversion).

(71) ${ }^{1} \mathrm{H}$ NMR $\left(500 \mathrm{MHz},\left(\mathrm{CD}_{3}\right)_{2} \mathrm{CO}\right): \delta / \operatorname{ppm} 9.09(\mathrm{~d}, J=5.1 \mathrm{~Hz}, 4 \mathrm{H}, \mathrm{H} 9), 8.44$ 
(t, $J=7.5 \mathrm{~Hz}, 4 \mathrm{H}, \mathrm{H} 7), 8.11(\mathrm{~m}, 4 \mathrm{H}, \mathrm{H} 6), 8.04(\mathrm{~m}, 4 \mathrm{H}, \mathrm{H} 8), 6.98$ (m, 2H, H4), $6.70(\mathrm{~m}, 2 \mathrm{H}, \mathrm{H} 3), 3.95$ (br s, $4 \mathrm{H}, \mathrm{H} 1) .{ }^{13} \mathrm{C} \mathrm{NMR}\left(125 \mathrm{MHz},\left(\mathrm{CD}_{3}\right)_{2} \mathrm{CO}\right): \delta / \mathrm{ppm}$ 156.84 (m, C5), 147.47 (br s, C9), 143.83 (m, C7), 134.17 (m, C2), 133.93 (m, C6), 131.75 (s, C3), 128.55 (s, C4), 128.11 (s, C8), 120.50 (qm, ${ }^{1} J_{\mathrm{CF}}=311.5 \mathrm{~Hz}$, $\left.\mathrm{CH}\left(\mathrm{SO}_{2} \mathrm{CF}_{3}\right)_{2}\right), 63.80$ (br s, $\left.\mathrm{CH}\left(\mathrm{SO}_{2} \mathrm{CF}_{3}\right)_{2}\right), 34.05$ (m, C1). ${ }^{19} \mathrm{~F}$ NMR $(282 \mathrm{MHz}$, $\left.\left(\mathrm{CD}_{3}\right)_{2} \mathrm{CO}\right): \delta / \mathrm{ppm}-78.15\left(\mathrm{~m}, \mathrm{CH}\left(\mathrm{SO}_{2} \mathrm{CF}_{3}\right)_{2}\right) .{ }^{31} \mathrm{P} \mathrm{NMR}\left(121 \mathrm{MHz},\left(\mathrm{CD}_{3}\right)_{2} \mathrm{CO}\right)$ : $\delta / \mathrm{ppm}-27.04(\mathrm{~m})$. IR (film from $\left.\left(\mathrm{CH}_{3}\right)_{2} \mathrm{CO}\right): \nu_{\max } / \mathrm{cm}^{-1} 3103(\mathrm{~N}-\mathrm{H}$ stretch), 1607 $(\mathrm{C}=\mathrm{N}$ stretch $)$.

\section{Reaction of six equivalents of $\mathrm{H}_{2} \mathrm{C}\left(\mathrm{SO}_{2} \mathrm{CF}_{3}\right)_{2}$ with 3}

To a solution of ligand $3(30 \mathrm{mg}, 0.063 \mathrm{mmol})$ in $d_{6}$-acetone $(0.4 \mathrm{~mL})$, six equivalents of $\mathrm{H}_{2} \mathrm{C}\left(\mathrm{SO}_{2} \mathrm{CF}_{3}\right)_{2}(105 \mathrm{mg}, 0.38 \mathrm{mmol})$ were added. The ${ }^{31} \mathrm{P},{ }^{1} \mathrm{H}$ and ${ }^{19} \mathrm{~F} \mathrm{NMR}$ spectra recorded 15 minutes after the addition of acid showed the formation of a fully protonated product (quantitative conversion).

(72) ${ }^{1} \mathrm{H}$ NMR $\left(500 \mathrm{MHz},\left(\mathrm{CD}_{3}\right)_{2} \mathrm{CO}\right): \delta / \mathrm{ppm} 9.09(\mathrm{~d}, J=5.5 \mathrm{~Hz}, 4 \mathrm{H}, \mathrm{H} 9), 8.56$ (t, $J=7.5 \mathrm{~Hz}, 4 \mathrm{H}, \mathrm{H} 7), 8.26(\mathrm{~d}, J=6.5 \mathrm{~Hz}, 4 \mathrm{H}, \mathrm{H} 6), 8.14(\mathrm{t}, J=6.5 \mathrm{~Hz}, 4 \mathrm{H}$, $\mathrm{H} 8), 6.97$ (m, 2H, H4), 6.71 (m, 2H, H3), 4.14 (br s, 4H, H1). ${ }^{13} \mathrm{C}$ NMR $(125 \mathrm{MHz}$, $\left.\left(\mathrm{CD}_{3}\right)_{2} \mathrm{CO}\right): \delta / \mathrm{ppm} 155.19$ (m, C5), 146.39 (s, C9), 144.62 (br s, C7), 133.78 (m, C6), 132.72 (br s, C2), 131.38 (s, C3), 128.33 (s, C4), 128.16 (br s, C8), 120.19 (q, $\left.{ }^{1} J_{\mathrm{CF}}=325.3 \mathrm{~Hz}, \mathrm{CH}\left(\mathrm{SO}_{2} C \mathrm{~F}_{3}\right)_{2}\right), 61.50\left(\mathrm{br} \mathrm{s}, \mathrm{CH}\left(\mathrm{SO}_{2} \mathrm{CF}_{3}\right)_{2}\right), 32.66$ (br s, C1). ${ }^{19} \mathrm{~F}$ $\operatorname{NMR}\left(282 \mathrm{MHz},\left(\mathrm{CD}_{3}\right)_{2} \mathrm{CO}\right): \delta / \mathrm{ppm}-78.96$ (br s, $\left.\mathrm{CH}\left(\mathrm{SO}_{2} \mathrm{CF}_{3}\right)_{2}\right) .{ }^{31} \mathrm{P} \mathrm{NMR}(121$ $\left.\mathrm{MHz},\left(\mathrm{CD}_{3}\right)_{2} \mathrm{CO}\right): \delta / \mathrm{ppm}-24.11$ (br s). IR (film from $\left(\mathrm{CH}_{3}\right)_{2} \mathrm{CO}$ ): $\nu_{\max } / \mathrm{cm}^{-1}$ 3100 ( $\mathrm{N}-\mathrm{H}$ stretch), 2361 ( $\mathrm{P}-\mathrm{H}$ stretch), $1606(\mathrm{C}=\mathrm{N}$ stretch).

\subsubsection{Protonation of dpyp $m x$}

\section{Reaction of one equivalent of $\mathrm{H}_{2} \mathrm{C}\left(\mathrm{SO}_{2} \mathrm{CF}_{3}\right)_{2}$ with 4}

To a solution of 4 (30 $\mathrm{mg}, 0.063 \mathrm{mmol})$ in $d_{6}$-acetone $(0.4 \mathrm{~mL})$, one equivalent of $\mathrm{H}_{2} \mathrm{C}\left(\mathrm{SO}_{2} \mathrm{CF}_{3}\right)_{2}(18 \mathrm{mg}, 0.063 \mathrm{mmol})$ was added. The ${ }^{31} \mathrm{P},{ }^{1} \mathrm{H}$ and ${ }^{19} \mathrm{~F} \mathrm{NMR}$ spectra recorded 15 minutes after the addition of acid showed the formation of a protonated product (quantitative conversion).

(73) ${ }^{1} \mathrm{H}$ NMR $\left(500 \mathrm{MHz},\left(\mathrm{CD}_{3}\right)_{2} \mathrm{CO}\right): \delta / \mathrm{ppm} 8.99(\mathrm{~d}, J=5.1 \mathrm{~Hz}, 4 \mathrm{H}, \mathrm{H} 10), 8.30$ $(\mathrm{t}, J=7.8 \mathrm{~Hz}, 4 \mathrm{H}, \mathrm{H} 8), 7.98(\mathrm{t}, J=6.7 \mathrm{~Hz}, 4 \mathrm{H}, \mathrm{H} 7), 7.87$ (t, $J=6.6 \mathrm{~Hz}, 4 \mathrm{H}$, 
H9), $6.87\left(\mathrm{t},{ }^{3} J_{\mathrm{HH}}=7.6 \mathrm{~Hz}, 1 \mathrm{H}, \mathrm{H} 4\right), 6.58\left(\mathrm{~d},{ }^{3} J_{\mathrm{HH}}=7.6 \mathrm{~Hz}, 2 \mathrm{H}, \mathrm{H} 3\right), 6.45(\mathrm{~s}, 1 \mathrm{H}$, $\mathrm{H} 5), 3.83$ (br s, $\left.1 \mathrm{H}, \mathrm{CH}\left(\mathrm{SO}_{2} \mathrm{CF}_{3}\right)_{2}\right), 3.64(\mathrm{~d}, J=3.0 \mathrm{~Hz}, 4 \mathrm{H}, \mathrm{H} 1) .{ }^{13} \mathrm{C} \mathrm{NMR}(125$ $\left.\mathrm{MHz},\left(\mathrm{CD}_{3}\right)_{2} \mathrm{CO}\right): \delta / \mathrm{ppm} 159.05\left(\mathrm{~d},{ }^{1} J_{\mathrm{PC}}=26.5 \mathrm{~Hz}, \mathrm{C} 6\right), 147.76(\mathrm{~s}, \mathrm{C} 10), 141.94$ $\left(\mathrm{d},{ }^{3} J_{\mathrm{PC}}=9.6 \mathrm{~Hz}, \mathrm{C} 8\right), 136.60(\mathrm{~s}, \mathrm{C} 2), 132.98\left(\mathrm{~d},{ }^{2} J_{\mathrm{PC}}=34.1 \mathrm{~Hz}, \mathrm{C} 7\right), 130.1(\mathrm{~m}$, C5), 129.45 (s, C4), 128.08 (s, C3), 126.93 (s, C9), 122.18 (q, ${ }^{1} J_{\mathrm{CF}}=325.8 \mathrm{~Hz}$, $\left.\mathrm{CH}\left(\mathrm{SO}_{2} \mathrm{CF}_{3}\right)_{2}\right), 55.06$ (br s, $\left.C \mathrm{H}\left(\mathrm{SO}_{2} \mathrm{CF}_{3}\right)_{2}\right), 36.70$ (d, $\left.{ }^{1} J_{\mathrm{PC}}=18.2 \mathrm{~Hz}, \mathrm{C} 1\right) .{ }^{19} \mathrm{~F}$ NMR $\left(282 \mathrm{MHz},\left(\mathrm{CD}_{3}\right)_{2} \mathrm{CO}\right): \delta / \mathrm{ppm}-81.73\left(\mathrm{~s}, \mathrm{CH}\left(\mathrm{SO}_{2} \mathrm{CF}_{3}\right)_{2}\right) .{ }^{31} \mathrm{P} \mathrm{NMR}(121$ $\left.\mathrm{MHz},\left(\mathrm{CD}_{3}\right)_{2} \mathrm{CO}\right): \delta / \mathrm{ppm}-24.52(\mathrm{~s})$. IR (film from $\left.\left(\mathrm{CH}_{3}\right)_{2} \mathrm{CO}\right): \nu_{\max } / \mathrm{cm}^{-1} 3081$ (N-H stretch), 1606, $1580(\mathrm{C}=\mathrm{N}$ stretch $)$.

\section{Reaction of four equivalents of $\mathrm{H}_{2} \mathrm{C}\left(\mathrm{SO}_{2} \mathrm{CF}_{3}\right)_{2}$ with 4}

To a solution of $4(30 \mathrm{mg}, 0.063 \mathrm{mmol})$ in $d_{6}$-acetone $(0.4 \mathrm{~mL})$, four equivalents of $\mathrm{H}_{2} \mathrm{C}\left(\mathrm{SO}_{2} \mathrm{CF}_{3}\right)_{2}$ (70 mg, $0.25 \mathrm{mmol}$ ) were added. The ${ }^{31} \mathrm{P},{ }^{1} \mathrm{H}$ and ${ }^{19} \mathrm{~F} \mathrm{NMR}$ spectra recorded 15 minutes after the addition of acid showed the formation of a protonated product (quantitative conversion).

(74) ${ }^{1} \mathrm{H}$ NMR $\left(500 \mathrm{MHz},\left(\mathrm{CD}_{3}\right)_{2} \mathrm{CO}\right): \delta / \mathrm{ppm} 9.07$ (m, 4H, H10), 8.52 (m, 4H, H8), 8.23 (m, 4H, H7), 8.07 (m, 4H, H9), 6.98 (m, 1H, H4), 6.74 (br s, 2H, H3), 6.67 (br s, $1 \mathrm{H}, \mathrm{H} 5), 3.92$ (br s, $\left.4 \mathrm{H}, \mathrm{CH}\left(\mathrm{SO}_{2} \mathrm{CF}_{3}\right)_{2}\right), 3.84$ (br s, $\left.4 \mathrm{H}, \mathrm{H} 1\right) .{ }^{13} \mathrm{C} \mathrm{NMR}(125$ $\left.\mathrm{MHz},\left(\mathrm{CD}_{3}\right)_{2} \mathrm{CO}\right): \delta / \mathrm{ppm} 156.93$ (m, C6), 146.99 (s, C10), 144.32 (m, C8), 135.90 (s, C2), $133.71\left(\mathrm{~d},{ }^{2} J_{\mathrm{PC}}=26.4 \mathrm{~Hz}, \mathrm{C} 7\right), 130.41$ (m, C5), 130.00 (s, C4), 128.52 (m, C3), $128.10(\mathrm{~m}, \mathrm{C} 9), 120.76\left(\mathrm{qm},{ }^{1} J_{\mathrm{CF}}=315.7 \mathrm{~Hz}, \mathrm{CH}\left(\mathrm{SO}_{2} C \mathrm{~F}_{3}\right)_{2}\right), 62.5(\mathrm{br} \mathrm{s}$, $\left.\mathrm{CH}\left(\mathrm{SO}_{2} \mathrm{CF}_{3}\right)_{2}\right), 35.71$ (m, C1). ${ }^{19} \mathrm{~F} \mathrm{NMR}\left(282 \mathrm{MHz},\left(\mathrm{CD}_{3}\right)_{2} \mathrm{CO}\right): \delta / \mathrm{ppm}-78.73$ $\left(\mathrm{s}, \mathrm{CH}\left(\mathrm{SO}_{2} \mathrm{CF}_{3}\right)_{2}\right)$. ${ }^{31} \mathrm{P} \mathrm{NMR}\left(121 \mathrm{MHz},\left(\mathrm{CD}_{3}\right)_{2} \mathrm{CO}\right): \delta / \mathrm{ppm}-22.45$ (br s). IR (film from $\left.\left(\mathrm{CH}_{3}\right)_{2} \mathrm{CO}\right): \nu_{\max } / \mathrm{cm}^{-1} 3100(\mathrm{~N}-\mathrm{H}$ stretch), $1607(\mathrm{C}=\mathrm{N}$ stretch).

\section{Reaction of six equivalents of $\mathrm{H}_{2} \mathrm{C}\left(\mathrm{SO}_{2} \mathrm{CF}_{3}\right)_{2}$ with 4}

To a solution of $4(30 \mathrm{mg}, 0.063 \mathrm{mmol})$ in $d_{6}$-acetone $(0.4 \mathrm{~mL})$, six equivalents of $\mathrm{H}_{2} \mathrm{C}\left(\mathrm{SO}_{2} \mathrm{CF}_{3}\right)_{2}(105 \mathrm{mg}, 0.38 \mathrm{mmol})$ were added. The ${ }^{31} \mathrm{P},{ }^{1} \mathrm{H}$ and ${ }^{19} \mathrm{~F} \mathrm{NMR}$ spectra recorded 15 minutes after the addition of acid showed the formation of a fully protonated product (quantitative conversion).

(75) ${ }^{1} \mathrm{H}$ NMR (500 MHz, $\left.\left(\mathrm{CD}_{3}\right)_{2} \mathrm{CO}\right): \delta / \mathrm{ppm} 9.08$ (m, 4H, H10), 8.61 (m, 4H, H8), 8.33 (m, 4H, H7), 8.15 (m, 4H, H9), 7.04 (m, 1H, H4), 6.95 (br s, 6H, CH( $\left.\mathrm{SO}_{2} \mathrm{CF}_{3}\right)_{2}$ ), $6.92(\mathrm{~m}, 1 \mathrm{H}, \mathrm{H} 5), 6.83$ (m, 2H, H3), 3.96 (br s, 4H, H1). ${ }^{13} \mathrm{C}$ NMR (125 MHz, $\left.\left(\mathrm{CD}_{3}\right)_{2} \mathrm{CO}\right): \delta / \mathrm{ppm} 155.53\left(\mathrm{dm},{ }^{1} J_{\mathrm{PC}}=21.3 \mathrm{~Hz}, \mathrm{C} 6\right), 146.60(\mathrm{~s}, \mathrm{C} 10), 145.65(\mathrm{~m}$, 
C8), 135.51 (s, C2), 133.99 (d, $\left.{ }^{2} J_{\mathrm{PC}}=19.6 \mathrm{~Hz}, \mathrm{C} 7\right), 130.70$ (s, C5), 130.36 (s, C4), 128.73 (m, C9), 128.49 (s, C3), $120.42\left(\mathrm{qm},{ }^{1} J_{\mathrm{CF}}=326.3 \mathrm{~Hz}, \mathrm{CH}\left(\mathrm{SO}_{2} C \mathrm{~F}_{3}\right)_{2}\right), 64.5$ (br m, $\left.\mathrm{CH}\left(\mathrm{SO}_{2} \mathrm{CF}_{3}\right)_{2}\right), 34.72$ (m, C1). ${ }^{19} \mathrm{~F} \mathrm{NMR}\left(282 \mathrm{MHz},\left(\mathrm{CD}_{3}\right)_{2} \mathrm{CO}\right): \delta / \mathrm{ppm}$ -78.59 (br s, $\left.\mathrm{CH}\left(\mathrm{SO}_{2} \mathrm{CF}_{3}\right)_{2}\right) .{ }^{31} \mathrm{P} \mathrm{NMR}\left(121 \mathrm{MHz},\left(\mathrm{CD}_{3}\right)_{2} \mathrm{CO}\right): \delta / \mathrm{ppm}-19.81$. IR (film from $\left.\left(\mathrm{CH}_{3}\right)_{2} \mathrm{CO}\right): \nu_{\max } / \mathrm{cm}^{-1} 3098$ (N-H stretch), 2363 (P-H stretch), 1607 $(\mathrm{C}=\mathrm{N}$ stretch).

\subsubsection{Reaction with $\mathrm{HCl}$ to acheive water-solubility}

Degassed water $(2 \mathrm{~mL})$ was added to 3 or 4 (50 mg, $0.10 \mathrm{mmol})$. To this concentrated hydrochloric acid was added dropwise until all of the solid had dissolved. The water and acid were removed under reduced pressure to give a brown oil which was dissolved in $\mathrm{D}_{2} \mathrm{O}$ to allow characterisation by NMR methods.

\section{dpypox}

${ }^{1} \mathrm{H}$ NMR (500 MHz, D $\left.2 \mathrm{O}\right): \delta / \operatorname{ppm} 8.64(\mathrm{~d}, J=5.6 \mathrm{~Hz}, 4 \mathrm{H}, \mathrm{H} 9), 8.51$ (t, $J=8.0$ $\mathrm{Hz}, 4 \mathrm{H}, \mathrm{H} 7), 8.18$ (d, $J=7.8 \mathrm{~Hz}, 4 \mathrm{H}, \mathrm{H} 6), 8.00$ (t, $J=6.9 \mathrm{~Hz}, 4 \mathrm{H}, \mathrm{H} 8), 6.80$ (m, $2 \mathrm{H}, \mathrm{H} 4), 6.44$ (t, $J=4.2 \mathrm{~Hz}, 2 \mathrm{H}, \mathrm{H} 3), 4.15$ (s, 4H, H1). ${ }^{13} \mathrm{C}$ NMR $\left(125 \mathrm{MHz}, \mathrm{D}_{2} \mathrm{O}\right)$ : $\delta / \mathrm{ppm} 153.29\left(\mathrm{~d},{ }^{1} J_{\mathrm{PC}}=29.3 \mathrm{~Hz}, \mathrm{C} 5\right), 147.99$ (s, C7), 145.31 (s, C9), 134.33 (s, C6), 132.48 (m, C3), $132.09\left(\mathrm{vt},{ }^{2} J_{\mathrm{PC}}+{ }^{3} J_{\mathrm{PC}}=4.6 \mathrm{~Hz}, \mathrm{C} 2\right), 129.86$ (s, C4), 129.76 $(\mathrm{s}, \mathrm{C} 8), 32.06\left(\mathrm{~d},{ }^{1} J_{\mathrm{PC}}=9.6 \mathrm{~Hz}, \mathrm{C} 1\right) .{ }^{31} \mathrm{P} \mathrm{NMR}\left(121 \mathrm{MHz}, \mathrm{D}_{2} \mathrm{O}\right): \delta / \mathrm{ppm}-19.78(\mathrm{~s})$.

\section{$\operatorname{dpyp} m x$}

${ }^{1} \mathrm{H}$ NMR (500 MHz, D $\left.2 \mathrm{O}\right): \delta / \mathrm{ppm} 8.67$ (d, $\left.J=5.6 \mathrm{~Hz}, 4 \mathrm{H}, \mathrm{H} 10\right), 8.49$ (t, $J=7.7$ $\mathrm{Hz}, 4 \mathrm{H}, \mathrm{H} 8), 8.12$ (t, $J=7.3 \mathrm{~Hz}, 4 \mathrm{H}, \mathrm{H} 7), 7.99$ (m, 4H, H9), 6.95 (dd, $J=7.6$, $3.3 \mathrm{~Hz}, 2 \mathrm{H}, \mathrm{H} 3), 6.77$ (d, J = 7.6 Hz, 1H, H4), 6.72 (s, 1H, H5), 3.81 (s, 4H, H1). ${ }^{13} \mathrm{C}$ NMR (125 MHz, $\left.\mathrm{D}_{2} \mathrm{O}\right): \delta / \mathrm{ppm} 151.75$ (d, $\left.{ }^{1} J_{\mathrm{PC}}=31.6 \mathrm{~Hz}, \mathrm{C} 6\right), 146.68$ (s, C8), $144.03(\mathrm{~s}, \mathrm{C} 10), 134.52\left(\mathrm{~d},{ }^{2} J_{\mathrm{PC}}=11.5 \mathrm{~Hz}, \mathrm{C} 2\right), 132.72\left(\mathrm{~d},{ }^{2} J_{\mathrm{PC}}=5.8 \mathrm{~Hz}, \mathrm{C} 7\right)$, 129.97 (s, C3), 129.64 (d, $\left.{ }^{3} J_{\mathrm{PC}}=6.6 \mathrm{~Hz}, \mathrm{C} 5\right), 128.35$ (br s, C9), 128.30 (m, C4), $31.70\left(\mathrm{~d},{ }^{1} J_{\mathrm{PC}}=14.8 \mathrm{~Hz}, \mathrm{C} 1\right) .{ }^{31} \mathrm{P}$ NMR $\left(121 \mathrm{MHz}, \mathrm{D}_{2} \mathrm{O}\right): \delta / \mathrm{ppm}-16.08(\mathrm{~s})$. 


\subsection{Borane Protection}

\subsubsection{General method}

To a solution of the ligand ( $50 \mathrm{mg}, 0.10 \mathrm{mmol}), 3$ or $\mathbf{4}$, in THF (2 mL) boranedimethylsulfide complex $(0.02 \mathrm{~mL}, 10 \mathrm{M}, 0.20 \mathrm{mmol})$ was added and stirred for 1 hour, 22 hours or 48 hours. At the end of the reaction time the solvent was removed under reduced pressure. A reaction time of one hour gave the product with the borane groups on the phosphorus atoms, 14 and 15. Stirring for longer than 1 hour resulted in the same products, with the borane groups attached to the phosphorus atoms even after stirring at room temperature for 48 hours. Due to the low solubility of $\mathbf{1 4}$ and $\mathbf{1 5}$ it was not possible to obtain ${ }^{13} \mathrm{C}$ NMR data on these compounds.

$\operatorname{dpypox}\left(\mathrm{P}-\mathrm{BH}_{3}\right)_{2}(14)$

${ }^{1} \mathrm{H}$ NMR $\left(500 \mathrm{MHz}, \mathrm{CDCl}_{3}\right): \delta / p p m 8.77$ (d, $\left.J=5.1 \mathrm{~Hz}, 4 \mathrm{H}, \mathrm{H} 9\right), 7.79$ (m, 4H, H6), $7.66(\mathrm{~m}, 4 \mathrm{H}, \mathrm{H} 7), 7.32(\mathrm{~m}, 4 \mathrm{H}, \mathrm{H} 8), 6.81(\mathrm{~m}, 4 \mathrm{H}, \mathrm{H} 3+\mathrm{H} 4), 4.15\left(\mathrm{~d},{ }^{2} J_{\mathrm{PH}}=\right.$ $13.5 \mathrm{~Hz}, 4 \mathrm{H}, \mathrm{H} 1) .{ }^{31} \mathrm{P} \mathrm{NMR}\left(121 \mathrm{MHz}, \mathrm{CDCl}_{3}\right): \delta / \mathrm{ppm} 32.46(\mathrm{~m}) .{ }^{11} \mathrm{~B} \operatorname{NMR}(96$ $\mathrm{MHz}, \mathrm{CDCl}_{3}$ ): $\delta / \mathrm{ppm}-40.08$ (br s). IR (film from $\left.\mathrm{CHCl}_{3}\right): \nu_{\max } / \mathrm{cm}^{-1} 2383(\mathrm{~B}-\mathrm{H}$ stretch), $1573\left(\mathrm{C}=\mathrm{N}\right.$ stretch). HRMS calcd for $\mathrm{C}_{28} \mathrm{H}_{28} \mathrm{BN}_{4} \mathrm{P}_{2}\left[\mathrm{M}-\mathrm{BH}_{3}+\mathrm{H}\right]^{+}: \mathrm{m} / \mathrm{z}$ $=493.1882$; found $=493.1900$.

$\operatorname{dpyp} m \times\left(\mathrm{P}-\mathrm{BH}_{3}\right)_{2}(15)$

${ }^{1} \mathrm{H}$ NMR $\left(500 \mathrm{MHz},\left(\mathrm{CD}_{3}\right){ }_{2} \mathrm{CO}\right): \delta / \mathrm{ppm} 8.81(\mathrm{~d}, J=4.0 \mathrm{~Hz}, 4 \mathrm{H}, \mathrm{H} 10), 7.76$ (t, $J$ $=6.5 \mathrm{~Hz}, 4 \mathrm{H}, \mathrm{H} 7), 7.67$ (m, 4H, H8), 7.33 (m, 4H, H9), 6.84 (m, 4H, H3, H4+H5), $3.87\left(\mathrm{~d},{ }^{2} J_{\mathrm{PH}}=14.0 \mathrm{~Hz}, 4 \mathrm{H}, \mathrm{H} 1\right) .{ }^{31} \mathrm{P} \mathrm{NMR}\left(121 \mathrm{MHz},\left(\mathrm{CD}_{3}\right)_{2} \mathrm{CO}\right): \delta / \mathrm{ppm} 23.03$ (m). ${ }^{11} \mathrm{~B} \mathrm{NMR}\left(96 \mathrm{MHz}, \mathrm{CDCl}_{3}\right): \delta / \mathrm{ppm}-40.68$ (br s). IR (film from $\mathrm{CHCl}_{3}$ ): $\nu_{\max } / \mathrm{cm}^{-1} 2381$ (B-H stretch), $1574(\mathrm{C}=\mathrm{N}$ stretch).

\subsubsection{Deprotection method}

A solution of phosphine-borane (55 mg, $0.10 \mathrm{mmol}$ ), 14 or 15, in diethylamine (2 $\mathrm{mL}$ ) was heated at $60{ }^{\circ} \mathrm{C}$ overnight. The solvent was then removed under reduced pressure and the resulting solid was left under reduced pressure overnight to sublime the byproduct, EtNH $\cdot \mathrm{BH}_{3} \cdot{ }^{31} \mathrm{P}$ and ${ }^{1} \mathrm{H}$ NMR recorded of the resulting solid in $\mathrm{CDCl}_{3}$ showed the ligands, 3 or $\mathbf{4}$, had been reformed. 


\subsection{Transition Metal Complexes}

\subsubsection{Platinum(II) complexes of dpypox}

\section{Synthesis of $\left[\mathrm{PtCl}_{2}(\mathrm{PP})\right](16)$}

Dichloro(hexa-1,5-diene)platinum (17 $\mathrm{mg}, 0.05 \mathrm{mmol}$ ) was added to a solution of ligand 3 (23 mg, $0.05 \mathrm{mmol})$ in $\mathrm{CDCl}_{3}(0.5 \mathrm{~mL})$ in an $\mathrm{NMR}$ tube. The ${ }^{31} \mathrm{P}$ and ${ }^{1} \mathrm{H}$ NMR spectra recorded after 15 minutes showed that the reaction had gone to completion (quantitative conversion).

${ }^{1} \mathrm{H}$ NMR (500 MHz, $\mathrm{CDCl}_{3}$ ): $\delta / \mathrm{ppm} 8.82$ (d, $\left.J=4.8 \mathrm{~Hz}, 4 \mathrm{H}, \mathrm{H} 9\right), 8.14$ (br s, 4H, H6), 7.70 (m, 4H, H7), 7.38 (m, 4H, H8), 6.71 (m, 2H, H4), 6.10 (m, 2H, H3), 4.54 (br s, 4H, H1). ${ }^{13} \mathrm{C}$ NMR $\left(125 \mathrm{MHz}, \mathrm{CDCl}_{3}\right): \delta / \mathrm{ppm} 153.56\left(\mathrm{~d},{ }^{1} J_{\mathrm{PC}}=90.9 \mathrm{~Hz}\right.$, C5), $149.65\left(\mathrm{vt},{ }^{3} J_{\mathrm{PC}}+{ }^{8} J_{\mathrm{PC}}=8.1 \mathrm{~Hz}, \mathrm{C} 9\right), 135.74(\mathrm{~s}, \mathrm{C} 7), 133.56$ (br s, C6), 132.00 (s, C2), 130.30 (s, C3), 127.19 (s, C4), 125.15 (s, C8), 32.11 (d, $\left.{ }^{1} J_{\mathrm{PC}}=37.9 \mathrm{~Hz}, \mathrm{C} 1\right)$. ${ }^{31} \mathrm{P}$ NMR $\left(121 \mathrm{MHz}, \mathrm{CDCl}_{3}\right): \delta / \mathrm{ppm} 0.64\left(\mathrm{~s},{ }^{1} J_{\mathrm{PtP}}=3500.0 \mathrm{~Hz}\right)$. IR (film from $\left.\mathrm{CH}_{2} \mathrm{Cl}_{2}\right): \nu_{\max } / \mathrm{cm}^{-1} 1573,1562(\mathrm{C}=\mathrm{N}$ stretch$)$. HRMS calcd for $\mathrm{C}_{28} \mathrm{H}_{24} \mathrm{ClN}_{4} \mathrm{P}_{2} \mathrm{Pt}$ $[\mathrm{M}-\mathrm{Cl}]^{+}: \mathrm{m} / \mathrm{z}=707.0792$; found $=707.0793$. HRMS calcd for $\mathrm{C}_{28} \mathrm{H}_{25} \mathrm{Cl}_{2} \mathrm{~N}_{4} \mathrm{P}_{2} \mathrm{Pt}$ $[\mathrm{M}+\mathrm{H}]^{+}: \mathrm{m} / \mathrm{z}=743.0558 ;$ found $=743.0556$.

\section{Synthesis of $\left[\mathrm{PtMe}_{2}(\mathrm{PP})\right](17)$}

Dimethyl(hexa-1,5-diene)platinum (203 $\mathrm{mg}, 0.66 \mathrm{mmol}$ ) was added to a solution of ligand 3 (315 mg, $0.66 \mathrm{mmol})$ in $\mathrm{CH}_{2} \mathrm{Cl}_{2}(5 \mathrm{~mL})$. The resulting reaction mixture was stirred for 20 minutes. The solvent was then removed under reduced pressure to give a brown solid. This was washed with hexane $(3 \times 10 \mathrm{~mL})$ and then dried under vacuum to give a red brown powder (350 mg, 76\%).

${ }^{1} \mathrm{H} \mathrm{NMR}\left(500 \mathrm{MHz}, \mathrm{CDCl}_{3}\right.$ ): $\delta / \mathrm{ppm} 8.86$ (d, $\left.J=4.5 \mathrm{~Hz}, 4 \mathrm{H}, \mathrm{H} 9\right), 7.75$ (br s, 4H, H6), 7.64 (t, $J=7.1 \mathrm{~Hz}, 4 \mathrm{H}, \mathrm{H} 7), 7.29$ (t, $J=6.0 \mathrm{~Hz}, 4 \mathrm{H}, \mathrm{H} 8), 6.58$ (m, 2H, H4), $6.11(\mathrm{~m}, 2 \mathrm{H}, \mathrm{H} 3), 4.56(\mathrm{br} \mathrm{s}, 4 \mathrm{H}, \mathrm{H} 1), 0.30\left(\mathrm{q},{ }^{3} J_{\mathrm{PH}}=5.9,{ }^{2} J_{\mathrm{PtH}}=68.7 \mathrm{~Hz}, 6 \mathrm{H}\right.$, $\left.\mathrm{Pt}-\mathrm{CH}_{3}\right) .{ }^{13} \mathrm{C} \operatorname{NMR}\left(125 \mathrm{MHz}_{,} \mathrm{CDCl}_{3}\right): \delta / \mathrm{ppm} 157.13\left(\mathrm{~d},{ }^{1} J_{\mathrm{PC}}=69.3 \mathrm{~Hz}, \mathrm{C} 5\right)$, 150.22 (s, C9), 135.30 (s, C7), 134.35 (s, C2), 131.78 (s, C6), 130.48 (s, C3), 125.99 (s, C4), $124.02(\mathrm{~s}, \mathrm{C} 8), 34.01\left(\mathrm{~d},{ }^{1} J_{\mathrm{PC}}=23.2 \mathrm{~Hz}, \mathrm{C} 1\right), 5.40\left(\mathrm{dd},{ }^{2} J_{\mathrm{PC}}=97.0,9.6\right.$, $\left.{ }^{1} J_{\mathrm{PtC}}=598.8 \mathrm{~Hz}, \mathrm{Pt}-\mathrm{CH}_{3}\right) .{ }^{31} \mathrm{P} \mathrm{NMR}\left(121 \mathrm{MHz}, \mathrm{CDCl}_{3}\right): \delta / \mathrm{ppm} 10.50\left(\mathrm{~s},{ }^{1} J_{\mathrm{PtP}}=\right.$ $1839.9 \mathrm{~Hz}$ ). IR (film from $\left.\mathrm{CH}_{2} \mathrm{Cl}_{2}\right): \nu_{\max } / \mathrm{cm}^{-1} 1574,1562(\mathrm{C}=\mathrm{N}$ stretch). HRMS calcd for $\mathrm{C}_{29} \mathrm{H}_{27} \mathrm{~N}_{4} \mathrm{P}_{2} \mathrm{Pt}\left[\mathrm{M}-\mathrm{CH}_{3}\right]^{+}: \mathrm{m} / \mathrm{z}=687.1338$; found $=687.1332$. Elemental 
Analysis: C, 50.9; H, 4.0; N, 7.7\% $\left(\mathrm{C}_{30} \mathrm{H}_{30} \mathrm{~N}_{4} \mathrm{P}_{2}\right.$ Pt requires C, 51.2; H, 4.3; N, 7.9\%).

\section{Synthesis of $\left[\mathrm{PtI}_{2}(\mathrm{PP})\right](18)$}

A solution of diiodo(hexa-1,5-diene)platinum (26 mg, $0.05 \mathrm{mmol})$ in $\mathrm{CDCl}_{3}(0.3 \mathrm{~mL})$ was combined with a solution of ligand $3(23 \mathrm{mg}, 0.05 \mathrm{mmol})$ in $\mathrm{CDCl}_{3}(0.3 \mathrm{~mL})$ in an NMR tube. ${ }^{31} \mathrm{P}$ and ${ }^{1} \mathrm{H}$ NMR spectra recorded after 10 minutes showed that the reaction had gone to completion (quantitative conversion).

${ }^{1} \mathrm{H} \mathrm{NMR}\left(500 \mathrm{MHz}, \mathrm{CDCl}_{3}\right): \delta / \mathrm{ppm} 8.83(\mathrm{~d}, J=4.5 \mathrm{~Hz}, 4 \mathrm{H}, \mathrm{H} 9), 8.16(\mathrm{~m}, 4 \mathrm{H}$, H6), 7.69 (m, 4H, H7), 7.38 (m, 4H, H8), 6.64 (m, 2H, H4), 6.01 (m, 2H, H3), 4.55 $\left(\mathrm{d},{ }^{2} J_{\mathrm{PH}}=10.6 \mathrm{~Hz}, 4 \mathrm{H}, \mathrm{H} 1\right) .{ }^{13} \mathrm{C} \mathrm{NMR}\left(125 \mathrm{MHz}, \mathrm{CDCl}_{3}\right): \delta / \mathrm{ppm} 155.75(\mathrm{~d}$, $\left.{ }^{1} J_{\mathrm{PC}}=91.7 \mathrm{~Hz}, \mathrm{C} 5\right), 149.46$ (m, C9), 135.26 (s, C7), 133.78 (m, C6), 132.20 (s, C2), 130.10 (s, C3), 126.97 (s, C4), 124.93 (s, C8), 33.65 (d, ${ }^{1} J_{\mathrm{PC}}=32.1 \mathrm{~Hz}, \mathrm{C} 1$ ). ${ }^{31} \mathrm{P}$ NMR $\left(121 \mathrm{MHz}, \mathrm{CDCl}_{3}\right): \delta / \mathrm{ppm}-13.0\left(\mathrm{~s},{ }^{1} J_{\mathrm{PtP}}=3303.5 \mathrm{~Hz}\right)$. HRMS calcd for $\mathrm{C}_{28} \mathrm{H}_{25} \mathrm{I}_{2} \mathrm{~N}_{4} \mathrm{P}_{2} \mathrm{Pt}[\mathrm{M}+\mathrm{H}]^{+}: \mathrm{m} / \mathrm{z}=926.9271$; found $=926.9279$. HRMS calcd for $\mathrm{C}_{28} \mathrm{H}_{24} \mathrm{I}_{2} \mathrm{~N}_{4} \mathrm{NaP}_{2} \mathrm{Pt}[\mathrm{M}+\mathrm{Na}]^{+}: \mathrm{m} / \mathrm{z}=948.9090$; found $=948.9089$.

\section{Synthesis of $\left[\mathrm{PtEt}_{2}(\mathrm{PP})\right](19)$}

Diethyl(cycloocta-1,5-diene)platinum (15 mg, $0.04 \mathrm{mmol}$ ) was added to a solution of ligand 3 (20 mg, $0.04 \mathrm{mmol})$ in $\mathrm{CDCl}_{3}(0.5 \mathrm{~mL})$ in a NMR tube. ${ }^{31} \mathrm{P}$ and ${ }^{1} \mathrm{H} \mathrm{NMR}$ spectra recorded after 10 minutes showed that the reaction had gone to completion (quantitative conversion).

${ }^{1} \mathrm{H}$ NMR (500 MHz, $\mathrm{CDCl}_{3}$ ): $\delta / \mathrm{ppm} 8.85$ (d, $\left.J=4.8 \mathrm{~Hz}, 4 \mathrm{H}, \mathrm{H} 9\right), 7.76$ (br s, 4H, H6), 7.62 (d, $J=5.9 \mathrm{~Hz}, 4 \mathrm{H}, \mathrm{H} 7), 7.27$ (d, $J=6.1 \mathrm{~Hz}, 4 \mathrm{H}, \mathrm{H} 8), 6.60$ (br s, 2H, H4), 6.23 (s, 2H, H3), 4.43 (br s, 4H, H1), 0.92 (q, ${ }^{3} J_{\mathrm{HH}}=6.6,{ }^{2} J_{\mathrm{PtH}}=104.3 \mathrm{~Hz}$, $\left.\mathrm{Pt}-\mathrm{CH}_{2} \mathrm{CH}_{3}\right), 0.61\left(\mathrm{t},{ }^{3} J_{\mathrm{HH}}=7.0,{ }^{3} J_{\mathrm{PtH}}=70.4 \mathrm{~Hz}, \mathrm{Pt}-\mathrm{CH}_{2} \mathrm{CH}_{3}\right) \cdot{ }^{13} \mathrm{C} \mathrm{NMR}(125$ $\mathrm{MHz}, \mathrm{CDCl}_{3}$ ): $\delta / \mathrm{ppm} 157.08\left(\mathrm{~d},{ }^{1} J_{\mathrm{PC}}=65.1 \mathrm{~Hz}, \mathrm{C} 5\right), 149.96$ (s, C9), 135.14 (s, C7), 134.39 (s, C2), 131.71 (s, C6), 130.64 (s, C3), 125.84 (s, C4), 123.82 (s, C8), $34.58\left(\mathrm{~d},{ }^{1} J_{\mathrm{PC}}=21.1 \mathrm{~Hz}, \mathrm{C} 1\right), 15.38\left(\mathrm{~m}, \mathrm{Pt}-\mathrm{CH}_{2} \mathrm{CH}_{3}\right), 13.72\left(\mathrm{~m}, \mathrm{Pt}-\mathrm{CH}_{2} \mathrm{CH}_{3}\right)$. ${ }^{31} \mathrm{P}$ NMR $\left(121 \mathrm{MHz}, \mathrm{CDCl}_{3}\right): \delta / \mathrm{ppm} 9.47\left(\mathrm{~s},{ }^{1} J_{\mathrm{PtP}}=1687.1 \mathrm{~Hz}\right)$. HRMS calcd for $\mathrm{C}_{30} \mathrm{H}_{29} \mathrm{~N}_{4} \mathrm{P}_{2} \mathrm{Pt}\left[\mathrm{M}-\mathrm{C}_{2} \mathrm{H}_{5}\right]^{+}: \mathrm{m} / \mathrm{z}=701.1494$; found $=701.1495$. 


\subsubsection{Palladium(II) complexes of dpypox}

\section{Synthesis of $\left[\mathrm{PdCl}_{2}(\mathrm{PP})\right](20)$}

Dichloro(cycloocta-1,5-diene)palladium (175 mg, $0.6 \mathrm{mmol}$ ) was added to a solution of ligand 3 (294 mg, $0.6 \mathrm{mmol})$ in $\mathrm{CH}_{2} \mathrm{Cl}_{2}(5 \mathrm{~mL})$ in a schlenk tube and stirred for 15 minutes. The solvent was removed under reduced pressure and the resulting yellow solid washed with hexane $(2 \times 5 \mathrm{~mL})$. The solid was dissolved in $\mathrm{CH}_{2} \mathrm{Cl}_{2}$, filtered and hexane was added. After 4 days at $-20{ }^{\circ} \mathrm{C}$ the product had crystallised out (122 $\mathrm{mg}, 31 \%$ ). While these crystals were found to be unsuitable for single crystal X-ray structure determination, X-ray quality crystals were grown from inwards diffusion of hexane into $\mathrm{CH}_{2} \mathrm{Cl}_{2}$ at $4{ }^{\circ} \mathrm{C}$.

${ }^{1} \mathrm{H}$ NMR (500 MHz, $\mathrm{CDCl}_{3}$ ): $\delta / \mathrm{ppm} 8.80$ (d, $\left.J=4.5 \mathrm{~Hz}, 4 \mathrm{H}, \mathrm{H} 9\right), 8.15$ (br s, 4H, H6), 7.70 (m, 4H, H7), 7.38 (m, 4H, H8), 6.70 (m, 2H, H4), 6.08 (br s, 2H, H3), $4.35\left(\mathrm{~d},{ }^{2} J_{\mathrm{PH}}=8.0 \mathrm{~Hz}, 4 \mathrm{H}, \mathrm{H} 1\right) .{ }^{13} \mathrm{C} \mathrm{NMR}\left(125 \mathrm{MHz} \mathrm{CDCl}_{3}\right): \delta / \mathrm{ppm} 156.29(\mathrm{~d}$, $\left.{ }^{1} J_{\mathrm{PC}}=23.6 \mathrm{~Hz}, \mathrm{C} 5\right), 149.54(\mathrm{~s}, \mathrm{C} 9), 135.85$ (s, C7), 134.05 (br s, C6), 131.78 (s, C2), 130.39 (s, C3), 127.28 (s, C4), 125.19 (s, C8), 32.15 (d, ${ }^{1} J_{\mathrm{PC}}=32.0 \mathrm{~Hz}, \mathrm{C} 1$ ). ${ }^{31} \mathrm{P}$ NMR $\left(121 \mathrm{MHz}, \mathrm{CDCl}_{3}\right.$ ): $\delta / \mathrm{ppm} 17.56$ (s). HRMS calcd for $\mathrm{C}_{28} \mathrm{H}_{24} \mathrm{ClN}_{4} \mathrm{P}_{2} \mathrm{Pd}$ $[\mathrm{M}-\mathrm{Cl}]^{+}: \mathrm{m} / \mathrm{z}=617.0205$; found $=617.0209$.

\section{Synthesis of $\left[\mathrm{PdMe}_{2}(\mathrm{PP})\right](21)$}

Dimethyl(N,N, $\mathrm{N}^{\prime}, \mathrm{N}^{\prime}$-tetramethylethylenediamine)palladium (10 mg, $0.04 \mathrm{mmol}$ ) was added to a solution of ligand $3(20 \mathrm{mg}, 0.04 \mathrm{mmol})$ in $\mathrm{CDCl}_{3}(0.5 \mathrm{~mL})$ in an $\mathrm{NMR}$ tube. The ${ }^{31} \mathrm{P}$ and ${ }^{1} \mathrm{H}$ NMR spectra recorded after 10 minutes showed that the reaction was complete (quantitative conversion).

${ }^{1} \mathrm{H}$ NMR (500 MHz, $\left.\mathrm{CDCl}_{3}\right): \delta / \mathrm{ppm} 8.83(\mathrm{~d}, J=4.2 \mathrm{~Hz}, 4 \mathrm{H}, \mathrm{H} 9), 7.80(\mathrm{~m}, 4 \mathrm{H}$, H6), 7.60 (m, 4H, H7), 7.27 (m, 4H, H8), 6.69 (m, 2H, H4), 6.13 (t, J = 4.1 Hz, 2H, H3), 4.36 (br s, 4H, H1), $0.40\left(\mathrm{~s}, \mathrm{Pd}-\mathrm{CH}_{3}\right) .{ }^{31} \mathrm{P} \mathrm{NMR}\left(121 \mathrm{MHz}, \mathrm{CDCl}_{3}\right): \delta / \mathrm{ppm}$ 14.71 (s). HRMS calcd for $\mathrm{C}_{29} \mathrm{H}_{27} \mathrm{~N}_{4} \mathrm{P}_{2} \mathrm{Pd}\left[\mathrm{M}-\mathrm{CH}_{3}\right]^{+}: \mathrm{m} / \mathrm{z}=598.0762$; found $=$ 598.766. 


\subsubsection{Platinum(II) complexes of dpypp}

\section{Synthesis of $\left[\mathrm{PtCl}_{2}(\mathrm{PP})\right](22)$}

Dichloro(hexa-1,5-diene)platinum (17 $\mathrm{mg}, 0.05 \mathrm{mmol}$ ) was added to a solution of ligand 5 (20 mg, $0.05 \mathrm{mmol})$ in $\mathrm{CDCl}_{3}(0.5 \mathrm{~mL})$ in an NMR tube. The ${ }^{31} \mathrm{P}$ and ${ }^{1} \mathrm{H}$ NMR spectra recorded after 15 minutes showed the reaction had gone to completion (quantitative conversion).

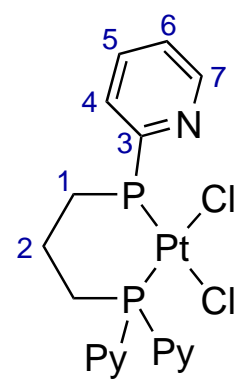

${ }^{1} \mathrm{H} \mathrm{NMR}\left(500 \mathrm{MHz}, \mathrm{CDCl}_{3}\right): \delta / \mathrm{ppm} 8.69(\mathrm{~d}, J=3.3 \mathrm{~Hz}, 4 \mathrm{H}, \mathrm{H} 7), 8.14(\mathrm{~m}, 4 \mathrm{H}$, H4), 7.72 (m, 4H, H5), 7.33 (m, 4H, H6), 2.86 (t, $J=7.8 \mathrm{~Hz}, 4 \mathrm{H}, \mathrm{H} 1$ ), 1.78 (quin, $J$ $=7.5 \mathrm{~Hz}, 2 \mathrm{H}, \mathrm{H} 2) .{ }^{13} \mathrm{C} \mathrm{NMR}\left(125 \mathrm{MHz}, \mathrm{CDCl}_{3}\right): \delta / \mathrm{ppm} 162.11(\mathrm{~s}, \mathrm{C} 3), 149.30(\mathrm{~s}$, C7), $135.78\left(\mathrm{~d},{ }^{3} J_{\mathrm{PC}}=7.2 \mathrm{~Hz}, \mathrm{C} 5\right), 133.00\left(\mathrm{~d},{ }^{2} J_{\mathrm{PC}}=22.5 \mathrm{~Hz}, \mathrm{C} 4\right), 125.15$ (s, C6), $38.24(\mathrm{~s}, \mathrm{C} 1), 32.01(\mathrm{~s}, \mathrm{C} 2) .{ }^{31} \mathrm{P} \mathrm{NMR}\left(121 \mathrm{MHz}, \mathrm{CDCl}_{3}\right): \delta / \mathrm{ppm} 3.05\left(\mathrm{~s},{ }^{1} J_{\mathrm{PtP}}=\right.$ $3318.7 \mathrm{~Hz}$ ). HRMS calcd for $\mathrm{C}_{23} \mathrm{H}_{22} \mathrm{ClN}_{4} \mathrm{P}_{2} \mathrm{Pt}[\mathrm{M}-\mathrm{Cl}]^{+}: \mathrm{m} / \mathrm{z}=645.0635$; found $=$ 645.0643.

\section{Synthesis of $\left[\mathrm{PtMe}_{2}(\mathrm{PP})\right](23)$}

A solution of ligand $5(20 \mathrm{mg}, 0.05 \mathrm{mmol})$ in $\mathrm{CDCl}_{3}(0.5 \mathrm{~mL})$ was added to dimethyl(hexa-1,5-diene)platinum $\left(15 \mathrm{mg}, 0.05 \mathrm{mmol}\right.$ ) in an NMR tube. The ${ }^{31} \mathrm{P}$ and ${ }^{1} \mathrm{H}$ NMR spectra recorded after 15 minutes showed the reaction had gone to completion (quantitative conversion).

${ }^{1} \mathrm{H}$ NMR (500 MHz, $\left.\mathrm{CDCl}_{3}\right): \delta / \mathrm{ppm} 8.68(\mathrm{~d}, J=5.0 \mathrm{~Hz}, 4 \mathrm{H}, \mathrm{H} 7), 7.75(\mathrm{~m}, 4 \mathrm{H}$, H4), $7.61(\mathrm{~m}, 4 \mathrm{H}, \mathrm{H} 5), 7.19(\mathrm{~m}, 4 \mathrm{H}, \mathrm{H} 6), 2.87$ (t, $\left.{ }^{3} J_{\mathrm{HH}}=7.8 \mathrm{~Hz}, 4 \mathrm{H}, \mathrm{H} 1\right), 1.79$ (quin, $\left.{ }^{3} J_{\mathrm{HH}}=7.8 \mathrm{~Hz}, 2 \mathrm{H}, \mathrm{H} 2\right), 0.41\left(\mathrm{q}, J_{\mathrm{PH}}=4.8,{ }^{2} J_{\mathrm{PtH}}=69.2 \mathrm{~Hz}, 6 \mathrm{H}, \mathrm{Pt}-\mathrm{CH}_{3}\right.$ ). ${ }^{13} \mathrm{C} \mathrm{NMR}\left(125 \mathrm{MHz}, \mathrm{CDCl}_{3}\right.$ ): $\delta / \mathrm{ppm} 162.12$ (s, C3), 150.31 (vt, ${ }^{3} J_{\mathrm{PC}}+{ }^{5} J_{\mathrm{PC}}=5.8$ $\mathrm{Hz}, \mathrm{C} 7), 135.07\left(\mathrm{vt},{ }^{3} J_{\mathrm{PC}}+{ }^{5} J_{\mathrm{PC}}=4.3 \mathrm{~Hz}, \mathrm{C} 5\right), 131.35\left(\mathrm{vt},{ }^{2} J_{\mathrm{PC}}+{ }^{4} J_{\mathrm{PC}}=12.4\right.$ $\mathrm{Hz}, \mathrm{C} 4), 123.73$ (s, C6), 38.29 (s, C1), 32.04 (s, C2), 4.11 (dd, ${ }^{2} J_{\mathrm{PC}}=98.4,11.0$ $\left.\mathrm{Hz}, \mathrm{Pt}-\mathrm{CH}_{3}\right) .{ }^{31} \mathrm{P} \mathrm{NMR}\left(121 \mathrm{MHz}, \mathrm{CDCl}_{3}\right): \delta / \mathrm{ppm} 9.30\left(\mathrm{~s},{ }^{1} J_{\mathrm{PtP}}=1736.5 \mathrm{~Hz}\right)$. 
HRMS calcd for $\mathrm{C}_{24} \mathrm{H}_{25} \mathrm{~N}_{4} \mathrm{P}_{2} \mathrm{Pt}\left[\mathrm{M}-\mathrm{CH}_{3}\right]^{+}: \mathrm{m} / \mathrm{z}=625.1181$; found $=625.1187$.

\section{Synthesis of $\left[\mathrm{PtEt}_{2}(\mathrm{PP})\right](24)$}

Diethyl(cycloocta-1,5-diene)platinum (17 mg, $0.05 \mathrm{mmol}$ ) was added to a solution of ligand 5 (20 mg, $0.05 \mathrm{mmol})$ in $\mathrm{CDCl}_{3}(0.5 \mathrm{~mL})$ in an NMR tube. ${ }^{31} \mathrm{P}$ and ${ }^{1} \mathrm{H} \mathrm{NMR}$ spectra recorded after 15 minutes showed the reaction was complete (quantitative conversion).

${ }^{1} \mathrm{H}$ NMR $\left(500 \mathrm{MHz}, \mathrm{CDCl}_{3}\right): \delta / \mathrm{ppm} 8.69(\mathrm{~d}, J=4.5 \mathrm{~Hz}, 4 \mathrm{H}, \mathrm{H} 7), 7.71(\mathrm{~m}, 4 \mathrm{H}$, H4), $7.62(\mathrm{tm}, J=7.7 \mathrm{~Hz}, 4 \mathrm{H}, \mathrm{H} 5), 7.21(\mathrm{t}, J=6.2 \mathrm{~Hz}, 4 \mathrm{H}, \mathrm{H} 6), 2.86\left(\mathrm{t},{ }^{3} J_{\mathrm{HH}}\right.$ $=7.8 \mathrm{~Hz}, 4 \mathrm{H}, \mathrm{H} 1$ ), 1.79 (quin, $\left.{ }^{3} J_{\mathrm{HH}}=7.8 \mathrm{~Hz}, 2 \mathrm{H}, \mathrm{H} 2\right), 1.43$ (q, ${ }^{3} J_{\mathrm{HH}}=7.5 \mathrm{~Hz}$, $\left.4 \mathrm{H}, \mathrm{Pt}-\mathrm{CH}_{2} \mathrm{CH}_{3}\right), 0.96\left(\mathrm{t},{ }^{3} J_{\mathrm{HH}}=7.5 \mathrm{~Hz}, 6 \mathrm{H}, \mathrm{Pt}-\mathrm{CH}_{2} \mathrm{CH}_{3}\right) \cdot{ }^{13} \mathrm{C} \mathrm{NMR}(125 \mathrm{MHz}$, $\mathrm{CDCl}_{3}$ ): $\delta / \mathrm{ppm} 162.11$ (s, C3), $150.21\left(\mathrm{vt},{ }^{3} J_{\mathrm{PC}}+{ }^{5} J_{\mathrm{PC}}=26.0 \mathrm{~Hz}, \mathrm{C} 7\right), 134.93$ (vt, $\left.{ }^{3} J_{\mathrm{PC}}+{ }^{5} J_{\mathrm{PC}}=4.06 \mathrm{~Hz}, \mathrm{C} 5\right), 131.39\left(\mathrm{vt},{ }^{2} J_{\mathrm{PC}}+{ }^{4} J_{\mathrm{PC}}=12.1 \mathrm{~Hz}, \mathrm{C} 4\right), 123.59(\mathrm{~s}$, C6), 38.28 (s, C1), 32.03 (s, C2), 22.64 (m, Pt- $\mathrm{CH}_{2} \mathrm{CH}_{3}$ ), 14.16 (m, Pt- $\mathrm{CH}_{2} \mathrm{CH}_{3}$ ). ${ }^{31} \mathrm{P}$ NMR $\left(121 \mathrm{MHz}, \mathrm{CDCl}_{3}\right): \delta / \mathrm{ppm} 8.83\left(\mathrm{~s},{ }^{1} J_{\mathrm{PtP}}=1568.9 \mathrm{~Hz}\right)$. HRMS calcd for $\mathrm{C}_{25} \mathrm{H}_{27} \mathrm{~N}_{4} \mathrm{P}_{2} \mathrm{Pt}\left[\mathrm{M}-\mathrm{C}_{2} \mathrm{H}_{5}\right]^{+}: \mathrm{m} / \mathrm{z}=639.1338$; found $=639.1346$. HRMS calcd for $\mathrm{C}_{23} \mathrm{H}_{23} \mathrm{~N}_{4} \mathrm{P}_{2} \mathrm{Pt}\left[\mathrm{M}-2 \mathrm{C}_{2} \mathrm{H}_{5}+\mathrm{H}\right]^{+}: \mathrm{m} / \mathrm{z}=611.1025$; found $=611.1022$.

\subsubsection{Palladium(II) complexes of dpypp}

\section{Synthesis of $\left[\mathrm{PdCl}_{2}(\mathrm{PP})\right](25)$}

Dichloro(cycloocta-1,5-diene)palladium (14 mg, $0.05 \mathrm{mmol}$ ) was added to a solution of ligand 5 (20 mg, $0.05 \mathrm{mmol})$ in $\mathrm{CDCl}_{3}(0.5 \mathrm{~mL})$ in an NMR tube. The ${ }^{31} \mathrm{P}$ and ${ }^{1} \mathrm{H}$ NMR spectra recorded after 15 minutes showed the reaction was complete (quantitative conversion).

${ }^{1} \mathrm{H}$ NMR (500 MHz, $\mathrm{CDCl}_{3}$ ): $\delta / \operatorname{ppm} 8.64(\mathrm{~d}, J=4.4 \mathrm{~Hz}, 4 \mathrm{H}, \mathrm{H} 7), 8.15$ (m, 4H, H4), 7.70 (m, 4H, H5), 7.33 (m, 4H, H6), 2.84 (t, $J=7.8 \mathrm{~Hz}, 4 \mathrm{H}, \mathrm{H} 1$ ), 1.76 (quin, $J=7.6$ $\mathrm{Hz}, 2 \mathrm{H}, \mathrm{H} 2) .{ }^{13} \mathrm{C} \mathrm{NMR}\left(125 \mathrm{MHz}, \mathrm{CDCl}_{3}\right): \delta / \mathrm{ppm} 162.03(\mathrm{~s}, \mathrm{C} 3), 150.01$ (d, ${ }^{3} J_{\mathrm{PC}}=$ $16.4 \mathrm{~Hz}, \mathrm{C} 7), 135.97$ (d, $\left.{ }^{3} J_{\mathrm{PC}}=9.1 \mathrm{~Hz}, \mathrm{C} 5\right), 133.20$ (d, $\left.{ }^{2} J_{\mathrm{PC}}=24.9 \mathrm{~Hz}, \mathrm{C} 4\right), 125.15$ (s, C6), 38.16 (s, C1), 31.94 (s, C2). ${ }^{31} \mathrm{P}$ NMR (121 MHz, $\mathrm{CDCl}_{3}$ ): $\delta / \mathrm{ppm} 14.03$ (s). HRMS calcd for $\mathrm{C}_{23} \mathrm{H}_{22} \mathrm{ClN}_{4} \mathrm{P}_{2} \mathrm{Pd}[\mathrm{M}-\mathrm{Cl}]^{+}: \mathrm{m} / \mathrm{z}=556.0059$; found $=556.0066$. 


\section{Synthesis of $\left[\mathrm{PdMe}_{2}(\mathrm{PP})\right](26)$}

Dimethyl(N,N,N', $\mathrm{N}^{\prime}$-tetramethylethylenediamine)palladium (12 mg, $0.05 \mathrm{mmol}$ ) was added to a solution of ligand $5(20 \mathrm{mg}, 0.05 \mathrm{mmol})$ in $\mathrm{CDCl}_{3}(0.5 \mathrm{~mL})$ in an $\mathrm{NMR}$ tube. The ${ }^{31} \mathrm{P}$ and ${ }^{1} \mathrm{H}$ NMR spectra recorded after 15 minutes showed the reaction was complete (quantitative conversion).

${ }^{1} \mathrm{H}$ NMR $\left(500 \mathrm{MHz}, \mathrm{CDCl}_{3}\right): \delta / \mathrm{ppm} 8.71$ (d, $\left.J=4.2 \mathrm{~Hz}, 4 \mathrm{H}, \mathrm{H} 7\right), 7.69(\mathrm{~m}, 4 \mathrm{H}$, H4), 7.63 (t, $J=7.5 \mathrm{~Hz}, 4 \mathrm{H}, \mathrm{H} 5$ ), 7.25 (m, 4H, H6), 4.52 (br s, H1), 3.05 (br s, H2), $0.11\left(\mathrm{~s}, \mathrm{Pd}-\mathrm{CH}_{3}\right) .{ }^{31} \mathrm{P} \mathrm{NMR}\left(121 \mathrm{MHz}, \mathrm{CDCl}_{3}\right): \delta / \mathrm{ppm} 12.64$ (s). HRMS calcd for $\mathrm{C}_{24} \mathrm{H}_{25} \mathrm{~N}_{4} \mathrm{P} 2 \mathrm{Pd}\left[\mathrm{M}-\mathrm{CH}_{3}\right]^{+}: \mathrm{m} / \mathrm{z}=536.0605$; found $=536.0602$.

\subsubsection{Unsymmetric platinum(II) complexes of dpypox}

\section{Synthesis of $[\mathrm{PtClMe}(\mathrm{PP})](27)$}

A solution of ligand $3(100 \mathrm{mg}, 0.21 \mathrm{mmol})$ in $\mathrm{CH}_{2} \mathrm{Cl}_{2}(2 \mathrm{~mL})$ was added to chloromethyl(hexa-1,5-diene)platinum (68 mg, $0.21 \mathrm{mmol}$ ). An immediate colour change was observed. After five minutes of stirring the solvent was removed under reduced pressure. The resulting brown oil was washed with hexane $(2 \times 2 \mathrm{~mL})$ to give a brown solid. Yellow crystals of the product were grown via inward diffusion of hexane into a concentrated solution of the product in $\mathrm{CH}_{2} \mathrm{Cl}_{2}(129 \mathrm{mg}, 85 \%)$.

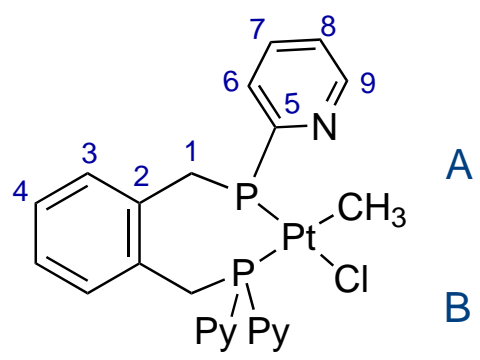

${ }^{1} \mathrm{H}$ NMR $\left(600 \mathrm{MHz},\left(\mathrm{CD}_{3}\right)_{2} \mathrm{CO}\right): \delta / \mathrm{ppm} 8.87$ (d, $\left.J=4.4 \mathrm{~Hz}, 2 \mathrm{H}, \mathrm{H} 9 \mathrm{a}\right), 8.80$ (d, $J$ $=4.6 \mathrm{~Hz}, 2 \mathrm{H}, \mathrm{H} 9 \mathrm{~b}), 7.97$ (br s, 4H, H6a+H6b), 7.86 (m, 2H, H7a), 7.73 (m, 2H, H7b), 7.51 (br s, 2H, H8a), 7.43 (m, 2H, H8b), 6.66 (m, 2H, H4a+H4b), 6.17 (d, J $=7.4 \mathrm{~Hz}, 1 \mathrm{H}, \mathrm{H} 3 \mathrm{a}), 6.12$ (d, J = 7.2 Hz, 1H, H3b), 4.53 (br s, 2H, H1b), 4.43 (br s, $2 \mathrm{H}, \mathrm{H} 1 \mathrm{a}), 0.40\left(\mathrm{dd},{ }^{3} J_{\mathrm{PH}}=7.4,4.7,{ }^{2} J_{\mathrm{PtH}}=53.9 \mathrm{~Hz}, 3 \mathrm{H}, \mathrm{Pt}-\mathrm{CH}_{3}\right) .{ }^{13} \mathrm{C} \mathrm{NMR}(150$ $\left.\left.\mathrm{MHz},\left(\mathrm{CD}_{3}\right)_{2} \mathrm{CO}\right)\right): \delta / \mathrm{ppm} 158.01$ (m, C5b), 156.20 (m, C5a), 150.91 (d, ${ }^{3} J_{\mathrm{PC}}=$ $15.6 \mathrm{~Hz}, \mathrm{C} 9 \mathrm{a}), 150.48$ (br d, $\left.{ }^{3} J_{\mathrm{PC}}=13.7 \mathrm{~Hz}, \mathrm{C} 9 \mathrm{~b}\right), 136.51$ (d, $\left.{ }^{3} J_{\mathrm{PC}}=8.7 \mathrm{~Hz}, \mathrm{C} 7 \mathrm{a}\right)$, $135.62\left(\mathrm{~d},{ }^{3} J_{\mathrm{PC}}=8.7 \mathrm{~Hz}, \mathrm{C} 7 \mathrm{~b}\right), 134.69\left(\mathrm{~d},{ }^{2} J_{\mathrm{PC}}=4.5 \mathrm{~Hz}, \mathrm{C} 2 \mathrm{~b}\right), 133.73\left(\mathrm{vt},{ }^{2} J_{\mathrm{PC}}\right.$ 
$\left.+{ }^{3} J_{\mathrm{PC}}=3.8, \mathrm{C} 2 \mathrm{a}\right), 131.23(\mathrm{~m}, \mathrm{C} 3 \mathrm{a}+\mathrm{C} 3 \mathrm{~b}+\mathrm{C} 6 \mathrm{a}+\mathrm{C} 6 \mathrm{~b}), 127.37(\mathrm{~s}, \mathrm{C} 4 \mathrm{~b}), 127.16(\mathrm{~s}$, C4a), 125.76 (br s, C8a), 125.14 (br s, C8b), 34.19 (d, $\left.{ }^{1} J_{\mathrm{PC}}=39.3 \mathrm{~Hz}, \mathrm{C} 1 \mathrm{~b}\right), 33.04$ $\left(\mathrm{d},{ }^{1} J_{\mathrm{PC}}=24.8 \mathrm{~Hz}, \mathrm{C} 1 \mathrm{a}\right), 9.85\left(\mathrm{dd},{ }^{2} J_{\mathrm{PC}}=93.6,7.5 \mathrm{~Hz}, \mathrm{Pt}-\mathrm{CH}_{3}\right){ }^{31} \mathrm{P} \mathrm{NMR}(121$ $\left.\mathrm{MHz},\left(\mathrm{CD}_{3}\right)_{2} \mathrm{CO}\right): \delta / \mathrm{ppm} 10.86\left(\mathrm{~d},{ }^{2} J_{\mathrm{PP}}=14.0,{ }^{1} J_{\mathrm{PtP}}=1728.0 \mathrm{~Hz}\right.$, trans $\left.\mathrm{CH}_{3}\right)$, $9.47\left(\mathrm{~d},{ }^{2} J_{\mathrm{PP}}=14.0,{ }^{1} J_{\mathrm{PtP}}=4158.7 \mathrm{~Hz}\right.$, trans $\left.\mathrm{Cl}\right)$. HRMS calcd for $\mathrm{C}_{29} \mathrm{H}_{27} \mathrm{~N}_{4} \mathrm{P}_{2} \mathrm{Pt}$ $[\mathrm{M}-\mathrm{Cl}]^{+}: \mathrm{m} / \mathrm{z}=688.1356$; found $=688.1370$.

${ }^{1} \mathrm{H}$ NMR $\left(600 \mathrm{MHz}, \mathrm{CD}_{2} \mathrm{Cl}_{2}\right): \delta / \mathrm{ppm} 8.88(\mathrm{~d}, J=4.5 \mathrm{~Hz}, 2 \mathrm{H}, \mathrm{H} 9 \mathrm{a}), 8.81(\mathrm{~d}, J=$ $4.5 \mathrm{~Hz}, 2 \mathrm{H}, \mathrm{H} 9 \mathrm{~b}), 7.94$ (br s, 2H, H6a), 7.84 (m, 2H, H6b), 7.73 (m, 2H, H7a), 7.67 (m, 2H, H7b), 7.40 (m, 2H, H8a), 7.35 (m, 2H, H8b), 6.64 (m, 2H, H4a+H4b), 6.18 (d, $J=6.5 \mathrm{~Hz}, 1 \mathrm{H}, \mathrm{H} 3 \mathrm{~b}), 6.12(\mathrm{~d}, J=6.5 \mathrm{~Hz}, 1 \mathrm{H}, \mathrm{H} 3 \mathrm{a}), 4.52$ (br s, 2H, H1a), 4.41 (br s, 2H, H1b), 0.39 (dd, $\left.{ }^{3} J_{\mathrm{PH}}=6.9,4.5,{ }^{2} J_{\mathrm{PtH}}=52.8 \mathrm{~Hz}, 3 \mathrm{H}, \mathrm{Pt}-\mathrm{CH}_{3}\right) .{ }^{13} \mathrm{C}$ NMR (150 MHz, $\mathrm{CD}_{2} \mathrm{Cl}_{2}$ ): $\delta / \mathrm{ppm} 157.20$ (m, C5b), 154.34 (m, C5a), 150.34 (m, C9a), 150.20 (m, C9b), 136.00 (d, $\left.{ }^{3} J_{\mathrm{PC}}=8.6 \mathrm{~Hz}, \mathrm{C} 7 \mathrm{a}\right), 135.36$ (d, ${ }^{3} J_{\mathrm{PC}}=8.6 \mathrm{~Hz}$, C7b), 134.01 (s, C2a), 132.96 (s, C2b), 130.89 (br s, C3b), 130.69 (s, C3a) 126.85 (s, C4a), 126.65 (s, C4b), 125.14 (s, C8a), 124.62 (s, C8b), 33.87 (d, ${ }^{1} J_{\mathrm{PC}}=35.0$ $\mathrm{Hz}, \mathrm{C} 1 \mathrm{a}), 32.69\left(\mathrm{~d},{ }^{1} J_{\mathrm{PC}}=23.0 \mathrm{~Hz}, \mathrm{C} 1 \mathrm{~b}\right), 9.64\left(\mathrm{dd},{ }^{2} J_{\mathrm{PC}}=92.1,7.6 \mathrm{~Hz}, \mathrm{Pt}-\mathrm{CH}_{3}\right)$ ${ }^{31} \mathrm{P}$ NMR $\left(121 \mathrm{MHz}, \mathrm{CD}_{2} \mathrm{Cl}_{2}\right): \delta / \mathrm{ppm} 11.31\left(\mathrm{~d},{ }^{2} J_{\mathrm{PP}}=14.0,{ }^{1} J_{\mathrm{PtP}}=1724.6 \mathrm{~Hz}\right.$, trans $\left.\mathrm{CH}_{3}\right), 10.04\left(\mathrm{~d},{ }^{2} J_{\mathrm{PP}}=13.9,{ }^{1} J_{\mathrm{PtP}}=4210.6 \mathrm{~Hz}\right.$, trans $\left.\mathrm{Cl}\right)$. HRMS calcd for $\mathrm{C}_{29} \mathrm{H}_{27} \mathrm{~N}_{4} \mathrm{P}_{2} \mathrm{Pt}[\mathrm{M}-\mathrm{Cl}]^{+}: \mathrm{m} / \mathrm{z}=688.1356$; found $=688.1370$.

\section{Reactions of $[\mathrm{PtClMe}(\mathrm{PP})](27)$ with phosphine ligands}

One equivalent of the appropriate phosphine $\left(\mathrm{PPh}_{3} 7.2 \mathrm{mg}\right.$, PTA $\left.4.3 \mathrm{mg}\right)$ was added to a solution of $\mathbf{2 7}(20 \mathrm{mg}, 0.03 \mathrm{mmol})$ in $\mathrm{CD}_{2} \mathrm{Cl}_{2}(0.4 \mathrm{~mL})$. Immediate formation of the mixed phosphine complexes was observed in the ${ }^{31} \mathrm{P}$ and ${ }^{1} \mathrm{H}$ NMR spectra recorded. In the triphenylphosphine reaction, the formation of trans-[PtClMe $\left.\left(\mathrm{PPh}_{3}\right)_{2}\right]$ (30) was also observed in the NMR spectra recorded. This then crystallised out of solution as white rod-shaped crystals. In the PTA reaction the equivalent complex was never observed in the NMR spectra of the reaction mixture as it precipitated out of solution almost immediately as a white solid. The white solid was isolated and NMR recorded in $\mathrm{D}_{2} \mathrm{O}$ confirmed it was trans-[PtClMe(PTA $\left.)_{2}\right](\mathbf{3 1})$.

$\left[\mathrm{PtMe}(\mathrm{PP}) \mathrm{PPh}_{3}\right] \mathrm{Cl}(\mathbf{2 8})$ 


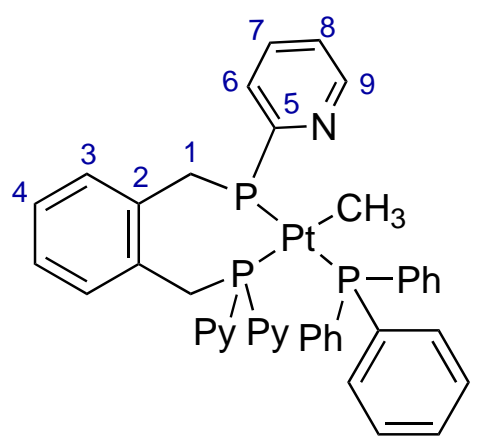

$7 \mathrm{cl}$

A

B

${ }^{1} \mathrm{H}$ NMR $\left(300 \mathrm{MHz}, \mathrm{CD}_{2} \mathrm{Cl}_{2}\right.$ ): $\delta / \mathrm{ppm} 8.98$ (d, $\left.J=3.6 \mathrm{~Hz}, 2 \mathrm{H}, \mathrm{H} 9 \mathrm{a}\right), 8.72(\mathrm{~m}$, 2H, H9b), 8.35 (m, 2H, H6a), 8.10 (m, 2H, H7a), 7.90 (m, 2H, H7b), 7.72 (m, 5H, H6b+3Ar-H), 7.43 (m, 16H, H8a+H8b+12Ar-H), 6.71 (m, 2H, H4a+H4b), 6.11 (d, $J=5.7 \mathrm{~Hz}, 1 \mathrm{H}, \mathrm{H} 3 \mathrm{~b}), 5.94$ (d, $J=6.9 \mathrm{~Hz}, 1 \mathrm{H}, \mathrm{H} 3 \mathrm{a}), 4.36$ (dd, $J=12.6,4.8 \mathrm{~Hz}, 2 \mathrm{H}$, $\mathrm{H} 1 \mathrm{a}), 4.03$ (d, $J=11.1 \mathrm{~Hz}, 2 \mathrm{H}, \mathrm{H} 1 \mathrm{~b}), 0.40\left(\mathrm{~m},{ }^{2} J_{\mathrm{PtH}}=52.5 \mathrm{~Hz}, 3 \mathrm{H}, \mathrm{Pt}-\mathrm{CH}_{3}\right) .{ }^{31} \mathrm{P}$ $\operatorname{NMR}\left(121 \mathrm{MHz}, \mathrm{CD}_{2} \mathrm{Cl}_{2}\right): \delta / \mathrm{ppm} 26.57\left(\mathrm{dd},{ }^{2} J_{\mathrm{PP}}=376.0,23.6,{ }^{1} J_{\mathrm{PtP}}=2904.2 \mathrm{~Hz}\right.$, $\left.\mathrm{PPh}_{3}\right), 8.44\left(\mathrm{dd},{ }^{2} J_{\mathrm{PP}}=376.0,25.5,{ }^{1} J_{\mathrm{PtP}}=2871.4 \mathrm{~Hz}, \mathrm{P}\right.$ trans $\left.\mathrm{PPh}_{3}\right),-0.61(\mathrm{t}$, ${ }^{2} J_{\mathrm{PP}}=24.8,{ }^{1} J_{\mathrm{PtP}}=2076.3 \mathrm{~Hz}, \mathrm{P}$ trans $\left.\mathrm{CH}_{3}\right)$. HRMS calcd for $\mathrm{C}_{47} \mathrm{H}_{42} \mathrm{~N}_{4} \mathrm{P}_{3} \mathrm{Pt}$ $[\mathrm{M}-\mathrm{Cl}]^{+}: \mathrm{m} / \mathrm{z}=950.2268$; found $=950.2232$.

$[\mathrm{PtMe}(\mathrm{PP}) \mathrm{PTA}] \mathrm{Cl}(\mathbf{2 9})$

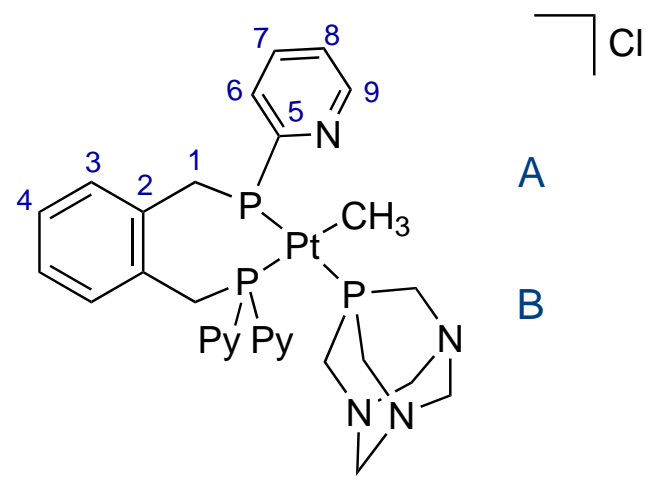

${ }^{1} \mathrm{H}$ NMR (600 MHz, $\mathrm{CD}_{2} \mathrm{Cl}_{2}$ ): $\delta / \mathrm{ppm} 8.92(\mathrm{~d}, J=4.4 \mathrm{~Hz}, 2 \mathrm{H}, \mathrm{H} 9 \mathrm{a}), 8.86(\mathrm{~d}, J=$ $4.4 \mathrm{~Hz}, 2 \mathrm{H}, \mathrm{H} 9 \mathrm{~b}), 8.30$ (m, 2H, H6a), 8.01 (m, 2H, H7a), 7.81 (m, 2H, H7b), 7.75 (m, 2H, H6b), 7.58 (br s, 2H, H8a), 7.48 (br s, 2H, H8b), 6.76 (m, 2H, H4a+H4b), $6.18(\mathrm{~d}, J=5.4 \mathrm{~Hz}, 1 \mathrm{H}, \mathrm{H} 3 \mathrm{~b}), 6.13(\mathrm{~d}, J=5.6 \mathrm{~Hz}, 1 \mathrm{H}, \mathrm{H} 3 \mathrm{a}), 4.45$ (d, $J=9.0$ $\mathrm{Hz}, 2 \mathrm{H}, \mathrm{H1a}), 4.41\left(\mathrm{~m}, 3 \mathrm{H}, \mathrm{CH}_{2}\right), 4.30\left(\mathrm{~d},{ }^{2} J_{\mathrm{PH}}=11.5 \mathrm{~Hz}, 2 \mathrm{H}, \mathrm{H} 1 \mathrm{~b}\right), 4.12$ (d, $\left.J_{\mathrm{PH}}=13.4 \mathrm{~Hz}, 3 \mathrm{H}, \mathrm{CH}_{2}\right), 3.76\left(\mathrm{~s}, 3 \mathrm{H}, \mathrm{CH}_{2}\right), 3.56\left(\mathrm{~s}, 3 \mathrm{H}, \mathrm{CH}_{2}\right), 0.37(\mathrm{t}, J=6.0$, $\left.{ }^{2} J_{\mathrm{PtH}}=52.5 \mathrm{~Hz}, 3 \mathrm{H}, \mathrm{Pt}-\mathrm{CH}_{3}\right) .{ }^{31} \mathrm{P} \mathrm{NMR}\left(121 \mathrm{MHz}, \mathrm{CD}_{2} \mathrm{Cl}_{2}\right): \delta / \mathrm{ppm} 8.77(\mathrm{~d}$, ${ }^{2} J_{\mathrm{PP}}=348.0,{ }^{1} J_{\mathrm{PtP}}=2803.7 \mathrm{~Hz}, \mathrm{P}$ trans $\left.\mathrm{PTA}\right),-0.68\left(\mathrm{~s},{ }^{1} J_{\mathrm{PtP}}=1962.2 \mathrm{~Hz}\right.$, $\mathrm{P}$ trans $\left.\mathrm{CH}_{3}\right),-70.16\left(\mathrm{~d},{ }^{2} J_{\mathrm{PP}}=362.0,{ }^{1} J_{\mathrm{PtP}}=2495.5 \mathrm{~Hz}\right.$, PTA $)$. HRMS calcd 
for $\mathrm{C}_{35} \mathrm{H}_{39} \mathrm{~N}_{7} \mathrm{P}_{3} \mathrm{Pt}[\mathrm{M}-\mathrm{Cl}]^{+}: \mathrm{m} / \mathrm{z}=845.2125$; found $=845.2091$. HRMS calcd for $\mathrm{C}_{29} \mathrm{H}_{27} \mathrm{~N}_{4} \mathrm{P}_{2} \mathrm{Pt}\left[\mathrm{M}-\mathrm{Cl}-\mathrm{C}_{6} \mathrm{H}_{12} \mathrm{~N}_{3} \mathrm{P}\right]^{+}: \mathrm{m} / \mathrm{z}=688.1356$; found $=688.1326$.

trans- $\left[\mathrm{PtClMe}\left(\mathrm{PPh}_{3}\right)_{2}\right]$

${ }^{1} \mathrm{H}$ NMR $\left(500 \mathrm{MHz},\left(\mathrm{CD}_{3}\right)_{2} \mathrm{CO}\right): \delta / \mathrm{ppm} 7.76(\mathrm{~m}, 12 \mathrm{H}, \mathrm{Ph}), 7.48-7.39(\mathrm{~m}, 18 \mathrm{H}$, $\mathrm{Ph}),-0.11\left(\mathrm{t},{ }^{3} J_{\mathrm{PH}}=6.2,{ }^{2} J_{\mathrm{PtH}}=78.1 \mathrm{~Hz}, 3 \mathrm{H}, \mathrm{Pt}-\mathrm{CH}_{3}\right) .{ }^{31} \mathrm{P} \mathrm{NMR}(121 \mathrm{MHz}$, $\left.\left(\mathrm{CD}_{3}\right)_{2} \mathrm{CO}\right): \delta / \mathrm{ppm} 29.42\left(\mathrm{~s},{ }^{1} J_{\mathrm{PtP}}=3146.5 \mathrm{~Hz}\right)$.

trans-[PtClMe(PTA $\left.)_{2}\right](\mathbf{3 1})$

${ }^{1} \mathrm{H}$ NMR (500 MHz, $\mathrm{D}_{2} \mathrm{O}$ ): $\delta /$ ppm 4.50 (br s, $12 \mathrm{H}, \mathrm{CH}_{2}$ ), 4.20 (br s, $12 \mathrm{H}, \mathrm{CH}_{2}$ ), $0.42\left(\mathrm{t},{ }^{3} J_{\mathrm{PH}}=7.2,{ }^{2} J_{\mathrm{PtH}}=82.2 \mathrm{~Hz}, 3 \mathrm{H}, \mathrm{Pt}-\mathrm{CH}_{3}\right) .{ }^{31} \mathrm{P} \mathrm{NMR}\left(121 \mathrm{MHz}, \mathrm{D}_{2} \mathrm{O}\right)$ : $\delta / \mathrm{ppm}-55.8\left(\mathrm{~s},{ }^{1} J_{\mathrm{PtP}}=2812.0 \mathrm{~Hz}\right)$.

\section{Reaction of [PtClMe(PP)] (27) with acetonitrile, diethylsulfide, dimethyl- sulfoxide or pyridine}

One drop of pyridine, acetonitrile, diethylsulfide or dimethylsulfoxide was added to a solution of 27 (30 mg, $0.04 \mathrm{mmol}$ ) in $\mathrm{CD}_{2} \mathrm{Cl}_{2}(0.4 \mathrm{~mL}) \cdot{ }^{1} \mathrm{H}$ and ${ }^{31} \mathrm{P}$ NMR spectra recorded after 20 minutes showed no reaction had occurred. The samples were left at room temperature over a week and no change in the NMR spectra was observed. Heating at $35^{\circ} \mathrm{C}$ over a week also did not cause any reaction to take place.

\section{Reaction of $[\mathrm{PtClMe}(\mathrm{PP})](27)$ with carbon monoxide or ethene}

Carbon monoxide or ethene was bubbled through a solution of 27 (30 mg, 0.04 mmol) in $\mathrm{CD}_{2} \mathrm{Cl}_{2}(0.4 \mathrm{~mL})$ for 10 minutes. No reaction was observed in the ${ }^{1} \mathrm{H}$ and ${ }^{31} \mathrm{P}$ NMR spectra recorded initially. After sitting at room temperature for a week no reaction had occurred. The samples were then heated to $35^{\circ} \mathrm{C}$ for a week, which did not result in any reaction taking place.

Reaction of $[\mathrm{PtClMe}(\mathrm{PP})](27)$ with $\mathrm{H}_{2} \mathrm{C}\left(\mathrm{SO}_{2} \mathrm{CF}_{3}\right)_{2}$ (synthesis of complex 32)

$\mathrm{H}_{2} \mathrm{C}\left(\mathrm{SO}_{2} \mathrm{CF}_{3}\right)_{2}(11 \mathrm{mg}, 0.04 \mathrm{mmol})$ was added to a solution of $\mathbf{2 7}$ (30 mg, $\left.0.04 \mathrm{mmol}\right)$ in $\left(\mathrm{CD}_{3}\right)_{2} \mathrm{CO}(0.5 \mathrm{~mL}) .{ }^{1} \mathrm{H}$ and ${ }^{31} \mathrm{P} \mathrm{NMR}$ spectra were recorded after 10 minutes, two and three hours and one day. Initial ${ }^{1} \mathrm{H}$ and ${ }^{31} \mathrm{P}$ NMR spectra recorded of the reaction mixture showed the presence of one unsymmetrical complex $\mathbf{3 2}$, where $\mathbf{3}$ has been protonated. Over time this reacted to form the $\left[\mathrm{PtCl}_{2}(\mathrm{PP})\right]$ complex 16 
and methane.

$32{ }^{1} \mathrm{H}$ NMR $\left(300 \mathrm{MHz},\left(\mathrm{CD}_{3}\right){ }_{2} \mathrm{CO}\right): 0.49\left(\mathrm{dd},{ }^{3} J_{\mathrm{PH}}=7.2,5.1,{ }^{2} J_{\mathrm{PtH}}=53.1 \mathrm{~Hz}, 3 \mathrm{H}\right.$, $\left.\mathrm{Pt}-\mathrm{CH}_{3}\right) .{ }^{31} \mathrm{P} \mathrm{NMR}\left(121 \mathrm{MHz},\left(\mathrm{CD}_{3}\right)_{2} \mathrm{CO}\right): \delta / \mathrm{ppm} 6.96\left(\mathrm{br} \mathrm{s},{ }^{1} J_{\mathrm{PtP}}=4177.8 \mathrm{~Hz}\right.$, trans $\mathrm{Cl}), 9.43\left(\mathrm{~m},{ }^{1} J_{\mathrm{PtP}}=1671.3 \mathrm{~Hz}\right.$, trans $\left.\mathrm{CH}_{3}\right)$.

\section{Reaction of $[\mathrm{PtClMe}(\mathrm{PP})](27)$ with $\mathrm{NaCH}\left(\mathrm{SO}_{2} \mathrm{CF}_{3}\right)_{2}$ (synthesis of com- plex 33)}

$\mathrm{NaCH}\left(\mathrm{SO}_{2} \mathrm{CF}_{3}\right)_{2}(13 \mathrm{mg}, 0.04 \mathrm{mmol})$ was added to a solution of 27 (30 mg, 0.04 $\mathrm{mmol})$ in $\left(\mathrm{CD}_{3}\right)_{2} \mathrm{CO}(0.4 \mathrm{~mL}) .{ }^{1} \mathrm{H}$ and ${ }^{31} \mathrm{P}$ NMR spectra were recorded after 20 minutes.

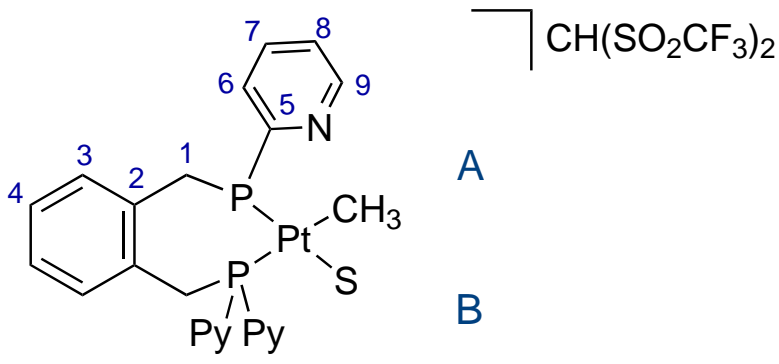

$33{ }^{1} \mathrm{H}$ NMR (500 MHz, $\left.\left(\mathrm{CD}_{3}\right)_{2} \mathrm{CO}\right): \delta / \mathrm{ppm} 8.86$ (d, $\left.J=4.5 \mathrm{~Hz}, 2 \mathrm{H}, \mathrm{H} 9 \mathrm{a}\right), 8.79$ (d, $J=4.5 \mathrm{~Hz}, 2 \mathrm{H}, \mathrm{H} 9 \mathrm{~b}), 8.01$ (m, 4H, H6a+H6b), 7.85 (br s, 2H, H7a), 7.71 (m, 2H, H7b), 7.50 (m, 2H, H8a), 7.41 (m, 2H, H8b), 6.65 (m, 2H, H4a+H4b), 6.17 (d, J = $7.0 \mathrm{~Hz}, 1 \mathrm{H}, \mathrm{H} 3 \mathrm{~b}), 6.12$ (d, $J=6.9 \mathrm{~Hz}, 1 \mathrm{H}, \mathrm{H} 3 \mathrm{a}), 4.53$ (m, 2H, H1a), 4.43 (br s, 2H, $\mathrm{H} 1 \mathrm{~b}), 3.79\left(\mathrm{~s}, 1 \mathrm{H}, \mathrm{CH}\left(\mathrm{SO}_{2} \mathrm{CF}_{3}\right)_{2}\right), 0.40\left(\mathrm{dd},{ }^{3} J_{\mathrm{PH}}=7.0,4.5,{ }^{2} J_{\mathrm{PtH}}=53.5 \mathrm{~Hz}, 3 \mathrm{H}\right.$, $\left.\mathrm{Pt}-\mathrm{CH}_{3}\right) .{ }^{13} \mathrm{C} \mathrm{NMR}\left(125 \mathrm{MHz},\left(\mathrm{CD}_{3}\right)_{2} \mathrm{CO}\right): \delta / \mathrm{ppm} 158.02$ (m, C5b), 154.50 (m, C5a), 150.87 (d, $\left.{ }^{3} J_{\mathrm{PC}}=16.1 \mathrm{~Hz}, \mathrm{C} 9 \mathrm{a}\right), 150.65$ (d, $\left.{ }^{3} J_{\mathrm{PC}}=15.8 \mathrm{~Hz}, \mathrm{C} 9 \mathrm{~b}\right), 137.44$ (d, $\left.{ }^{3} J_{\mathrm{PC}}=8.6 \mathrm{~Hz}, \mathrm{C} 7 \mathrm{a}\right), 136.38\left(\mathrm{~d},{ }^{3} J_{\mathrm{PC}}=8.6 \mathrm{~Hz}, \mathrm{C} 7 \mathrm{~b}\right), 134.45\left(\mathrm{~d},{ }^{2} J_{\mathrm{PC}}=4.6 \mathrm{~Hz}\right.$, C2a), 133.39 (d, $\left.{ }^{2} J_{\mathrm{PC}}=4.0 \mathrm{~Hz}, \mathrm{C} 2 \mathrm{~b}\right), 131.40$ (m, C6a+C6b), 130.96 (m, C3a+C3b), 127.13 (m, C4a), 126.93 (m, C4b), 126.11 (s, C8a), 125.53 (s, C8b), 122.01 (q, ${ }^{1} J_{\mathrm{CF}}$ $\left.=325.3 \mathrm{~Hz}, \mathrm{CH}\left(\mathrm{SO}_{2} C \mathrm{~F}_{3}\right)_{2}\right), 54.84\left(\mathrm{sept},{ }^{3} J_{\mathrm{CF}}=2.6 \mathrm{~Hz}, C \mathrm{H}\left(\mathrm{SO}_{2} \mathrm{CF}_{3}\right)_{2}\right) 34.31$ (d, $\left.{ }^{1} J_{\mathrm{PC}}=39.5 \mathrm{~Hz}, \mathrm{C} 1 \mathrm{a}\right), 33.22\left(\mathrm{~d},{ }^{1} J_{\mathrm{PC}}=24.8 \mathrm{~Hz}, \mathrm{C} 1 \mathrm{~b}\right), 9.85\left(\mathrm{dd}, J_{\mathrm{PC}}=93.3,7.0\right.$ $\left.\mathrm{Hz}, \mathrm{Pt}-\mathrm{CH}_{3}\right) .{ }^{19} \mathrm{~F} \mathrm{NMR}\left(282 \mathrm{MHz},\left(\mathrm{CD}_{3}\right)_{2} \mathrm{CO}\right): \delta / \mathrm{ppm}-81.92\left(\mathrm{~s}, \mathrm{CH}\left(\mathrm{SO}_{2} \mathrm{CF}_{3}\right)_{2}\right)$. ${ }^{31} \mathrm{P}$ NMR $\left(121 \mathrm{MHz},\left(\mathrm{CD}_{3}\right)_{2} \mathrm{CO}\right): \delta / \mathrm{ppm} 10.86\left(\mathrm{~d},{ }^{2} J_{\mathrm{PP}}=13.3,{ }^{1} J_{\mathrm{PtP}}=1728.4 \mathrm{~Hz}\right.$, trans $\left.\mathrm{CH}_{3}\right), 9.43\left(\mathrm{~d},{ }^{2} J_{\mathrm{PP}}=13.3,{ }^{1} J_{\mathrm{PtP}}=4159.8 \mathrm{~Hz}\right.$, trans acetone). HRMS calcd for $\mathrm{C}_{29} \mathrm{H}_{27} \mathrm{~N}_{4} \mathrm{P}_{2} \mathrm{Pt}\left[\mathrm{M}-\mathrm{CH}\left(\mathrm{SO}_{2} \mathrm{CF}_{3}\right)_{2}\right]^{+}: \mathrm{m} / \mathrm{z}=688.1356$; found $=688.1327$. 
$\mathrm{NaCH}\left(\mathrm{SO}_{2} \mathrm{CF}_{3}\right)_{2}(13 \mathrm{mg}, 0.04 \mathrm{mmol})$ and a drop of pyridine was added to a solution of 27 (30 mg, $0.04 \mathrm{mmol})$ in $\mathrm{CD}_{2} \mathrm{Cl}_{2}(0.4 \mathrm{~mL}) .{ }^{1} \mathrm{H}$ and ${ }^{31} \mathrm{P}$ NMR spectra recorded after 20 minutes showed the formation of complex $\mathbf{3 4}$ (quantitative conversion).

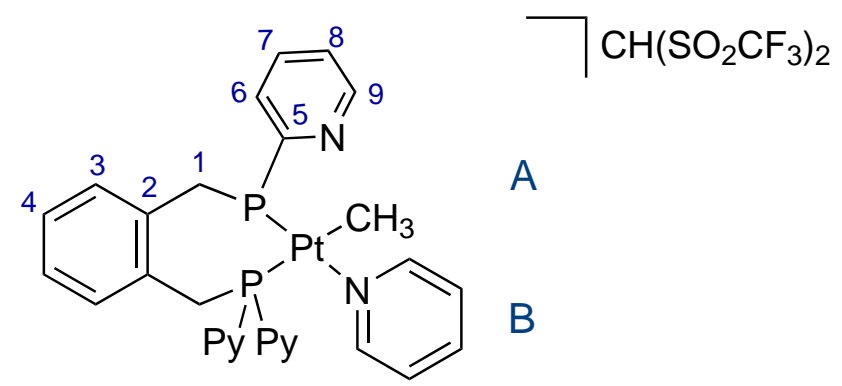

${ }^{1} \mathrm{H}$ NMR $\left(500 \mathrm{MHz}, \mathrm{CD}_{2} \mathrm{Cl}_{2}\right.$ ): $\delta / \mathrm{ppm} 8.89$ (s, 2H, Py), 8.77 (br s, 2H, Py), 8.65 (br s, 2H, Py), 8.08 (s, 1H, Py), 7.93 (br s, 2H, Py), 7.84 (br s, 2H, Py), 7.60 (br s, 2H, Py), 7.48 (br s, 2H, Py), 7.40 (br s, 2H, Py), 7.35 (br s, 2H, Py), 7.14 (m, 2H, Py), 6.82 (m, 1H, H4a), 6.72 (m, 1H, H4b), 6.57 (d, J = 6.5 Hz, 1H, H3b), 6.34 (d, J $=6.5 \mathrm{~Hz}, 1 \mathrm{H}, \mathrm{H} 3 \mathrm{a}), 4.47\left(\mathrm{~d},{ }^{2} J_{\mathrm{PH}}=13.9 \mathrm{~Hz}, 2 \mathrm{H}, \mathrm{H} 1 \mathrm{a}\right), 4.41\left(\mathrm{~d},{ }^{2} J_{\mathrm{PH}}=11.7 \mathrm{~Hz}\right.$, $2 \mathrm{H}, \mathrm{H} 1 \mathrm{~b}), 3.92\left(\mathrm{~s}, 1 \mathrm{H}, \mathrm{CH}\left(\mathrm{SO}_{2} \mathrm{CF}_{3}\right)_{2}\right), 0.26$ (br s, $\left.{ }^{2} J_{\mathrm{PtH}}=50.8 \mathrm{~Hz}, 3 \mathrm{H}, \mathrm{Pt}-\mathrm{CH}_{3}\right)$. ${ }^{13} \mathrm{C}$ NMR (125 MHz, $\mathrm{CD}_{2} \mathrm{Cl}_{2}$ ): $\delta / \mathrm{ppm} 155.03\left(\mathrm{~d}, J_{\mathrm{PC}}=65.8 \mathrm{~Hz}, \mathrm{Py}\right) 153.57(\mathrm{~m}$, Py), 151.18 (d, $\left.J_{\mathrm{PC}}=14.9 \mathrm{~Hz}, \mathrm{Py}\right), 150.72$ (d, $\left.J_{\mathrm{PC}}=15.3 \mathrm{~Hz}, \mathrm{Py}\right), 150.68$ (s, Py), 136.59 (s, Py), 136.53 (s, Py), 132.87 (br s, C2a), 132.05 (br s, C2b), 131.95 (br s, Py), 131.57 (br s, C3b), 131.37 (br s, C3a), 130.56 (br s, Py), 130.39 (br s, Py), 127.56 (br s, C4a), 127.44 (br s, C4b), 126.83 (s, Py), 125.81 (s, Py), 125.39 (s, Py), $121.58\left(\mathrm{q},{ }^{1} J_{\mathrm{CF}}=325.6 \mathrm{~Hz}, \mathrm{CH}\left(\mathrm{SO}_{2} C \mathrm{~F}_{3}\right)_{2}\right), 54.46\left(\mathrm{~s}, C \mathrm{H}\left(\mathrm{SO}_{2} \mathrm{CF}_{3}\right)_{2}\right), 33.66$ $\left(\mathrm{d},{ }^{1} J_{\mathrm{PC}}=37.3 \mathrm{~Hz}, \mathrm{C} 1 \mathrm{a}\right), 33.33\left(\mathrm{~d},{ }^{1} J_{\mathrm{PC}}=25.4 \mathrm{~Hz}, \mathrm{C} 1 \mathrm{~b}\right), 9.62\left(\mathrm{dd}, J_{\mathrm{PC}}=80.5\right.$, $\left.5.3 \mathrm{~Hz}, \mathrm{Pt}-\mathrm{CH}_{3}\right) .{ }^{19} \mathrm{~F} \mathrm{NMR}\left(282 \mathrm{MHz}, \mathrm{CD}_{2} \mathrm{Cl}_{2}\right): \delta / \mathrm{ppm}-81.48\left(\mathrm{~s}, \mathrm{CH}\left(\mathrm{SO}_{2} \mathrm{CF}_{3}\right)_{2}\right)$. ${ }^{31} \mathrm{P}$ NMR $\left(121 \mathrm{MHz}, \mathrm{CD}_{2} \mathrm{Cl}_{2}\right): \delta / \mathrm{ppm} 7.71\left(\mathrm{~d},{ }^{2} J_{\mathrm{PP}}=16.1,{ }^{1} J_{\mathrm{PtP}}=1720.8 \mathrm{~Hz}, \mathrm{P}\right.$ trans $\left.\mathrm{CH}_{3}\right), 3.88\left(\mathrm{~d},{ }^{2} J_{\mathrm{PP}}=16.7,{ }^{1} J_{\mathrm{PtP}}=3743.5 \mathrm{~Hz}, \mathrm{P}\right.$ trans pyridine).

\section{Synthesis of $\left[\mathrm{PtMe}(\mathrm{PP}) \mathrm{SEt}_{2}\right] \mathrm{CH}\left(\mathrm{SO}_{2} \mathrm{CF}_{3}\right)_{2}(35)$}

$\mathrm{NaCH}\left(\mathrm{SO}_{2} \mathrm{CF}_{3}\right)_{2}(13 \mathrm{mg}, 0.04 \mathrm{mmol})$ and a drop of diethylsulfide was added to a solution of 27 (30 mg, $0.04 \mathrm{mmol})$ in $\mathrm{CD}_{2} \mathrm{Cl}_{2}(0.4 \mathrm{~mL}) .{ }^{1} \mathrm{H}$ and ${ }^{31} \mathrm{P}$ NMR spectra recorded after 20 minutes showed the formation of complex 35 (quantitative conversion). 


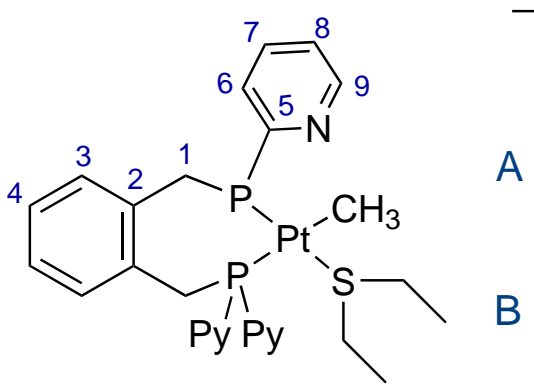

${ }^{1} \mathrm{H}$ NMR $\left(500 \mathrm{MHz}, \mathrm{CD}_{2} \mathrm{Cl}_{2}\right.$ ): $\delta / \operatorname{ppm} 8.91(\mathrm{~d}, J=4.5 \mathrm{~Hz}, 2 \mathrm{H}, \mathrm{H} 9 \mathrm{a}), 8.88(\mathrm{~d}, J=4.5$ $\mathrm{Hz}, 2 \mathrm{H}, \mathrm{H9b}$ ), 7.85 (m, 8H, H6+H7), 7.50 (m, 4H, H8), 6.75 (m, 2H, H4), 6.26 (d, $J$ $=6.0 \mathrm{~Hz}, 1 \mathrm{H}, \mathrm{H} 3 \mathrm{~b}), 6.20(\mathrm{~d}, J=6.0 \mathrm{~Hz}, 1 \mathrm{H}, \mathrm{H} 3 \mathrm{a}), 4.52\left(\mathrm{~d},{ }^{2} J_{\mathrm{PH}}=14.0,{ }^{3} J_{\mathrm{PtH}}=\right.$ $51.0 \mathrm{~Hz}, 2 \mathrm{H}, \mathrm{H1a}), 4.41\left(\mathrm{~d},{ }^{2} J_{\mathrm{PH}}=12.5 \mathrm{~Hz}, 2 \mathrm{H}, \mathrm{H} 1 \mathrm{~b}\right), 3.85\left(\mathrm{~s}, 1 \mathrm{H}, \mathrm{CH}\left(\mathrm{SO}_{2} \mathrm{CF}_{3}\right)_{2}\right)$, $2.66\left(\mathrm{q},{ }^{3} J_{\mathrm{HH}}=7.5 \mathrm{~Hz}, 2 \mathrm{H}, \mathrm{SCH}_{2} \mathrm{CH}_{3}\right), 2.63\left(\mathrm{q},{ }^{3} J_{\mathrm{HH}}=7.5 \mathrm{~Hz}, 2 \mathrm{H}, \mathrm{SCH}_{2} \mathrm{CH}_{3}\right.$ ), $1.28\left(\mathrm{t},{ }^{3} J_{\mathrm{HH}}=7.5 \mathrm{~Hz}, 3 \mathrm{H}, \mathrm{SCH}_{2} \mathrm{CH}_{3}\right), 1.27\left(\mathrm{br} \mathrm{s}, 3 \mathrm{H}, \mathrm{SCH}_{2} \mathrm{CH}_{3}\right), 0.37\left(\mathrm{vt},{ }^{3} J_{\mathrm{PH}}+\right.$ $\left.{ }^{3} J_{\mathrm{PH}}=5.0,{ }^{2} J_{\mathrm{PtH}}=53.5 \mathrm{~Hz}, 3 \mathrm{H}, \mathrm{Pt}-\mathrm{CH}_{3}\right) \cdot{ }^{13} \mathrm{C} \mathrm{NMR}\left(125 \mathrm{MHz}, \mathrm{CD}_{2} \mathrm{Cl}_{2}\right): \delta / \mathrm{ppm}$ $154.70\left(\mathrm{~d},{ }^{1} J_{\mathrm{PC}}=67.4 \mathrm{~Hz}, \mathrm{C} 5\right), 151.21\left(\mathrm{~d},{ }^{3} J_{\mathrm{PC}}=15.3 \mathrm{~Hz}, \mathrm{C} 9 \mathrm{~b}\right), 150.90\left(\mathrm{~d},{ }^{3} J_{\mathrm{PC}}\right.$ $=16.6 \mathrm{~Hz}, \mathrm{C} 9 \mathrm{a}), 136.65\left(\mathrm{~d},{ }^{3} J_{\mathrm{PC}}=9.1 \mathrm{~Hz}, \mathrm{C} 7 \mathrm{a}\right), 136.46\left(\mathrm{~d},{ }^{3} J_{\mathrm{PC}}=7.1 \mathrm{~Hz}, \mathrm{C} 7 \mathrm{~b}\right)$, 132.34 (m, C2a+C2b), 131.79 (m, C6a+C6b), 131.02 (br s, C3a+C3b), 127.71 (m, $\mathrm{C} 4 \mathrm{a}+\mathrm{C} 4 \mathrm{~b}), 125.93(\mathrm{~s}, \mathrm{C} 8 \mathrm{a}+\mathrm{C} 8 \mathrm{~b}), 121.51\left(\mathrm{q},{ }^{1} J_{\mathrm{CF}}=325.6 \mathrm{~Hz}, \mathrm{CH}\left(\mathrm{SO}_{2} \mathrm{CF}_{3}\right)_{2}\right), 54.11$ (s, $\left.C \mathrm{H}\left(\mathrm{SO}_{2} \mathrm{CF}_{3}\right)_{2}\right), 34.15\left(\mathrm{~d},{ }^{1} J_{\mathrm{PC}}=33.5 \mathrm{~Hz}, \mathrm{Cla}\right), 33.92\left(\mathrm{~d},{ }^{1} J_{\mathrm{PC}}=24.3 \mathrm{~Hz}, \mathrm{C} 1 \mathrm{~b}\right)$, $45.29\left(\mathrm{~s}, \mathrm{SCH}_{2} \mathrm{CH}_{3}\right), 6.89\left(\mathrm{~s}, \mathrm{SCH}_{2} \mathrm{CH}_{3}\right), 4.99\left(\mathrm{dd},{ }^{2} J_{\mathrm{PC}}=79.2,7.0 \mathrm{~Hz}, \mathrm{Pt}-\mathrm{CH}_{3}\right)$. ${ }^{19} \mathrm{~F}$ NMR $\left(282 \mathrm{MHz}, \mathrm{CD}_{2} \mathrm{Cl}_{2}\right): \delta / \mathrm{ppm}-81.57\left(\mathrm{~s}, \mathrm{CH}\left(\mathrm{SO}_{2} \mathrm{CF}_{3}\right)_{2}\right) .{ }^{31} \mathrm{P}$ NMR $(121$ $\left.\mathrm{MHz}, \mathrm{CD}_{2} \mathrm{Cl}_{2}\right): \delta / \mathrm{ppm} 9.88\left(\mathrm{~d},{ }^{2} J_{\mathrm{PP}}=19.0,{ }^{1} J_{\mathrm{PtP}}=3690.0 \mathrm{~Hz}, \mathrm{P}\right.$ trans $\left.\mathrm{SEt}_{2}\right)$, $5.51\left(\mathrm{~d},{ }^{2} J_{\mathrm{PP}}=19.0,{ }^{1} J_{\mathrm{PtP}}=1793.7 \mathrm{~Hz}, \mathrm{P}\right.$ trans $\left.\mathrm{CH}_{3}\right)$.

\section{Reaction of $[\mathrm{PtClMe}(\mathrm{PP})](27)$ with $\mathrm{NaCH}\left(\mathrm{SO}_{2} \mathrm{CF}_{3}\right)_{2}$ and phosphine lig- ands}

$\mathrm{NaCH}\left(\mathrm{SO}_{2} \mathrm{CF}_{3}\right)_{2}(13 \mathrm{mg}, 0.04 \mathrm{mmol})$ and one equivalent of phosphine $\left(\mathrm{PPh}_{3} 10.8\right.$ $\mathrm{mg}$, PTA $6.5 \mathrm{mg}$ ) were added to a solution of $\mathbf{2 7}$ (30 mg, $0.04 \mathrm{mmol})$ in $\mathrm{CD}_{2} \mathrm{Cl}_{2}$ $(0.4 \mathrm{~mL}) .{ }^{1} \mathrm{H}$ and ${ }^{31} \mathrm{P}$ NMR spectra were recorded after 20 minutes showed complete formation of the desired complexes 36 and $\mathbf{3 7}$ (quantitative conversion). However, the ${ }^{1} \mathrm{H}$ and ${ }^{31} \mathrm{P}$ NMR spectra recorded after one day showed these complexes were not stable and decomposed into an intractable mixture. 


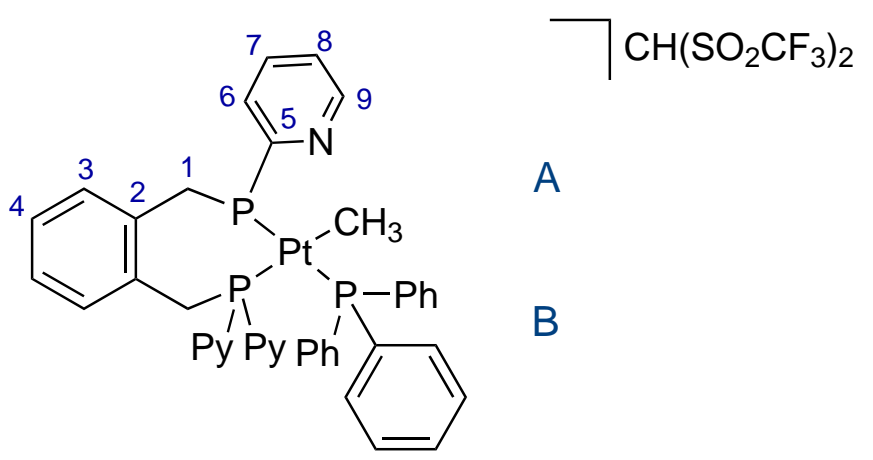

${ }^{1} \mathrm{H}$ NMR $\left(600 \mathrm{MHz}, \mathrm{CD}_{2} \mathrm{Cl}_{2}\right): \delta / \operatorname{ppm} 8.96(\mathrm{~d}, J=3.6 \mathrm{~Hz}, 2 \mathrm{H}, \mathrm{H} 9 \mathrm{a}), 8.72(\mathrm{~m}$, 2H, H9b), 8.33 (m, 2H, H6a), 8.10 (m, 2H, H7a), 7.90 (m, 2H, H7b), 7.72 (m, 5H, H6b+3Ar-H), 7.43 (m, 16H, H8a+H8b+12Ar-H), 6.71 (m, 2H, H4a+H4b), 6.11 (d, $J=5.7 \mathrm{~Hz}, 1 \mathrm{H}, \mathrm{H} 3 \mathrm{~b}), 5.94(\mathrm{~d}, J=6.9 \mathrm{~Hz}, 1 \mathrm{H}, \mathrm{H} 3 \mathrm{a}), 4.36(\mathrm{dd}, J=12.6,4.8 \mathrm{~Hz}$, $2 \mathrm{H}, \mathrm{H1a}), 4.03(\mathrm{~d}, J=11.1 \mathrm{~Hz}, 2 \mathrm{H}, \mathrm{H} 1 \mathrm{~b}), 3.89\left(\mathrm{~s}, 1 \mathrm{H}, \mathrm{CH}\left(\mathrm{SO}_{2} \mathrm{CF}_{3}\right)_{2}\right), 0.38(\mathrm{~m}$, $\left.{ }^{2} J_{\mathrm{PtH}}=52.5 \mathrm{~Hz}, 3 \mathrm{H}, \mathrm{Pt}-\mathrm{CH}_{3}\right) \cdot{ }^{19} \mathrm{~F}$ NMR $\left(282 \mathrm{MHz},\left(\mathrm{CD}_{3}\right)_{2} \mathrm{CO}\right): \delta / \mathrm{ppm}-81.92$ $\left(\mathrm{s}, \mathrm{CH}\left(\mathrm{SO}_{2} \mathrm{CF}_{3}\right)_{2}\right) .{ }^{31} \mathrm{P} \mathrm{NMR}\left(121 \mathrm{MHz}, \mathrm{CD}_{2} \mathrm{Cl}_{2}\right): \delta / \mathrm{ppm} 26.55\left(\mathrm{dd},{ }^{2} J_{\mathrm{PP}}=376.0\right.$, $\left.23.6,{ }^{1} J_{\mathrm{PtP}}=2904.2 \mathrm{~Hz}, \mathrm{PPh}_{3}\right), 8.45\left(\mathrm{dd},{ }^{2} J_{\mathrm{PP}}=376.0,25.5,{ }^{1} J_{\mathrm{PtP}}=2871.4 \mathrm{~Hz}\right.$, $\mathrm{P}$ trans $\left.\mathrm{PPh}_{3}\right),-0.61\left(\mathrm{t},{ }^{2} J_{\mathrm{PP}}=24.8,{ }^{1} J_{\mathrm{PtP}}=2076.3 \mathrm{~Hz}, \mathrm{P}\right.$ trans $\left.\mathrm{CH}_{3}\right)$. HRMS calcd for $\mathrm{C}_{47} \mathrm{H}_{42} \mathrm{~N}_{4} \mathrm{P}_{3} \mathrm{Pt}\left[\mathrm{M}-\mathrm{CH}\left(\mathrm{SO}_{2} \mathrm{CF}_{3}\right)_{2}\right]^{+}: \mathrm{m} / \mathrm{z}=950.2268$; found $=950.2232$.

$[\mathrm{PtMe}(\mathrm{PP}) \mathrm{PTA}] \mathrm{CH}\left(\mathrm{SO}_{2} \mathrm{CF}_{3}\right)_{2}(\mathbf{3 7})$

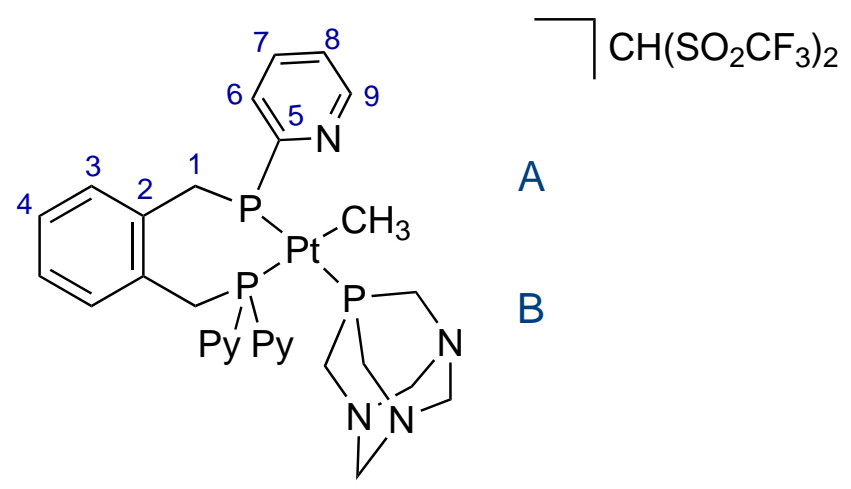

${ }^{1} \mathrm{H}$ NMR $\left(600 \mathrm{MHz}, \mathrm{CD}_{2} \mathrm{Cl}_{2}\right): \delta / \operatorname{ppm} 8.91(\mathrm{~d}, J=4.4 \mathrm{~Hz}, 2 \mathrm{H}, \mathrm{H} 9 \mathrm{a}), 8.87(\mathrm{~d}, J=$ $4.4 \mathrm{~Hz}, 2 \mathrm{H}, \mathrm{H} 9 \mathrm{~b}), 8.30$ (m, 2H, H6a), 8.01 (m, 2H, H7a), 7.81 (m, 2H, H7b), 7.75 (m, 2H, H6b), 7.58 (br s, 2H, H8a), 7.48 (br s, 2H, H8b), 6.76 (m, 2H, H4a+H4b), $6.18(\mathrm{~d}, J=5.4 \mathrm{~Hz}, 1 \mathrm{H}, \mathrm{H} 3 \mathrm{~b}), 6.11(\mathrm{~d}, J=5.6 \mathrm{~Hz}, 1 \mathrm{H}, \mathrm{H} 3 \mathrm{a}), 4.45$ (d, $J=9.0$ $\mathrm{Hz}, 2 \mathrm{H}, \mathrm{H1a}), 4.41\left(\mathrm{~m}, 3 \mathrm{H}, \mathrm{CH}_{2}\right), 4.30\left(\mathrm{~d},{ }^{2} J_{\mathrm{PH}}=11.5 \mathrm{~Hz}, 2 \mathrm{H}, \mathrm{H} 1 \mathrm{~b}\right), 4.11$ (d, $\left.J_{\mathrm{PH}}=13.4 \mathrm{~Hz}, 3 \mathrm{H}, \mathrm{CH}_{2}\right), 3.89\left(\mathrm{~s}, 1 \mathrm{H}, \mathrm{CH}\left(\mathrm{SO}_{2} \mathrm{CF}_{3}\right)_{2}\right), 3.77\left(\mathrm{~s}, 3 \mathrm{H}, \mathrm{CH}_{2}\right), 3.56(\mathrm{~s}$, 
$\left.3 \mathrm{H}, \mathrm{CH}_{2}\right), 0.46\left(\mathrm{dd},{ }^{3} J_{\mathrm{PH}}=13.8,7.7,{ }^{2} J_{\mathrm{PtH}}=52.5 \mathrm{~Hz}, 3 \mathrm{H}, \mathrm{Pt}-\mathrm{CH}_{3}\right) .{ }^{19} \mathrm{~F} \mathrm{NMR}$ $\left(282 \mathrm{MHz},\left(\mathrm{CD}_{3}\right)_{2} \mathrm{CO}\right): \delta / \mathrm{ppm}-81.92\left(\mathrm{~s}, \mathrm{CH}\left(\mathrm{SO}_{2} \mathrm{CF}_{3}\right)_{2}\right) .{ }^{31} \mathrm{P} \mathrm{NMR}(121 \mathrm{MHz}$, $\left.\mathrm{CD}_{2} \mathrm{Cl}_{2}\right): \delta / \mathrm{ppm} 8.75\left(\mathrm{~d},{ }^{2} J_{\mathrm{PP}}=348.0,{ }^{1} J_{\mathrm{PtP}}=2803.7 \mathrm{~Hz}, \mathrm{P}\right.$ trans $\left.\mathrm{PTA}\right),-0.68$ $\left(\mathrm{s},{ }^{1} J_{\mathrm{PtP}}=1962.2 \mathrm{~Hz}, \mathrm{P}\right.$ trans $\left.\mathrm{CH}_{3}\right),-70.17\left(\mathrm{~d},{ }^{2} J_{\mathrm{PP}}=362.0,{ }^{1} J_{\mathrm{PtP}}=2495.5 \mathrm{~Hz}\right.$, PTA). HRMS calcd for $\mathrm{C}_{35} \mathrm{H}_{39} \mathrm{~N}_{7} \mathrm{P}_{3} \mathrm{Pt}\left[\mathrm{M}-\mathrm{CH}\left(\mathrm{SO}_{2} \mathrm{CF}_{3}\right)_{2}\right]^{+}: \mathrm{m} / \mathrm{z}=845.2125$; found $=845.2091$. HRMS calcd for $\mathrm{C}_{29} \mathrm{H}_{27} \mathrm{~N}_{4} \mathrm{P}_{2} \mathrm{Pt}\left[\mathrm{M}-\mathrm{CH}\left(\mathrm{SO}_{2} \mathrm{CF}_{3}\right)_{2}-\mathrm{C}_{6} \mathrm{H}_{12} \mathrm{~N}_{3} \mathrm{P}\right]^{+}: \mathrm{m} / \mathrm{z}$ $=688.1356$; found $=688.1326$.

Reaction of $[\mathrm{PtClMe}(\mathrm{PP})](27)$ with $\mathrm{NaCH}\left(\mathrm{SO}_{2} \mathrm{CF}_{3}\right)_{3}$ and carbon monoxide (synthesis of complex 38 )

$\mathrm{NaCH}\left(\mathrm{SO}_{2} \mathrm{CF}_{3}\right)_{2}(13 \mathrm{mg}, 0.04 \mathrm{mmol})$ was added to a solution of $\mathbf{2 7}(30 \mathrm{mg}, 0.04$ $\mathrm{mmol})$ in $\left(\mathrm{CD}_{3}\right)_{2} \mathrm{CO}(0.5 \mathrm{~mL})$. Carbon monoxide was then bubbled through the solution for 10 minutes. ${ }^{1} \mathrm{H}$ and ${ }^{31} \mathrm{P}$ NMR spectra recorded after 20 minutes showed the sample was a mixture of $\mathbf{3 3}$ and a very small amount of a new platinum complex 38. It took a week at room temperature for $\mathbf{3 8}$ to be the major species in solution.

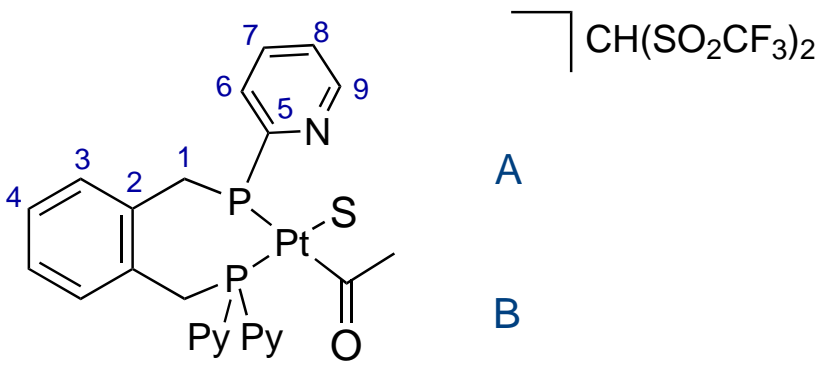

$38{ }^{1} \mathrm{H} \mathrm{NMR}\left(500 \mathrm{MHz},\left(\mathrm{CD}_{3}\right)_{2} \mathrm{CO}\right): \delta / \mathrm{ppm} 8.86$ (br s, 4H, H9), 7.85 (br m, 4H, H6), 7.74 (m, 4H, H7), 7.45 (m, 4H, H8), 6.64 (m, 2H, H4), 6.31 (d, $J=6.5 \mathrm{~Hz}, 1 \mathrm{H}, \mathrm{H} 3 \mathrm{~b})$, $6.26(\mathrm{~d}, J=6.5 \mathrm{~Hz}, 1 \mathrm{H}, \mathrm{H} 3 \mathrm{a}), 4.33(\mathrm{~m}, 4 \mathrm{H}, \mathrm{H} 1), 3.89\left(\mathrm{~s}, 1 \mathrm{H}, \mathrm{CH}\left(\mathrm{SO}_{2} \mathrm{CF}_{3}\right)_{2}\right), 1.54$ (s, $\left.3 \mathrm{H}, \mathrm{COCH}_{3}\right) .{ }^{19} \mathrm{~F} \mathrm{NMR}\left(282 \mathrm{MHz},\left(\mathrm{CD}_{3}\right)_{2} \mathrm{CO}\right): \delta / \mathrm{ppm}-81.59\left(\mathrm{~s}, \mathrm{CH}\left(\mathrm{SO}_{2} \mathrm{CF}_{3}\right)_{2}\right)$. ${ }^{31} \mathrm{P}$ NMR $\left(121 \mathrm{MHz},\left(\mathrm{CD}_{3}\right)_{2} \mathrm{CO}\right): \delta / \mathrm{ppm} 3.22\left(\mathrm{~d},{ }^{2} J_{\mathrm{PP}}=23.0,{ }^{1} J_{\mathrm{PtP}}=1389.9 \mathrm{~Hz}\right.$, $\mathrm{P}$ trans $\left.\mathrm{COCH}_{3}\right), 1.67\left(\mathrm{~d},{ }^{2} J_{\mathrm{PP}}=23.0,{ }^{1} J_{\mathrm{PtP}}=4500.7 \mathrm{~Hz}, \mathrm{P}\right.$ trans solvent).

Reaction of $[\mathrm{PtClMe}(\mathrm{PP})](27)$ with $\mathrm{NaCH}\left(\mathrm{SO}_{2} \mathrm{CF}_{3}\right)_{3}$ and dimethylsulfoxide, acetonitrile or benzonitrile

To a solution of 27 (30 mg, $0.04 \mathrm{mmol})$ in $\mathrm{CD}_{2} \mathrm{Cl}_{2}(0.4 \mathrm{~mL}), \mathrm{NaCH}\left(\mathrm{SO}_{2} \mathrm{CF}_{3}\right)_{2}(13$ $\mathrm{mg}, 0.04 \mathrm{mmol}$ ) and a drop of dimethylsulfoxide, acetonitrile or benzonitrile were added. ${ }^{1} \mathrm{H}$ and ${ }^{31} \mathrm{P}$ NMR spectra recorded after 20 minutes showed the sample was a mixture of $\mathbf{3 3}$ and DMSO, NCMe or NCPh. The samples were left at room 
temperature over a week and no change in the NMR spectra was observed. Heating at $35^{\circ} \mathrm{C}$ over a week also did not cause any reaction to take place.

\section{Reaction of $[\mathrm{PtClMe}(\mathrm{PP})](27)$ with $\mathrm{NaCH}\left(\mathrm{SO}_{2} \mathrm{CF}_{3}\right)_{3}$ and ethene}

$\mathrm{NaCH}\left(\mathrm{SO}_{2} \mathrm{CF}_{3}\right)_{2}(13 \mathrm{mg}, 0.04 \mathrm{mmol})$ was added to a solution of 27 (30 mg, 0.04 $\mathrm{mmol})$ in $\mathrm{CD}_{2} \mathrm{Cl}_{2}(0.4 \mathrm{~mL})$. Ethene was then bubbled through the solution for 10 minutes. ${ }^{1} \mathrm{H}$ and ${ }^{31} \mathrm{P}$ NMR spectra recorded after 20 minutes showed the sample was a mixture of $\mathbf{3 3}$ and ethene. The samples were left at room temperature over a week and no change in the NMR spectra was observed. The sample was heated to $35{ }^{\circ} \mathrm{C}$ for a week, which did not result in any reaction taking place.

\subsubsection{Platinum(0) complexes of dpypox}

\section{Synthesis of $\left[\mathrm{Pt}(\mathrm{PP})_{2}\right](39)$}

A solution of tris(norbornene)platinum $\left(15 \mathrm{mg}, 0.031 \mathrm{mmol}\right.$ ) in $\mathrm{C}_{6} \mathrm{D}_{6}$ was added to ligand 3 (30 mg, $0.063 \mathrm{mmol}$ ) in an NMR tube. The ${ }^{31} \mathrm{P}$ and ${ }^{1} \mathrm{H}$ NMR spectra recorded after 15 minutes showed that the reaction was complete (quantitative conversion). As the $\left[\mathrm{Pt}(\mathrm{PP})_{2}\right]$ complex 39 was not very soluble in $\mathrm{C}_{6} \mathrm{D}_{6}$, the complex was dissolved in a mixture of $\mathrm{C}_{6} \mathrm{D}_{6}$ and $\mathrm{CDCl}_{3}$ to obtain NMR data. The $\left[\mathrm{Pt}(\mathrm{PP})_{2}\right]$ complex 39 reacted with $\mathrm{CDCl}_{3}$ to form the $\left[\mathrm{PtCl}_{2}(\mathrm{PP})\right]$ complex 16. Reaction with $\mathrm{CDCl}_{3}$ took one day for a significant amount of $\left[\mathrm{PtCl}_{2}(\mathrm{PP})\right]$ complex $\mathbf{1 6}$ to be observed.

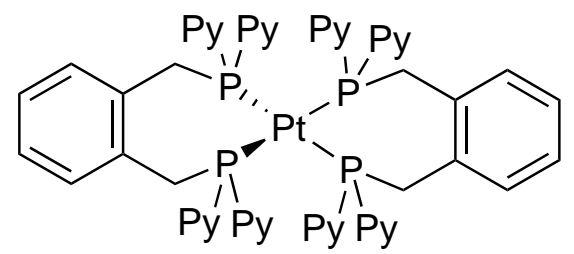

\footnotetext{
${ }^{1} \mathrm{H}$ NMR $\left(500 \mathrm{MHz}, \mathrm{CDCl}_{3} / \mathrm{C}_{6} \mathrm{D}_{6}\right): \delta / \mathrm{ppm} 8.54$ (br s, 2H, Ar-H), 8.48 (br s, $2 \mathrm{H}$, Ar-H), 8.44 (br s, 2H, Ar-H), 8.37 (br s, 2H, Ar-H), 7.77 (d, J=7.50 Hz, 2H, Ar-H), $7.23(\mathrm{~d}, J=7.00 \mathrm{~Hz}, 2 \mathrm{H}, \mathrm{Ar}-\mathrm{H}), 7.19$ (br s, 2H, Ar-H), 7.03 (m, 4H, Ar-H), 6.90 (m, 4H, Ar-H), 6.69 (br s, 4H, Ar-H), 6.61 (br s, 4H, Ar-H), 6.53 (m, 2H, Ar-H), 6.41 (m, 2H, Ar-H), 6.39 (m, 2H, Ar-H), 6.21 (br s, 2H, Ar-H), 5.54 (s, 2H, Ar-H), $5.21\left(\mathrm{~m}, 2 \mathrm{H}, \mathrm{CH}_{2}\right.$ ), 4.79 (br s, $2 \mathrm{H}, \mathrm{CH}_{2}$ ), 4.76 (br s, $2 \mathrm{H}, \mathrm{CH}_{2}$ ), 4.58 (br s, $2 \mathrm{H}, \mathrm{CH}_{2}$ ). ${ }^{13} \mathrm{C}$ NMR (125 MHz, $\mathrm{CDCl}_{3} / \mathrm{C}_{6} \mathrm{D}_{6}$ ): $\delta / \mathrm{ppm} 169.39$ (m, Ar-C), 166.87 (m, Ar-C), 160.47 (m, Ar-C), 158.23 (m, Ar-C), 148.90 (m, Ar-C), 148.80 (m, Ar-C), 147.73 (m,
} 
Ar-C), 147.39 (m, Ar-C), 139.34 (m, Ar-C), 139.23 (m, Ar-C), 134.21 (m, Ar-C), 132.10 (m, Ar-C), 131.80 (m, Ar-C), 131.39 (m, Ar-C), 131.07 (m, Ar-C), 125.29 (br s, Ar-C), 125.15 (br s, Ar-C), 124.18 (s, Ar-C), 121.78 (br s, Ar-C), 121.54 (m, Ar-C), 120.43 (m, Ar-C), 120.43 (m, Ar-C), $35.89\left(\mathrm{~m}, \mathrm{CH}_{2}\right), 33.62\left(\mathrm{~m}, \mathrm{CH}_{2}\right) .{ }^{31} \mathrm{P}$ $\operatorname{NMR}\left(121 \mathrm{MHz}, \mathrm{CDCl}_{3} / \mathrm{C}_{6} \mathrm{D}_{6}\right): \delta / \mathrm{ppm} 6.69\left(\mathrm{t},{ }^{2} J_{\mathrm{PP}}=40.7,{ }^{1} J_{\mathrm{PtP}}=3815.8 \mathrm{~Hz}\right)$, $3.16\left(\mathrm{t},{ }^{2} J_{\mathrm{PP}}=40.7,{ }^{1} J_{\mathrm{PtP}}=3548.2 \mathrm{~Hz}\right)$. HRMS calcd for $\mathrm{C}_{56} \mathrm{H}_{49} \mathrm{~N}_{8} \mathrm{P}{ }_{4} \mathrm{Pt}[\mathrm{M}+\mathrm{H}]^{+}$: $\mathrm{m} / \mathrm{z}=1151.2658 ;$ found $=1151.2649$.

\subsubsection{Palladium(0) complexes of dpypox}

\section{Synthesis of $\left[\mathrm{Pd}(\mathrm{PP})_{2}\right](40)$}

A solution of tris(norbornene)palladium (12 mg, $0.031 \mathrm{mmol}$ ) in $\mathrm{C}_{6} \mathrm{D}_{6}$ was added to ligand 3 (30 mg, $0.063 \mathrm{mmol}$ ) in an NMR tube. The ${ }^{31} \mathrm{P}$ and ${ }^{1} \mathrm{H}$ NMR spectra recorded after 15 minutes showed that the reaction was complete (quantitative conversion). As the $\left[\mathrm{Pd}(\mathrm{PP})_{2}\right]$ complex 40 was not very soluble in $\mathrm{C}_{6} \mathrm{D}_{6}$, the complex was dissolved in $\mathrm{CDCl}_{3}$ to obtain NMR data. However, the $\left[\mathrm{Pd}(\mathrm{PP})_{2}\right]$ complex 40 reacted with $\mathrm{CDCl}_{3}$ to form the $\left[\mathrm{PdCl}_{2}(\mathrm{PP})\right]$ complex 20 within 30 minutes and as such this was not an appropriate solvent to obtain ${ }^{13} \mathrm{C} N M R$ data in. (Reaction with $\mathrm{CDCl}_{3}$ complete after one day).

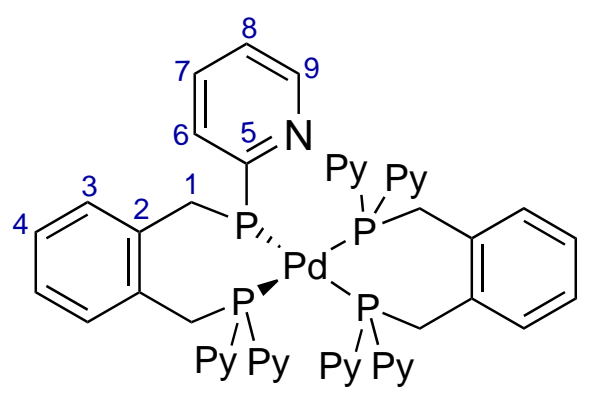

${ }^{1} \mathrm{H}$ NMR (500 MHz, $\mathrm{CDCl}_{3}$ ): $\delta / \mathrm{ppm} 8.82$ (d, $\left.J=4.5 \mathrm{~Hz}, 8 \mathrm{H}, \mathrm{H} 9\right), 8.17$ (br s, $8 \mathrm{H}$, H6), 7.71 (m, 8H, H7), 7.39 (m, 8H, H8), 6.70 (m, 4H, H4), 6.04 (m, 4H, H3), 4.40 (br s, 8H, H1). ${ }^{31} \mathrm{P}$ NMR (121 MHz, $\mathrm{CDCl}_{3}$ ): $\delta / \mathrm{ppm} 19.54$ (s), 16.97 (s). 


\subsubsection{Silver(I) complexes of dpypox}

\section{Reaction of 3 with silver tetrafluoroborate $\left([41] \mathrm{BF}_{4}\right)$}

A solution of the ligand $3(35 \mathrm{mg}, 0.073 \mathrm{mmol})$ in $\mathrm{CD}_{2} \mathrm{Cl}_{2}(0.4 \mathrm{~mL})$ was added to $\mathrm{AgBF}_{4}(7 \mathrm{mg}, 0.037 \mathrm{mmol})$ in an NMR tube. As the speed of the reaction was limited by the solubility of the $\mathrm{AgBF}_{4}$ in $\mathrm{CD}_{2} \mathrm{Cl}_{2}$, the reaction mixture was heated gently to dissolve the silver tetrafluoroborate. ${ }^{31} \mathrm{P},{ }^{1} \mathrm{H}$ and ${ }^{19} \mathrm{~F}$ NMR spectra recorded after 20 minutes showed the reaction had gone to completion (quantitative conversion).

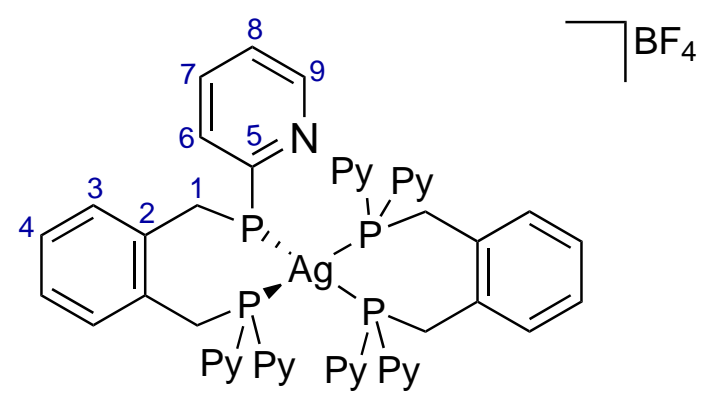

$[41] \mathrm{BF}_{4}{ }^{1} \mathrm{H}$ NMR $\left(500 \mathrm{MHz}, \mathrm{CD}_{2} \mathrm{Cl}_{2}\right.$ ): $\delta / \mathrm{ppm} 8.54$ (br s, 8H, H9), 7.12 (br s, 16H, H6+H7), 6.99 (m, 8H, H8), 6.37 (br s, 8H, H3+H4), 4.47 (br s, 8H, H1). ${ }^{19} \mathrm{~F}$ NMR $\left(282 \mathrm{MHz}, \mathrm{CD}_{2} \mathrm{Cl}_{2}\right): \delta / \mathrm{ppm}-152.97\left(\mathrm{~s}, \mathrm{BF}_{4}^{-}\right) .{ }^{31} \mathrm{P} \mathrm{NMR}(121 \mathrm{MHz}$, $\left.\mathrm{CD}_{2} \mathrm{Cl}_{2}\right): \delta / \mathrm{ppm} 4.06\left(\mathrm{dd},{ }^{1} J_{107} \mathrm{AgP}=224.1,{ }^{1} J_{109} \mathrm{AgP}=258.0 \mathrm{~Hz}\right)$. IR (film from $\left.\mathrm{CH}_{2} \mathrm{Cl}_{2}\right): \nu_{\max } / \mathrm{cm}^{-1} 1573,1561\left(\mathrm{C}=\mathrm{N}\right.$ stretch). HRMS calcd for $\mathrm{C}_{56} \mathrm{H}_{48} \mathrm{AgN}_{8} \mathrm{P}_{4}$ $\left[\mathrm{M}-\mathrm{BF}_{4}\right]^{+}: \mathrm{m} / \mathrm{z}=1065.2006$; found $=1065.2045$. HRMS calcd for $\mathrm{C}_{28} \mathrm{H}_{24} \mathrm{AgN}_{4} \mathrm{P}_{2}$ $\left[\mathrm{M}-\mathrm{BF}_{4}-\mathrm{C}_{28} \mathrm{H}_{24} \mathrm{~N}_{4} \mathrm{P}_{2}\right]^{+}: \mathrm{m} / \mathrm{z}=585.0522 ;$ found $=585.0522$.

\section{Reaction of 3 with silver nitrate $\left([41] \mathrm{NO}_{3}\right)$}

A solution of the ligand $3(35 \mathrm{mg}, 0.073 \mathrm{mmol})$ in $\mathrm{CDCl}_{3}(0.3 \mathrm{~mL})$ was added to $\mathrm{AgNO}_{3}(6 \mathrm{mg}, 0.037 \mathrm{mmol})$ in $\left(\mathrm{CD}_{3}\right)_{2} \mathrm{CO}(0.3 \mathrm{~mL})$ in an NMR tube. The speed of the reaction was once again limited by the solubility of the $\mathrm{AgNO}_{3}$ in the solvent mixture. ${ }^{31} \mathrm{P}$ and ${ }^{1} \mathrm{H}$ NMR spectra recorded after one hour showed the reaction mixture was comprised of $70 \% 3$ and $30 \%\left[\mathrm{Ag}(\mathrm{PP})_{2}\right] \mathrm{NO}_{3}\left([\mathbf{4 1}] \mathrm{NO}_{3}\right)$. The reaction mixture was then heated in a water bath at $35{ }^{\circ} \mathrm{C} .{ }^{31} \mathrm{P}$ and ${ }^{1} \mathrm{H}$ NMR spectra recorded after 48 hours of heating showed the reaction had gone to completion (quantitative conversion).

[41] $\mathrm{NO}_{3}:{ }^{1} \mathrm{H}$ NMR $\left(600 \mathrm{MHz},\left(\mathrm{CD}_{3}\right)_{2} \mathrm{CO}\right): \delta / \mathrm{ppm} 8.52$ (br s, 8H, H9), 7.12 (br s, 
16H, H6+H7), 6.97 (m, 8H, H8), 6.32 (br s, 8H, H3+H4), 4.56 (br s, 8H, H1). ${ }^{13} \mathrm{C}$ NMR (150 MHz, $\left.\left(\mathrm{CD}_{3}\right)_{2} \mathrm{CO}\right): \delta / \mathrm{ppm} 160.3$ (br m, C5), 150.30 (br s, C9), 135.98 (br s, C7), 132.2 (br m, C2+C3), 131.86 (br s, C6), 127.02 (s, C8), 124.2 (br m, C4), $37.5(\mathrm{~m}, \mathrm{C} 1) .{ }^{31} \mathrm{P} \mathrm{NMR}\left(121 \mathrm{MHz},\left(\mathrm{CD}_{3}\right){ }_{2} \mathrm{CO}\right): \delta / \mathrm{ppm} 4.02\left(\mathrm{dd},{ }^{1} J^{107} \mathrm{AgP}=\right.$ $\left.224.2,{ }^{1} J_{109} \mathrm{AgP}=257.0 \mathrm{~Hz}\right)$. IR (film from $\left.\mathrm{CH}_{2} \mathrm{Cl}_{2}\right): \nu_{\max } / \mathrm{cm}^{-1} 1573,1561(\mathrm{C}=\mathrm{N}$ stretch). HRMS calcd for $\mathrm{C}_{56} \mathrm{H}_{48} \mathrm{AgN}_{8} \mathrm{P}_{4}\left[\mathrm{M}-\mathrm{NO}_{3}\right]^{+}: \mathrm{m} / \mathrm{z}=1065.2006$; found $=$ 1065.2043.

\subsubsection{Rhodium complexes of dpypox}

\section{Reaction of 3 with $[\mathrm{Rh}(\mathrm{COD})(\mu-\mathrm{Cl})]_{2}$}

A solution of the ligand $3(30 \mathrm{mg}, 0.063 \mathrm{mmol})$ in $\mathrm{CDCl}_{3}(0.4 \mathrm{ml})$ was added to $[\mathrm{RhCl}(\mathrm{COD})]_{2}(15 \mathrm{mg}, 0.031 \mathrm{mmol})$ in an NMR tube. The ${ }^{31} \mathrm{P}$ and ${ }^{1} \mathrm{H}$ NMR spectra recorded after 20 minutes showed that all of the starting materials had reacted.

IR (film from $\mathrm{CHCl}_{3}$ ): $\nu_{\max } / \mathrm{cm}^{-1} 1573\left(\mathrm{C}=\mathrm{N}\right.$ stretch). HRMS calcd for $\mathrm{C}_{28} \mathrm{H}_{24} \mathrm{Cl}_{2} \mathrm{~N}_{4} \mathrm{P}_{2} \mathrm{Rh}$ $\left[\mathrm{M}-\mathrm{C}_{28} \mathrm{H}_{24} \mathrm{~N}_{4} \mathrm{P}_{2} \mathrm{Rh}\right]^{+}: \mathrm{m} / \mathrm{z}=650.9903 ;$ found $=650.9904$.

\section{Reaction of 3 with $[\mathrm{Rh}(\mathrm{COD})(\mu-\mathrm{Cl})]_{2}$ and $\mathrm{NaCH}\left(\mathrm{SO}_{2} \mathrm{CF}_{3}\right)_{2}$}

A solution of the ligand $3(30 \mathrm{mg}, 0.063 \mathrm{mmol})$ in $\mathrm{CDCl}_{3}(0.4 \mathrm{ml})$ was added to $[\mathrm{RhCl}(\mathrm{COD})]_{2}(15 \mathrm{mg}, 0.031 \mathrm{mmol})$ and $\mathrm{NaCH}\left(\mathrm{SO}_{2} \mathrm{CF}_{3}\right)_{3}(19 \mathrm{mg}, 0.063 \mathrm{mmol})$ in an NMR tube. The ${ }^{31} \mathrm{P}$ and ${ }^{1} \mathrm{H}$ NMR spectra recorded after 20 minutes showed that all of the starting materials had reacted.

HRMS calcd for $\mathrm{C}_{28} \mathrm{H}_{24} \mathrm{Cl}_{2} \mathrm{~N}_{4} \mathrm{P}_{2} \mathrm{Rh}\left[\mathrm{M}-\mathrm{C}_{28} \mathrm{H}_{24} \mathrm{~N}_{4} \mathrm{P}_{2} \mathrm{Rh}\right]^{+}: \mathrm{m} / \mathrm{z}=650.9903$; found $=650.9904$.

\subsubsection{Iridium complexes of dpypox}

\section{Synthesis of $[\operatorname{IrCl}(\mathrm{PP})(\mathrm{COD})](42)$}

A solution of the ligand $3(30 \mathrm{mg}, 0.063 \mathrm{mmol})$ in $\mathrm{CDCl}_{3}(0.4 \mathrm{ml})$ was added to $[\operatorname{Ir}(\mathrm{COD})(\mu-\mathrm{Cl})]_{2}(21 \mathrm{mg}, 0.031 \mathrm{mmol})$ in an NMR tube. The ${ }^{31} \mathrm{P}$ and ${ }^{1} \mathrm{H} \mathrm{NMR}$ spectra recorded after 20 minutes showed the formation of complex 42 (quantitative 
conversion). However, NMR spectra recorded after 1 day showed that this new complex was not stable and was decomposing over time.

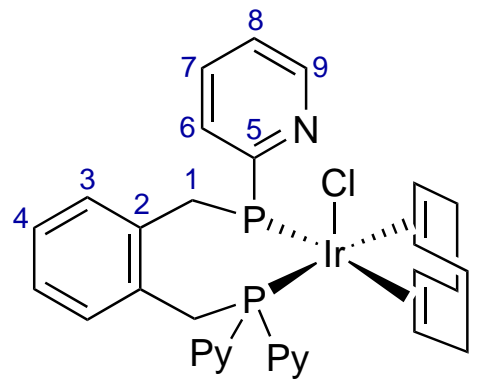

${ }^{1} \mathrm{H}$ NMR (500 MHz, $\mathrm{CDCl}_{3}$ ): $\delta /$ ppm 8.53 (br s, 4H, H9), 8.23 (br s, 4H, H6), 7.70 (br s, 4H, H7), 7.18 (m, 4H, H8), 6.52 (m, 2H, H3), 6.50 (m, 2H, H4), 5.06 (br m, $4 \mathrm{H}, \mathrm{COD}=\mathrm{CH}), 4.30(\mathrm{br} \mathrm{s}, 4 \mathrm{H}, \mathrm{H} 1), 2.21\left(\mathrm{~d},{ }^{2} J_{\mathrm{HH}}=8.5 \mathrm{~Hz}, 4 \mathrm{H}, \mathrm{COD} \mathrm{CH}_{2}\right), 1.75$ $\left(\mathrm{d},{ }^{2} J_{\mathrm{HH}}=8.5 \mathrm{~Hz}, 4 \mathrm{H}, \mathrm{COD} \mathrm{CH}_{2}\right) \cdot{ }^{13} \mathrm{C} \mathrm{NMR}\left(125 \mathrm{MHz}, \mathrm{CDCl}_{3}\right): \delta / \mathrm{ppm} 155.6$ (br m, C5), 148.61 (br m, C9), 135.20 (br m, C7), 134.01 (s, C2), 131.82 (s, C3), 125.54 (s, C4), 123.58 (br s C8), 33.09 (d, $\left.{ }^{1} J_{\mathrm{PC}}=13.4 \mathrm{~Hz}, \mathrm{C} 1\right), 32.85$ (s, COD $\mathrm{CH}_{2}$ ). ${ }^{31} \mathrm{P} \operatorname{NMR}\left(121 \mathrm{MHz}, \mathrm{CDCl}_{3}\right.$ ): $\delta / \mathrm{ppm}-13.62$ (s). IR (film from $\mathrm{CHCl}_{3}$ ): $\nu_{\max } / \mathrm{cm}^{-1} 1573\left(\mathrm{C}=\mathrm{N}\right.$ stretch). HRMS calcd for $\mathrm{C}_{28} \mathrm{H}_{25} \mathrm{ClIrN}_{4} \mathrm{P}_{2}\left[\mathrm{M}-\mathrm{C}_{8} \mathrm{H}_{12}+\mathrm{H}\right]^{+}$: $\mathrm{m} / \mathrm{z}=707.0859 ;$ found $=707.0870$.

\section{Synthesis of $\left[\operatorname{Ir}\left(1-\kappa-4,5,6-\eta^{3}-\mathrm{C}_{8} \mathrm{H}_{12}\right)(\mathrm{PPN})\right] \mathrm{CH}\left(\mathrm{SO}_{2} \mathrm{CF}_{3}\right)_{2}\left([43] \mathrm{CH}\left(\mathrm{SO}_{2} \mathrm{CF}_{3}\right)_{2}\right)$}

A solution of the ligand $3(30 \mathrm{mg}, 0.063 \mathrm{mmol})$ in $\mathrm{CDCl}_{3}(0.4 \mathrm{ml})$ was added to $[\operatorname{Ir}(\mathrm{COD})(\mu-\mathrm{Cl})]_{2}(21 \mathrm{mg}, 0.031 \mathrm{mmol})$ and $\mathrm{NaCH}\left(\mathrm{SO}_{2} \mathrm{CF}_{3}\right)_{3}(19 \mathrm{mg}, 0.063 \mathrm{mmol})$ in an NMR tube. The signals in the ${ }^{31} \mathrm{P},{ }^{1} \mathrm{H}$ and ${ }^{19} \mathrm{~F}$ NMR spectra recorded after 20 minutes were broad except for those associated with the $\mathrm{CH}\left(\mathrm{SO}_{2} \mathrm{CF}_{3}\right)_{2}^{-}$anion and showed that the starting materials had completely reacted. After 16 hours the NMR spectra showed the formation of $\left[\operatorname{Ir}\left(1-\kappa-4,5,6-\eta^{3}-\mathrm{C}_{8} \mathrm{H}_{12}\right)(\mathrm{PPN})\right] \mathrm{CH}\left(\mathrm{SO}_{2} \mathrm{CF}_{3}\right)_{2}$ compound $[43] \mathrm{CH}\left(\mathrm{SO}_{2} \mathrm{CF}_{3}\right)_{2}$ was complete (quantitative conversion).

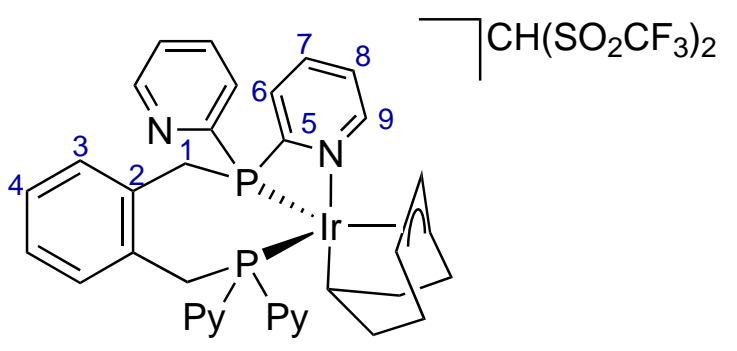

${ }^{1} \mathrm{H} \mathrm{NMR}\left(500 \mathrm{MHz}, \mathrm{CDCl}_{3}\right.$ ): $\delta / \mathrm{ppm} 8.89$ (d, $\left.J=4.5 \mathrm{~Hz}, 2 \mathrm{H}, \mathrm{H} 9 \mathrm{a}\right), 7.93$ (br s, 2H, H6a), 7.89 (m, 2H, H7a), 7.73 (br s, 2H, H9b), 7.70 (tm, $J=7.8$ Hz, 2H, H7b), 7.56 
(br s, 2H, H3), 7.50 (dd, $J=8.0,3.5 \mathrm{~Hz}, 2 \mathrm{H}, \mathrm{H} 6 \mathrm{~b}), 7.44$ (m, 2H, H8a), 7.13 (br s, 2H, H4), 7.05 (t, $J=5.5 \mathrm{~Hz}, 2 \mathrm{H}, \mathrm{H} 8 \mathrm{~b}), 5.29\left(\mathrm{~m}, 2 \mathrm{H}\right.$, allyl CH), 5.17 (t, ${ }^{2} J_{\mathrm{PH}}=14.0 \mathrm{~Hz}$, $2 \mathrm{H}, \mathrm{H} 1), 4.69\left(\mathrm{dd},{ }^{2} J_{\mathrm{PH}}=13.0,11.5 \mathrm{~Hz}, 2 \mathrm{H}, \mathrm{H} 1\right), 4.45(\mathrm{t}, J=8.0 \mathrm{~Hz}, 1 \mathrm{H}$, allyl $\mathrm{CH}), 3.96\left(\mathrm{~s}, 1 \mathrm{H}, \mathrm{CH}\left(\mathrm{SO}_{2} \mathrm{CF}_{3}\right)_{2}\right), 1.29\left(\mathrm{~m}, 3 \mathrm{H}, \mathrm{CH}_{2}+\mathrm{CH}\right), 0.89\left(\mathrm{~m}, 2 \mathrm{H}, \mathrm{CH}_{2}\right), 0.54$ $\left(\mathrm{m}, 2 \mathrm{H}, \mathrm{CH}_{2}\right), 0.38\left(\mathrm{~m}, 2 \mathrm{H}, \mathrm{CH}_{2}\right) \cdot{ }^{13} \mathrm{C} \mathrm{NMR}\left(125 \mathrm{MHz}, \mathrm{CDCl}_{3}\right): \delta / \mathrm{ppm} 162.25(\mathrm{~d}$, $\left.{ }^{1} J_{\mathrm{PC}}=63.4 \mathrm{~Hz}, \mathrm{C} 5 \mathrm{~b}\right), 155.72\left(\mathrm{~d},{ }^{1} J_{\mathrm{PC}}=71.0 \mathrm{~Hz}, \mathrm{C} 5 \mathrm{a}\right), 150.29\left(\mathrm{~d},{ }^{3} J_{\mathrm{PC}}=14.8 \mathrm{~Hz}\right.$, C9a), 149.18 (d, $\left.{ }^{3} J_{\mathrm{PC}}=15.8 \mathrm{~Hz}, \mathrm{C} 9 \mathrm{~b}\right), 136.95$ (d, $\left.{ }^{3} J_{\mathrm{PC}}=5.8 \mathrm{~Hz}, \mathrm{C} 7 \mathrm{~b}\right), 136.62$ (d, $\left.{ }^{3} J_{\mathrm{PC}}=8.1 \mathrm{~Hz}, \mathrm{C} 7 \mathrm{a}\right), 134.76(\mathrm{~m}, \mathrm{C} 2), 131.79\left(\mathrm{dd}, J_{\mathrm{PC}}=6.3,3.9 \mathrm{~Hz}, \mathrm{C} 3\right), 128.10(\mathrm{~s}$, C6a), 127.91 (s, C6b), 127.63 (vt, $\left.{ }^{4} J_{\mathrm{PC}}+{ }^{5} J_{\mathrm{PC}}=3.4 \mathrm{~Hz}, \mathrm{C} 4\right), 125.82$ (br s, C8b), $125.09\left(\mathrm{~d},{ }^{4} J_{\mathrm{PC}}=2.5 \mathrm{~Hz}, \mathrm{C} 8 \mathrm{a}\right), 121.30\left(\mathrm{q},{ }^{1} J_{\mathrm{CF}}=325.6 \mathrm{~Hz}, \mathrm{CH}\left(\mathrm{SO}_{2} C \mathrm{~F}_{3}\right)_{2}\right), 97.88$ (s, allyl CH), $77.92\left(\mathrm{~d},{ }^{2} J_{\mathrm{PC}}=27.8 \mathrm{~Hz}\right.$, allyl CH), $53.85\left(\mathrm{br} \mathrm{s}, \mathrm{CH}\left(\mathrm{SO}_{2} \mathrm{CF}_{3}\right)_{2}\right), 50.73$ $\left(\mathrm{m}, \mathrm{CH}_{2}\right), 30.52\left(\mathrm{dm},{ }^{1} J_{\mathrm{PC}}=28.4 \mathrm{~Hz}, \mathrm{C} 1\right), 29.79(\mathrm{~s}, \mathrm{CH}), 23.18\left(\mathrm{~d}, J_{\mathrm{PC}}=2.8 \mathrm{~Hz}\right.$, $\left.\mathrm{CH}_{2}\right) \cdot{ }^{19} \mathrm{~F} \mathrm{NMR}\left(282 \mathrm{MHz}, \mathrm{CDCl}_{3}\right): \delta / \mathrm{ppm}-80.88\left(\mathrm{~s}, \mathrm{CH}\left(\mathrm{SO}_{2} \mathrm{CF}_{3}\right)_{2}\right) .{ }^{31} \mathrm{P} \mathrm{NMR}$ $\left(121 \mathrm{MHz}, \mathrm{CDCl}_{3}\right.$ ): $\delta / \mathrm{ppm}-27.36$ (br s). IR (film from $\mathrm{CHCl}_{3}$ ): $\nu_{\max } / \mathrm{cm}^{-1} 1587$, $1573\left(\mathrm{C}=\mathrm{N}\right.$ stretch). HRMS calcd for $\mathrm{C}_{36} \mathrm{H}_{36} \mathrm{IrN}_{4} \mathrm{P}_{2}\left[\mathrm{M}-\mathrm{CH}\left(\mathrm{SO}_{2} \mathrm{CF}_{3}\right)_{2}\right]^{+}: \mathrm{m} / \mathrm{z}=$ 779.2041 ; found $=779.2055$.

\section{Reaction of complex 43 with carbon monoxide (synthesis of complex 44)}

Carbon monooxide was bubbled through a solution of compound $[43] \mathrm{CH}\left(\mathrm{SO}_{2} \mathrm{CF}_{3}\right)_{2}$ in $\mathrm{CDCl}_{3}(0.4 \mathrm{~mL})$ for 10 minutes. ${ }^{1} \mathrm{H}$ and ${ }^{31} \mathrm{P}$ NMR spectra recorded after $15 \mathrm{~min}$ utes showed complete formation of complex $[44] \mathrm{CH}\left(\mathrm{SO}_{2} \mathrm{CF}_{3}\right)_{2}$ (quantitative conversion).

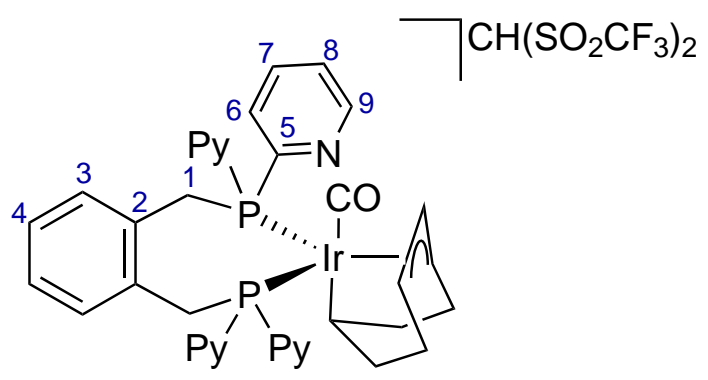

${ }^{1} \mathrm{H}$ NMR $\left(600 \mathrm{MHz}, \mathrm{CDCl}_{3}\right): \delta / p p m 8.91(\mathrm{~d}, J=4.5 \mathrm{~Hz}, 2 \mathrm{H}, \mathrm{H} 9 \mathrm{a}), 8.75(\mathrm{~d}, J=$ $4.5 \mathrm{~Hz}, 2 \mathrm{H}, \mathrm{H} 9 \mathrm{~b}), 8.31$ (dd, $J=7.7,3.0 \mathrm{~Hz}, 2 \mathrm{H}, \mathrm{H} 6 \mathrm{a}), 8.00$ (m, 4H, H6b+H7b), 7.94 (m, 2H, H7a), 7.51 (m, 4H, H8a+H8b), 6.91 (m, 2H, H4), 6.52 (m, 2H, H3), 5.23 (br s, 2H, allyl CH), $5.03(\mathrm{t}, J=7.8 \mathrm{~Hz}, 1 \mathrm{H}$, allyl $\mathrm{CH}$ ), 4.81 (dd, $J=14.1,8.4$ $\mathrm{Hz}, 2 \mathrm{H}, \mathrm{H} 1 \mathrm{a}), 4.44\left(\mathrm{t},{ }^{2} J_{\mathrm{PH}}=14.6 \mathrm{~Hz}, 2 \mathrm{H}, \mathrm{H} 1 \mathrm{~b}\right), 3.94\left(\mathrm{~s}, 1 \mathrm{H}, \mathrm{CH}\left(\mathrm{SO}_{2} \mathrm{CF}_{3}\right)_{2}\right), 1.70$ $\left(\mathrm{m}, 2 \mathrm{H}, \mathrm{CH}_{2}\right), 1.32\left(\mathrm{~m}, 2 \mathrm{H}, \mathrm{CH}_{2}\right), 1.25\left(\mathrm{~m}, 3 \mathrm{H}, \mathrm{CH}_{2}+\mathrm{CH}\right), 0.85\left(\mathrm{~m}, 2 \mathrm{H}, \mathrm{CH}_{2}\right)$. ${ }^{13} \mathrm{C} \mathrm{NMR}\left(150 \mathrm{MHz}, \mathrm{CDCl}_{3}\right): \delta / \mathrm{ppm} 155.14\left(\mathrm{~d},{ }^{1} J_{\mathrm{PC}}=39.2 \mathrm{~Hz}, \mathrm{C} 5 \mathrm{~b}\right), 154.37$ (d, 
$\left.{ }^{1} J_{\mathrm{PC}}=38.0 \mathrm{~Hz}, \mathrm{C} 5 \mathrm{a}\right), 150.22\left(\mathrm{~d},{ }^{3} J_{\mathrm{PC}}=16.7 \mathrm{~Hz}, \mathrm{C} 9 \mathrm{a}\right), 149.75\left(\mathrm{~d},{ }^{3} J_{\mathrm{PC}}=18.3 \mathrm{~Hz}\right.$, C9b), 136.80 (m, C7a+C7b), 133.02 (br s, C2), 131.21 (br s, C3), 129.44 (s, C6a), 128.82 (s, C6b), 128.33 (s, C4), 125.78 (s, C8a+C8b), 121.26 (q, ${ }^{1} J_{\mathrm{CF}}=324.3 \mathrm{~Hz}$, $\left.\mathrm{CH}\left(\mathrm{SO}_{2} \mathrm{CF}_{3}\right)_{2}\right), 94.93(\mathrm{~s}$, allyl $\mathrm{CH}), 86.18\left(\mathrm{~d},{ }^{2} J_{\mathrm{PC}}=28.1 \mathrm{~Hz}\right.$, allyl $\left.\mathrm{CH}\right), 53.81$ (br $\left.\mathrm{s}, C \mathrm{H}\left(\mathrm{SO}_{2} \mathrm{CF}_{3}\right)_{2}\right), 51.32\left(\mathrm{~m}, \mathrm{CH}_{2}\right), 39.09\left(\mathrm{~d},{ }^{1} J_{\mathrm{PC}}=30.0 \mathrm{~Hz}, \mathrm{C} 1\right), 22.84\left(\mathrm{~s}, \mathrm{CH}_{2}\right)$. ${ }^{19} \mathrm{~F} \mathrm{NMR}\left(282 \mathrm{MHz}, \mathrm{CDCl}_{3}\right): \delta / \mathrm{ppm}-80.94\left(\mathrm{~s}, \mathrm{CH}\left(\mathrm{SO}_{2} \mathrm{CF}_{3}\right)_{2}\right) .{ }^{31} \mathrm{P} \mathrm{NMR}(121$ $\left.\mathrm{MHz}, \mathrm{CDCl}_{3}\right): \delta / \mathrm{ppm}-1.64$ (br s).

\subsubsection{Platinum(II) complexes of dpyp $m x$}

Dimer formation $\left[\mathrm{PtX}_{2}(\mu-\mathrm{PP})\right]_{2}\left(\mathrm{PP}=4 ; \mathrm{X}_{2}=\mathrm{Cl}_{2}(47), \mathrm{ClMe}(48), \mathrm{Me}_{2}\right.$ (50))

To a solution of dpyp $m \mathrm{x}$ ligand $4(50 \mathrm{mg}, 0.1 \mathrm{mmol})$ in $\mathrm{CH}_{2} \mathrm{Cl}_{2}(2 \mathrm{~mL}$, dried and degassed) the appropriate platinum precursor complex was added (dichlorobishexa-1,5dieneplatinum, dimethyl(hexa-1,5-diene)platinum or chloromethyl(hexa-1,5-diene)platinum, $0.1 \mathrm{mmol}$ ). The reaction mixture was stirred for 30 minutes. The solvent was then removed under reduced pressure to give solids. These were washed with hexane $(3 \times 4 \mathrm{~mL})$.

$\left[\mathrm{PtCl}_{2}(\mu-\mathrm{PP})\right]_{2}(47)$

${ }^{31} \mathrm{P}$ NMR $\left(121 \mathrm{MHz}, \mathrm{CDCl}_{3}\right): \delta / \mathrm{ppm} 20.23\left(\mathrm{br} \mathrm{s},{ }^{1} J_{\mathrm{PtP}}=3902.2 \mathrm{~Hz}\right.$ ). IR (film from $\left.\mathrm{CH}_{2} \mathrm{Cl}_{2}\right): \nu_{\max } / \mathrm{cm}^{-1} 3045\left(\mathrm{sp}^{2} \mathrm{C}-\mathrm{H}\right.$ stretch $), 2967\left(\mathrm{sp}^{3} \mathrm{C}-\mathrm{H}\right.$ stretch $), 1573(\mathrm{C}=\mathrm{N}$ stretch).

$[\operatorname{PtClMe}(\mu-\mathrm{PP})]_{2}(48)$

${ }^{31} \mathrm{P}$ NMR $\left(121 \mathrm{MHz}, \mathrm{CDCl}_{3}\right): \delta / \mathrm{ppm} 29.53\left(\mathrm{br} \mathrm{s},{ }^{1} J_{\mathrm{PtP}}=3069.9 \mathrm{~Hz}\right)$. IR (film from $\left.\mathrm{CH}_{2} \mathrm{Cl}_{2}\right): \nu_{\max } / \mathrm{cm}^{-1} 3044\left(\mathrm{sp}^{2} \mathrm{C}-\mathrm{H}\right.$ stretch$), 2960\left(\mathrm{sp}^{3} \mathrm{C}-\mathrm{H}\right.$ stretch$), 1573(\mathrm{C}=\mathrm{N}$ stretch).

$\left[\mathrm{PtMe}_{2}(\mu-\mathrm{PP})\right]_{2}(\mathbf{5 0})$

${ }^{31} \mathrm{P}$ NMR $\left(121 \mathrm{MHz}, \mathrm{CDCl}_{3}\right): \delta / \mathrm{ppm} 30.99$ (br s, ${ }^{1} J_{\mathrm{PtP}}=1921.9 \mathrm{~Hz}$ ). IR (film from $\left.\mathrm{CH}_{2} \mathrm{Cl}_{2}\right): \nu_{\max } / \mathrm{cm}^{-1} 3043\left(\mathrm{sp}^{2} \mathrm{C}-\mathrm{H}\right.$ stretch$), 2957$ ( $\mathrm{sp}^{3} \mathrm{C}-\mathrm{H}$ stretch), $1573(\mathrm{C}=\mathrm{N}$ stretch). 
A mixture of ligand 4 (102 mg, $0.21 \mathrm{mmol}$ ) and chloromethyl(hexa-1,5-diene)platinum (70 mg, $0.21 \mathrm{mmol})$ in chloroform $\left(5 \mathrm{~mL}\right.$, degassed) was heated to $60{ }^{\circ} \mathrm{C}$ with stirring for three days. The reaction mixture was filtered and the brown solid washed with $\mathrm{CH}_{2} \mathrm{Cl}_{2}(15 \mathrm{~mL})$. The filtrate was isolated and the solvent removed under vacuum. The resulting solid was washed with hexane $(2 \times 5 \mathrm{~mL})$ and then dried under vacuum to give 49 as a yellow solid (126 mg, 84\%).

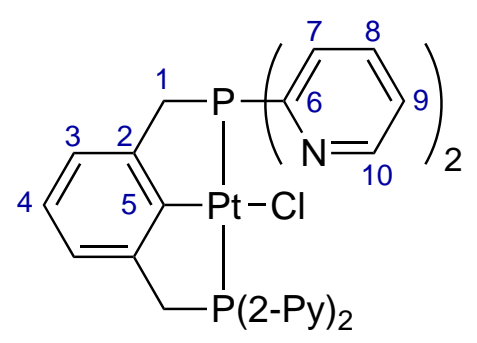

${ }^{1} \mathrm{H}$ NMR (500 MHz, $\left.\mathrm{CDCl}_{3}\right): \delta / p p m 8.72(\mathrm{~d}, J=4.8 \mathrm{~Hz}, 4 \mathrm{H}, \mathrm{H} 10), 8.54(\mathrm{~m}, 4 \mathrm{H}$, H7), $7.72(\mathrm{td}, J=7.7,1.7 \mathrm{~Hz}, 4 \mathrm{H}, \mathrm{H} 8), 7.28(\mathrm{~m}, 4 \mathrm{H}, \mathrm{H} 9), 7.15\left(\mathrm{~d},{ }^{3} J_{\mathrm{HH}}=7.4 \mathrm{~Hz}\right.$, $2 \mathrm{H}, \mathrm{H} 3), 7.03\left(\mathrm{t},{ }^{3} J_{\mathrm{HH}}=7.4 \mathrm{~Hz}, 1 \mathrm{H}, \mathrm{H} 4\right), 4.47\left(\mathrm{vt},{ }^{2} J_{\mathrm{PH}}+{ }^{4} J_{\mathrm{PH}}=5.8 \mathrm{~Hz}, 4 \mathrm{H}\right.$, H1). ${ }^{13} \mathrm{C} \mathrm{NMR}\left(125 \mathrm{MHz}, \mathrm{CDCl}_{3}\right): \delta / \mathrm{ppm} 154.98\left(\mathrm{vt},{ }^{1} J_{\mathrm{PC}}+{ }^{3} J_{\mathrm{PC}}=36.9 \mathrm{~Hz}, \mathrm{C} 6\right)$, $150.56\left(\mathrm{vt},{ }^{3} J_{\mathrm{PC}}+{ }^{5} J_{\mathrm{PC}}=6.7 \mathrm{~Hz}, \mathrm{C} 10\right), 147.93\left(\mathrm{vt},{ }^{2} J_{\mathrm{PC}}+{ }^{4} J_{\mathrm{PC}}=11.1 \mathrm{~Hz}, \mathrm{C} 2\right)$, 146.16 (s, C5), 136.37 (m, C8), 131.61 (vt, $\left.{ }^{2} J_{\mathrm{PC}}+{ }^{4} J_{\mathrm{PC}}=14.4 \mathrm{~Hz}, \mathrm{C} 7\right), 125.68$ (br s, C4), 124.84 (br s, C9), $123.42\left(\mathrm{vt},{ }^{3} J_{\mathrm{PC}}+{ }^{5} J_{\mathrm{PC}}=10.6 \mathrm{~Hz}, \mathrm{C} 3\right), 37.42\left(\mathrm{vt},{ }^{1} J_{\mathrm{PC}}\right.$ $\left.+{ }^{3} J_{\mathrm{PC}}=20.4 \mathrm{~Hz}, \mathrm{C} 1\right) \cdot{ }^{31} \mathrm{P} \mathrm{NMR}\left(121 \mathrm{MHz}, \mathrm{CDCl}_{3}\right): \delta / \mathrm{ppm} 38.05\left(\mathrm{~s},{ }^{1} J_{\mathrm{PtP}}=\right.$ $2915.8 \mathrm{~Hz}$ ). HRMS calcd for $\mathrm{C}_{28} \mathrm{H}_{24} \mathrm{ClN}_{4} \mathrm{P}_{2} \mathrm{Pt}[\mathrm{M}+\mathrm{H}]^{+}: \mathrm{m} / \mathrm{z}=709.0805$; found $=$ 709.0799. HRMS calcd for $\mathrm{C}_{28} \mathrm{H}_{23} \mathrm{ClN}_{4} \mathrm{NaP}_{2} \mathrm{Pt}[\mathrm{M}+\mathrm{Na}]^{+}: \mathrm{m} / \mathrm{z}=731.0625$; found $=731.0614$.

\section{Synthesis of $[\mathrm{PtMe}(\mathrm{PCP})](51)$}

Dimethyl(hexa-1,5-diene)platinum (114 $\mathrm{mg}, 0.37 \mathrm{mmol}$ ) was added to a solution of ligand 4 (177 mg, $0.37 \mathrm{mmol})$ in chloroform ( $5 \mathrm{~mL}$, degassed). The reaction mixture was heated to $60{ }^{\circ} \mathrm{C}$ over four days. After which the reaction mixture was filtered and the solid washed with $\mathrm{CH}_{2} \mathrm{Cl}_{2}(2 \times 5 \mathrm{~mL})$. The filtrate was isolated and the solvent removed to give $\mathbf{5 1}$ as a brown oil (232 mg, 92\%). Crystals were grown from inwards diffusion of hexane into $\mathrm{CH}_{2} \mathrm{Cl}_{2}$.

${ }^{1} \mathrm{H}$ NMR (500 MHz, $\left.\mathrm{CDCl}_{3}\right): \delta / \mathrm{ppm} 8.72(\mathrm{~d}, J=4.5 \mathrm{~Hz}, 4 \mathrm{H}, \mathrm{H} 10), 8.53(\mathrm{~m}, 4 \mathrm{H}$, H7), $7.72(\mathrm{tq}, J=7.8,2.0 \mathrm{~Hz}, 4 \mathrm{H}, \mathrm{H} 8), 7.28$ (m, 4H, H9), $7.15\left(\mathrm{~d},{ }^{3} J_{\mathrm{HH}}=7.5 \mathrm{~Hz}\right.$, 
$2 \mathrm{H}, \mathrm{H} 3), 7.03\left(\mathrm{t},{ }^{3} J_{\mathrm{HH}}=7.5 \mathrm{~Hz}, 1 \mathrm{H}, \mathrm{H} 4\right), 4.46\left(\mathrm{vt},{ }^{2} J_{\mathrm{PH}}+{ }^{4} J_{\mathrm{PH}}=5.9 \mathrm{~Hz}, 4 \mathrm{H}\right.$, $\mathrm{H} 1), 0.48\left(\mathrm{~s},{ }^{2} J_{\mathrm{PtH}}=75.2 \mathrm{~Hz}, 3 \mathrm{H}, \mathrm{Pt}-\mathrm{CH}_{3}\right) \cdot{ }^{13} \mathrm{C} \mathrm{NMR}\left(125 \mathrm{MHz}, \mathrm{CDCl}_{3}\right): \delta / \mathrm{ppm}$ $154.93\left(\mathrm{vt},{ }^{1} J_{\mathrm{PC}}+{ }^{3} J_{\mathrm{PC}}=36.5 \mathrm{~Hz}, \mathrm{C} 6\right), 150.61\left(\mathrm{vt},{ }^{3} J_{\mathrm{PC}}+{ }^{5} J_{\mathrm{PC}}=7.2 \mathrm{~Hz}, \mathrm{C} 10\right)$, $147.99\left(\mathrm{vt},{ }^{2} J_{\mathrm{PC}}+{ }^{4} J_{\mathrm{PC}}=10.7 \mathrm{~Hz}, \mathrm{C} 2\right), 146.19(\mathrm{~s}, \mathrm{C} 5), 136.23\left(\mathrm{vt},{ }^{3} J_{\mathrm{PC}}+{ }^{5} J_{\mathrm{PC}}\right.$ $=4.8 \mathrm{~Hz}, \mathrm{C} 8), 131.59\left(\mathrm{vt},{ }^{2} J_{\mathrm{PC}}+{ }^{4} J_{\mathrm{PC}}=14.6 \mathrm{~Hz}, \mathrm{C} 7\right), 125.62(\mathrm{~s}, \mathrm{C} 4), 124.79(\mathrm{~s}$, C9), $123.35\left(\mathrm{vt},{ }^{3} J_{\mathrm{PC}}+{ }^{5} J_{\mathrm{PC}}=10.8 \mathrm{~Hz}, \mathrm{C} 3\right), 37.44\left(\mathrm{vt},{ }^{1} J_{\mathrm{PC}}+{ }^{3} J_{\mathrm{PC}}=20.6 \mathrm{~Hz}\right.$, $\mathrm{C} 1),-4.72\left(\mathrm{~s},{ }^{1} J_{\mathrm{PtC}}=689.5 \mathrm{~Hz}, \mathrm{Pt}-\mathrm{CH}_{3}\right) .{ }^{31} \mathrm{P} \mathrm{NMR}\left(121 \mathrm{MHz}, \mathrm{CDCl}_{3}\right): \delta / \mathrm{ppm}$ $38.08\left(\mathrm{~s},{ }^{1} J_{\mathrm{PtP}}=2912.8 \mathrm{~Hz}\right)$. IR (film from $\left.\mathrm{CH}_{2} \mathrm{Cl}_{2}\right): \nu_{\max } / \mathrm{cm}^{-1} 1573,1563(\mathrm{C}=\mathrm{N}$ stretch). HRMS calcd for $\mathrm{C}_{28} \mathrm{H}_{23} \mathrm{~N}_{4} \mathrm{P}_{2} \mathrm{Pt}\left[\mathrm{M}-\mathrm{CH}_{3}\right]^{+}: \mathrm{m} / \mathrm{z}=672.1043$; found $=$ 672.1048. HRMS calcd for $\mathrm{C}_{30} \mathrm{H}_{26} \mathrm{~N}_{5} \mathrm{P} 2 \mathrm{Pt}\left[\mathrm{M}-\mathrm{CH}_{3}+\mathrm{CH}_{3} \mathrm{CN}\right]^{+}: \mathrm{m} / \mathrm{z}=713.1308$; found $=713.1304$. Elemental Analysis: $\mathrm{C}, 50.9 ; \mathrm{H}, 4.1 ; \mathrm{N}, 8.4 \%\left(\mathrm{C}_{29} \mathrm{H}_{26} \mathrm{~N}_{4} \mathrm{P}_{2} \mathrm{Pt}\right.$ requires $\mathrm{C}, 50.7 ; \mathrm{H}, 3.8 ; \mathrm{N}, 8.2 \%)$.

\subsubsection{Palladium(II) complexes of dpyp $m x$}

\section{Synthesis of $[\mathrm{PdCl}(\mathrm{PCP})](53)$}

Dichlorobis(acetonitrile)palladium (104 mg, $0.40 \mathrm{mmol}$ ) was added to a solution of 4 (191 $\mathrm{mg}, 0.40 \mathrm{mmol}$ ) in chloroform $(5 \mathrm{~mL}$, degassed). The reaction mixture was heated to $60{ }^{\circ} \mathrm{C}$ over three days. After which the reaction mixture was allowed to cool to room temperature and then the solution was filtered and the solid washed with $\mathrm{CH}_{2} \mathrm{Cl}_{2}(2 \times 5 \mathrm{~mL})$. The filtrate was isolated and the solvent removed to give 53 as an orange oil (141 mg, 57\%). Crystals were grown from inwards diffusion of hexane into $\mathrm{CH}_{2} \mathrm{Cl}_{2}$.

${ }^{1} \mathrm{H}$ NMR (500 MHz, $\left.\mathrm{CDCl}_{3}\right): \delta / \mathrm{ppm} 8.71(\mathrm{~d}, J=4.1 \mathrm{~Hz}, 4 \mathrm{H}, \mathrm{H} 10), 8.50(\mathrm{~m}, 4 \mathrm{H}$, $\mathrm{H} 7), 7.71$ (t, $J=7.3 \mathrm{~Hz}, 4 \mathrm{H}, \mathrm{H} 8), 7.28$ (m, 4H, H9), $7.16\left(\mathrm{~d},{ }^{3} J_{\mathrm{HH}}=7.5 \mathrm{~Hz}, 2 \mathrm{H}\right.$, H3), $7.03\left(\mathrm{t},{ }^{3} J_{\mathrm{HH}}=7.5 \mathrm{~Hz}, 1 \mathrm{H}, \mathrm{H} 4\right), 4.53\left(\mathrm{vt},{ }^{2} J_{\mathrm{PH}}+{ }^{4} J_{\mathrm{PH}}=5.8 \mathrm{~Hz}, 4 \mathrm{H}, \mathrm{H} 1\right) .{ }^{13} \mathrm{C}$ $\operatorname{NMR}\left(125 \mathrm{MHz}, \mathrm{CDCl}_{3}\right): \delta / \mathrm{ppm} 155.17\left(\mathrm{vt},{ }^{1} J_{\mathrm{PC}}+{ }^{3} J_{\mathrm{PC}}=31.0 \mathrm{~Hz}, \mathrm{C} 6\right), 150.61$ $\left(\mathrm{vt},{ }^{3} J_{\mathrm{PC}}+{ }^{5} J_{\mathrm{PC}}=6.7 \mathrm{~Hz}, \mathrm{C} 10\right), 149.33\left(\mathrm{vt},{ }^{2} J_{\mathrm{PC}}+{ }^{4} J_{\mathrm{PC}}=12.5 \mathrm{~Hz}, \mathrm{C} 2\right), 136.37$ $\left(\mathrm{vt},{ }^{3} J_{\mathrm{PC}}+{ }^{5} J_{\mathrm{PC}}=4.8 \mathrm{~Hz}, \mathrm{C} 8\right), 131.93\left(\mathrm{vt},{ }^{2} J_{\mathrm{PC}}+{ }^{4} J_{\mathrm{PC}}=15.1 \mathrm{~Hz}, \mathrm{C} 7\right), 126.31$ (s, C4), 124.71 (s, C9), $124.00\left(\mathrm{vt},{ }^{3} J_{\mathrm{PC}}+{ }^{5} J_{\mathrm{PC}}=12.8 \mathrm{~Hz}, \mathrm{C} 3\right), 37.41$ (vt, ${ }^{1} J_{\mathrm{PC}}+$ $\left.{ }^{3} J_{\mathrm{PC}}=16.3 \mathrm{~Hz}, \mathrm{C} 1\right) .{ }^{31} \mathrm{P} \mathrm{NMR}\left(121 \mathrm{MHz}, \mathrm{CDCl}_{3}\right): \delta / \mathrm{ppm} 39.70$ (s). HRMS calcd for $\mathrm{C}_{28} \mathrm{H}_{23} \mathrm{~N}_{4} \mathrm{P} 2 \mathrm{Pd}[\mathrm{M}-\mathrm{Cl}]^{+}: \mathrm{m} / \mathrm{z}=579.0454$; found $=579.0453$. 


\subsection{Trimetallic Complexes}

\subsubsection{Homotrimetallic complexes of dpypox}

\section{Synthesis of $\left[\left(\mathrm{PtMe}_{2}\right)_{3}(\mathrm{PP})\right](55)$}

Dimethyl(hexa-1,5-diene)platinum (39 $\mathrm{mg}, 0.12 \mathrm{mmol}$ ) was added to a solution of the dpypox ligand 3 (20 mg, $0.04 \mathrm{mmol})$ in $\mathrm{CDCl}_{3}(0.5 \mathrm{~mL}) .{ }^{31} \mathrm{P}$ and ${ }^{1} \mathrm{H} \mathrm{NMR}$ spectra recorded after 15 minutes showed the formation of the monometallic $\left[\mathrm{PtMe}_{2}(\mathrm{PP})\right]$ complex 17. After one night the NMR spectra recorded showed the formation of two new species, one being the trimetallic $\left[\left(\mathrm{PtMe}_{2}\right)_{3}(\mathrm{PP})\right]$ complex 55 and the other the intermediate dimetallic $\left[\left(\mathrm{PtMe}_{2}\right)_{2}(\mathrm{PP})\right]$ complex 54. After two nights the only species present in solution was the trimetallic $\left[\left(\mathrm{PtMe}_{2}\right)_{3}(\mathrm{PP})\right]$ complex 55 (quantitative conversion). Over a week the $\left[\left(\mathrm{PtMe}_{2}\right)_{3}(\mathrm{PP})\right]$ complex 55 crystallised out of solution as yellow block crystals. Unfortunately these were found to be twinned and good X-ray structure data could not be obtained of this complex.

$\left[\left(\mathrm{PtMe}_{2}\right)_{2}(\mathrm{PP})\right](\mathbf{5 4})$

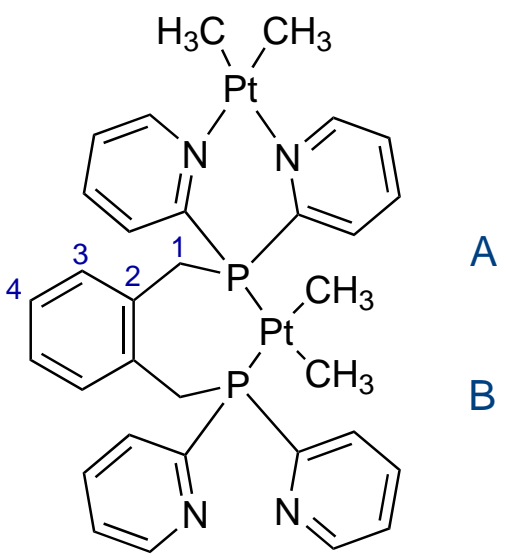

${ }^{1} \mathrm{H}$ NMR (500 MHz, $\left.\mathrm{CDCl}_{3}\right): \delta / p p m 8.34(\mathrm{~m}, 1 \mathrm{H}, \mathrm{H1a}), 6.69$ (m, 1H, H4a), 6.64 (m, 2H, H4b+H3a), 6.06 (d, $J=7.0 \mathrm{~Hz}, 1 \mathrm{H}, \mathrm{H} 3 \mathrm{~b}), 4.54$ (m, 2H, H1b), 4.20 (m, 1H, H1a), $0.41\left(\mathrm{dd},{ }^{3} J_{\mathrm{PH}}=9.0,7.0,{ }^{2} J_{\mathrm{PtH}}=68.3 \mathrm{~Hz}, 3 \mathrm{H}, \mathrm{Pt}-\mathrm{CH}_{3}\right),-0.12\left(\mathrm{dd},{ }^{3} J_{\mathrm{PH}}\right.$ $\left.=8.0,6.5,{ }^{2} J_{\mathrm{PtH}}=68.3 \mathrm{~Hz}, 3 \mathrm{H}, \mathrm{Pt}-\mathrm{CH}_{3}\right) \cdot{ }^{13} \mathrm{C} \mathrm{NMR}\left(125 \mathrm{MHz}, \mathrm{CDCl}_{3}\right): \delta / \mathrm{ppm}$ $33.84\left(\mathrm{~d},{ }^{1} J_{\mathrm{PC}}=23.4 \mathrm{~Hz}, \mathrm{C} 1\right), 6.78\left(\mathrm{dd},{ }^{2} J_{\mathrm{PC}}=95.5,7.7 \mathrm{~Hz}, \mathrm{Pt}-\mathrm{CH}_{3}\right), 6.01(\mathrm{dd}$, $\left.{ }^{2} J_{\mathrm{PC}}=97.7,8.2 \mathrm{~Hz}, \mathrm{Pt}-\mathrm{CH}_{3}\right) .{ }^{31} \mathrm{P} \mathrm{NMR}\left(121 \mathrm{MHz}, \mathrm{CDCl}_{3}\right): \delta / \mathrm{ppm} 25.50\left(\mathrm{~d},{ }^{2} J_{\mathrm{PP}}\right.$ $\left.=10.5,{ }^{1} J_{\mathrm{PtP}}=2019.2,{ }^{3} J_{\mathrm{PtP}}=79.4 \mathrm{~Hz}\right), 13.31\left(\mathrm{~d},{ }^{2} J_{\mathrm{PP}}=10.5,{ }^{1} J_{\mathrm{PtP}}=1828.3 \mathrm{~Hz}\right)$. 


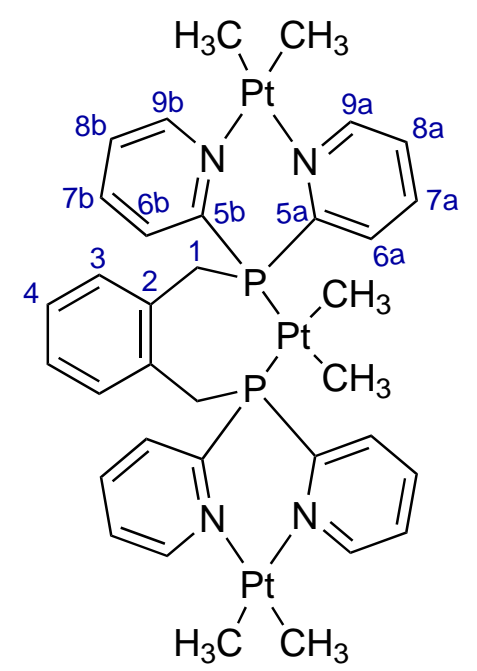

${ }^{1} \mathrm{H}$ NMR (500 MHz, $\mathrm{CDCl}_{3}$ ): $\delta / p p m 9.19$ (m, 2H, H9b), 8.82 (m, 4H, H6b+H9a), $8.42(\mathrm{dd}, J=17.1,14,1 \mathrm{~Hz}, 2 \mathrm{H}, \mathrm{H} 1 \mathrm{a}), 8.21$ (m, 2H, H6a), 8.00 (m, 4H, H8a+H8b), 7.80 (t, $J=8.0 \mathrm{~Hz}, 2 \mathrm{H}, \mathrm{H} 7 \mathrm{a}), 7.56$ (m, 2H, H7b), 6.63 (m, 4H, H3+H4), 3.84 (d, $J=13.5 \mathrm{~Hz}, 2 \mathrm{H}, \mathrm{H} 1 \mathrm{~b}), 0.23\left(\mathrm{dd},{ }^{3} J_{\mathrm{PH}}=8.1,6.6,{ }^{2} J_{\mathrm{PtH}}=68.0 \mathrm{~Hz}, 6 \mathrm{H}, \mathrm{Pt}-\mathrm{CH}_{3}\right)$. ${ }^{31} \mathrm{P}$ NMR $\left(121 \mathrm{MHz}, \mathrm{CDCl}_{3}\right): \delta / \mathrm{ppm} 27.11\left(\mathrm{~s},{ }^{1} J_{\mathrm{PtP}}=1970.4,{ }^{3} J_{\mathrm{PtP}}=74 \mathrm{~Hz}\right) . \mathrm{IR}$ (film from $\mathrm{CH}_{2} \mathrm{Cl}_{2}$ ): $\nu_{\max } / \mathrm{cm}^{-1} 1601,1587$ (C=N stretch).

\section{Synthesis of $\left[\left(\mathrm{PtCl}_{2}\right)_{3}(\mathrm{PP})\right](56)$}

Dichloro(hexa-1,5-diene)platinum (120 mg, $0.33 \mathrm{mmol}$ ) was added to a solution of the ligand 3 (55 mg, $0.11 \mathrm{mmol})$ in $\mathrm{CH}_{2} \mathrm{Cl}_{2}(2 \mathrm{~mL})$. The solution was stirred for 15 minutes and then left overnight. The solid that formed was isolated by filtration, washed with $\mathrm{CH}_{2} \mathrm{Cl}_{2}(3 \times 5 \mathrm{~mL})$ to remove any unreacted starting materials and dried under vacuum to give a yellow solid (43 mg, 29\%). Due to the low solubility of 56, ${ }^{31} \mathrm{P},{ }^{1} \mathrm{H}$ and ${ }^{13} \mathrm{C} \mathrm{NMR}$ and mass spectrometry data were not able to be obtained.

IR $(\mathrm{KBr}): \nu_{\max } / \mathrm{cm}^{-1} 1630(\mathrm{C}=\mathrm{N}$ stretch). Elemental Analysis: $\mathrm{C}, 26.0 ; \mathrm{H}, 1.7 ; \mathrm{N}$, $4.1 \%\left(\mathrm{C}_{28} \mathrm{H}_{24} \mathrm{Cl}_{6} \mathrm{~N}_{4} \mathrm{P}_{2} \mathrm{Pt}_{3}\right.$ requires $\left.\mathrm{C}, 26.3 ; \mathrm{H}, 1.9 ; \mathrm{N}, 4.4 \%\right)$.

\section{Synthesis of $\left[\left(\mathrm{PdCl}_{2}\right)_{3}(\mathrm{PP})\right](57)$}

Dichlorobis(acetonitrile)palladium (72 $\mathrm{mg}, 0.27 \mathrm{mmol}$ ) was added to a solution of the ligand 3 (44 mg, $0.09 \mathrm{mmol})$ in $\mathrm{CHCl}_{3}(0.6 \mathrm{~mL})$. After five minutes the solution had solidified due to the large amount of brown solid formed in the reaction. The solid was isolated by filtration and washed with $\mathrm{CH}_{2} \mathrm{Cl}_{2}(3 \times 5 \mathrm{~mL})$ and dried under 
vacuum to give a light brown solid (85 $\mathrm{mg}, 91 \%)$. Due to the low solubility of $\mathbf{5 7}$, ${ }^{31} \mathrm{P},{ }^{1} \mathrm{H}$ and ${ }^{13} \mathrm{C}$ NMR and mass spectrometry data were not able to be obtained.

IR (KBr): $\nu_{\max } / \mathrm{cm}^{-1} 1613,1585(\mathrm{C}=\mathrm{N}$ stretch). Elemental Analysis: $\mathrm{C}, 33.0 ; \mathrm{H}$, $2.2 ; \mathrm{N}, 5.1 \%\left(\mathrm{C}_{28} \mathrm{H}_{24} \mathrm{Cl}_{6} \mathrm{~N}_{4} \mathrm{P}_{2} \mathrm{Pd}_{3}\right.$ requires $\left.\mathrm{C}, 33.3 ; \mathrm{H}, 2.4 ; \mathrm{N}, 5.5 \%\right)$.

\section{Synthesis of $\left[\left(\mathrm{PtMe}_{2}\right) \mathrm{PtClMe}(\mathrm{PP})\right](58)$}

One equivalent of dimethyl(hexa-1,5-diene)platinum (13 $\mathrm{mg}, 0.04 \mathrm{mmol}$ ) was added to a solution of the $[\mathrm{PtClMe}(\mathrm{PP})]$ complex $27(30 \mathrm{mg}, 0.04 \mathrm{mmol})$ in $\mathrm{CDCl}_{3}(0.4$ $\mathrm{mL})$ in an NMR tube. The reaction was followed by ${ }^{31} \mathrm{P}$ and ${ }^{1} \mathrm{H}$ NMR. After 24 hours at room temperature the dimetallic $\left[\left(\mathrm{PtMe}_{2}\right) \mathrm{PtClMe}(\mathrm{PP})\right]$ complex $\mathbf{5 8}$ was the major species in solution.

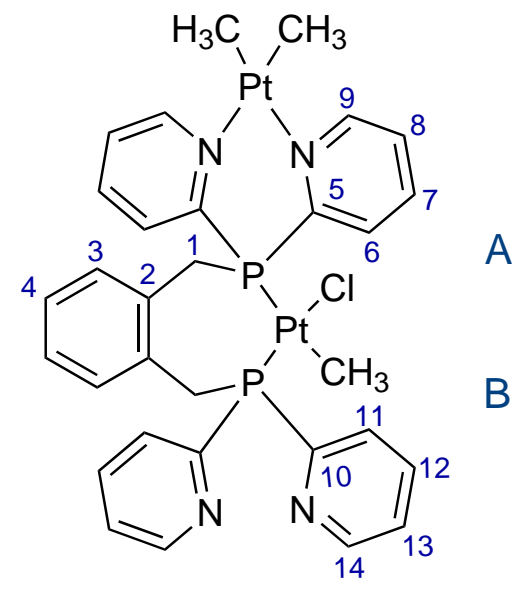

${ }^{1} \mathrm{H}$ NMR (500 MHz, $\mathrm{CDCl}_{3}$ ): $\delta / p p m 9.15$ (m, 1H, H9), 9.00 (m, 1H, H6), 8.93 (m, 2H, H14), 8.81 (br s, 1H, H9), 8.32 (m, 1H, H1a), 8.12 (m, 1H, H6), 7.92-7.68 (m, 6H, H7, H11+H12), 7.62 (m, 2H, H8), 7.35 (m, 2H, H13), 6.73 (m, 1H, H4a), 6.67 (m, 2H, H3a+ H4b), 5.98 (d, J = 7.5 Hz, 1H, H3b), 4.56 (br s, 2H, H1b), 4.13 (m, $1 \mathrm{H}, \mathrm{H} 1 \mathrm{a}), 0.64\left(\mathrm{dd} .{ }^{3} J_{\mathrm{PH}}=7.0,4.5,{ }^{2} J_{\mathrm{PtH}}=62.0 \mathrm{~Hz}, 3 \mathrm{H}, \mathrm{Pt}-\mathrm{CH}_{3}\right) .{ }^{13} \mathrm{C} \mathrm{NMR}(125$ $\mathrm{MHz}, \mathrm{CDCl}_{3}$ ): $\delta / \mathrm{ppm} 152.88$ (m, C9), 150.37 (s, C14), 150.27 (s, C9), 137.73 (m, Py), $135.76\left(\mathrm{~d},{ }^{3} J_{\mathrm{PC}}=9.0 \mathrm{~Hz}, \mathrm{C} 12\right), 132.94\left(\mathrm{~d},{ }^{2} J_{\mathrm{PC}}=4.3 \mathrm{~Hz}, \mathrm{C} 2\right), 130.53(\mathrm{~m}, \mathrm{Py})$, 130.22 (m, C3a), 129.91 (m, C3b), 127.23 (m, C4a+C4b), 126.96 (m, Py), 124.81 $(\mathrm{m}, \mathrm{Py}), 33.43\left(\mathrm{~d},{ }^{1} J_{\mathrm{PC}}=36.3 \mathrm{~Hz}, \mathrm{C} 1 \mathrm{~b}\right), 28.92\left(\mathrm{~d},{ }^{1} J_{\mathrm{PC}}=23.4 \mathrm{~Hz}, \mathrm{C} 1 \mathrm{a}\right), 10.98$ $\left(\mathrm{dd},{ }^{2} J_{\mathrm{PC}}=92.6,7.2 \mathrm{~Hz}, \mathrm{Pt}-\mathrm{CH}_{3}\right) .{ }^{31} \mathrm{P} \mathrm{NMR}\left(121 \mathrm{MHz}, \mathrm{CDCl}_{3}\right): \delta / \mathrm{ppm} 24.21(\mathrm{~d}$, ${ }^{2} J_{\mathrm{PP}}=12.1,{ }^{1} J_{\mathrm{PtP}}=1839.3,{ }^{3} J_{\mathrm{PtP}}=88.7 \mathrm{~Hz}, \mathrm{P}$ trans $\left.\mathrm{Me}\right), 12.00\left(\mathrm{~d},{ }^{2} J_{\mathrm{PP}}=12.1\right.$, ${ }^{1} J_{\mathrm{PtP}}=4203.4 \mathrm{~Hz}, \mathrm{P}$ trans $\mathrm{Cl}$ ). IR (film from $\mathrm{CHCl}_{3}$ ): $\nu_{\max } / \mathrm{cm}^{-1} 1585,1573,1562$ $(\mathrm{C}=\mathrm{N}$ stretch). 


\section{Synthesis of $\left[\left(\mathrm{PtMe}_{2}\right)_{2} \mathrm{PtClMe}(\mathrm{PP})\right](59)$}

A solution of the $[\mathrm{PtClMe}(\mathrm{PP})]$ complex $27(30 \mathrm{mg}, 0.04 \mathrm{mmol})$ in $\mathrm{CDCl}_{3}(0.4 \mathrm{~mL})$ was added to dimethyl(hexa-1,5-diene)platinum (26 mg, $0.08 \mathrm{mmol}$ ) in an NMR tube. The reaction was followed by ${ }^{31} \mathrm{P}$ and ${ }^{1} \mathrm{H}$ NMR. After 24 hours at room temperature the dimetallic $\left[\left(\mathrm{PtMe}_{2}\right) \mathrm{PtClMe}(\mathrm{PP})\right]$ complex 58 was the major species in solution. However, after 48 hours the NMR spectra showed the formation of several products. After 72 hours a solid had precipitated out of solution. This solid was found to be insoluble in a broad range of solvents. However, an infrared spectrum recorded of the solid indicated that all of the pyridyl nitrogens were coordinated to a metal centre.

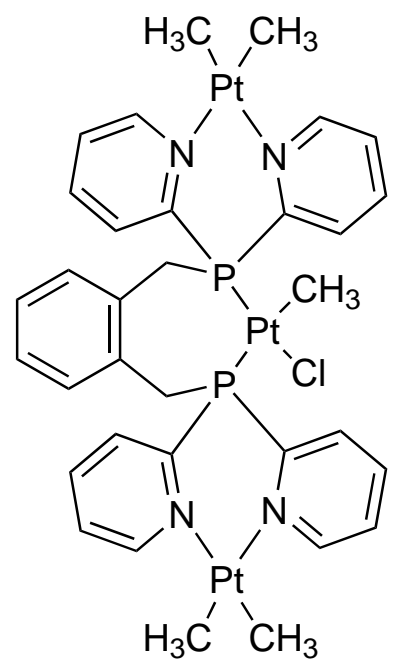

IR (KBr disc): $\nu_{\max } / \mathrm{cm}^{-1} 1585(\mathrm{C}=\mathrm{N}$ stretch $)$.

\subsubsection{Heterotrimetallic complexes of dpypox}

\section{Synthesis of $\left[\{\mathrm{Rh}(\mathrm{COD})\}_{2} \mathrm{PtMe}_{2}(\mathrm{PP})\right]\left\{\mathrm{CH}\left(\mathrm{SO}_{2} \mathrm{CF}_{3}\right)_{2}\right\}_{2}(60)$}

A solution of the $\left[\mathrm{PtMe}_{2}(\mathrm{PP})\right]$ complex $17(30 \mathrm{mg}, 0.04 \mathrm{mmol})$ in $\mathrm{CDCl}_{3}(0.5 \mathrm{~mL})$ was added to $[\mathrm{Rh}(\mathrm{COD})(\mu-\mathrm{Cl})]_{2}(22 \mathrm{mg}, 0.04 \mathrm{mmol})$ and $\mathrm{NaCH}\left(\mathrm{SO}_{2} \mathrm{CF}_{3}\right)_{2}(26 \mathrm{mg}$, $0.08 \mathrm{mmol}$ ) in an NMR tube under argon. The ${ }^{31} \mathrm{P},{ }^{1} \mathrm{H}$ and ${ }^{19} \mathrm{~F}$ NMR spectra recorded after 20 minutes showed that $\left[\{\mathrm{Rh}(\mathrm{COD})\}_{2} \mathrm{PtMe}_{2}(\mathrm{PP})\right]\left\{\mathrm{CH}\left(\mathrm{SO}_{2} \mathrm{CF}_{3}\right)_{2}\right\}_{2}$ 60 was the only species present in solution (quantitative conversion). 


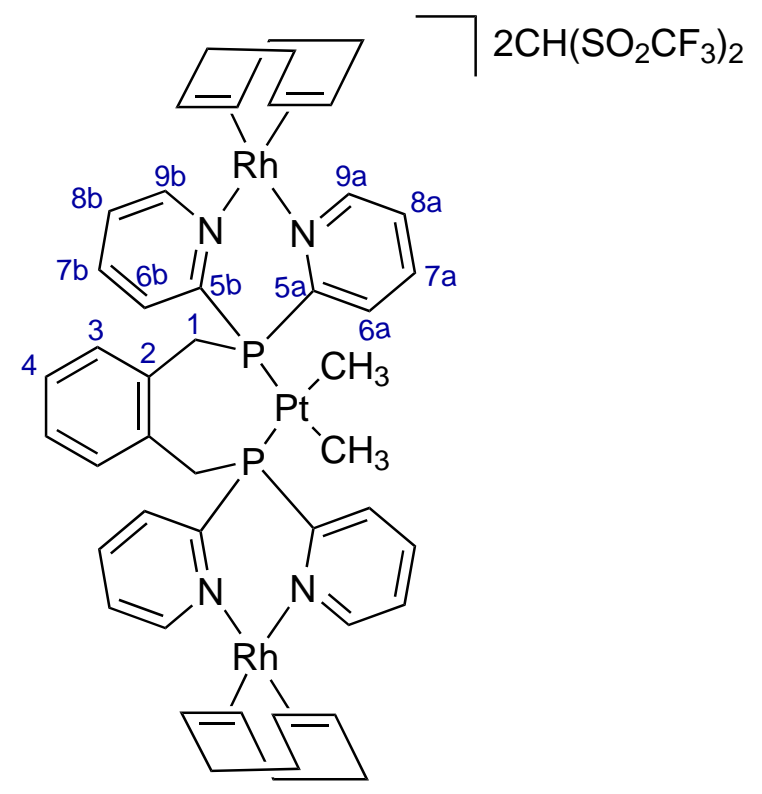

${ }^{1} \mathrm{H} \mathrm{NMR}\left(600 \mathrm{MHz}, \mathrm{CDCl}_{3}\right): \delta / \mathrm{ppm} 9.08(\mathrm{~d}, J=5.4 \mathrm{~Hz}, 2 \mathrm{H}, \mathrm{H} 9 \mathrm{~b}), 8.98(\mathrm{t}, J=$ $8.1 \mathrm{~Hz}, 2 \mathrm{H}, \mathrm{H6b}), 8.76$ (d, $J=5.4 \mathrm{~Hz}, 2 \mathrm{H}, \mathrm{H} 9 \mathrm{a}), 8.21$ (t, $J=17.4,2 \mathrm{H}, \mathrm{H} 1 \mathrm{a}), 8.18$ $(\mathrm{m}, 2 \mathrm{H}, \mathrm{H6a}), 8.02$ (t, $J=7.8 \mathrm{~Hz}, 2 \mathrm{H}, \mathrm{H} 7 \mathrm{~b}), 7.91$ (t, $J=7.8 \mathrm{~Hz}, 2 \mathrm{H}, \mathrm{H} 7 \mathrm{a}), 7.60$ (m, 2H, H8a), 7.53 (m, 2H, H8b), 7.01 (m, 2H, H4), 6.60 (m, 2H, H3), 5.28 (dd, J $=13.8,2.4 \mathrm{~Hz}, 2 \mathrm{H}, \mathrm{H} 1 \mathrm{~b}), 4.76(\mathrm{~m}, 2 \mathrm{H}, \mathrm{COD}=\mathrm{CH}), 4.67(\mathrm{~m}, 2 \mathrm{H}, \mathrm{COD}=\mathrm{CH}), 4.16$ $(\mathrm{m}, 2 \mathrm{H}, \mathrm{COD}=\mathrm{CH}), 3.95(\mathrm{~m}, 2 \mathrm{H}, \mathrm{COD}=\mathrm{CH}), 3.80\left(\mathrm{~s}, 2 \mathrm{H}, \mathrm{CH}\left(\mathrm{SO}_{2} \mathrm{CF}_{3}\right)_{2}\right), 3.04$ $\left(\mathrm{m}, 2 \mathrm{H}, \mathrm{COD} \mathrm{CH}_{2}\right), 2.82\left(\mathrm{~m}, 2 \mathrm{H}, \mathrm{COD} \mathrm{CH}_{2}\right), 2.62\left(\mathrm{~m}, 2 \mathrm{H}, \mathrm{COD} \mathrm{CH}_{2}\right), 2.48(\mathrm{~m}$, $\left.4 \mathrm{H}, \mathrm{COD} \mathrm{CH} \mathrm{CH}_{2}\right), 2.31\left(\mathrm{~m}, 2 \mathrm{H}, \mathrm{COD} \mathrm{CH} \mathrm{CH}_{2}\right), 2.09\left(\mathrm{~m}, 2 \mathrm{H}, \mathrm{COD} \mathrm{CH}_{2}\right), 1.80(\mathrm{br} \mathrm{d}, J=$ $\left.7.5 \mathrm{~Hz}, 2 \mathrm{H}, \mathrm{COD} \mathrm{CH} \mathrm{CH}_{2}\right), 0.01\left(\mathrm{t},{ }^{3} J_{\mathrm{PH}}=7.3,{ }^{2} J_{\mathrm{PtH}}=69.9 \mathrm{~Hz}, 6 \mathrm{H}, \mathrm{Pt}-\mathrm{CH}_{3}\right) .{ }^{13} \mathrm{C}$ NMR (150 MHz, $\mathrm{CDCl}_{3}$ ): $\delta / \mathrm{ppm} 152.71$ (s, C9a), 152.63 (s, C9b), 152.48 (m, C5b), 152.41 (m, C5a), 138.21 (m, C6b+C7b), 137.88 (m, C6a+C7a), 133.41 (d, ${ }^{2} J_{\mathrm{PC}}=$ $4.3 \mathrm{~Hz}, \mathrm{C} 2$ ), 130.40 (s, C3), 128.25 (s, C4), 127.59 (s, C8a), 126.75 (s, C8b), 121.10 $\left(\mathrm{q},{ }^{1} J_{\mathrm{CF}}=325.6 \mathrm{~Hz}, \mathrm{CH}\left(\mathrm{SO}_{2} C \mathrm{~F}_{3}\right)_{2}\right), 92.12\left(\mathrm{~d},{ }^{1} J_{\mathrm{RhC}}=11.9 \mathrm{~Hz}, \mathrm{COD}=\mathrm{CH}\right), 88.75$ $\left(\mathrm{d},{ }^{1} J_{\mathrm{RhC}}=11.4 \mathrm{~Hz}, \mathrm{COD}=\mathrm{CH}\right), 88.08\left(\mathrm{~d},{ }^{1} J_{\mathrm{RhC}}=8.4 \mathrm{~Hz}, \mathrm{COD}=\mathrm{CH}\right), 83.63(\mathrm{~d}$, $\left.{ }^{1} J_{\mathrm{RhC}}=9.7 \mathrm{~Hz}, \mathrm{COD}=\mathrm{CH}\right), 53.38\left(\mathrm{~s}, C \mathrm{H}\left(\mathrm{SO}_{2} \mathrm{CF}_{3}\right)_{2}\right), 35.00\left(\mathrm{~d},{ }^{1} J_{\mathrm{PC}}=19.5 \mathrm{~Hz}\right.$, C1), $31.80\left(\mathrm{~s}, \mathrm{COD} \mathrm{CH} \mathrm{CH}_{2}\right), 31.38\left(\mathrm{~s}, \mathrm{COD} \mathrm{CH} \mathrm{CH}_{2}\right), 31.26\left(\mathrm{~s}, \mathrm{COD} \mathrm{CH}_{2}\right), 29.61(\mathrm{~s}, \mathrm{COD}$ $\left.\mathrm{CH}_{2}\right), 8.56\left(\mathrm{dd},{ }^{2} J_{\mathrm{PC}}=98.8,8.7,{ }^{1} J_{\mathrm{PtC}}=618.5 \mathrm{~Hz}, \mathrm{Pt}-\mathrm{CH}_{3}\right) \cdot{ }^{19} \mathrm{~F} \mathrm{NMR}(282 \mathrm{MHz}$, $\left.\mathrm{CDCl}_{3}\right): \delta / \mathrm{ppm}-80.93\left(\mathrm{~s}, \mathrm{CH}\left(\mathrm{SO}_{2} \mathrm{CF}_{3}\right)_{2}\right) \cdot{ }^{31} \mathrm{P} \mathrm{NMR}\left(121 \mathrm{MHz}, \mathrm{CDCl}_{3}\right): \delta / \mathrm{ppm}$ $32.15\left(\mathrm{~s},{ }^{1} J_{\mathrm{PtP}}=1981.2 \mathrm{~Hz}\right)$. IR (film from $\left.\mathrm{CH}_{2} \mathrm{Cl}_{2}\right): \nu_{\max } / \mathrm{cm}^{-1} 1602,1585(\mathrm{C}=\mathrm{N}$ stretch).

\section{Synthesis of $\left[\{\operatorname{Ir}(\mathrm{COD})\}_{2} \mathrm{PtMe}_{2}(\mathrm{PP})\right]\left\{\mathrm{CH}\left(\mathrm{SO}_{2} \mathrm{CF}_{3}\right)_{2}\right\}_{2}(61)$}

A solution of the $\left[\mathrm{PtMe}_{2}(\mathrm{PP})\right]$ complex $17(30 \mathrm{mg}, 0.04 \mathrm{mmol})$ in $\mathrm{CDCl}_{3}(0.5 \mathrm{~mL})$ was added to $[\operatorname{Ir}(\mathrm{COD})(\mu-\mathrm{Cl})]_{2}(29 \mathrm{mg}, 0.04 \mathrm{mmol})$ and $\mathrm{NaCH}\left(\mathrm{SO}_{2} \mathrm{CF}_{3}\right)_{2}(26 \mathrm{mg}$, $0.08 \mathrm{mmol}$ ) in an NMR tube under argon. The ${ }^{31} \mathrm{P},{ }^{1} \mathrm{H}$ and ${ }^{19} \mathrm{~F} \mathrm{NMR}$ spectra 
recorded after 20 minutes showed that the $\left[\{\mathrm{Ir}(\mathrm{COD})\}_{2} \mathrm{PtMe}_{2}(\mathrm{PP})\right]\left\{\mathrm{CH}\left(\mathrm{SO}_{2} \mathrm{CF}_{3}\right)_{2}\right\}_{2}$ complex 61 was the only species present in solution (quantitative conversion).

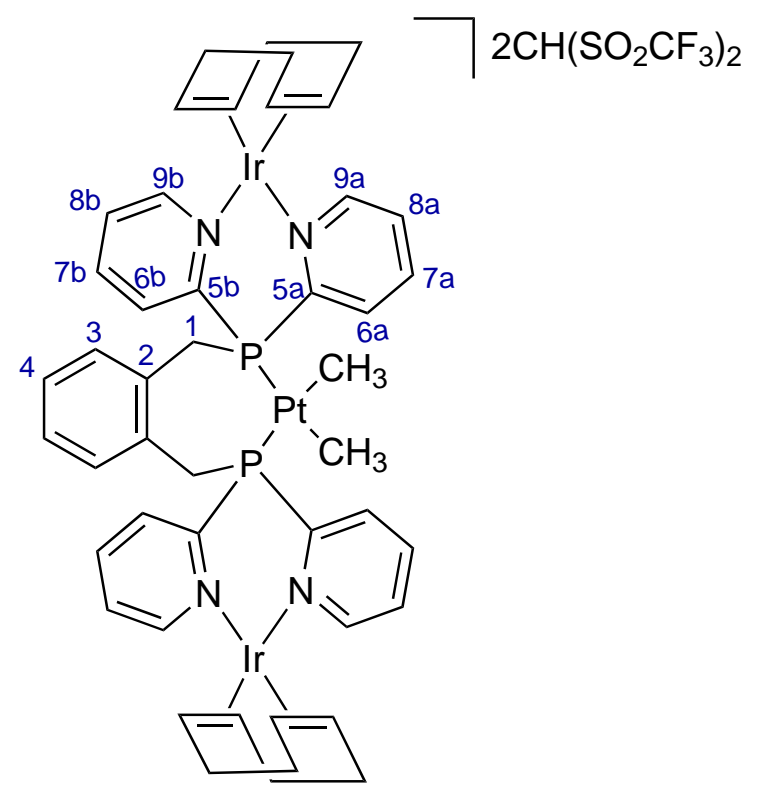

${ }^{1} \mathrm{H} \mathrm{NMR}\left(600 \mathrm{MHz}, \mathrm{CDCl}_{3}\right): \delta / \mathrm{ppm} 9.10(\mathrm{t}, J=8.5 \mathrm{~Hz}, 2 \mathrm{H}, \mathrm{H} 6 \mathrm{~b}), 9.04(\mathrm{~d}, J=$ $5.5 \mathrm{~Hz}, 2 \mathrm{H}, \mathrm{H} 9 \mathrm{~b}), 8.91$ (d, $J=5.5 \mathrm{~Hz}, 2 \mathrm{H}, \mathrm{H} 9 \mathrm{a}), 8.27$ (t, $J=8.0 \mathrm{~Hz}, 2 \mathrm{H}, \mathrm{H} 6 \mathrm{a})$, $8.08(\mathrm{t}, J=7.8 \mathrm{~Hz}, 2 \mathrm{H}, \mathrm{H} 7 \mathrm{~b}), 7.98(\mathrm{t}, J=7.8 \mathrm{~Hz}, 2 \mathrm{H}, \mathrm{H} 7 \mathrm{a}), 7.68$ (t, $J=6.5$ $\mathrm{Hz}, 2 \mathrm{H}, \mathrm{H} 8 \mathrm{a}), 7.59$ (t, $J=6.5 \mathrm{~Hz}, 2 \mathrm{H}, \mathrm{H} 8 \mathrm{~b}), 7.38$ (t, $J=15.3 \mathrm{~Hz}, 2 \mathrm{H}, \mathrm{H} 1 \mathrm{a}), 6.98$ (m, 2H, H4), 6.53 (m, 2H, H3), 5.09 (dd, J = 14.0, $2.5 \mathrm{~Hz}, 2 \mathrm{H}, \mathrm{H} 1 \mathrm{~b}), 4.52$ (m, 2H, $\mathrm{COD}=\mathrm{CH}), 4.34(\mathrm{t}, J=6.5 \mathrm{~Hz}, 2 \mathrm{H}, \mathrm{COD}=\mathrm{CH}), 3.94(\mathrm{~m}, 2 \mathrm{H}, \mathrm{COD}=\mathrm{CH}), 3.75$ $\left(\mathrm{s}, 2 \mathrm{H}, \mathrm{CH}\left(\mathrm{SO}_{2} \mathrm{CF}_{3}\right)_{2}\right), 3.68(\mathrm{~m}, 2 \mathrm{H}, \mathrm{COD}=\mathrm{CH}), 2.80\left(\mathrm{~m}, 2 \mathrm{H}, \mathrm{COD} \mathrm{CH}_{2}\right), 2.63$ $\left(\mathrm{m}, 2 \mathrm{H}, \mathrm{COD} \mathrm{CH}_{2}\right), 2.36\left(\mathrm{~m}, 4 \mathrm{H}, \mathrm{COD} \mathrm{CH}_{2}\right), 2.16\left(\mathrm{~m}, 2 \mathrm{H}, \mathrm{COD} \mathrm{CH}_{2}\right), 1.96(\mathrm{~m}$, $\left.2 \mathrm{H}, \mathrm{COD} \mathrm{CH} \mathrm{CH}_{2}\right), 1.76\left(\mathrm{~m}, 4 \mathrm{H}, \mathrm{COD} \mathrm{CH} \mathrm{CH}_{2}\right),-0.01\left(\mathrm{t},{ }^{3} J_{\mathrm{PH}}=7.5,{ }^{2} J_{\mathrm{PtH}}=69.0 \mathrm{~Hz}\right.$, 6H, Pt- $\mathrm{CH}_{3}$ ). ${ }^{13} \mathrm{C} \mathrm{NMR}\left(150 \mathrm{MHz}, \mathrm{CDCl}_{3}\right.$ ): $\delta / \mathrm{ppm} 152.65$ (s, C9a), 152.33 (s, C9b), $151.44\left(\mathrm{~d},{ }^{1} J_{\mathrm{PC}}=22.0 \mathrm{~Hz}, \mathrm{C} 5 \mathrm{a}\right), 151.12\left(\mathrm{~d},{ }^{1} J_{\mathrm{PC}}=20.6 \mathrm{~Hz}, \mathrm{C} 5 \mathrm{~b}\right), 138.4(\mathrm{~m}$, C6b+C7b), 138.0 (m, C6a+C7a), 132.86 (s, C2), 130.32 (s, C3), 128.19 (s, C8a), 128.04 (s, C4), 127.39 (s, C8b), $120.84\left(\mathrm{q},{ }^{1} J_{\mathrm{CF}}=325.8 \mathrm{~Hz}, \mathrm{CH}\left(\mathrm{SO}_{2} C \mathrm{~F}_{3}\right)_{2}\right), 77.1$ (observed in HSQC, COD =CH), $73.95(\mathrm{~s}, \mathrm{COD}=\mathrm{CH}), 73.68(\mathrm{~s}, \mathrm{COD}=\mathrm{CH}), 69.04$ $(\mathrm{s}, \mathrm{COD}=\mathrm{CH}), 53.22\left(\mathrm{br} \mathrm{s}, \mathrm{CH}\left(\mathrm{SO}_{2} \mathrm{CF}_{3}\right)_{2}\right), 34.84\left(\mathrm{~d},{ }^{1} J_{\mathrm{PC}}=17.1 \mathrm{~Hz}, \mathrm{C} 1\right), 31.51$ (s, $\left.\mathrm{COD} \mathrm{CH} \mathrm{CH}_{2}\right), 31.40\left(\mathrm{~s}, \mathrm{COD} \mathrm{CH} \mathrm{CH}_{2}\right), 29.73\left(\mathrm{~s}, \mathrm{COD} \mathrm{CH}_{2}\right), 29.56\left(\mathrm{~s}, \mathrm{COD} \mathrm{CH}_{2}\right), 8.55$ $\left(\mathrm{dd},{ }^{2} J_{\mathrm{PC}}=98.4,8.7,{ }^{1} J_{\mathrm{PtC}}=617.6 \mathrm{~Hz}, \mathrm{Pt}-\mathrm{CH}_{3}\right) .{ }^{19} \mathrm{~F} \mathrm{NMR}\left(282 \mathrm{MHz}, \mathrm{CDCl}_{3}\right)$ : $\delta / \mathrm{ppm}-80.93\left(\mathrm{~s}, \mathrm{CH}\left(\mathrm{SO}_{2} \mathrm{CF}_{3}\right)_{2}\right) .{ }^{31} \mathrm{P} \mathrm{NMR}\left(121 \mathrm{MHz}, \mathrm{CDCl}_{3}\right): \delta / \mathrm{ppm} 32.56(\mathrm{~s}$, $\left.{ }^{1} J_{\mathrm{PtP}}=1975.1 \mathrm{~Hz}\right)$. IR (film from $\left.\mathrm{CH}_{2} \mathrm{Cl}_{2}\right): \nu_{\max } / \mathrm{cm}^{-1} 1586(\mathrm{C}=\mathrm{N}$ stretch).

\section{Synthesis of $\left[\{\mathrm{Rh}(\mathrm{COD})\} \mathrm{PtMe}_{2}(\mathrm{PP})\right] \mathrm{CH}\left(\mathrm{SO}_{2} \mathrm{CF}_{3}\right)_{2}(62)$}

A solution of $\left[\mathrm{PtMe}_{2}(\mathrm{PP})\right]$ complex $17(30 \mathrm{mg}, 0.04 \mathrm{mmol})$ in $\mathrm{CDCl}_{3}$ was added to 
$[\mathrm{Rh}(\mathrm{COD})(\mu-\mathrm{Cl})]_{2}(11 \mathrm{mg}, 0.02 \mathrm{mmol})$ and $\mathrm{NaCH}\left(\mathrm{SO}_{2} \mathrm{CF}_{3}\right)_{2}(13 \mathrm{mg}, 0.04 \mathrm{mmol})$ in an NMR tube under argon. The ${ }^{31} \mathrm{P},{ }^{1} \mathrm{H}$ and ${ }^{19} \mathrm{~F}$ NMR spectra recorded after $20 \mathrm{~min}-$ utes showed the formation of a mixture of the $\left[\mathrm{PtMe}_{2}(\mathrm{PP})\right]$ complex 17, the dimetallic complex $\left[\{\mathrm{Rh}(\mathrm{COD})\} \mathrm{PtMe}_{2}(\mathrm{PP})\right] \mathrm{CH}\left(\mathrm{SO}_{2} \mathrm{CF}_{3}\right)_{2} \mathbf{6 2}$ and the trimetallic complex 60. Addition of $[\mathrm{Rh}(\mathrm{COD})(\mu-\mathrm{Cl})]_{2}(11 \mathrm{mg}, 0.02 \mathrm{mmol})$ and $\mathrm{NaCH}\left(\mathrm{SO}_{2} \mathrm{CF}_{3}\right)_{2}(13$ $\mathrm{mg}, 0.04 \mathrm{mmol}$ ) resulted in complete conversion of this mixture to the trimetallic complex 60 (determined by NMR).

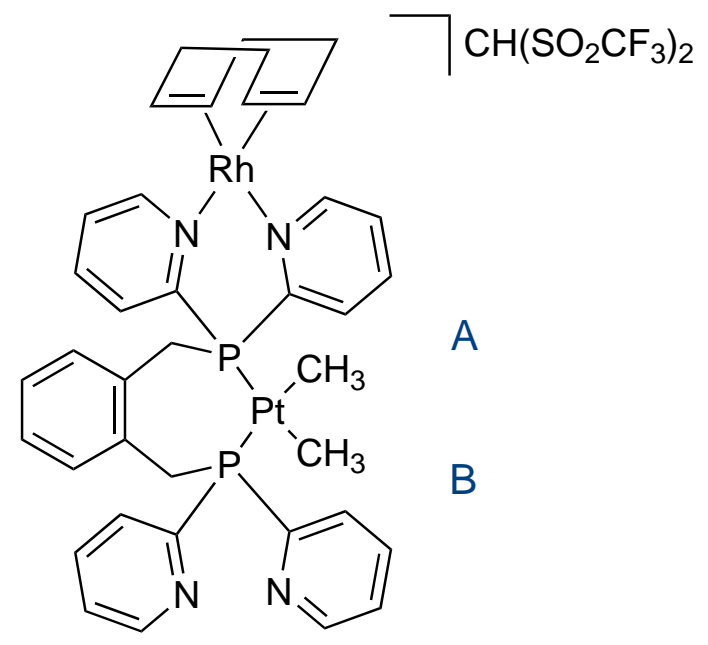

${ }^{1} \mathrm{H}$ NMR $\left(600 \mathrm{MHz}, \mathrm{CDCl}_{3}\right): \delta / \mathrm{ppm} 6.93\left(\mathrm{t},{ }^{2} J_{\mathrm{HH}}=7.0 \mathrm{~Hz}, 1 \mathrm{H}, \mathrm{H} 4 \mathrm{a}\right), 6.81\left(\mathrm{t},{ }^{2} J_{\mathrm{HH}}\right.$ $=7.5 \mathrm{~Hz}, 1 \mathrm{H}, \mathrm{H} 4 \mathrm{~b}), 6.56\left(\mathrm{~d},{ }^{2} J_{\mathrm{HH}}=7.0 \mathrm{~Hz}, 1 \mathrm{H}, \mathrm{H} 3 \mathrm{a}\right), 6.15\left(\mathrm{~d},{ }^{2} J_{\mathrm{HH}}=7.5 \mathrm{~Hz}, 1 \mathrm{H}\right.$, H3b), $0.42\left(\mathrm{dd},{ }^{3} J_{\mathrm{PH}}=8.8,7.3,{ }^{1} J_{\mathrm{PtH}}=70.0 \mathrm{~Hz}, 3 \mathrm{H}, \mathrm{Pt}-\mathrm{CH}_{3}\right)-0.28\left(\mathrm{dd},{ }^{3} J_{\mathrm{PH}}=\right.$ 8.8, 6.8, $\left.{ }^{1} J_{\mathrm{PtH}}=68.0 \mathrm{~Hz}, 3 \mathrm{H}, \mathrm{Pt}-\mathrm{CH}_{3}\right) .{ }^{31} \mathrm{P} \mathrm{NMR}\left(121 \mathrm{MHz}, \mathrm{CDCl}_{3}\right): \delta / \mathrm{ppm} 29.48$ $\left(\mathrm{d},{ }^{2} J_{\mathrm{PP}}=10.7,{ }^{1} J_{\mathrm{PtP}}=2002.5 \mathrm{~Hz}\right), 15.48\left(\mathrm{~d},{ }^{2} J_{\mathrm{PP}}=10.7,{ }^{1} J_{\mathrm{PtP}}=1818.5 \mathrm{~Hz}\right)$.

\section{Synthesis of $\left[\{\operatorname{Ir}(\mathrm{COD})\} \mathrm{PtMe}_{2}(\mathrm{PP})\right] \mathrm{CH}\left(\mathrm{SO}_{2} \mathrm{CF}_{3}\right)_{2}(63)$}

A solution of $\left[\mathrm{PtMe}_{2}(\mathrm{PP})\right]$ complex $17(30 \mathrm{mg}, 0.04 \mathrm{mmol})$ in $\mathrm{CDCl}_{3}$ was added to $[\operatorname{Ir}(\mathrm{COD})(\mu-\mathrm{Cl})]_{2}(15 \mathrm{mg}, 0.02 \mathrm{mmol})$ and $\mathrm{NaCH}\left(\mathrm{SO}_{2} \mathrm{CF}_{3}\right)_{2}(13 \mathrm{mg}, 0.04 \mathrm{mmol})$ in an NMR tube under argon. ${ }^{31} \mathrm{P},{ }^{1} \mathrm{H}$ and ${ }^{19} \mathrm{~F}$ NMR recorded after 20 minutes showed the formation of a mixture of the $\left[\mathrm{PtMe}_{2}(\mathrm{PP})\right]$ complex 17, the dimetallic complex $\left[\{\operatorname{Ir}(\mathrm{COD})\} \mathrm{PtMe}_{2}(\mathrm{PP})\right] \mathrm{CH}\left(\mathrm{SO}_{2} \mathrm{CF}_{3}\right)_{2} \mathbf{6 3}$ and the trimetallic complex $\mathbf{6 1 .}$ Addition of $[\operatorname{Ir}(\mathrm{COD})(\mu-\mathrm{Cl})]_{2}(15 \mathrm{mg}, 0.02 \mathrm{mmol})$ and $\mathrm{NaCH}\left(\mathrm{SO}_{2} \mathrm{CF}_{3}\right)_{2}(13 \mathrm{mg}, 0.04$ mmol) resulted in complete conversion of this mixture to the trimetallic complex 61 (determined by NMR). 


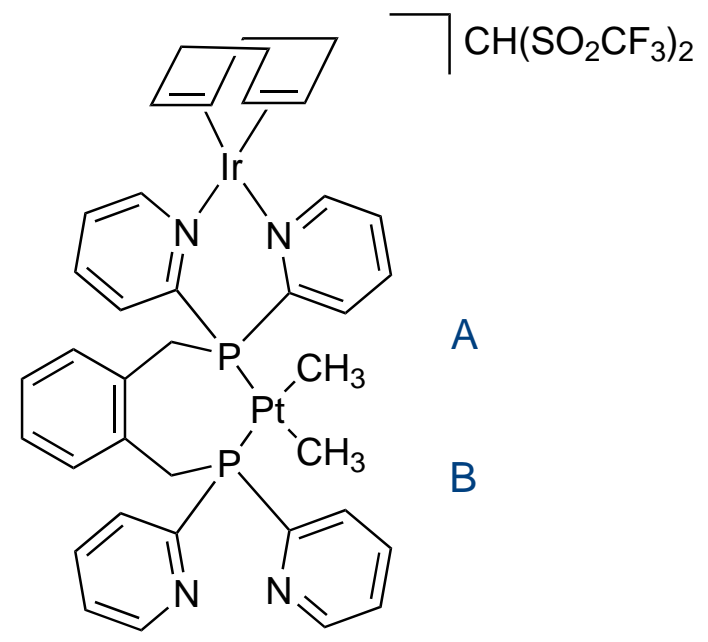

${ }^{1} \mathrm{H} \mathrm{NMR}\left(600 \mathrm{MHz}, \mathrm{CDCl}_{3}\right): \delta / \mathrm{ppm} 6.95(\mathrm{t}, J=7.3 \mathrm{~Hz}, 1 \mathrm{H}, \mathrm{H} 4 \mathrm{a}), 6.83(\mathrm{~m}, 1 \mathrm{H}$, H4b), 6.75 (d, $J=7.5 \mathrm{~Hz}, \mathrm{H} 3 \mathrm{a}), 6.16$ (d, $J=7.0 \mathrm{~Hz}, \mathrm{H} 3 \mathrm{~b}), 0.42$ (dd, ${ }^{3} J_{\mathrm{PH}}=8.4$, $\left.7.5,{ }^{1} J_{\mathrm{PtH}}=71.4 \mathrm{~Hz}, 3 \mathrm{H}, \mathrm{Pt}-\mathrm{CH}_{3}\right),-0.30\left(\mathrm{dd},{ }^{3} J_{\mathrm{PH}}=8.4,6.9,{ }^{1} J_{\mathrm{PtH}}=67.2 \mathrm{~Hz}\right.$, $\left.3 \mathrm{H}, \mathrm{Pt}-\mathrm{CH}_{3}\right) \cdot{ }^{19} \mathrm{~F} \mathrm{NMR}\left(282 \mathrm{MHz}, \mathrm{CDCl}_{3}\right): \delta / \mathrm{ppm}-81.03\left(\mathrm{~s}, \mathrm{CH}\left(\mathrm{SO}_{2} \mathrm{CF}_{3}\right){ }_{2}\right) .{ }^{31} \mathrm{P}$ $\operatorname{NMR}\left(121 \mathrm{MHz}, \mathrm{CDCl}_{3}\right): \delta / \mathrm{ppm} 29.84\left(\mathrm{~d},{ }^{2} J_{\mathrm{PP}}=10.3,{ }^{1} J_{\mathrm{PtP}}=2000.2 \mathrm{~Hz}\right), 15.35$ $\left(\mathrm{d},{ }^{2} J_{\mathrm{PP}}=10.3,{ }^{1} J_{\mathrm{PtP}}=1810.7 \mathrm{~Hz}\right)$.

\subsubsection{Trimetallic complexes of dpypmx}

\section{Synthesis of $\left[\left(\mathrm{PtMe}_{2}\right)_{2} \mathrm{PtMe}(\mathrm{PCP})\right](65)$}

Dimethyl(hexa-1,5-diene)platinum (27 mg, $0.08 \mathrm{mmol}$ ) was added to a solution of the [PtMe(PCP)] complex 51 (30 mg, $0.04 \mathrm{mmol})$ in $\mathrm{CDCl}_{3}(0.5 \mathrm{~mL})$. The ${ }^{31} \mathrm{P}$ and ${ }^{1} \mathrm{H}$ NMR spectra recorded after 20 minutes showed the formation of a small amount of the $\left[\left(\mathrm{PtMe}_{2}\right) \mathrm{PtMe}(\mathrm{PCP})\right]$ complex 64. After three hours 64 was the major species in solution while there was now also a small amount of the $\left[\left(\mathrm{PtMe}_{2}\right)_{2} \mathrm{PtMe}(\mathrm{PCP})\right] \mathrm{com}$ plex 65 present. After 23 hours the ${ }^{31} \mathrm{P}$ and ${ }^{1} \mathrm{H}$ NMR spectra showed that complex 65 and displaced hexa-1,5-diene were the only species left in solution (quantitative conversion). 
$\left[\left(\mathrm{PtMe}_{2}\right) \operatorname{Pt}(\mathrm{PCP})\right](\mathbf{6 4})$

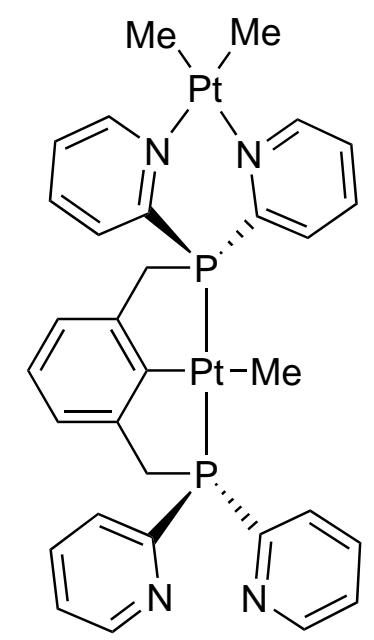

${ }^{31} \mathrm{P}$ NMR $\left(121 \mathrm{MHz}, \mathrm{CDCl}_{3}\right): \delta / \mathrm{ppm} 53.67\left(\mathrm{~d},{ }^{2} J_{\mathrm{PP}}=392.0,{ }^{1} J_{\mathrm{PtP}}=3058.4 \mathrm{~Hz}\right)$, $37.81\left(\mathrm{~d},{ }^{2} J_{\mathrm{PP}}=392.0,{ }^{1} J_{\mathrm{PtP}}=2949.8 \mathrm{~Hz}\right)$.

$\left[\left(\mathrm{PtMe}_{2}\right)_{2} \mathrm{Pt}(\mathrm{PCP})\right](\mathbf{6 5})$

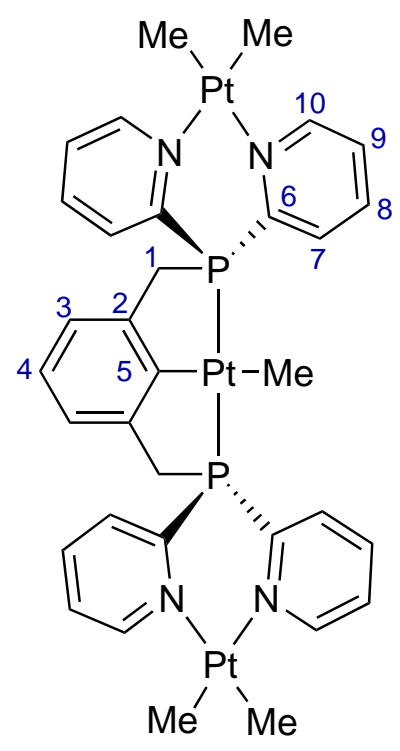

${ }^{1} \mathrm{H}$ NMR (500 MHz, $\mathrm{CDCl}_{3}$ ): $\delta / \mathrm{ppm} 9.13(\mathrm{~d}, J=5.0 \mathrm{~Hz}, 4 \mathrm{H}, \mathrm{H} 10), 9.10(\mathrm{~m}, 4 \mathrm{H}$, H7), $8.04(\mathrm{t}, J=6.9 \mathrm{~Hz}, 4 \mathrm{H}, \mathrm{H} 8), 7.44(\mathrm{t}, J=6.3 \mathrm{~Hz}, 4 \mathrm{H}, \mathrm{H} 9), 7.13\left(\mathrm{~d},{ }^{3} J_{\mathrm{HH}}\right.$ $=7.5 \mathrm{~Hz}, 2 \mathrm{H}, \mathrm{H} 3), 7.02\left(\mathrm{t},{ }^{3} J_{\mathrm{HH}}=7.5 \mathrm{~Hz}, 1 \mathrm{H}, \mathrm{H} 4\right), 5.00(\mathrm{br} \mathrm{s}, 4 \mathrm{H}, \mathrm{H} 1), 0.96(\mathrm{~s}$, ${ }^{2} J_{\mathrm{PtH}}=83.7 \mathrm{~Hz}, 12 \mathrm{H}, \mathrm{Pt}-\mathrm{CH}_{3}$ trans $\left.\mathrm{N}\right), 0.45\left(\mathrm{~s},{ }^{2} J_{\mathrm{PtH}}=76.0 \mathrm{~Hz}, 3 \mathrm{H}, \mathrm{Pt}-\mathrm{CH}_{3}\right)$. ${ }^{13} \mathrm{C}$ NMR (125 MHz, $\mathrm{CDCl}_{3}$ ): $\delta / \mathrm{ppm} 153.31$ (br s, C10), 150.98 (vt, ${ }^{1} J_{\mathrm{PC}}+{ }^{3} J_{\mathrm{PC}}$ $=33.9 \mathrm{~Hz}, \mathrm{C} 6), 147.24\left(\mathrm{vt},{ }^{2} J_{\mathrm{PC}}+{ }^{4} J_{\mathrm{PC}}=11.3 \mathrm{~Hz}, \mathrm{C} 2\right), 143.70$ (s, C5), 136.08 $\left(\mathrm{vt},{ }^{3} J_{\mathrm{PC}}+{ }^{5} J_{\mathrm{PC}}=6.0 \mathrm{~Hz}, \mathrm{C} 8\right), 135.48\left(\mathrm{vt},{ }^{2} J_{\mathrm{PC}}+{ }^{4} J_{\mathrm{PC}}=16.0 \mathrm{~Hz}, \mathrm{C} 7\right), 127.94$ 
(s, C9), $126.41(\mathrm{~s}, \mathrm{C} 4), 123.85$ (vt, $\left.{ }^{3} J_{\mathrm{PC}}+{ }^{5} J_{\mathrm{PC}}=11.8 \mathrm{~Hz}, \mathrm{C} 3\right), 42.70\left(\mathrm{vt},{ }^{1} J_{\mathrm{PC}}\right.$ $\left.+{ }^{3} J_{\mathrm{PC}}=19.4 \mathrm{~Hz}, \mathrm{C} 1\right),-4.72\left(\mathrm{~s}, \mathrm{Pt}-\mathrm{CH}_{3}\right),-17.38\left(\mathrm{~s},{ }^{1} J_{\mathrm{PtC}}=827.4 \mathrm{~Hz}, \mathrm{Pt}_{-} \mathrm{CH}_{3}\right.$ trans $\mathrm{N}) \cdot{ }^{31} \mathrm{P} \mathrm{NMR}\left(121 \mathrm{MHz}, \mathrm{CDCl}_{3}\right): \delta / \mathrm{ppm} 52.67\left(\mathrm{~s},{ }^{1} J_{\mathrm{PtP}}=3096.9,{ }^{3} J_{\mathrm{PtP}}=\right.$ $41.8 \mathrm{~Hz}$ ). IR (film from $\mathrm{CH}_{2} \mathrm{Cl}_{2}$ ): $\nu_{\max } / \mathrm{cm}^{-1} 1601,1585$ (C=N stretch).

\section{Synthesis of $\left[\{\mathrm{Rh}(\mathrm{COD})\}_{2} \mathrm{PtMe}(\mathrm{PCP})\right]\left\{\mathrm{CH}\left(\mathrm{SO}_{2} \mathrm{CF}_{3}\right)_{2}\right\}_{2}(66)$}

A solution of the $[\mathrm{PtMe}(\mathrm{PCP})]$ complex $51(30 \mathrm{mg}, 0.04 \mathrm{mmol})$ in $\mathrm{CDCl}_{3}(0.5 \mathrm{~mL})$ was added to $[\mathrm{Rh}(\mathrm{COD})(\mu-\mathrm{Cl})]_{2}(22 \mathrm{mg}, 0.04 \mathrm{mmol})$ and $\mathrm{NaCH}\left(\mathrm{SO}_{2} \mathrm{CF}_{3}\right)_{2}(26 \mathrm{mg}$, $0.08 \mathrm{mmol})$ in an NMR tube under argon. The ${ }^{31} \mathrm{P},{ }^{1} \mathrm{H}$ and ${ }^{19} \mathrm{~F}$ NMR spectra recorded after 20 minutes showed that $\left[\{\mathrm{Rh}(\mathrm{COD})\}_{2} \mathrm{PtMe}(\mathrm{PCP})\right]\left\{\mathrm{CH}\left(\mathrm{SO}_{2} \mathrm{CF}_{3}\right)_{2}\right\}_{2}$ (66) was the only species present in solution (quantitative conversion).

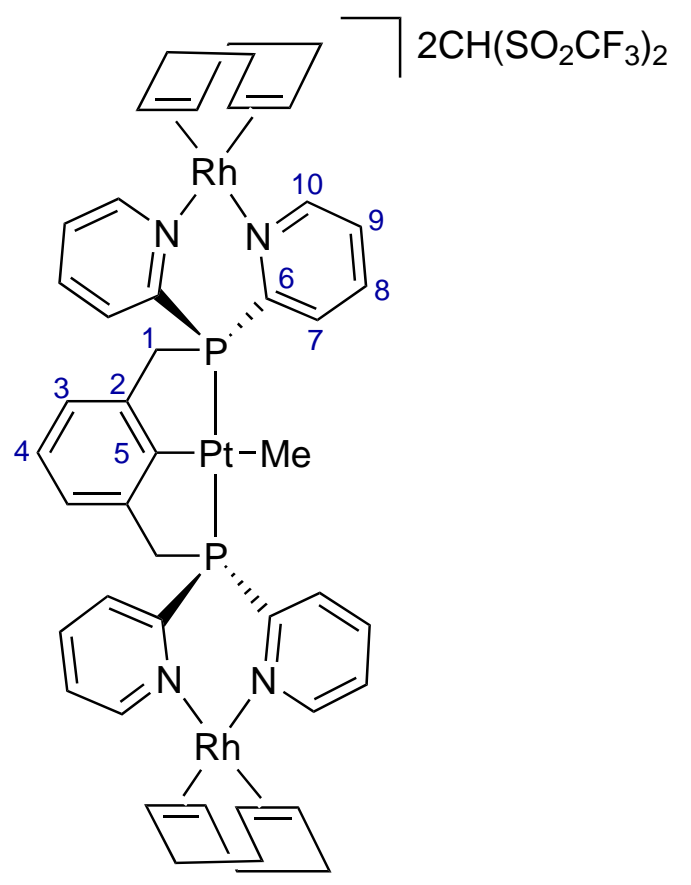

${ }^{1} \mathrm{H} \mathrm{NMR}\left(500 \mathrm{MHz},\left(\mathrm{CD}_{3}\right)_{2} \mathrm{CO}\right): \delta / \mathrm{ppm} 9.27(\mathrm{~m}, 4 \mathrm{H}, \mathrm{H} 7), 9.25(\mathrm{~d}, J=5.5 \mathrm{~Hz}$, $4 \mathrm{H}, \mathrm{H} 10), 8.24(\mathrm{t}, J=6.8 \mathrm{~Hz}, 4 \mathrm{H}, \mathrm{H} 8), 7.81(\mathrm{~m}, 4 \mathrm{H}, \mathrm{H} 9), 7.44\left(\mathrm{~d},{ }^{3} J_{\mathrm{HH}}=7.5 \mathrm{~Hz}\right.$, $2 \mathrm{H}, \mathrm{H} 3), 7.28\left(\mathrm{t},{ }^{3} J_{\mathrm{HH}}=7.5 \mathrm{~Hz}, 1 \mathrm{H}, \mathrm{H} 4\right), 5.97$ (br s, $4 \mathrm{H}, \mathrm{H} 1$ ), 4.65 (br s, 4H, COD $=\mathrm{CH}), 4.22(\mathrm{br} \mathrm{s}, 4 \mathrm{H}, \mathrm{COD}=\mathrm{CH}), 3.80\left(\mathrm{~s}, 2 \mathrm{H}, \mathrm{CH}\left(\mathrm{SO}_{2} \mathrm{CF}_{3}\right)_{2}\right), 2.89(\mathrm{br} \mathrm{s}, 4 \mathrm{H}$, COD $\mathrm{CH}_{2}$ ), 2.49 (br s, 4H, COD $\mathrm{CH}_{2}$ ), $2.23\left(\mathrm{~m}, 4 \mathrm{H}, \mathrm{COD} \mathrm{CH}_{2}\right.$ ), 1.81 (d, $J=8.5$ $\left.\mathrm{Hz}, 4 \mathrm{H}, \mathrm{COD} \mathrm{CH} \mathrm{CH}_{2}\right), 0.39\left(\mathrm{~s},{ }^{2} J_{\mathrm{PtH}}=74.0 \mathrm{~Hz}, 3 \mathrm{H}, \mathrm{Pt}-\mathrm{CH}_{3}\right) \cdot{ }^{19} \mathrm{~F} \mathrm{NMR}(282 \mathrm{MHz}$, $\left.\left(\mathrm{CD}_{3}\right)_{2} \mathrm{CO}\right): \delta / \mathrm{ppm}-81.94\left(\mathrm{~s}, \mathrm{CH}\left(\mathrm{SO}_{2} \mathrm{CF}_{3}\right)_{2}\right) .{ }^{31} \mathrm{P} \mathrm{NMR}\left(121 \mathrm{MHz},\left(\mathrm{CD}_{3}\right)_{2} \mathrm{CO}\right)$ : $\delta / \mathrm{ppm} 53.08\left(\mathrm{~s},{ }^{1} J_{\mathrm{PtP}}=3244.2 \mathrm{~Hz}\right.$ ). IR (film from $\mathrm{CH}_{2} \mathrm{Cl}_{2}$ ): $\nu_{\max } / \mathrm{cm}^{-1} 1604,1587$ $(\mathrm{C}=\mathrm{N}$ stretch $)$. 


\section{Synthesis of $\left[\{\operatorname{Ir}(\mathrm{COD})\}_{2} \mathrm{PtMe}(\mathrm{PCP})\right]\left\{\mathrm{CH}\left(\mathrm{SO}_{2} \mathrm{CF}_{3}\right)_{2}\right\}_{2}(67)$}

A solution of the $[\mathrm{PtMe}(\mathrm{PCP})]$ complex $51(30 \mathrm{mg}, 0.04 \mathrm{mmol})$ in $\mathrm{CDCl}_{3}(0.5 \mathrm{~mL})$ was added to $[\operatorname{Ir}(\mathrm{COD})(\mu-\mathrm{Cl})]_{2}(29 \mathrm{mg}, 0.04 \mathrm{mmol})$ and $\mathrm{NaCH}\left(\mathrm{SO}_{2} \mathrm{CF}_{3}\right)_{2}(26 \mathrm{mg}$, $0.08 \mathrm{mmol}$ ) in an NMR tube under argon. The ${ }^{31} \mathrm{P},{ }^{1} \mathrm{H}$ and ${ }^{19} \mathrm{~F}$ NMR spectra recorded after 20 minutes showed that $\left[\{\mathrm{Ir}(\mathrm{COD})\}_{2} \mathrm{PtMe}(\mathrm{PCP})\right]\left\{\mathrm{CH}\left(\mathrm{SO}_{2} \mathrm{CF}_{3}\right)_{2}\right\}_{2}$ (67) was the only species present in solution (quantitative conversion).

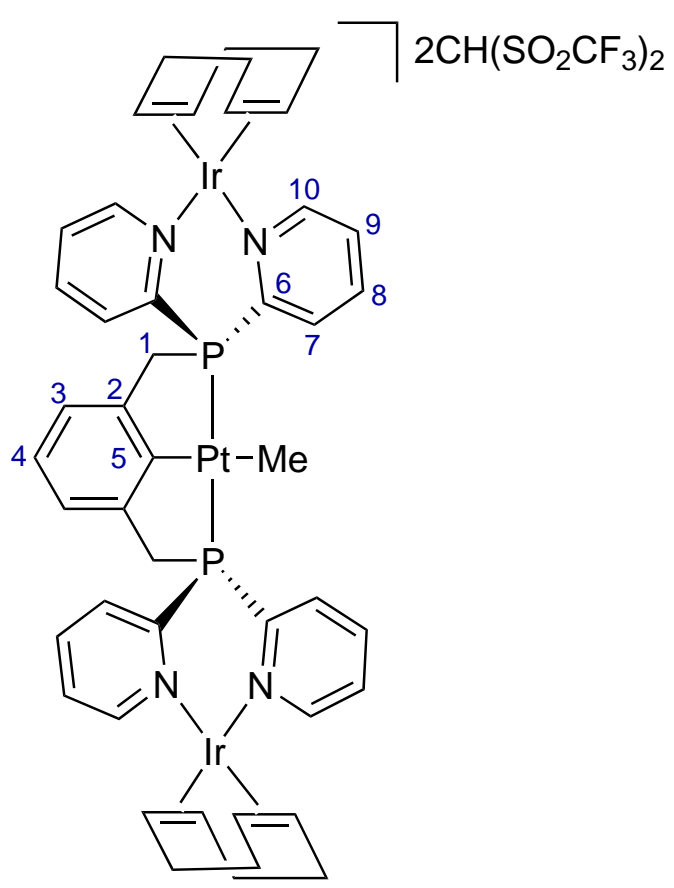

${ }^{1} \mathrm{H}$ NMR (500 MHz, $\left.\left.\mathrm{CD}_{3}\right)_{2} \mathrm{CO}\right): \delta / \mathrm{ppm} 9.39(\mathrm{~m}, 4 \mathrm{H}, \mathrm{H} 7), 9.32(\mathrm{~d}, J=5.5 \mathrm{~Hz}$, $4 \mathrm{H}, \mathrm{H} 10), 8.30$ (t, $J=7.5 \mathrm{~Hz}, 4 \mathrm{H}, \mathrm{H} 8), 7.89$ (t, $J=6.5 \mathrm{~Hz}, 4 \mathrm{H}, \mathrm{H} 9), 7.32$ (d, $\left.{ }^{3} J_{\mathrm{HH}}=7.5 \mathrm{~Hz}, 2 \mathrm{H}, \mathrm{H} 3\right), 7.23\left(\mathrm{t},{ }^{3} J_{\mathrm{HH}}=7.5 \mathrm{~Hz}, 1 \mathrm{H}, \mathrm{H} 4\right), 5.50\left(\mathrm{vt},{ }^{2} J_{\mathrm{PH}}+{ }^{4} J_{\mathrm{PH}}\right.$ $=6.0 \mathrm{~Hz}, 4 \mathrm{H}, \mathrm{H1}), 4.47(\mathrm{br} \mathrm{s}, 4 \mathrm{H}, \mathrm{COD}=\mathrm{CH}), 4.32(\mathrm{br} \mathrm{s}, 4 \mathrm{H}, \mathrm{COD}=\mathrm{CH}), 3.81$ $\left(\mathrm{s}, 2 \mathrm{H}, \mathrm{CH}\left(\mathrm{SO}_{2} \mathrm{CF}_{3}\right)_{2}\right), 2.70$ (br s, 8H, COD CH $\left.\mathrm{CH}_{2}\right), 2.13\left(\mathrm{~m}, 4 \mathrm{H}, \mathrm{COD} \mathrm{CH}_{2}\right), 1.98$ $\left(\mathrm{m}, 4 \mathrm{H}, \mathrm{COD} \mathrm{CH}_{2}\right), 0.40\left(\mathrm{~s},{ }^{2} J_{\mathrm{PtH}}=74.0 \mathrm{~Hz}, 3 \mathrm{H}, \mathrm{Pt}-\mathrm{CH}_{3}\right) \cdot{ }^{19} \mathrm{~F} \mathrm{NMR}(282 \mathrm{MHz}$, $\left.\left.\left.\mathrm{CD}_{3}\right)_{2} \mathrm{CO}\right): \delta / \mathrm{ppm}-81.94\left(\mathrm{~s}, \mathrm{CH}\left(\mathrm{SO}_{2} \mathrm{CF}_{3}\right)_{2}\right) .{ }^{31} \mathrm{P} \mathrm{NMR}\left(121 \mathrm{MHz}, \mathrm{CD}_{3}\right)_{2} \mathrm{CO}\right)$ : $\delta / \mathrm{ppm} 53.77\left(\mathrm{~s},{ }^{1} J_{\mathrm{PtP}}=3246.5 \mathrm{~Hz}\right)$. IR (film from $\left.\mathrm{CH}_{2} \mathrm{Cl}_{2}\right): \nu_{\max } / \mathrm{cm}^{-1} 1602,1589$ $(\mathrm{C}=\mathrm{N}$ stretch $)$.

\section{Synthesis of $[\{\mathrm{Rh}(\mathrm{COD})\} \mathrm{PtMe}(\mathrm{PCP})] \mathrm{CH}\left(\mathrm{SO}_{2} \mathrm{CF}_{3}\right)_{2}(68)$}

When $[\mathrm{Rh}(\mathrm{COD})(\mu-\mathrm{Cl})]_{2}(11 \mathrm{mg}, 0.02 \mathrm{mmol})$ and $\mathrm{NaCH}\left(\mathrm{SO}_{2} \mathrm{CF}_{3}\right)_{2}(13 \mathrm{mg}, 0.04$ $\mathrm{mmol}$ ) were added to a solution of the $[\mathrm{PtMe}(\mathrm{PCP})]$ complex 51 (30 mg, 0.04 $\mathrm{mmol})$ in $\mathrm{CDCl}_{3}(0.5 \mathrm{~mL})$ a mixture of the starting $[\mathrm{PtMe}(\mathrm{PCP})]$ complex $\mathbf{5 1}$, the $[\{\mathrm{Rh}(\mathrm{COD})\} \mathrm{PtMe}(\mathrm{PCP})] \mathrm{CH}\left(\mathrm{SO}_{2} \mathrm{CF}_{3}\right)_{2}$ complex $\mathbf{6 8}$ and the trimetallic complex 
66 was formed after 20 minutes at room temperature. If another equivalent of $[\mathrm{Rh}(\mathrm{COD})(\mu-\mathrm{Cl})]_{2}$ and $\mathrm{NaCH}\left(\mathrm{SO}_{2} \mathrm{CF}_{3}\right)_{2}$ was added to this mixture the NMR spectra recorded after 20 minutes showed that the trimetallic complex $\mathbf{6 6}$ was the only species present in solution (quantitative conversion).

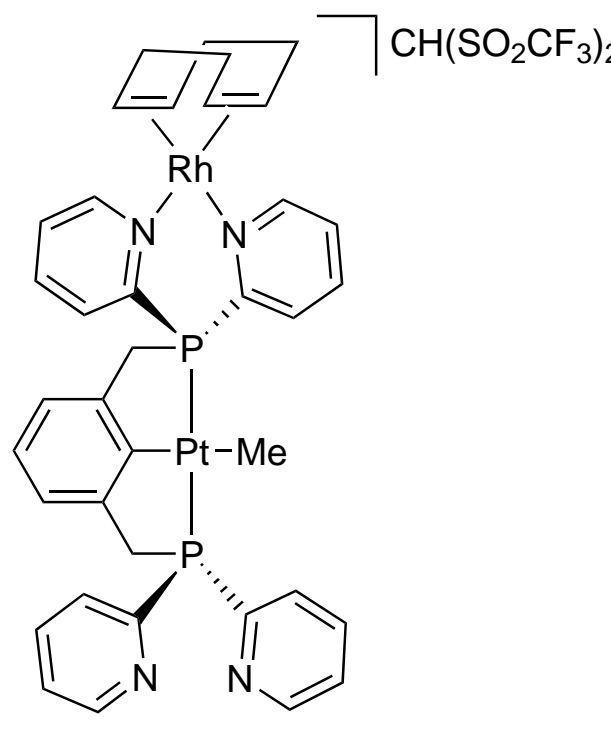

${ }^{31} \mathrm{P}$ NMR $\left(121 \mathrm{MHz}, \mathrm{CDCl}_{3}\right): \delta / \mathrm{ppm} 52.90\left(\mathrm{~d},{ }^{2} J_{\mathrm{PP}}=405.1,{ }^{1} J_{\mathrm{PtP}}=3079.0 \mathrm{~Hz}\right)$, $37.40\left(\mathrm{~d},{ }^{2} J_{\mathrm{PP}}=405.1,{ }^{1} J_{\mathrm{PtP}}=3051.3 \mathrm{~Hz}\right)$.

\section{Synthesis of $[\{\operatorname{Ir}(\mathrm{COD})\} \mathrm{PtMe}(\mathrm{PCP})] \mathrm{CH}\left(\mathrm{SO}_{2} \mathrm{CF}_{3}\right)_{2}(69)$}

In an identical manner to the reactions with $[\operatorname{Rh}(\mathrm{COD})(\mu-\mathrm{Cl})]_{2}$ when $[\operatorname{Ir}(\mathrm{COD})(\mu-$ $\mathrm{Cl})]_{2}(15 \mathrm{mg}, 0.02 \mathrm{mmol})$ and $\mathrm{NaCH}\left(\mathrm{SO}_{2} \mathrm{CF}_{3}\right)_{2}(13 \mathrm{mg}, 0.04 \mathrm{mmol})$ were added to a solution of the $[\mathrm{PtMe}(\mathrm{PCP})]$ complex 51 (30 mg, $0.04 \mathrm{mmol})$ in $\mathrm{CDCl}_{3}(0.5 \mathrm{~mL})$ a mixture of the starting complex 51, the $[\{\operatorname{Ir}(\mathrm{COD})\} \mathrm{PtMe}(\mathrm{PCP})] \mathrm{CH}\left(\mathrm{SO}_{2} \mathrm{CF}_{3}\right)_{2}$ compound 69 and the trimetallic complex 67 was formed after 20 minutes at room temperature. If another equivalent of $[\mathrm{Rh}(\mathrm{COD})(\mu-\mathrm{Cl})]_{2}$ and $\mathrm{NaCH}\left(\mathrm{SO}_{2} \mathrm{CF}_{3}\right)_{2}$ was added this mixture was converted into the complex 67 (quantitative conversion). 


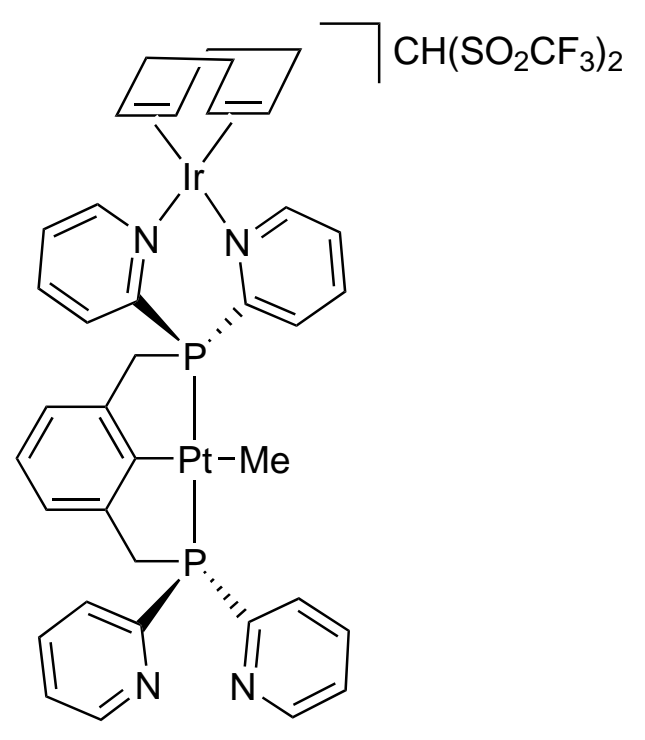

${ }^{31} \mathrm{P}$ NMR $\left(121 \mathrm{MHz}, \mathrm{CDCl}_{3}\right): \delta / \mathrm{ppm} 55.06\left(\mathrm{~d},{ }^{2} J_{\mathrm{PP}}=401.2,{ }^{1} J_{\mathrm{PtP}}=3079.6 \mathrm{~Hz}\right)$, $37.84\left(\mathrm{~d},{ }^{2} J_{\mathrm{PP}}=401.2,{ }^{1} J_{\mathrm{PtP}}=3025.9 \mathrm{~Hz}\right)$. 


\section{References}

1. van Leeuwen, P. W. N. M. Homogeneous Catalysis: Understanding the Art; Klumer Academic Publishers: Dordrect, 2004.

2. Berners-Price, S. J.; Bowen, R. J.; Galettis, P.; Healy, P. C.; McKeage, M. J. Coord. Chem. Rev. 1999, 185-186, 823-836.

3. Bowen, R. J.; Navarro, M.; Shearwood, A.-M. J.; Healy, P. C.; Skelton, B. W. et al. Dalton Trans. 2009, 10861-10870.

4. Tolman, C. A. Chem. Rev. 1977, 77, 313-348.

5. Dyer, P. W.; Fawcett, J.; Hanton, M. J.; Kemmitt, R. D. W.; Padda, R. et al. Dalton Trans. 2003, 104-113.

6. Banger, K. K.; Brisdon, A. K.; Herbert, C. J.; Ghaba, H. A.; Tidmarsh, I. S. J. Fluorine Chem. 2009, 130, 1117-1129.

7. Gusev, D. G. Organometallics 2009, 28, 763-770.

8. Shriver, D. F.; Atkins, P. W. Inorganic Chemistry, third edit ed.; Oxford University Press: Oxford, 1999.

9. Dierkes, P.; van Leeuwen, P. W. N. M. J. Am. Chem. Soc. 1999, 1519-1530.

10. Casey, C. P.; Whiteker, G. T. Isr. J. Chem. 1990, 30, 299-304.

11. van Leeuwen, P. W. N. M.; Kamer, P. C. J.; Reek, J. N. H.; Dierkes, P. Chem. Rev. 2000, 100, 2741-2770.

12. Togni, A.; Venanzi, L. M. Angew. Chem., Int. Ed. 1994, 33, 497-526.

13. Wajda-Hermanowicz, K.; Ciunik, Z.; Kochel, A. Inorg. Chem. 2006, 45, 33693377 .

14. Jeffrey, J. C.; Rauchfuss, T. B. Inorg. Chem. 1979, 18, 2658-2666.

15. Werner, H.; Hampp, A.; Windmüller, B. J. Organomet. Chem. 1992, 435, 169-183.

16. Appleton, T. G.; Bennett, M. A. Inorg. Chem. 1978, 17, 738-747.

17. Kapoor, P.; Kukushkin, V. Y.; Lövqvist, K.; Oskarsson, A. k. J. Organomet. Chem. 1996, 517, 71-79.

18. Yang, H.; Alvarez-Gressier, M.; Lugan, N.; Mathieu, R. Organometallics 1997, 16, 1401-1409. 
19. Zhang, W.-H.; Chien, S. W.; Hor, T. A. Coord. Chem. Rev. 2011, 255, 19912024.

20. Newkome, G. R. Chem. Rev. 1993, 93, 2067-2089.

21. Zhang, Z.-Z.; Cheng, H. Coord. Chem. Rev. 1996, 147, 1-39.

22. Espinet, P.; Soulantica, K. Coord. Chem. Rev. 1999, 193-195, 499-556.

23. Pinault, N.; Bruce, D. Coord. Chem. Rev. 2003, 241, 1-25.

24. Jain, V. K.; Jakkal, V.; Bohra, R. J. Organomet. Chem. 1990, 389, 417-426.

25. Calhorda, M. J.; Ceamanos, C.; Crespo, O.; Gimeno, M. C.; Laguna, A. et al. Inorg. Chem. 2010, 49, 8255-8269.

26. Purcell, W.; Conradie, J.; Chiweshe, T. T.; Venter, J. A.; Visser, H. G. et al. J. Mol. Struct. 2013, 1038, 220-229.

27. García-Álvarez, R.; García-Garrido, S. E.; Díez, J.; Crochet, P.; Cadierno, V. Eur. J. Inorg. Chem. 2012, 4218-4230.

28. Grotjahn, D. B. Top Catal 2010, 53, 1009-1014.

29. Oshiki, T.; Yamashita, H.; Sawada, K.; Utsunomiya, M.; Takahashi, K. et al. Organometallics 2005, 24, 6287-6290.

30. Grotjahn, D. B. Pure Appl. Chem. 2010, 82, 635-647.

31. Grotjahn, D. B.; Lev, D. A. J. Am. Chem. Soc. 2004, 126, 12232-12233.

32. Ahmed, T. J.; Knapp, S. M. M.; Tyler, D. R. Coord. Chem. Rev. 2011, 255, 949-974.

33. Muranaka, M.; Hyodo, I.; Okumura, W.; Oshiki, T. Catal. Today 2011, 164, $552-555$.

34. García-Álvarez, R.; Crochet, P.; Cadierno, V. Green Chem. 2013, 15, 46-66.

35. Almeida Leñero, K. Q.; Guari, Y.; Kamer, P. C. J.; van Leeuwen, P. W. N. M.; Donnadieu, B. et al. Dalton Trans. 2013, 42, 6495-6512.

36. Clarke, M. L.; Slawin, A. M. Z.; Wheatley, M. V.; Woollins, J. D. J. Chem. Soc., Dalton Trans. 2001, 3421-3429.

37. Vaughan, T. F.; Koedyk, D. J.; Spencer, J. L. Organometallics 2011, 30, $5170-5180$.

38. Jamali, S.; Ghazfar, R.; Lalinde, E.; Jamshidi, Z.; Samouei, H. et al. Dalton Trans. 2014, 43, 1105-1116.

39. Jamali, S.; Mazloomi, Z.; Nabavizadeh, S. M.; Milić, D.; Kia, R. et al. Inorg. Chem. 2010, 49, 2721-2726.

40. Meijboom, R.; Bowen, R. J.; Berners-Price, S. J. Coord. Chem. Rev. 2009, 253, 325-342. 
41. Shafaatian, B.; Akbari, A.; Nabavizadeh, S. M.; Heinemann, F. W.; Rashidi, M. Dalton Trans. 2007, 4715-4725.

42. Cingolani, A.; Martini, D.; Pettinari, C.; Skelton, B. W.; White, A. H. Inorg. Chim. Acta 2006, 359, 2183-2193.

43. Rashidi, M.; Jennings, M. C.; Puddephatt, R. J. Organometallics 2003, 22, $2612-2618$.

44. Maisonnat, A.; Farr, J. P.; Balch, A. L. Inorg. Chim. Acta 1981, 53, L217L218.

45. Schutte, R. P.; Rettig, S. J.; Joshi, A. M.; James, B. R. Inorg. Chem. 1997, $36,5809-5817$.

46. Espinet, P.; Goómez-Elipe, P.; Villafañe, F. J. Organomet. Chem. 1993, 450, $145-150$.

47. Casares, J. A.; Espinet, P.; Martín-Alvarez, J. M.; Santos, V. Inorg. Chem. 2004, 43, 189-197.

48. Casares, J. A.; Espinet, P.; Martín-Alvarez, J. M.; Santos, V. Inorg. Chem. 2006, 45, 6628-6636.

49. Baird, I. R.; Smith, M. B.; James, B. R. Inorg. Chim. Acta 1995, 235, 291-297.

50. Casares, J. A.; Espinet, P.; Hernando, R.; Iturbe, G.; Villafañe, F. et al. Inorg. Chem. 1997, 36, 44-49.

51. Ehrlich, M. G.; Fronczek, F. R.; Watkins, S. F.; Newkome, G. R.; Hager, D. C. Acta Crystallogr., Sect. C 1984, 40, 78-80.

52. Gregorzik, R.; Wirbser, J.; Vahrenkamp, H. Chem. Ber. 1992, 125, 1575-1581.

53. Keene, F. R.; Snow, M. R.; Stephenson, P. J.; Tiekink, E. R. T. Inorg. Chem. 1988, 27, 2040-2045.

54. Boggess, R. K.; Zatko, D. A. J. Coord. Chem. 1975, 4, 217-224.

55. Nemati Kharat, A.; Bakhoda, A.; Foroutannejad, S.; Foroutannejad, C. Z. Anorg. Allg. Chem. 2011, 637, 2260-2264.

56. Song, H.-B.; Zhang, Z.-Z.; Hui, Z.; Che, C.-M.; Mak, T. C. W. Inorg. Chem. 2002, 41, 3146-3154.

57. Balch, A. L.; Fossett, L. A.; Olmstead, M. M. Inorg. Chem. 1986, 25, 45264529 .

58. Cochran, B. M.; Michael, F. E. J. Am. Chem. Soc. 2008, 130, 2786-2792.

59. Chen, L.; Ai, P.; Gu, J.; Jie, S.; Li, B.-G. J. Organomet. Chem. 2012, 716, $55-61$.

60. Berners-Price, S. J.; Bowen, R. J.; Harvey, P. J.; Healy, P. C.; Koutsantonis, G. A. J. Chem. Soc., Dalton Trans. 1998, 3, 1743-1750. 
61. Berners-Price, S. J.; Bowen, R. J.; Hambley, T. W.; Healy, P. C. J. Chem. Soc., Dalton Trans. 1999, 1337-1346.

62. McKeage, M. J.; Berners-Price, S. J.; Galettis, P.; Bowen, R. J.; Brouwer, W. et al. Cancer Chemother. Pharmacol. 2000, 46, 343-350.

63. Liu, J. J.; Galettis, P.; Farr, A.; Maharaj, L.; Samarasinha, H. et al. J. Inorg. Biochem. 2008, 102, 303-310.

64. Humphreys, A. S.; Filipovska, A.; Berners-Price, S. J.; Koutsantonis, G. A.; Skelton, B. W. et al. Dalton Trans. 2007, 4943-4950.

65. Jones, N. D.; MacFarlane, K. S.; Smith, M. B.; Schutte, R. P.; Rettig, S. J. et al. Inorg. Chem. 1999, 38, 3956-3966.

66. Jones, N. D.; Rettig, S. J.; James, B. R. J. Cluster Sci. 1998, 9, 243-257.

67. Freixa, Z.; van Leeuwen, P. W. N. M. Dalton Trans. 2003, 1890-1901.

68. Kamer, P. C. J.; van Leeuwen, P. W. N. M.; Reek, J. N. H. Acc. Chem. Res. 2001, 34, 895-904.

69. Kranenburg, M.; van der Burgt, Y. E. M.; Kamer, P. C. J.; van Leeuwen, P. W. N. M.; Goubitz, K. et al. Organometallics 1995, 14, 3081-3089.

70. Clegg, W.; Elsegood, M. R. J.; Eastham, G. R.; Tooze, R. P.; Wang, X. L. et al. Chem. Commun. 1999, 1877-1878.

71. Fanjul, T.; Eastham, G.; Fey, N.; Hamilton, A.; Orpen, a. G. et al. Organometallics 2010, 29, 2292-2305.

72. Eastham, G. R.; Waugh, M.; Pringle, P. G.; Turner, T. P. W. Int. Pat; WO 2011083305, 2011.

73. Brown, M. D.; Levason, W.; Reid, G.; Watts, R. Polyhedron 2005, 24, 75-87.

74. Selander, N.; Szabo, K. J. Chem. Rev. 2011, 111, 2048-2076.

75. Anderson, B. G. Late transition metal complexes of pentafluorophenylphosphino-pincer ligands. Ph.D. thesis, Victoria University of Wellington, 2012.

76. Goldman, A. S.; Roy, A. H.; Huang, Z.; Ahuja, R.; Schinski, W. et al. Science 2006, 312, 257-261.

77. Haibach, M. C.; Kundu, S.; Brookhart, M.; Goldman, A. S. Acc. Chem. Res. 2012, 45, 947-958.

78. Bowen, R. J.; Garner, A.; Berners-Price, S. J.; Jenkins, I. D.; Sue, R. E. J. Organomet. Chem. 1998, 554, 181-184.

79. Steiner, A.; Stalke, D. J. Chem. Soc., Chem Commun. 1993, 444-446.

80. Moret, E.; Desponds, O.; Schlosser, M. J. Organomet. Chem. 1991, 409, 83-91. 
81. Schlosser, M.; Totter, F.; Rittmeyer, P.; Reetz, M. T.; Lipshutz, B. H. et al. In Organometallics in Synthesis; Schlosser, M., Ed.; Wiley: New York, Chichester, West Sussex, 1994; p 603.

82. Uchida, Y.; Kawai, M.; Masauji, H.; Oae, S. Heteroat. Chem. 1993, 4, 421-426.

83. Steiner, A.; Stalke, D. Organometallics 1995, 14, 2422-2429.

84. Uchida, Y.; Takaya, Y.; Oae, S. Heterocycles 1990, 30, 347-351.

85. Uchida, Y.; Kozawa, H.; Oae, S. Tetrahedron Lett. 1989, 30, 6365-6368.

86. Somerville, R. J. unpublished work

87. Muller, A.; Otto, S.; Roodt, A. Dalton Trans. 2008, 650-657.

88. Andersen, N. G.; Keay, B. A. Chem. Rev. 2001, 101, 997-1030.

89. Barnard, T. S.; Mason, M. R. Organometallics 2001, 20, 206-214.

90. Barnard, T. S.; Mason, M. R. Inorg. Chem. 2001, 40, 5001-5009.

91. Allen, D. W.; Taylor, B. F. J. Chem. Soc., Dalton Trans. 1982, 51-54.

92. Cowley, A. H.; Damasco, M. C. J. Am. Chem. Soc. 1971, 93, 6815-6821.

93. Glidewell, C.; Leslie, E. J. J. Chem. Soc., Dalton Trans. 1977, 527-531.

94. McFarlane, W.; Rycroft, D. S. J. Chem. Soc., Dalton Trans. 1973, 2162-2166.

95. Allen, D. W.; Nowell, I. W.; Taylor, B. F. J. Chem. Soc., Dalton Trans. 1985, $2505-2508$.

96. Beckmann, U.; Süslüyan, D.; Kunz, P. C. Phosphorus, Sulfur Silicon Relat. Elem. 2011, 186, 2061-2070.

97. Adams, D. J.; Bennett, J. A.; Duncan, D.; Hope, E. G.; Hopewell, J. et al. Polyhedron 2007, 26, 1505-1513.

98. Bent, H. A. Chem. Rev. 1961, 61, 275-311.

99. Allen, D. W.; March, L. A.; Nowell, I. W. J. Chem. Soc., Dalton Trans. 1984, 483-485.

100. Genin, E.; Amengual, R.; Michelet, V.; Savignac, M.; Jutand, A. et al. Adv. Synth. Catal. 2004, 346, 1733-1741.

101. Aylward, G.; Findlay, T. SI Chemical Data, 5th ed.; John Wiley \& Sons Australia, Ltd, 2002; p 202.

102. Koshar, R. J.; Mitsch, R. A. J. Org. Chem. 1973, 38, 3358-3363.

103. Koppel, I. A.; Koppel, J.; Pihl, V.; Leito, I.; Mishima, M. et al. J. Chem. Soc., Perkin Trans. 2 2000, 1125-1133.

104. Buffin, B. P.; Squattrito, P. J.; Ojewole, A. O. Inorg. Chem. Commun. 2004, 7, 14-17. 
105. Allan, K. M. Hybrid P,E Ligands: Synthesis, Coordination Chemistry and Catalysis. Ph.D. thesis, Victoria University of Wellington, 2014.

106. Nelson, M. R. M. Synthesis, Properties and Coordination Chemistry of t-BuXantphos Ligands. Ph.D. thesis, Victoria University of Wellingon, 2015.

107. Müller, G.; Klinga, M.; Leskelä, M.; Rieger, B. Z. Anorg. Allg. Chem. 2002, 628, 2839-2846.

108. Brunel, J. M.; Faure, B.; Maffei, M. Coord. Chem. Rev. 1998, 178-180, 665698.

109. Fanjul, T.; Eastham, G.; Floure, J.; Forrest, S. J. K.; Haddow, M. F. et al. Dalton Trans. 2013, 42, 100-115.

110. Núñez Magro, A. A.; Robb, L.-M.; Pogorzelec, P. J.; Slawin, A. M. Z.; Eastham, G. R. et al. Chem. Sci. 2010, 1, 723-730.

111. Deacon, G. B.; Elliott, P. W.; Erven, A. P.; Meyer, G. Z. Anorg. Allg. Chem. 2005, 631, 843-850.

112. Fun, H.-K.; Chantrapromma, S.; Liu, Y.-C.; Chen, Z.-F.; Liang, H. Acta Crystallogr., Sect. E: Struct. Rep. Online 2006, 62, m1252-m1254.

113. Crabtree, R. H. Chem. Rev. 2012, 112, 1536-1554.

114. Conelly-Espinosa, P.; Morales-Morales, D. Inorg. Chim. Acta 2010, 363, 13111315 .

115. Rigamonti, L.; Manassero, C.; Rusconi, M.; Manassero, M.; Pasini, A. Dalton Trans. 2009, 1206-1213.

116. Rigamonti, L.; Forni, A.; Manassero, M.; Manassero, C.; Pasini, A. Inorg. Chem. 2010, 49, 123-135.

117. Goel, A.; Goel, S. Inorg. Chim. Acta 1982, 59, 237-240.

118. Payne, N. C.; Stephan, D. W. J. Organomet. Chem. 1982, 228, 203-215.

119. Rigamonti, L.; Rusconi, M.; Manassero, C.; Manassero, M.; Pasini, A. Inorg. Chim. Acta 2010, 363, 3498-3505.

120. Otto, S. Inorg. Chim. Acta 2010, 363, 3316-3320.

121. Fulmer, G. R.; Miller, A. J. M.; Sherden, N. H.; Gottlieb, H. E.; Nudelman, A. et al. Organometallics 2010, 29, 2176-2179.

122. Pignat, K.; Vallotto, J.; Pinna, F.; Strukul, G. Organometallics 2000, 19, $5160-5167$.

123. Slack, D.; Baird, M. Inorg. Chim. Acta 1977, 24, 277-280.

124. Scarcia, V.; Furlani, A.; Longato, B.; Corain, B.; Pilloni, G. Inorg. Chim. Acta 1988, 153, 67-70.

125. Bennett, M. A.; Rokicki, A. Aust. J. Chem 1985, 38, 1307-1318. 
126. Garrou, P. E. Chem. Rev. 1981, 81, 229-266.

127. Lewis, J. E. M.; McAdam, C. J.; Gardiner, M. G.; Crowley, J. D. Chem. Commun. 2013, 49, 3398-3400.

128. Siedle, A. R.; Newmark, R. A.; Gleason, W. B. J. Am. Chem. Soc. 1986, 108, $767-773$.

129. Belluco, U.; Bertani, R.; Coppetti, S.; Michelin, R. A.; Mozzon, M. Inorg. Chim. Acta 2003, 343, 329-334.

130. Drommi, D.; Arena, C. G.; Nicoló, F.; Bruno, G.; Faraone, F. J. Organomet. Chem. 1995, 485, 115-121.

131. Kapoor, P.; Lövqvist, K.; Oskarsson, A. k. J. Mol. Struct 1998, 470, 39-47.

132. Murray, S. G.; Hartley, F. R. Chem. Rev. 1981, 81, 365-414.

133. Somerville, R. J.; Northcote, P. T.; Spencer, J. L. Platinum(0) Alkene Complexes as Tools for the Structural Characterisation of Sulfur-Containing Molecules; 2015.

134. Dahlhoff, W. V.; Nelson, S. M. J. Chem. Soc. (A) 1971, 2184-2190.

135. Dahlhoff, W. V.; Dick, T. R.; Ford, G. H.; Nelson, S. M. Journal Inorg. Nucl. Chem. 1971, 33, 1799-1811.

136. da Mota, M. M.; Rodgers, J.; Nelson, S. M. J. Chem. Soc. (A) 1969, 20362044.

137. McCleverty, J. A., Meyer, T. J., Eds. Comprehensive Coordination Chemistry II, first edit ed.; Elsevier Ltd: Oxford, UK, 2004.

138. Boulanger, J.; Bricout, H.; Tilloy, S.; Fihri, A.; Len, C. et al. Catal. Commun. 2012, 29, 77-81.

139. Li, R.-X.; Li, X.-J.; Wong, N.-B.; Tin, K.-C.; Zhou, Z.-Y. et al. J. Mol. Catal. A: Chem. 2002, 178, 181-190.

140. Lin, C.-H.; Chi, Y.; Chung, M.-W.; Chen, Y.-J.; Wang, K.-W. et al. Dalton Trans. 2011, 40, 1132-1143.

141. Wajda-Hermanowicz, K.; Pruchnik, F. P. Transition Met. Chem. 1988, 13, 101-103.

142. Suzuki, T.; Kotera, M.; Takayama, A.; Kojima, M. Polyhedron 2009, 28, 22872293.

143. Oster, S. S.; Jones, W. D. Polyhedron 2004, 23, 2959-2965.

144. Schnabel, R. C.; Roddick, D. M. Inorg. Chem. 1993, 32, 1513-1518.

145. Ma, X.-Y.; Wang, K.; Zhang, L.; Li, X.-J.; Li, R.-X. Chin. J. Chem. 2007, 25, 1503-1507.

146. Borah, G.; Boruah, D.; Sarmah, G.; Bharadwaj, S. K.; Bora, U. Appl. Organometal. Chem. 2013, 27, 688-694. 
147. Gridnev, I. D.; Higashi, N.; Imamoto, T. Organometallics 2001, 20, 4542-4553.

148. Raebiger, J. W.; Miedaner, A.; Curtis, C. J.; Miller, S. M.; Anderson, O. P. et al. J. Am. Chem. Soc. 2004, 126, 5502-5514.

149. Esteruelas, M. A.; Olivan, M.; Oro, L. A.; Schulz, M.; Sola, E. et al. Organometallics 1992, 11, 3659-3664.

150. Martín, M.; Sola, E.; Torres, O.; Plou, P.; Oro, L. A. Organometallics 2003, 22, 5406-5417.

151. Merola, J. S.; Franks, M. A. J. Organomet. Chem. 2013, 723, 49-55.

152. Rahaman, S. M. W.; Dinda, S.; Sinha, A.; Bera, J. K. Organometallics 2013, 32, 192-201.

153. Martín, M.; Torres, O.; Oñate, E.; Sola, E.; Oro, L. A. J. Am. Chem. Soc. 2005, 12\%, 18074-18084.

154. Yoshida, K.; Nakashima, T.; Yamaguchi, S.; Osuka, A.; Shinokubo, H. Dalton Trans. 2011, 40, 8773-8775.

155. Flood, T. C.; Iimura, M.; Perotti, J. M.; Rheingold, A. L.; Concolino, T. E. Chem. Commun. 2000, 1681-1682.

156. Day, V. W.; Eberspacher, T. A.; Klemperer, W. G.; Zhong, B. J. Am. Chem. Soc. 1994, 116, 3119-3120.

157. Day, V. W.; Klemperer, W. G.; Lockledge, S. P.; Main, D. J. J. Am. Chem. Soc. 1990, 112, 2031-2033.

158. Volger, H.; Vrieze, K. J. Organomet. Chem. 1968, 13, 495-503.

159. Anderson, B. G.; Spencer, J. L. Chem. Eur. J. 2014, 20, 6421-6432.

160. Moulton, C. J.; Shaw, B. L. J. Chem. Soc., Dalton Trans. 1976, 1020-1024.

161. Rimml, H.; Venanzi, L. M. J. Organomet. Chem. 1983, 259, C6-C7.

162. Bennett, M. A.; Jin, H.; Willis, A. C. J. Organomet. Chem. 1993, 451, 249256.

163. Waddell, P. G.; Slawin, A. M. Z.; Woollins, J. D. Dalton Trans. 2010, 39, 8620-8625.

164. van Der Boom, M. E.; Gozin, M.; Ben-David, Y.; Shimon, L. J. W.; Frolow, F. et al. Inorg. Chem. 1996, 35, 7068-7073.

165. Hughes, R. P.; Williamson, A.; Incarvito, C. D.; Rheingold, A. L. Organometallics 2001, 4741-4744.

166. Cross, R.; Kennedy, A.; Muir, K. J. Organomet. Chem. 1995, 487, 227-233.

167. Johnson, M. T.; Wendt, O. F. Inorg. Chim. Acta 2011, 367, 222-224.

168. Olsson, D.; Arunachalampillai, A.; Wendt, O. F. Dalton Trans. 2007, 54275433. 
169. Ozerov, O. V.; Guo, C.; Foxman, B. M. J. Organomet. Chem. 2006, 691, 4802-4806.

170. Adams, J. J.; Lau, A.; Arulsamy, N.; Roddick, D. M. Inorg. Chem. 2007, 46, $11328-11334$.

171. Hill, W. E.; Minahan, D. M. A.; Taylor, J. G.; McAuliffe, C. A. J. Am. Chem. Soc. 1982, 104, 6001-6005.

172. Harvey, J. N.; Heslop, K. M.; Orpen, A. G.; Pringle, P. G. Chem. Commun. 2003, 278-279.

173. Pearson, R. G. Inorg. Chem. 1973, 12, 712-713.

174. Duncan, D.; Hope, E. G.; Singh, K.; Stuart, A. M. Dalton Trans. 2011, 40, 1998-2005.

175. Lewis, J. E. M.; Gavey, E. L.; Cameron, S. A.; Crowley, J. D. Chem. Sci. 2012, 3, 778-780.

176. Alonso, M. A.; Casares, J. A.; Espinet, P.; Soulantica, K.; Charmant, J. P. H. et al. Inorg. Chem. 2000, 39, 705-711.

177. Miller, R. G.; Stauffer, R. D.; Fahey, D. R.; Parnell, D. R. J. Am. Chem. Soc. 1970, 92, 1511-1521.

178. Nielson, A. J. Transition Met. Chem. 1981, 6, 180-184.

179. Pregosin, P. S. NMR in Organometallic Chemistry; Wiley-VCH Verlag \& Co., 2012; p 392.

180. Zayya, A. I.; Spencer, J. L. Organometallics 2012, 31, 2841-2853.

181. Pauling, L. The Nature of the Chemical Bond and the Structure of Molecules and Crystals: An Introduction to Modern Structural Chemistry, third edit ed.; Cornell University Press: New York, 1960; p 644.

182. Gramstad, T.; Haszeldine, R. N. J. Chem. Soc. 1957, 4069-4071.

183. Daigle, D. J.; Decuir, T. J.; Robertson, J. B.; Darensbourg, D. J. Inorg. Synth. 1998, 32, 40-45.

184. Jensen, K. A. Acta Chem. Scand. 1953, 7, 866-868.

185. Albrecht, M.; Gossage, R. A.; Lutz, M.; Spek, A. L.; van Koten, G. Chem. Eur. J. 2000, 6, 1431-1445.

186. Crascall, L. E.; Spencer, J. L. Inorg. Synth. 1990, 28, 126-132.

187. Carr, N.; Mole, L.; Orpena, A. G.; Spencer, J. L. J. Chem. Soc., Dalton Trans. 1992, 2653-2662.

188. Nelson, M. R. M. unpublished work

189. Rimoldi, M.; Ragaini, F.; Gallo, E.; Ferretti, F.; Macchi, P. et al. Dalton Trans. 2012, 41, 3648-3658. 
190. Byers, P. K.; Canty, A. J.; Jin, H.; Kruis, D.; Markies, B. A. et al. Inorg. Synth. 1998, 32, 162-172.

191. Green, M.; Howard, J. A. K.; Spencer, J. L.; Stone, F. G. A. J. Chem. Soc., Dalton Trans. 1977, 271-273.

192. Ukai, T.; Kawazura, H.; Ishii, Y.; Bonnet, J.; Ibers, J. A. J. Organomet. Chem. 1974, 65, 253-266.

193. Giordano, G.; Crabtree, R. H. Inorg. Synth. 1990, 28, 88-90.

194. Tajuddin, H.; Harrisson, P.; Bitterlich, B.; Collings, J. C.; Sim, N. et al. Chem. Sci. 2012, 3, 3505-3515.

195. Gottlieb, H. E.; Kotlyar, V.; Nudelman, A. J. Org. Chem. 1997, 62, 7512-7515.

196. Harris, R. K.; Becker, E. D.; Cabral de Menezes, S. M.; Goodfellow, R.; Granger, P. Magn. Reson. Chem. 2002, 40, 489-505.

197. Dolomanov, O. V.; Bourhis, L. J.; Gildea, R. J.; Howard, J. A. K.; Puschmann, H. J. Appl. Crystallogr. 2009, 42, 339-341.

198. Sheldrick, G. M. Acta Crystallogr., Sect. A: Found. Crystallogr. 2008, 64, 112 122.

199. Palatinus, L.; Chapuis, G. J. Appl. Crystallogr. 2007, 40, 786-790.

200. Allan, K. M.; Spencer, J. L. Tetrahedron Lett. 2009, 50, 834-835. 